\title{
LOWER SCOTTS CREEK FLOODPLAIN AND HABITAT ENHANCEMENT PROJECT
}

\author{
A Thesis \\ presented to \\ the Faculty of California Polytechnic State University, \\ San Luis Obispo
}

\author{
In Partial Fulfillment \\ of the Requirements for the Degree \\ Master of Science in Forestry Sciences
}

by

Benjamin O. Cook

June 2016 
(C) 2016

Benjamin O. Cook

ALL RIGHTS RESERVED 


\section{COMMITTEE MEMBERSHIP}

TITLE: Lower Scotts Creek Floodplain and Habitat Enhancement Project

AUTHOR: $\quad$ Benjamin O. Cook

DATE SUBMITTED: June 2016

COMMITTEE CHAIR: $\quad$ Brian C. Dietterick, Ph.D., P.H.

Director, Swanton Pacific Ranch

COMMITTEE MEMBER: James D. Robins, M.S.

Coordinator, Integrated Watershed Restoration Program

COMMITTEE MEMBER: $\quad$ Christopher G. Surfleet, Ph.D.

Professor of Hydrology and Watershed Management 


\section{ABSTRACT \\ Lower Scotts Creek Floodplain and Habitat Enhancement Project \\ Benjamin O. Cook}

Scotts Creek, located in northern Santa Cruz County, maintains the southernmost persistent population of Central California Coast (CCC) Coho Salmon (endangered) in addition to CCC steelhead (threatened). Fisheries biologists believe overwinter mortality due to lack of refuge habitat is the primary factor limiting salmonid production. Instream rearing habitat may also be limiting, especially during drought years. The legacy effects of historic land use practices, including dredging, wood removal, and the construction of levees, continued to limit refuge and rearing opportunities. A restoration project was implemented to improve refuge and rearing opportunities for salmonids along lower Scotts Creek by removing portions of the deteriorating levee, grading new connections with existing off-channel features, enhancing tributary confluences, constructing alcove habitat features at the margins of the stream channel, and constructing large wood complexes (LWCs) instream.

Novel restoration techniques were employed on an experimental basis. Whole in-situ alder trees were pushed into the stream channel with their root systems left partially intact to establish living key pieces. Individual log, boulder, and rootwad LWC components were attached together with couplers that permitted some freedom of independent movement among the individual components. LWCs were braced against live, standing trees and stabilized with boulder ballasts placed on the streambed, which eliminated excavation of the streambed/banks and the need to dewater or divert the stream during construction.

Project performance, changes to physical habitat characteristics, and changes to stream morphology associated with implementation were monitored using habitat assessment methods derived from the California Department of Fish and Wildlife's (CDFW) salmonid habitat survey protocol (Flosi 
et al. 2010), and topographic survey techniques and data analysis adapted from Columbia Habitat Monitoring Protocol (Bouwes et al. 2011). Preliminary results indicated that LWCs remained stable and functional. In addition, implementation of the restoration project increased pool frequency, low-flow pool volume, instream cover, frequency of instream, alcove, and off-channel refuge habitat features, and frequency of points of connectivity with the floodplain. Long-term monitoring will be required to determine the survivorship, decay rates, and overall persistence of alder recruits. 


\section{ACKNOWLEDGMENTS}

The California State Coastal Conservancy funded the design of the Lower Scotts Creek Floodplain and Habitat Enhancement Project. The Wildlife Conservation Board and the California Department of Fish and Wildlife Fisheries Restoration Grant Program funded the implementation of the project. The Resource Conservation District of Santa Cruz County (RCDSCC) and the Integrated Watershed Restoration Program (IWRP) coordinated the design, funding, and permitting. The IWRP Technical Advisory Committee (TAC) guided the project's design. The TAC's input was crucial to realizing the collectively-held desire to see lower Scotts Creek reconnected to its prehistoric floodplain.

This project was a joint effort of Cal Poly/Swanton Pacific Ranch staff, interns, faculty, students, and volunteers. Swanton community members Jim West and Roberta Smith enriched this work by generously extending their invaluable botanical and geological expertise (respectively), friendship, and mentorship. Jim Robins (IWRP), Alicia Moss and Kelli Camara (RCDSCC) supported Cal Poly's efforts throughout.

The contributions of individuals from various agencies including the California Department of Fish and Wildlife, US Fish and Wildlife Service, NOAA Fisheries, and the Natural Resources Conservation Service were essential to the realization of this project. I would especially like to thank the team at the Southwest Fisheries Science Center for sharing their extensive knowledge and experience freely over the last three years.

This project is one example of Dr. Brian Dietterick's persistent efforts to initiate and guide studentdriven restoration projects within the Scotts Creek watershed. His efforts carry on the legacy of the late Al Smith, a Cal Poly alum, who donated Swanton Pacific Ranch to Cal Poly in 1992 with the intent "to see Swanton kept intact and natural, a laboratory and classroom for 'Learn by Doing' forever." 


\section{TABLE OF CONTENTS}

\section{Page}

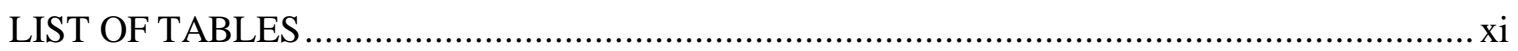

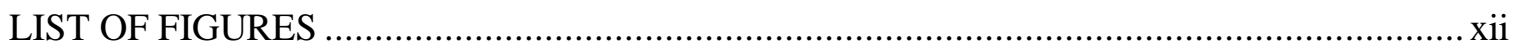

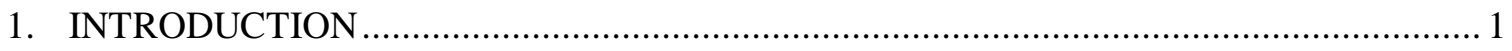

1.1 Decline of Central California Coast Salmon ............................................................. 1

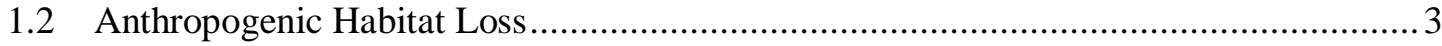

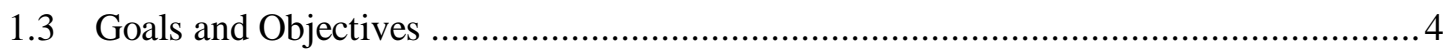

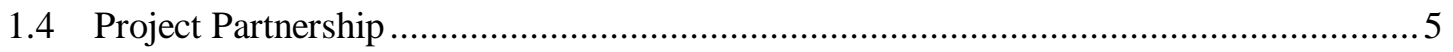

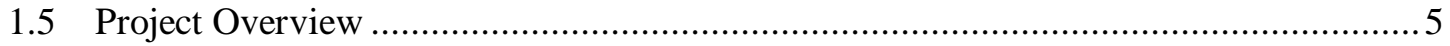

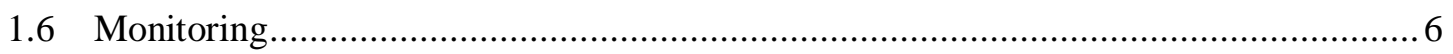

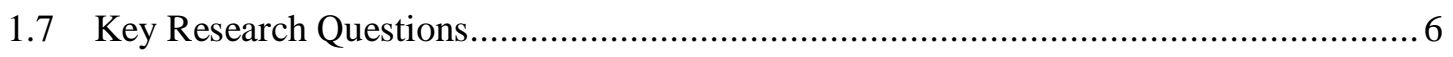

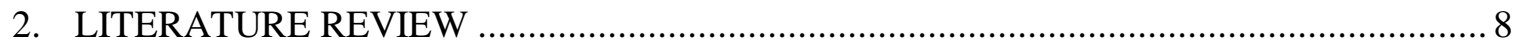

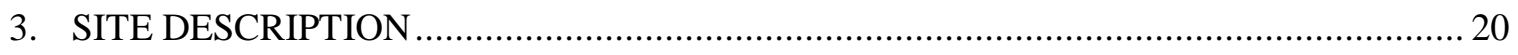

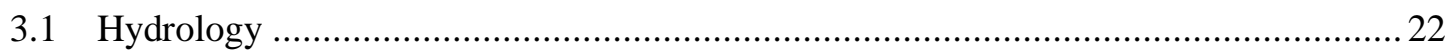

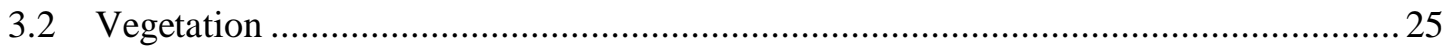

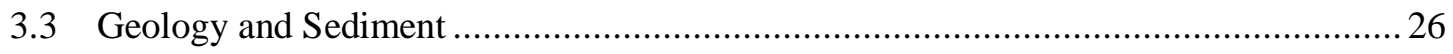

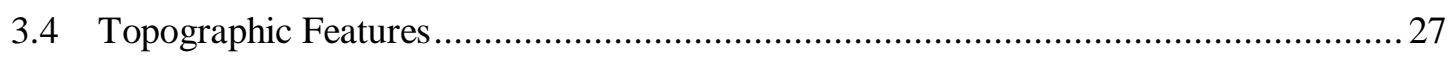

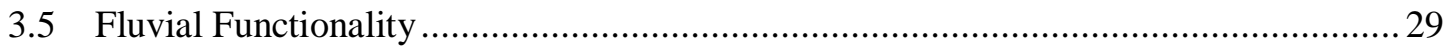

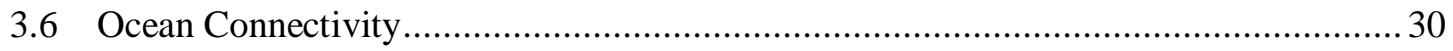

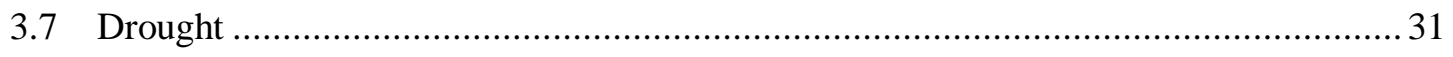

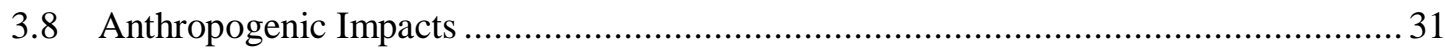

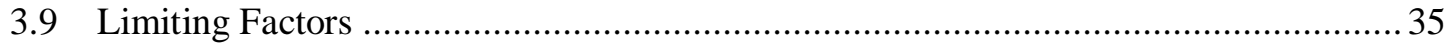

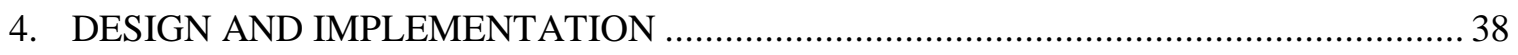

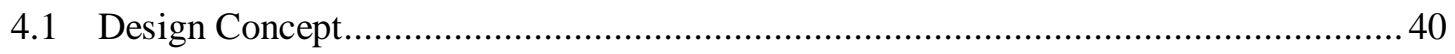

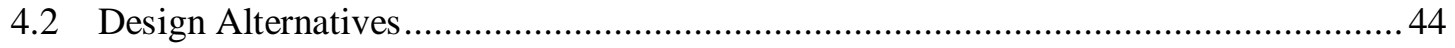

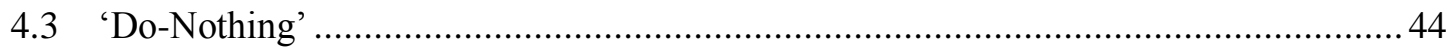

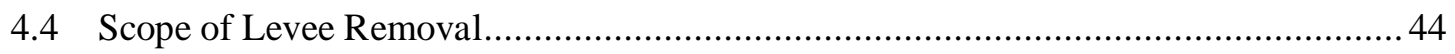




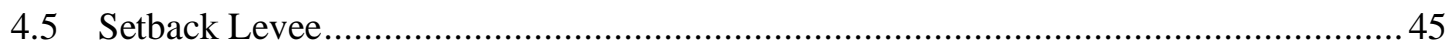

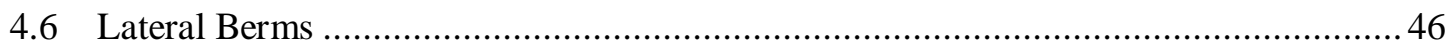

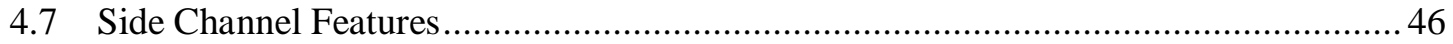

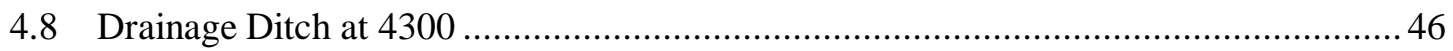

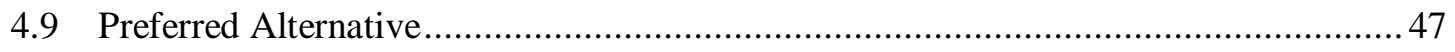

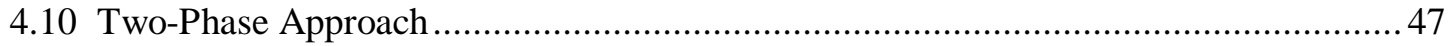

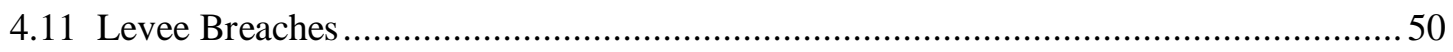

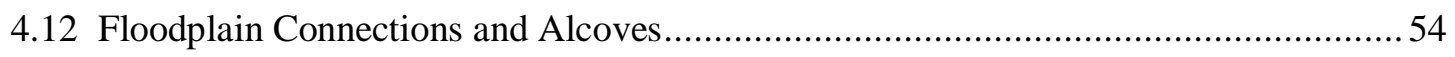

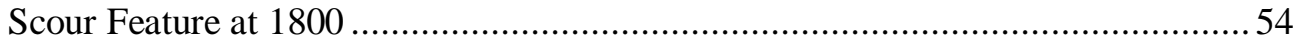

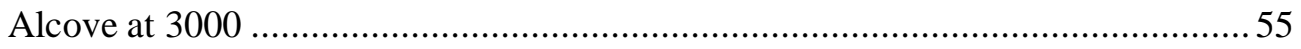

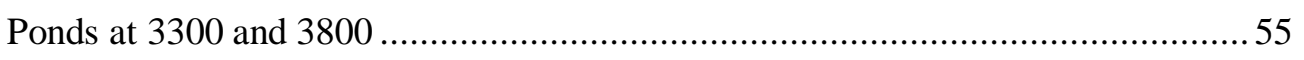

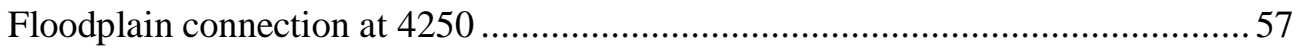

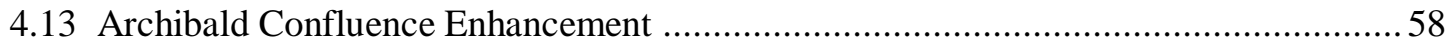

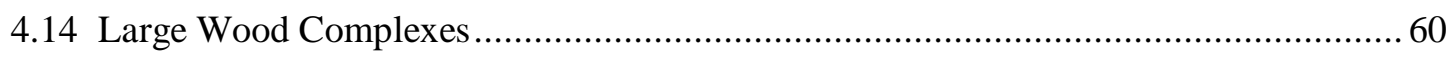

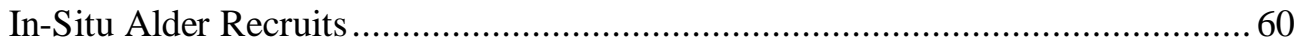

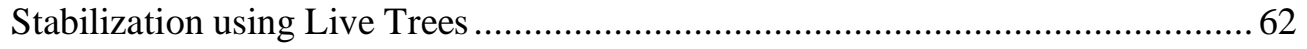

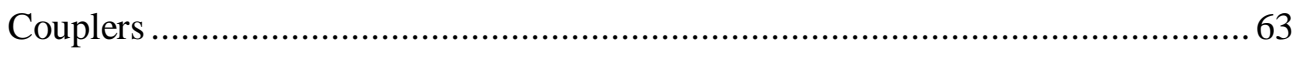

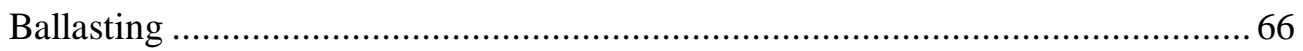

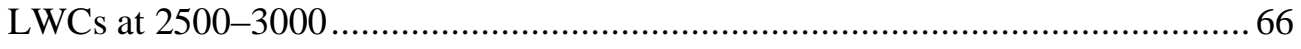

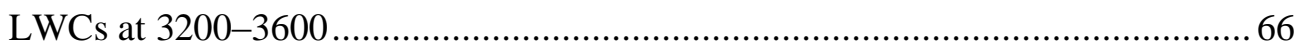

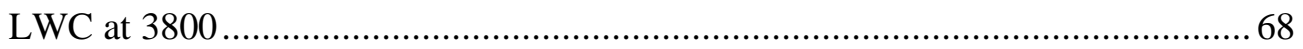

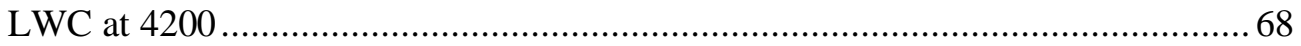

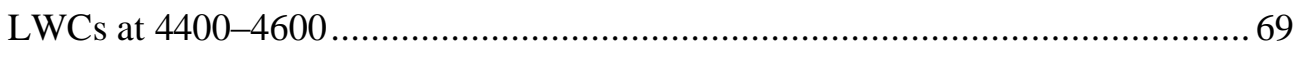

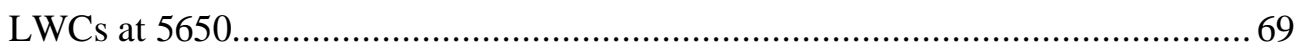

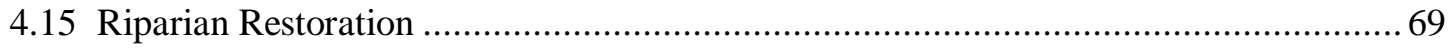

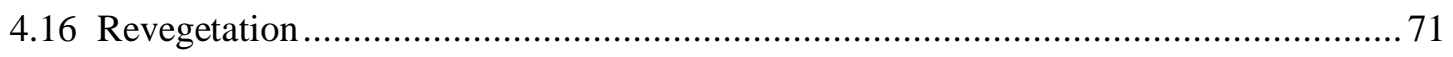

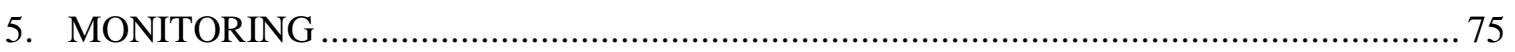

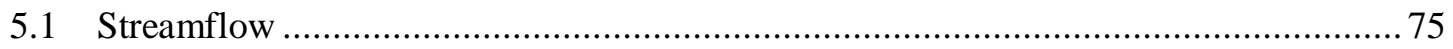




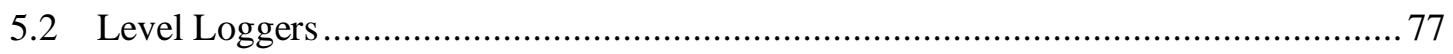

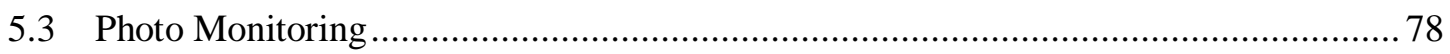

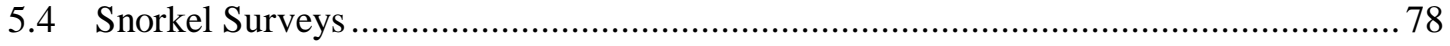

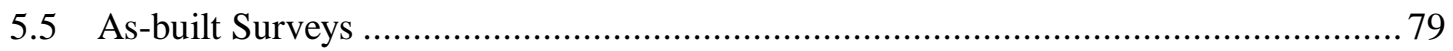

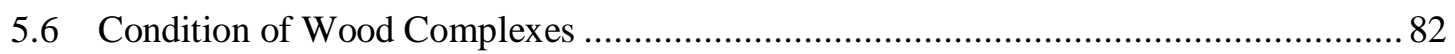

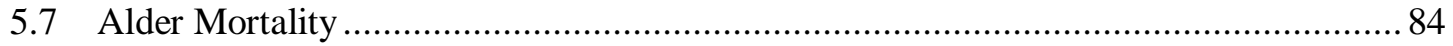

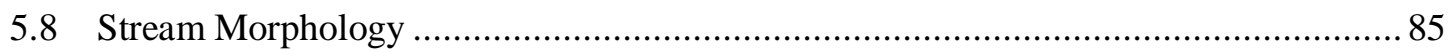

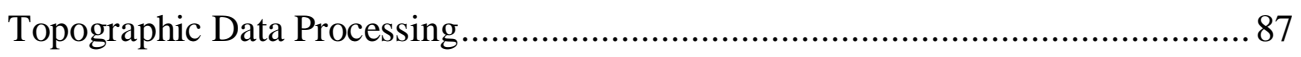

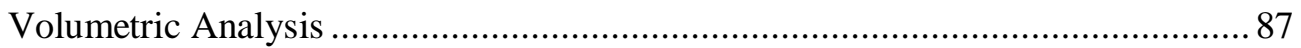

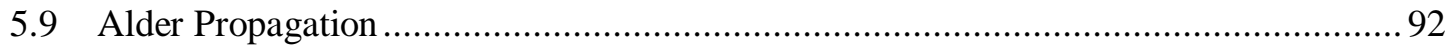

5.10 Performance, Stability, and Hydraulic Influences of Phase I LWCs ............................ 93

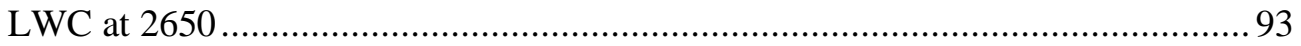

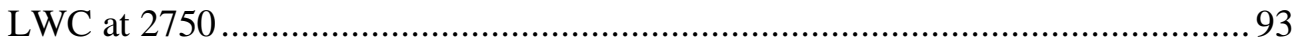

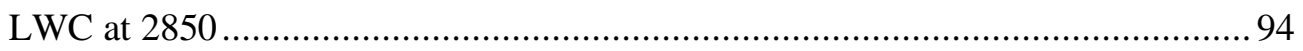

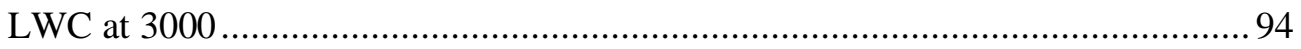

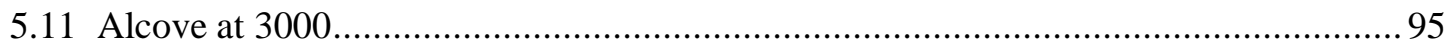

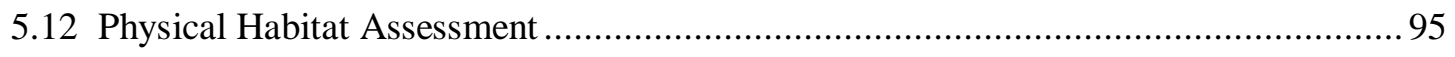

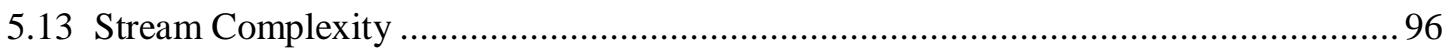

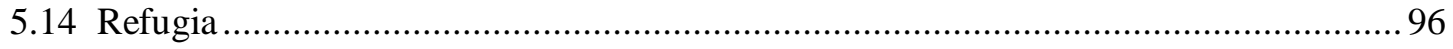

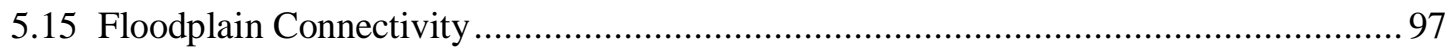

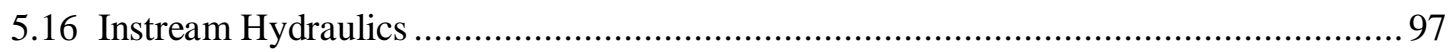

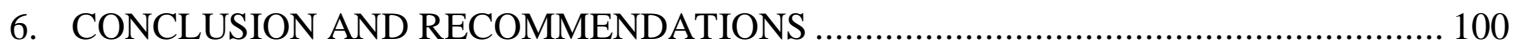

6.1 Salmonid Production and Restoration Effectiveness ........................................... 100

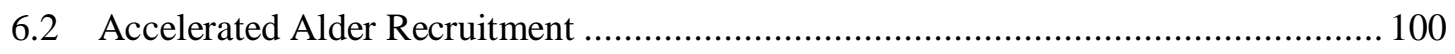

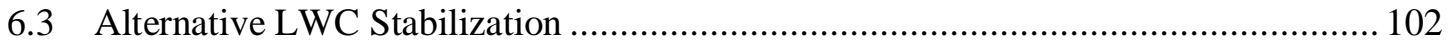

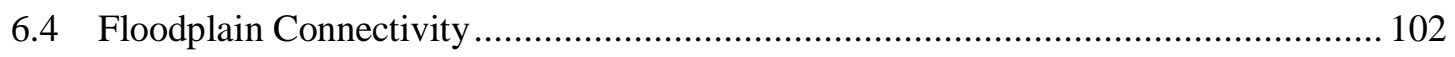

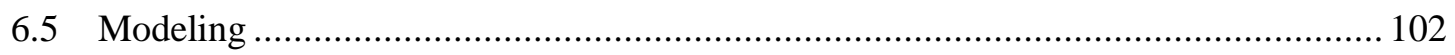

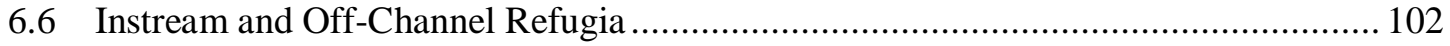




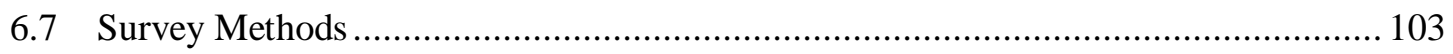

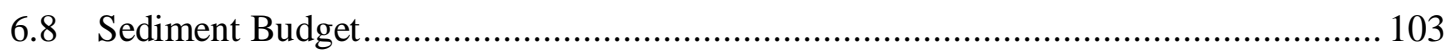

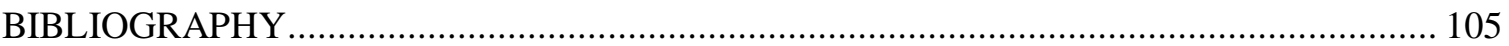

\section{APPENDICES}

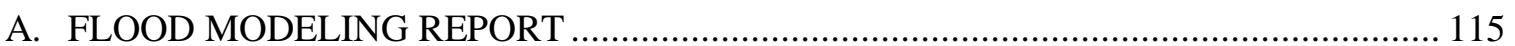

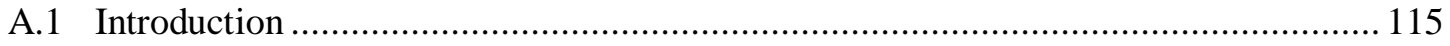

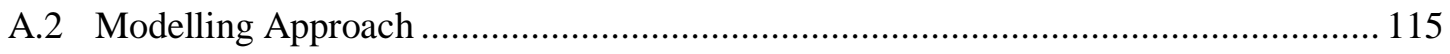

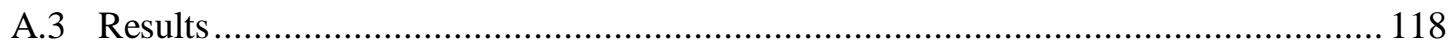

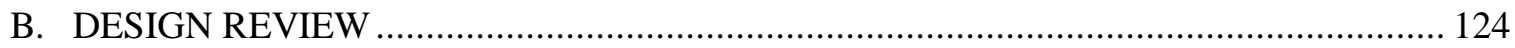

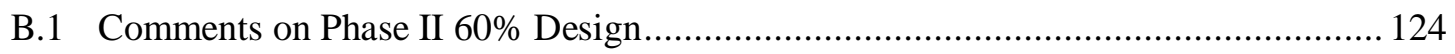

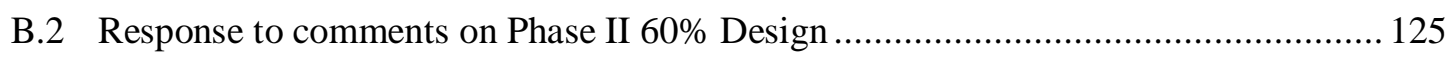

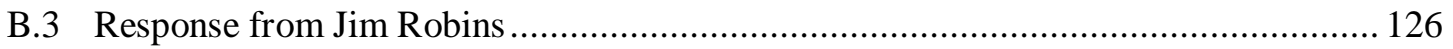

B.4 Lower Scotts Creek Design Review Meeting, 1/22/14 …..................................... 127

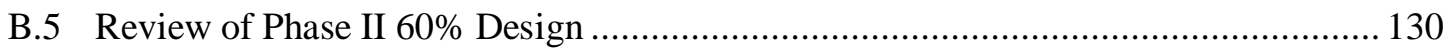

B.6 Response to Phase II 60\% Design Review ............................................................ 131

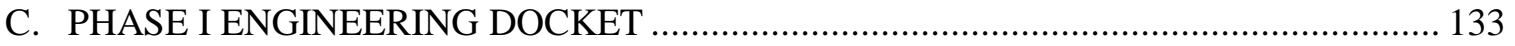

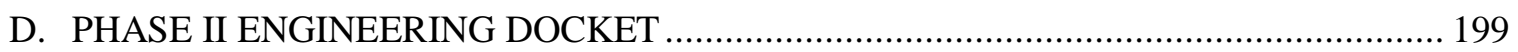

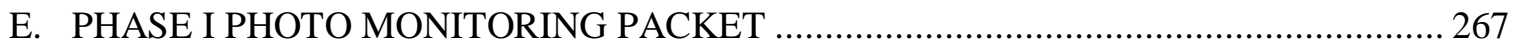

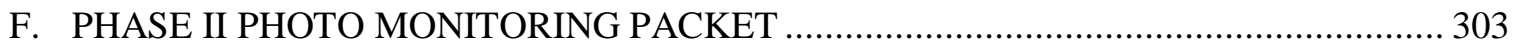

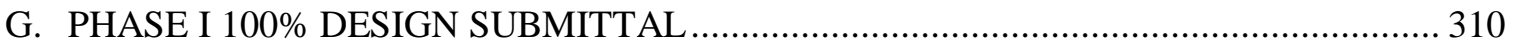

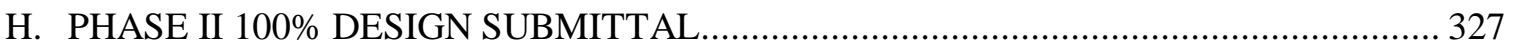

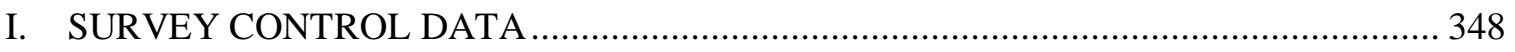

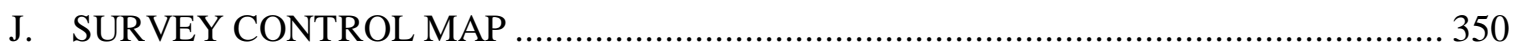




\section{LIST OF TABLES}

Table

1. Population estimates for CCC Coho Salmon abundance since the 1940s (excerpted from

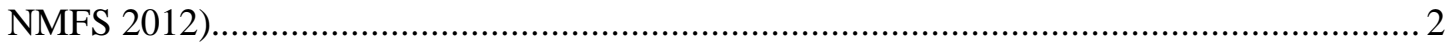

2. Dissolved oxygen levels and temperatures in existing off-channel ponds on $9 / 20 / 2013 \ldots \ldots . .28$

3. Frequency of habitat units per river mile. Project reach is italicized.................................. 35

4. Percent of each reach dominated by habitat type. Project reach is italicized....................... 35

5. Lengths and locations of target sub-reaches along lower Scotts Creek. ............................. 36

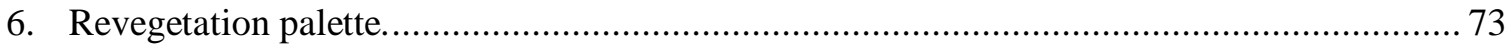

7. Pre-project snorkel survey results for the Phase I study reach. ....................................... 79

8. Pre- and post- season topographic survey point statistics for the Phase I study reach. ......... 87

9. Comparison of results from the AutoCAD Civil 3D (TIN) and Geomorphic Change Detection (DEM) analyses. 


\section{LIST OF FIGURES}

Figure

1. The Scotts Creek watershed (outlined in black), and project reach (dotted line), on the USGS Davenport topographic map. The inset shows the location (circled) within the state.

2. Stage (top) and estimated discharge (bottom) hydrographs for lower Scotts Creek below Archibald Creek from 1/17/2010-12/12/2012.

3. Flow histogram with flow regimes for the Scotts Creek stream gage below Archibald Creek for $1 / 17 / 2010-12 / 16 / 2012$.

4. Results of 2013 vegetation survey for the project reach.

5. Hillshade view of lower Scotts Creek showing deteriorating levees (highlighted in yellow) along the left bank.

6. Orthographic aerial images of project reach showing regeneration of riparian vegetation from 1993 (above, representative of the vegetative condition that persisted until the establishment of the WRP) to 2012 (below), and approximate 2003 WRP boundary (hatched area). The CA-1 bridge is visible at top left.

7. Conceptual map showing restoration opportunities along lower Scotts Creek (Perkins, 2012).

8. Diagonal berm.

9. Project reaches with river stationing in feet upstream from the CA-1 bridge. Blue denotes Phase I, cyan Phase II. Stationing is offset by approximately -100 feet compared to stationing shown in the $100 \%$ design drawings.

10. HEC RAS model results for the bankfull event showing potential inundation (shaded blue) through the proposed levee breaches

11. Log-rootwad coupler.

12. Log-boulder coupler.

13. Photo taken during the $12 / 11 / 2014$ storm of the access road segment that was to be decomissioned. 
14. A comparison of water surface elevations in the alcove feature (solid line) and the drainage ditch (dashed line) during a December 2014 peak flow event..

15. Log survey method.

16. Surveying the permiter of a boulder.

17. Surveying bolt heads.

18. Plan view plot of the fall 2014 as-built survey (red) overlain with the spring 2015 postseason survey(black) of the Phase I constructed large wood complexes showing displacement of the individual components. The stream flow was from top to bottom relative to the page.

19. Elevation change histogram of scour (red) and deposition (blue) within the study reach showing bias towards deposition (distribution is skewed to the right).

20. Study reach survey results showing habitat units, instream wood, and channel change between June 2014 DEM (top) and March 2014 DEM (bottom), and DEM of difference (bottom).

21. Habitat volumes at varying water surface elevations (primary axis), and volumetric differences (secondary axis) between June 2014 and March 2015.

22. Photo of LWC at 2750 following stormflow showing depositon of cobbles, pool scour, and debris racking.

23. Looking NE on 12/11/2014 at breach at 1900 (foreground) and 2000 (background). Photo shows outflow through both breaches and floodplain inundation.

24. Looking east at debris racked across the throat of the breach at 2000 on $12 / 18 / 2014$. Scotts

Creek is directly behind the vantage point.

25. Rilling at the mouth of levee breach at 2000 on $12 / 18 / 2014$

26. Standing in the breach channel at 1900 looking west at Scotts Creek on 12/18/2014. Vegetation is laid down in the outflow direction (towards camera).

27. Hillshade DEMs showing existing (left) and proposed (right) ground surfacess. Top: Archibald Creek confluence area with "Field 2" at right of frames. Bottom: Locations of floodplain and pond connections. Red dots highlight the proposed locations of large wood complexes 
28. Pre- (left) and post-restoration (right) water surface extents and depths for the bankfull flow. Red dots represent wood habitat structures, with river stations labeled in yellow (Note: stations in this report do not correspond to stationing found elswhere in the parent document)

29. Pre- (left) and post-restoration (right) instream and flood extents and depths for the bankfull discharge. Close-up is near the ag drain at 3657 and proposed off channel pond habitat at 3869. Red dots represent LWCs with river stations labelled in yellow. The combination of wood structures slowed the velocity of the water increasing water depth such that some water overtopped the ag field drain berm and flowed on to floodplain.

30. Pre- and Post- restoration water surface elevations for the bankfull flow at the location of a wood vane structure and pond connection channel junction (top, cross section 4569), and upstream of pond connection channel, but intersecting the pond at section station 700 (bottom, cross section 4598). Notice innundation of pond post-restoration.

31. Pre- and post- restoration water surface elevations for the bankfull flow at the location of a LWC at cross-section 3535 (top), and at cross-section 3579 immediately upstream of the structure. Notice the higher water surface elevation and flooding originating from upstream via the ag drain at 3657 (see Figure 3).

32. Pre- and post- restoration water surface elevations for the bankfull flow at the location of a LWC and connection channel (top, cross-section 3657), and upstream (bottom, cross section 3694). Notice the higher water surface elevations post-restoration.

33. Longitudinal water surface profiles for the bankfull (top), 10-year (middle) and 100-year (bottom) flow events pre- and post-restoration, with locations of LWCs (blue diamonds).. 123 


\section{INTRODUCTION}

\subsection{Decline of Central California Coast Salmon}

The Santa Cruz Mountains Diversity Stratum of the Central California Coast (CCC) Coho Salmon Oncorhynchus kisutch Evolutionarily Significant Unit (ESU) encompasses the southernmost historical populations of Coho Salmon in North America. Currently, only Scotts Creek (Santa Cruz County) maintains a persistent population within the stratum, represented by all three year classes. Consequently, Scotts Creek is the focal point of Coho Salmon recovery in the region (Kiernan, personal communication, 11/25/2015). With virtually no urbanization, high water quality, and cold perennial flows, Scotts Creek has the potential to help rebuild Coho Salmon populations within the greater Santa Cruz Mountains Diversity Stratum and maintain the historic range of the species. Conversely, further loss of habitat or failure to address factors limiting Coho Salmon production in Scotts Creek could lead to the extirpation of the local diversity stratum, and hinder recovery efforts throughout the entire CCC Coho Salmon ESU.

In 1971 the California Department of Fish and Game documented 80\%, 65\%, and 64\% declines in North Coast steelhead Oncorhynchus mykiss, Coho Salmon, and Chinook Oncorhynchus tshawytscha runs respectively, from 1940 to 1970, and a 46\% decline in the Sacramento-San Joaquin Chinook fall-run. In the 1970s, environmental legislation including the California Forest Practices Act, Porter-Cologne Water Quality Act, the California Environmental Quality Act (CEQA), and the National Environmental Policy Act (NEPA) were enacted to protect declining species and habitats, including fisheries (Flosi et al., 2010). According to the California Advisory Committee on Salmon and Steelhead Trout (1988), "this trend of decline is the cumulative result of nearly a century of water and land use practices and policies that have favored development of other natural resources over the conservation of fish..." Estimates of CCC Coho Salmon abundance show a decline since the 1940s, and then a collapse across nearly all populations in the late 2000 s (Table 1). 
Table 1. Population estimates for CCC Coho Salmon abundance since the 1940s (excerpted from NMFS 2012).

$\begin{array}{ll}\text { Year or range } & \text { Population estimate } \\ 1940 \mathrm{~s} & 200,000-500,000 \text { statewide } \\ 1963 & 99,000 \text { statewide, approximately 56,100 in CCC Coho Salmon ESU streams } \\ 1984 / 1985 & 6,000 \text { wild CCC Coho Salmon adults } \\ 1990 \mathrm{~s} & >500 \text { wild adults } \\ 2009 & 2,000-3,000 \text { wild adults }\end{array}$

The CCC Coho Salmon ESU was listed under the Federal Endangered Species Act as threatened with extinction in 1997, and its protection status was upgraded to endangered in 2005. In response to the 2005 listing, the National Marine Fisheries Service (NMFS) Southwest Region Protected Resources Division, North Central Coast Office recovery team developed the Recovery Plan for the Evolutionarily Significant Unit of Central California Coast Coho Salmon (Final Plan, NMFS 2012), a non-regulatory document that describes "site-specific management actions as may be necessary to achieve the Plan's goal for the conservation and survival of the species" (16 U.S.C. 1531). Across the CCC ESU, Coho Salmon populations alarmingly collapsed in 2006 and remained depressed for the remainder of the decade affecting all three year classes. Spence and Williams (2011) concluded that the CCC Coho Salmon ESU was in danger of extinction, reinforcing the 2005 state and federal listings, and added that the risk of extinction was greater than five years before. The findings of Spence and Williams (2011) caused the NMFS Fisheries Protected Resources Division to "shift our focus from long-term recovery to include a short-term strategy to prevent extinction" (NMFS 2012, Executive Summary, p. 16). 


\subsection{Anthropogenic Habitat Loss}

According to NMFS (2012), the "destruction and modification of habitat over 150 years has been identified as a primary cause" for the decline of CCC Coho Salmon. Across the CCC Coho Salmon ESU domain, researchers identified low juvenile summer and winter rearing survival due to impaired instream habitats, combined with poor ocean conditions as the primary causes of the decline of CCC Coho Salmon populations (NMFS, 2012, vol. I, p. vii). Recovery domain streams were found to be impaired by low stream complexity associated with lack of instream wood, high sediment loads, lack of winter refugia, inadequate summer flows, and high temperatures. Low stream complexity is associated with historic land management practices of dredging, channelization, and wood removal. In the past, these practices were widely accepted methods of increasing agricultural production and protecting structures or roads from flood damage. Statewide, habitat losses are associated with past and current land use activities, including hydroelectric development, dams and reservoirs, instream hydraulic and dredge mining, water diversions, floodplain encroachment including urbanization and farming agriculture (on floodplains), timber harvesting, and the construction of highways and railways.

Habitat conditions in lower Scotts Creek were degraded by a number of anthropogenic effects (NMFS 2012). Habitat loss was associated with a legacy of dredging, channelization, wood removal, clearing of riparian forest, and the construction of levees along lower Scotts Creek. In particular, the deteriorating levees along the lower one-mile reach of Scotts Creek continued to limit floodplain connectivity and high-flow refugia (NMFS 2012). Although dredging and levee maintenance ceased in the early 1980s, and the practice of wood removal was strictly limited, the associated habitat impairments persisted. The straightened morphology, deteriorating levees, and impaired wood recruitment likely contributed to the long-term stability of simplified, planar-bed reaches lacking functional rearing and refuge habitat and LWD. While observations suggested that floodplain connectivity was slowly improving as the levees deteriorated, NMFS (2012) found 
salmonid habitat was impaired by low habitat complexity in terms of pool:riffle:flatwater ratio and shelter rating, and an independent 2013 habitat survey found lower Scotts Creek lacking in percent primary pools and density of key large woody debris (LWD) pieces (Brubaker 2015).

\subsection{Goals and Objectives}

The goals of the project were to restore floodplain connectivity and improve salmonid habitat conditions, with a focus on addressing the physical habitat impairments limiting salmonid production on lower Scotts Creek. The project's specific objectives were to:

1. Increase the frequency of instream and alcove refugia

2. Increase the frequency of points of floodplain connectivity

3. Increase the frequency, depth, and volume of pools

4. Increase the frequency of primary pools

5. Increase stream percent cover and pool shelter ratings

6. Improve sediment sorting and increase the frequency of spawning habitat

The objectives of the project were consistent with high-priority federal recovery actions. The NMFS Recovery Strategy for Scotts Creek (Recovery Strategy ScC-CCC, 2012) recommends specific recovery actions necessary to prevent extinction of the CCC Coho Salmon ESU. The goal of the recommended actions is to "address the present or threatened destruction, modification, or curtailment of the species habitat or range" by restoring floodplain connectivity, habitat complexity, hydrology, sediment regime, and species viability (NMFS 2012). The recommended recovery actions included enhancing floodplain connectivity by breaching levees and increasing alcove and side-channel refuge and rearing habitat (Recovery Actions 2.1.1.1 and 2.1.1.2), increasing large wood frequency by constructing instream wood features to restore habitat complexity (3.1.1.1), improving shelter rating, habitat complexity, pool frequency and pool depths by maintaining or enhancing instream woody debris or other instream structures (3.1.2.1), improving pool:riffle:flatwater ratios by increasing the frequency of riffles (3.1.3.1), minimizing redd scour by constructing instream wood features (4.1.1.1), improving instream gravel quality by decommissioning riparian roads (9.1.1.5), and monitoring the performance of recovery efforts (10.1.1.5). 


\subsection{Project Partnership}

There has been considerable interest from local, state, and federal fisheries biologists in restoring floodplain connectivity and ecological function in lower Scotts Creek to benefit both Coho Salmon and steelhead. The importance of Scotts Creek to the survival and recovery of Coho Salmon led to a partnership between the Cal Poly Corporation (the landowner) and the Resource Conservation District of Santa Cruz County to design and implement a project to "improve salmonid and terrestrial amphibian habitat quality along a one-mile reach of Lower Scotts Creek", and 'benefit hydrologic and overall riparian function by remediating the adverse effects that resulted from the channel modification and levee system" (IWRP Phase 3 Individual Design Project Work Program, revised 11/4/2013).

\subsection{Project Overview}

The lower one-mile reach of Scotts Creek, upstream from the estuary, was targeted for restoration. Portions of the existing levees along lower Scotts Creek were breached to increase the frequency and duration of floodplain inundation and increase high flow refugia. Alcove features were excavated at the margins of the main channel, and connection channels with existing hydrologic features on the floodplain were excavated, to increase winter refugia. The Archibald Creek confluence was enhanced to form backwater winter refugia. Instream large wood complexes (LWCs) were constructed to increase instream habitat complexity in terms of percent cover and pool frequency, depth, and volume. Accelerated hardwood recruitment was used to enhance LWC performance, and alternative techniques were used to stabilize the LWCs. A riparian road was decommissioned and revegetated to improve riparian function and address a potential sediment source.

The project was largely focused on process-based restoration. It was recognized that the legacy effects of past land uses likely interrupted important hydraulic and vegetative processes responsible for driving morphologic change and forming salmonid habitat, including bed and bank scour, 
sediment sorting/deposition, bar development, and riparian forest colonization and recruitment. The project sought to jump-start these natural processes that were interrupted by a legacy of frequent and intense anthropogenic disturbance.

\subsection{Monitoring}

A monitoring plan was developed and implemented to determine if the project met its objectives, and answer key research questions related to stream and floodplain restoration. Proposed metrics included the quantity, frequency, and volume or depth of pools; the quantity, frequency, and quality of instream refugia, and the frequency and duration of inundation of off-channel, and floodplain refugia. Post-project monitoring was viewed as essential because of the experimental nature of the proposed wood recruitment and LWC stabilization techniques, and the constructed connection channels with existing off-channel habitat features.

\subsection{Key Research Questions}

The project served as a platform for answering key research questions related to stream and floodplain restoration. In Central California coastal streams, the effectiveness of restoration on salmonid populations is a key unknown. Demonstrating a link between restoration and salmonid recovery is critical to maintaining funding and political support for restoration. The Life Cycle Monitoring Station (LCMS) on Scotts Creek, operated by NMFS since 2001 as part of the California Coastal Salmonid Monitoring Plan (CMP), presents a unique opportunity to track project effectiveness on salmonid populations at both the watershed and regional levels. CMP's objectives are to measure fish production in coastal rivers and streams. The Scotts Creek LCMS is one of several monitoring stations which support this program by helping to determine what factors affect Coho Salmon and steelhead production. LCMS baseline data and post-project data may be useful for evaluating restoration effectiveness.

The project sought to increase instream habitat complexity through accelerated hardwood recruitment, a technique that had not been previously documented in the literature. Opperman 
$(2002,2005)$ and Opperman and Merenlender (2007) found that the majority of intact, natural LWD in response reaches of coastal streams were formed by living hardwood key pieces, and that debris jams formed by living key pieces were more likely to remain stable and influence stream morphology and habitat. This research prompted an attempt to mimic natural recruitment of hardwood living key pieces through accelerated recruitment, with a focus on the feasibility and longevity of in-situ red alder Alnus rubra, the dominant riparian tree species along lower Scotts Creek. Short-term monitoring was used to document the effects of accelerated alder recruitment on habitat complexity and instream hydraulics, and long-term monitoring was begun to track the stability and survivorship of red alder recruits.

Standard anchoring techniques for constructed wood features are outlined in Flosi et al. (2010). Alternative stabilization techniques were used in the project that offered potential advantages over standard techniques. The performance of these techniques was monitored during and after winter stormflows and the results are documented herein.

Finally, lower Scotts Creek represents a demonstration site for the interaction between floodplain restoration and agricultural operations. The project may provide research opportunities for studying the ecosystem services afforded by increased floodplain activation related to agricultural production and groundwater storage. 


\section{LITERATURE REVIEW}

Central California Coast (CCC) populations of native Coho Salmon and steelhead are on the brink of extinction or threatened with extinction from streams where once historically abundant or present (Nehlsen et al. 1991; Brown et al. 1994; Adams et al. 1999, 2007; Good et al. 2005; Spence et al. 2011; NMFS 2012), including some streams draining to the San Francisco estuary (Leidy et al. 2005). CCC Coho Salmon and steelhead, and their habitat, are federally protected under the Federal Endangered Species Act (ESA). For the purpose of implementing the ESA, salmonid populations are defined as discreet, locative, demographic units (Waples 1991; McElhany et al. 2000; Bjorkstedt et al. 2005). Coho Salmon Evolutionarily Significant Units (ESUs) and steelhead Distinct Population Segments (DPSs) are considered genetically significant metapopulations (McElhany et al. 2010) and are classified as distinct species under the ESA. The CCC Coho Salmon ESU and steelhead DPS are recognized as endangered and threatened respectively (Good et al. 2005). In 2011, the Southwest Fisheries Science Center reviewed and updated the status of the CCC steelhead DPS (Williams et al. 2011a). The status of the CCC Coho Salmon ESU was updated (Williams et al. 2011b) following the completion of a response to petitions challenging the southern extent of the ESU. Petitioners challenged the historical precedence of Coho Salmon south of San Francisco prior to the introduction of hatchery-reared fish beginning in the 1890s (see McCrary, unpublished letters, 2003, 2004, 2005; Alvarado et al., unpublished comments on CDFG review, 2005; Kaczynski and Alvarado 2006). A special review established the precedence of wild Coho Salmon south of San Francisco, updated the listing status, and expanded the southern extent of the ESU to include Soquel and Aptos Creeks (Adams et al. 2007; Spence et al. 2011; Williams et al. 2011). CCC Coho Salmon critical habitat is defined as all accessible streams and estuaries from Punta Gorda to the San Lorenzo River, and two additional streams south of the San Lorenzo River (Soquel and Aptos Creeks) (Weitkamp et al. 1995; NMFS 1999; Adams et al. 2007; Spence et al. 2011b). 
NMFS is required by federal law to guide the recovery of ESA listed populations of Coho Salmon and steelhead, and protect their critical habitat (McElhany et al. 2000). The Recovery Plan for the Evolutionarily Significant Unit of Central California Coast Coho Salmon (NMFS 2012), mandated by the ESA, was created to prevent the extinction of, and promote the recovery of, the CCC Coho Salmon ESU. Immediate recovery action is needed to prevent the extinction of the CCC Coho Salmon ESU (Spence and Williams 2011; NMFS 2012; J.J Smith 2013). To plan recovery efforts, NMFS analyzed recovery domain streams using The Nature Conservancy's Conservation Action Planning Analysis. Streams were evaluated by comparing physical habitat and population survey data to the intrinsic potential (IP) of each stream to support salmonids. IP, a proxy for historical carrying capacity, is a GIS-derived composite of mean channel gradient, mean annual discharge, and valley constraint (ratio of floodplain width to width of active channel), all of which are indicators of critical watershed processes capable of supporting Coho Salmon (Burnett et al. 2003; Agrawal et al. 2005; Bjorkstedt et al. 2005).

Habitat complexity and floodplain connectivity along Scotts Creek were found to be impaired respectively by lack of instream wood and the deteriorating levee system (NMFS 2012). The Recovery Strategy for Scotts Creek (Recovery Strategy ScC-CCC, 2012) recommended specific recovery actions including enhancing floodplain connectivity and increasing alcove and sidechannel refuge and rearing habitat by breaching levees (NMFS 2012). Refugia allow organisms to survive natural disturbances (Lake et al. 2007) and winter refuge habitat was found to be critically important to salmonid production in systems limited by overwinter parr-smolt survival (Zimmerman et al. 2012). Recovery Strategy ScC-CCC also recommended increasing habitat complexity by constructing instream wood features to restore habitat complexity, improving shelter rating, habitat complexity, pool frequency and pool depths by maintaining or enhancing instream woody debris or other instream structures, improving pool:riffle:flatwater ratios by increasing the frequency of riffles, minimizing redd scour by constructing instream wood features, improving 
instream gravel quality by decommissioning riparian roads, and monitoring the performance of recovery efforts.

Coho Salmon require clean loose gravels free of fine sediment for successful spawning, adequate pools with cover for juvenile rearing, alcove and off-channel refuge habitat, cool water, and sufficient ocean connectivity to permit outmigration and escapement (Flosi et al. 2010; NMFS 2012). Spawning and incubation occur in riffles with coarse permeable gravels (Shapovalov and Taft 1954; Beschta and Platts 1986; Flosi et al. 2010). Successful incubation requires adequate oxygenated flow. Deposition of fine sediment on redds increases mortality of pre-emergent salmonids (Beschta and Platts 1986). Emergent juveniles prefer shallow, slow water zones, associated with backwater pools, side channels, and stream margins (Flosi et al. 2010). Juvenile Coho Salmon prefer to forage and rear in slow current with temperatures between 48 and 60 degrees Fahrenheit (Flosi et al.2010). Preferred summer rearing habitat includes primary pools or backwater eddies with cool water associated with direct cover from undercut banks, living vegetation, and woody debris (Flosi et al. 2010). During high flows, juvenile Coho Salmon disperse to refuge habitats including slow and deep instream pools, and side- and off-channel backwater pools (Flosi et al. 2010). Pool depth and volume have been found to positively correlate with salmonid production. Survival is negatively correlated with increased water temperature and turbidity. There is mounting evidence that winter high flows limit survival and lack of winter habitat (refugia) limits Coho Salmon production in Northern California streams (Gallagher et al. 2012). Increased habitat complexity, in terms of the distribution of flow depths and velocities, large woody debris, bed substrate, temperature zoning, refugia, and shelter, has been found to reduce travel distance, risk of predation, and mortality (Columbia Habitat Monitoring Protocol 2014). Freshwater salmonid populations are strongly density dependent reinforcing the hypothesis that production is limited by lack of functional habitat (Gallagher et al. 2012). 
Dynamic natural processes, including LWD recruitment, vegetative growth and succession, sediment transport, channel meander, bed, bank and floodplain scour, aggradation, and bar formation, form a variety of salmonid habitat (Swanson et al. 1976; Beschta and Platts 1986; Sedell et al. 1988; Gregory et al. 1991; Abbe and Montgomery 1996; Beechie and Bolton 1999; Naiman et al. 2000; Florsheim and Mount 2002; Mount et al. 2003; Beechie et al. 2010). Streams reach a dynamic equilibrium of long-term processes, constrained by hydraulic, geologic, and vegetative conditions, that support non-random groupings, frequencies, and proportions of pools, riffles, bed material, and vegetation, all of which comprise critical salmonid habitat (Beschta and Platts 1986). Pool-riffle patterns are formed by localized scour and deposition during higher flows. Channel planform geometry strongly influences the frequency and distribution of habitat units. In a meandering stream, pools typically form at the outside of meander bends while riffles form at meander inflection points (Beschta and Platts 1986; Montgomery and Buffington 1997). Watershed processes and habitat conditions capable of supporting salmonids were historically present in Central California Coast recovery domain streams (Spence et al. 1996; Beechie and Bolton 1999; Bjorkstedt et al. 2005; NMFS 2012).

The decline of salmonid populations is attributed in part to loss of freshwater habitat associated with past and current land-use (Bisson et al. 1992; Gregory and Bisson 1997) and anthropogenic disruption of "natural rates of critical watershed processes" (NMFS 2012). Rapid disruption of local conditions to which native stocks are adapted threatens the viability of those local stocks, because stocks adapt on evolutionary time-scale to the specific areas they inhabit (Beechie and Bolton 1999). Historical reconstruction can reveal the root causes of disruption, establish benchmarks for stream functionality, and help prioritize restoration activities for the recovery of a selected species (Beechie and Bolton 1999). A comparison of historical and current conditions in Pescadero Creek, a coastal stream in southern San Mateo County revealed a doubling of sediment loads in the last 200 years due to anthropogenic surface erosion and channel incision related to 
logging, grazing, and agriculture. The lower floodplain is now a sediment source instead of a storage area and the rate of deposition in the lagoon is approximately 15 times the pre-European settlement rate which has resulted in a $75 \%$ reduction in the tidal prism and a $50 \%$ reduction in estuary surface water. Elevated sediment loads persist despite the cessation of the highest-intensity land-use practices, and the current sediment regime is expected to continue indefinitely (S.B. Frucht, 2/12/2015 presentation to the IWRP TAC on channel changes and sediment loads in the Pescadero-Butano watershed).

These findings highlight two important concepts. First that managing land use and land cover on a watershed scale can lead to improved aquatic habitat conditions because doing so addresses landscape-scale processes that contribute to habitat degradation (Opperman and Merenlender 2004), and second, that the negative impacts of high-intensity land use to persist long after the cessation of those land use activities (Foster et al. 2003). Cutting of riparian forests impairs large woody debris recruitment and the development of instream habitat for at least 50 years after (Grette 1985; Andrus et al. 1988), and instream wood loading will not return to pre-European levels for 250 years after (Murphy and Koski 1989).

Stream restoration is an effective means of counteracting the legacy effects of land use. The overall impact since European settlement can be characterized as a simplification of freshwater habitat. Restoration counteracts this trend by directly creating habitat units/components, and by restoring natural processes responsible for forming habitat and supporting the life-histories of native salmonid populations. Process-based restoration restores processes and morphologies which match long-term equilibrium conditions to which salmonids are adapted (Beschta and Platts 1986; Beechie and Bolton 1999). Restoration of habitat-forming processes may be more effective than constructing individual habitat features, partly because constructing habitat features may fail to address the ongoing processes responsible for habitat degradation, and constructed features may be damaged by these ongoing processes (i.e. sedimentation of constructed wood features, Beechie and 
Bolton 1999). Restoration of freshwater habitat will be effective at increasing productivity, and as a result, increasing population viability, because freshwater survival is strongly density dependent and, in addition, high quality freshwater habitat will buffer poor marine survival rates (Gallagher et al. 2012).

The legacy effects of land use combined with the steep decline of pacific salmon warrant the application of accelerated approaches to jump-start critical watershed processes responsible for maintaining salmonid populations. Jump-starting critical watershed processes must be done on a landscape scale to produce measureable results on the population level (Roni et al. 2010). Landscape scale restoration will require the development of low-cost and low-disturbance techniques in order to be affordable and applicable on a landscape scale. Accelerated wood recruitment may provide a viable alternative to engineered wood features to improve instream habitat in degraded systems that is applicable on a watershed or landscape scale.

CDFW and other agencies published standardized restoration techniques developed over several decades. The California Salmonid Stream Habitat Restoration Manual, 4th edition (Flosi et al. 2010) describes recommended stream restoration planning, design, implementation, and monitoring practices within the State of California. The manual focuses on improving fish passage, and on increasing habitat complexity by constructing instream structures including divide logs, digger logs, spider logs, log-rootwad-boulder combinations, log and boulder weirs, and log or boulder barbs. The manual provides detailed guidelines for appropriately sizing constructed features to the target stream based on parameters such as stream order and bankfull width, and for anchoring buoyant structures to boulder ballasts or buried deadman anchors using wire rope or rebar/all-thread pins. The manual includes brief guidance regarding the construction and sizing of unanchored LWD. Specifically, unanchored LWD is best suited for 1st-3rd order streams and should be constructed from $\geq 12$ in diameter logs with a length at least 1.5 times the bankfull width, or from $\geq 5 \mathrm{ft}$ diameter rootwads with $\geq 15 \mathrm{ft}$ in length and at least one-half the bankfull width (Flosi 
et al. 2010). Burial by bedload, anchor bolt failure, cable failure, stranding, and undermining due to bed/bank scour are prominent failure modes of constructed instream features (Frissell and Nawa 1992).

Large wood strongly influences channel morphology of smaller streams and is a critical element in the formation of freshwater salmonid habitat. LWD forms pools (Bisson et al. 1987; Montgomery et al. 1995, Abbe and Montgomery 1996), increases pool frequency in response reaches of small to moderately sized channels (Montgomery et al. 1995; Beechie and Sibley 1997), and retains sediment and POM (Bilby 1981; Megehan 1982; Bilby and Ward 1989). Salmonids prefer pools with LWD (Bisson et al. 1988). Debris jams retain organic material which fuels biotic processes in headwater streams (Bilby and Likens 1980). LWD increases prey availability which enhances fish production (Benke et al. 1985; Bilby and Bisson 1987; Naiman et al. 2002). Debris jams can influence stream hydraulics and facilitate colonization of portions of the stream channel with riparian vegetation leading to the development of patches of riparian forest (Abbe et al. 1996).

Recent studies have documented the effectiveness of restoration projects involving the placement of large wood pieces in the stream channel and floodplain (Roni et al. 2008). Input of large wood improved salmonid survival rates by sorting sediment, improving habitat shelter, increasing pool frequency and depth, and reconnecting floodplains (Gallagher et al. 2012). Managing stream energy using LWD has been a successful means for improving winter refuge opportunites for salmonids. Installation of LWD should be done in the lower portion of the watershed to create or preserve high-quality salmonid habitat, improve floodplain connectivity, and create new connections to ephemeral waterways (Gallagher et al. 2012).

Wood features constructed with whole tree materials were more effective than simple structures at providing instream cover, increasing pool habitat, sorting gravel, and improving habitat heterogeneity. Increasing wood piece count and jam volume generally increased effectiveness at achieving habitat objectives. Jam volume positively correlated with residual pool depth and 
upstream aggradation (Benegar 2011). Live wood is morphologically significant and debris jams that had living key pieces were more stable and persistent than those without living key pieces, were more likely to facilitate pool formation, and were associated with deeper pools with higher shelter ratings. Live wood will be more stable because of an attached rootwad and increased resistance to decay. Surveys should include living pieces, and further studies should be conducted to track the persistence and decay rates of living pieces (Opperman and Merenlender 2007). Northern California Alnus spp. and Salix spp. are capable of regenerating from pieces or whole fallen trees (Francis 2007). Recruitment of live wood occurs typically when trees fall into the channel as a result of bank erosion (Opperman et al. 2008). Opperman et al. (2008) hypothesize that living wood may be more geomorphically functional at smaller sizes than dead wood (Opperman et al. 2008).

Red alder is the most common hardwood in the Pacific Northwest, ranging from Southern Alaska $\left(60^{\circ} \mathrm{N}\right)$ to Southern California $\left(34^{\circ} \mathrm{N}\right)$ (Harrington 1990), and would be an attractive source of material for instream habitat enhancement except that red alder decays fastest compared to other species (Harmon et al. 1986, Harrington 1990, Naiman et al. 2002). For these reasons it is typically not used to create instream large wood structures. Conifer logs (redwood, cedar, hemlock) are preferred to create instream structures because of their resistance to decay (Harmon et al. 1986, Flosi et al. 2010). Establishing living red alder LWD through an accelerated recruitment technique may allow red alder to be effectively utilized to enhance instream habitat. Living red alder is “exceptionally resistant to decay after typical stem injuries" (Niemiec et al. 1995, p. 95).

Key studies in Pacific Northwest streams describe salmonid habitat preferences, and habitat characteristics which promote salmonid production, or overall ecosystem productivity. Juvenile Coho Salmon prefer to overwinter in off-channel habitat compared to the main channel (Swales et al. 1988). Juvenile Coho Salmon abundance in winter remained higher in stream reaches with adequate refuge habitat (Tschaplinski and Hartman 1983). Pre- and post-flood survey data from a 
Northern California stream showed high fidelity to and densities within off-channel alcove habitat. Fidelity, immigration, and density was highest in off-channel alcoves, second-highest in instream backwater zones, and lowest in main-channel pools (Bell et al. 2001), indicating strong preference and suggesting off-channel alcoves provide the highest-quality winter refuge habitat.

Coho Salmon disperse to instream structures and off-channel habitat features in summer and winter to seek temperature and velocity refuge (Morley et al. 2005; Whitmore 2014). Constructed offchannel habitat was utilized at a rate comparable to or higher than natural off-channel habitat features (Morley et al. 2005). Off-channel pond temperatures were presumably attenuated by groundwater inputs which provided temperature refuge in summer. Constructed off-channel ponds had higher temperatures in winter and lower temperatures in summer compared to natural features (Morley et al. 2005). Restoration of instream and off-channel habitat through the construction of large wood structures and off-channel ponds increased overwinter/oversummer survival, and growth/retention rates (Gallagher 2012; Whitmore 2014).

The flood pulse concept (Junk et al. 1989; Tockner et al. 2000) established the importance of the natural flood cycle to ecosystem function in tropical and temperate systems. Natural floodplains exhibit high biologic productivity and diversity (Tockner and Sanford 2002). In the Pacific Northwest, species richness and diversity was generally found to be higher in riparian zones than upslope habitat, and exhibits a gradient in the transition from lotic to upslope communities (Gregory et al. 1991). This gradient of productivity and diversity from lotic to upslope communities suggests that restoring the flood pulse to the historical floodplain will increase biologic productivity and species diversity and richness in riparian ecosystems. The short- and long-term effects of curtailment of flood pulse in riparian systems by the construction of flood control structures are not fully understood. Flood pulse restoration restructured ecosystem function of the riparian forest floor (Molles et al. 1998). Managed flooding jump-started chemical and physical processes and microbial populations (Ellis et al. 1996). Microbial populations and forest floor respiration 
increased, as did decomposition of leaf litter following a flood pulse. In addition, the riparian forestfloor arthropod community was restructured (Molles et al. 1998). Levee breaching can restore floodplain topographic variation, leading to greater habitat variability, and by extension may induce ecological response (Florsheim and Mount 2002). Levee removal can be effective when legacy channelization structures continue to limit channel meander and the development of wetland areas and a functional riparian corridor. Increased groundwater recharge associated with improved floodplain connectivity can improve flow levels during summer low flows (California Environmental Protection Agency 2009). Computer modeling has shown that levee removal can reduce flood stages in zones of backwater influence (Hammersmark et al. 2005).

Unanchored wood structures may be a viable and cost-effective alternative to anchored structures in Northern California coastal streams (Carah et al. 2014). Accelerated wood recruitment mimics natural processes at considerably lower costs per length of stream treated compared to engineered wood structures (Carah et al. 2014). A project carried out on Soquel Creek, a 42 square-mile coastal stream in Santa Cruz County, introduced unanchored multi-stem redwood trees along a 300-foot reach. Rootwads were excavated from the streambanks and placed in the channel with stems attached to emulate the natural recruitment processes of landslides, debris flows or bank erosion that deliver key structural woody debris elements ("key logs") to the stream channel. Key logs are stable, capable of racking debris, provide instream cover, and facilitate geomorphic change and habitat forming processes (Reynolds 2013). Further research into the effectiveness of unanchored LWD is needed. The long-term retention rates and the differences, if any, in effectiveness between unanchored and anchored structures, are still unknown and under investigation (Carah et al. 2014).

Large instream wood structures were constructed in lower San Vicente Creek to increase stream complexity and improve habitat conditions for salmonids. These structures were constructed from imported redwood rootwads and granitic boulders. These structures improved instream cover and facilitated scour and aggradation. The highest densities of juvenile salmonids were observed in and 
around the constructed features (J. Kiernan, personal communication, cited by S. Gillett et al. 2014, report on salmonid recovery in the San Vicente Creek watershed). Design flow depths, velocities, and shear stresses were modeled using the Army Corps of Engineers Hydrologic Engineering Center's River Analysis System (HEC-RAS) and these modeled parameters were used to engineer the instream features. The 100-year flow was modeled to evaluate the effect of the addition of the proposed wood structures on flood elevations. Wood features were designed to obstruct no more than $50 \%$ of the bankfull channel. Wood elements were ballasted with boulders. Anchoring was achieved by attaching wood structures to boulder ballasts with rigid all-thread/nut/washer fasteners, according to methods described in Flosi et al. (2010). Boulder anchors were buried in the streambed to withstand the drag forces on the structures applied by streamflow (Ruttenberg, unpublished engineering docket, 2011).

The major question surrounding the practice of stream restoration for Coho Salmon recovery in California is whether or not restoration is effective at increasing production on a watershed or landscape scale (Gallagher et al. 2012), or recovering or preventing the extinction of Coho Salmon at a population or metapopulation level (Swales, personal communication, 2015; Kiernan, personal communication 2/2/2016.) Arrays of monitoring activities combined with regional data warehousing and analysis has been used to determine whether or not the cumulative effects of restoration projects are leading to the recovery of the species, whether individual projects are meeting their intended objectives, and to compare the benefit of restoration effort versus the environmental and economic costs (e.g. Columbia Habitat Monitoring Program [CHaMP]). The CDFW Fisheries Restoration Grant Program (FRGP) requires specific monitoring activities as a condition of funding. FRGP views off-channel and side-channel habitat projects as "experimental" and project proposals "must include physical and biological monitoring appropriate to the targeted species and targeted time period of project use" to demonstrate the "biological and geomorphic merits of these projects" on a landscape/population scale (FRGP, 2015 Public Solicitation Notice, 
Part V, p. 38). Projects resulting in neutral or negative biological effects are likely underrepresented in the literature. Documentation of failures is important in order to prevent costly mistakes (Hamilton 1989; Frissell and Nawa 1992).

Effectiveness monitoring has been carried-out on a watershed scale. Eleven years of Coho Salmon parr, smolt, and adult abundance data from three coastal Life Cycle Monitoring Streams in Mendocino County, California were analyzed to evaluate the effectiveness of restoration on Coho Salmon productivity. Abundance and survival at each life-stage was estimated using capturerecapture, depletion sampling, and PIT-tagging. Marine and freshwater survival, and carrying capacity were estimated. Survival estimates were carried out through a panel of survey methods including mark and release, PIT tagging, electrofishing, flashboard weirs (Gallagher et al. 2012).

Establishing the relationship between restoration effort and species recovery is critical because policy makers and government officials need scientific data to support their policy decisions and budget expenditures. While salmonid utilization of LWD is documented, it is not known how much wood is enough to bolster a declining population, or by extension, how much freshwater restoration will be required to recover threatened and endangered salmonids in California. 


\section{SITE DESCRIPTION}

Scotts Creek, located near the town of Davenport in northern Santa Cruz County (Figure 1), California, drains 30 sq mi of the Santa Cruz Mountains to the Pacific Ocean. Tributaries include Queseria, Archibald, Winter, Little, Big, and Mill Creeks (downstream to upstream order). The upper watershed consists of steep inner gorges in redwood and mixed conifer forest. The lower watershed (below the Swanton Road bridge) consists of a forested multi-story riparian stream corridor dominated by red alder and 65 acres of organic crop fields set on a broad alluvial/colluvial floodplain. Soils are generally characterized as sandy loam with high erosion potential. Erosion is curbed by dense vegetative cover within the riparian corridor. The bed substrate in lower Scotts Creek is composed mostly of low specific gravity $(<1.4)$ Santa Cruz mudstone gravel and cobbles embedded in granitic sands. Extensive shaping of the floodplain has occurred as a result of agricultural operations that date back nearly 200 years, the construction of a railroad in the early 1900s, the construction of the CA-1 bridge, road prism, and levees in the estuary in 1938, and the construction of additional levees along the crop fields in the late 1950s (Rowley [ed] 2003, unpublished Scotts Creek watershed assessment). Lower crop fields were laser-levelled in the 1990s. Other land uses include uneven-aged forest management for single tree selection harvesting of primarily redwood in the upper watershed, and rotational planned grazing (or 'holistic') rangeland management on the coastal terraces within the watershed. Thirty-six percent of the watershed (primarily the upper watershed) burned in August of 2009 (Auten 2012). Ninety-five percent of the watershed is privately owned, mostly in large parcels with some residential subdivisions. Scotts Creek is not listed as impaired on the State 303(d) list for any Total Maximum Daily Load (TMDL) constituents (State Water Resources Control Board 2012). There are 14.3 miles of anadromous streams within the watershed, including upper watershed reaches of the mainstem and three major tributaries, Little Creek, Big Creek, and Mill Creek, below migration barriers (Hayes et al. 2012). 


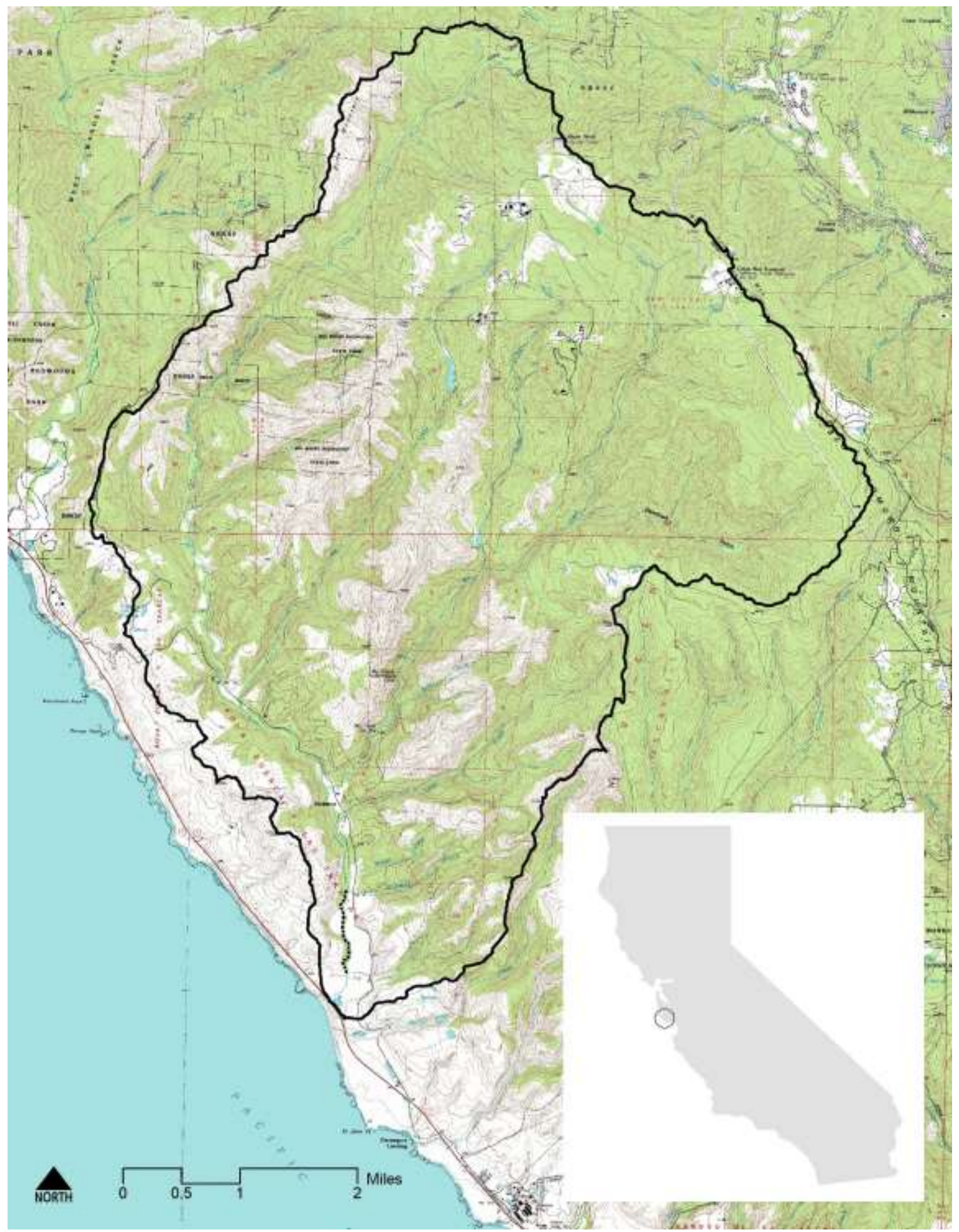

Figure 1. The Scotts Creek watershed (outlined in black), and project reach (dotted line), on the USGS Davenport topographic map. The inset shows the location (circled) within the state. 


\subsection{Hydrology}

Precipitation is orographically influenced, with annual precipitation totals averaging 30 in at the mouth and 49 in along high ridgelines (Perkins 2012). The channel gradient averages $0.3 \%$ from the CA-1 bridge to Archibald Creek at station 5900. Throughout this document, features are located by river station in feet upstream from the CA-1 bridge (see Figure 9 on page 49). The active channel is typically $\sim 30 \mathrm{ft}$ wide. The representative bankfull channel cross section in this reach is 55 feet wide and 5 feet deep with an effective flow area of 200 square feet (Akers 1999; Goin 2011, unpublished reports). There is support that the 1- to 2-year flow corresponds to the flow at which incipient flooding occurs along lower Scotts Creek (Dietterick, personal communication, 7/9/2013).

The bankfull discharge in lower Scotts Creek is estimated to be $\sim 1000 \mathrm{ft}^{3} / \mathrm{s}$ with a mean velocity of $\sim 5 \mathrm{ft} / \mathrm{s}$. Recent summer low-flow depths in riffles have been typically $<0.5 \mathrm{ft}$ with flow rates $<10$ $\mathrm{ft}^{3} / \mathrm{s}$ and velocities of $\leq 1 \mathrm{ft} / \mathrm{s}$ (J. Louen, personal communication, 3/27/2014). In addition to manual flow measurements, a stream gage records continuous stage data near the confluence with Archibald Creek at station 5700. A rating curve is used to estimate discharge on stage. Stage and discharge hydrographs for 2010-2012 show typical seasonal flow cycles (Figure 2). For the period of record represented below, Scotts Creek flowed at 0-20 $\mathrm{ft}^{3} / \mathrm{s}$ (summer low flow) for $58 \%$ of the time, from 20-200 $\mathrm{ft}^{3} / \mathrm{s}$ (winter base flow) for $38 \%$, and above $200 \mathrm{ft}^{3} / \mathrm{s}$ (high flow) for $4 \%$ of the time (Figure 3). Major flood events occurred recently in 1998, 1999, and late in December 2012. 

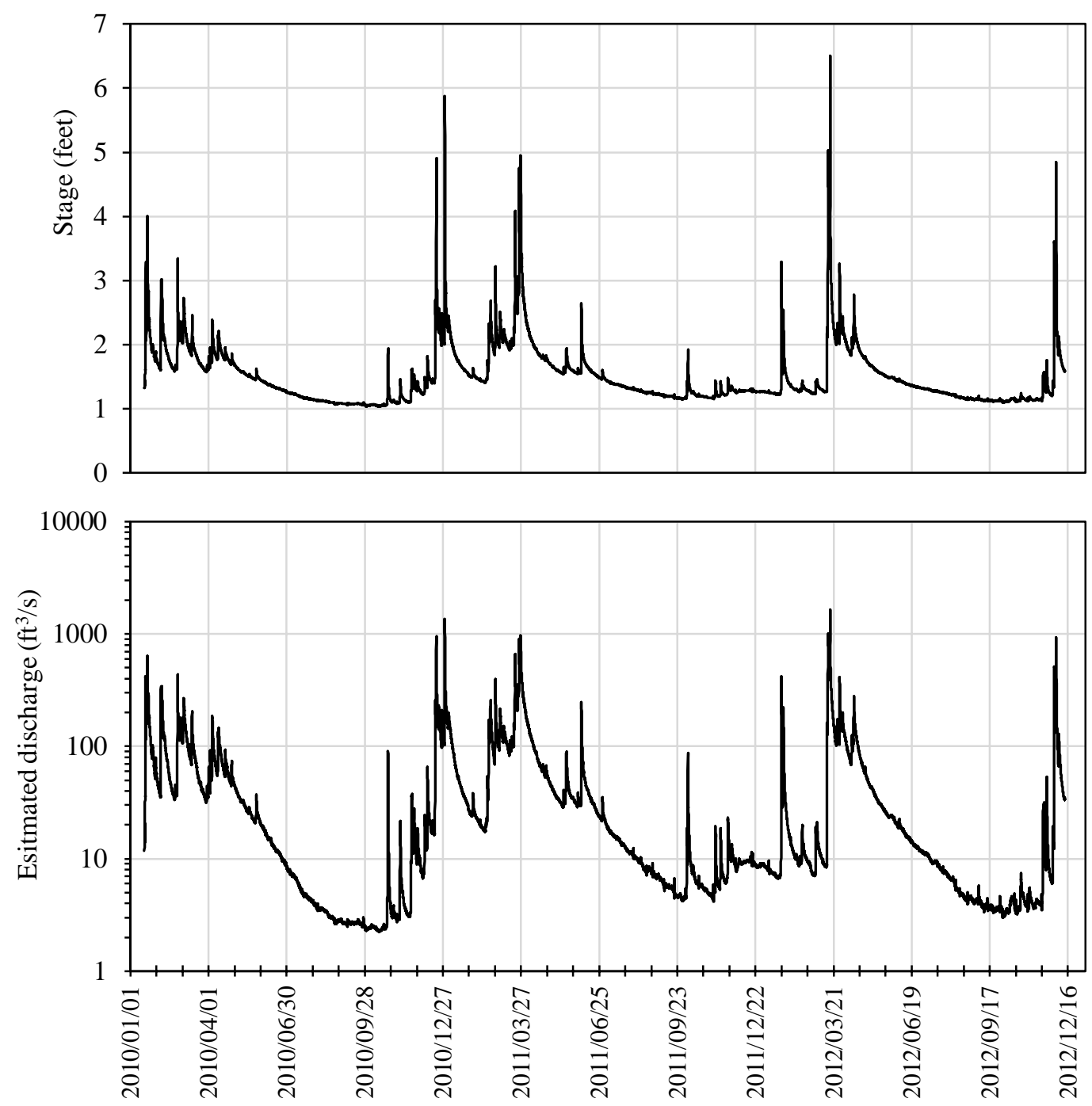

Figure 2. Stage (top) and estimated discharge (bottom) hydrographs for lower Scotts Creek below Archibald Creek from 1/17/2010-12/12/2012. 


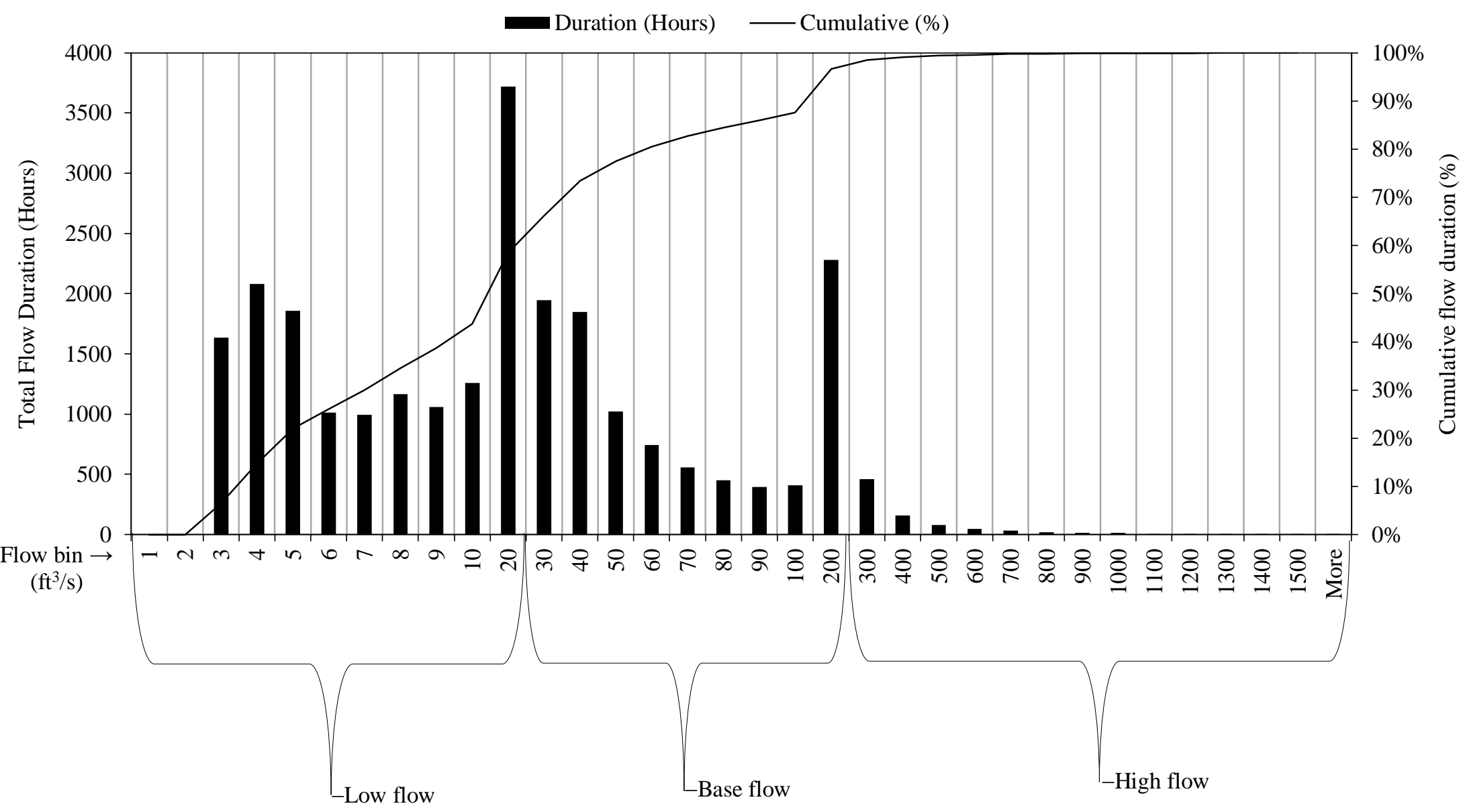

Figure 3. Flow histogram with flow regimes for the Scotts Creek stream gage below Archibald Creek for 1/17/2010-12/16/2012. 


\subsection{Vegetation}

Along lower Scotts Creek, the riparian corridor is $50-300 \mathrm{ft}$ wide, and canopy cover generally approaches $100 \%$. The dominant tree species are red alder and arroyo willow Salix lasiolepis. Other tree species include boxelder acer negundo, big leaf maple acer macrophyllum, California buckeye Aesculus californica, coast live oak Quercus agrifolia, and California bay Umbellularia californica. The dominant understory species were found to be California blackberry Rubus ursinus, American stinging nettle Urtica dioica, Cape ivy Delairea odorata, California hedge nettle Stachys bullata, and red elderberry Sambuchus racemosa red elderberry. Cape ivy, periwinkle Vinca major, and veldtgrass Ehrharta erecta are the most aggressive non-native invasive species within the riparian corridor along lower Scotts Creek. On the floodplain, Italian thistle Carduus pycnocephalus, poison hemlock Conium maculatum, bristly ox-tongue Helminthotheca echioides, radish Raphanus sativus, and summer mustard Hirschfeldia incana dominate open areas adjacent to the crop fields. A vegetation survey was performed along the project reach within the riparian corridor in summer of 2013. Quadrat sampling at random locations along multiple transects was utilized to quantify percent ground cover by species (Figure 4, A. Broz 2013, unpublished vegetation survey report).

Historically, lower Scotts Creek experienced frequent, intense disturbance which probably resulted in a loss of plant species diversity (J. West, personal communications). Historic disturbances include farming, grazing, and large flood events. The introduction of non-native invasive plants has resulted in large, monocrop colonies of Italian thistle and poison hemlock, occurring mostly on the margins of the crop fields, with the largest colony occurring between Queseria Creek and the field to the north. Poison hemlock grows well over head-high in these areas, and Italian thistle grows shoulder- to head-high. These colonies limit the establishment of native plants. A colony of velvet grass Holcus lanatus occupies the floodplain of Queseria Creek south of the creek. Cape ivy is aggressively colonizing the riparian corridor of lower Scotts Creek and is causing tree mortality 
and loss of riparian habitat. This species is known to occur in the upper watershed, making eradication impossible without a watershed-wide approach. Eradication of poison hemlock and Italian thistle are probably not feasible, however mowing combined with revegetation with overstory species, especially those that produce dense leaf-litter, such as deciduous trees, may be an effective treatment for suppressing these invasive plant species.

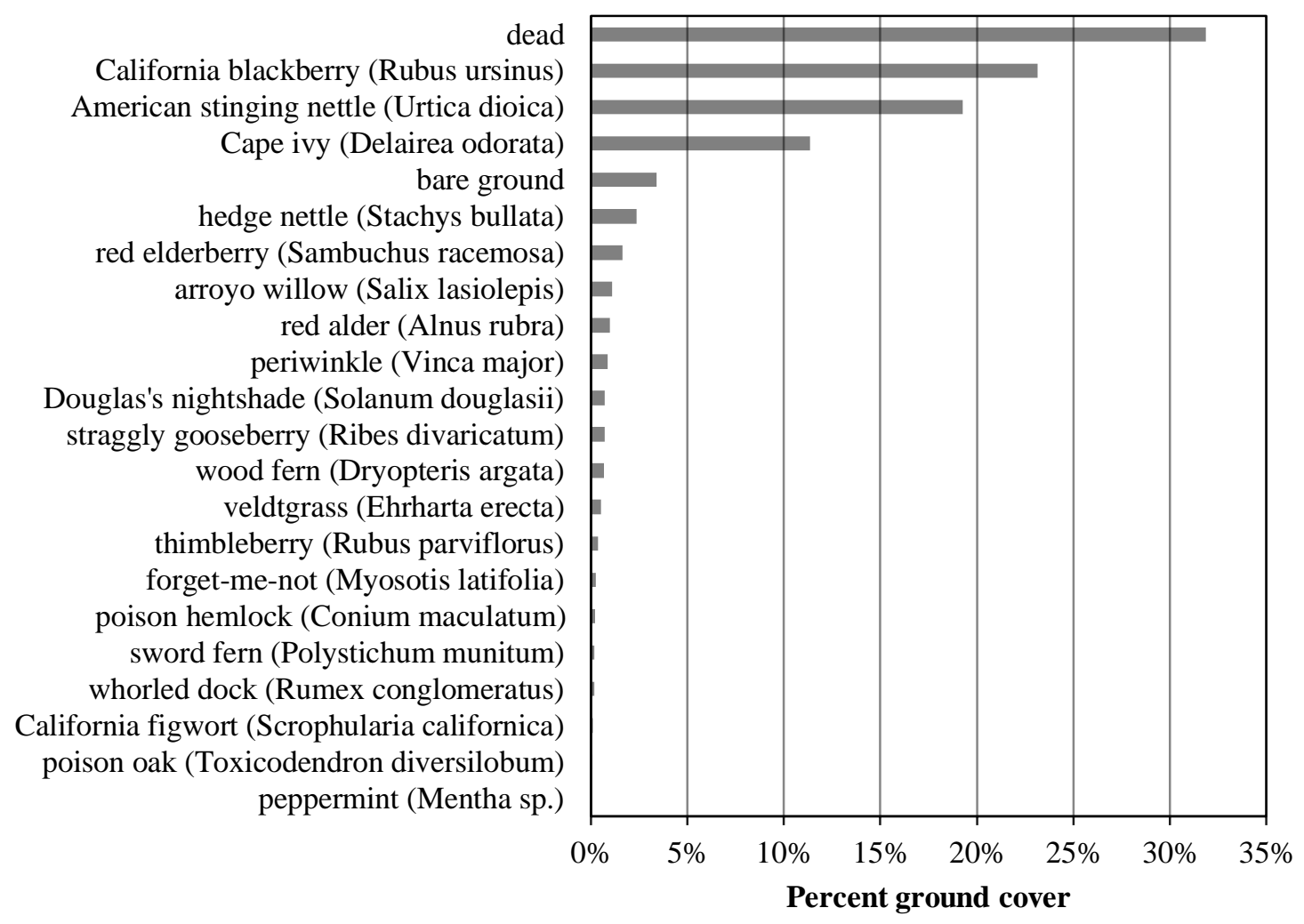

Figure 4. Results of 2013 vegetation survey for the project reach.

\subsection{Geology and Sediment}

The background sediment delivery rate in the Scotts Creek watershed may significantly impact Coho Salmon viability and productivity. Landslides have caused major disruptions to the location of the lower Scotts Creek stream channel within the valley and delivered large quantities of colluvium in the form of debris flows directly to the stream (R. Smith, personal communication, 11/18/2015). Within the watershed, intrusive igneous granitic and associated metasedimentary basement rocks are overlain by erodible Santa Margarita Sandstone and primarily the younger 
Santa Cruz Mudstone. Steep inner gorges, rapid uplift, earthquakes, and high rainfall intensity contribute to frequent landslides and associated high background delivery rates of sediment composed of mudstone and granitic material. Landslides initiated by bedding plane failures occur episodically resulting in delivery of mudstone and sandstone derived colluvium to the floodplain along its eastern edge. Such landslides may deliver sufficient amounts of material to cause the stream channel to migrate west or even dam the valley (R. Smith, personal communication, 5/9/2015). Alluvium composed of mudstone, sandstone, and granitic rock is delivered to lower Scotts Creek from the upper watershed. Mudstone of varying particle sizes and granitic sand dominate the sediment load. The prevalence of mudstone in the bedload exacerbates redd scour because mudstone gravels can be easily mobilized by late season stormflows. Lower Scotts Creek is subject to the input of granitic sands from Big Creek which can clog redds. This combined with a mobile streambed makes redd survival along lower Scotts Creek tenuous (J. Smith, personal communication, 8/1/2013). Fish density in a lower Scotts Creek survey site is typically half that found in sites upstream from the Big Creek confluence. The contrast in fish density may be attributed to low spawning success and recruitment occurring in lower Scotts Creek due to flushing of redds and limited velocity refuge (J. Smith, personal communication, 8/1/2013).

\subsection{Topographic Features}

Two small ponds are present on the floodplain at 3300 and 3800. The large flood events of 1982 and 1998 initially scoured these ponds (Dietterick, personal communication). The ponds remain wetted perennially through the current drought, probably through groundwater discharge. In summer of 2013, water quality measurements were recorded for each of the two off-channel ponds. The purpose of these measurements was to determine the suitability of the ponds to support aquatic species. The results of September 2013 water quality measurements are shown below in Table 2 . Readings taken nearby in Scotts Creek are included for comparison. 
Table 2. Dissolved oxygen levels and temperatures in existing off-channel ponds on 9/20/2013.

\begin{tabular}{|c|c|c|c|c|}
\hline & $\frac{\text { Scotts Creek }}{\underline{(3800)}}$ & $\frac{\text { Scotts Creek }}{\underline{(3000)}}$ & $\frac{\text { Upper Pond }}{\underline{(3800)}}$ & $\begin{array}{r}\text { Lower Pond } \\
\underline{(3300)}\end{array}$ \\
\hline DO \% & 67.4 & 69.5 & 2.5 & 18.0 \\
\hline $\mathrm{DO} \mathrm{mg} / \mathrm{L}$ & 7.02 & 7.22 & 0.25 & 1.90 \\
\hline Temp C & & 13.61 & 15.23 & 13.69 \\
\hline Comments: & pool, still water & moving water & & \\
\hline
\end{tabular}

These ponds supported limited populations of rearing but not breeding Rana draytonii (California red-legged frog [CRLF]) (Swaim 2014). While the location and migration pattern of the source population has not been recently studied, J. Bulger documented CRLF breeding in a nearby pond adjacent to the Scotts-Queseria confluence at station 1500 in 2004. CRLF may be migrating to the ponds at 3300 and 3800 from the pond at 1500 .

A small 10 -foot-wide by 20 -foot-long by 4 -foot-deep scour feature is located next to the main channel of Queseria Creek adjacent to station 1800. This feature develops surface water in winter through direct rainfall or groundwater discharge, and through seepage in summer as a result of an elevated water table driven by backwater from the lagoon.

Agricultural ditches drain portions of the crop fields adjacent to Scotts Creek. One of these ditches, located at station 3000, drained to the main channel of Scotts Creek through an 18 in culvert under the levee berm.

Archibald Creek joins lower Scotts Creek at station 5800. Field observations indicate that the main channel of Archibald Creek overflows into a vegetated auxiliary channel that flows south, losing definition at a swale below station 5650 .

A network of gullies and swales are present in the riparian corridor to the east of the main channel. Many of these are not represented by existing topographic datasets and are difficult to identify in 
the field due to dense multi-story vegetation. Some of these swales and gullies appear to be points of connectivity with lower Scotts Creek, exemplified by those in the vicinity of the pond at 3800 . Others are separated from the main channel by levees or berms. These gullies indicate flow parallel to the main channel for significant distances, having infrequent points of connectivity with the main channel. Parallel flow paths are evidenced by gullies and berms just north of the Queseria Creek confluence area, and swales along lower Scotts Creek behind the levees in the vicinity of the NMFS fish weir at station 4300 . The scour ponds and gullies indicate that large flood flows are capable of developing sufficient velocity parallel to the main channel to scour the floodplain.

\subsection{Fluvial Functionality}

The connectivity between lower Scotts Creek and its floodplain is generally assumed to be poor, due to the functional remnants of a deteriorating levee system constructed in 1938 associated with the Highway One Bridge project and late 1950s flood-control projects designed to maximize farmland on the floodplain. The levees extend one mile upstream from the CA-1 bridge, and continue to influence the hydrology of the lower reach of Scotts Creek by confining flows and entrained sediments to a straightened, low-complexity channel. The levees appear to be the primary limitation to floodplain connectivity along a reach that is otherwise not acutely incised. Flooding may occur when confined flows at artificially elevated stages overtop the levees, causing incipient flooding on the floodplain at stages greater than bankfull. The levees are accepted to seriously limit the frequency of return flow paths to the main channel. Insufficient return flow paths to the main channel limit floodplain exchange, which is assumed to negatively impact salmonids by limiting nutrient availability, and increasing the potential for stranding. Stream complexity in lower Scotts Creek appears to be slowly improving as evidenced by bank erosion, natural wood recruitment, and pool formation. Brubaker (2015) reports that since 1997, "instream cover and LWD appear to be improving without direct management actions and may only need time to recover to desirable levels" (p.53), however "the overall number of pools has remained steady, [and] pool quality has 
generally decreased" (p.56). Brubaker suggests that direct management intervention may be warranted to increase the percentage of primary pools, and recommends long-term monitoring to determine the factors affecting pool formation and persistence.

\subsection{Ocean Connectivity}

River mouth dynamics control ocean connectivity and the hydrology of lower Scotts Creek below Queseria Creek. Summer low flow conditions combined with adequate wave energy allow a sandbar to form at the mouth of Scotts Creek, creating an estuarine lagoon that typically extends upstream to the confluence with Queseria Creek, approximately 1500 feet upstream from the CA1 bridge, with water surface elevations approaching 11 feet. The lagoon generally persists from July through mid-December. Winter stormflows breach the sandbar, establishing ocean connectivity from mid-December through June. It is worth noting that Shapovalov and Taft (1954) report substantially earlier timing of ocean connectivity at Waddell Creek (next watershed north) for the years 1933-1942 and that "the mouth of Scott Creek has usually opened and closed on the same dates [as Waddell Creek]" (p. 15).

Lagoon dynamics strongly influence the life-history of anadromous fish by determining the timing of spawning and smolting events. The lagoon provides critical rearing habitat for juvenile steelhead (Bond 2006; Hayes et al., 2008), and there is evidence that the lagoon may also provide critical rearing habitat for Coho Salmon in drought years, when low flows limit access to upper watershed reaches normally used for spawning and rearing (Kiernan, personal communication, 2/4/2014). The lagoon dynamics were likely altered by the CA-1 bridge and levees, constructed in 1938 . The CA1 road prism, bridge abutments, and levees on both sides of the stream channelize flow through the bridge opening. These alterations likely influence the timing of breach events, tidal prism, and lagoon and estuary habitat volumes. 


\subsection{Drought}

Coho Salmon in Scotts Creek displayed atypical patterns of utilization of riverine and estuarine habitat during their life cycle related to the ongoing drought. During a non-drought water year, juvenile Coho Salmon only briefly utilize the estuary during outmigration. In the 2013-2014 water year, precipitation totals and mainstem flow rates were some of the lowest on record. Early formation of the sand bar and delayed breaching, combined with limited access to upper reaches, trapped smolts in the lower watershed, requiring them to survive an extended period of time in freshwater. Surveys conducted by NMFS in February of 2014 indicated that Coho Salmon were ranging from the estuarine lagoon to the life-cycle station on lower Scotts Creek approximately 4,000 feet upstream from the CA-1 bridge. This range includes 2,500 feet of the 4,500-foot-long restoration project reach on lower Scotts Creek. This change in behavior suggests that lower Scotts Creek may provide critical rearing habitat in drought years (Kiernan, personal communication, 2/4/2014). In dry winters, when low flows limit access to upper reaches or tributaries normally preferred by salmonids, lower Scotts Creek may also provide critical spawning habitat (J. Smith, personal communication, 8/1/2013).

\subsection{Anthropogenic Impacts}

Land management practices linked to habitat loss were common throughout Santa Cruz and San Mateo Counties. Scotts Creek experienced impacts typical of Central Coast streams: the construction of the CA-1 bridge and road prism across the estuary, the construction of levees to channelize flow through the CA-1 bridge opening and to protect the crop fields from flooding, the construction of road and railway prisms parallel to lower Scotts Creek and through the historic floodplains of several tributaries, intense row-cropping and the associated loss of riparian habitat, stream channelization, and a legacy of wood removal. Scotts Creek is, however, set apart from many other central coast streams in that intense urbanization and habitat loss associated with urbanization has not occurred, which affords a rare restoration opportunity. "Urbanization is a more 
prominent factor for the future than logging, and likely a more significant influence on the fate of CCC Coho Salmon..." (NMFS 2012 vol. 1, p.38).

Wood removal was performed extensively throughout Santa Cruz County to protect homes and other important resources such as crop fields. The practice was also supported by the California Department of Fish and Game, because it was deemed necessary for the maintenance of fish passage. This culture arose in part to deal with legacy effects from intense logging that occurred in the late 1800s and in the early 1900s following the 1906 earthquake, when logging activities further intensified to supply wood to rebuild San Francisco after the devastating earthquake and fires of 1906. Intense logging left large quantities of debris of various sizes in forested watersheds. Woody debris, both natural and anthropogenic, was episodically delivered to the stream channels during storm events or landslides where it often formed debris jams. Small woody debris played an important role in the ability of log jams to impound water or induce flooding, because small debris plugs gaps in log jams. The practice of wood removal was reconsidered when studies following the 1982 flood in Soquel Village suggested that wood removal was not effective in preventing destructive log jams because large quantities of wood were delivered to the stream channel during storm events, and because wood removal promoted the formation of larger, more destructive log jams by removing instream structures that accumulate debris in smaller, more evenly distributed units. The County of Santa Cruz now "recognizes the value of allowing large woody material to remain in these streams to the greatest extent possible and its importance for sorting sediment, protecting steam banks and channel stability, providing pools and refuges, and generally benefiting stream habitat, when such material does not threaten life, public infrastructure, public safety, or aquatic habitat" (Santa Cruz County Environmental Health Department 2009).

Major impacts to habitat in lower Scotts Creek were mostly associated with agricultural practices and the construction of the CA-1 crossing. Agricultural activities involving tilling began within the watershed in the mid-1800s. The riparian corridor was cleared and tilled up to the edge of the stream 
channel to maximize the area of crop fields (Rowley 2003). Scotts Creek was straightened and dredging was performed to maintain the straightened channel. Levees were constructed in the late 1938/9 on both sides of the stream to channel flow through the CA-1 Bridge opening. The United States Army Corps of Engineers (USACE) constructed additional levees and revetments along the lower crop fields beginning in 1956 (Figure 5). Portions of the streambanks were armored with steel vertical piles linked together with steel cable and welded wire fence. USACE continued to dredge the stream channel and maintain the levees through 1982 (Rowley 2003). Wood was historically removed from the lower Scotts Creek stream channel (County of Santa Cruz 1982). 


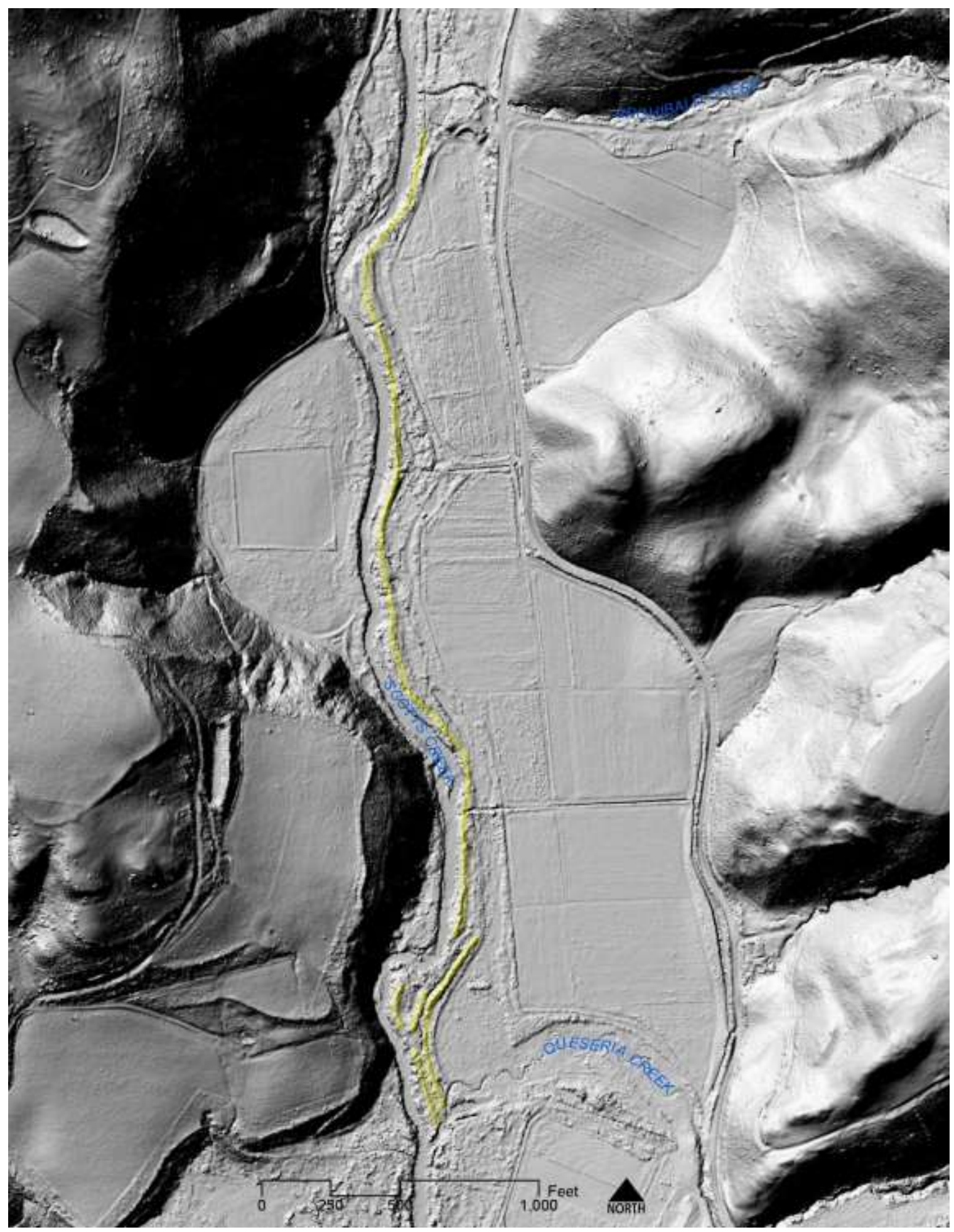

Figure 5. Hillshade view of lower Scotts Creek showing deteriorating levees (highlighted in yellow) along the left bank. 


\subsection{Limiting Factors}

Coho Salmon viability in Scotts Creek is primarily limited by low habitat complexity including poor pool:riffle:flatwater ratio and shelter rating (NMFS 2012). In September of 2013, a physical habitat survey was conducted on the mainstem of Scotts Creek to evaluate physical habitat conditions for salmonids (see Brubaker 2015). These data show a spatial contrast in habitat availability on Scotts Creek. Pool frequency and percent pools was found to be diminished in the project reach compared to upper reaches (Tables 2 and 3). Survey data combined with additional field observations indicate a lack of instream woody debris and low stream complexity in three sub-reaches of the project reach (Table 5, also see Brubaker 2015). These sub-reaches are dominated by runs or glides with shallow, infrequent pools lacking adequate cover and having virtually no instream wood.

Table 3. Frequency of habitat units per river mile. Project reach is italicized.

$\begin{array}{lrrrr}\text { Reach } & \text { Glides } & \underline{\text { Pools }} & \underline{\text { Riffles }} & \underline{\text { Runs }} \\ \text { Queseria to Stream Gage } & 12.7 & 15.6 & 5.7 & 8.5 \\ \text { Stream Gage to Little Creek } & 4.3 & 28.8 & 7.2 & 10.1 \\ \text { Little Creek to Big Creek } & 9.1 & 24.1 & 9.1 & 12.1 \\ \text { Big Creek to Mill Creek } & 5.9 & 47.0 & 6.5 & 23.5 \\ \text { Mill Creek to Swanton Road } & 12.8 & 40.9 & 15.3 & 12.8 \\ \text { Above Swanton Road } & 5.9 & 42.0 & 16.0 & 17.7\end{array}$

Table 4. Percent of each reach dominated by habitat type. Project reach is italicized.

\begin{tabular}{|c|c|c|c|c|}
\hline$\underline{\text { Reach }}$ & $\underline{\text { Glide }}$ & $\underline{\text { Pool }}$ & $\underline{\text { Riffle }}$ & $\underline{\text { Run }}$ \\
\hline Queseria to Stream Gage & $38 \%$ & $19 \%$ & $10 \%$ & $34 \%$ \\
\hline Stream Gage to Little Creek & $16 \%$ & $33 \%$ & $11 \%$ & $41 \%$ \\
\hline Little Creek to Big Creek & $11 \%$ & $28 \%$ & $10 \%$ & $51 \%$ \\
\hline Big Creek to Mill Creek & $6 \%$ & $39 \%$ & $4 \%$ & $51 \%$ \\
\hline Mill Creek to Swanton Road & $21 \%$ & $36 \%$ & $9 \%$ & $34 \%$ \\
\hline Above Swanton Road & $10 \%$ & $46 \%$ & $13 \%$ & $31 \%$ \\
\hline
\end{tabular}


Table 5. Lengths and locations of target sub-reaches along lower Scotts Creek.

$\begin{array}{lrrr}\text { Sub-Reach } & \text { Length (ft.) } & \text { Downstream Extent } & \text { Upstream Extent } \\ 1 & 400 & 2600 & 3000 \\ 2 & 300 & 3300 & 3600 \\ 3 & 500 & 4300 & 4800\end{array}$

The persistence of low-complexity reaches dominated by planar beds may be attributed to a lack of instream wood coupled with the legacy of stream straightening and dredging. Lack of instream wood likely limits complexity in the form of sinuosity within the bankfull channel, pool frequency and depth, and instream refuge habitat. The deteriorating levees continue to limit floodplain connectivity by confining flows to the main channel. The levees may significantly limit access to, or the development of, critical refuge and foraging habitat for fish during high flows and may limit the ability of the floodplain to store flood waters and sediment.

The straightened, channelized geometry of the main channel, maintained by the presence of levees and bank armoring, likely increases main channel velocities, depths, shear stresses, and sediment loads over pre-agrarian levels. These conditions may significantly increase Coho Salmon red scour and egg-parr and parr-smolt overwinter mortality. Juvenile overwinter mortality is attributed to harsh conditions in the main channel exacerbated by lack of accessible refuge habitat. High velocity stormflows transporting low specific gravity bedload substrate through straightened and leveed reaches of lower Scotts Creek may bludgeon and flush overwintering juveniles into the ocean (the "bowling alley" effect) (J. Kiernan, personal communication). Fisheries biologists hypothesize that juvenile winter mortality is a primary factor limiting salmonid production in lower Scotts Creek (J. Kiernan, J. Smith, personal communications).

To summarize, the factors limiting salmonid production on lower Scotts Creek, as understood by local fisheries biologists and as outlined in NMFS (2012), are juvenile winter mortality attributed 
to lack of instream, alcove, off-channel, and floodplain refuge habitat (refugia), oversummer mortality or limited oversummer growth due to lack of productive instream and alcove rearing habitat with adequate cover and foraging opportunities, scouring or sedimentation of redds due to lack of instream wood to sort sediment or manage instream velocities during high flows, and unsuccessful spawning due to lack of or inaccessibility (during drought years) of spawning habitat. 


\section{DESIGN AND IMPLEMENTATION}

In the early 2000s, Cal Poly staff and agency representatives, including NMFS biologists, began planning restoration projects along lower Scotts Creek to improve floodplain connectivity and habitat conditions for salmonids. The restoration of Queseria Creek, the lowest tributary to Scotts Creek, was the first of Cal Poly's planned restoration projects for lower Scotts Creek to be implemented. Lower Queseria Creek had been channelized to a straight ditch designed to route flow away from structures and farmland sometime in the late 1800s or early 1900s. Coho Salmon utilized this ditch for summer rearing and winter refuge habitat, though habitat conditions were impaired by high summer temperatures, lack of cover and complexity, migration barriers, and high velocities during winter stormflows. The Queseria Creek project was completed in 2004 to improve refuge and rearing habitat conditions by reducing summer stream temperatures and high-flow velocities, improve floodplain connectivity, increase cover and habitat complexity, and remove migration barriers. The project replaced the 950-ft-long ditch with a $1300-\mathrm{ft}-$ long meandering stream channel inset into a low, vegetated floodway, constructed a sequence of instream cross-vane and j-hook structures using logs and boulders, replaced a 36-in perched culvert under Swanton Road that had been a migration barrier with a $14-\mathrm{ft}$ bottomless arched culvert, replaced the failed barn access road culvert and washed out road prism with a 30 -ft flat car bridge, and revegetated the reconstructed stream corridor with native riparian vegetation (Pearson 2004).

During the planning of the Queseria Creek project, a project to improve floodplain connectivity and refuge opportunities by breaching the levee system along lower Scotts Creek was considered. Cal Poly anticipated that the project would significantly increase the frequency and duration of floodplain inundation. At that time, the riparian corridor of lower Scotts Creek was far less vegetated than today, and Cal Poly decided to suspend plans to breach the levee system until a vegetated riparian buffer could be established that would stabilize the floodplain and minimize the risk of flood damage to crop fields. In 2003, the crop fields were set back from the stream channel, 
and 20.4 acres of the riparian corridor were placed in a NRCS Wetland Reserve Program (WRP) conservation easement (Casale, personal communication, 11/9/2015). By 2012, the riparian buffer had visibly increased in width and density (Figure 6). Riparian restoration is linked to improved habitat conditions. Opperman and Merenlender (2004) found that restoration of riparian buffers and associated vegetation through cattle exclosures was effective at improving instream salmonid habitat, potentially more so than placement of instream structures.

In 2012, Cal Poly partnered with the Resource Conservation District of Santa Cruz County (RCDSCC) to initiate a formal design process for a restoration project on lower Scotts Creek to restore floodplain connectivity and improve habitat conditions for salmonids and associated aquatic and terrestrial species. The design phase was funded by the California State Coastal Conservancy, and coordinated by the Integrated Watershed Restoration Program (IWRP). IWRP was founded in 2002 to facilitate and coordinate restoration projects on a watershed scale in California's Central Coast region. The RCDSCC allocated funding to design a project "to improve salmonid and terrestrial amphibian habitat quality along a one-mile reach of Lower Scotts Creek" and "benefit hydrologic and overall riparian function by remediating the adverse effects that resulted from the channel modification and levee system that was constructed along with the Scotts Creek Highway One bridge crossing in 1938" (IWRP Phase 3 Individual Design Project Work Program 2012, p.1). The design process was guided by a recognition of "the value in presenting a project that benefits floodplain connectivity while preserving prime agricultural land" (J. Robins, personal communication, 12/20/2012).

The project fit criteria specified by RCDSCC's Partners in Restoration (PIR) Permit Coordination Program. PIR, developed through IWRP in 2003, facilitates small-scale restoration projects with clear environmental benefits. Projects utilizing one or more of 15 pre-approved NRCS Field Office Technical Guide conservation practices for erosion control, stream restoration, or wildlife habitat enhancement may qualify for implementation under PIR. Regulatory agencies including U.S. Fish 
and Wildlife Service, NMFS, USACOE (includes National Environmental Policy Act compliance), Regional Water Quality Control Board, The County of Santa Cruz (includes California Environmental Quality Act compliance), and the California Coastal Commission have issued fiveor ten-year programmatic permits for PIR. For projects that qualify for PIR, RCDSCC submits a Pre-Construction Notification (PCN) to each regulatory agency, which is not a permit application, but instead documents each project's compliance with each agency's existing programmatic permit.

PIR criteria, or other criteria identified as important by the IWRP Technical Advisory Committee (TAC) and Cal Poly, included placing no fill on the 100-year floodplain, limiting the volume of excavation to no more than 1000 cubic yards, not dewatering more than 300 feet of stream, and limiting the combined areas of temporary access and staging areas to 0.25 acres or less. Additionally, the total area of disturbance was limited to less than 1.0 acres to avoid triggering the implementation of an EPA-mandated Storm Water Pollution Prevention Plan (SWPPP).

\subsection{Design Concept}

Cal Poly staff, along with members of the IWRP TAC, identified restoration opportunities in the field and drafted a restoration concept map (Figure 7). In December of 2012, the IWRP TAC convened in the field to refine the preliminary design and provide technical guidance regarding the formal design and permitting process. The design objectives that were discussed included breaching portions of the levees to increase floodplain connectivity, constructing a low-profile setback levee to protect crop fields, constructing backwater connections with existing tributaries and floodplain ponds, and constructing large wood features instream using a combination of imported and locallysourced materials including redwood logs, rootwads, boulders, and in-situ alders located on the streambanks of lower Scotts Creek. During the meeting, the extents of the project reach were defined as the reach of lower Scotts Creek between Queseria and Archibald Creeks. This reach was chosen for four main reasons: 1) it is seen as critical to salmonid productivity and recovery, 2) it contains the legacy levee system prioritized for removal, 3) habitat conditions in this reach are 
highly degraded compared to other reaches, and 4) it avoids the estuary which is governed by tidal influences that may change hydrologically with the planned CA-1 bridge replacement/estuary restoration.

The preliminary design proposed increasing floodplain connectivity by excavating five to ten 300600-ft-long breaches in the existing levee, protecting crop fields by constructing a low-profile setback levee to replace the unmaintained levees, constructing lateral berms on the floodplain to slow flood flows, constructing backwater connections with tributaries and existing off-channel ponds, and constructing 12 large wood complexes (LWCs) using a combination of in-situ alders and locally-sourced redwood logs. Large alders would be recruited from the streambanks and be kept alive and anchored by pushing the trees over into the stream with their roots partially intact.

The incorporation of in-situ alders into the design of the LWCs was proposed to 1) reduce the cost and impact associated with importing materials, 2) add complexity and cover value to the LWCs, 3) to answer the important research question of whether the recruitment technique is a viable restoration alternative by monitoring mortality, decay rate, and persistence of the alder recruits. Work done by Opperman (2002), Opperman and Merenlender (2007), and Opperman et al. (2008) showed that coastal riparian hardwood species play an important in influencing stream morphology and instream hydraulics when trees remained living and anchored by their roots. These findings led to the first documented attempt to the author's knowledge (described below) to develop a restoration technique around recruitment of living hardwood species. 


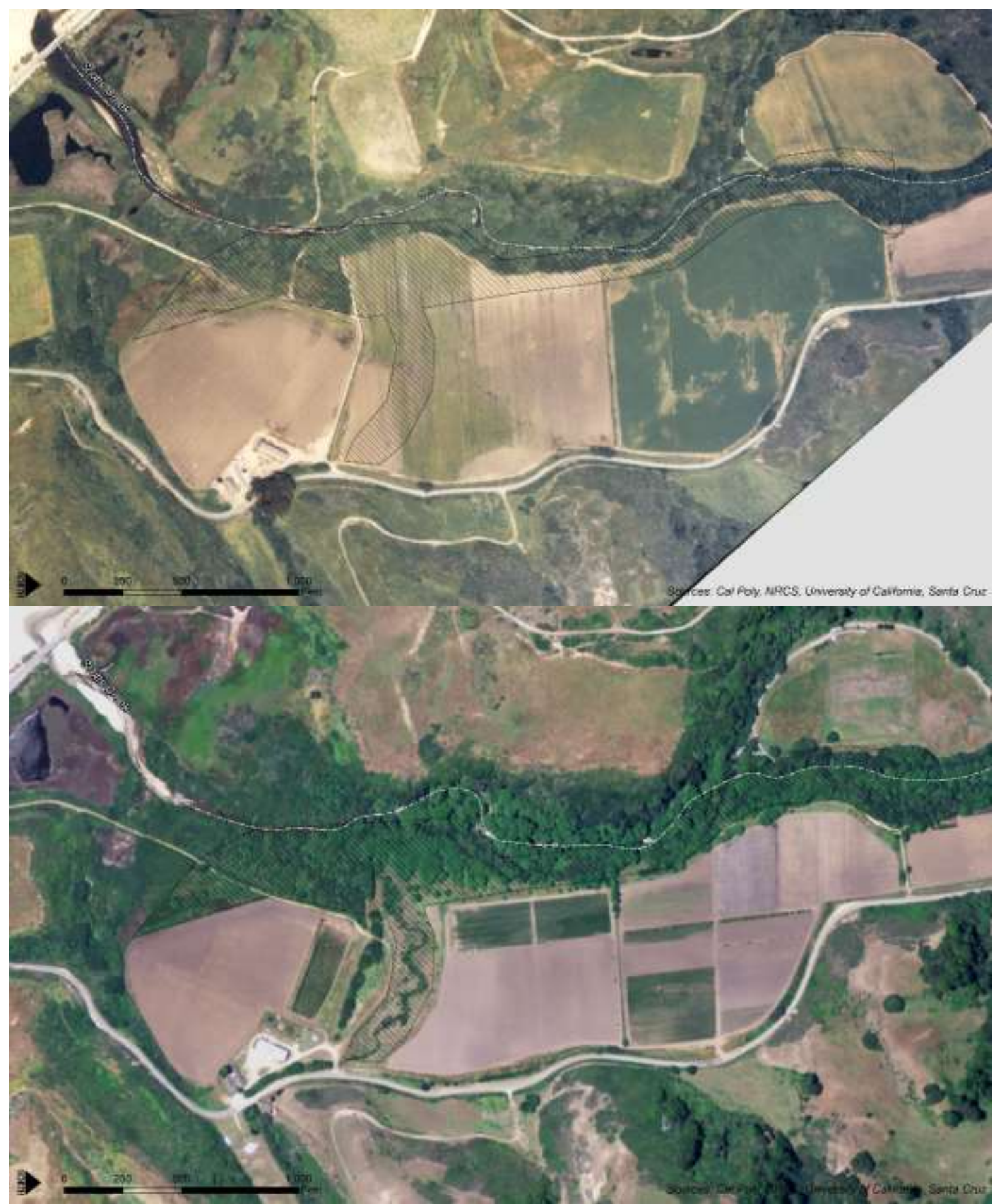

Figure 6. Orthographic aerial images of project reach showing regeneration of riparian vegetation from 1993 (above, representative of the vegetative condition that persisted until the establishment of the WRP) to 2012 (below), and approximate 2003 WRP boundary (hatched area). The CA-1 bridge is visible at top left. 


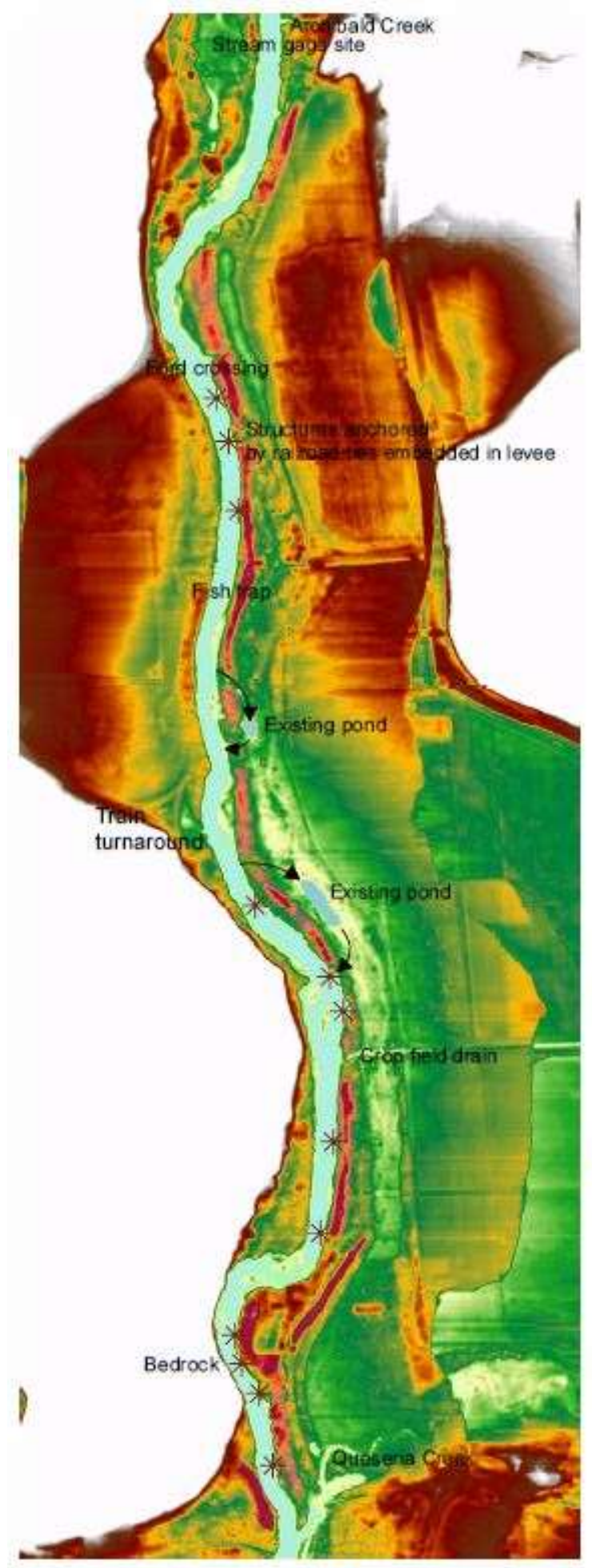

\title{
Lower Scotts Creek Restoration Concept Map
}

\author{
Cal Poly Swanton Pacific Ranch
}

This map identifies potential restoration opportunities in the Lower Scotts Creek channel. Much of this channel has been leveed and straightened in the past 150 years. Habitat quality is generally low in leveed reaches due to low channel complexity, lack of woody debris, shallow pools, and lack of high flow refuge habitat. Restoration activites proposed include construction of large woody debris features, removal and/or breaching of levees to reconnect the floodplain, connection of existing off channel ponds, and construction of a low levee adjacent to the cropfields.

\section{Legend}

\author{
* Construct LWD feature \\ Potential off channel habitat \\ Existing Levee
}

\section{River Elevation Model}

\author{
Elevation above channel \\ -15 feet \\ -0 feet
}

River elevation model shows elevation relative to the adjacent stream channel. It is calculated by subtracting the ground elevation from the the lowest point in the horizontally adjacent 450 feet.

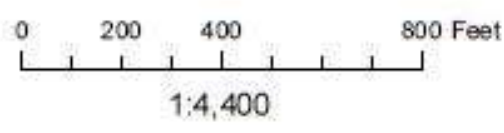

Figure 7. Conceptual map showing restoration opportunities along lower Scotts Creek (Perkins, 2012). 


\subsection{Design Alternatives}

All practical design alternatives were considered. Iterations of the preliminary design included a number of alternatives that were not implemented, including the 'do nothing' alternative. These are discussed below:

\section{3 'Do-Nothing'}

The 'do-nothing' alternative was considered to avoid disturbing the biota of lower Scotts Creek, and incurring the anticipated cost and resource expenditure. The preliminary design proposed extensive disturbance to the project reach at a significant cost. When the design was later refined to minimize disturbance and expenditure, the 'do-nothing alternative' was subsequently discarded, because the benefits of implementing the project were seen as strongly outweighing the negative impacts associated with the anticipated disturbance, cost, and use of resources.

\subsection{Scope of Levee Removal}

Alternative levee removal options were considered. The preliminary design called for five to ten 300- to 600-foot-long breaches, and an iteration of the design proposed up to twelve 75 - to 100foot-long breaches, with the objective of maximizing floodplain connectivity, and refuge and foraging opportunities. The IWRP TAC concluded that 2D modeling and extensive data collection would be required to predict how the stream would respond to removal of large portions of levee. The TAC alternatively recommended breaching the levees near the downstream extent of the project reach to minimize the risk of damage to crop fields and wells, where floodplain access is maximized by lower Queseria Creek. There was consensus within the IWPR TAC that a setback levee would not be necessary, nor would 2D modeling be required, if levee removal was restricted to the lower portion of the project reach.

Removing a 350-foot-long section of levee ("diagonal berm") located on the floodplain between Scotts Creek and Queseria Creek adjacent to river stations 2000-2500 was considered (FigureFigure 8). A HEC RAS model showed that the bankfull event would not activate the 
diagonal berm (C.G. Surfleet, 2013, unpublished report on the proposed restoration project's modeled effect on flood levels, see Appendix A). Visual observations of bankfull indicators and measurements of the cross sectional geometry of the main channel indicated that the channel was incised adjacent to the diagonal berm, supporting the model's results. These analyses, combined with examinations of other alternatives, led the design team to conclude that removing the diagonal berm would not effectively improve floodplain connectivity.

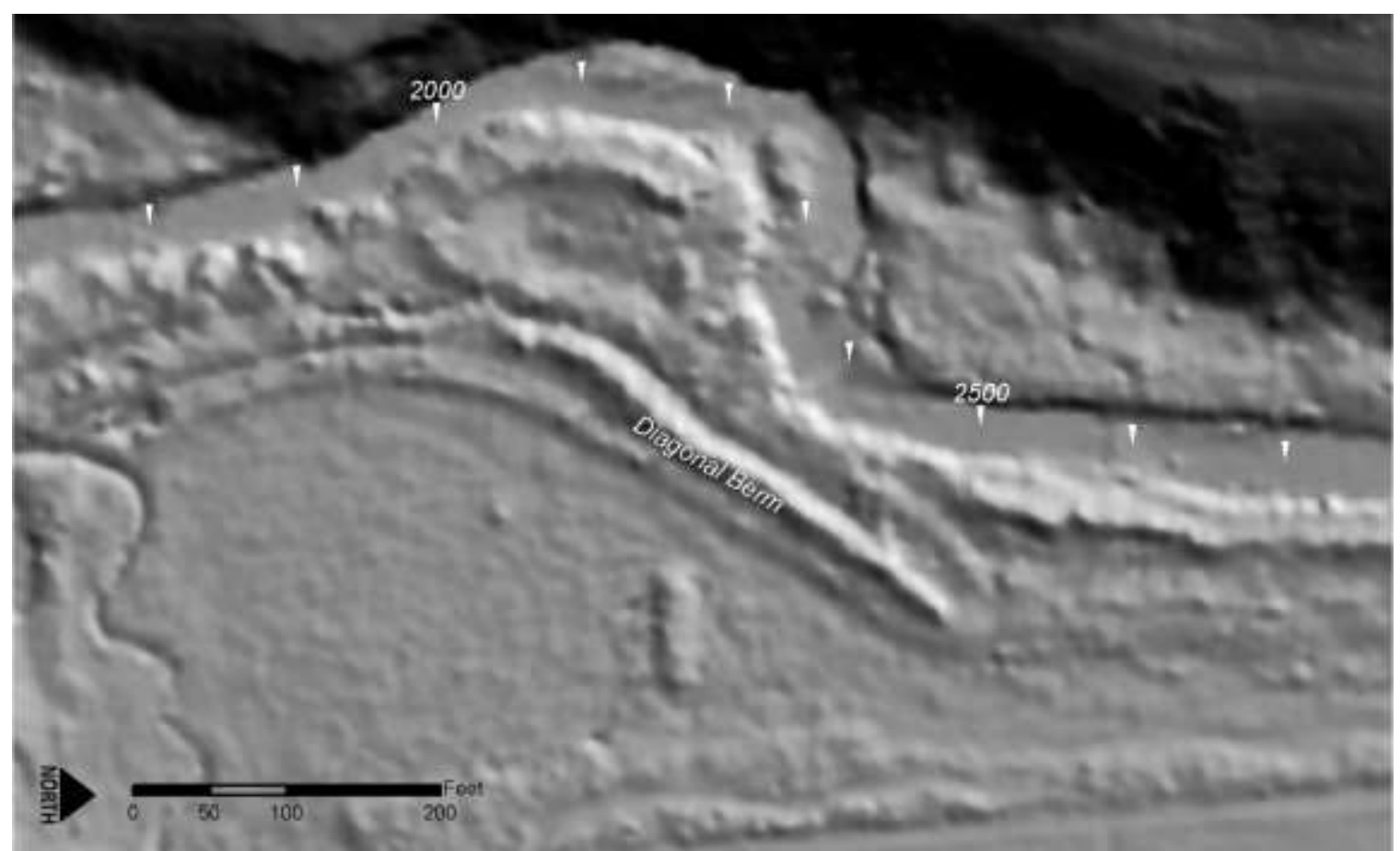

Figure 8. Diagonal berm.

\subsection{Setback Levee}

The design team considered using the spoils from the restoration project to construct a continuous low-profile ( 3-ft-high) setback levee along the western edge of the crop fields. The TAC recommended further analysis to determine the appropriate height and location of the setback levee, and determine if the levee should run the entire length of the crop fields or be constructed in key flood-prone locations. The design team ultimately moved away from this idea because the magnitude of levee removal was reduced and restricted to the lower end of the project reach, where the risk of damage to crop fields would be minimized by the wide riparian buffer and backwater 
effects from Queseria Creek, and because it was determined that the setback levee would exacerbate ponding on the crop fields by impounding subsurface flows that emerge in the middle of the crop fields during stormflow.

\subsection{Lateral Berms}

The design team proposed constructing lateral berms on the floodplain adjacent to Scotts Creek, oriented perpendicular to streamflow, to slow flood flows in the downstream direction. The TAC advised that placement of significant fill on the floodplain would warrant extensive data collection and 2D modeling to ensure its function. The design team abandoned the concept, primarily because the scope of levee removal was reduced and did not warrant the construction of lateral berms.

\subsection{Side Channel Features}

The design team considered constructing side-channels to circulate stream flow through each of two existing floodplain ponds. This alternative would potentially maximize side-channel refuge habitat and maintain sediment transport through the features. The design team discarded this alternative because of the difficulty in predicting side-channel velocities and thus the quality of side-channel refuge habitat, and because of the unknown risks of dewatering the ponds or causing the channel to avulse.

\subsection{Drainage Ditch at 4300}

The design team considered connecting the main channel to the drainage ditch at 4300 to provide off-channel refuge habitat. Runoff from the ditch enters a network of gullies and swales running south, parallel to lower Scotts Creek on the east side of the left bank levee. These gullies converge into a single defined gully at station 4250 , where the gully bottom is lower than the bankfull indicators in the main channel, indicating the gully had the potential to activate below the bankfull stage. The design team instead decided to connect the main channel to the swale at 4250 because it was expected to activate the gully and floodplain more frequently at a reduced disturbance and cost. 


\subsection{Preferred Alternative}

A design team and TAC identified a preferred alternative that would best meet the most important habitat and hydrologic objectives while minimizing risk to agriculture and infrastructure. The preferred alternative, later implemented, is summarized below:

1. Levee breaches were excavated to allow the stream to access the floodplain bounded by Scotts and Queseria Creeks

2. Floodplain connection channels were excavated to create backwater connections with existing hydrologically active features on the left bank and floodplain of Scotts Creek

3. Alcove pools were inset into the left bank of Scotts Creek at the confluences of floodplain connections to provide additional refuge habitat.

4. The Archibald Creek confluence was reconfigured to provide additional backwater winter refuge habitat.

5. Large wood complexes (LWCs) were constructed in sub-reaches of low-complexity lacking wood using imported redwood materials, boulder ballasts, and in-situ alder trees

6. Riparian restoration was accomplished by decommissioning an existing road segment and revegetating the road and all disturbed areas following construction with appropriate native riparian vegetation to stabilize the floodplain and improve habitat diversity.

The preferred alternative's measureable objectives were to:

1. Increase the number of points of connectivity with the floodplain at the bankfull stage

2. Increase pool frequency, depth and volume

3. Increase LWD frequency, density and stream percent cover

4. Increase the number and frequency of instream, alcove, and off-channel refuge habitat units

Additionally, the project was expected to improve access to floodplain refuge and foraging habitat during high flows, reduce the risk of floodplain stranding by providing additional points of ingress back to the main channel, increase groundwater recharge, take advantage of floodplain storage and conveyance to attenuate stormflows, and increase the delivery of floodplain-derived food to the main channel. CDFW engineers reviewed the design of both phases (see Appendix B).

\subsection{Two-Phase Approach}

The project was implemented in two sequential phases (Figure 9) to address several challenges related to funding, permitting, and implementation. RCDSCC coordinated the design, funding, permitting, and implementation of both phases. Implementation of Phase I was funded by a grant from the Wildlife Conservation Board with permitting assistance through PIR. Phase I was 
implemented in October of 2014 and spanned from station 1500 to 3000 (Queseria Creek to an agricultural drainage ditch near 3000). Phase I included five levee breaches, four instream large wood complexes, an alcove feature and backwater connection with the drainage ditch at 3000, and a backwater connection with an existing alcove feature adjacent to Queseria Creek at 1800. Phase II was funded by a grant from the California Department of Fish and Wildlife's Fisheries Restoration Grant Program with permitting assistance through FRGP and PIR. Phase II was implemented in September 2015 and spanned 3000-6000 (just upstream from the ditch to Archibald Creek). Phase II included nine instream large wood complexes, two backwater pond connections and alcove features, an alcove feature and backwater connection with an existing hydrologically active swale feature, the enhancement of the Archibald Creek confluence, and the decommissioning of an existing road segment within the riparian corridor.

The two-phase approach allowed the design team to make adjustments to the design of Phase II based on observations of the performance of Phase I. Below are four lessons learned from Phase I that were applied to the design of Phase II.

1. LWCs sometimes influenced the cross-sectional velocity profile to a degree that would scour large, deep pools. Scour was most pronounced when channel capacity was obviously reduced. Large, densely foliated alder crowns, in combination with stabile redwood and boulder structures, appeared to be effective at reducing channel capacity.

2. Velocity refuge appeared to form in the hydraulic shadow of alder crowns and rootwads, as evidenced by observations of the velocity profile across the channel during stormflow, and the location of depositional features.

3. LWCs constructed on the left bank generally pushed the thalweg towards the right bank. Downstream from the LWC, the thalweg swung back towards the left bank.

4. LWC frequency matched the natural thalweg frequency. LWC frequency should not exceed the sinuosity that the thalweg is capable of, otherwise the thalweg may simply migrate away from the LWCs. Maximum thalweg sinuosity probably depends on channel gradient.

A comparison of Phase I and Phase II implementation techniques yielded an important lesson.

During Phase I, the contractor used a rubber-tracked loader to ship spoils and load trucks, whereas during Phase II, the contractor used an excavator. The rubber tracked loader was faster and resulted in a smaller area of disturbance compared to the excavator. The author recommends that future projects require the use of a rubber-tracked loader at the pre-contracting stage. 


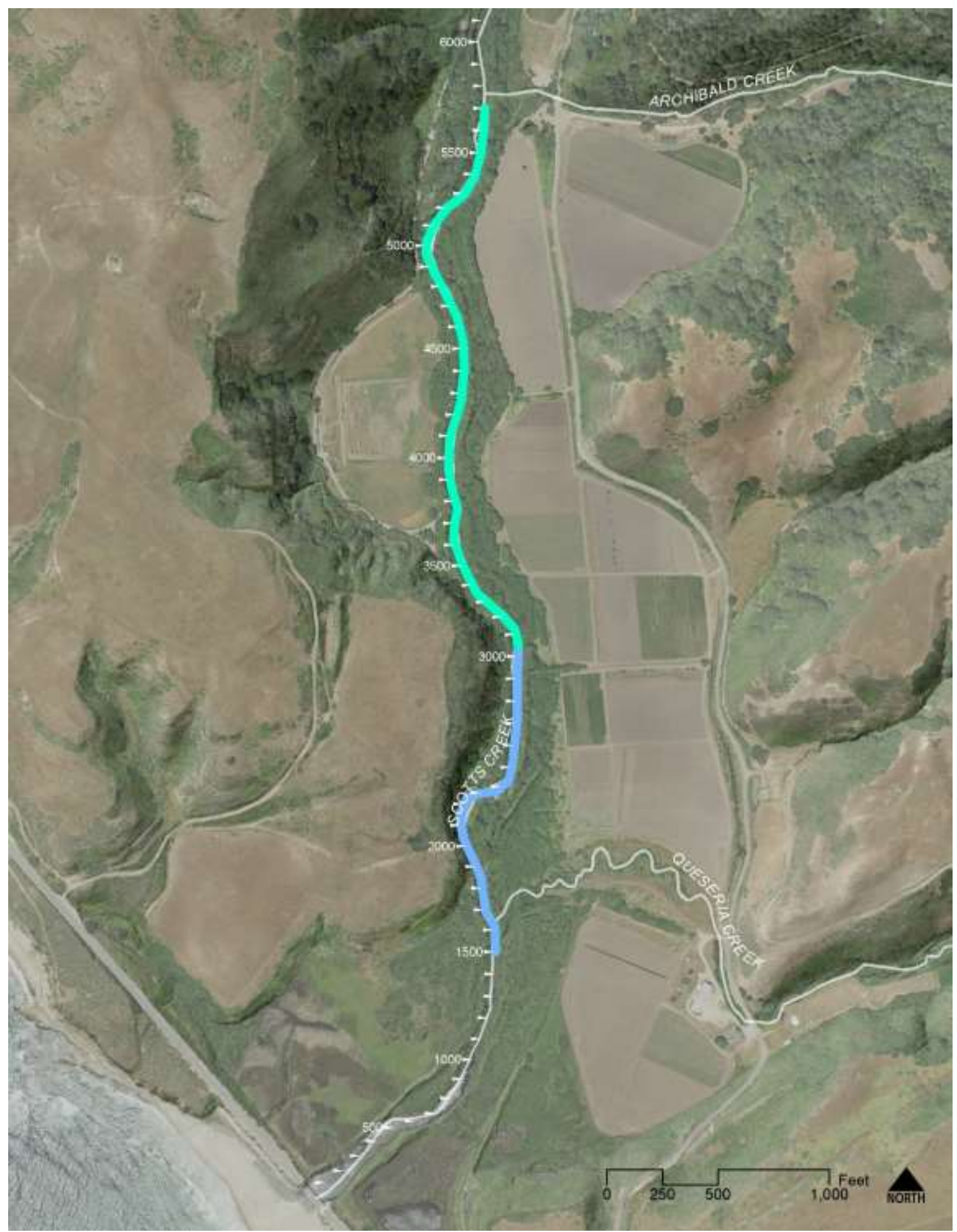

Figure 9. Project reaches with river stationing in feet upstream from the CA-1 bridge. Blue denotes Phase I, cyan Phase II. Stationing is offset by approximately-100 feet compared to stationing shown in the 100\% design drawings. 


\subsection{Levee Breaches}

Portions of the existing levees were removed to increase the number of points of connectivity with the floodplain bounded by Scotts and Queseria Creeks, increase the number and frequency of refuge habitat units, and create access to floodplain refuge and foraging habitat (Recovery Actions 2.1.1.1 and 2.1.1.2, NMFS 2012). Five levee breaches were distributed along the reach spanning from the Queseria Creek confluence to the drainage ditch at 3000, at approximate stations 1900, 2000, 2650, 2750, and 2850. This reach was chosen because the wide vegetated riparian buffer and low floodplain gradient $(<0.3 \%)$ are expected to minimize risk of flood damage to crop fields by slowing floodflows, and because observations during overbank events suggest that flood flow velocities are buffered by backwater effects from the Queseria confluence. Breaches were cited

along sub-reaches where they would likely activate the floodplain at the bankfull stage. The likelihood of activation was determined by comparing the elevation of bankfull indicators in the main channel to adjacent floodplain elevations. Two sub-reaches were identified where these elevations were approximately equal (1800-2100 and 2500-3000) whereas the channel was more incised from 2100-2500 and was avoided for that reason. Within the favorable sub-reaches, the approximate locations of the levee breaches were determined by selecting gaps in vegetation, and by attempting to evenly distribute the breaches throughout the sub-reach.

The sizes of the breaches were minimized to reduce the volume of excavation and the area of disturbance. Breaches were laid out perpendicular to the main channel and levee berm to minimize the length required to connect the main channel to the floodplain. The breach bottom widths were minimized and the side slopes were optimized to minimize volume yet remain stable. While the breach openings were conceptually regarded as pilot channels with the potential to adjust in size during a very large flood event, it was necessary to determine a stable geometry to prevent masswasting and sediment delivery to the main channel, and promote regeneration of native riparian habitat. The minimum bottom width required to keep the velocity of lateral outflow/inflow below 
an erosive threshold was chosen, because it resulted in a stable configuration and minimal disturbance (see hydraulic calculations in Phase I Engineering Docket, Appendix C).

Levee breaches were expected to result in an array of hydrologic, hydraulic, and habitat-related effects. The breach openings were expected to form five additional refuge habitat features at the margins of the stream channel during high flows. Increased floodplain connectivity was expected to improve access to floodplain refuge and foraging habitat, primarily for spawning adults, and reduce the potential for stranding by providing five additional points of egress/ingress. Additionally, increased floodplain connectivity could deliver additional floodplain-derived nutrients to the main channel which would improve instream foraging opportunities.

In addition to increasing floodplain refuge and foraging opportunities for salmonids, levee breaches were intended to improve floodplain function and increase riparian habitat and species diversity by restoring the historical frequency and duration of floodplain inundation along lower Scotts Creek. High productivity, biodiversity and species richness of natural floodplains, and the importance of the flood pulse to floodplain function, has been documented (Junk et al. 1989, Gregory et al. 1991, Naiman et al. 2000, Tockner et al. 2000). Intentional levee breaches were found to influence floodplain topography through depositional sand-splay formation and floodplain scour, and delivery of large wood to the floodplain which further facilitates scour (Florsheim and Mount 2002). Restoring the flood pulse along lower Scotts Creek may increase variation in floodplain topography, and as a consequence, increase habitat and species diversity.

Hydrologically, the levee breaches were designed to increase the frequency (spatial) and number of points of connectivity with the floodplain, the frequency (temporal), duration, and area of floodplain activation, and increase groundwater recharge. Hydraulically, levee breaches were expected to reduce main channel discharge, velocities and shear stresses above the bankfull stage by taking advantage of floodplain storage and conveyance. Levee breaches have the potential to reduce sediment transport capacity and aggrade the main channel, however this effect may be 
mitigated by the constructed instream features (see Large Wood Complexes below) located to increase flow competence in the vicinity of the breach openings, and by a reduction in sediment loads in the main channel due to conveyance and storage of sediment on the floodplain. Multi-year repeat longitudinal profiles or topo surveys should be done to track these potential effects (see Chapter 6. Monitoring).

HEC RAS 4.1.0 was used to check whether the levee breaches, and other features, would activate at the bankfull stage as designed. To accomplish this, AutoCAD Civil 3D 2014 Imperial was first used to create a DEM of a design iteration which included five levee breaches, 12 instream large wood complexes (modeled as prism-shaped obstructions in select main channel cross-sections), connections with two off-channel ponds, connections with two drainage ditches, and the enhancement of the Archibald Creek confluence. HEC RAS was used to model the bankfull discharge through the main channel on the design DEM. The results were analyzed with the HEC GeoRAS plugin for ArcMap 10.2 (Figure 10). While the one-dimensional HEC RAS model cannot accurately model overbank flow (Roni and Beechie 2012), the results were useful for comparing bankfull water surface elevations (WSEs) to the bottom elevations of the proposed features. 


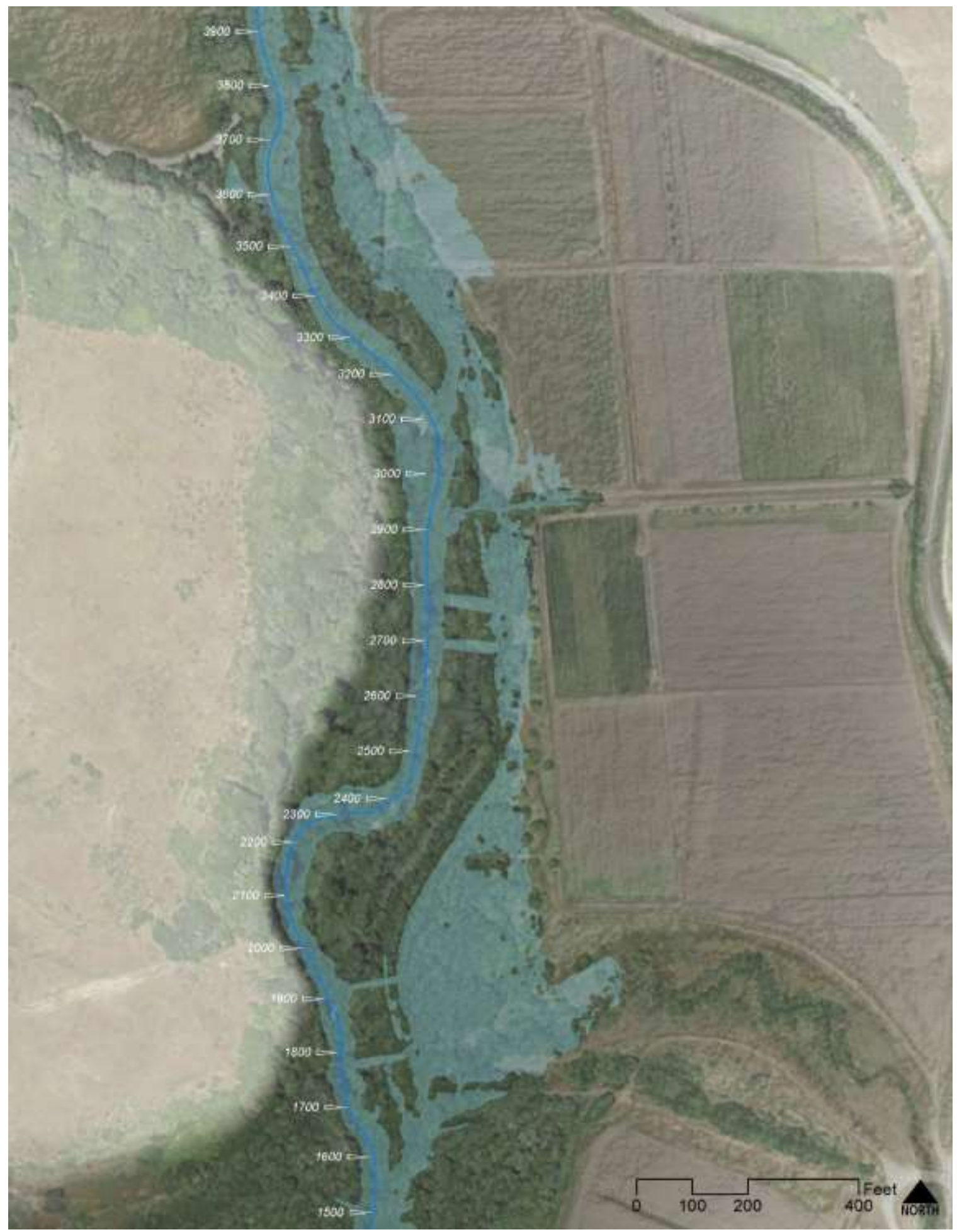

Figure 10. HEC RAS model results for the bankfull event showing potential inundation (shaded blue) through the proposed levee breaches. 


\subsection{Floodplain Connections and Alcoves}

Low-gradient backwater connection channels were sited to establish hydrologic connectivity between the main channel and existing hydrologically active features on the floodplain (NMFS Recovery Action 2.1.1.2). These existing features included one small depression at 1800, an existing drainage ditch at station 3000, two floodplain ponds at stations 3300 and 3800, and an existing network of swales and gullies in the vicinity of station 4250. The small depression at 1800 and the two ponds at 3300 and 3800 were likely scoured by large flood events in 1982 and 1998. The measureable objectives were to increase the number and frequency of instream, alcove, and off-channel refuge habitat units, and increase the number of points of connectivity with the floodplain at the bankfull stage.

Alcove features were constructed at the confluence of each constructed connection channel, and at tributary confluences within the project reach. Alcoves were irregular teardrop shaped, with a nominal bottom diameter of 12 feet with 3:1 side-slopes. Alcoves were typically graded at the elevation of the streambed outside of the wetted low-flow channel and were expected to activate above summer base flow conditions ( $>20 \mathrm{ft}^{3} / \mathrm{s}$ by visual estimate).

\section{Scour Feature at 1800}

At station 1800, a short channel was excavated to connect an existing depression to the main channel of Queseria Creek (tributary to Scotts Creek). The existing depression, formed by major recent flood events, was approximately $30 \mathrm{ft}$ long by $20 \mathrm{ft}$ wide by $4 \mathrm{ft}$ deep, and located approximately $30 \mathrm{ft}$ northwest of the main channel of Queseria Creek. The excavation removed the mass of soil between the scour feature and the main channel of Queseria Creek $210 \mathrm{ft}$ upstream from the confluence of Queseria and Scotts Creeks, adjacent to station 1800 of Scotts Creek. The objective was to create a backwater connection with an existing but disconnected feature to provide additional refuge habitat. The constructed channel bottom was $6 \mathrm{ft}$ wide and was graded at the elevation of the existing Queseria invert and scour feature invert. Rock was uncovered during 
excavation and used in place to armor a section of the cut bank of the connection channel. In December 2014, flood flows in the vicinity of the scour feature were observed to have low velocities, due to a backwater effect from Scotts Creek. This area was revegetated with rushes Juncus spp., barberpole sedge Scirpus microcarpus, and umbrella sedge Cyperus eragrostis.

\section{Alcove at 3000}

An alcove pool feature was excavated, and a culvert and a portion of the existing levee berm were removed where a crop field ditch drained to Scotts Creek at station 3000. The ditch had previously passed under the levee into the main channel of Scotts Creek through an 18 in culvert that was $\sim 50 \%$ plugged. The alcove feature was graded at the elevation of the bottom of the ditch/culvert. The alcove was teardrop shaped, with a nominal diameter of $12 \mathrm{ft}$. The objective of this feature was to create alcove and off-channel refuge habitat, reduce the potential for floodplain stranding, and reduce the main channel flood stage. The alcove feature was expected to activate at or above winter baseflows and fully connect to the floodplain at the bankfull stage.

\section{Ponds at 3300 and 3800}

Pond connections were excavated to provide an additional 0.25 acres of off-channel refuge and foraging habitat during high flows, with the goal of improving juvenile overwinter survival rates. The hydrologic objective of connecting these ponds to the main channel was to increase the frequency and duration of inundation of the ponds. Alders on the south side of the ponds were pushed over to increase insolation. Ecologically, improved connectivity combined with reduced canopy cover is expected to increase primary productivity within the ponds.

Off-channel ponds may provide important winter rearing and refuge habitat. Salmonids were found to overwinter in off-channel ponds at much higher rates than main channel habitat features (Swales and Levings 1989, Whitmore 2014). Patterns of utilization in arid or Mediterranean climates near the southern extent of the range of Oncorhynchus spp. are not well understood, though utilization of off-channel features appears to be more transient and temperature limited (Merz et al. 2015). 
Anthropogenic impacts limit the availability of off-channel habitat. The construction of off-channel ponds and other habitat features is an accepted method of increasing refuge opportunities in Pacific Northwest systems. Salmonids were observed to use constructed off-channel ponds as winter refuge habitat with higher occupancy than the main channel (Whitmore 2014, Morley et al. 2005).

The ponds at 3300 ("lower pond") and 3800 ("upper pond") were determined to be groundwaterfed and remained wetted perennially over the 2013-2015 drought. Rana draytonii were found in both ponds, however they were not breeding populations (Swaim, unpublished report, 2013). An important design objective was to connect the ponds to the main channel without dewatering them, because the ponds provided functional habitat for Rana draytonii, and potential salmonid habitat.

Pond connection channels were excavated at a depth that corresponded to the winter baseflow stage $\left(>20 \mathrm{ft}^{3} / \mathrm{s}\right)$ and became fully connected to the ponds at the 0.5 to 1 -year flow event. The channels began at the tail crest of each pond and terminated at the main channel in a constructed alcove feature. The geometries of the channels varied slightly along the length of the channels but were generally 4 feet wide with 3:1 side slopes. The preliminary design called for log or rock check dams to be placed in the channels to mitigate the potential for head-cutting that could dewater the ponds. The final design instead utilized vegetation, woody debris, sinuosity, and topographic variation to mitigate the potential for headcutting while promoting a natural appearance.

At station 3250, the "lower pond" connection channel was aligned to follow an existing swale that began at the pond tail crest and ran south, parallel to Scotts Creek. The channel diverged from the existing swale and cut through the existing levee to join the main channel of Scotts Creek at station 3200. The design length was approximately 140 feet. Mild irregularity was incorporated into the channel's alignment and longitudinal profile to naturalize the feature, increase roughness and flowpath length, and create small residual pools capable of retaining surface water within the feature. The bottom width of the channel was 4 feet, and the slope was $<1 \%$ towards the alcove. 
The channel slope increased briefly to transition to the alcove as per the plan set. Planting density was increased at the transition to control erosion.

The "upper pond" connection channel at 3800 was excavated perpendicular to the main channel to connect the "upper pond" to main channel. The plan set called for angling the channel in the downstream direction from the pond to Scotts Creek, however multiple woodrat nests were discovered along the proposed alignment prior to construction and the channel was realigned to avoid disturbing the nests. The final alignment followed an existing gully running perpendicular to the main channel of Scotts Creek, which further reduced the volume of excavation. The channel was approximately 60 feet long.

Live in-situ alders were pushed into or over the ponds to provide escape cover for salmonids and CRLF, increase the productivity of the ponds by increasing insolation, and provide habitat for macroinvertebrates and breeding CRLF. Native aquatic vegetation is expected to colonize the ponds. If natural colonization does not occur, native aquatic vegetation will be transplanted to the ponds from other wetlands adjacent to Scotts Creek.

Alcove features were inset into the left bank of Scotts Creek, at the outlets of the pond connections. The alcove features were graded at the elevation of the bed of the active channel, but above the wetted summer low-flow channel. The construction of alcove features at the outlets of the offchannel pond connections was expected to provide additional refuge habitat at or above winter baseflow conditions.

\section{Floodplain connection at 4250}

An existing network of gullies was connected to the main channel of Scotts Creek by excavating an irregular channel through the existing levee. The objective was to increase alcove and offchannel refuge habitat, and increase floodplain connectivity. The channel was excavated through the levee at the elevation of the gully bottom. The connection channel terminated at teardrop-shaped constructed alcove feature inset into the left bank of Scotts Creek. The bottom of the alcove feature 
was excavated at the elevation of the active channel with a nominal diameter of 12 feet. The location was chosen because the bottom elevation of the gully was below the bankfull indicators in the main channel, indicating that the feature would activate frequently, because of the relatively short distance between the gully network and the main channel, and because a large natural debris jam formed immediately downstream which was expected to backwater the feature and further increase the depth and frequency of activation.

\subsection{Archibald Confluence Enhancement}

At 5600, the confluence of Archibald Creek was enhanced by excavating a backwater pool, excavating a connection to increase activation of an existing auxiliary channel parallel to Archibald Creek, and constructing two LWCs to increase the functionality of the confluence and increase habitat complexity. The objectives of enhancing the confluence were to increase the frequency, distribution, and volume of alcove refuge habitat at or above winter baseflow conditions, increase instream cover over a wide range of flows, and create access to additional tributary habitat along the mainstem of Archibald Creek during stormflows.

Archibald is a seasonal tributary to Scotts Creek that behaved ephemerally in the current drought. West of Swanton Road, Archibald Creek emerged onto a terrace above Scotts Creek, and then cascaded east-west down a series of step-pools with cobble/boulder substrate into Scotts Creek at station 5850. The total channel length between Swanton Road and Scotts Creek was 300 feet at an average slope of $4.4 \%$. The floodplain south of where Archibald Creek emerged onto the terrace activated when Archibald Creek experienced overbank flows. Activation was evidenced by debris racking and a gravel/cobble auxiliary channel bed running southwest from the terrace and terminating in a swale adjacent to Scotts Creek at station 5650.

The confluence enhancement took advantage of this existing auxiliary channel and swale by excavating a pool at 5650 to connect the swale to Scotts Creek, and by excavating a connection between Archibald Creek and the existing auxiliary channel to increase the frequency of activation. 
An existing downed willow that fell into Archibald Creek just downstream from the connection was repositioned to further increase activation of the auxiliary channel.

The enhanced confluence was sited to avoid removing trees, and to utilize trees as bank armor. A teardrop-shaped pool was excavated in the left bank of Scotts Creek at 5650 to connect the swale with Scotts Creek.

One wood complex was placed in the main channel of Scotts Creek along the left bank, just upstream from the confluence. The log was oriented parallel to streamflow to shunt water into the confluence and create an eddy. A boulder ballast was attached to the upstream end of the log, and a rootwad was attached to the downstream end of the log at the mouth of the confluence to provide cover and enhance the eddy. The parallel orientation of the log reduced the drag profile sufficiently to eliminate need for additional anchoring.

A second wood complex was constructed downstream to backwater the confluence. An alder on the left bank was pushed over in the upstream direction. A log was place over the alder, perpendicular to flow. The log was braced against a live standing alder on the streambank. A boulder was attached near the midpoint of the log. A rootwad was attached to the log near the center of the active channel to shunt some flow under the log and against the left bank in an attempt to maintain the thalweg near the confluence.

The auxiliary channel was expected to activate anytime flow was present in Archibald Creek. Scotts Creek was expected to backwater the constructed pool at or above the low-flow stage and the backwater effect will be enhanced by the downstream LWC. Flow from Archibald Creek, combined with the eddy generated by the upstream LWC, was expected to maintain sediment transport through the constructed pool feature. Backwater effects from Scotts Creek were expected to inundate the alcove feature and connection channel at the downstream end of the auxiliary channel. Full connectivity from Scotts Creek upstream along Archibald Creek to the top of the auxiliary 
channel was expected to occur annually for several hours or days when flow overwhelmed the subsurface storage capacity along the auxiliary channel.

\subsection{Large Wood Complexes}

A total of 13 large wood complexes (LWCs) were constructed using redwood rootwads, logs, insitu alders, and boulder ballasts along lower Scotts Creek, to increase habitat complexity in subreaches lacking wood, activate the floodplain, and enhance the functionality of other existing or constructed habitat features. The objectives of constructing LWCs were to increase the frequency of instream refuge habitat and rearing pools, backwater alcove and off-channel features, increase stream percent cover, sort sediment, and store organic debris. Storage of organic debris was expected to increase macroinvertebrate production.

LWC placement generally targeted sub-reaches lacking wood and functional habitat (2500-3000, $3200-3600,4600-4800)$ and avoided sub-reaches where functional habitat was present (2100-2500; 3600-3800; 4200-4300 and 5100-5300). The size of LWCs was constrained to span no more than half of the main channel width to reduce the potential for channel-spanning debris jams to form and minimize the risk of flooding the crop fields in large events. LWCs were stabilized using a combination of boulder ballasts and bracing against or attaching to live, standing trees located along the streambanks. Bracing LWCs against live standing trees, rather than creating fixed attachment points, allowed the complex to rise and fall with changes in stream stage, as might occur with naturally recruited large wood pieces. A novel fastening technique was utilized to attach individual components to one another to avoid the pit-falls of traditional cable and all-thread fasteners.

\section{In-Situ Alder Recruits}

Opperman and Merenlender (2007) found that the majority of intact, natural LWD in response reaches of coastal streams was created by living hardwood. The project sought to mimic natural recruitment of hardwoods by pushing alders or other hardwood species into the stream in a way that would promote stability and survival. Living LWD could be a cost-effective way to improve 
stream complexity because it may minimize or eliminate the need to import conifers. This technique was carried out at a small additional cost to overall project and may provide important data leading to development of low-disturbance and cost-effective restoration techniques. The project used a combination of redwood and alder to insure stability and longevity of the LWCs. In-situ Alnus rubra offered several benefits:

1. Foliage, branches, and dendritic structure adds complexity to LWCs.

2. Complex structure is capable of racking debris of varying sizes. Crowns, with foliage and small, dense branches and twigs, can rack small debris particles.

3. Alders add to the shelter rating of the LWC.

4. Alder crowns may have strong hydraulic influence.

5. Use of in-situ materials reduces impact and cost of importing redwood materials.

Alders were downed by partially excavating their rootmass (when feasible) and then pulling or pushing the tree over into the stream channel, leaving some of the root structure intact and anchored. The alders were effectively pinned-down by placing the redwood log on top of the downed alder recruit. The log was then stabilized in the manner described above, which limited the movement of the alder recruit enough to keep it in place during stormflow. Alders and other hardwoods are not typically utilized to create instream structures. The use of hardwoods is not listed in the California Salmonid Stream Restoration Handbook (CDFW, 2010) and in the past FRGP has cautioned against constructing instream hardwood features, because LWD loading in N. California streams dominated by hardwoods is much lower than that in conifer-dominated streams. This suggests that hardwood LWD may be less influential on physical habitat conditions than conifer LWD (Opperman, 2002). Opperman (2002) reasons that LWD loading in hardwood-dominated streams is lower for four important reasons: 1) individual hardwood LWD pieces tend to be lower in volume than conifer pieces (results are reported in LWD volume/stream area); 2) stability is a function of piece size (among other factors), implying that hardwood LWD will be more easily mobilized by flows; 3) hardwood LWD is less resistant to decay than conifer debris; and 4) hardwood trees are shorter than conifers and thus the distance from which they can be recruited into the channel is shorter. 
Recruitment of in-situ alders is analogous to the accelerated recruitment technique used by Redwood Forest Foundation/Blencowe Watershed Management and Soquel Demonstration State Forest on redwood-dominated reaches of coastal streams. Accelerated recruitment utilizes unanchored or minimally-anchored near-stream redwood materials instead of imported materials anchored using engineered anchors and ballasts (Carah et al. 2014).

\section{Stabilization using Live Trees}

Large wood features are frequently constructed well within the margins of the bankfull channel, and anchored to the stream bed, to ensure the feature is hydraulically influential, or capable of providing direct cover, at even the lowest flows. The drawback is that features constructed in this way may easily be buried in bedload (Frissell and Nawa 1992), and additionally, that the features are located at the bottom of the water column during high flows where shear stresses are highest, where the greatest sediment transport is occurring including potentially lethal transport of boulder and cobble material, where oxygen levels are lowest, and where there is the least opportunity for foraging.

To address these problems, large wood complexes were stabilized by bracing one end of the redwood log backbone against a live-standing alder or willow growing on the streambank. Bracing would resist drag force in the downstream direction and enhance the stability of the feature. Configuring the logs in this way had two other important implications. First, the end of the log that was braced generally did not need to be anchored, which would allow it a degree of freedom (vertical). Vertical freedom of movement allowed the feature to rise and fall with stream stage. Probably the most important implication of this configuration was that a portion of the $\log$ was outside of the active channel. The intended effect was to create an eddy and backwater at the margin of the bankfull channel that would serve as refuge habitat. The author hypothesizes that wood features that occupy the top of the water column and the margins of the active channel during high flows will be more likely to provide functional refuge habitat, provide higher refuge quality habitat, 
and be more stable, because the features will form eddies, capture insect drift and promote foraging, rack buoyant debris, mix oxygen into the top of the water column, and will be subject to lower velocities and shear stresses.

\section{Couplers}

An alternative fastening technique to traditional cable or all-thread fasteners was used to attach the components of the LWC structure together. Typically, constructed wood features are cabled or pinned to boulder ballasts or buried deadman anchors (Flosi et al. 2010). Rigidly anchored structures are susceptible to burial in bedload which reduces functionality (Frissell and Nawa 1992). Boulder ballasts are commonly used to anchor buoyant instream structures (Flosi et al. 2010, also see Ruttenberg 2011). Boulders are typically attached to instream log structures using rigid all-thread/nut/washer fasteners (Flosi et al. 2010). Through-holes are bored through the diameter of the log. A slip-fit hole is drilled several inches deep into the boulder ballast, and a length of allthread is driven through the log and epoxied in place in the slip-fit hole in the boulder. A nut and washer is used to rigidly clamp the log against the boulder. Rigid all-thread connections are very strong in tension, but lack strength in bending and torsion, especially when subjected to cyclic loads. Bending and twisting may result from drag and buoyant forces, shock-loading due to debris impacts, static loading from sediment accumulation, or displacement of the structure. Cyclic loading may occur with the rise and fall of the stream. All-thread fasteners present additional challenges related to assembly. Very long drill bits may be required to drill through-holes. Long bits are prone to overheating and breakage. Long through-holes may be crooked or misaligned. Unanchored LWD structures avoid problems related to fasteners and assembly but requires the use of very large wood material or whole trees, often spanning the entire channel (Carah et al. 2014, Reynolds 2013).

An alternative to bolting or cabling was used that was not found in the literature. Quick-links (a steel carabiner with a locking gate) or shackles were used to couple the individual log, boulder, and 
rootwad LWC components together. These couplers securely held the structure together while allowing some independent movement among the individual components. Freedom of independent movement allowed the individual log and rootwad components to float above the bedload, adjust under large loads, and allowed debris jams to pass that could have otherwise caused the structures to fail.

To create attachment points for the couplers in each of the LWC components, the design drawings called for the use of large-diameter eyeleted fasteners. Due to the difficulty and expense in sourcing large-diameter eyeleted bolts and lag screws, an alternative was devised by Jack Dietrich of Dietrich Ironworks (Santa Cruz). Steel angle brackets were coupled using a quick-link and then bolted to the boulder or log (Figure 11 and Figure 12). Go Native, Inc. alternatively used a pair of shackles instead of a single quick-link (see Figure 17 later in Chapter 5). An extra quick-link or shackle was added when it was necessary to extend the reach of the coupler.

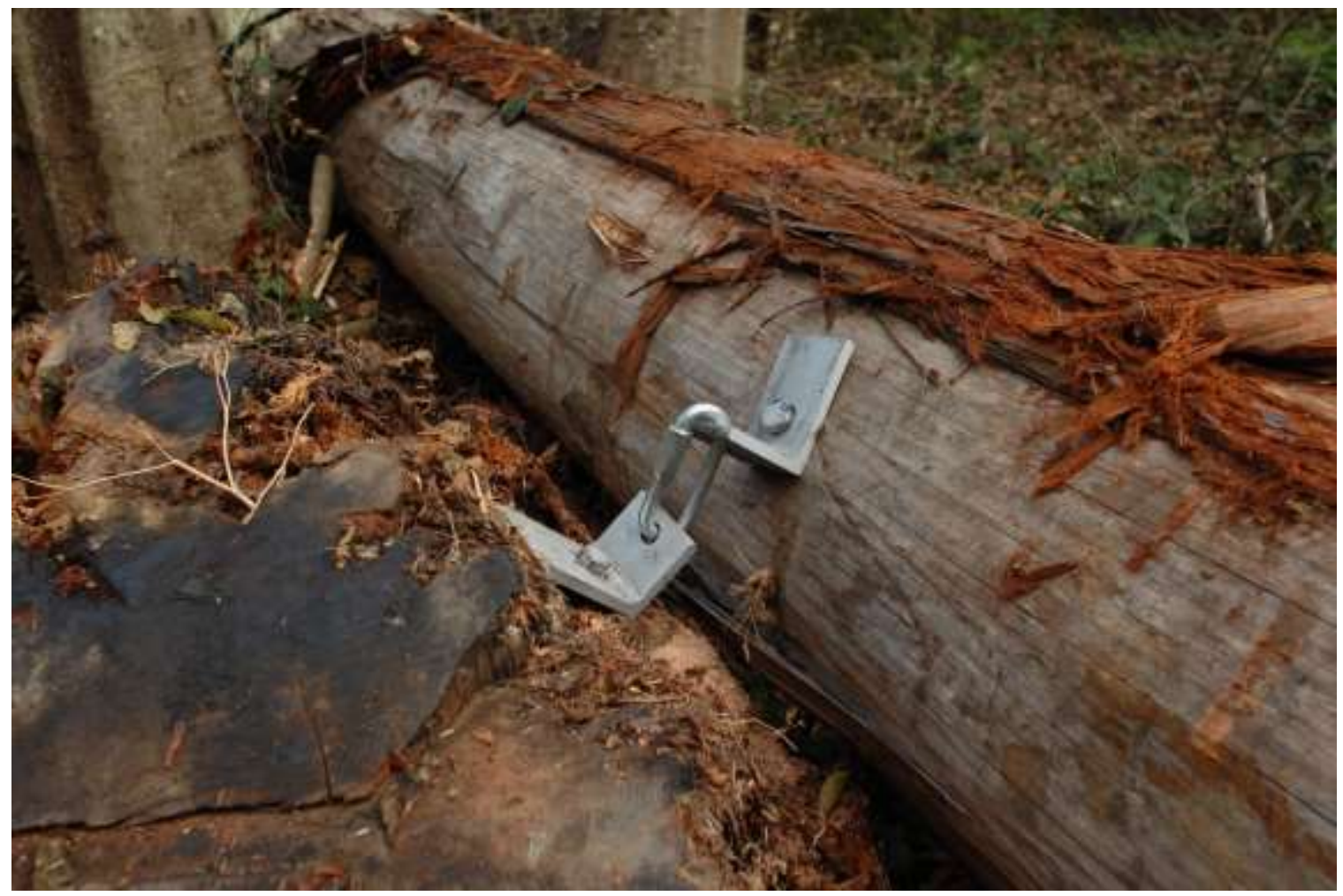

Figure 11. Log-rootwad coupler. 


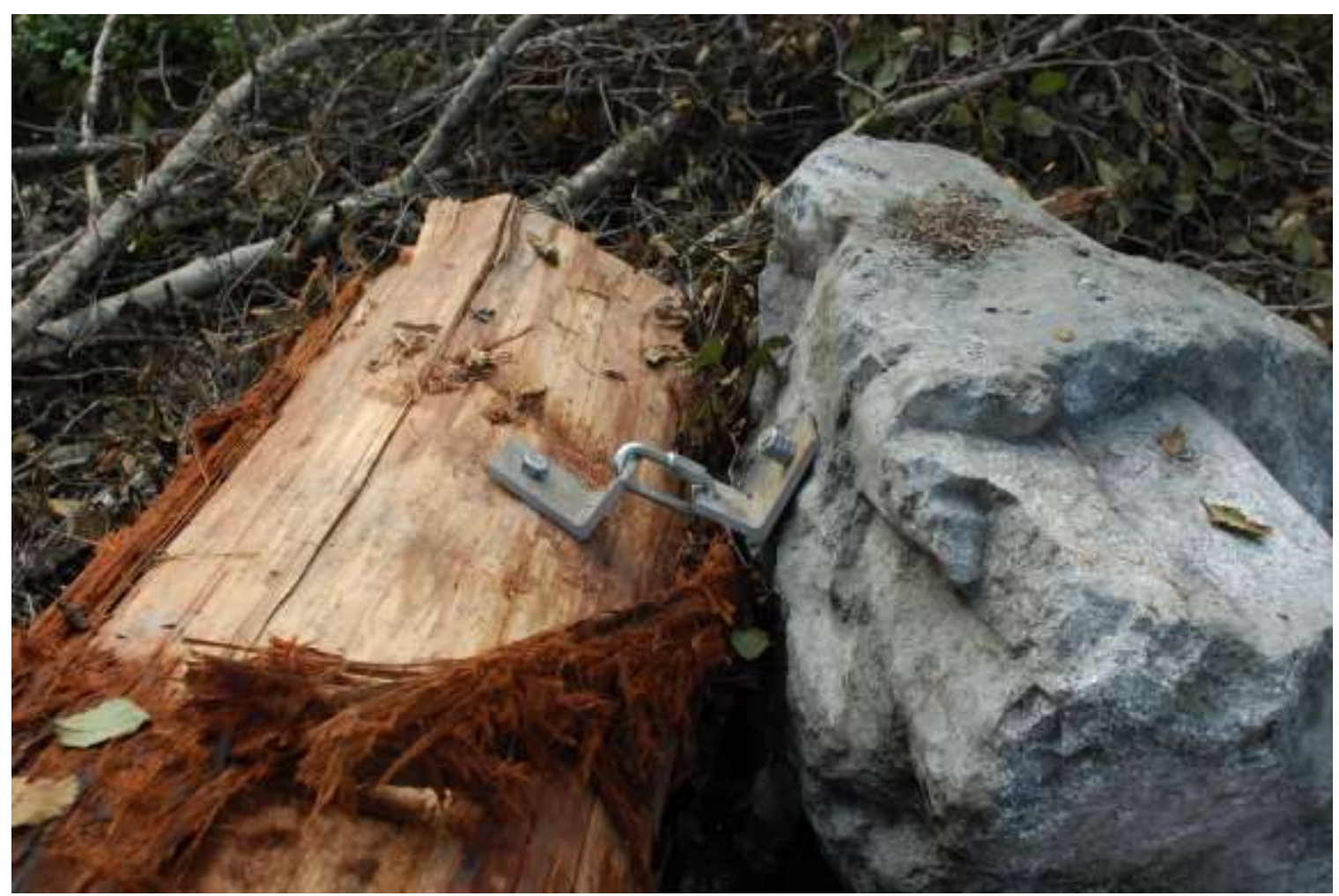

Figure 12. Log-boulder coupler.

The connections were relatively easy to assemble. The narrow gate of the quick-link required that the brackets be linked together prior to assembly, however this was an advantage (discussed below). The coupler assembly was placed on the log/boulder and hole locations were marked. Eight-inch deep, slip-fit (7/8 in) or slightly oversized (15/16 in or 1 in) holes were drilled in the boulders using a masonry bit. A 12 inch long, 7/8-inch diameter, length of galvanized all-thread was bonded was epoxied in place, with $\sim 4$ in protruding (room for bracket, washer, and double-nuts), using Simpson SET-XP® epoxy anchoring adhesive (manufacturer's model number SET-XP22-N) dispensed through a Simpson 18-element mixing nozzle (Model number EMN22I) and allowed to cure for at least 24 hours. A 12-inch-deep interference-fit (5/8 in or 3/4 in) hole was drilled in the redwood component (log or rootwad). One bracket was placed over the all-thread protruding from the boulder and secured with a double-nut. The opposing bracket was attached to the redwood component using a 7/8 in diameter galvanized lag-screw. Tightening the lag screw against the bracket was used to draw the components together when necessary. 


\section{Ballasting}

The use of boulder ballasts is an accepted technique for stabilizing buoyant instream structures (Flosi et al. 2010) and was used in combination with the aforementioned techniques to create stable features that mimicked naturally-recruited large woody debris (see ballast calculations in Appendices $\mathrm{C}$ and D). Together, quick-link attachments, bracing against live trees, and ballasting facilitated the use of moderately-sized buoyant materials spanning less than half the active channel, while addressing performance, failure, and construction issues associated with traditional constructed wood features.

\section{LWCs at 2500-3000}

Four LWCs were constructed in the reach from 2500-3000 to increase instream wood and stream percent cover, facilitate pool scour and enhance pool habitat, increase instream refuge opportunities, and enhance floodplain connectivity along the sub-reach containing three constructed levee breaches and one constructed alcove feature. Each LWC was ballasted by at least one boulder and braced against a live tree on the left bank. Each LWC incorporated one in-situ alder and one rootwad to enhance the complexity of the features. At 2750 and 3000, rootwads were attached to the log near the left bank to create eddies near the margin of the stream channel. In the case of the LWC at 3000, the log and rootwad were oriented to establish an eddy in the constructed alcove feature. The rootwad was placed at the margin of the alcove to provide cover. At 2650 and 2850 , rootwads were attached to the end of the log near the middle of the stream to facilitate pool scour. The LWCs at 2650 and 2850 resembled naturally-recruited rootwads with large stems. Alders at 2650 and 2750 were topped and limbed. Alders at 2850 and 3000 were only partially limbed.

\section{LWCs at 3200-3600}

Four wood features were constructed in the sub-reach from 3200-3600. One large wood complex was placed to backwater the constructed alcove and connection channel at 3250 . The redwood log 
was positioned to span the low flow channel and thalweg, with one end near the center of the active channel and one end braced against a live tree on the streambank. The log was positioned so there would be a large gap under the log near the left bank. One rootwad was attached to the downstream side of the log near the log-end in the middle of the channel. One alder was felled upstream with the top pinned under the log and rootwad. One boulder was placed upstream of log and the log was attached to the boulder. The feature was designed to constrict the stream channel substantially to backwater alcove and facilitate scour within the active channel. Scour is expected to occur through the gap between the log and the left bank, at the outlet of the alcove feature/off-channel pond connection. The zone of scour/gap is expected to help maintain sediment transport through the alcove feature as floodwaters return to the main channel following stormflow. Scour is expected to occur at the end of the log and around the rootwad, near the center of the active channel. The gap under the log may cause the left bank to erode until channel capacity adjusts. A large gravel bar was present on stream right at the time of construction. A single alder was felled in the downstream direction over the gravel bar to maintain the gravel bar and keep the thalweg close to the alcove and wood complex.

The feature at station 3350 was constructed to mimic the feature at 2850 , constructed during Phase I. A large alder was felled upstream along the left bank. A redwood log, boulder, and rootwad, were placed in the channel. The log extended from the left bank to the middle of the channel. The rootwad and boulder were placed near the end of the log. The feature was located opposite the downed alder rootmass to focus flow at end of $\log /$ rootwad and facilitate deep scour pool. The feature is expected to reduce velocities along the left bank, providing instream refuge habitat and facilitating deposition, and increase velocities near the middle-right of the channel, especially near the end of the log, to facilitate scour. where the channel is constricted.

At station 3450, the log was set above the thalweg in the middle of the active channel, nearly parallel to flow, to reduce the drag profile and keep the feature activated during low flows. The 
feature was designed to provide cover over an exposed riffle-run. A large rootwad and boulder were attached to the downstream end of the log, and the upstream end was braced against an alder growing at the edge of the low-flow channel. The feature will likely direct flow towards the right bank and produce substantial bank scour.

A large wood complex was constructed at 3600 to enhance an existing pool and provide instream cover. This feature was configured similarly to the structures at 2850 and 3350 . The feature was located in middle of existing pool to enhance pool depth, and set-back from pool tail crest to maintain the pool tail crest elevation. The pool was targeted mainly because it is one of the largest pools in the project reach, yet lacked instream cover and velocity refuge.

\section{LWC at 3800}

One LWC was constructed to enhance the functionality of the constructed alcove feature at the confluence of the upper pond connection channel. The stream channel near the alcove had existing functional spawning habitat (2015 NMFS spawner survey), and existing woody debris. To avoid impacting the existing habitat, the feature was placed against the left bank and oriented parallel to flow to avoid significantly altering the original flow characteristics through the existing spawning area. This orientation was also intended to shunt flow along the length of the log and form an eddy within the alcove. A rootwad was attached to the downstream end of log.to provide cover and enhance the eddy. A boulder was attached to the upstream end of the log to ballast the feature. The log was attached to a live tree using a coupler. The upstream end of the log was ballasted with a boulder. The log was oriented parallel to streamflow to minimize obstruction to streamflow and the drag profile of the feature. The feature is expected to settle as the left bank scours around the end of the $\log$ and rootwad.

\section{LWC at 4200}

At station 4200, the plan set called for constructing a wood complex near the constructed alcove, however a large debris jam formed just downstream between design and implementation. The large 
wood feature was not constructed at this location but instead installed at the Archibald Creek confluence enhancement.

\section{LWCs at 4400-4600}

Two large wood complexes were constructed between the NMFS PIT tag reader antenna arrays at stations 4400 and 4600. The downstream LWC was constructed on the right bank of the stream using an excavator parked on the left bank. The log was manipulated into place on the right bank without disturbing the streambed, using the excavator and rigging. The boulder and rootwad were placed at the end of the log in the center of the channel using the 30,000 lb. excavator. The feature was designed in tandem with the LWC just upstream to induce thalweg sinuosity within the bankfull channel. Rootwads and boulders were placed near the center of the active channel to achieve the greatest hydraulic influence. These features were designed to facilitate scour, form instream pools and refugia, and provide instream cover.

\section{LWCs at 5650}

Two large wood complexes were constructed to enhance functionality of the reconfigured Archibald Creek confluence. One LWC was positioned upstream and parallel to flow to shunt water into the confluence and provide cover over the backwater area. A second LWC was positioned downstream and perpendicular to flow to backwater the feature, facilitate scour, and provide additional cover.

\subsection{Riparian Restoration}

Passive and active restoration of riparian vegetation are accepted techniques for improving aquatic habitat conditions and increasing the resiliency of near-stream areas to flooding. NMFS (2012) recommended decommissioning riparian road systems to protect spawning habitat by minimizing the delivery of sediment to the stream channel (NMFS Recovery Action 9.1.1.5.). Restoring riparian function through passive restoration of riparian vegetation was shown to improve salmonid habitat conditions in coastal watersheds (Beschta 1997; Kauffman et al. 1997; Opperman and 
Merenlender 2004). A 12- to 16-foot-wide, 860-foot-long segment of an existing access road that ran through the riparian corridor of Scotts Creek from 4400-5300 was identified as a potential sediment source (Figure 13). The road segment had become a concern because it was straight, incised, and the road surface was devoid of vegetation or other roughness or stabilizing features. The top of the road segment was oriented towards the outside of a meander bend in Scotts Creek where flood flows had damaged a portion of the existing levee. The levee had been repaired using a combination of rock and rootwads, but chronic erosion continued at that location. Levee maintenance was seen as undesirable due to the ongoing cost and disturbance to the riparian corridor, and Cal Poly instead sought to control erosion of the road surface by decommissioning and revegetating the road segment with native riparian over- and understory species.

This alternative was chosen because provided multiple management and habitat benefits at relatively low cost, including increasing flood protection by increasing floodplain roughness, increasing habitat diversity and the area of riparian habitat. The road surface was de-compacted, strewn with slash and downed wood, and revegetated with locally-sourced native riparian plant species, including rushes, sedges, red alder, and willow.

The road was replaced by a six-foot-wide sinuous trail located between the old road alignment and the streambank. The trail was placed on an elevated alignment and incorporated multiple grade reversals utilizing existing topographic features. The elevated alignment and grade reversals improved drainage of the trail surface and when combined with a sinuous alignment, should be effective at preventing unimpeded flow along the trail. 


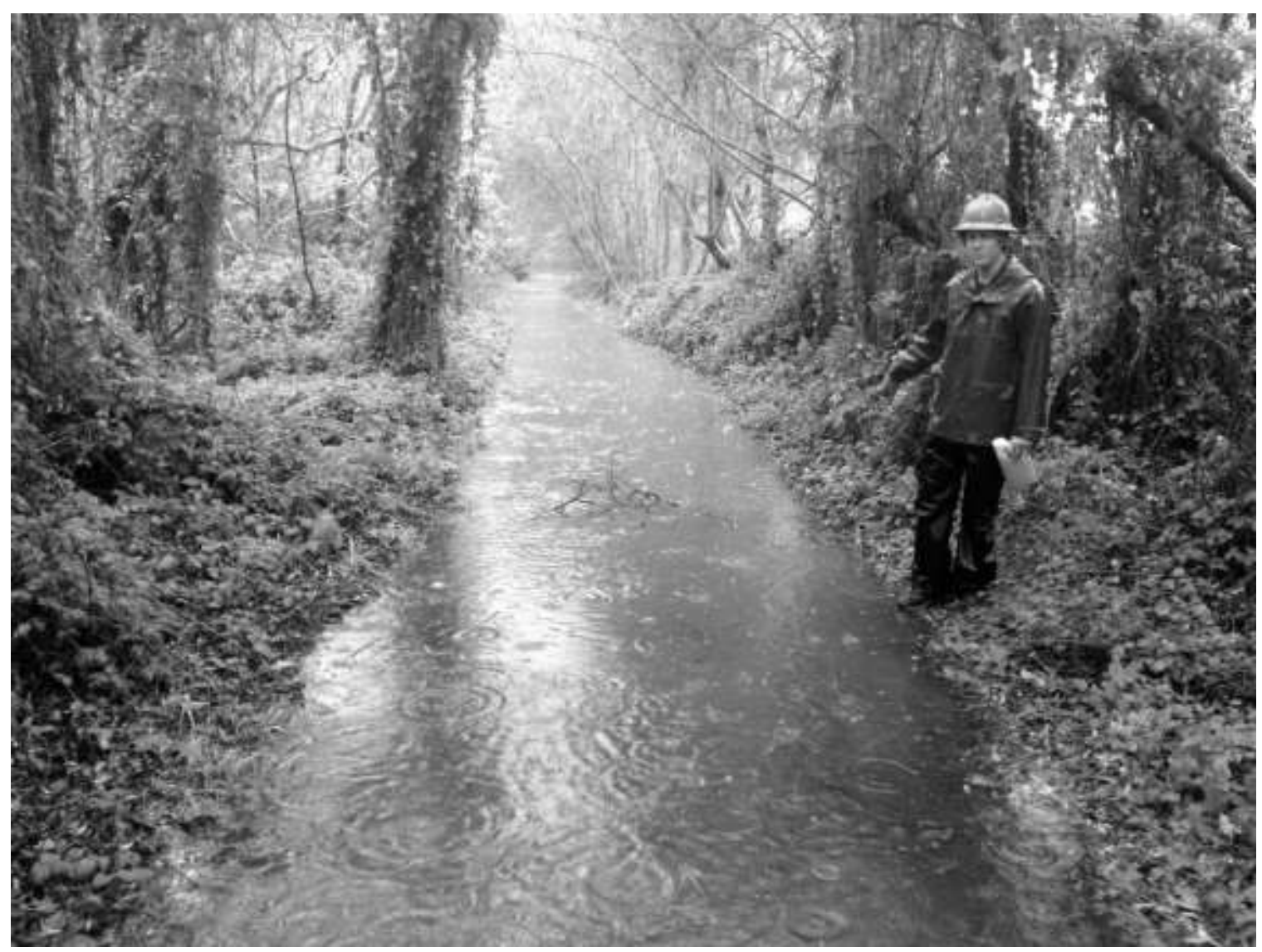

Figure 13. Photo taken during the 12/11/2014 storm of the access road segment that was to be decomissioned.

\subsection{Revegetation}

Erosion control and revegetation was performed to prevent erosion of disturbed areas, stabilize the constructed channels and alcoves, and increase plant species diversity in the riparian corridor of lower Scotts Creek. Weed-free rice straw was applied to bare soil. A revegetation palette (Table 6) was developed in consultation with botanist James West. Revegetation occurred in October and November following implementation of each phase. Disturbed areas were revegetated with transplants sourced from the Scotts Creek watershed and nearby coastal terraces, however a portion of the plants were sourced several weeks before implementation and stored in a shade structure.

Barberpole sedge was sourced from the upper estuary marsh and big-leaf sedge from the streambank of north of the Archibald confluence. The crews planted most plants in the alcove/channel features, with barberpole sedge at the base of the alcove and big-leaf sedge in the 
channel set back from the creek at $1 /$ sq. yd. Crews planted remaining plants on temporary access routes near the streambanks. Crews sourced red alder seedlings and water knotweed Persicaria punctata from gravel bars in lower Scotts Creek. Crews planted red alder seedlings on streambanks above alcove features or on temporary access routes. Crews planted water knotweed at the bottom of alcoves near the edge of the active channel. Crews sourced 6-8 tons of rushes (includes weight of soil) from the coastal bluffs using a backhoe. Transplants were installed in disturbed areas in the project site, including connection channels and the decommissioned road segment. Rushes were divided into gallon-sized plugs and planted 2-3 ft apart in the graded areas. Cut banks were planted at higher density than the bottom of gradings. 
Table 6. Revegetation palette.

\begin{tabular}{|c|c|c|c|}
\hline Common Name & Scientific Name & Function & Location \\
\hline Shreve oak & Quercus parvula var. shrevei & & \\
\hline California buckeye & Aesculus californica & & \\
\hline Boxelder & Acer negundo & SS, S, C & $\mathrm{RC}$ \\
\hline Red alder & Alnus rubra & SS, S & $\mathrm{RC}$ \\
\hline Red elderberry & Sambucus racemosa var. racemosa & SS, S, C & $\mathrm{RC}$ \\
\hline Blue elderberry & Sambucus nigra subsp. caerulea & SS, S, C & $\mathrm{RC}$ \\
\hline Willow & Salix spp & SS, S, C & $\mathrm{FP}, \mathrm{RC}$ \\
\hline Creek dogwood & Cornus sericea & SS, S, C & $\mathrm{FP}, \mathrm{RC}$ \\
\hline Brown rush & Juncus spp & SS, EC & FPA \\
\hline Bigleaf sedge & Carex amplifolia & SS, EC & FPA \\
\hline Barberpole sedge & Scirpus microcarpus & SS, EC & $\mathrm{FP}, \mathrm{RC}$ \\
\hline Cyperus & Cyperus eragrostis & SS, EC & $\mathrm{FP}, \mathrm{RC}$ \\
\hline Slough sedge & Carex obnupta & SS, EC & $\mathrm{FP}, \mathrm{RC}$ \\
\hline Salmonberry & Rubus spectabilis & $\mathrm{EC}$ & $\mathrm{RC}$ \\
\hline Blackberry & Rubus ursinus & $\mathrm{EC}$ & $\mathrm{RC}$ \\
\hline Thimbleberry & Rubus parviflorus & $\mathrm{EC}$ & $\mathrm{RC}$ \\
\hline Woodland strawberry & Fragaria vesca & $\mathrm{EC}$ & $\mathrm{RC}$ \\
\hline Straggly gooseberry & Ribes divaricatum var. pubiflorum & $\mathrm{EC}$ & $\mathrm{RC}$ \\
\hline California hedge-nettle & Stachys bullata & $\mathrm{EC}$ & $\mathrm{RC}$ \\
\hline California figwart & Scrophularia californica & $\mathrm{EC}$ & $\mathrm{RC}$ \\
\hline Douglas' nightshade & Solanum douglasii & $\mathrm{EC}$ & $\mathrm{RC}$ \\
\hline Golden yarrow & Eriophyllum confertiflorum & EC & $\mathrm{RC}$ \\
\hline Lady fern & Athyrium felix-femina var. cyclosorum & $\mathrm{EC}$ & $\mathrm{RC}$ \\
\hline Giant chain fern & Woodwardia fimbriata & $\mathrm{EC}$ & $\mathrm{RC}$ \\
\hline Sword fern & Polystichum munitum & $\mathrm{EC}$ & $\mathrm{RC}$ \\
\hline Wood fern & Dryopteris arguta & EC & $\mathrm{RC}$ \\
\hline Common yarrow & Achillea millefolium & $\mathrm{EC}$ & $\mathrm{RC}$ \\
\hline
\end{tabular}

Key:

$\begin{array}{ll}S S=\text { soil stabilization } & R C=\text { riparian corridor } \\ E C=\text { erosion control } & F P=\text { floodplain } \\ S=\text { shade } & F P A=\text { floodprone area } \\ C=\text { cover } & \end{array}$


Transplants with dense root structures performed the best, especially rushed and sedges. Willow, big-leaf maple, California buckeye, creek dogwood, and elderberry cuttings were planted during Phase I, but experienced near-100\% mortality in the first year. Overall mortality of transplants was estimated to be $>50 \%$ after one year, probably due to winter floods and extreme drought. Cal Poly personnel watered once in November 2014 and once in June 2015. Watering was insufficient to sustain most plants through the drought. Tree cuttings were probably not planted deep enough to remain in contact with moist soil throughout the summer. In June of 2015, approximately 50 additional plants were transplanted to the Phase I project area to augment plantings that had failed. Overall, vegetation survival rates from the original plantings that occurred in November of 2014 were highest in areas with moist soil (near-stream or low floodplain) and deep shade. 


\section{MONITORING}

A panel of monitoring activities were initiated to monitor both phases. The purpose of the monitoring activities was threefold: first, to track the stability and performance of the constructed features; second, to track the longevity and survivorship of the alder recruits, and third, to determine whether the project met its objectives of increasing refuge and rearing habitat, wood density, stream percent cover, and floodplain connectivity. Preliminary monitoring activities provided important information that may help to guide future restoration projects in coastal streams. In order to determine whether or not the project succeeded in achieving its objectives and document project effectiveness, the following panel of monitoring activities was implemented:

1. Physical habitat surveys

2. Photo monitoring

3. Collection of stream flow and floodplain inundation data

4. Repeat topographic surveys in designated study sites

5. As-built surveys

6. A characterization of the ground-surface water relationship

7. Water quality in the existing off-channel ponds

Components of physical habitat assessment protocol described in the California Salmonid Stream Habitat Restoration Manual, Part VIII, were selected and implemented (California Department of Fish and Wildlife, 1997). Additional appropriate protocols specified in Scientific Protocol for Salmonid Habitat Surveys within the Columbia Habitat Monitoring Program (Bouwes et al. 2011), were selected and adapted for monitoring the project.

\subsection{Streamflow}

Streamflow was monitored using continuous flow data from the automated stream gage (pressure transducer with data logger and telemetry) located on Scotts Creek just below the Archibald Creek confluence. Discharge was estimated on stage using a calibrated rating curve. Manual flow measurements were taken opportunistically since the installation of the gage in 2010 to develop and maintain the stage-discharge rating curve for the gage. The accuracy of the automated gage was verified by observing a staff plate installed at the same depth as the gage's pressure transducer. 
The two largest peak flow events of the 2014-2015 rain season occurred on December 3rd and December 12th, 2014. The first event breached the sandbar at the mouth of Scotts Creek which resulted in the partial draining of the estuarine lagoon. The peak stage for this event was 3.2 feet. Prior to December 3rd, backwater from the lagoon had partially inundated the lower portion of the Queseria Creek stream channel, the newly constructed connection channel at station 1800, and the existing scour feature. Photos show a progression of wetting, draining, and re-wetting of the scour feature as the lagoon filled, drained, and then filled again as a result of stormflow. The largest peak flow event occurred on December 12th. This event slightly exceeded bankfull and produced minor flooding along the project reach. The stream gage above Archibald Creek recorded a peak stage of 5.52 feet. Videos were taken of stormflows around the constructed features on the afternoon of December 11th, on the rising limb of the hydrograph near peak flow. Videos are available at: http://www.youtube.com/playlist?list=PLRRplD3jkK_Fn-Ryg_IktLgrGWw6qUZ14

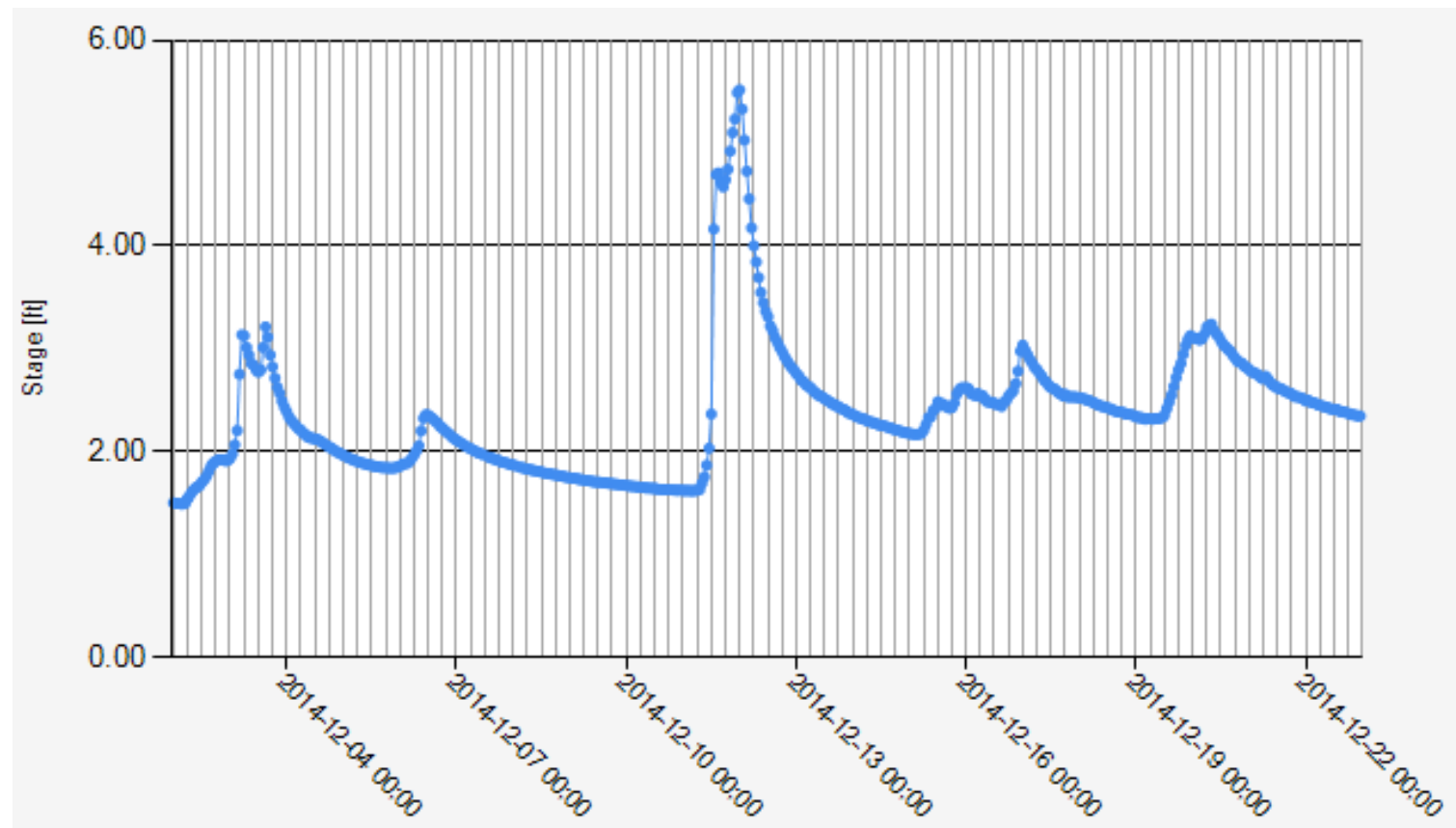

Figure 11. Hydrograph for Scotts Creek at the stream gage above Archibald Creek for December 2-22, 2014. Vertical grid lines represent 6-hour intervals. 


\section{$5.2 \quad$ Level Loggers}

Level loggers (Odyssey capacitive, 1.5 meter) were deployed to monitor floodflow stages for the purpose of characterizing floodplain connectivity. The level loggers were calibrated according to the procedures described in the technical manual available at http://odysseydatarecording.com. One level logger was installed in the constructed alcove feature at the outlet of the agricultural ditch at 3000 and the other was installed in the ditch 115 feet to the east. The level logger locations and elevations were surveyed using a total station. These loggers recorded depth data at 15 minute intervals in winter and spring of both 2015 and 2016. Redeployed in the same locations may reveal changes to the flood regime associated with Phase II.

Data from the level loggers were plotted for the mid-December 2014 stormflow events (Figure 14). These plots show that the WSE in the alcove feature was higher than that of the ditch before and during the peak of the December 11-12 stormflow, indicating that lateral outflow was occurring. These data were in agreement with field observations on the afternoon of $12 / 11 / 2014$. This suggests that the feature was backwatering the floodplain as intended through the improved connection.

Four hours after peakflow, the WSE in the alcove feature fell below the ditch WSE and remained lower as storm flows receded. This condition suggests that surface water on the floodplain was draining back into the main channel, and that water was ponding in the ditch. Field observations of rilling at the ditch outflow confirm that the ditch drained the floodplain with enough velocity to erode the silt deposit that formed during stormflows. This indicates that the improved connection provided a return flow path for floodwaters, and could provide a point of return to the main channel for fish utilizing the floodplain during peak flows.

Video from December 12th shows surface water flowing down the access road, located between the two level-loggers. An unknown portion of floodwaters flowed south down the access road which lies between the two level loggers. The access road was an apparent preferential flow path 
which probably confounds the dataset's usefulness in determining connectivity between the two level logger locations.

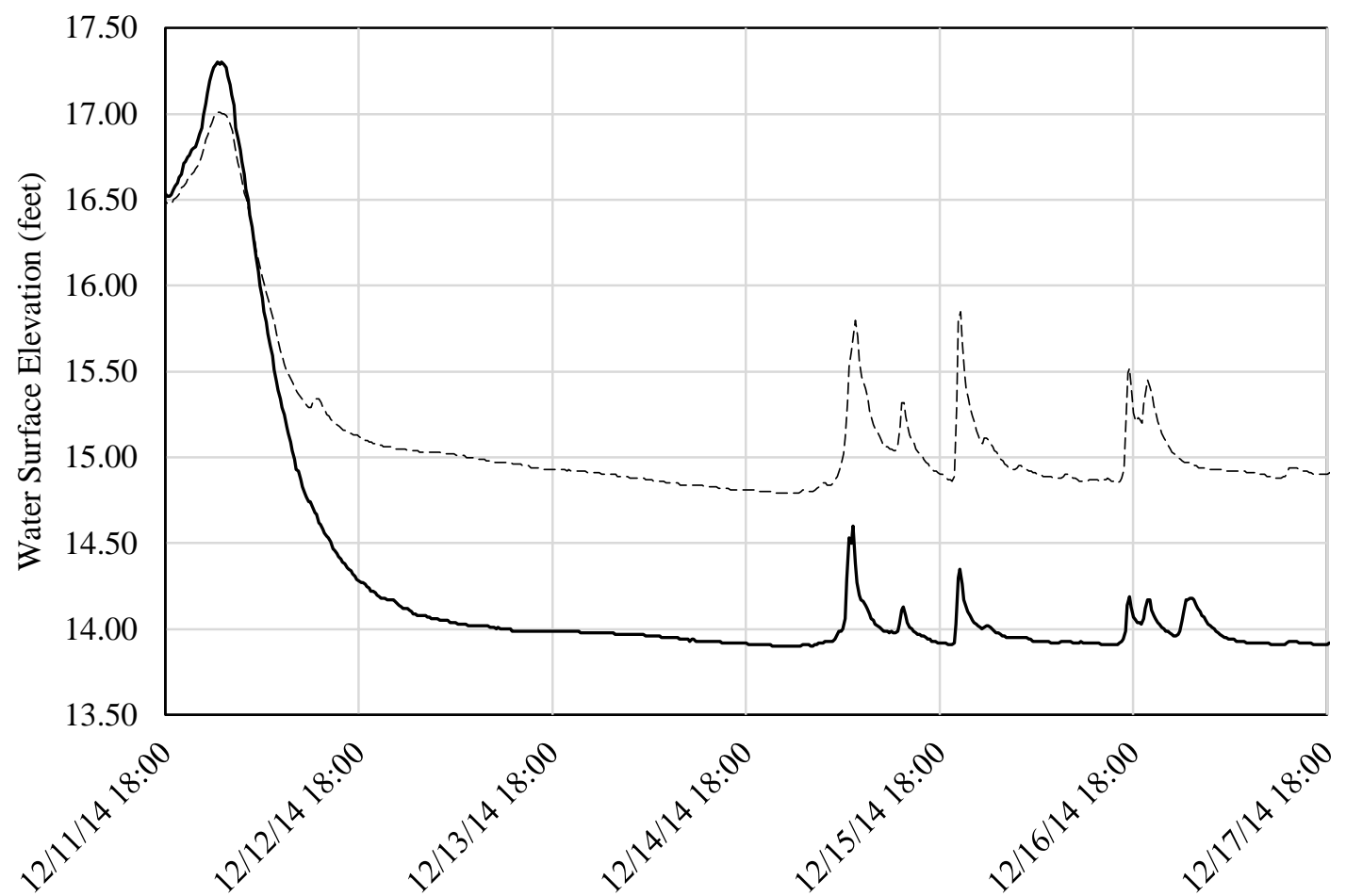

Figure 14. A comparison of water surface elevations in the alcove feature (solid line) and the drainage ditch (dashed line) during a December 2014 peak flow event.

\subsection{Photo Monitoring}

Pre-construction, during-construction, and post-construction photographs were taken of each of the features that were constructed during both project phases. Additional photos were taken opportunistically of each of the features during and after winter stormflow events (see Appendices $\mathrm{E}$ and F). Photos are dated and arranged to document pre- and post-construction conditions, to illustrate the performance of each of the project features during storm flow events, and to document changes that were apparent after stormflows subsided.

\subsection{Snorkel Surveys}

NMFS staff conduct an array of ongoing salmonid life-cycle monitoring studies in Scotts Creek, including snorkel surveys to document the abundance and distribution of juvenile Coho Salmon. 
Snorkel survey protocol is described in NMFS Santa Cruz/San Mateo County Coho Salmon Presence-Absence Study: Protocols for Snorkel Counts and Habitat Typing_2008 (Spence 2008). In 2015, NMFS snorkeled in July and again in November. Survey data has reach-scale resolution. Georeferenced survey data is forthcoming (Kiernan 2015).

NOAA Fisheries staff conducted repeat snorkel surveys along lower Scotts Creek within the project reach to characterize salmonid utilization and survival. Total steelhead and Coho Salmon abundance by size class were recorded in every other pool, in summer, fall, and spring. The results of the snorkel survey for salmonid abundance by size class conducted on 7/31/2014 in the Phase I study reach are show below in Table 7 . These data will later be used to track juvenile oversummer and overwinter survival rates.

Table 7. Pre-project snorkel survey results for the Phase I study reach.

$\begin{array}{lrr}\text { Lengths }(\mathrm{mm}) & \text { Coho Salmon } & \text { Steelhead } \\ <25 & 1 & 2 \\ 25-50 & 1 & 12 \\ 51-75 & & 24 \\ 76-100 & 13 \\ 101+ & 4\end{array}$

In addition to salmonids, four Three-Spined Stickleback Gasterosteus aculeatus and four Sculpin Cottoidea sp. were observed.

\subsection{As-built Surveys}

Georeferenced as-built surveys of the constructed features were performed by a two-person crew using a Topcon OS-103 total station, a SECO tripod, a SECO 8.5-foot reflector pole, and -30mm offset prism. Tom Mastin, (L.S., Professor, Cal Poly) set permanent and temporary survey control along the project reach using a combination of existing survey benchmarks and GPS-based survey techniques. New permanent survey control points were set in the Phase II project reach (point numbers 1089-1099) to supplement existing control (see Appendices I and $\mathbf{J}$ for a map and table of 
survey control points). Point 1089 and 1090 are in field 4 near point 1500. Point 1500 is USGS benchmark M1238, located at the base of the utility pole at the intersection of Swanton Road and the farm access road between fields 2 and 4 . The total station was set up over permanent survey control with line-of-sight to each feature. Each log, rootwad, boulder, and alder were surveyed. Logs were surveyed by taking two points at each of the two ends at the widest point in plan view (Figure 15). Rootwads and boulders were surveyed by taking select points on the top surface, which included the highest point, and around the perimeter, to capture the irregular surface and plan-view footprint of the element (Figure 16). Alders were surveyed by capturing select points on the top surface and perimeter of the rootmass, and pairs of points along the trunk and major branches at the widest point in plan view, single points at crotches, and a single or pairs of points at the tips of major branches or trunks, depending on whether the limb tapered to a point or terminated at a break or cut. Additionally, the center of each of the bolt-heads were surveyed. Surveying the bolt-heads was useful for determining displacement, including rotational displacement, of the elements, or may be useful in the future for capturing joint failure (Figure 17). Overhung features that could not be surveyed with the rod, usually bolt-heads, were surveyed using a reflectorless sideshot. Log points were coded "LOG", boulder points were coded "BLDR", alder points were coded "ALDR", rootwad points were coded "RW", and bolt-head centers were coded "BOLT". 


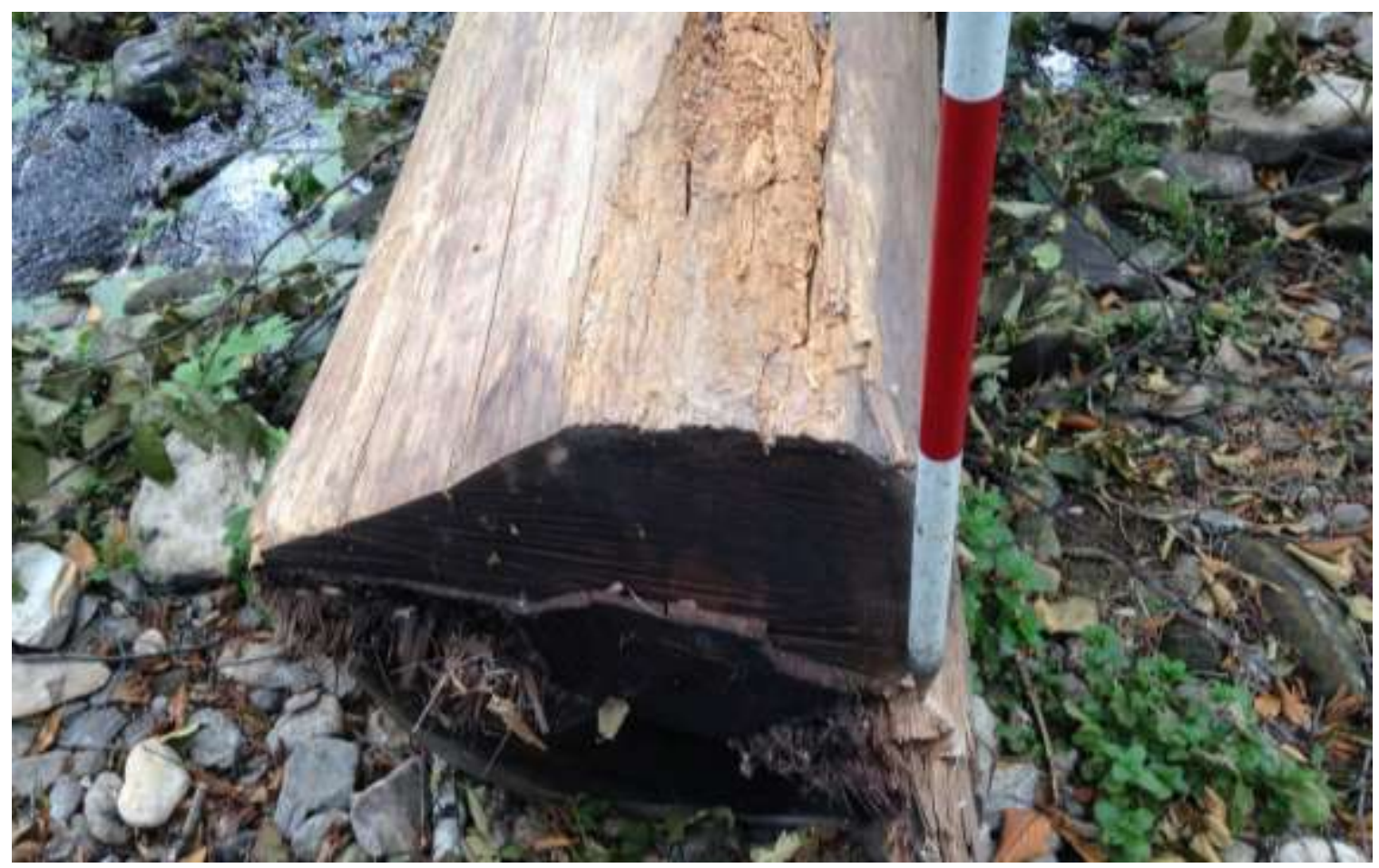

Figure 15. Log survey method.

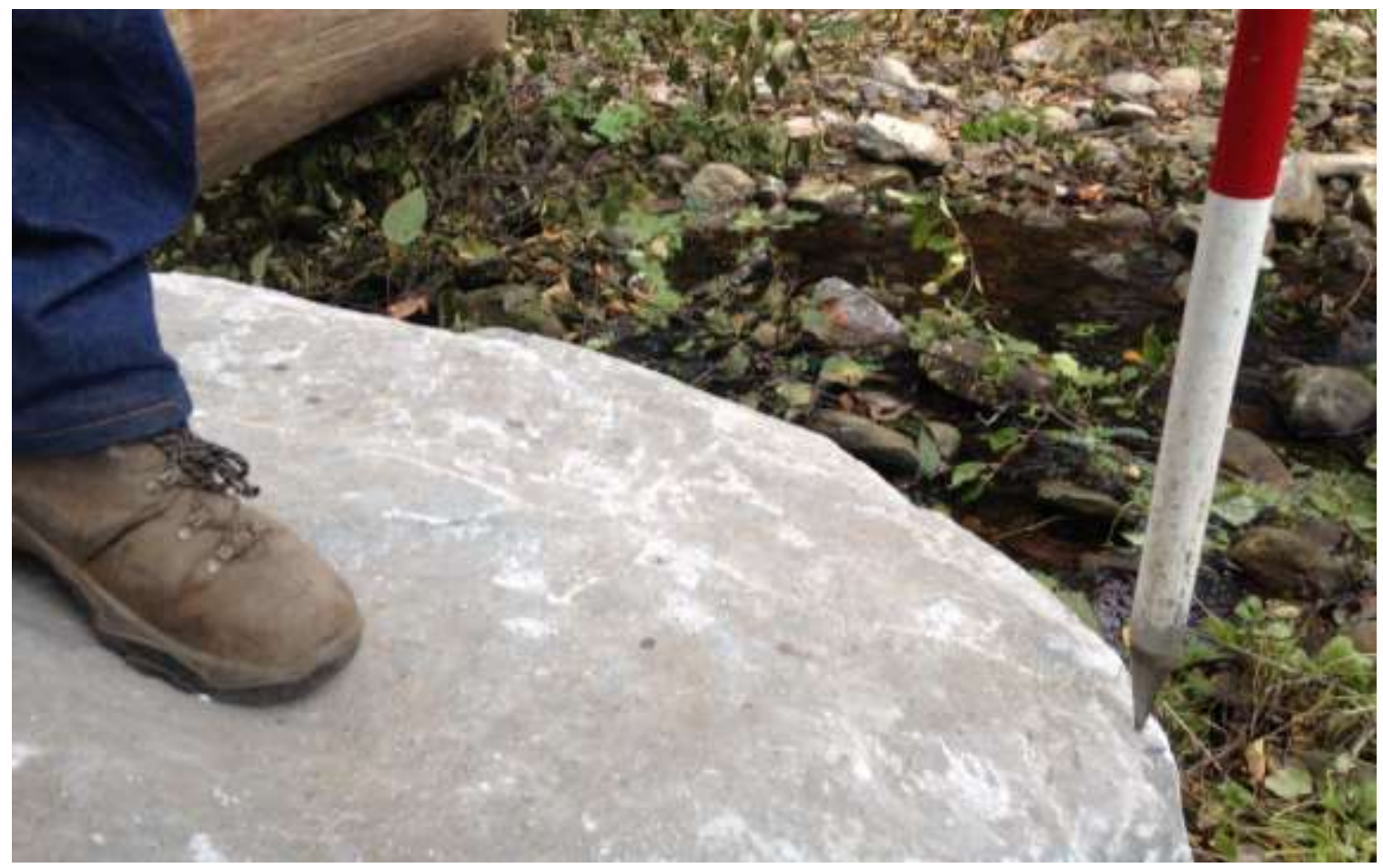

Figure 16. Surveying the permiter of a boulder. 


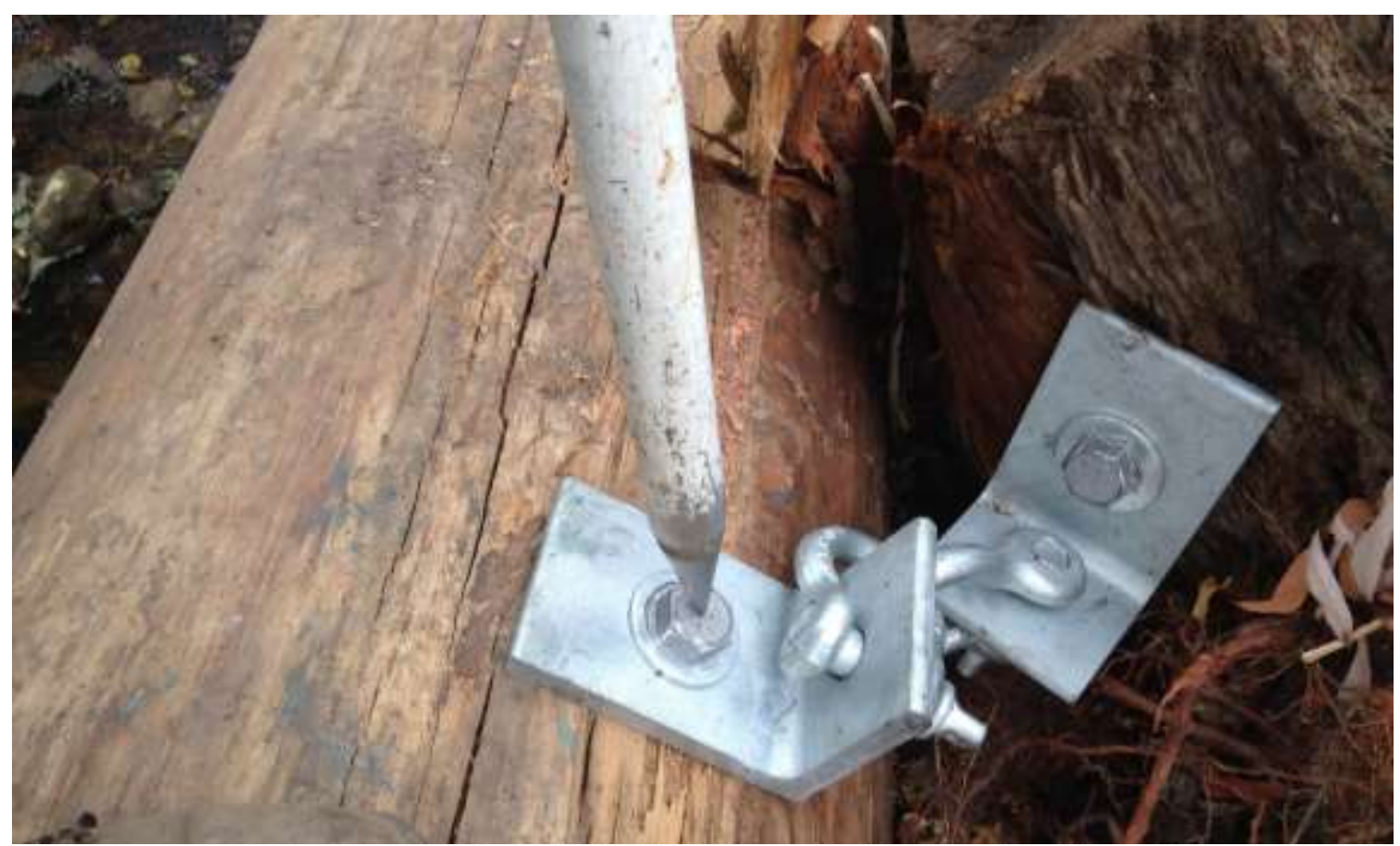

Figure 17. Surveying bolt heads.

Each graded feature was surveyed. These were the five levee breaches, the alcove feature/drainage ditch connection, and the alcove connection along Queseria Creek. The features were treated as having trapezoidal cross sections, with break lines at the top and bottom of the cut bank. Break lines were surveyed (coded 'TB' for top bank and 'BB' for bottom bank). TB points were taken at the top of the cut bank of each graded feature, which represented the feature's footprint. BB points were taken at the hinge point between the cut bank and bottom of each graded feature. TB and BB break lines were chosen to converge at a common terminus along the perimeter of each grading.

\subsection{Condition of Wood Complexes}

Phase I wood complexes were surveyed during the as-built survey and during the post-season survey to track displacements of each element within the features and the condition of the couplers. The as-built survey was compared to the March 2015 survey to look for displacement (Figure 18). 

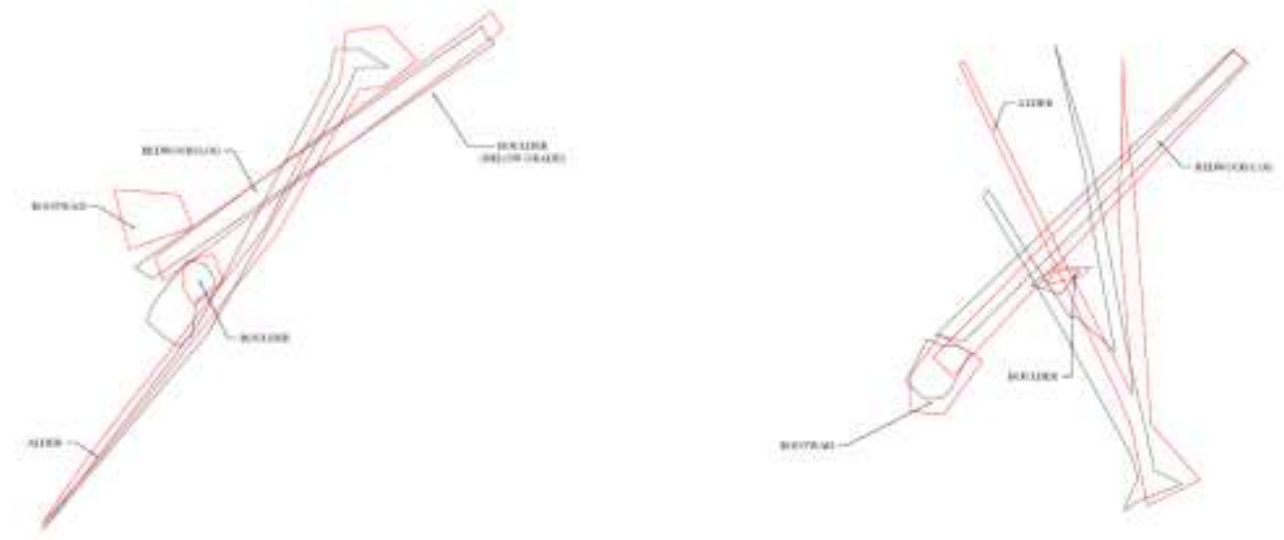

2750

3000
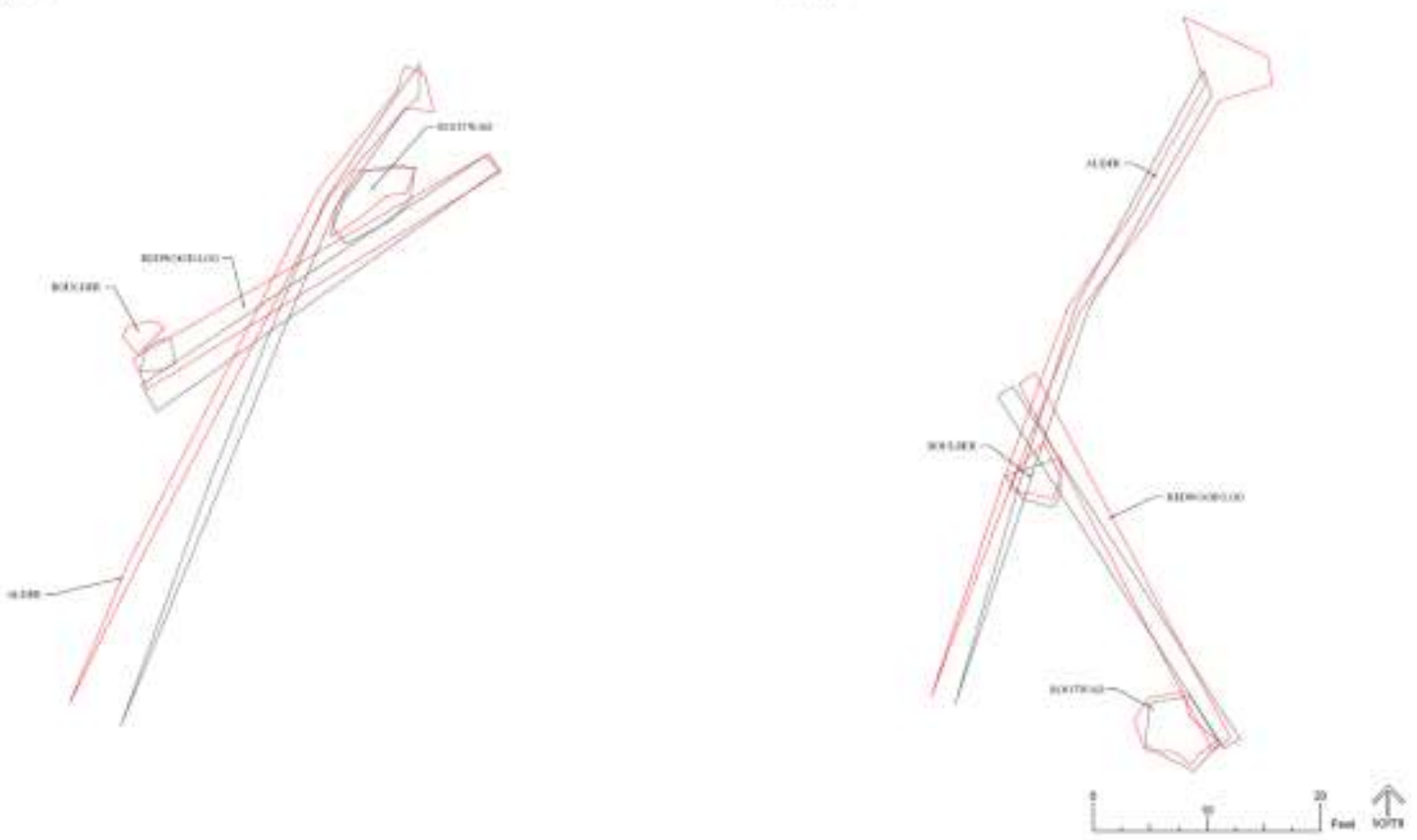

Figure 18. Plan view plot of the fall 2014 as-built survey (red) overlain with the spring 2015 post-season survey(black) of the Phase I constructed large wood complexes showing displacement of the individual components. The stream flow was from top to bottom relative to the page. 
All of the constructed wood features exhibited mild displacement (Figure 18). Movement of logs is attributed to the couplers elongating to their maximum extent in the downstream direction. In the case of the large wood complex at 2650, the rootwad was constructed upstream from the log. Stormflows flipped the rootwad over the log, rotated the log slightly, and displaced the log axially $\sim 2$ feet towards the center of the channel. The design team anticipated that the rootwad might change positions if placed upstream from the log. The rootwad was placed upstream because the excavator could not reach the downstream position without significant disturbance to the streambank vegetation. The design team was confident that the feature would self-adjust to a stable configuration. None of the other features exhibited visually discernable displacement.

Alder components generally were displaced by stormflow. The downstream end of the alder at 2750 swung towards the streambank $\sim 5$ feet whereas the upstream end, anchored by the rootmass was not measurably displaced. The upstream end (unanchored) of the alder at 2850 swung out towards the center of the channel $\sim 4$ feet while the rootmass remained stable at the downstream end.

The boulders at 2650, 2850, and 3000 were not measurably displaced, while the boulder at 2750 moved downstream and slightly inboard toward the left bank a total of $\sim 3$ feet, possibly because the boulder was undersized. At 2650, the boulder in the stream channel was covered by the rootwad and its displacement could not be measured with the total station. However, it does not appear to have been displaced as evidenced by the lack of measured displacement of the log end that is anchored to the boulder.

\subsection{Alder Mortality}

The project proposed to utilize in-situ alders in addition to importing rock and redwood materials to construct instream wood features. Preliminary work by Opperman (2002), and Opperman and Merenlender (2007) suggests that hardwoods may play an important geomorphic role in hardwooddominated streams if recruited pieces remain alive and partially rooted. By extension, recruiting in- 
situ hardwoods may be a viable restoration technique, but the effectiveness of this experimental technique is unknown. Due to the experimental nature of using alder recruits, long-term monitoring was begun to track the longevity and mortality of alder recruits.

Alder recruits were monitored visually throughout 2015 to track their survival. Visual indicators of survival were live foliage or shoots. In October 2015, the alder recruit at 2650 had a handful of live green leaves/shoots. The recruited alder at 2750 had no live or dead foliage/shoots. The alder at 2850 had dead foliage, that had previously been green in the summer of 2015 . The alder at 3000 had live, green foliage.

\subsection{Stream Morphology}

The design team sought to track morphologic change associated with the constructed features, and to collect information that would inform the design of Phase II. Since the 1980s, repeat topographic surveys have been used in streams to track physical habitat changes over time, and volumetric analysis using DEM differencing has been used since the late 1990s (Wheaton, 2008).

A total-station-based topographic survey protocol based on "Scientific Protocol for Salmonid Habitat Surveys within the Columbia Habitat Monitoring Program” (see Bouwes et al. 2011) was used to track changes in channel morphology. Topographic surveys of the channel segment of interest were repeated once in summer/fall to capture the as-built, pre-stormflow condition, and once in spring following implementation to capture the post-stormflow condition. Triangulated irregular network (TIN) and digital elevation model (DEM) surfaces were constructed from survey point data and overlain with habitat unit vector data to construct a physical habitat snapshot of the channel.

These repeat topographic surveys were performed in one study reach within the Phase I project reach (2500-3000), two study reaches within the Phase II project reach (3000-3800 and 42004800), and a control reach (6000-6600). The objective was to track morphologic change associated with project implementation. The Phase I study reach included the four constructed wood features, 
three of the five levee breaches, and the alcove feature/drain confluence enhancement. The Phase II study reach from 3000-3800 included four wood complexes and one alcove/pond connection, and the study reach from 4200-4800 included two wood complexes. The control reach where no restoration activities occurred was morphologically similar to the study reaches in that it was a straight, low-gradient reach with a planar bed lacking woody debris.

In addition, portions of the floodplain where floodplain connections and alcove features were constructed at 3200-3300. A georeferenced longitudinal profile of the entire Phase II project reach was also performed. The topographic surveys and longitudinal profile were georeferenced using a combination of existing survey monuments and new temporary survey control points. Going forward, repeat longitudinal profiles or topographic surveys of the study reach and the constructed off-channel features will be conducted once in each of the first (2016) and second (2017) postconstruction seasons. The volumetric analysis performed for Phase I will be applied to the pre- and post-project survey data for the Phase II study reach. Additionally, a repeat longitudinal profile could help evaluate overall geomorphic change of the Phase II project reach.

Repeat topographic surveys were performed using the set of equipment that was used for the asbuilt surveys. Break lines for the top of levee (coded TL), bottom of levee (BL), top of bank (TB), bank bottom (BB), and thalweg (TW) were surveyed. Ground points (coded SD for side ditch or BD for bottom ditch) were surveyed to capture topographic variation in between break lines. The bottoms of pools, tops of gravel bars, maximum pool tail crest elevations, riffles, and other significant features were surveyed. Additional points were surveyed to capture all visually obvious breaks in slope. In addition, all existing wood >6 in dia. was surveyed within the bankfull channel. Points were taken to approximate the footprints of existing LWD. Only debris within the bankfull channel and below or partially below bankfull were surveyed. The topographic/LWD survey was repeated in spring of 2015 following winter stormflows. All prominent bathymetric features, and all constructed wood features were surveyed. The spring 2015 LWD survey included each 
component of the constructed wood features using the survey methods described above for the asbuilt survey.

\section{Topographic Data Processing}

Survey points for both summer 2014 and spring 2015 surveys were imported into AutoCAD Civil 3D 2014 Imperial (C3D). Survey statistics are shown in Table 8. These statistics do not include the LWD survey. The point density of the spring 2015 topographic survey was more than double that of the summer 2014 topographic survey. A triangulated irregular network (TIN) surface was constructed from each set of points. Polygon shapes were constructed using the LWD survey points to represent the location of surveyed wood features. C3D was used to export LWD polygons as shapefiles and then imported to ArcMap for display and later analysis. C3D was used to generate a raster DEM (.tiff format) of each TIN. The DEMs were imported into ArcMap 10.2 for analysis using Geomorphic Change Detection Software.

Table 8. Pre-and post- season topographic survey point statistics for the Phase I study reach.

Surface:

Number of Points

2D Surface Area (sq. ft.)

2D Point Density (\#/sq. ft.)
Summer 2014

814

29,835

0.027
Spring 2015

2,110

35,244

0.060

\section{Volumetric Analysis}

A boundary mask (polygon) was drawn on each of the two surfaces (summer 2014 and spring 2015). The two polygons were intersected, and then the two TINs were clipped based on the intersected mask, so that the subsequent analysis would only be performed on the intersection of the two surfaces. A simple volume analysis was performed on the pre- and post-season TINs using C3D. A TIN volume surface was created using the June 2014 TIN as the base surface and the March 
2015 TIN as the comparison surface. C3D was used to perform a cut/fill summary for the TIN volume surface to characterize volumetric changes within the study reach.

The TINs were converted to DEMs in C3D and then imported into ESRI ArcMap 10.2. Within ArcMap, Geomorphic Change Detection Software 6.1.6.0 (GCD) was used to perform a simple Thresholding Change Detection analysis using minimum level of detection of 0.10 feet to reflect the typical vertical error observed when performing backsights.

The DEMs were differenced to create a DEM of difference (DoD) and the results were displayed graphically by color coding the pre- and post-season DEMs, and the DEM of DoD. Raster cells in the DoD that fell under the minimum level of detection were greyed out. The polygon layer representing existing wood at the time of the fall 2014 survey were overlaid on the fall 2014 DEM. The polygon layer representing the constructed instream large wood complexes were overlaid on the spring 2014 DEM and DoD.

A final analysis was performed in ArcMap to compare summer 2014 and spring 2015 total lowflow pool habitat volumes within the study reach. An ArcMap "model” was used to run the Surface Volume tool (toolboxes \system toolboxes $13 \mathrm{~d}$ analyst tools.tbx|functional surfacelsurface volume) to calculate habitat volume for a range of uniform water surface elevations within the study reach in 0.01 -foot increments. The analysis was repeated for each surface (pre- and post-season) and identical processing extents were used for each analysis, which was the polygon formed by the intersection of both surfaces. Modeling volume using uniform water surface elevations was thought to closely approximate actual low-flow conditions because the overall channel gradient of the study reach is low $(<0.3 \%)$. It would be worthwhile to compare the results of this analysis and a similar analysis done on detrended DEMs, or to model habitat volume based on surveyed WSEs.

The results of the two volumetric analyses (GCD and AutoCAD Civil 3D) are shown in Table 9. GCD plotted an elevation change histogram for the analysis which is skewed towards deposition (Figure 19). 
Table 9. Comparison of results from the AutoCAD Civil $3 D(T I N)$ and Geomorphic Change Detection (DEM) analyses.

$\begin{array}{lrrrr} & \frac{2 \mathrm{~d} \text { Area }}{\underline{(\mathrm{sq} . \mathrm{ft})}} & \underline{\text { Cut }(\mathrm{cy})} & \underline{\text { Fill (cy) }} & \underline{\text { Net (cy) }} \\ \text { AutoCAD Civil 3D } & 27962.79 & 301.60 & 342.02 & 40.41 \\ \text { GCD } & 27489 & 300.60 & 328.34 & 27.05\end{array}$

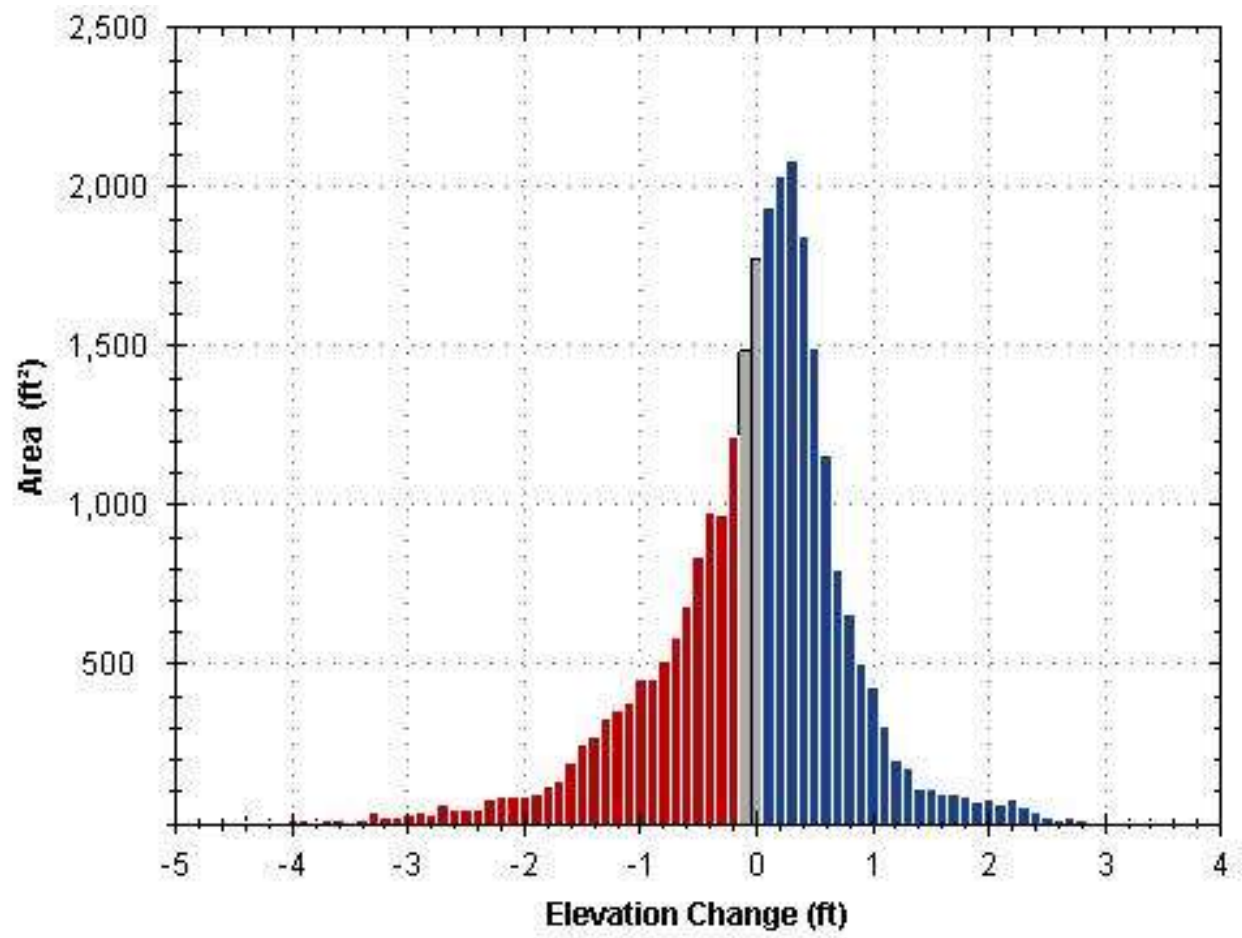

Figure 19. Elevation change histogram of scour (red) and deposition (blue) within the study reach showing bias towards deposition (distribution is skewed to the right).

The results of the topographic surveys, including the surveyed wood features, and habitat units, are displayed graphically in Figure 20. The volumetric analysis is plotted in Figure 21.

It was found that pool volumes and depths increased within the study reach in the vicinity of the constructed features. Preliminary results indicate low-flow pool habitat volume increased by nearly 2500 cubic feet assuming a low flow condition with a uniform water surface elevation of 11.3 feet (Figure 21). 
The volumetric analysis showed net deposition occurred within the study reach, despite large areas of scour. Net deposition indicates a reduction in mean shear stresses, either because mean velocities decreased, or because bankfull depths decreased as a result of increased floodplain connectivity. Rates of deposition may yield information regarding localized velocities. Deposition was pronounced in the hydraulic shadow of downed, foliated alders, indicating the presence of slowwater zones. More than 3 feet of deposition occurred downstream from the alder component of the LWC at 3000.

Significant error in the volumetric analysis could occur if the elevation of one or more of the survey control points changed as might occur if the rebar were accidentally pushed into the ground by a vehicle tire or a person walking. The error would exaggerate the detected magnitude of deposition and diminish the magnitude of scour, because the total station would over-calculate the elevation of each topo point. 

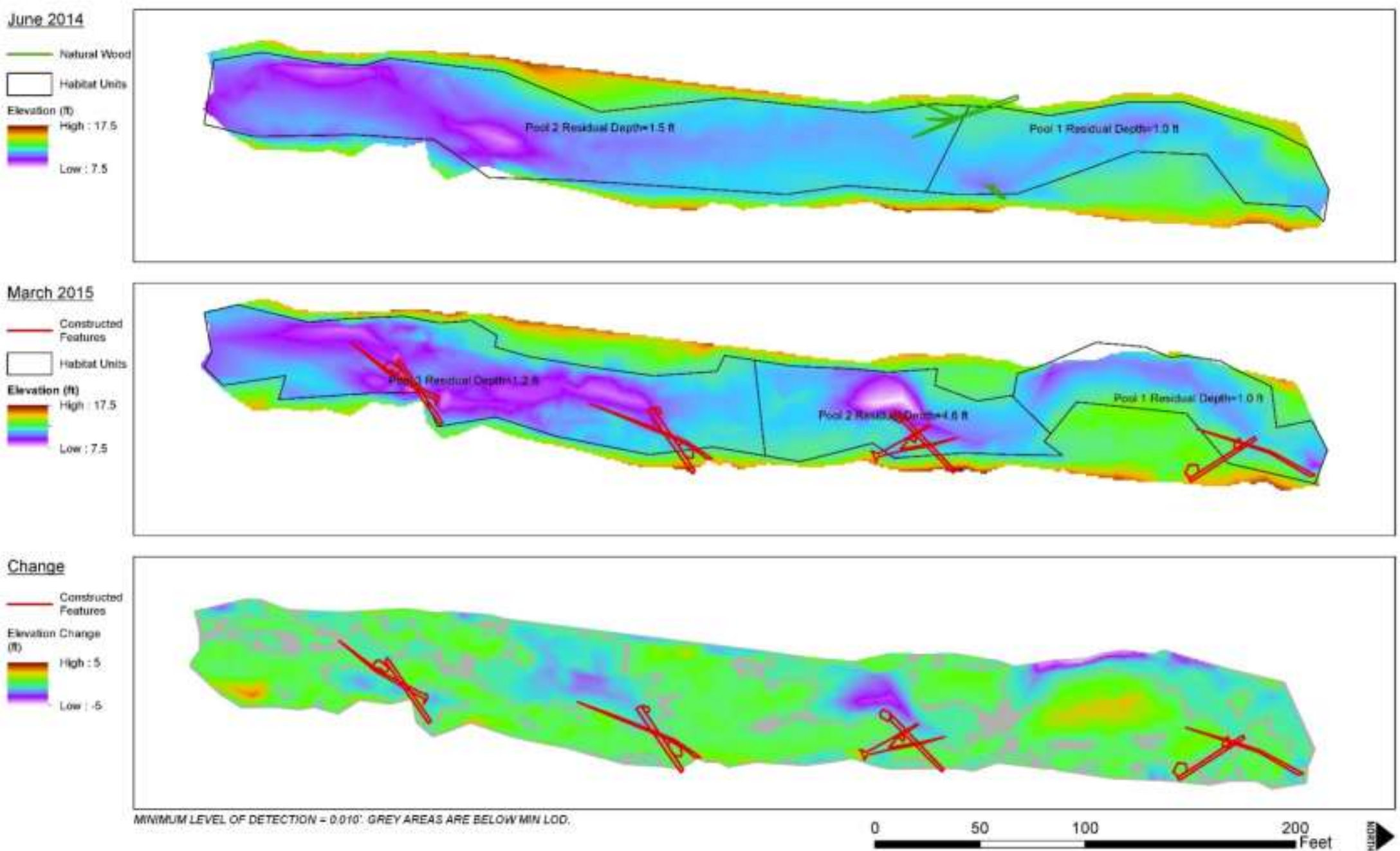

Figure 20. Study reach survey results showing habitat units, instream wood, and channel change between June 2014 DEM (top) and March 2014 DEM (bottom), and DEM of difference (bottom). 


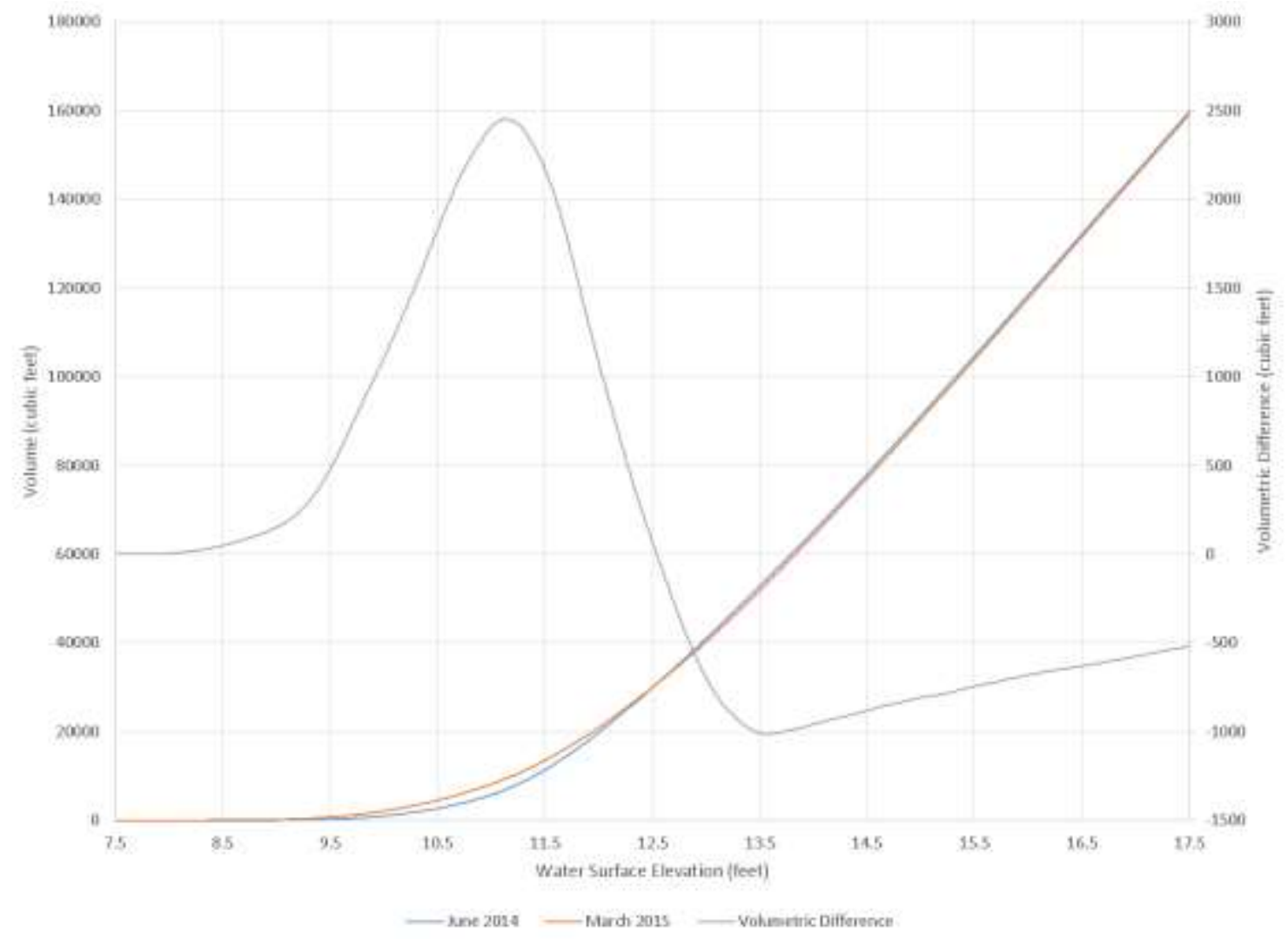

Figure 21. Habitat volumes at varying water surface elevations (primary axis), and volumetric differences (secondary axis) between June 2014 and March 2015.

\subsection{Alder Propagation}

The short-term and small-scale morphological influence of the constructed instream LWCs may initiate vegetative processes capable of driving long-term channel-scale and morphologic change (West, personal communication, 12/9/2016). The constructed LWCs were observed to facilitate the formation of deeper, more frequent pools, and also taller (bathymetrically) and potentially more stable bars. Alder seedlings were observed growing on many bars along lower Scotts Creek, including those bars that formed in association with LWCs. If these bars persist (for an unknown length of time) the alders themselves will likely begin to stabilize the bars. Once the bars are stabilized by durable vegetation, they may begin to control channel morphology, though the LWC or other hydraulically influential feature that facilitated the formation of the bar may no longer be present. Once stable, bars with rigid vegetation should be capable of racking debris and storing 
sediment until some dynamic equilibrium is reached. These bars may begin to influence reach-scale morphology in terms of increasing sinuosity of the thalweg or even meander frequency/amplitude of the channel.

\subsection{Performance, Stability, and Hydraulic Influences of Phase I LWCs}

LWC at 2650

The LWC at 2650 may have backwatered the upstream breach at 2750. Following stormflow, some scour was observed under the log, and around the end of the log near the center of the channel. Deposition occurred in the hydraulic shadow of the feature near the left bank. This feature had two boulder ballasts, unlike all other LWCs which utilized only one boulder per feature. One boulder was attached to each end of the log. One rootwad was attached to the end of the log on the upstream side. During stormflow on December $11^{\text {th }}, 2014$, the rootwad floated and flipped over the $\log$, rotating $\log$ in the downstream direction. The log also moved axially toward the center of stream $\sim 2$ feet, probably as the log was destabilized during rotation. The flexible connections remained intact and no deformation of the individual hardware was observed. During construction, the alder was topped and all limbs were removed. The alder had live shoots as of October 2015. This feature appeared to be less influential on facilitating scour/deposition, possibly because the alder had been fully limbed and no crown structure remained. Limbing probably reduced its effectiveness at slowing instream velocities and constricting the channel's effective cross-sectional flow area.

\section{LWC at 2750}

The LWC at 2750 noticeably changed the velocity profile across the stream channel during high flows in December 2014. The feature influenced the pattern of slow, turbulent flow near the left bank, and rapid, laminar flow near the right bank. The large rootwad placed near the left bank combined with the alder trunk facilitated deposition of coarse material downstream as evidenced by the formation of a narrow bar against the left bank (Figure 22). Debris racked against the alder crown and log. Pool scour occurred at the end of the redwood log. 


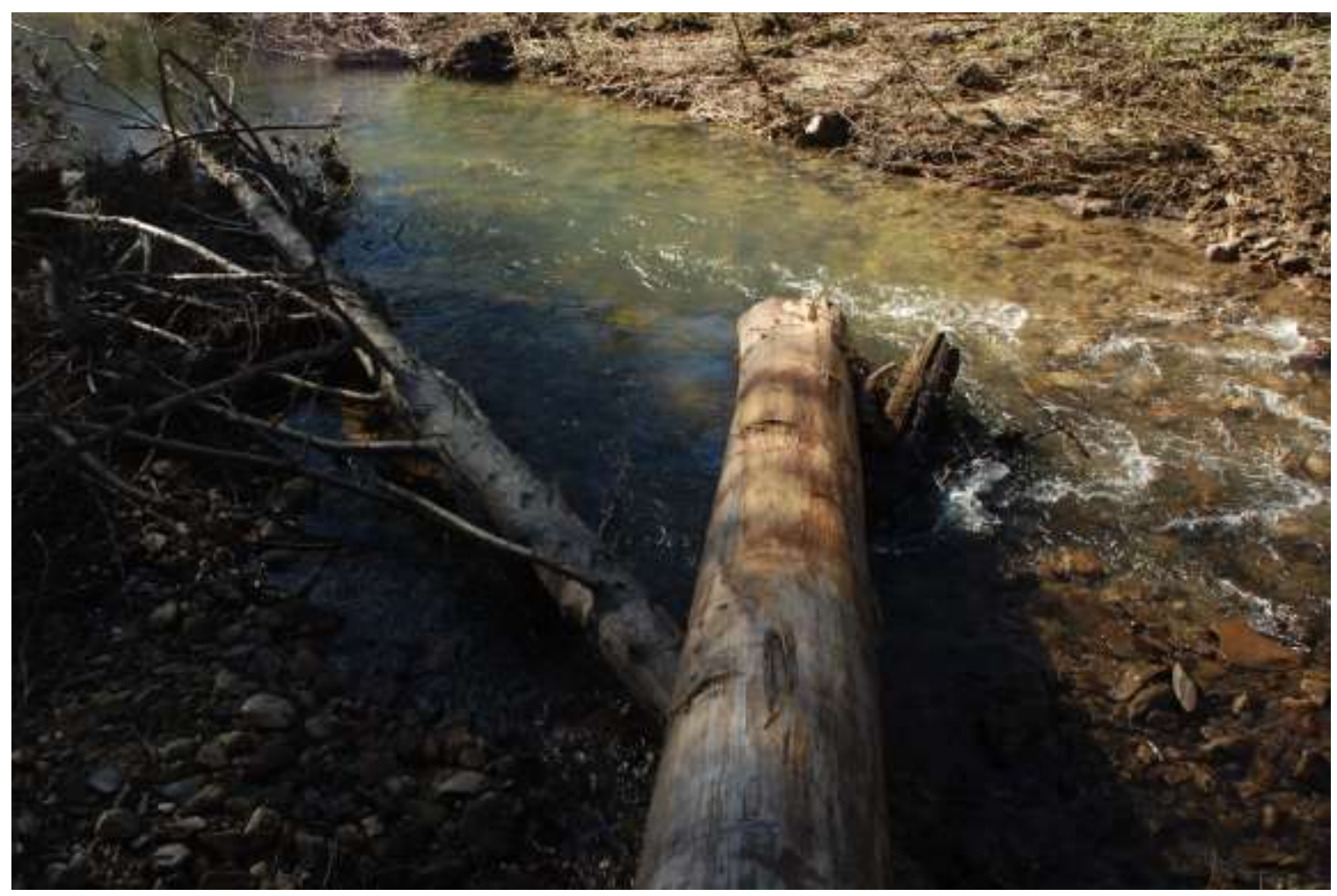

Figure 22. Photo of LWC at 2750 following stormflow showing depositon of cobbles, pool scour, and debris racking.

\section{LWC at 2850}

The LWC at 2850 constricted the channel and directed flow between the rootwad at the end of the $\log$ and the right bank of the channel. The large alder crown apparently had a substantial effect on instream velocities, evidenced by deposition near the left bank and scour near the right bank. The feature scoured a large pool with a residual depth of 4.5 feet, and the rootwad provided direct cover over the pool. Prior to implementation, the section of stream had been a low-complexity glide lacking wood. Following stormflow, pool scour exceeded -3 feet near the right bank.

\section{LWC at 3000}

The LWC at 3000 moved the thalweg against the right bank, shunted flow into the alcove, formed a large gravel bar, and enhanced the depth of an existing pool. More than 3 feet of deposition occurred in the hydraulic shadow of the downed alder crown (Figure 20), forming a large gravel bar in the middle of the channel. A high-velocity region occurred between the LWC and right bank 
which scoured the streambed and right bank. Bed scour enhanced the depth of the pre-existing pool at that location. A large amount of debris racked on the LWC and in between the log and streambank, partially obstructing shunting effect. Despite racking, the log shunted water into the alcove, and circular flow was observed within the alcove with a velocity of $\sim 2-3 \mathrm{ft} / \mathrm{s}$.

\subsection{Alcove at $\mathbf{3 0 0 0}$}

The existing point of connectivity at 3000 was improved by increasing the cross-sectional area of the connection from $\sim 1.8$ sq. ft. -9 sq. ft., an increase of 509\%. The max. discharge of the culvert was estimated to be $13 \mathrm{ft}^{3} / \mathrm{s}$ using the FHWA culvert nomograph (18 in culvert, W/D=2 [36 in flow depth], in actuality, the culvert was $~ 50 \%$ filled with sediment). Using Manning's equation, the max. discharge through the reconfigured ditch was estimated to be $200 \mathrm{ft}^{3} / \mathrm{s}$ at $13.3 \mathrm{ft} / \mathrm{s}$ as floodwaters return to the main channel (depth=3 feet, bottom width=2 feet, 1:1 side slopes, channel slope $=2 \%$ (measured from DEM), $n=0.02$ ). although velocity will be buffered by backwater effects from the main channel. Several inches of silt were deposited in the alcove during the December 2014 stormflows, however return flows downcut through the silt deposit as evidenced by rilling. Narrowing of the alcove feature occurred somewhat, though the bottom elevation of the alcove feature was maintained at 13.5 feet which was the as-built condition (see photo packet).

\subsection{Physical Habitat Assessment}

As-built and repeat topographic survey data were used in combination with photos, stormflow videos, field measurements, and observations, to quantify changes in the following habitat complexity and floodplain connectivity parameters associated with implementation.

- Pool frequency per unit length of stream

- Pool depth

- The number of primary pools per unit length of stream

- Percent stream cover

- LWD density (LWD per unit length)

- The number of high flow refuge habitat units per unit length of stream

- The number of points of connectivity with the floodplain per unit length of stream

- The potential reduction of flood stages/velocities/shear stresses in the main channel 


\subsection{Stream Complexity}

The pre- and post-stormflow DEMs were used in combination with field observations and depth measurements to quantify changes in the number and frequency of pools per unit length of stream, and pool depth. Overall pool frequency increased within the study reach. While NMFS considers the entire study reach to be one pool, prior to implementation of Phase I there were two distinguishable pools at 2600 and 2900 with residual depths of 1.5 and 1.0 feet respectively. In spring 2015, one additional pool formed at 2800, with a residual depth of 4.6 feet.

The number of primary pools within the Phase I project reach increased from zero to one as a result of scour associated with the constructed large wood complexes. The pre-project condition is based on a 2013 habitat typing survey (Brubaker 2015). A primary pool developed around the rootwad component of the large wood complex at 2850. The pool/riffle/flatwater ratio increased within the study reach due to scour and deposition associated with the constructed large wood complexes. The footprint of instream debris, calculated in GIS using topographic survey data, was used as a proxy for cover. The footprint increased from 85.9 to 645.7 sq. ft., a $652 \%$ increase. The percent stream cover (measured as a percent of the active low-flow channel within the study reach AOI polygon) increased from $0.44 \%$ (from pre-existing natural wood) to $3.37 \%$ (from the constructed features). The LWD count increased from 2 pieces to 12 pieces (logs, rootwads, and downed alders) over 500 feet of stream, or 2/500 feet - 12/500 feet within the study reach. Key LWD pieces increased from zero to four pieces per 500 feet of stream (count of redwood logs).

\subsection{Refugia}

The number of high flow refuge habitat units increased by at least six within the study reach. Refuge habitat units included the five breach openings and the constructed alcove feature. This count is based on field observations and video of activation of the breach openings and alcove feature, and visual indicators of low velocity regions. Additional instream refuge areas were visible in the vicinity of the LWCs, including backwater refuge areas upstream from some of the LWCs. 


\subsection{Floodplain Connectivity}

The number of new points of floodplain connectivity increased along the 1500 -foot-long project reach by five due to the excavation of five levee breaches. Hydrologic modeling of the bankfull flow on the pre-project ground surface showed that prior to restoration, the project reach had one point of connectivity with the floodplain through the culvert/ditch at 3000 (see Appendix A).

All five of the levee breaches activated during December 2014. Outflow was directly observed through the breaches at 1900 and 2000 on December 11 (Figure 23) Debris racked across the throat of 2000, apparently during outflow (Figure 18). Rilling at the mouth of 2000 indicated that return flow occurred (Figure 25).Vegetation in 1900 was laid down in the outflow direction and rilling was not observed at the mouth, suggesting that return flow did not occur there (Figure 26). One possible explanation for return flow at 2000 and not at 1900 is that floodwaters that were routed down the access road returned to the channel through 2000 before they could reach 1900 .

\subsection{Instream Hydraulics}

Additional points of connectivity with the floodplain combined with roughness elements represented by the LWCs likely reduced instream flood stages, velocities and shear stresses. Overall, the sediment balance within the study reach tipped towards deposition (see Volumetric Analysis above). The reduction in sediment transport through the study reach indicates that shear stresses were reduced as a result of implementation. 2D modeling should be performed to test this hypothesis. 


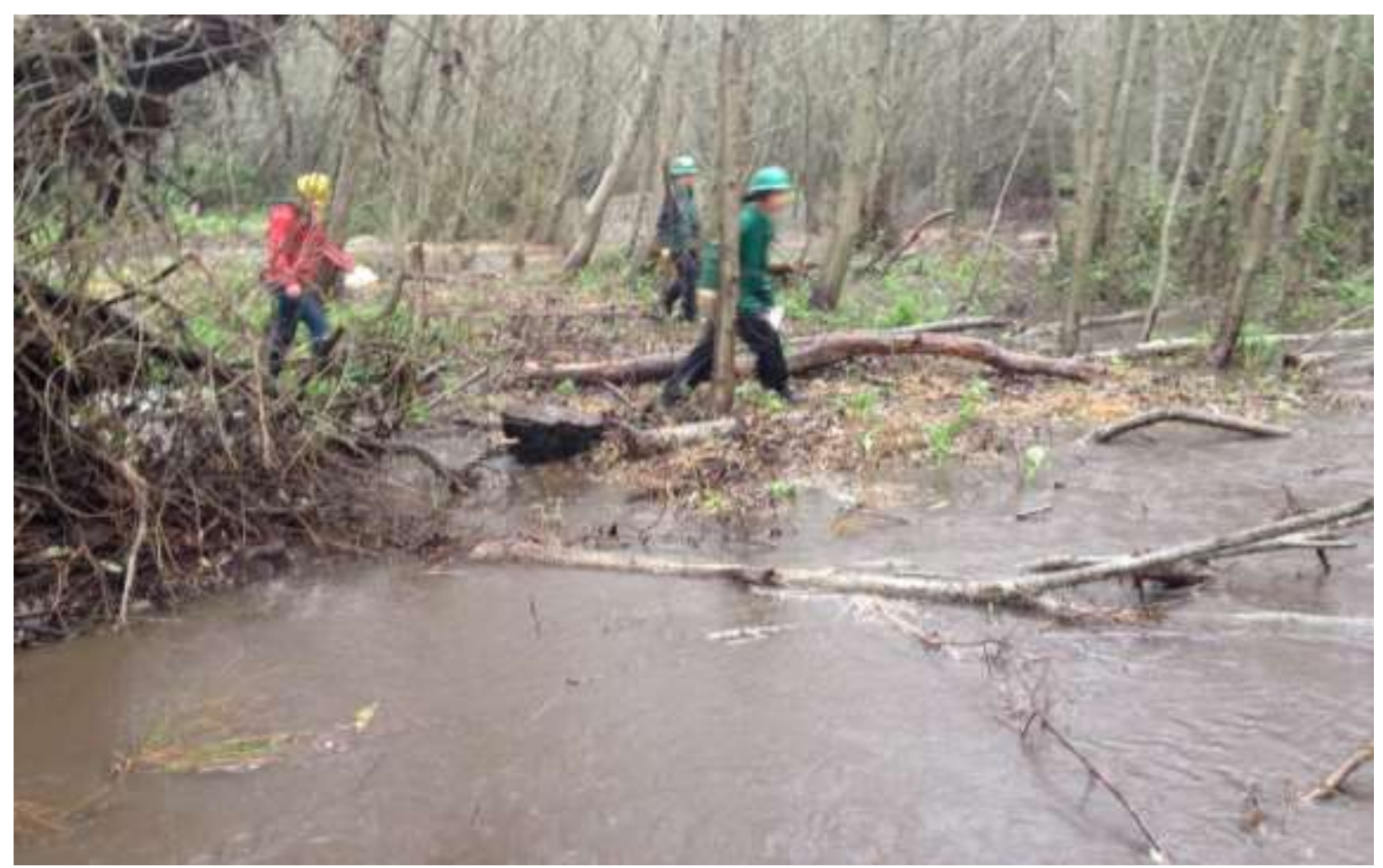

Figure 23. Looking NE on 12/11/2014 at breach at 1900 (foreground) and 2000 (background). Photo shows outflow through both breaches and floodplain inundation.

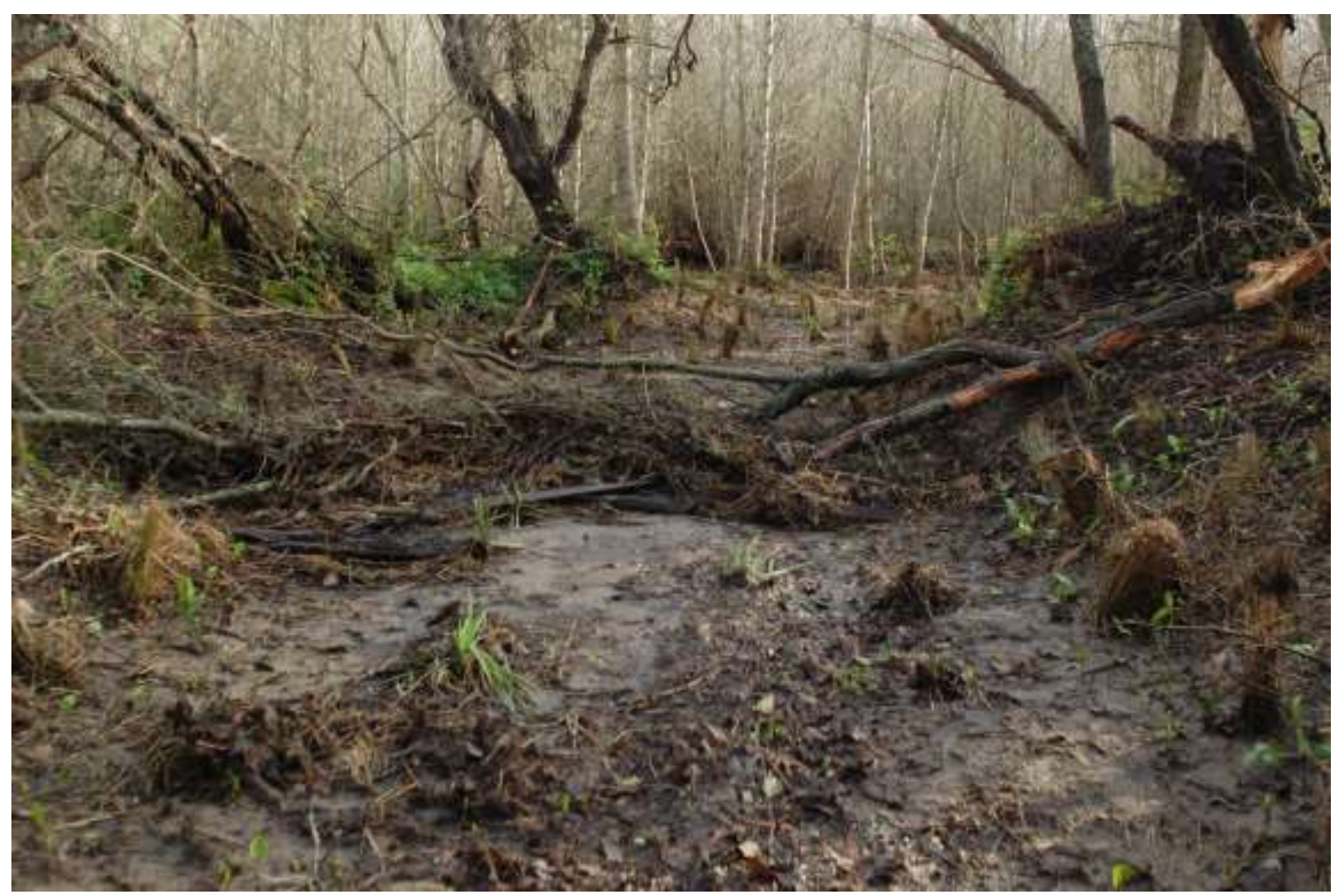

Figure 24. Looking east at debris racked across the throat of the breach at 2000 on 12/18/2014. Scotts Creek is directly behind the vantage point. 


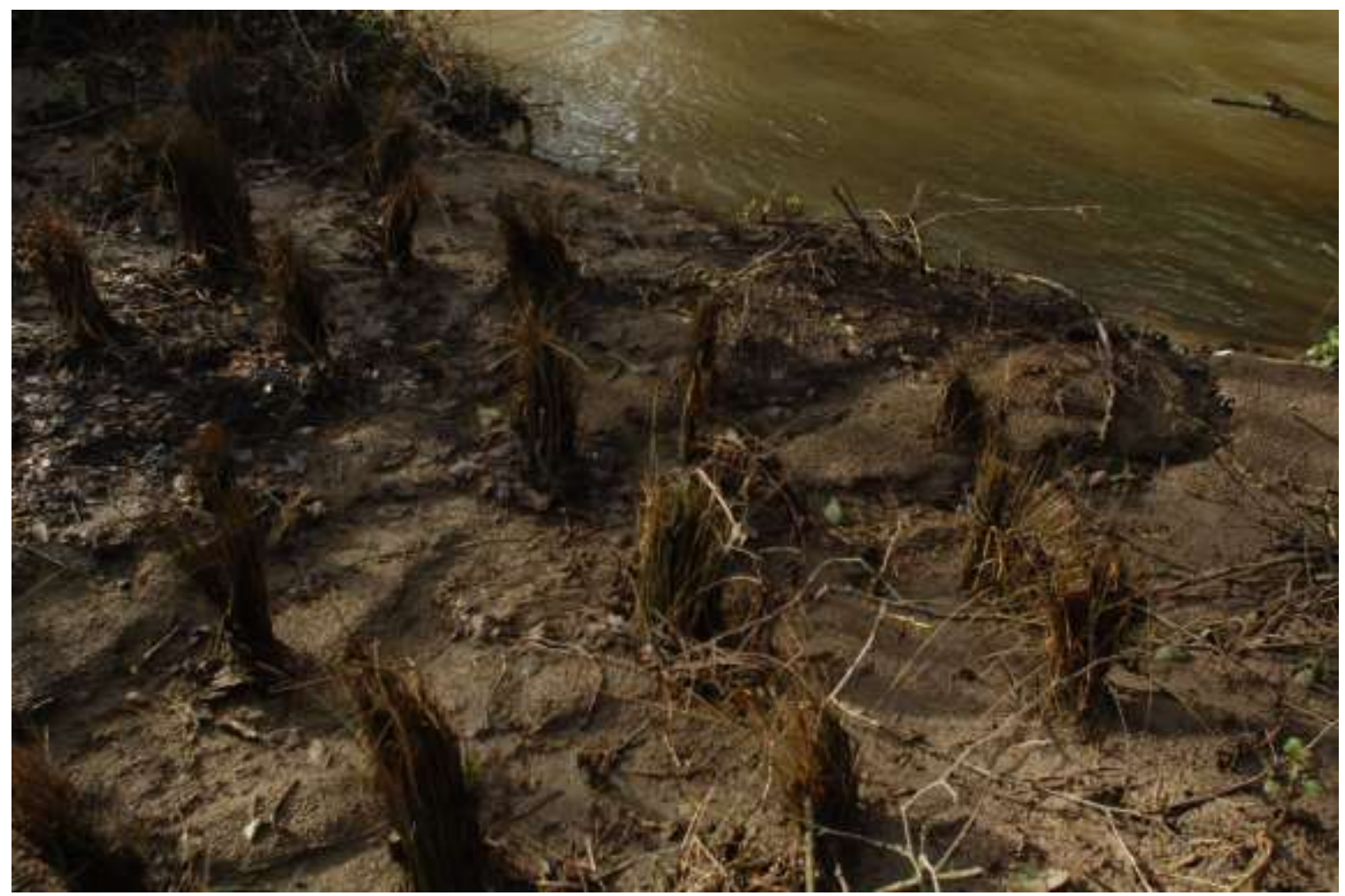

Figure 25. Rilling at the mouth of levee breach at 2000 on 12/18/2014

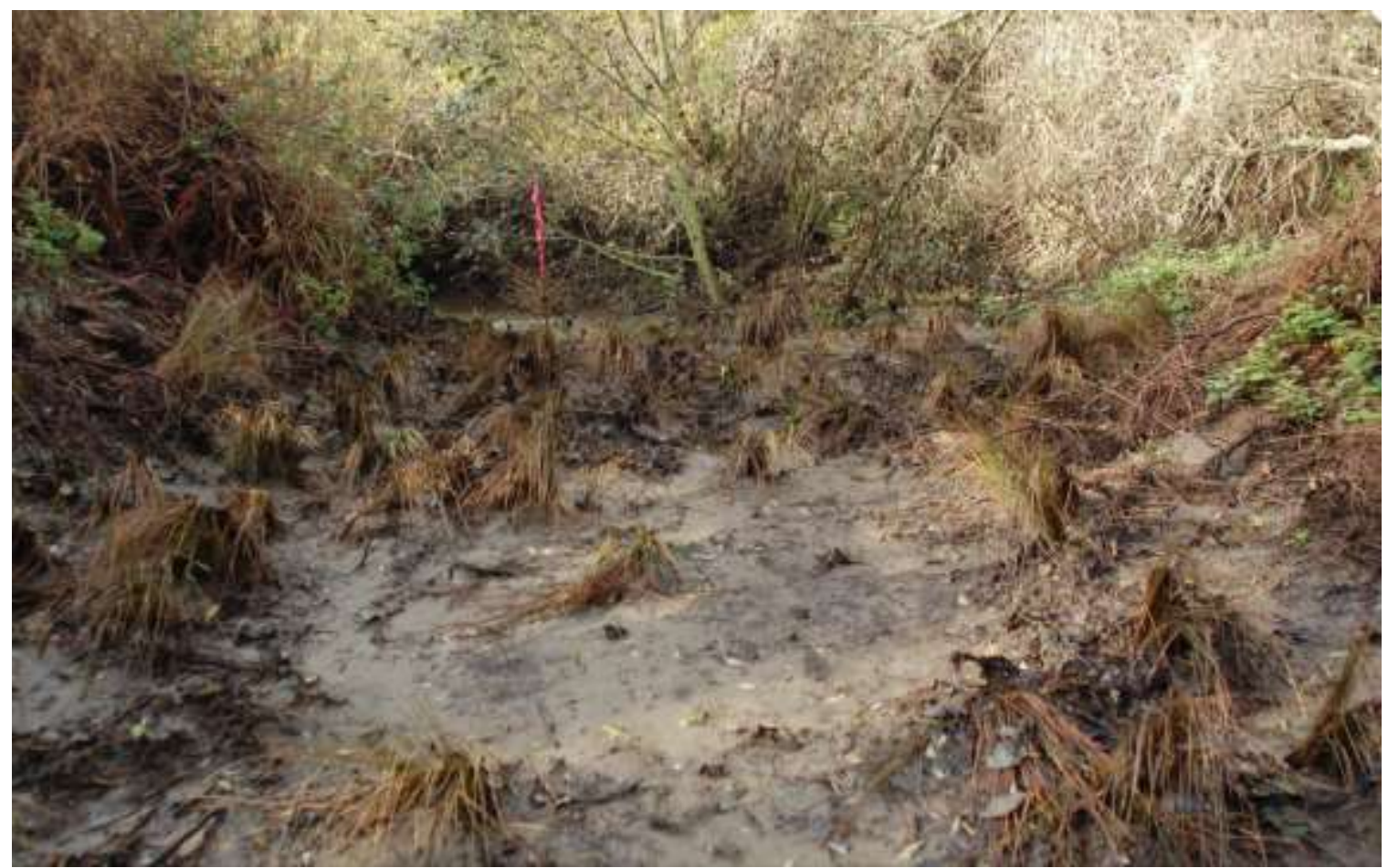

Figure 26. Standing in the breach channel at 1900 looking west at Scotts Creek on 12/18/2014. Vegetation is laid down in the outflow direction (towards camera). 


\section{CONCLUSION AND RECOMMENDATIONS}

Overall, installing large wood complexes measurably increased habitat complexity in terms of percent cover, frequency of key wood pieces, frequency of primary pools, and bathymetric variability. Preliminary results indicated low-flow habitat volume increased as a result of the constructed large wood complexes. Debris racking increased dramatically with the installation of large wood complexes in a reach previously lacking wood. Specific outcomes are discussed below along with recommendations for additional monitoring to more thoroughly understand the effectiveness of the project over time.

\subsection{Salmonid Production and Restoration Effectiveness}

Gallagher et al. (2012) estimated adult, parr, and smolt abundance on Caspar Creek, Pudding Creek, and south fork Noyo River (California Coastal Salmonid Monitoring Plan Life Cycle Monitoring Streams) using capture-recapture, depletion sampling, and PIT tagging. Survival at each life stage was estimated, including marine survival. Survival rates were used to estimate carrying capacity, and relate survival to abiotic factors, including physical habitat conditions and restoration effort. NMFS performs all of the necessary surveys and data collection to perform a similar analysis of the effectiveness of restoration effort in the Scotts Creek watershed.

In addition, fine-spatial-scale fish abundance surveys which include size estimates may reveal habitat preference and growth potential of restored reaches versus control reaches. A Before-AfterControl-Impact (BACI) study could be carried out with existing data because the project was implemented in two phases. NMFS snorkel surveys may provide the necessary data to perform a fine spatial scale BACI analysis.

\subsection{Accelerated Alder Recruitment}

While short-term monitoring suggests that the hardwood components enhanced percent cover and were hydraulically and ecologically influential, long-term monitoring of stability, longevity, and 
survivorship are required to reveal whether or not accelerated hardwood recruitment in stream reaches dominated by Alnus rubra will be a feasible and cost-effective restoration technique for enhancing stream complexity. Although some recruited trees had new green foliage in the first year following recruitment, the observation was inconclusive because new growth may have been a product of the previous year's stored energy within the root system or tree.

Alder recruits had noticeable hydraulic effect, especially those that were not substantially limbed or topped. Deposition occurred in the lee of foliated alder crowns, and the thalweg tended to migrate away from the crown or the region of deposition that occurred just downstream. Flow appeared to accelerate in cross sections occupied by the crown, as indicated by bed and bank scour. Foliated alder crowns also provided enhanced cover over a large area compared to the cover provided by simple log or boulder elements. Additionally, foliage and small branches retained leaf litter and other small debris. The upturned rootmass and cavity that resulted from pushing whole trees into the stream channel, created complex pools with cover at the margins of the stream channel. Pools formed by upturned alder rootwads were also observed to form slow water zones during high flows, especially in the lee of flow.

Accelerated alder recruitment may increase natural rates of LWD recruitment in the future. Key LWD pieces, often in the form of a downed tree pointing downstream with an upturned rootwad at the upstream end, were found to provide refugia for the development mature riparian forest patches through the processes of debris and sediment accumulation (Abbe et al. 1996). Bars along lower Scotts Creek were observed to be nurseries for alder seedlings. Accelerated alder recruitment may initiate a feedback loop which increases future recruitment through the propagation of riparian forest patches. This may lead to the restoration of dynamic habitat-forming processes. These potential benefits suggest that accelerated alder recruitment warrants further investigation. 


\subsection{Alternative LWC Stabilization}

The use of couplers is a viable alternative to cabling or rigid all-thread connections in the construction of instream wood features. Additionally, bracing structures against live trees enhanced stability and in combination with couplers, prevented the structures from becoming buried in bedload. These alternative stabilization techniques offer significant advantages over traditional techniques.

\subsection{Floodplain Connectivity}

Levee perforation and the construction of floodplain connections was expected to increase floodplain activation. This project may provide opportunities to monitor the effects of increased activation on crop production and groundwater recharge.

\subsection{Modeling}

Uncertainty over the potential effects of increased floodplain connectivity may be reduced through the use of 2D modeling. 2D modeling may help quantify floodplain velocities, and additionally help evaluate the project's effectiveness by quantifying changes to floodplain inundation and offchannel habitat volume associated with implementation.

\subsection{Instream and Off-Channel Refugia}

The development of instream refugia during high flows is difficult to assess through direct velocity measurements due to a number of challenges including extreme hazard to personnel. Due to the difficulty in measuring instream velocities during peak flows, a forensic means of estimating instream velocities is desirable. Mapping particle size distributions may provide information regarding instream velocities. Occupation of off-channel features during high flows may be quantified through the use of PIT-tag readers installed in the off-channel connection channels. 


\subsection{Survey Methods}

Given the cost and disturbance associated with habitat surveys, it is recommended that remote sensing techniques be utilized as much as possible, especially during the spawning season. UAVmounted photography offers a means of capturing reach-scale changes to both particle size distributions and stream morphology (Carbonneau 2005; Carbonneau et al. 2003, 2004, 2005a, 2005b, 2006; Lejot et al. 2007; Fonstad et al. 2013) and should be considered in the future.

\section{8 $\quad$ Sediment Budget}

Sediment loads, whether anthropogenic or natural, may be attenuated by constructing large wood complexes. The placement of complex structures instream may decrease mean instream velocities and facilitate net deposition. Net deposition may reduce downstream sedimentation by storing sediment locally. Overall, 300 yards of cut and 340 yards of fill (bank volumes) occurred in the stream channel associated with the construction of four large wood complexes, compared to 580730 yards (bulk volume) excavated using heavy equipment during the construction of the levee breaches and alcove connection channel. This comparison illustrates the ability of wood features to harness stream energy to do work that would otherwise be done by equipment running on fossil fuels.

Given the desire to reduce greenhouse gas emissions, conserve resources, lower project costs, and reduce disturbance to riparian and instream habitats, future projects should explore alternative techniques that minimize the use of imported materials and heavy equipment. Restoration techniques that utilize in-situ materials, such as riparian hardwoods, or that incorporate specialized techniques from other fields (i.e. arboriculture, forestry, back-country trail construction), may offer worthwhile advantages.

An efficiency analysis should be done to track the efficiency of contemporary construction techniques by comparing fossil fuels consumed during construction versus work done in terms of grading volumes and masses, end-hauling distances, and masses and displacements of imported 
materials. An efficiency analysis would establish baseline efficiency against which progressive techniques could be evaluated. Overall, the practice of stream restoration is still young and offers plenty of opportunities for research and development. 


\section{BIBLIOGRAPHY}

Abbe, T.B.; and D.R. Montgomery. 1996. Large woody debris jams, channel hydraulics, and habitat formation in large rivers. Regulated Rivers 12: 201-222.

Adams, P.B., M.J. Bowers, H.E Fish, T.E Laidig, and K. Silberberg. 1999. Historical and current presence-absence of Coho Salmon (Oncorhynchus kisutch) in the Central California Coast Evolutionarily Significant Unit. National Marine Fisheries Service, Southwest Fisheries Science Center Administrative Report SC-99-03.

Adams, P.B., L.W. Botsford, K.W. Gobalet, R.A. Leidy, D.R. McEwan, P.B. Moyle, J.J. Smith, J.G. Williams, and R.M. Yoshiyama. 2007: Coho Salmon are native south of San Francisco Bay: a reexamination of North American Coho Salmon's southern range limit. Fisheries 32(9):441-451.

Advisory Committee on Salmon and Steelhead Trout, 1988. The tragedy continues. Annual Report. California Department of Fish and Game.

Alvarado, F., R.O. Briggs, and H.T. McCrary. 2005. Comments on the CDFG December 2004 response to the CCFA and Big Creek Lumber Co. June 17, 2004 petition to the CDFG to redefine the southern boundary of the Central California Coast Coho ESU, dated January 26, 2004. Big Creek Lumber Co. and Central Coast Forest Association. Davenport, CA.

Beechie, T., and S. Bolton. 1999. An approach to restoring salmonid habitat-forming processes in Pacific Northwest watersheds. Fisheries 24(4):6-15.

Beechie, T.J., D.A. Sear, J.D. Olden, G.R. Pess, J.M. Buffington, H. Moir, P. Roni, and M.M. Pollock. 2010. Process-based principles for restoring river ecosystems. BioScience 60(3):209222.

Beechie, T.J., and T.H. Sibley. 1997. Relationships between channel characteristics, woody debris, and fish habitat in Northwestern Washington streams. Transactions of the American Fisheries Society $126: 217-229$.

Bell, E., W.G. Duffy, and T.D. Roelofs, 2001. Fidelity and survival of juvenile Coho Salmon in response to a flood. Transactions of the American Fisheries Society 130(3):450-458. 
Benegar, J.R. 2011. Evaluation of constructed wood jams in a forested, graveled stream. Master's thesis. Humboldt State University.

Benke, A.C., R.L. Henry III, D.M. Gillespie, and R.J. Hunter. 1985. Importance of snag habitat for animal production in Southeastern streams. Fisheries 10(5):8-13.

Beschta, R.L. 1997. Restoration of riparian and aquatic systems for improved aquatic habitats in the upper Columbia River basin. Pages 475-491 in Stouter, D.J, P.A. Bisson, and R.J. Naiman, eds. Pacific salmon and their ecosystems: status and future options. Chapman and Hall, New York.

Beschta, R.L., and W.S. Platts. 1986. Morphological features of small streams: significance and function. Water Resources Bulletin 22(3):369-379.

Bilby, R.E., and G.E. Likens. 1980. Importance of organic debris dams in the structure and function of stream ecosystems. Ecology 61(5): 1107-1113.

Bjorkstedt, E.P., B.C. Spence, J.C. Garza, D.G. Hankin, D.F uller, W.E. Jones, J.J. Smith, and R. Macedo. 2005. An analysis of historical population structure for evolutionarily significant units of chinook salmon, Coho Salmon, and steelhead in the North-Central California coast recovery domain. NOAA Technical Memorandum NMFS-SWFSC-382. U.S. Department of Commerce National Oceanic and Atmospheric Administration National Marine Fisheries Service Southwest Fisheries Science Center.

Bouwes, N., J. Moberg, N. Weber, B. Bouwes, S. Bennett, C. Beasley, C.E. Jordan, P. Nelle, M. Polino, S. Rentmeester, B. Semmens, C. Volk, M.B. Ward, and J. White. 2011. Scientific protocol for salmonid habitat surveys within the Columbia Habitat Monitoring Program. Prepared by the Integrated Status and Effectiveness Monitoring Program and published by Terraqua, Inc., Wauconda, WA.

Bulger, J.B. Unpublished letter to Dr. Brian Dietterick dated September 2, 2004. College of Agriculture, Food, and Environmental Sciences, California Polytechnic State University, San Luis Obispo. 
Carah, J.K., C.C. Blencowe, D.W. Wright, and L.A. Bolton. 2014. Low-cost restoration techniques for rapidly increasing wood cover in coastal Coho Salmon streams. North American Journal of Fisheries Management 34(5):1003-1013.

Chartrand, S., B. Hecht, D. Shaw. 2003. Soquel Creek watershed assessment: geomorphology and baseflow hydrology. Balance Hydrologics. Unpublished report for the Resource Conservation District of Santa Cruz County.

Cramer, M.L. (ed.) 2012. Stream habitat restoration guidelines. Washington Departments of Fish and Wildlife, Natural Resources, Transportation and Ecology, Washington State Recreation and Conservation Office, Puget Sound Partnership, and the U.S. Fish and Wildlife Service. Olympia, Washington.

Federal Register 1978. Memorandum of understanding between the U.S. Fish and Wildlife Service, United States Department of The Interior, and the National Marine Fisheries Service, National Oceanic and Atmospheric Administration, United States Department of Commerce, regarding jurisdictional responsibilities and listing procedures under the endangered species act of 1973.

Federal Register. 1999. 50 CFR Part 226. 64(86):24049-24062.

Fisheries Restoration Grant Program. 2015. Proposal solicitation notice. California Department of Fish and Wildlife. http://www.dfg.ca.gov/fish/administration/Grants/FRGP/Solicitation.asp

Florsheim, J.L., and J.F. Mount. 2002. Restoration of floodplain topography by sand-splay complex formation in response to intentional levee breaches, Lower Cosumnes River, California. Geomorphology, 44(1-2):67-94.

Flosi G., S. Downie, J. Hopelain, M. Bird, R. Coey, and B. Collins. 2010. California salmonid stream habitat restoration manual 4th edition. Wildlife and Fisheries Division, California Department of Fish and Wildlife.

Fonstad, M.A., J.T. Dietrich, B.C. Courville, J.L. Jensen, and P.E. Carbonneau. 2013. Topographic structure from motion: a new development in photogrammetric measurement. Earth Surface Processes and Landforms 38(4):421-430. 
Foster, D., F.J. Swanson, J. Aber, I. Burke, N. Brokaw, D. Tillman, and A. Knapp. 2003. The importance of land-use legacies to ecology and conservation. Bioscience 53(1):77-88.

Francis, R.A. 2007. Size and position matter: riparian plant establishment from fluvially depositied trees. Earth Surface Professes and Landforms 32(8):1239-1243.

Frissell, C.A. 1992. Cumulative effects of land use on salmon habitat in Southwest Oregon Coastal Streams. Thesis. Oregon State University.

Frissell, C.A. and R.K. Nawa. 1992. Incidence and causes of physical failure of artificial habitat structures in streams of Western Oregon and Washington. North American Journal of Fisheries Management 12(1):182-197.

Gallagher, S. P., S. Thompson and D. W. Wright. 2012. Identifying factors limiting Coho Salmon to inform stream restoration in coastal Northern California. California Fish and Game 98(4):185-201.

Gillett, S., C. Tan, J. Morley, J. Missaghian, G. Wesolowski, J. Robins, M. Podlech, K. Camara. 2014. San Vicente Creek watershed plan for salmonid recovery. Resource Conservation District of Santa Cruz County. Capiltola, California.

Gobalet, K.W., P.D. Schulz, T.A. Wake and N. Siefkin. 2004. Archaeological perspectives on native American fisheries of California, with emphasis on steelhead and salmon, Transactions of the American Fisheries Society 133(4):801-833.

Good, T.P., R.S. Waples, and P. Adams (eds.). 2005. Updated status of federally listed ESUs of west coast salmon and steelhead. U.S. Department of Commerce, NOAA Technical Memorandum NMFS-NWFSC-66.

Harmon, M.E. and twelve coauthors. 1986. Ecology of coarse woody debris in temperate ecosystems. Advances in Ecological Research 15:133-302.

Harrington, C.A. 1990. Red alder. P. 116-123 in Silvics of North America, Volume 2, Hardwoods. Burns, R.M and B.H. Honkala, technical coordinators. USDA Forest Service Agriculture Handbook 654. 
Hammersmark, C. T., W. E. Fleenor, and S. G. Schladow. 2005. Simulation of flood impact and habitat extent for a tidal freshwater marsh restoration. Ecological Engineering 25(2):137-152

Hayes, S.A. 2013. Untitled Presentation. Class lecture, Watershed Management, February 23, 2013. Cal Poly/Swanton Pacific Ranch, Davenport, CA.

Hayes, S.A., C.V. Hanson, D.E. Pearse, M.H. Bond, J.C. Garza, R.B. MacFarlane. 2012. Should I stay or should I go? the influence of genetic origin on emigration behavior and physiology of resident and anadromous juvenile Oncorhynchus mykiss. North American Journal of Fisheries Management 32:722-780.

Hilderbrand, R.H., A.D. Lemly, C.A. Dolloff, K.L. Harpster. 1998. Design considerations for large woody debris placement in stream enhancement projects. North American Journal of Fisheries Management 18:161-167.

Hillard, A.B. 2015. Detecting change in Central California Coast Coho Salmon habitat in Scotts Creek, California, from 1997 -2013. Master's thesis. California Polytechnic State University, San Luis Obispo.

Integrated Watershed Restoration Program. 2012. IWRP Phase 3 Individual Design Project Work Program, amended 11/4/2013. Resource Conservation District of Santa Cruz County, Capitola, California.

Junk, W.J., P.B. Bayley, and R.E. Sparks. 1989. The flood pulse concept in river-floodplain systems. Proceedings of the International Large River Symposium. Canadian Special Publication of Fisheries and Aquatic Sciences 106:110-127.

Kaczynski, V.W., and Alvarado, F. 2006. Assessment of the southern range limit of North American Coho Salmon: difficulties in establishing natural range boundaries. Fisheries 31(8):374-391.

Kauffman, J.B., R.L. Beschta, N. Otting and D. Lytjen. 1997. An ecological perspective of riparian and stream restoration in the Western United States. Fisheries 22(5):12-24.

Koopman, J. 4/11/2008. Salmon fishing closed for California, Oregon-California, parts of Oregon coasts closed-fishing industry braces for disaster. San Francisco Chronicle. 
http://www.sfgate.com/green/article/Salmon-fishing-closed-for-California-Oregon3288476.php

Lake, P.S., N. Bond, and P. Reich. 2007. Linking ecological theory with stream restoration. Freshwater Biology 52(4):597-615.

Lejot, J., C. Delacourt, H. Piégay, T. Fournier, M.L. Trémélo, and P. Allemand. 2007. Very high spatial resolution imagery for channel bathymetry and topography from an unmanned mapping controlled platform. Earth Surface Processes and Landforms 32(11):1705-1725.

Marcus, W.A. and M.A. Fonstad. 2008. Optical remote mapping of rivers at sub-meter resolutions and watershed extents. Earth Surface Processes and Landforms 33(1):4-24.

Marston, D. 1992. June-July 1992 stream survey report of lower Scott Creek, Santa Cruz County. State of California, The Resources Agency, Department of Fish and Game.

McCrary, H.T. 2003. Petition to redefine the southern extent of the Central California Coho ESU. Letter dated November 23, 2003 to R. McInnis, Acting Regional Administrator, NOAA Fisheries, Southwest Region, Long Beach, CA.

McCrary, H.T. 2004. Addendum to the petition to redefine the southern extent of the Central California Coho ESU, submitted to NOAA Fisheries on November 6, 2003. Letter dated February 6, 2004 to R. McGinnis, Acting Regional Administrator, NOAA Fisheries, Southwest Region, Long Beach, CA.

McCrary, H.T. 2005. Response to the NOAA Fisheries, Santa Cruz Laboratory's second review of the November 6, 2003 petition from Homer T. McCrary concerning coho salmon south of San Francisco. Letter dated 10 May 2005 to R. McGinnis, NOAA Fisheries, Southwest Region, Long Beach, CA.

McElhany, P., M.H. Ruckelshaus, M.J. Ford, T.C. Wainwright, and E.P. Bjorkstedt. 2000. Viable salmonid populations and the recovery of evolutionarily significant units. U.S. Department of Commerce, NOAA Technical Memorandum NMFS-NWFSC-42. 
Merz, J.E., D.G. Delaney, J.D. Setka And M.L. Workman. In press. Seasonal rearing habitat in a large Mediterranean-climate river: Management implications at the southern extent of Pacific salmon (Oncorhynchus spp.). River Research and Applications.

Molles, M. C., C. S. Crawford, L. M. Ellis, H. M. Valett, and C. N. Dahm. 1998. Managed flooding for riparian ecosystem restoration. Bioscience 48:749-756.

Morley, S.A., P.S. Garcia, T.R. Bennett, P. Roni. 2005. Juvenile salmonid (Oncorhynchus spp.) use of constructed and natural side channels in Pacific Northwest rivers. Canadian Journal of Fisheries and Aquatic Sciences 62(12):2811-2821.

Naiman, R.J., E.V. Balian, K.K. Bartz, R.E. Bilby, and J.J. Latterell. 2002. USDA Forest Service General Technical Report PSW-GTR-181.

National Agriculture Imagery Program. 2012. Aerial photograph. 1-meter resolution. CA 087.

National Marine Fisheries Service. 2012. Final recovery plan for the Evolutionarily Significant Unit of Central California Coast Coho Salmon. National Marine Fisheries Service, Southwest Region, Santa Rosa, California.

Nehlsen, W., J.E. Williams, and J.A. Lichatowich. 1991. Pacific Salmon at the Crossroads: Stocks at Risk from California, Oregon, Idaho, and Washington, Fisheries 16(2):4-21.

Niemiec, S.S., G.R. Ahrens, S. Willits, and D.E. Hibbs. 1995. Hardwoods of the Pacific Northwest. Research Contribution 8. Oregon State University, Forest Research Laboratory.

Opperman, J.J., 2002. Anadromous fish habitat in California's Mediterranean-climate watersheds: influences of riparian vegetation, instream large woody debris, and watershed-scale land use. Doctoral dissertation. University of California, Berkeley.

Opperman, J.J; and A.M. Merenlender. 2004. The effectiveness of riparian restoration for improving instream fish habitat in four hardwood-dominated California streams. North American Journal of Fisheries Management 24(3):822-834.

Opperman, J.J., and A.M. Merenlender. 2007. Living trees provide stable large wood in streams. Earth Surface Processes and Landforms 32:1229-1238. 
Opperman, J.J., M. Meleason, R.A. Francis, and R. Davies-Colley. 2008. "Livewood”: geomorphic and ecological functions of living trees in river channels. BioScience 58(11):1069-1078.

Pearson, J.A. 2004. Riparian restoration of Queseria Creek: A model for planning, design, and implementation. Master's thesis. California Polytechnic State University, San Luis Obispo.

Reynolds, S.D. 2013. Soquel Creek large woody debris project Site 1 as-built report. California Geological Survey, Department of Conservation. Sacramento, California.

Roni, P. and T. Beechie. 2012. Stream and watershed restoration: A guide to restoring riverine processes and habitats. John Wiley \& Sons.

Roni, P., K. Hanson, and T. Beechie. 2008. Global review of the physical and biological effectiveness of stream habitat rehabilitation techniques. North American Journal of Fisheries Management 28:856-890.

Rowley, M. (editor). 2003. Unpublished Scotts Creek watershed assessment. Scotts Creek Watershed Council, with major funding from the Salmon and Steelhead Trout Restoration Account (SB 271, 1997-Thompson).

Ruttenberg, D. 2011. Engineering docket-San Vicente Creek LWM (Large wood material installation on San Vicente Creek for coho and salmonid habitat restoration). Unpublished report. Natural Resources Conservation Service, Salinas Service Center, Monterey County, California.

Santa Cruz County Environmental Health Department. 2009. http://scceh.com/Home/Programs/WaterResources/WatershedandStreamHabitatProtection/Water shedRestoration/WoodyDebris.aspx)

Scrudato, M. 2010. Comparison of two potential stream gage locations on Scotts Creek at Swanton Pacific Ranch, California. Master's thesis. California Polytechnic State University, San Luis Obispo.

Sedell, J.R., P.A. Bisson, F.J. Swanson, and S.V. Gregory. 1988. What we know about large trees that fall into streams and rivers. In Maser, C., R.F. Tarrant, J.M. Trappe, and J.F. Franklin (eds). 
From the forest to the sea: a story of fallen trees. General Technical Report PNW-GTR-229, USDA Forest Service, Pacific Northwest Research Station, Portland, Oregon. 47-81.

Shapovalov, L., and A.C. Taft. 1954. The life histories of the steelhead rainbow trout (Salmo gairdneri gairdneri) and silver salmon (Oncorhynchus kisutch) with special reference to Waddell Creek, California, and recommendations regarding their management. State of California Department of Fish and Game, Fish Bulletin No. 98.

Skidmore, P., T. Beechie, G. Pess, J. Castro, B. Cluer, C. Thorne, C. Shea, and R. Chen. 2012. Developing, designing, and implementing restoration projects, in stream and watershed restoration: a guide to restoring riverine processes and habitats. Roni, P. and T. Beechie (eds). John Wiley \& Sons, Ltd, Chichester, UK.

Spence, B.C., W.G. Duffy, J.C. Garza, B.C. Harvey, S.M. Sogard, L.A. Weitkamp, T.H. Williams, and D.A. Boughton. 2011. Historical occurrence of Coho Salmon (Oncorhynchus kisutch) in streams of the Santa Cruz Mountain region of California: response to an endangered species act petition to delist Coho Salmon south of San Francisco Bay. National Marine Fisheries Service, Southwest Fisheries Science Center. Technical Memorandum 472.

Spence, B.C., G.A. Lomnicky, R.M. Hughes, and R.P. Novitzki. 1996. An ecosystem approach to salmonid conservation. TR-4501-96-6057. National Marine Fisheries Service, Portland, Oregon.)

Spence, B., and T.H. Williams. 2011. Status review update for Pacific salmon and steelhead listed under the Endangered Species Act: Central California coast Coho Salmon ESU. NOAA-TMNMFS-SWFSC-475. National Marine Fisheries Service, Southwest Fisheries Science Center, Santa Cruz, CA.

Surfleet, C.G., and R.R. Ziemer. 1996. Effects of forest harvesting on large organic debris in coastal streams. J. LeBlanc (ed). conference on coast redwood forest ecology and management, 18-20 June 1996, Humboldt State University, Arcata, CA. 134-136. 
Swaim, K. 2014. Annual Report TE 815537. Letter dated January 31, 2014 to Chris Kofron, Senior Biologist and Recovery Permit Coordinator, U.S. Fish and Wildlife Service, Ventura, CA Field Office.

Tockner, K. and J.A. Sanford. Riverine flood plains: present state and future trends. Environmental Conservation 29(3):308-330. Cambridge University Press.

Tockner, K., F. Malard and J.V. Ward. 2000. An extension of the flood-pulse concept. Hydrological Processes 14(16-17):2861-2883.

United Nations, Department of Economic and Social Affairs, Population Division. 2015. World population prospects: The 2015 revision, key findings and advance tables. Working Paper No. ESA/P/WP.241.

United States Congress. 1973. Endangered species act of 1973. United States Code 16:35 $§ 1531$.

United States Department of Agriculture Natural Resources Conservation Service. 1980. Soil survey of Santa Cruz County, California. National Cooperative Soil Survey.

University of California Santa Cruz Library Digital Collections. Santa Cruz County aerial photograph. 1:31,680. WAC 93-CA 124-23. Santa Cruz, CA, April 19, 1993.

Waples, R. 1991. Pacific salmon, Oncorhynchus spp., and the definition of "species" under the Endangered Species Act. Marine Fisheries Review 53(3):11-22.

Zimmerman, M., K. Krueger, B. Ehinger, P. Roni, B. Bilby, J. Walters, and T. Quinn. 2012. Intensively monitored watersheds program: an updated plan to monitor fish and habitat responses to restoration actions in the Lower Columbia watersheds. Washington Department of Fish and Wildlife. 


\section{APPENDICES}

\section{A. FLOOD MODELING REPORT}

\section{Comparison of Modeled Flood Extents and Levels for Existing vs. Proposed Restoration Design Conditions \\ Christopher Surfleet, Benjamin Cook, Brian Dietterick, October 14, 2013}

\section{A.1 Introduction}

This report presents the results of modeled flood depths and extents using the Hydrologic Engineering Center River Analysis System (HEC RAS) for lower Scotts Creek, near Davenport, in Santa Cruz County, California. Lower Scotts Creek is being assessed for the feasibility of a stream enhancement project that will increase instream and off-channel winter refuge habitat for native salmonid populations that utilize Scotts Creek. Specifically, 12 large wood structures are being proposed for habitat diversity within the Scotts Creek active channel (Figure 27). Additionally, offchannel habitat will be connected to Scotts Creek through construction of small breaches in a historic agriculture berm at the confluence of Archibald Creek, two historic wetland areas, and two outlets of agricultural field drainage ditches. The actual details of the stream enhancement's design will not be presented here; rather this report demonstrates the analysis of the water surface and potential flooding consequences associated with the design.

\section{A.2 Modelling Approach}

The HEC RAS model was used to predict peak flow events for the lower Scotts Creek valley. The objectives of the modeling were to:

- Determine water surface changes in Scotts Creek channel and flood plain from the conceptualized restoration design for the bankfull event $\left(1000 \mathrm{ft}^{3} / \mathrm{s}\right), 10$-year event (2550 $\left.\mathrm{ft}^{3} / \mathrm{s}\right)$, and the 100 -year event $\left(6500 \mathrm{ft}^{3} / \mathrm{s}\right)$.

- Determine if Scotts Creek streamflow accesses off channel habitat during the bankfull event. 


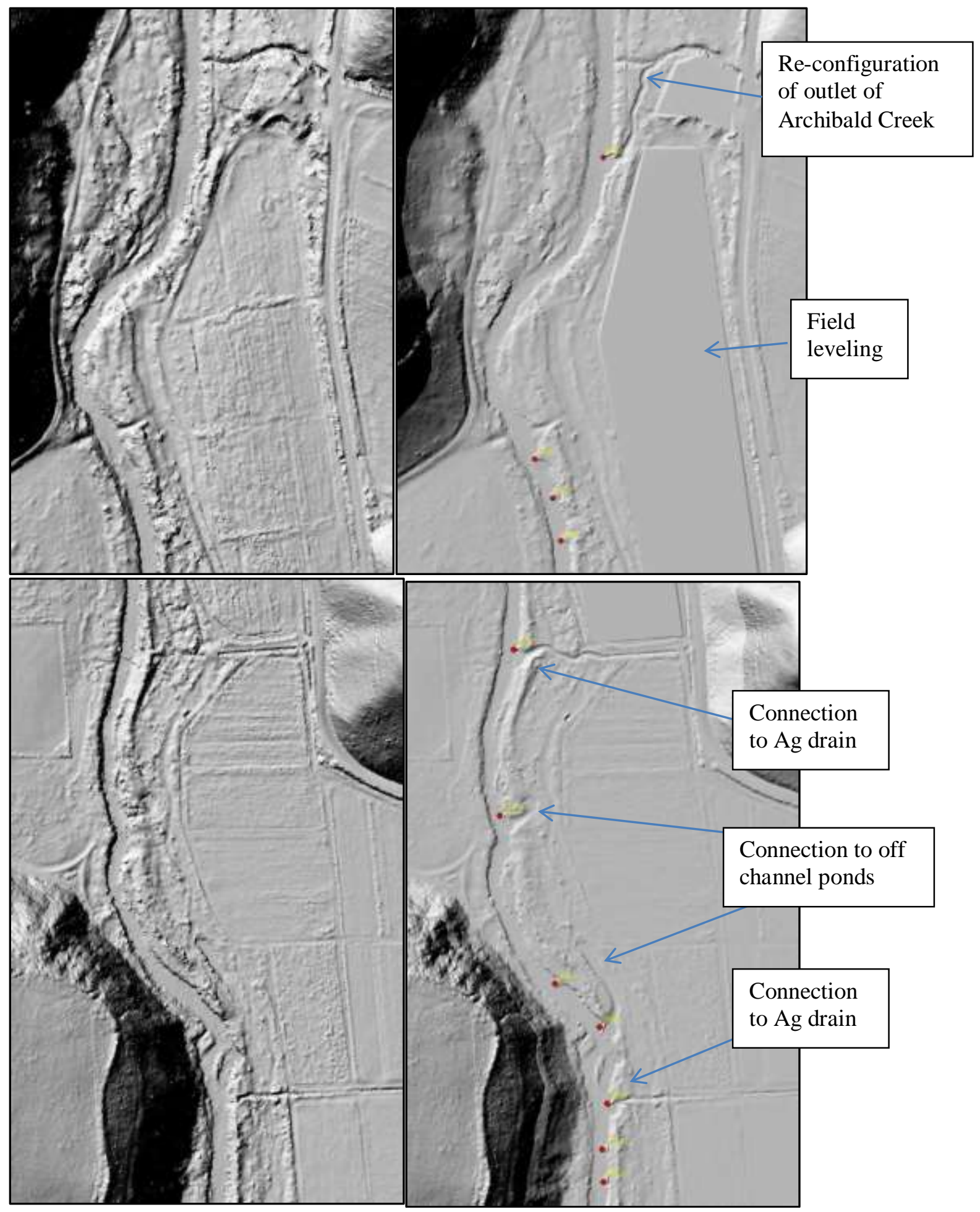

Figure 27. Hillshade DEMs showing existing (left) and proposed (right) ground surfacess. Top: Archibald Creek confluence area with "Field 2" at right of frames. Bottom: Locations of floodplain and pond connections. Red dots highlight the proposed locations of large wood complexes.

The HEC RAS model calculates water surfaces through an energy equation based on change in slope, roughness, and ground geometry through cross section profiles of a river and floodplain area. 
The geometry of the lower Scotts Creek valley was determined from a one-ft digital elevation model created from 2010 LiDAR data. Cross-section profiles for use in HEC RAS modeling were generated from the DEM using HEC GeoRAS tools in ArcMap.

We calibrated HEC RAS water surfaces using steady state stream flow simulations for $1000 \mathrm{ft}^{3} / \mathrm{s}$, our approximate bankfull discharge. Adjustments to the Manning's roughness coefficient (n) were the easiest method to calibrate the water surface predictions for HEC RAS. Local knowledge of water depth at the gaging station and past high flow events were compared to HEC RAS predictions. Analysis of the stream gaging location on Scotts Creek indicated a Manning's n value of 0.35 (Scrudato, 2010). This value was lowered considerably $(n=0.15)$ to fit the HEC RAS predicted bankfull water surface to measured water depths. The floodplain Manning's $n$ has been estimated to be between 0.1 and 0.2 due to variations in riparian vegetation. The floodplain roughness coefficients only affect high flows which access the floodplain, they have only a little effect on off-channel habitat water levels and no effect on instream habitat. For this reason, one nvalue for the entire floodplain was used $(n=0.1)$.

The modeling used a steady state flow analysis. Although streamflow down a river valley is most certainly unsteady, an unsteady flow analysis required considerably higher data requirements such as comprehensive streamflow measurements down Scotts Creek. These measurements were not available making any results from an unsteady flow analysis highly uncertain. In our modeling we make the assumption, that since we only evaluated instantaneous peak flows for the Scott's Creek valley, a steady flow analysis was reasonable.

The water surface modeling in HEC RAS produces water elevations based on the elevation of the cross section. Water surfaces are estimated based on the velocity and depth of the water in relation to the lowest elevations on the cross section. This often resulted in water predicted on the floodplain of Scotts Creek due to depressions on the floodplain even when the stream channel had the capacity to encompass all of the water. This spurious water surface was corrected by hand in the cross 
sections and plan view diagrams presented here. The water surface was corrected if it was a result of upstream inundation, in other words the water surface had a connection from the stream channel.

\section{A.3 Results}

The model results are presented in graphic format on the following pages (Figures 28-33).
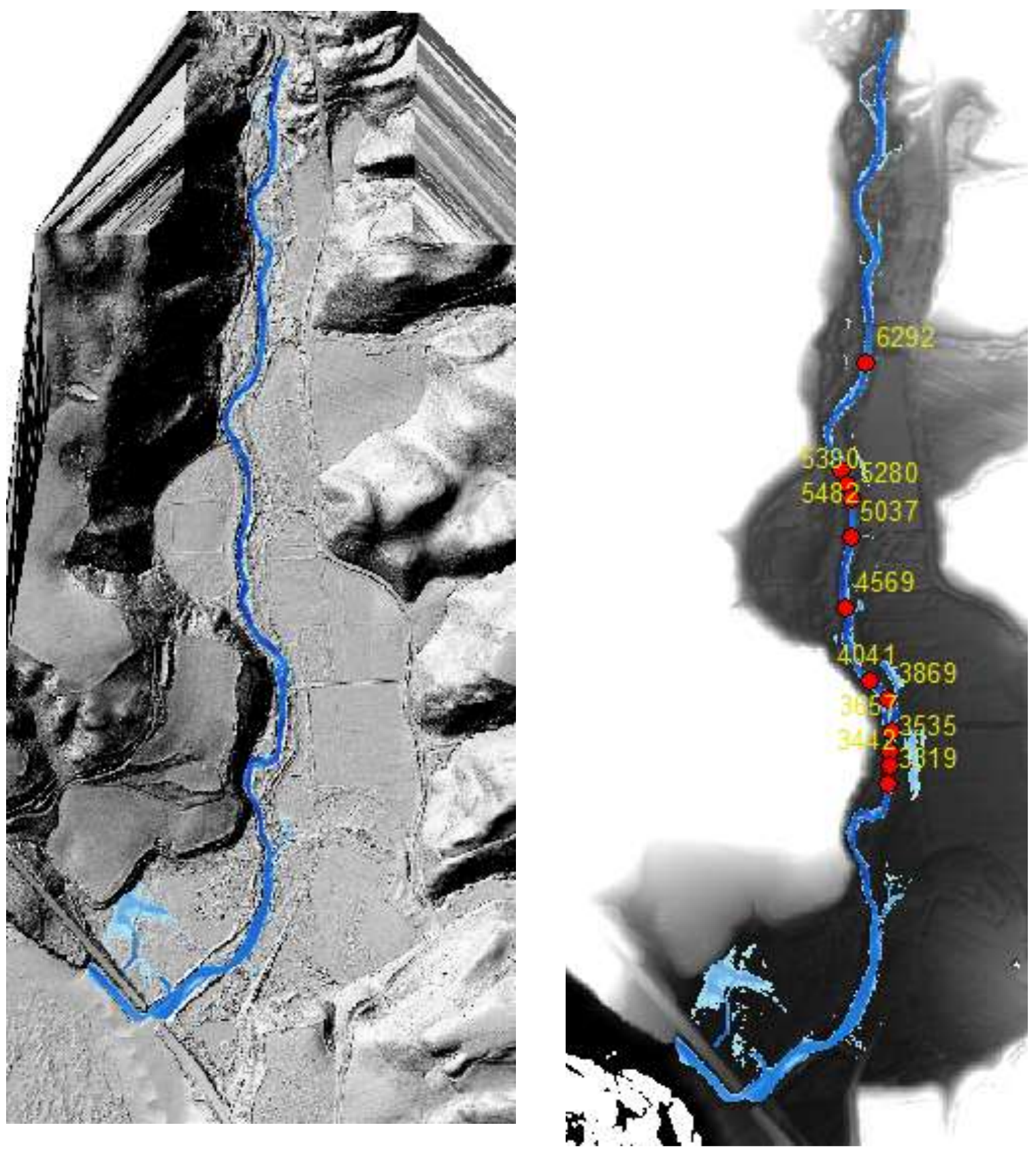

Figure 28. Pre- (left) and post-restoration (right) water surface extents and depths for the bankfull flow. Red dots represent wood habitat structures, with river stations labeled in yellow (Note: stations in this report do not correspond to stationing found elswhere in the parent document). 


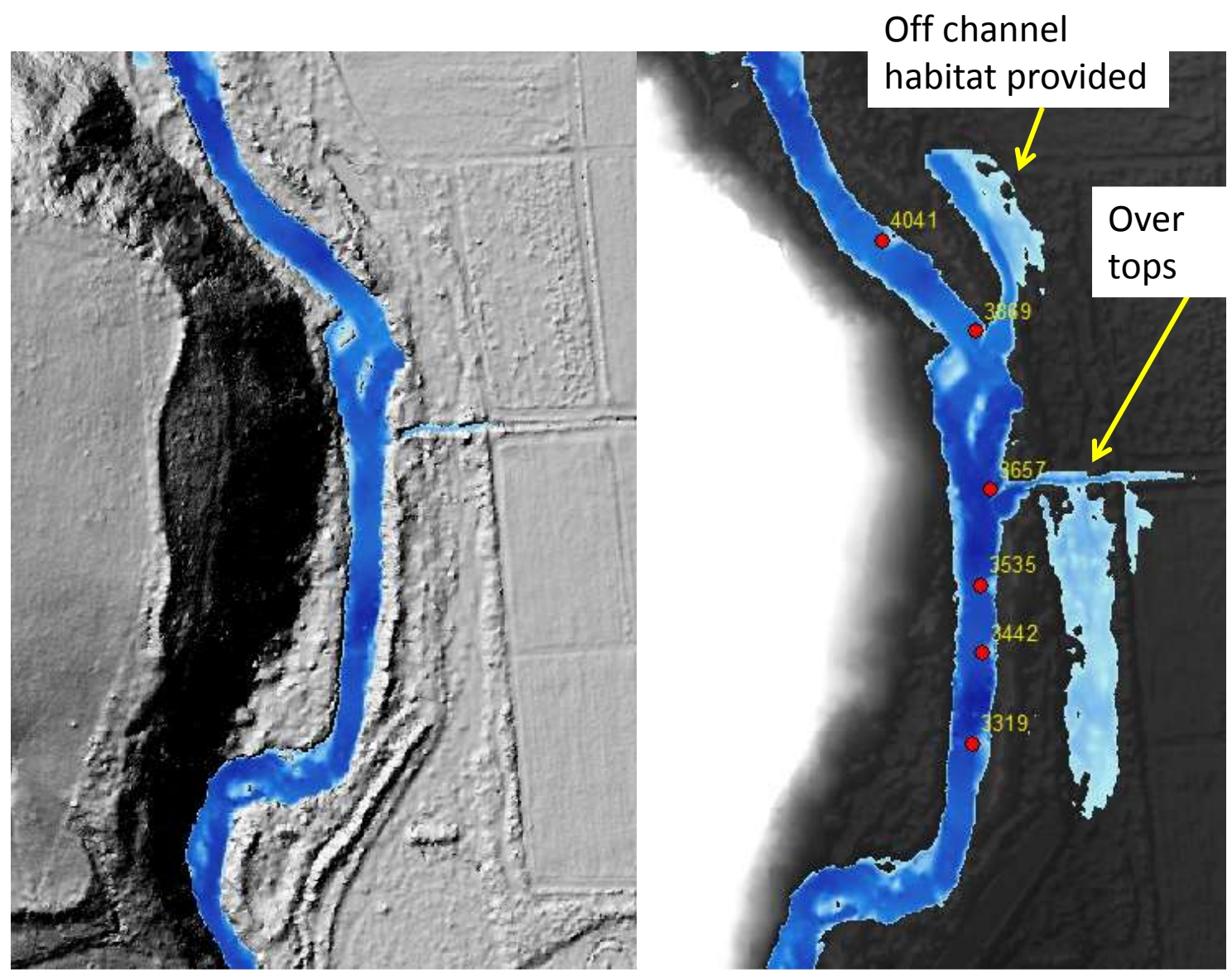

Figure 29. Pre-(left) and post-restoration (right) instream and flood extents and depths for the bankfull discharge. Close-up is near the ag drain at 3657 and proposed off channel pond habitat at 3869. Red dots represent LWCs with river stations labelled in yellow. The combination of wood structures slowed the velocity of the water increasing water depth such that some water overtopped the ag field drain berm and flowed on to floodplain. 

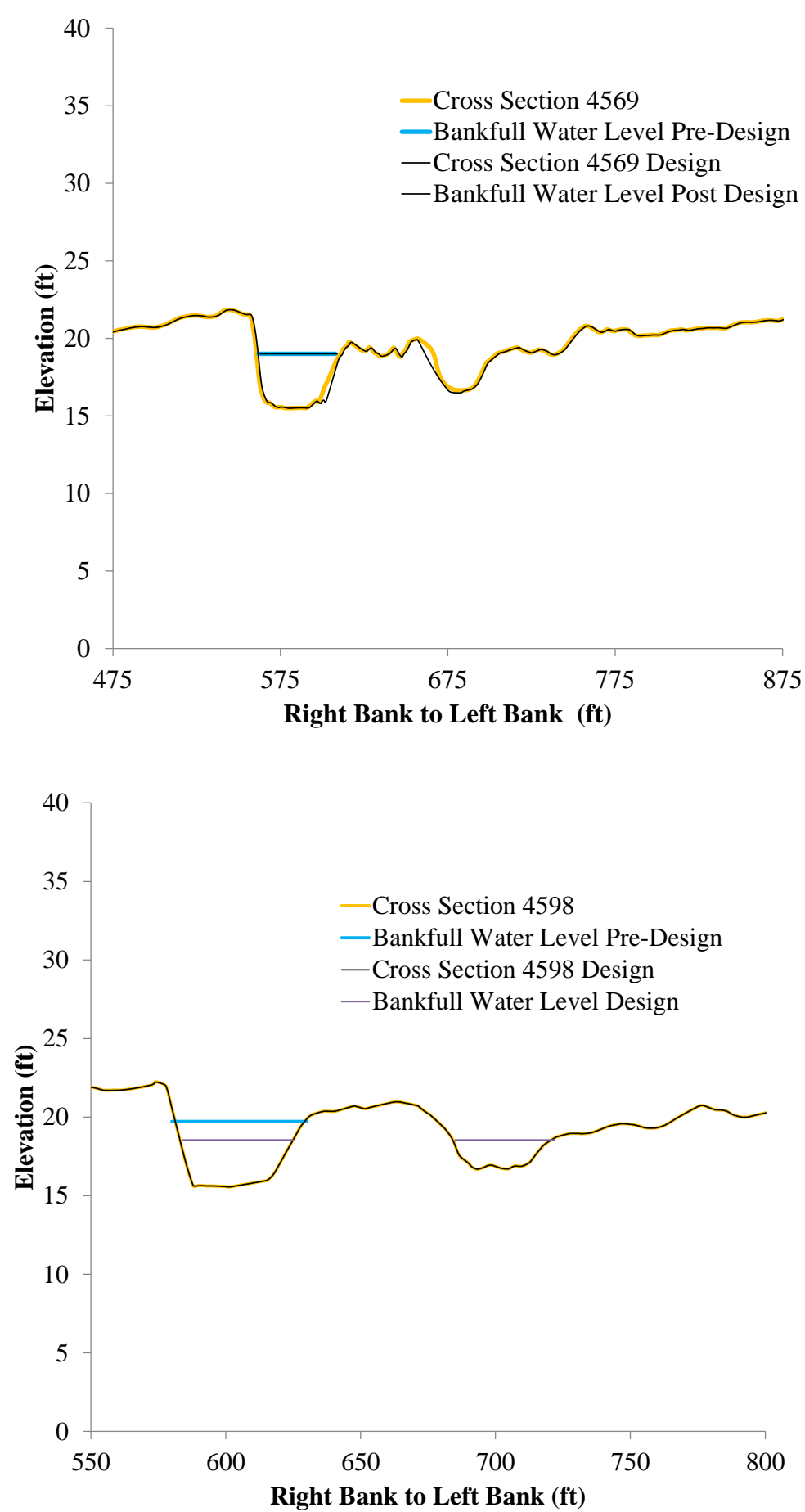

Figure 30. Pre- and Post-restoration water surface elevations for the bankfull flow at the location of a wood vane structure and pond connection channel junction (top, cross section 4569), and upstream of pond connection channel, but intersecting the pond at section station 700 (bottom, cross section 4598). Notice innundation of pond post-restoration. 

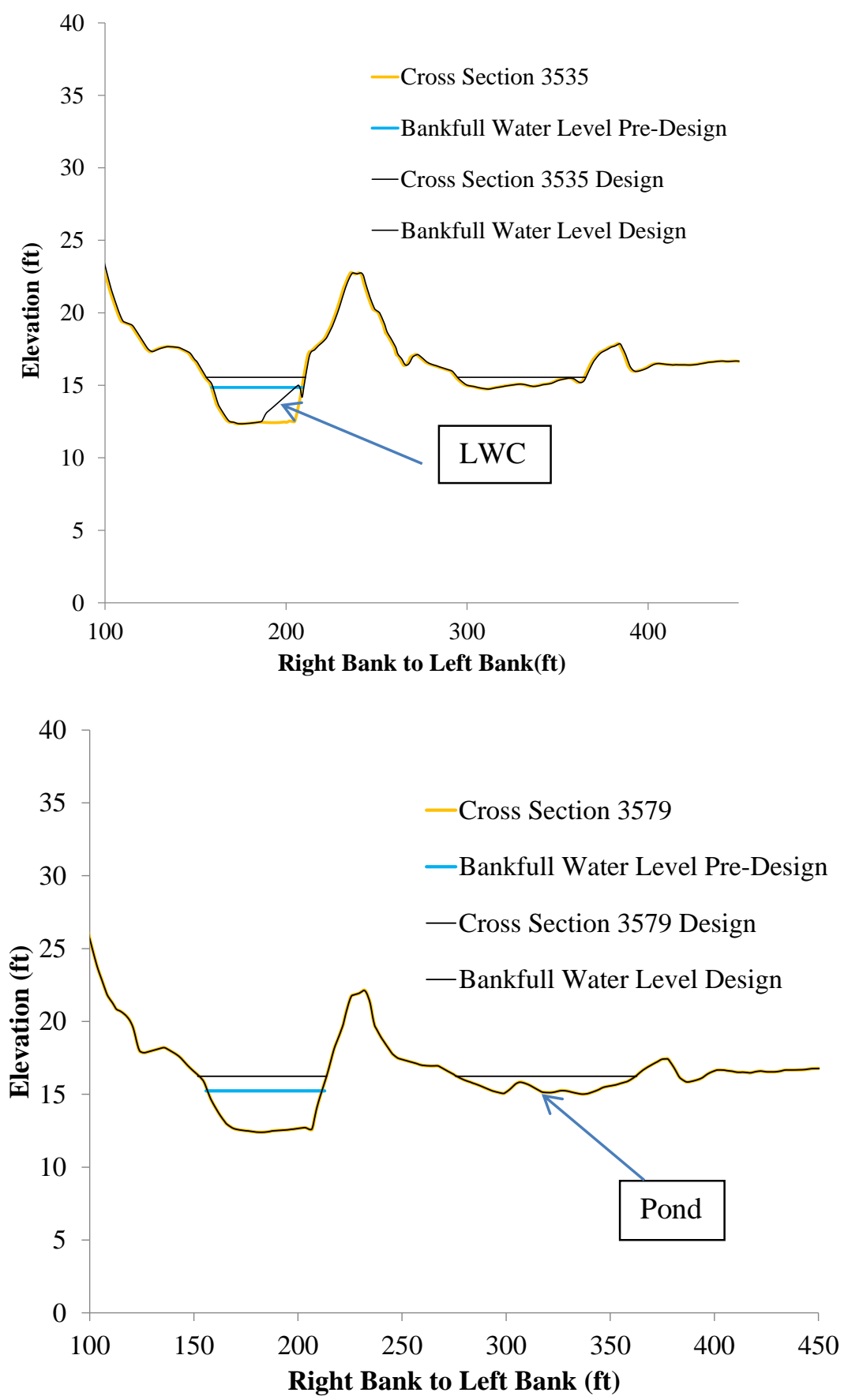

Figure 31. Pre-and post-restoration water surface elevations for the bankfull flow at the location of a LWC at cross-section 3535 (top), and at cross-section 3579 immediately upstream of the structure. Notice the higher water surface elevation and flooding originating from upstream via the ag drain at 3657 (see Figure 3). 

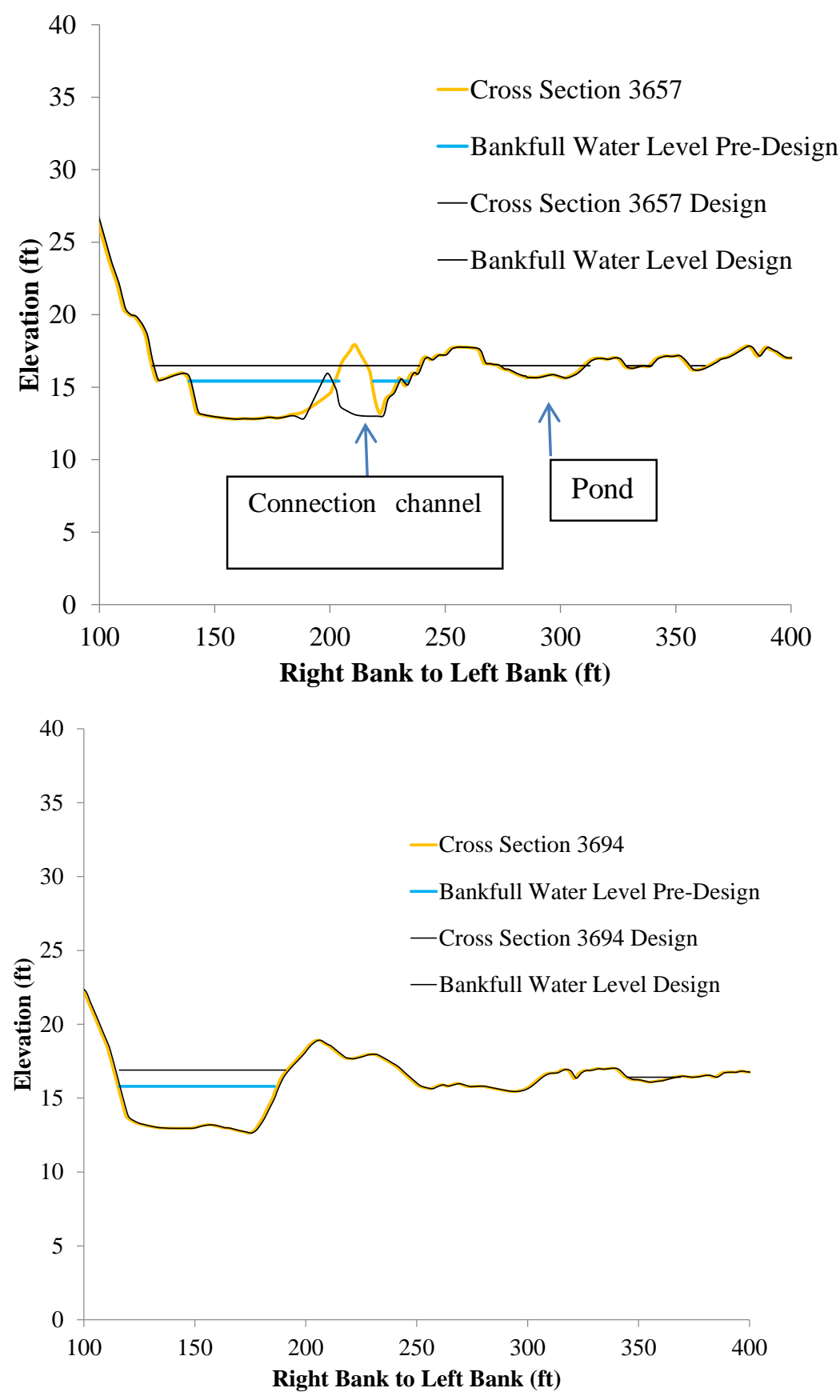

Figure 32. Pre-and post- restoration water surface elevations for the bankfull flow at the location of a LWC and connection channel (top, cross-section 3657), and upstream (bottom, cross section 3694). Notice the higher water surface elevations post-restoration. 

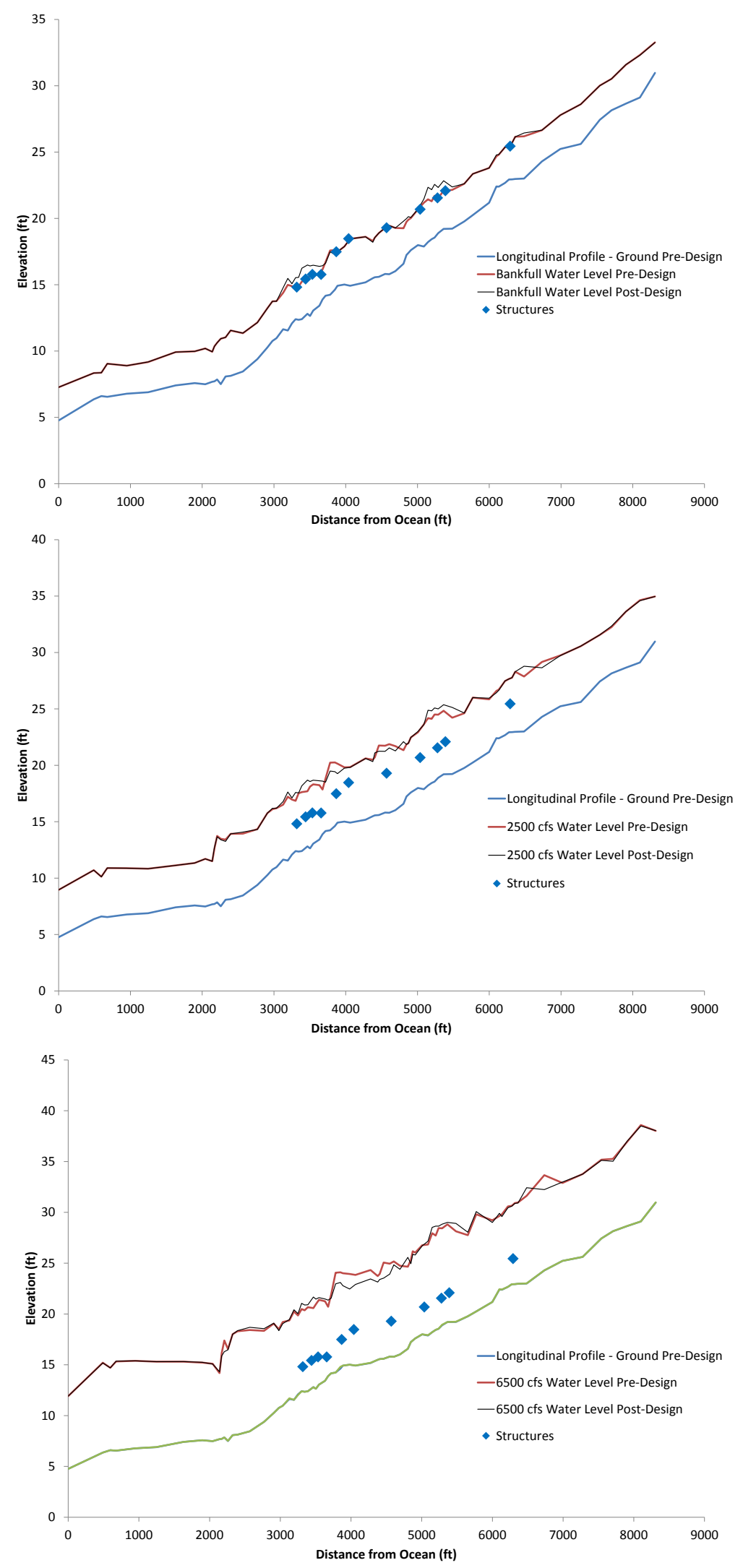

Figure 33. Longitudinal water surface profiles for the bankfull (top), 10-year (middle) and 100-year (bottom) flow events pre- and post-restoration, with locations of LWCs (blue diamonds). 


\title{
B. DESIGN REVIEW
}

\section{California Department of Fish and Wildlife Design Review Correspondence}

\section{B.1 Comments on Phase II 60\% Design}

\author{
by Marcin Whitman, CDFW Senior Engineer
}

Thanks for the opportunity to comment on the design for the Lower Scott Creek Habitat Improvement Project. The review is based on the following two documents:

Drawings and Specifications - Engineering Docket - Lower Scott Creek Habitat Improvement Project July 2014

\section{Lower Scott Creek Habitat Improvement Project 60\% Submittal Planset 7/25/14}

Ben Cook, graduate student at SLO has done an excellent a job designing and assembling this package and clear writing; he should be commended for professional level work. Note that some of the comments below are looking for clarification or detail not necessarily suggesting changes to the design.

\section{Comments on Engineering Docket:}

Title Page - Says "Drawings and Specifications" - should make clear that while there are drawings in this document, there is also a separate planset for this project. (Perhaps such is stated and I missed it?)

Page 4 - Summary say there will be ten instream wood complexes but below only nine are referred to.

Page 4 - General comment about floodplain connections: Literature has shown that to maintain a good opening at such a connection, angle of channel leading from the main channel and any "setup" from channel bends upstream are key parameters. The connections geometry and in-stream features to maintain scour appear to be set perpendicular to the channel; literature and current practice suggests a more acute angle.

Page 8 - soil samples: Do soil samples, perk rates or experience suggest that floodplain is also flooded by pore pressure through/under levee or is all inundation due to surface flows? My understanding is that only surface flows are being considered for the features being design in this effort.

Page $11 \& 12$ - Letter from NRCS appropriately appears in hydrology section but appears abruptly - suggest adding an introduction or a summary and including the letter as an attachment.

Page 14: Good work on doing a field verification of model stage. However, with respect to shear stress, HEC-RAS only gives average shear. Shear due to both reach level and local field effects (e.g transient debris moving downstream, bed configuration during a bed mobilizing event) can cause shear much higher than average. Similarly, velocities do not remain average but vary spatially and temporally even in "steady-state" conditions. Design of in-stream elements should be based on maximum shear/velocity likely to be experienced over the life of the project. Not sure if drag/velocity from HEC-RAS were used and for what event. Perhaps the Debris Factor on p22 is accounting for this. The matter would best be resolved in a conversation with the author. 
Page 18: Although use of toppled riparian trees is discussed in ERDC TN-EMRRP-SR-13 (2000), longevity of toppled alders in California has been found to be lacking and they are not included in the CDFW Restoration Manual nor paid for when a project is being performed under an FRGP grant. Felling alders to boot off-channel pond complexity is probably $\mathrm{OK}$ - will need to check with CDFS biological staff.

Page 20: Was the calculation of live tree anchors derived by the author or was this a method from literature (if literature, please cite). Similar with tractive force of typical wood complex estimated at 10 kips.

Page 21: Simple spheres (surrogate for rootball) and simple cones (surrogate for live tree) have much less surface and thus drag than the actual article. (However, interior surfaces of both also receive reduced velocities). Was this estimation method from literature (please cite) and is there any recommended safety factor to be applied?

Page 22: Buoyant force calculations are clear. For drag force, where did velocity of $7.3 \mathrm{ft} / \mathrm{s}$ come from? HEC-RAS? Other?

Page 25: Archibald Creek designed backwater channel is targeted to be $2.5 \%$. Is this substantially than Creek itself?

Page 28: Monitoring - besides photo monitoring, what other monitoring or measurements are intended?

Comments on Planset:

Sheet 1 : Good to see general job description and drawing date of draft on this sheet.

Sheet 1 (con't):

Is Aug 1-Oct 31 standard work window in Santa Cruz? I thought in-channel work ended Oct 15th.

Will NRCS engineering be stamping final planset ?

Sheet 2, etc.: Flow arrow should be shown on each sheet. Labeling average slope of reaches and/or overall slope on drawing would be helpful.

Sheet 5: Good to see access routes considered and depicted.

Sheet 14: Good to see drilling notes for anchor on plans. Note should also include clearing dust from holes before adding epoxy (failure to do so is frequent cause of connection failure).

Sheet 15: Good to see dewatering plan; CDFW biologist should comment on barrier, block nets and silt fencing.

Sheet 16: CDFW biological staff should comment on planting pallet.

\section{B.2 Response to comments on Phase II 60\% Design}

by Ben Cook

Added note about separate planset

Changed engineering docket to reflect only nine LWC's.

Design of floodplain connections has been through a number of iterations. Latest iteration prioritized minimizing soil volumes to meet PCP requirements. Soil volumes were minimized at 
the expense of connection orientations. Current soil volume for project is currently $30 \%$ below maximum. The drawings will be revised to achieve optimization between soil volume and connection orientation.

LWC's are to be field fit at the time of construction. LWC's will be configured to function as a vane-type structure (digger or spider log). The orientation and dimensioning of instream features shown in the drawings will be revised to better reflect their intended function.

Observations suggest subsurface flows play a limited role in floodplain inundation. The design of the project does not take subsurface flows into account because their effect is not expected to be significant at the design flow (Q10 event). The rate of floodplain inundation at or above the bankfull event is likely dominated by rapid surface flows through deteriorated sections of the existing levee, as evidenced by existing scour features/rilling.

The proposed LWC configurations rely on durable and proven materials (redwood log, redwood rootwad, boulder) to influence stream hydraulics. While the LWC's are designed to function without the in-situ alder component, in-situ alders are proposed to be utilized because they are expected to provide a significant benefit at a low additional cost. The added benefit of the in-situ alder component will be significant additional stream cover, feature complexity, hydraulic effect, and debris racking capability due to the presence of the trunk, limbs, and foliage of the toppled alders within and around the LWC's.

The proposed design will incorporate measures to increase the longevity of In-situ alders. Efforts will be made to topple alders while keeping major roots intact with the intention of keeping the trees alive, in a manner similar to that of existing naturally recruited alders observed on lower Scotts Creek. Bank undercutting has brought down several trees on lower Scotts Creek that continue to produce new growth in the form of vertical shoots and foliage. The proposed project will allow researchers to monitor and evaluate the longevity and effectiveness of the alder components.

The design team is confident that inclusion of these alder components is justified for the reasons discussed above.

The calculations in question were developed in consultation with an NRCS engineer. The engineer has reviewed the final calculations presented in the $60 \%$ designs.

This method was discussed with an NRCS engineer. The engineer was comfortable with this modeling approach. Further research will be conducted to either validate this approach or develop an alternative approach.

Lower Scotts Creek has a gradient of approximately $0.5 \%$.

A monitoring strategy is proposed that will include biological surveys, habitat typing, habitat volume, characterization of bed substrate. The monitoring strategy proposes to track changes in these metrics to evaluate the effectiveness of the proposed project in establishing the desired physical habitat conditions and determine how salmonids and potentially other aquatic species are utilizing the project reach.

\section{B.3 Response from Jim Robins}

Thanks so much Marcin. As always your comments are invaluable and appreciated. I will work with Ben and Brian to make sure we can address some of the easier comments in the final designs and perhaps set-up a call with you to discuss the 2-3 more complex comments. 
One thing that I would like to address is the felling of alders. The plan is experimental and we are building a literature by Dr. Jeff Opperman of TNC and others (2005, 2007, 2008, and 2009) looking at longevity of wood in small coast streams in Ca. Data by Opperman (who sat next to me from much of grad school...) suggests high levels of longevity for hardwoods- especially willows and alders IF the trees stay alive. From walking streams in SM and SC, it seems to me that Opperman's work really resonates in our region. To my knowledge, there has been very little experimental work to see if we can mimic natural processes (wind throw and hydraulic forces) that tip alders into the stream and create a situation that may enable the tree to survive. Since many of our coastal streams have tons of alders and very little redwood in the lower reaches (and limited upstream recruitment of redwoods) our hypothesis is that living LWD could be an incredibly cost-effective way to start recreating complexity without having to import nearly as many (or possibly any) conifers - which is costly and the import process can be damaging to the riparian corridor. Any way, I see your point about the Manual, but feel strongly that we need to start trying new techniques that could be ecologically effective and cost effective. This technique represents only a tiny piece of the overall cost and could provide invaluable data. CalPoly is committed to tracking the longevity of these pieces and providing solid monitoring data. Finally, I believe that for this project we are planning to use a combination of redwood and alder for the structures as an insurance policy to make sure that at least part of the structure is long-lived. I hope this helps clarify the whole alder felling thing.

Thanks,

Jim

\section{B.4 Lower Scotts Creek Design Review Meeting, 1/22/14}

Notes written by Jim Robins, IWRP TAC Coordinator, and Consultant, Alnus Ecological

Participants

Ben Cook (Cal Poly), Brian Dietterick (Cal Poly), Marcin Whitman (CFW), Devin Best (NOAA Fisheries), Jim Robins (Alnus Ecological) and Alicia Moss (RCD)

Goal of Meeting

Work with subset of the TAC on status of design and outstanding fisheries and engineering considerations that need to be addressed.

Meeting Minutes:

Brian provided background of project identification and development

Ben provided overview of proposed project elements and analysis completed thus far. Below are specific highlighted questions and issues regarding necessary future analysis:

Breaches in lower reach:

Key Question: How were height and width of breaches determined? Somewhat arbitrary, but based on visual cues. Ben use a combination of "natural" floodplain elevation as per cross sections AND visual estimate of bankfull ( $\sim 3 \mathrm{ft}$ above water baseflow water surface) to determine approximate elevation for breach. For width of the breach, Ben tried to balance minimizing disturbance while not increasing velocity too much by making breaches too narrow. CalPoly's design breaches are we intended to stay somewhat static and maintain general dimensions ove time, though we all clear expect some change, but don't want them to expand too much. Marcin suggested conducted 2 types of analyses to understand sheer calcs and velocity at each breach. The first analysis 
specifically focused on something like the $2 \mathrm{yr}$ event to understand wse elevation and velocity when water is moving in and out of the breach, but not overtopping the levee as a whole and the second looking at a larger flow $20 \mathrm{yr}$ or $100 \mathrm{yr}$ with a similar analysis. Key is to determine ascending and descending limbs (i.e. after $6 \mathrm{hrs,} \mathrm{what} \mathrm{is} \mathrm{happening} \mathrm{with} \mathrm{water} \mathrm{surface} \mathrm{on} \mathrm{landscape)} \mathrm{and}$ scour/velocity as water moves back through the breach to determine whether geometry is sufficient/within the ball park. There are tools available for this such as mass balance and embayment tools through ACOE. Overall, need to understand when floodplain will be activated, what that looks like and how long it's inundated. We need to be able to show due diligence that data shows a the notch dimensions will be stable at range of flows and design the notch dimenstion to ensure they are stable. Want breaches to have gentle slopes, 2:1-3:1, front could be steeper but back should be gentle sloped

LWD: would be helpful to include photos w/ diagrams of wood placement to include with FRGP proposal (Jim to send along some examples of past FRGP apps for LWD that were approved.

Confluence enhancements at Archibald and 2 ag drainages: Scope includes removing culverts and excavating pools. Will address filling of pools with installation of LWD structure. Need to look at what's need to create scour, what elevations are required and what sediment supply of watershed is to determine appropriate LWD structure at these confluence areas. Should consider including cover (i.e. rootwad) at scour holes. Should we push confluence areas out to thalweg more or keep near banks? Goal is high flow refuge then better to keep near banks.

Connect off-channel pond: These are for high flow refuge, may not be accessable at low flows. Add key way trenches, wood weirs and/or rock weirs ramp at grade at pond confluences to maintain elevations. Need to be sure to say ponds already exist, we're not creating ponds and that these are groundwater fed and project activities won't dewater them. Need to show what velocity differences are going to be between main channel and off-channel ponds to show ponds will provide winter velocity refuge. Should take photos of water level in current drought conditions. Need to address water supply for ponds. Are ponds dependent on existing levees? No.

Reveg on road: Rip and reveg. Would be good to show this on layout map.

Need to be sure to indicate goals and life stage affected for each project element. Overall goal we're trying to achieve is high flow velocity refuge but there are secondary benefits. Need to source coho recovery plan and fisheries biologists that have referenced need for high flow refuge and why (specific quotes are ideal); can't just reference hearsay. Other goal is trying to create more instream summer rearing habitat for coho since they have limited use of estuary as summer rearing habitat.

Fish may be stranded w/ floodplain connectivity and off channel pools, consensus is that this happens naturally and is okay so just make it clear that this is a potential and we are reducing the risk by $\mathrm{x}, \mathrm{y}$ and $\mathrm{z}$.

Post project monitoring: Need to identify biological and physical monitoring. Work with NOAA Science Center on ideas/opportunities and discuss w/ Jon Jankovitz by $2 / 1 / 14$. Will need to conduct photo monitoring and complete pre- and post- profiles.

How do we provide qualitative potential for channel avulsion? By taking culverts out of ag drainages, minimizing potential for plugging.

Be clear about which FRGP project type is applicable, can't mix project types in one proposal

PSN should be coming out by $2 / 1$, be sure to address everything called for in design criteria

Action Items:

Devin to follow-up with Joe P. regarding potential funding for IWRP projects (Scotts and/or Soquel?) 
Alicia/Jim to request FRGP comments from last FRGP proposal (check on licensed professional)

Brian to talk to NOAA Science Center about potential ideas/opportunities for biological and physical project monitoring and Alicia will then follow-up with Jon Jankovitz to discuss monitoring prior to $2 / 1$ (send him project layout docs)

Alicia to follow-up with Brian re: UCSC' LWD material available soon

Alicia to get Q10 flow from Brian and Ben

Ben/Brian to complete sheer calcs and velocity for levee breaches

Velocity/Shear Calcs for breach openings:

Assumptions:

Steady flow through opening

Elevated stage in stream, no water on floodplain

Clear-water

Breach opening bottom has no slope

Two events:

"2 year event" approximated by December 2012 storm event. (Has known ws elevations and extents)

Discharge $=1908 \mathrm{cfs}$, stage $=7.0$ '

Bottom of breach channel=5.0,

Contraction scour through opening

"25 year event" approximated by 1982 event

Discharge roughly 4400 cfs, from estimated discharge @ USGS gage, corrected for watershed area of 30.0 sq miles

Stage from HEC RAS model on existing ground surface=8' max, 8.0'@ RS 5594

Ben/Brian to show velocity of main channel and ponds to show that ponds will provide high flow velocity refuge

HEC RAS results have velocity output in main channel

Ben/Brian-take photos where LWD structures will be installed and include diagram of wood placement

Ben/Brian-address water supply for ponds

Groundwater relationship not shown, need to check depth again in well and take staff plate readings this week

Ben to take photos of ponds to show water present even in drought conditions

Next weekend

Send Marcin pond drawings and be sure he has copy of goals \& objectives

Sent drawings, goals and objectives in progress

Ben to research Queseria thesis to find Jennifer Nelson's observations on limiting factors observed in Scotts Creek 


\section{B.5 Review of Phase II $60 \%$ Design}

by Margie Caisley, Senior FRGP Hydraulic Engineer

From: Caisley, Marjorie@Wildlife

Sent: Friday, July 10, 2015 10:45 AM

To: Swales, Stephen@Wildlife

Cc: Seymour, Gail@Wildlife

Subject: RE: $100 \%$ designs revised 6/27

Hi Stephen,

I am concerned that the $100 \%$ plans still have widened alcove pools where they connect with Scotts Creek. I think these are invitations for deposition that risk disconnecting the floodplains and ponds that they are meant to connect. I also have the following concerns:

3250 Plan (Sheet 3): I am concerned that the woody debris meant to backwater the alcove connection will result in deposition. If this occurs, this element should be removed from the channel. The pulled over alder on the opposite bank is a good idea and should probably be mimicked at the rest of the sites.

3850 Plan (Sheet 5): I am concerned that there will be deposition downstream of the structure. Thus, it is essential that it be low profile such that even low flows plunge over the log rather than skirt around the end of the log. Is there any way to put a wood structure on the opposite bank at this site?

4250 Plan (Sheet 6): Same concerns as Site 3250. Is there any way to put a wood structure on the opposite bank at this site?

5650 Plan (Sheet 9): Same concern as Site 3850. Is there any way to put a wood structure on the opposite bank at this site?

Let me know you have any questions.

Thanks,

Margie

Marjorie Caisley, P.E.

Senior Hydraulic Engineer

California Department of Fish and Wildlife

18129 th Street

Sacramento, CA 95811

(916) 445-3162 


\section{B.6 Response to Phase II 60\% Design Review}

by Ben Cook, 7/13/2015

Margie,

Thank you for reviewing the LSCFHEP Phase II Designs and providing comments. The review we have received over the past two years has resulted in significant improvements to the design and we appreciate very much these opportunities to further refine the design.

As I am sure you are aware, Marcin Whitman has visited the project site and provided review at the $60 \%$ level when the project was planned as a single phase project. We soon after decided to break the project into two phases, and Marcin provided review at the $90 \%$ level for the Phase I designs, which included four instream wood features, five levee breaches, the connection of Queseria Creek (a tributary to Scotts) with an existing scour feature, and the construction of a floodplain connection and alcove feature.

The two-phase approach has allowed us to observe and also perform a preliminary study of the response of the restoration project to stormflow. We constructed Phase I in October of 2014, and then in December we had some decent storms, one of which produced a bankfull flow event. One of the monitoring activities we were excited about was tracking morphologic change instream around the wood features and constructed alcove pool. Some of our biggest questions were, 1) would there be serious deposition in the alcove feature, 2) how would the wood features perform, and 3) how would the stream respond in the vicinity of the wood features, particularly, would the wood feature that was configured to direct flow into the constructed alcove feature perform as intended, or would the alcove fill in and cease to be functional as refuge habitat?

To track the response of the project to stormflow, we performed a pre-construction topo survey of our study reach within the phase I project, using a total station. We surveyed the stream corridor, including the levee, streambanks, and streambed, and all existing LWD within the bankfull channel, and built a TIN with an LWD layer that we could overlay. Following construction, we performed an as-built survey of the constructed features (levee breaches, alcove feature, scour feature, and wood complexes), built a TIN of the gradings, merged it with the pre-construction TIN to represent the modified stream channel, and overlaid the constructed wood layer to lock-down the position of the wood features. Following the December storms, we performed a third TS topo survey (in April), built a post- TIN and subtracted the pre- TIN from the post-.

Additionally, we conducted long-term photo monitoring and visual observations during storm flow (video available at:

http://www.youtube.com/playlist?list=PLRRplD3jkK_Fn-Ryg_IktLgrGWw6qUZ14).

What we learned was invaluable in terms of the design of Phase II. A couple of things surprised us. First, there was deposition in the alcove feature, although not enough to prevent it from functioning as refuge habitat, but returning floodwaters through the floodplain drain cleared sediment and maintained the depth of the alcove feature. The second thing was that there was circular flow within the alcove feature with significant velocity. While it's difficult to estimate the velocity, it appears from the video to be $2-3 \mathrm{fps}$ around the perimeter.

There also was significant deposition under some of the downed alders that had small branches and foliage.

With regards to your first point, I tend to agree that the alcove features are drawn wider than they need to be. I expect that if we construct them at the specified widths, they will narrow over time. While it is too late to send out a bid addendum, narrowing the alcove features is a change that I 
think we could make at the time of construction. I don't want to decrease the volume of the features too much, so I would ask if we could simply elongate these features along the direction of expected flow as floodwaters return to the main channel through the connections.

Regarding your second point, that the wood feature at 3250 meant to backwater the alcove feature and pond connection will result in deposition (clarification: the concern would be deposition within the alcove, correct?), is a possibility, however I expect that flows will be directed along the east bank at the location of the alcove with adequate velocity to maintain the feature during stormflow (facilitated in part by the downed alder on the west bank), and then as flow subside, returning flood flows will maintain the feature.

In regards to 3850, yes a low-profile feature is essential there and we will achieve this to the greatest extent possible without losing the feature in the bedload. We are avoiding crossing the stream with equipment, thus constructing features on the opposite bank is not preferred, but pulling alders down is a possibility because we expect it will be feasible to do by rigging alders by hand and pulling

from equipment parked on the east bank. To address your concerns at 3850, 4250, and 5650, we will investigate the feasibility of downing alders on the opposite bank. There is an outside possibility of constructing features on the opposite bank at 3850 and 4250 because we have an approved ford crossing at 4900 that is used for farm operations that may be used for equipment during construction.

Thanks very much for your time. Your review will ultimately make this a better project. I hope I have addressed your concerns. Please feel free to contact me directly by email or phone.

\section{Ben Cook}

Graduate Assistant in Hydrology

Natural Resources Management and Environmental Sciences Department

Cal Poly State University, San Luis Obispo, CA 93407

cell: (831) 345-0508

bocook@calpoly.edu 
C. PHASE I ENGINEERING DOCKET 


\title{
DRAWINGS AND SPECIFICATIONS
}

\author{
ENGINEERING DOCKET
}

Lower Scotts Creek

Floodplain and Habitat Enhancement Project

Project Job Codes: $342 \mathrm{~A}, 342 \mathrm{G}, 395,580$ and 734

Engineering Class: $V$

Prepared For:

Santa Cruz County Partners in Restoration

Permit Coordination Program (PCP)

Santa Cruz County Resource Conservation District

In Cooperation with Cal Poly

Brian C. Dietterick, Ph.D.,P.H.

Director, Swanton Pacific Ranch

College of Agriculture, Food, and Environmental Sciences

Cal Poly State University, San Luis Obispo

Prepared by:

Ben Cook

Graduate Assistant in Hydrology

Natural Resources Management and Environmental Sciences

Department Cal Poly State University, San Luis Obispo

Mark Barnett, P.E.

NRCS Central Coast Team Engineer

June 2014 


\section{CALIFORNIA NATURAL RESOURCES CONSERVATION SERVICE}

Project:

NRCS Practices:

Location:

County:

RCD;

NRCS Office:

Contract No:
Lower Scotts Creek Floodplain and Habitat Enhancement Project

Stream Habitat Improvement and Management (395)

Streambank and Shoreline Protection (580)

Fish and Wildife Structure (734)

Critical Area Planting -Straw Mulch (342A)

Critical Area Planting -Woody Cuttings (342G)

Cal Poly Corporation

125 Swanton Road, Davenport, CA

Santa Cruz

Santa Cruz County

Templeton Field Office, Mark Barnett, Central Coast Team Engineer

N/A 


\section{Contents}

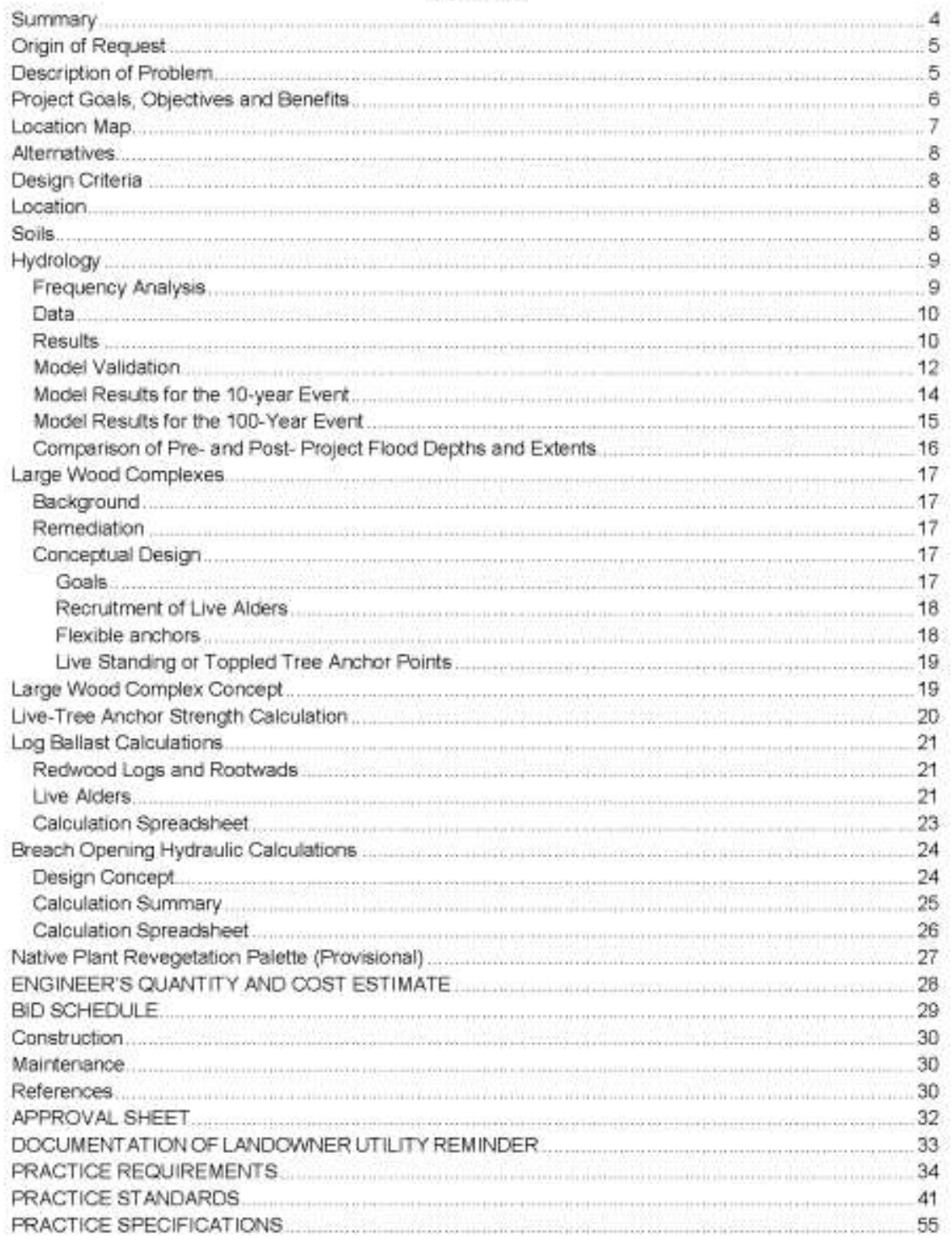




\section{Summary}

The proposed project will implement the following restoration elements:

1. Create five new connections between lower Scotts Creek and the floodplain by grading portions of the left bank levee, for the purpose of improving floodplain connectivity and facilitating a return to a natural flood cycle. These connections will be graded perpendicular to Scotts Creek on the left bank and floodplain of Scotts Creek at stations 1900, 2000, 2650, 2750 , and 2850 . The connections will vary in length from $43^{\prime} 130^{\prime}$ long, depending on the topography at each location. The total area of grading associated with the 5 breaches is 8313 square feet, with a total volume of 690 cubic yards. The maximum depth of grading will be 7 where breach 3 intersects the top of the existing historic levee at river station 2650 .

The connections will be graded level at the elevation of the adjacent floodplain. These connections are expected to improve the hydrologic connection between the main channel and the floodplain of lower Scotts Creek for the benefit of the ecology and hydrology of lower Scotts Creek.

2. Construct four instream wood complexes using a combination of materials including in-situ red alders, imported redwood logs and rootwads, and imported boulders, to increase channel complexity, provide instream cover, improve sediment sorting, and encourage the formation of instream pool habitat along a sub-reach of low complexity. The construction of these instream wood complexes will take place on the left bank of lower Scotts Creek between $2650^{\circ}$ and $3050^{\circ}$ upstream from the CA-1 Bridge over Scotts Creek. The wood complex at $3050 \mathrm{w}$ il direct flow and maintain sediment transport through the proposed floodplain drain connection confluence area,

3. Remove a culvert and a portion of the left bank levee that currently limits connectivity between lower Scotts Creek and the floodplain at the location of an existing ag drain. The proposed grading will occur on the left bank and floodplain adjacent to Scotts Creek $3000^{\circ}$ upstream from the CA-1 Bridge crossing over Scotts Creek. The dimensions of the proposed grading are $35^{\prime}$ long by $28^{\prime}$ wide with a maximum depth of $5.5^{\prime}$ where the grading intersects the top of the existing historic levee. The proposed grading is expected to allow a backwater pool to form at or above winter baseflows at the reconfigured confluence area between lower Scotts Creek and the ag drain, providing off-channel refuge habitat for salmonids and additional benefits for other aquatic species. 
4. Excavate a connection between an existing floodplain scour feature and lower Queseria Creek (a tributary to lower Scotts Creek) to increase stream complexity and create additional alcove habitat for aquatic species. The existing scour feature, formed by floodwaters during past peak flow events, is approximately $30^{\prime}$ long by $20^{\prime}$ wide by $3^{\prime}$ deep. It is located on the floodplain approximately 30 ' northwest of the main channel of Queseria Creek, The proposed excavation will take place on the right bank of Queseria Creek approximately $100^{\prime}$ upstream along Queseria Creek from the confluence of Queseria and Scotts Creeks.

All work will occur in Scotts Creek or on the adjacent floodplain between 1500' and 3050' upstream from the California State Highway 1 Bridge over Scotts Creek.

The project is located in the Scotts Creek watershed, near Davenport Calfornia, in Santa Cruz County. The site is accessible from Swanton road, via an existing ranch access road, and proposed access pathways through the floodplain.

\section{Origin of Request}

The Resource Conservation District of Santa Cruz County (RCDSCC) has requested a design for a restoration project on Lower Scotts Creek, as a component of the Integrated Watershed Restoration Program (INRP), and in fulfillment of a restoration design funded by the California Coastal Conservancy.

\section{Description of Problem}

Historic land practices on the floodplain of lower Scotts Creek, are accepted to have impaired critical hydrologic processes and habitat conditions. The main channel of Lower Scotts Creek remains isolated from the floodplain by the construction of levees dating back to 1938 . The levee continues to limit the formation of wetlands and instream and off-channel habitat features for aquatic species, including refuge opportunities for ESA listed saimonids. Lower Scotts Creek is in a channelized state as a result of riparian encroachment and efforts to maximize agricultural land on the adjacent floodplain. Instream complexity remains low compared with upper reaches, limiting the availability of alcove refuge habitat and escape cover for salmonids. Channelization has likely increased main channel velocities over pre-agricultural levels, contributing to harsh instream conditions during storm flow events. Fisheries biologists speculate that harsh instream conditions combined vith a lack of refuge habitat are limiting salmonid production on lower Scotts Creek by increasing overwintering juvenile mortality. 


\section{Project Goals, Objectives and Benefits}

The National Marine Fisheries Service Coho Recovery Plan calls for "rehabilitat[ing] and enhance[ing] floodplain connectivity" by "encourag[ing] breaching of old levees in the lower riparian reaches of Scott Creek' and 'reclaim[ing] alcove and side channels for winter refugia and summer rearing" (NMFS 2012 [Final Plan], p. 924).

The proposed project is expected to remediate the negative impacts of historic land use practices for the benefit of ESA-listed saimonid species. The proposed levee breaches will increase floodplain connectivity which will is expected to provide floodplain refuge habitat and foraging opportunities during peak flows. Increased floodplain connectivity is also expected to reduce the potential for floodplain stranding by providing return flow paths back to the main channel as floodwaters recede.

The construction of instream wood complexes will increase channel complexity and instream refuge opportunities by encouraging the formation of scour pools and backwater pools. Instream wood complexes are also expected to improve sediment sorting, which may provide additional spawning habitat. In addition, these wood complexes will increase the frequency and amount of instream escape cover.

The creation of a backwater connection with an existing ag drain is expected to provide offchannel refuge habitat during storm flows, and provide additional benefits associated with increased floodplain connectivity. The connection between Scotts Creek and the ag drain will be maintained by an instream wood complex, constructed in the main channel of Scotts Creek just upstream from the ag drain confluence, and configured to focus flow through the confluence area. The focusing of streamflow through the confluence area is expected to maintain sediment transport and maintain the backwater connection between Scotts Creek and the off-channel feature formed by the ag drain. 


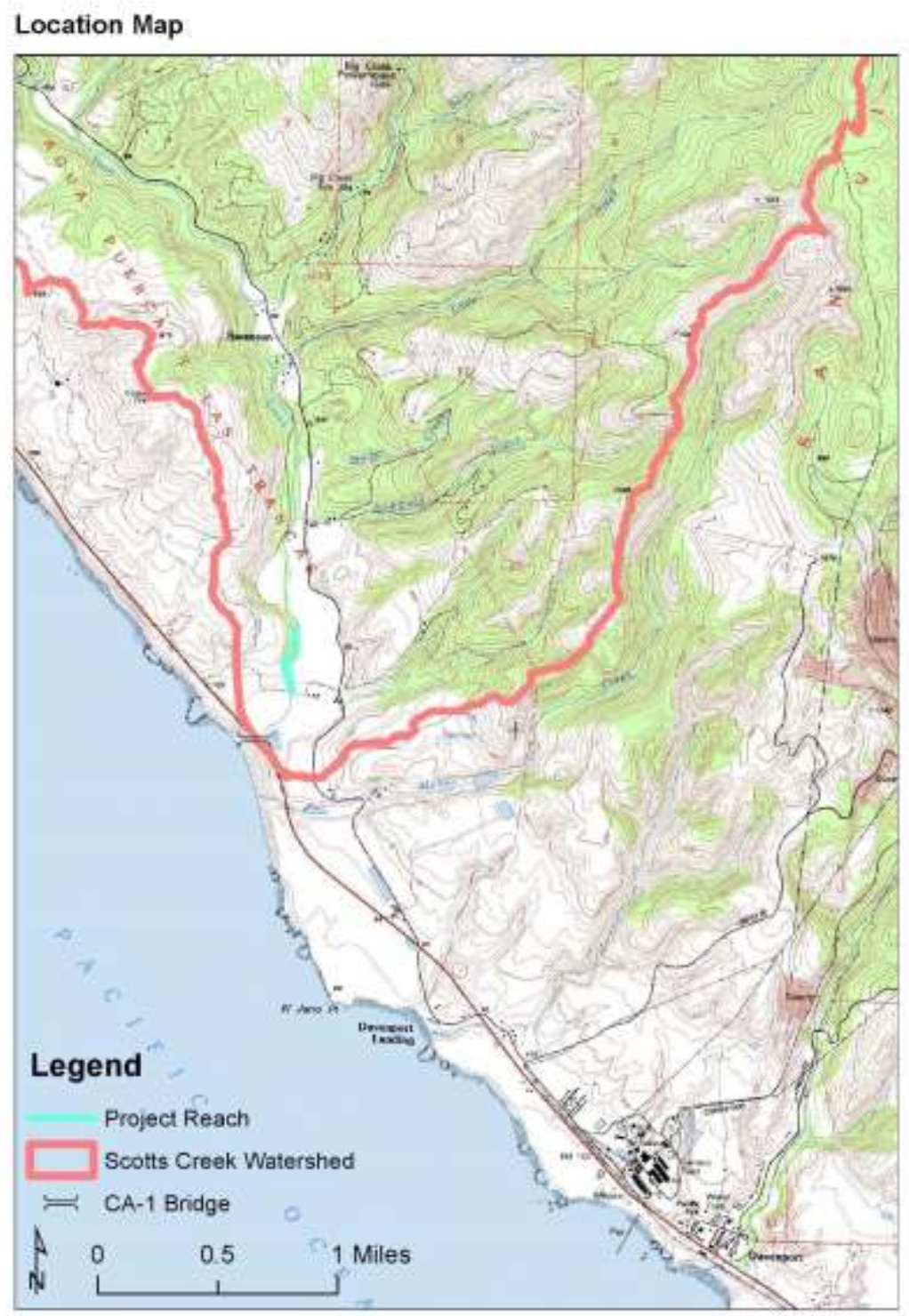

Figure 1. Location of the project reach on the USGS Davenport Topographic Map. 


\section{Alternatives}

The two primary altematives considered were:

1) Do nothing

2) Implement the proposed project

Alternative two was chosen based on the analysis and recommendations provided by the National Marine Fisheries Service Final Coho Recovery Plan, to address the loss of critical CCC coho ESU habitat, address the limiting factors in the Scotts Creek watershed, and prevent further decline of the species.

\section{Design Criteria}

The proposed design is in accordance with the following NRCS Design Standards:

Stream Habitat Improvement and Management (395)

Streambank and Shoreline Protection (580)

Fish and Wildlife Structure (734)

\section{Location}

The project is located on lower Scotts Creek, two miles north of Davenport, California, in Santa Cruz County (see Figure 1). The project reach spans from 1500-3050 feet upstream from the CA-1 Bridge over Scotts Creek. The project site is between 5 and 25 feet in elevation.

\section{Soils}

Soils data for the project area was obtained from the NRCS Web Soil Survey mapping tool. According to this data source, three types of soils may be present in the project area: Elder sandy loam (0-2\% slopes), Soquel loam (0-2\% slopes), and Eonnydoon-Rock outcrop complex (50-85\% slopes). The latter soil type likely applies to the steep cliff formation on the west side of the stream channel.

In general, the project reach flows on the western edge of a low, wide, alluvial floodplain. The present location of the main channel on the western edge of the floodplain is likely a result of channel and floodplain modifications related to agricultural practices dating back 200 years.

A Cal Poly faculty member and graduate student took soil samples at three locations within the project area on the levee on the east bank of the stream channel in the summer of 2013. The team identified all three samples as sandy loam. 
Soils data will inform staging, site access, excavation, backfill and revegetation methods related to the proposed project.

\section{Hydrology}

- Drainage area: 30.0 square miles

- Average annual precipitation: 40 inches

- The Santa Cruz County PCP specifies the 10 year storm event as the required design storm or $2500 \mathrm{cfs}$.

\section{Frequency Analysis}

M.C. Scrudato performed an extensive hydrologic analysis of the Scotts Creek watershed as part of his 2010 Master's thesis. Results from his analysis are summarized below.

Scrudato examined two potential stream gage locations for monitoring peak flow in lower Scotts Creek, near Davenport, CA, to determine the most suitable location for capturing peak flow measurements.

To facilitate this comparison, Scrudato conducted extensive flood frequency analysis of historic flow data using a Log-Pearson III Frequency Analysis. The U.S. Interagency Advisory Committee on Water Data (IACWD) recommends the Log-Pearson Type III analysis. "It is the standard method used by the USGS for flood studies" (Scrudato, 2010). The IACWD describes the procedure in Bulletin 178: Guidelines for Determining Flood Flow Frequency (1982).

Log-Pearson Type III Analysis is a statistical method for estimating the magnitude and recurrence interval for peak discharge events using a Log-Pearson type III frequency distribution. The frequency distribution is estimated from the mean, standard deviation, and skewness of historic data.

Bulletin 17B's procedure for calculating the skew coefficient is:

$$
\left.G s=(N /(N-1)) N-2) S^{3}\right) \sum_{i=1}^{N}\left(X_{i}-\bar{X}\right)^{3}
$$

Where

Gs=station's skew coefficient

$\mathrm{X}$ i=station's log-transformed annual peak discharge for year $\mathrm{i}$ 
$S=$ station's log-transformed standard deviation of annual peak discharges

$\mathrm{N}=$ station's number of years of peak discharge record

Data

Scrudato used historic peak flow data dating back to the 1930 's and recorded by the USGS at two gage stations on Scotts Creek. The data were adjusted to account for the difference in watershed area between the two gage stations.

Resuits

Scrudato estimated the 10 -year event at $2500 \mathrm{cfs}$, and the 100 -year event at $6520 \mathrm{cfs}$ for lower Scotts Creek. Results are discussed in detall in his thesis available at:

http://digitalcommons.calpoly.edutheses/330. 
Uaited states bepertmeat of $\Lambda$ gricultum

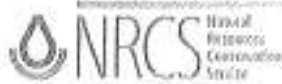

Kelli Camara-Lasher Program Manager

Resource Conservation District of Santa Cruz County

820 Bay Avenue, Suite 128

Capitola, CA 95010

Dear Kelli,

As required by the PCP, a hydraulic evaluation has been developed for the proposed installation of large wood material (LWM) within the main channel of Scotts Creek. The purpose of the LWM is to enhance habilat for Coho and other aquatic wildifie.

Based hydraulic modeling and field evaluation, installation of the proposed design will not cause a significant increase in the base flood elevation (BFE) or change channel velocity upstream, at or downstream of the project site. Adjacent struclures also will not be affected any differently than the current BFE as a result of the project. The flood plain is large, complex, and has a high roughness which effectively govorns water surface elevations for the BFE

Feel to contact me if you have any questions or comments.

Sincerely,

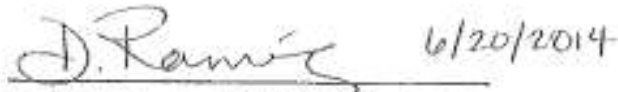

Desideria Ramirez, P.E. NRCS Area Engineer 
Modeling to Determine Hydraulic Design Parameters

Based on flow data from Scrudato, 2010, a HEC-RAS model of lower Scotts Creek was created to determine flow velocities, shear stresses, and depths in the project reach.

Model Validation

Steady flow modeling for lower Scotts Creek was performed for the December 23-24 2012 storm event in the Scotts Creek watershed. The stream gage at Archibald Creek recorded a peak flow depth of $7.02^{\prime}$, corresponding to an estimated discharge of $1908 \mathrm{cfs}$, derived from a rating curve developed for that gage station. These data, along with foughness estimates were used to parameterize the HEC RAS model. On a technical note, the model geometry was extracted from a digital elevation model (DEM) of the Scotts Creek watershed, using the HEC GeoRAS extension for ESRI ArcMap. The DEM was created from airborne LiDAR data, flown in March of 2010. The LiDAR reflected off of the surface of the water in the main channel, and does not represent the true channel bottom. Cal Poly's stream gage recorded a flow depth of $1.93^{\prime}$ at a discharge of $88 \mathrm{cfs}$ at the time of the LIDAR flight. Field observations indicate that depth readings at the gage location are representative of the project reach.

This flow event produced significant flooding, and the extents of the flooding were mapped using GPS following the event. The model results were compared to the GPS points and were found to be in close agreement (Figure 2). No adjustments were made to the model parameters to achieve this agreement. All initial estimations of roughness were maintained and default calculation methods were used. The model appears to have slightly overestimated the extent of flooding for most cross sections. 


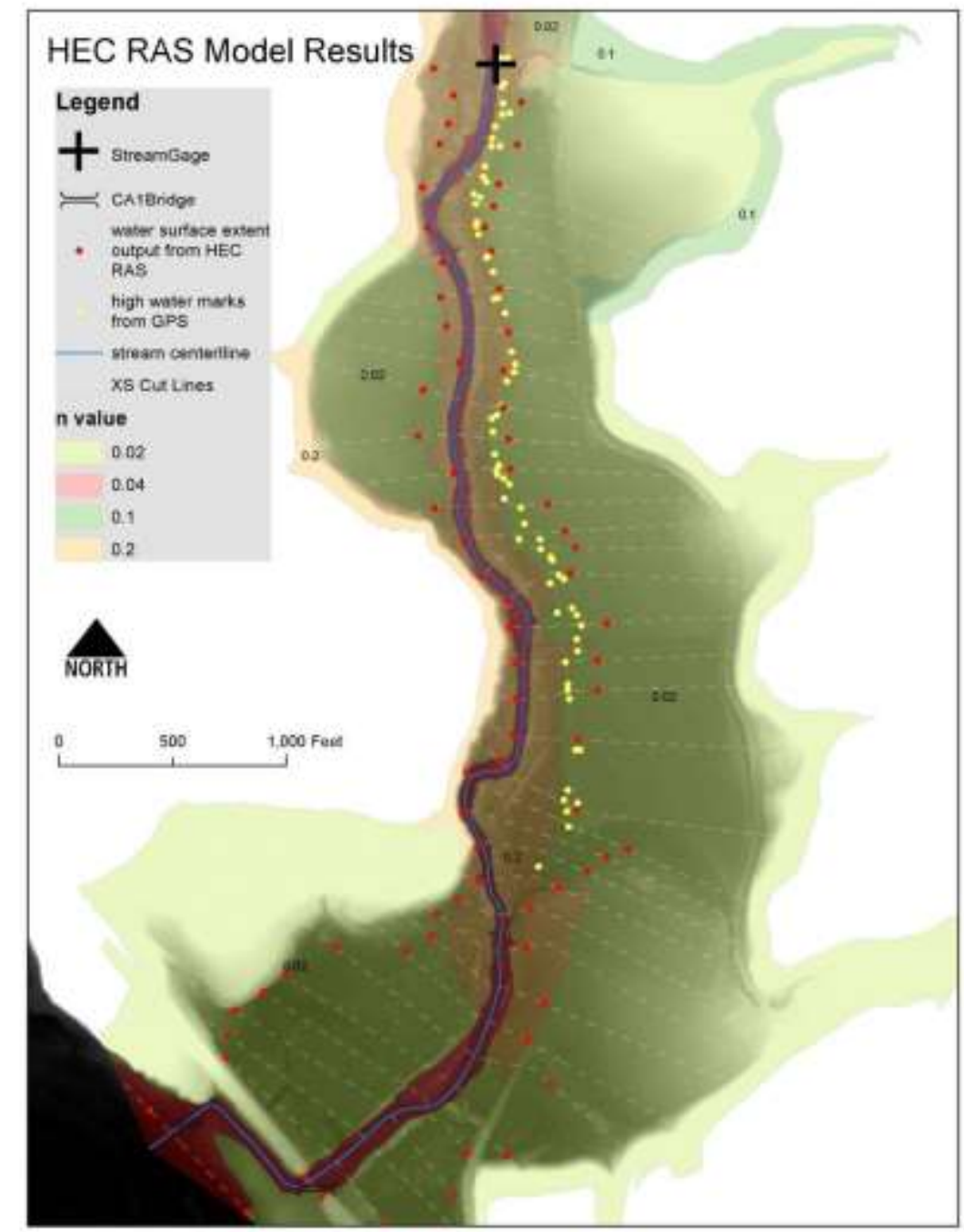

Figuve 2. HEC RAS model validation results for lower Scotts Creek comparing actual (yellow) to modeled (red) flood extents for the December 23-24 2012 storm event with a discharge of $1908 \mathrm{cfs}$. 


\section{Model Results for the 10-year Event}

For the 10-year event design storm flow, the average velocity was 5.2 fps with a peak velocity of $7.3 \mathrm{fps}$ in the project reach. The average shear stress was $0.84 \mathrm{lbs}^{2} \mathrm{t}^{2}$ and the maximum shear stress was $1.75 \mathrm{lbs} / \mathrm{ft}^{2}$. Hydraulic depth varied from 3.7 to 6.0 feet with an average of 4.9 feet.

These depths exceeded the bankfull depth. Figure 3 shows velocities, shear stresses, and hydraulic depths at each cross section within the project reach for the 10 year event.

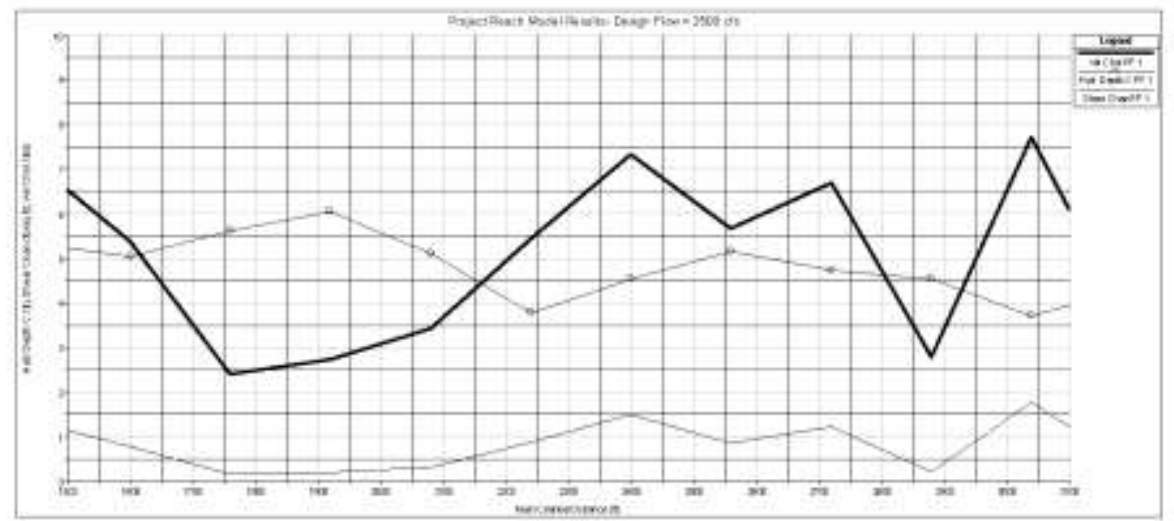

Figure 3. HEC RAS model results for velocity. hydrauhc depth, and shear, in the project reach at the cesign flow of 2500 cts

The model resulted in left and right overbank flow (Figure 4), Most of the flooding occurred on the left bank of the main channel. 


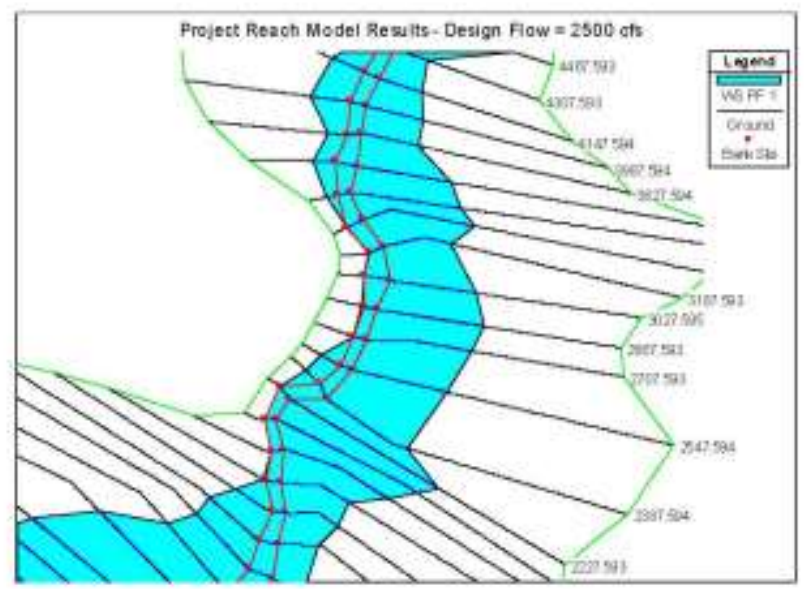

Figure 4. Water sufface extents on the lower Scolts Creek flocdplain. The bankfull channel is outlined in red. Flow is from top to bottom. Left overbank flow is on the right side of the plat.

Model Results for the 100-Year Event

For the 100-year event storm flow, the average velocity in the project reach was $5.96 \mathrm{fps}$ with a peak velocity of $10.4 \mathrm{fps}$ at station 1588 (not shown below). The average shear stress was 1.06 $\mathrm{lbs} / \mathrm{ft}^{2}$ and the maximum shear stress was $2.69 \mathrm{lbs} / \mathrm{ft}^{2}$. Hydraulic depth varied from 4.9 to 8.4 feet with an average of 6.8 feet. These depths exceeded the bankfull depth. Figure 5 shows velocities, shear stresses, and hydraulic depths at each cross section within the project reach for the 100 year event.

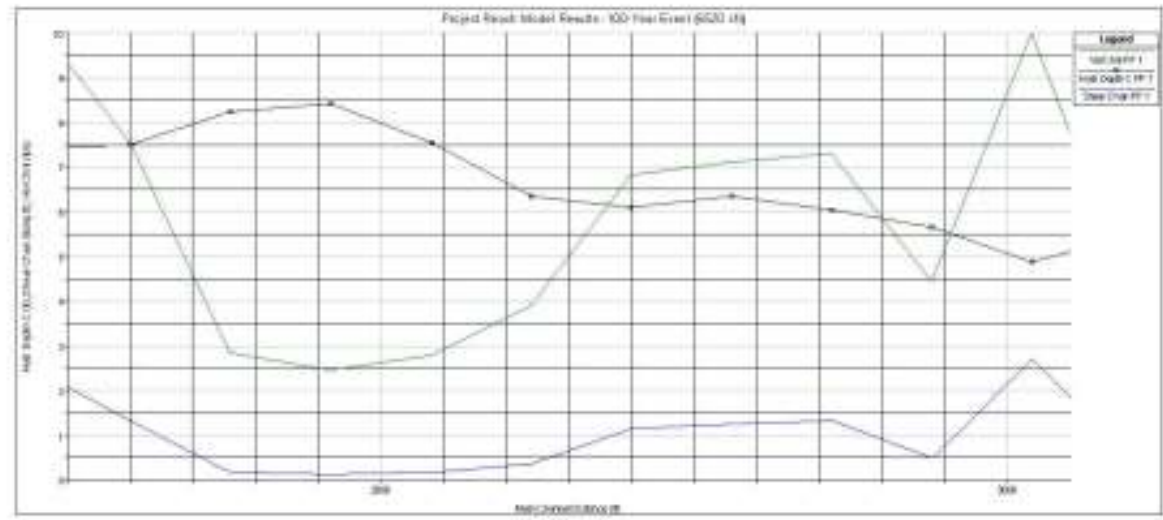


Figure 5 HEC RAS model resuits for velocity, hydraulic depth, and shear stress for the 100-year event.

The 100-year event model resulted in substantial overbank flooding, especially on the floodplain on the left bank (Figure 6).

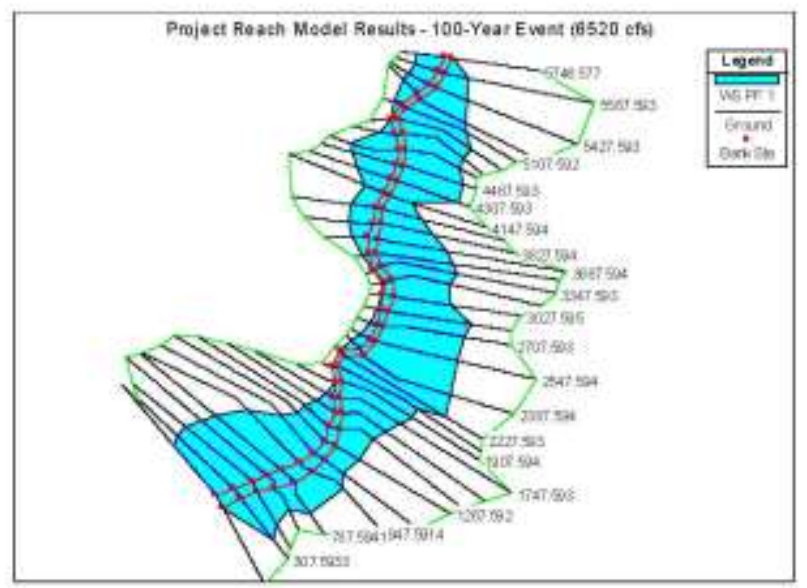

Figure 6. Overhead view plat of HEC RAS model water surface extents (bitie) for the 100-year event. Red Whes represent the main channel of Scotts Creekf Flow is from upper night to fower left. Flot shows lower Scotts Creek from CA-1 Brioge to approximatery 6000 feet upstream. Project reach is from station 1500 3100

Comparison of Pre- and Post-Project Flood Depths and Extents

Pre- and post- project conditions were modeled. The model results showed slight increases in water surface elevations, and slight decreases in channel velocities, resulting from the proposed project, for the 10-and 100-year events. Overall, the model indicates that the proposed project will not significantly increase flooding in the valley. For a detailed comparison of pre- and postproject flow conditions, see Modeling Results in the Appendix.

The December 2012 event, estimated to have a 5-year recurrence interval, overtopped portions of the deteriorating lovee and caused inundation of the lower floodplain, indicating that the levec is no longer effective in protecting the adjacent floodplain in its deteriorated state. The levee is expected to be overwhelmed during the 100 year event regardless of the proposed modifications.

Modeling results show that the majority of the discharge will be routed onto the left overbank flow path on the adjacent floodplain for the 100-year event, with total effective flow areas 
ranging from 1000-3500 square feet. Any instream structures will have a negligible effect on flooding, considering they will have cross-sectional areas on the order of 10 's of square feet.

Each instream wood complex was designed to obstruct no more than $50 \%$ of the low-flow channel. This was done in part to prevent the formation of hazardous debris jams spanning the entire bankfull width.

\section{Large Wood Complexes}

\section{Background}

In the summer of 2013, a Cal Poly graduate student conducted a physical habitat survey of 8 miles of the Scotts Creek mainstem (A. Brubaker, 2013, pending publication). Data on physical habitat conditions including residual pool depth, percent escape cover, and the presence of woody debris were recorded. A sub-reach of low channel complexity, and low quantity and frequency of woody debris within the proposed project reach was identified based on field observations and data from the physical habitat survey.

Remediation

The proposed project will remediate physical habitat conditions within this sub-reach by constructing instream large wood complexes to provide escape cover, pool habitat, and improve sediment sorting. Wood complexes will also function as "seed structures" by trapping entrained debris and forming collections of debris. In order to prevent debris jams from forming across the entire width of the channel, these wood structures will be designed to block no more than $50 \%$ of the width of the channel.

Conceptual Design

The conceptual design has been through several iterations, based in part on the designs of other local large wood projects that have been implemented in nearby coastal streams in the Santa Cruz Mountains.

Goals

The design concept has been refined to meet several design goals, including maximizing habitat benefit for salmonids and structure longevity, and minimizing cost, complexity, and riparian and instream disturbance. 
Recruitment of Live Alders

The concept aims to take advantage of the abundance of large alders growing on the banks of the project reach, by recruiting and incorporating them into the wood complexes and using them as anchors for the complexes.

Recruitment of live alders will be achieved by partially unearthing the rootmass and toppling the tive tree while keeping the largest roots intact, and then reburying the rootmass vith the excavated material, with zero net cutfill. The trees may then be laced into or lashed to other live alders, or bound to other structural and habitat elements such as redwood logs or boulder anchors.

The recruitment of live alders achieves several of the design goals. Most importantly, these live trees will provide a large, foliated instream habitat structures that will provide escape cover for salmonids, and facilitate pool formation and sediment sorting. Live alders are expected to cover significantly more stream area than a limbed log of the same length.

Partially unearthing the rootmass of live alders, toppling, and reburying requires only minimal excavation with no net cutffill, which will minimize disturbance and preclude other anchoring methods such as trenching that are associated with potentially higher levels of disturbance and possibly exporting spoils. In some cases, unearthing of the rootmass may be achieved using only hand tools, which would eliminate or reduce the need for heavy equipment in the riparian corridor.

Keeping the alders alive will increase the longevity of the structures by curtailing decay.

Taking advantage of these in-situ alders will also reduce the material costs and time required to construct these structures. Near-stream aiders have no material cost, but there will be a labor cost for unearthing and reburying the roots. The estimated volume of excavation needed to unearth the rootmass of a mature alder is 1 cubic yard.

A secondary effect of recruiting live, near-stream aiders is to increase sunlight penetration to the riparian zone. Recruitment is not expected to significantly impact sunlight penetration overall within the project reach, however localized increases may occur.

Flexible anchors

Flexible anchors have several advantages over fixed anchors. The first is that floxible anchors will allow the structure to move above the bedload, and help prevent the structure from becoming buried by sediment. A second advantage is that under extreme conditions, the 
structure can move to pass debris jams or debris flows that would otherwise cause the structure to fail. Flexible anchoring will be used in combination with live, standing tree anchors, to provide a pivot point that will allow the structure to rotate around the trunk of the live tree (see paragraph below).

Live Standing or Toppled Tree Anchor Points

Another central design concept is to use five, standing alders as anchors for the large wood complexes. This anchoring technique is outlined in ERDC TN-EMRRP-SR-13 (2000). This project is designed to be a category 2 project under ERDC guidelines, with flexible anchors that will allow the structures to move, described in Saldi-Caromile ef al, 2004.

Toppled trees with roots left intact vill provide some level of anchoring, due to the strength of the roots, the weight of the rootmass, and confinement provided by the soil around the rootmass.

\section{Large Wood Complex Concept}

Each large wood complex will be constructed from one redwood log, one boulder, one redwood rootwad, one toppled in-situ alder, and two live standing alders located on the left bank. One end of the rectwood log will be anchored to the streambed by the boulder, and the other end will be braced against the trunk of the upstream live standing alders. The live toppled alder will be pinned beneath the redwood log and braced against the trunk of the downstream live standing alder. The redvrood rootwad will be attached to the mid-point of the redwood log.

The redwood log, toppled alder, and redwood rootwad vill be located to provide instream cover and facilitate scour within the active channel. The structure will be functional whenever flow is present. The toppled alder will provide cover over the zone of scour that is expected to form around the redwood rootwad.

Alders will be toppled by excavating portions of the rootmass while leaving large hinge roots intact. The alder will pivot around the hinge material as it is toppled, similar to the way a tree falls around hinge material created by the face- and back-cuts during felling. The intent of toppling is to keep the alder alive and anchored to the stream bank.

The end of the log that is located on the streambank will be free to float. The rootwad attached near the log's midpoint will be free to float with the log as well. Allowing these structural elements to float will prevent them from becoming buried under sediment. 
The joint that attaches the redwood log to the boulder will be flexible in order to allow the log to float. The redwood $\log$ will be attached to the boulder by a joint that allows the log to pivot as the free end floats up and down with changes in stage. This joint will be achieved using two eye bolts linked together by a quick link. One eyebolt will be epoxied into a slip fit bore hole in the boulder, and the other eyebolt will be fastened by drilling a clearance fit through hole in the redwood log and securing the eyebolt with a nut and washer. Shouldered eyebolts or shoulder washers will be used to prevent the eyebolt from pulling through the log, and to prevent bending at the head of the bolt.

The boulder will opposed the drag and buoyant forces on the structure. The veight of the boulder will ballast the buoyant forces, and the boulder, when partially buried in the bed substrate, will act as a thrust block to oppose the drag forces. The boulder must weigh 3 tons to overcome the buoyant force with a safety factor of 1.5 . The boulder must be embedded 2 feet to oppose the drag force with a safety factor of 2 .

The redwood rootwad does not necessarily have to be attached to the midpoint of the redwood $\log$. If the rootwad is attached to the log nearer to the boulder, the ballast must be increased proportional to the distance the attachment point is moved.

The axis of the joint between the redwood log and boulder should be perpendicular to the centerline of the redwood log so that the joint because the redwood log will tend to pivot around the upstream alder trunk. and parallel to the Anchor bolts should be set in the structural materials so that their axes are in line with the direction of flow because the drag force is expected to be dominant.

\section{Live-Tree Anchor Strength Calculation}

One or more live standing alder trees located on the left bank of lower Scotts Creek will be utilized as anchor points for each instream large wood complexes. The large wood complex vill be attached to the tree trunk as low as possible (at ground level) to minimize the torsional shear force between the root ball and surrounding soil. The assumed failure mode of a five standing tree will be lateral shear between the root ball and surrounding soil. The lateral shear force will be produced by the tractive force of the submerged large wood complex applied to the tree trunk just above the root ball. The tractive force will be applied close enough to the center of mass of the root ball to be modeled as a lateral rather than a torsional force.

The effective area provided by the root ball was multiplied by the shear strength of the surrounding soil to calculate the strength of the live standing tree anchor. The root ball is 
assumed to be hemispherical with a semicircular effective area equal to one half the square of the root ball's radius times pi. The root ball's radius is assumed to be $40^{\prime \prime}$ which is one half of the standard root ball diameter listed in ANSI Z60,1-2004 for an upright field-grown tree with a caliper of $8^{*}$. The lateral shear strength of a single live standing alder is then estimated to be 52 kips. The tractive force of a typical large wood complex is estimated to be 10 kips. The anchoring strength of a single live standing alder is calculated to be sufficient to anchor a typical large nood complex, with a safety factor of 5 . Please see table 1 below.

\section{Log Ballast Calculations}

\section{Redwood Logs and Rootwads}

Individual logs will be no larger than 30 feet in length with an average diameter of 1.5 feet.

Anchoring requirements were calculated based on the guidelines in NRCS Technical Supplement 14E. A variation from TS 14E was incorporated into the anchoring calculations, following the example of the NRCS San Vicente LWM Engineering Docket (Ruttenberg, 2011). Instead of computing the sum of the buoyant force and the drag force as recommended by TS $14 \mathrm{E}$, the two forces were assumed to be perpendicular to one another, with the total force equal to the square root of the sum of the squares of the individual forces:

$$
F_{\text {totat }}=\sqrt{F_{d r a g}^{2}+F_{\text {buoyant }}^{2}}
$$

With a safety factor of 1.5 , each redwood log is required to have an anchoring force of $5950 \mathrm{lbs}$. This variation was maintained for all anchoring calculations below.

Redwood rootwads were modeled as simple spheres, with a diameter of 5 feet, sharing the same bulk material properties with redwood logs. Each rootwad will require an anchoring force of $4131 \mathrm{lbs}$.

\section{Live Alders}

The buoyant force was calculated by estimating the weight of the entire tree using the Jenkins method described in PNW-RP-584 published by the United States Forest Service Pacific Southwest Research Station. The method estimates aboveground biomass on DBH alone and applies to hardwood and softwood species nationally. The table of parameters given for the Jenkins method did not include alder. For the purpose of this estimate, parameters for aspen/cottonwoodiwillow were used. Using a DBH of 1.25 , the Jenkins method gives a total 
aboveground biomass of $651 \mathrm{~kg}$. This value was used to back-calculate a buoyant force of 1149 lbs for live aider.

Live alders were assumed to have a conical shape for the purpose of calculating drag forces, giving them a triangular drag profile that was calculated by multiplying the radius of the crowm by the height. The drag force was calculated to be $5695 \mathrm{lbs}$. The total force required to anchor a tive alder was calculated to be $8715 \mathrm{lbs}$. 


\section{Calculation Spreadsheet}

Table 1. Spreadsheet of LWC calculations.

\begin{tabular}{|c|c|c|c|c|}
\hline Structuratiemant & Beewood ting & Hedwone Hoctwas & Wve Aiser iGceenl & Bownte \\
\hline $\operatorname{shape}$ & Cylinser: & Sohere & cyinder (trunkiony) & cube \\
\hline Eneth (fort) & \multicolumn{2}{|c|}{$\infty$} & \multicolumn{2}{|c|}{ os } \\
\hline Averget Diameses (teet) & \multicolumn{2}{|c|}{179} & \multicolumn{2}{|l|}{ 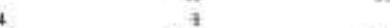 } \\
\hline Voume $(n)^{\prime}$ ) & \multicolumn{2}{|c|}{$722^{\circ}$} & 31.4 & 429 \\
\hline $5 \mathrm{pec}$ Gan. Dry & \multicolumn{2}{|c|}{05} & $\theta \neq x$ & 2.7 \\
\hline Modsum Conent & \multicolumn{2}{|c|}{0.12} & 05 & 0 \\
\hline Unt we nad I & \multicolumn{2}{|c|}{$62 \mathrm{a}$} & $62+$ & 624 \\
\hline Unt Weight (1) boitt's & \multicolumn{2}{|c|}{24} & w5 & 160 \\
\hline Weiguifias) & \multicolumn{2}{|c|}{ 175 } & 2068 & 7224 \\
\hline 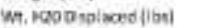 & \multicolumn{2}{|c|}{ งล83 } & 7960 & 2675 \\
\hline \multirow{2}{*}{ Auopast Feree (Uts) } & \multirow{2}{*}{\multicolumn{4}{|c|}{ 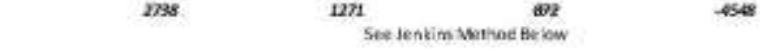 }} \\
\hline & & & & \\
\hline Dras fereu Calatiations & Draeforce an Leg & Draf forte as hootwa & Dreforas an Live Ader & Orag farte an Boulde \\
\hline ATEa $\mid$ trit| = LXD & \multicolumn{2}{|c|}{283} & 256 & 12.3 \\
\hline Ansie (Degrees) & \multicolumn{2}{|c|}{$90 \mathrm{~N} / \mathrm{A}$} & 50 & \\
\hline Elfective Arex $\left\{\mathrm{H}^{2}\right\rangle$ & \multicolumn{2}{|c|}{$525^{\circ}$} & 2560 & 12.3 \\
\hline Venocityit/s & \multicolumn{2}{|c|}{73} & 73 & 23 \\
\hline Desra factar D(1ebed s) & \multicolumn{2}{|c|}{15} & 2.5 & 1.5 \\
\hline Fermesality factures & \multirow{2}{*}{\multicolumn{2}{|c|}{3}} & es & \\
\hline Drag force & & & 9000 & 930 \\
\hline
\end{tabular}

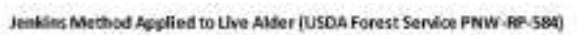

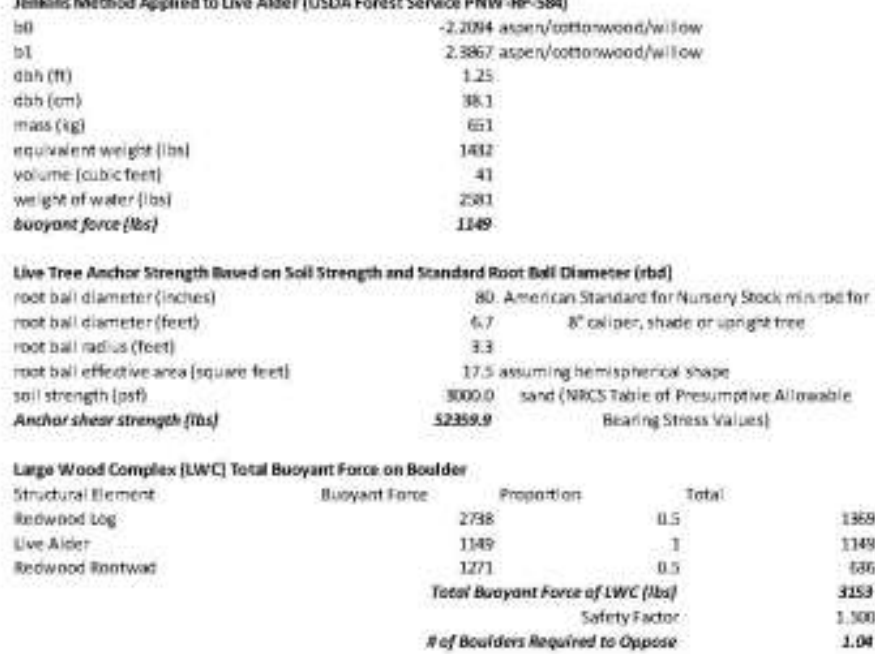

Lage Wood Complex ILW C Total Deas force on Bodider

Strodutai Eamers Drefare (tas)

Strocturai Eament

Beowood $\mathrm{Ve}$

tive Alcer

AeOw ood Nootwa: Dres fare (tas)

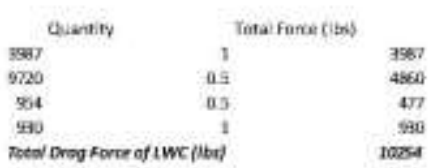




\begin{tabular}{|c|c|c|}
\hline \multicolumn{3}{|l|}{ Parres on Bouldar - Log joimt } \\
\hline Buopart force & 3253 & \\
\hline Drieg fera & jases & \\
\hline Sum of Component Force: & wans & \\
\hline Safect Factor & 2 & \\
\hline Strength of toulder - 100 . & nass & \\
\hline \multicolumn{3}{|l|}{ Tatal Tonnege of Hock Nequired for Project } \\
\hline A of balastes lwCHe tur & 4 & \\
\hline A of Boulders per fearure & 1 & \\
\hline Weight of tach Basider (t & 361 & \\
\hline Total Toesuge & $\$ 4.65$ & \\
\hline \multicolumn{3}{|l|}{ Thrust Biock Calculation for Boulder } \\
\hline Tond Drages os i We in Dire, & 30254 & \\
\hline 5oi 5trecth (ast) & 3000 sant & \\
\hline Thuse Block Areaist & 3.42 & \\
\hline Salow factar & 20 & \\
\hline Dopth of acoider to Opso & 255 & \\
\hline Dspizaiment $\langle d\}$ & 24 & \\
\hline Daviacement $\langle\varphi\rangle$ & 699 & \\
\hline onbeuleer & onrex: & \\
\hline \multirow[b]{2}{*}{ Anged of favererer Axstio } & $x \approx$ & $a \pi$ \\
\hline & s & $\leq$ \\
\hline Log-Bouker & 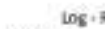 & \\
\hline 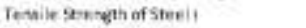 & $\sin x=$ & 60000 \\
\hline Strengtiof of int (las) & 21496 & 3179 \\
\hline $\begin{array}{l}\text { Cossisedional area of } 52 \\
\text { Mimum plometer of } f c^{2}\end{array}$ & 0758 : & 00043 \\
\hline \multicolumn{3}{|c|}{ 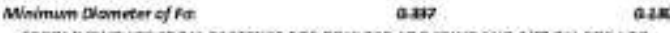 } \\
\hline \multicolumn{3}{|c|}{ 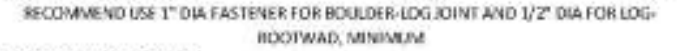 } \\
\hline \multicolumn{3}{|c|}{ Epoory bint Strength Calc } \\
\hline Sirengh of wint & 21456 & \\
\hline Mrimum Shear Steqest & 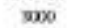 & \\
\hline Surface tecos (sa in) & 7.152 & \\
\hline Diamere- of fastenet & 1000 & \\
\hline Minimum Desth of intert & उस्न & \\
\hline
\end{tabular}

\section{Breach Opening Hydraulic Calculations}

Design Concept

The main driver for velocity through the levee breach openings is the hydraulic head between the main channel and the floodplain that develops during stormflow. In an extreme case, water surface elevations in the main channel rise above the elevation of the adjacent floodplain, until the levee is overtopped. When the levee is overtopped, the water pours over the levee due to the development of potential energy.

The proposed project will remediate this situation by connecting the floodplain to the main channel at the elevation of the adjacent floodplain, at five locations. These connections will be level, trapezoidal channels and will be revegetated with several species including native rushes 
(juncus) and groundcover. These connections will reduce the development of a potential energy gradient.

An energy gradient will develop as the water surface in the main channel rises above the elevation of the floodplain. This energy gradient will drive a lateral outflow through the breach openings, which will begin to inundate the floodplain. The breaches are designed to allow the floodplain to fill at the same rate as the main channel on the rising limb of a representative stormflow hydrograph. The hydraulic head between the main channel and floodplain will not continue to increase once the head reaches 0.25 feet at a velocity of $4 \mathrm{fps}$, because the lateral discharge will cause the water surface elevations on the floodplain to equilibrate with the main channel.

The geometry of the breaches may adjust over time, due to variations in storm hydrographs. If the flow in the main channel rises faster than the design hydrograph, an energy gradient may develop and increase velocities through the breach openings. Increased velocities may scour and enlarge the openings, allowing the floodplain to equilibrate with the main channel.

The lower drain effectively constitutes a breach in the levee that accesses the same storage area, and will further increase the lateral discharge and maintain hydraulic equilibrium between the main channel and floodplain.

\section{Calculation Summary}

The breaches were sized to allow the floodplain storage area to fill at the same rate as the main channel on the rising limb of the Q10 (2500 cfs) event. The actual hydrograph used was for the December 23-24 2012 storm event, which is estimated to be a $Q 5$ event. The max stage was 7 and peak discharge was $1908 \mathrm{cfs}$, estimated by a rating curve. Significant flooding occurred over the left bank on the floodplain of lower Scotts Creek. Observed debris racking indicated flood depths of two feet on the floodplain adjacent to the stream channel. The stroam rose from bankfull to maximum depth in 3 hours.

The estimated floodplain storage capacity at a floodplain depth of $2^{\prime}$ is 800000 cubic feet. A lateral outflow from Scotts Creek of 800000 cubic feet over 3 hours would require an average flow rate of $74 \mathrm{cfs}$. At this rate, the floodplain would fill at approximately the same rate as the main channel, and no hydraulic head would develop.

NRCS Practice Standard 840 "Grass-Lined Channer' specifies 4 fps as the maximum allowable velocity for a grass-lined channel vegetated with a grass-legume mixture (Table 1). Using the 
energy equation, the maximum allowable head is 0.25 feet to keep the velocity below 4 fps, assuming critical flow.

The effective flow area needed to pass $74 \mathrm{cfs}$ at $4 \mathrm{fps}$ is 18.5 square feet. A lateral outflow with an effective flow area of 18.5 square feet and a head of 0.25 feet would need to be 74.5 feet in length, Routing the flow through 5 breach openings gives a channel bottom width of 15 feet for each breach. Since the channel sides are sloped $2 \mathrm{H}: 1 \mathrm{~V}$, the actual velocity through the breach openings is expected to be lower than calculated, due to the increased cross-sectional area.

\section{Calculation Spreadsheet}

Table 2 Spreactsheet of caiculations related to the levee breaches

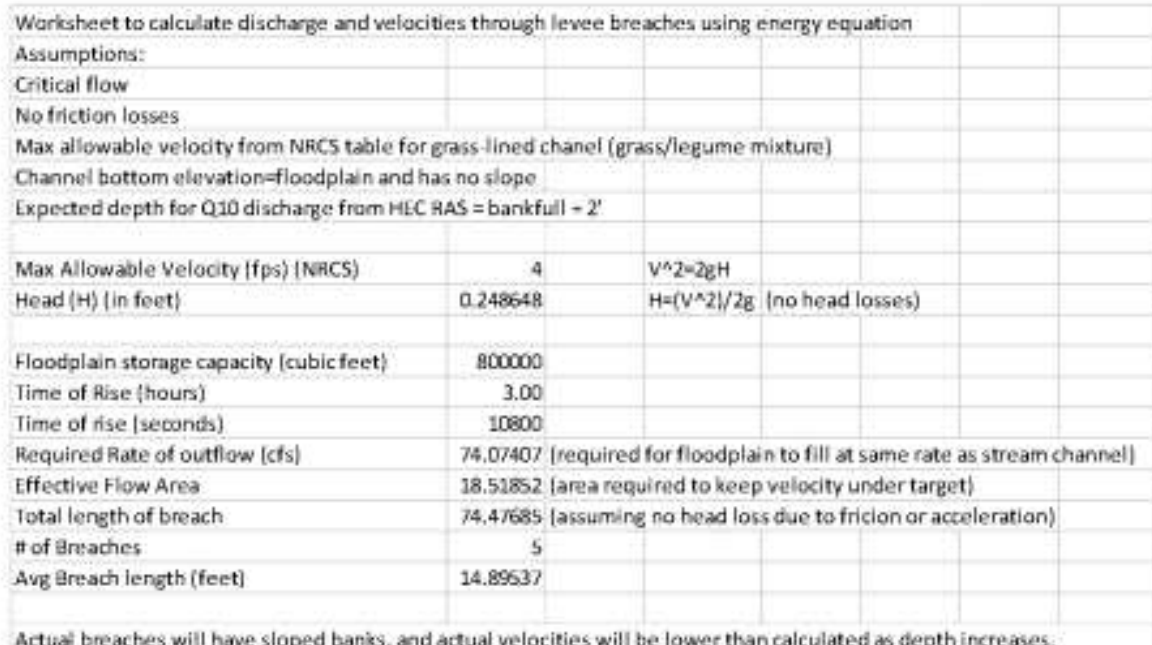

Actuat breaches will have sloped banis, and actual velocities will be lower than calculated as depth increases. 
Lower Scotts Creek Revegetation Plant Palette

\begin{tabular}{|c|c|c|c|}
\hline Commen Name & Species & Function & Loostion \\
\hline \multicolumn{4}{|l|}{ Trees } \\
\hline Box Elder & Acer negunds & ss, s, C & RC \\
\hline Fed Auder & Alows nors: & ss, s, & $\mathrm{RC}$ \\
\hline Fed Bewiberny & Sambuazas racemose var, racemosa & ss, s, C & RC. \\
\hline Buve Eldertbeny & Sambucus niga mubap caenilea & s5, s. C & AC \\
\hline Shiring willow & Sabx lasiandha var, laniandra & $5 s, 5, c$ & EP, $A C$ \\
\hline Artoge wilow & SaEr hasiolopit & ss, 5, c & $F P, R C$ \\
\hline Creet Dogwood & Comis senceea & ss, s, C & $F P, R C$ \\
\hline \multicolumn{4}{|l|}{ Emaven } \\
\hline Meardiess wid rye & Eyman fthoodes & EC & $A C$ \\
\hline \multicolumn{4}{|l|}{ Busties } \\
\hline Brown nush & Ancula hesperivas & SS, EC & FPA \\
\hline Spreading nesh & huncwa paters & ss, EC & FPA \\
\hline Bacifio nash & Ancus eftumus subep, pacheire & sS, tec & FPA \\
\hline \multicolumn{4}{|l|}{ Sedoen } \\
\hline Blyeat sedge & Corex anyifrobla & SS, EO & FPA \\
\hline Barterpole sedge & Solvpus microcispus & SS, EC & FP, RC \\
\hline Openus & Cypenas eragroutio & SS, EC & FP, RC \\
\hline Slowgh sudpe & Cavax oenuph & SS, EC & $F P, R C$ \\
\hline \multicolumn{4}{|l|}{ Shnde } \\
\hline Salmonberry & Rueves apectabils & EC & $A C$ \\
\hline Bischbery & Fubue urante & EC & AC \\
\hline Thimbiabery & Ratus pariforus & EC & RC \\
\hline Woodlend stambery & Fragaria weoca & EC & $R C$ \\
\hline Stragoty pocsebery & Rbeo dharicatum vas, pubiflonum & EC & $\mathrm{AC}$ \\
\hline Callomia tose & Rosa cablomica & EC & $R C$ \\
\hline Callomia hedge-nette & Stachya bulata & EC & RC \\
\hline American stinging nettle & Untica diolica acibega. & EC & RC: \\
\hline Caltomia flewart & Sornphudaria colitomico & EC & $\mathrm{AC}$ \\
\hline Douglas nigteshade & Solenim dougiasi: & EC & $\mathrm{RC}$ \\
\hline Golden yarmow & Ellophylim contursionum & EC & $R C$ \\
\hline \multicolumn{4}{|l|}{ Eema } \\
\hline Lady term & Athymum fete-temina ver eyclosorum & EC & $\mathrm{AC}$ \\
\hline Giant chain fem. & Woodwarta fimbrials & EC & RC \\
\hline Sevonf fem & Folyatichim manitum & EC & $R C$ \\
\hline \multicolumn{4}{|l|}{ Hentas } \\
\hline Commen yartow & Achilba milefolim & EC & $\mathrm{AC}$ \\
\hline \multicolumn{4}{|l|}{ Ner } \\
\hline SS - sol atabikrabion & $R C=$ rvpantan comidor & & \\
\hline EC = erotion control & FP = foodplain & & \\
\hline$S=$ athade & $F F / A=$ loodpresen area & & \\
\hline$c$ roover & & & \\
\hline
\end{tabular}




\section{ENGINEER'S QUANTITY AND COST ESTIMATE}

\begin{tabular}{|c|c|c|c|c|c|c|c|c|c|c|c|c|c|}
\hline \multicolumn{14}{|c|}{ 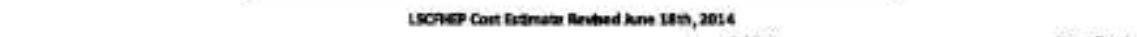 } \\
\hline $\tan$ & Unts & \multicolumn{2}{|r|}{ unitrice } & \multirow[t]{2}{*}{ atuine } & \multicolumn{3}{|c|}{ Toraicont } & \multirow[t]{2}{*}{ 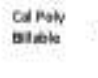 } & \multirow{2}{*}{\multicolumn{2}{|c|}{ Car Petp weth }} & Conerator ad & \multicolumn{2}{|c|}{ 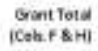 } \\
\hline \multicolumn{10}{|l|}{ Persened } & & & & \\
\hline 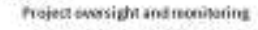 & teens & s & 2000 & 500 & s & to, 000000 & $s$ & 10,00000 & & & & s & 10,0000 \\
\hline \multirow[t]{2}{*}{ Alministuaton and opersight } & hoes: & s & 5600 & 200 & $\mathrm{~s}$ & to.10000 & & & $\$$ & 1008050 & & 5 & \\
\hline & & & & & & & & & & & & 5 & \\
\hline Motilisaten/Lamutilimatom & lentisum & $\$$ & s,obivo & 1 & $s$ & $\$, 00000$ & & & & & s,onese & $\$$ & simoso \\
\hline Cesring/Gobtire & lanessim & 5 & 300000 & 1 & s & 2.00000 & & & & & 300000 & 5 & 300000 \\
\hline Davilop Aatrss. & 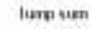 & 3 & 3000.00 & 1 & 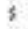 & 2,00000 & & & & & 300000 & 5 & 3,100000 \\
\hline Leculisotidewatering & pes sin & $s$ & 1000.60 & s & 5 & 5,00000 & & & & & 500000 & 5 & 500000 \\
\hline Exration & citicyards & \$ & 2600 & 796 & $\$$ & 15,90000 & & & & & $\$ 1592000$ & s & 1592000 \\
\hline installiwo & & & & & & & & & & & & $s$ & \\
\hline Sodkditivered & $\tan$ & s & 33.42 & is & 5 & 1.25130 & & & & & 125130 & $s$ & 1.251200 \\
\hline Hanowarck, detiuened & fost wad & 5 & 30000 & I & s & $\sin n 0_{0}$ & $s$ & $2800 \mathrm{~m}$ & 5 & 2,00000 & & 5 & 2 moan \\
\hline torat Hetheod toge, dotiveral & bot & s & 800.00 & - & s & 5,00090 & s & 6,400100 & & & & $s$ & 6.90000 \\
\hline Actowirg Mewrixt & Iues sum & 3 & 250000 & 1 & 5 & $2 \sin 00$ & & & & & 250000 & $s$ & 2,50600 \\
\hline \multirow[t]{2}{*}{ mbalisoor } & per vasctury & $s$ & smo.en & 4 & $s$ & 70, roman an & & & & & 5. 20 mose & 5 & somoon \\
\hline & & & & & & & & & & & & s & \\
\hline Ensien Contas & leap sign & & & & & & & & & & & $s$ & \\
\hline Bonums conerof nateriats & & 8 & 100000 & 1 & 5 & 1,100000 & 5 & $1, \mathrm{pmm} \mathrm{m}$ & & & & 5 & tmoso \\
\hline Goven conrol insathation & & s & 200000 & 1 & 5 & $2,000.00$ & & & $\$$ & $2,000,00$ & & $s$ & \\
\hline Armpasan & & & & & & & & & & & & 3 & \\
\hline Indignsis piant natariah. & per flant & 5 & 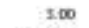 & 2500 & 5 & $x, 50000$ & $\$$ & $x, 500 \mathrm{~mm}$ & & & & $\$$ & 7,50000 \\
\hline Hareinstalation & Lapsim & 8 & 300600 & 1 & 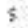 & $3,000,90$ & & & s & 3900000 & & s & \\
\hline Aant rainivioner & Іаяч & 5 & 1500.00 & 1 & 5 & 3,50006 & & & s & 130000 & & s & \\
\hline rones. & & & & & & $\sin , a z=90$ & 3 & 20,20000 & 3 & 18,5atac & \& $95,071=50$. & 5 & $02,5 \pi 1.90$ \\
\hline
\end{tabular}




\section{BID SCHEDULE}

Participant: Resource Conservation District of Santa Cruz County

Project: Lower Scotts Creek Floodplain and Habitat Enhancement

LSCFHEP Bid Schedule Revised June 18th, 2014

\begin{tabular}{|c|c|c|c|c|c|}
\hline Item & Units & Unit Prike & $\#$ of Units & & Cost \\
\hline Mobilization/Detrobilization & Iump sum & & 1 & $\$$ & \\
\hline Clearing/Grubbing & lump sum & & 1 & $\$$ & \\
\hline Develop Access & Iump sum & & 1 & \$ & \\
\hline Localized Dewatering & per site & & 5 & s & \\
\hline Excavation & cubic yards & & 796 & $\$$ & \\
\hline \multicolumn{6}{|l|}{ Install LWD } \\
\hline Rock, delivered & ton & & 15 & $\$$ & \\
\hline Rootwads, delivered & root wad & $N / A$ & N/A & & $N / A$ \\
\hline Local Redwood Logs, delivered & $\log$ & N/A & N/A & & N/A \\
\hline Achoring Materials & Iump sum & & 1 & $\$$ & \\
\hline Installation & per structure. & & 4 & 5 & \\
\hline
\end{tabular}




\section{Construction}

All construction shall adhere to the drawings and specifications. All instream wood complexes shall be constructed according to anchoring calculations described in this report.

Staging for construction will occur at the locations specfiled on the design drawings. The proposed project may be implemented concurrently with a land-levelling project that will utilize the spolis from the proposed gradings. Coordination betwoen potential projects will be outlinod prior to construction, and may be a requirement of implementation. No heavy equipment will cross the stream during construction. All construction requiring heavy equipment will occur on the east bank of the stream channel. Workers may be required to cross the stream on foot, If foot traffic is expected to cross the stream, crossing areas will be cleared beforehand by a qualified biologist.

\section{Maintenance}

As part of the PIR program for Santa Cruz County, the RCD SCC will monitor the project on an annual basis and report on progress and changes for five years after completion of construction. This also includes photo documentation of site progress. The RCD SCC will advise and assist the land owner with project status and any possible maintenance.

\section{References}

Fischenich, J.C., and Morrow, J.V. Jr. 1999. Streambank habitat enhancement with large woody debris. EMRRP Technical Notes Collection (ERDC TN-EMRRP-SR-13), U.S. Army Engineer Research and Development Center, Vicksburg, MS.

Flosi, G., Downie, S., Hopelain, J., Bird, M., Coey, R., Collins, B. 2010. Calfornia salmonid stream habitat restoration manual, $4^{\text {th }}$ edition. California Department of Fish and Wildlife, Widlife and Fisheries Division. Sacramento, California.

National Engineering Handbook, Part 654, Stream Restoration Design Handbook, The Use and Design of Soil Anchors (TS 14E), Use of Large Woody material for Habitat and Bank Protection (TS 14J). USDA Natural Resources Conservation Service, August 2007.

Scrudato, M.C. 2010. Comparison of two potential streamgage locations on Scott Creek at Swanton Pacific Ranch, California. Master's thesis, California Polytechnic State University, San Luis Obispo. 
Saldi-Caromile, K., Bates, K., Skidmore, P., Barenti, J., Pineo, D. 2004. Stream habitat restoration guidelines: Final draft. Co-published by the Washington Department of Fish and Widlife and Ecology and the U.S. Fish and Wildile Service. Olympia, Washington

Zhou, X., and Hemstrom, M.A. 2009. Estimating aboveground tree biomass on forest land in the Pacific Northwest a comparison of approaches. Research Paper PNW-RP-584. Portland,

Oregon: United States Department of Agriculture, Forest Service, Pacific Southwest Research Station. $18 \mathrm{p}$. 


\section{APPROVAL SHEET}

\section{ENGINEERING JOB CLASSIFICATION}

The controlling classification factors for Streambank and Shoreline Protection (580) are as follows:

1. Design Capacily is $2,500 \mathrm{cfs}$. $(2,000 \mathrm{cfs}<2500 \mathrm{cfs}<5,000 \mathrm{cfs}) \rightarrow$ Class 5

2. Drainage area is 30 square mites. $\{(50$ sqmi $<30$ sqmi $<75$ sqmi $) \rightarrow$ Class 3

3. Channel Depth (low bank) is a maximum of 6 feet. $\left(5^{\prime}<6^{\prime}<8^{\prime}\right) \rightarrow$ Class 4

4. Design Velocity is $7,3 \mathrm{fps},(7,3 \mathrm{fps}<10 \mathrm{f \rho s}) \rightarrow$ Class 5

The controlling olassificalion factor for design and engineering of this project is Streambank and Shoreline Protection ( 580 ). Based on the above values of confrolling classification factors, this project falls within an Engineeting Class $\mathrm{V}$ project. Other NRCS practices for this project are for planning and biological considerations and will be met, but do not fall within engineering delegation of authority.

DESIGNED BY:

DATE:

Ben Cook in cooperation with Dosign Team

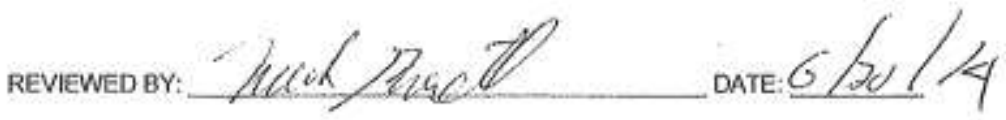

Mark Bamett, Central Coast Team Engineer

APPROVED BY: $\frac{\mathrm{D} \text { X Kunn }}{2}$ DATE: $\frac{6 / 20 / 14 \mathrm{f}}{2}$

Desidderia Ramirez, Area Engineer 


\section{DOCUMENTATION OF LANDOWNER UTILITY REMINDER}

California State Law Says, You Must Call Before You Dig!

If you are caught digging without a Dig Alert ticket you can be fined as much as $\$ 50,000$.

Why risk the possible financial impact?

All you do is dial a toll-free number, give your job site information to the Dig Alert

representative, and they will notify all of its members having underground facilities in the area.

\section{Here are the important highlights of the law.}

- Delineation of the proposed excavation ste is mandatory. Mark the area to be excavated with water soluble or chalk based white paint on paved surfaces or with other suitable markings such as flags or stakes on unpaved areas

- Call at least Two (2) full working days prior to digging.

- Permit for digging will not be valid without a Dig Alert ticket number.

- If utility members have facilities within the work area, they will mark them prior to the start of your excavation and if not, they will let you know there is no conflict.

- The Law requires one to hand expose to the point of no conflict $24^{\prime \prime}$ on either side of the underground facility, so one knows the exact location before using power equipment.

Signature:

Landownerioperator

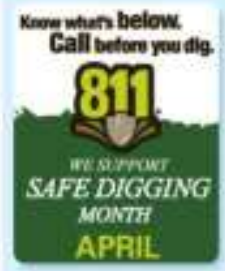

View the Current California Law, Government Code 4216 at: http/hrunu digalert.org/statelane asp 
PRACTICE REQUIREMENTS 
PRACTICE REQUIREMENTS FOR

580 - STREAMBANK AND SHORELINE PROTECTION

For: Resource Conservation District of Santa Cruz County

Job Location:125 Swanton Road, Davenport, CA

County: Santa Cruz: RCD: Santa Cruz

Prepared By: Mark Barnett

Date: March 2014

IT SHALL BE THE RESPONSIBILITY OF THE OWNER TO OBTAIN ALL NECESSARY PERMITS AND/OR RIGHTS, AND TO COMPLY WITH ALL ORDINANCES AND LAWS PERTAINING TO THIS INSTALLATION.

Installation shall be in accordance with the following drawings, specifications and special requirements. NO CHANGES ARE TO BE MADE IN THE DRAWINGS OR SPECIFICATIONS WITHOUT PRIOR APPROVAL OF THE NRCS TECHNICIAN.

1. Drawings: Sheets 1-15

2. Practice Specifications: Streambank and Shoreline Protection (580), Control of Water (909), Critical Area Planting (342A) and (342G).

3. Type of bank protection: Large Wood Material and anchor boulders.

4. Special Requirements:

- Grade and excavate project components according to elevation specified on drawing and/or specified cross sections and lengths.

- Separate top soil and duff material from mineral soil for later use as mulch during rehabilitation phase.

- Dewatering required as specified for particular project component. Follow procedures outlined in drawing. Dewatering shall comply with NRCS Control of Water (909) Construction Specification, and dewatering plan shown on drawing.

- Apply erosion control according to Erosion Control Plan shown on drawing

- The woody structures must not occupy more than $50 \%$ of active channel

- Site access and staging shall minimize impacts to existing native trees and vegetation. The Contractor shall restore access routes to pre-project grades, install erosion control, and revegetate disturbed areas as shown on the dravings.

- Construction activities must comply with the requirements of all permits.

5. Special Maintenance Requirements:

- The Resource Conservation District of Santa Cruz County (RCD SCC) will monitor the site on an annual basis for 5 years after construction. including photo documentation.

- Progress reports and recommendations from the RCD SCC will be submitted to the Land Omner. 
PRACTICE APPRONAL:

Job Classification: Streamband and Shereline Proteclan (500), (Ret: Section 501 NEM) This job to classiffed as, Class $V$

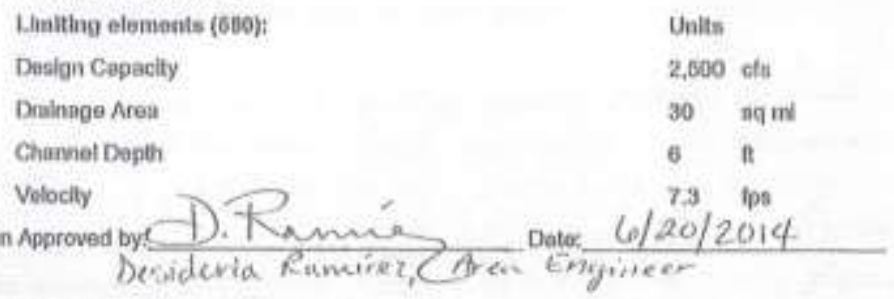
LANDOVAEER'SOPERATORYS ACINOWLEDGEMENT:

The landownekoperalor acknewledges that:

A Wabaha has recelved a copy of the drawings and epecilization, and that hevahe has an undaretandino of the contents, and the requirements.

B. Hehthe has obtutned all the neosasory petmils.

C. No changes will be mede in fha instetiation of the job without prior concurrence of the NRCS bechnician

D. Mabatenance of the instaligd work la necessary for proper parformance during the peofoct lifo.

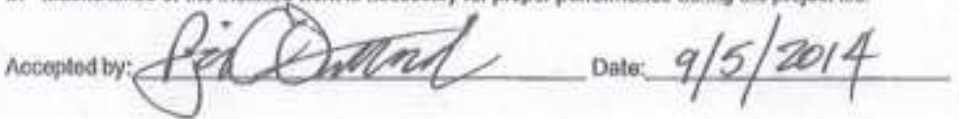
PRACTICE COMPLETION:

1 have made an onslle inspection (or I am accepting owner/contractor documentalicn), and heve determined that the job as installed does conform to the drawings and praotico specificallons.

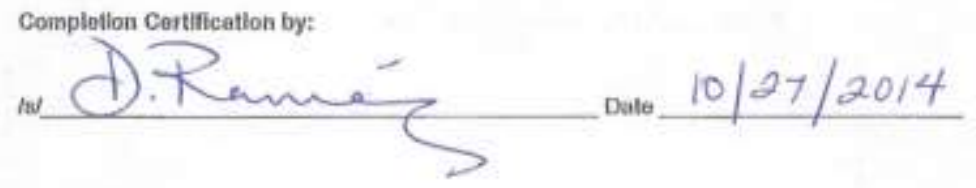




\section{PRACTICE REQUIREMENTS FOR}

\section{2a - CRITICAL AREA PLANTING - STRAW MULCH}

For: Resource Conservation District of Santa Cruz County

Job Location: 125 Swanton Road, Davenport, CA

County: Santa Cruz: RCD: Santa Cruz

Prepared By: Mark Barnett Date: March 2014

IT SHALL BE THE RESPONSIBILITY OF THE OWNER TO OBTAIN ALL NECESSARY PERMITS AND/OR RIGHTS, AND TO COMPLY WITH ALL ORDINANCES AND LAWS PERTAINING TO THIS INSTALLATION.

Installation shall be in accordance with the following drawings, specifications and special requirements, NO CHANGES ARE TO BE MADE IN THE DRAWINGS OR SPECIFICATIONS WITHOUT PRIOR APPROVAL OF THE NRCS TECHNICIAN.

Drawings: Sheets 1-15

Practice Specifications: Streambank and Shoreline Protection (580), Control of Water (909), Critical Area Planting (342A) and 342G.

Seedbed Preparation: See Practice Specification 342A

Seed: see Native Plant Revegetation Palette

Rate: $200 \mathrm{lbs} / \mathrm{ac}$

Fertilizer: N/A

Mulch: See Practice Specification 342A and drawing general notes. Reuse native duff or a mix of native duff and straw whenever possible.

Rate: $4000 \mathrm{lbs} / \mathrm{ac}$

Mulch anchoring shall be performed using Method: __ Method 1, hand tools,

crimping with shovel.

Planting shall be performed within the period: After completion of construction for erosion control

Special Requirements: Contractor shall minimize disturbance to existing riparian areas for temporary access and staging. Native trees shall be protected in place as much as possible.

Disturbed areas shall be treated with straw mulch and seed as needed for erosion control. 
PRACTICE APPROVAL:

Job Classification:

Show the limiting elements for this job. This job is classified as, Class N/A

Limiting elements:

Units

Area Treated $=$

0.15 acres

Approved by:

Date

\section{LANDOWNER'S/OPERATOR'S ACKNOWLEDGEMENT:}

The landownerioperator acknowledges that:

A He/she has received a Dopy of the drawings and specifications, and that hevishe has an understanding of the contents, and the requirements

B Helshe has obtained all the necessary permits.

C. No changes will be made in the installation of the job without prior concurrence of the NRCS technician.

D. Mairtenance of the installed work is necessary for proper performance during the project life

Accepted by:

Date:

PRACTICE COMPLETION:

I have made an onsite inspection of the site (or I am accepting ownericontractor documentation), and have determined that the job as installed does conform to the drawings and practice specifications.

Completion Certification by:

isi Date 
RACTICE REQUIREMENTS FOR

$342 \mathrm{~g}$ - CRITICAL AREA PLANTING - WOODY CUTTINGS

For: Resource Conservation District of Santa Cruz County

Job Location:125 Swanton Road, Davenport, CA

County: Santa Cruz: RCD: Santa Cruz

Prepared By: Mark Barnett Date: March 2014

IT SHALL BE THE RESPONSIBILITY OF THE OWNER TO OBTAIN ALL NECESSARY PERMITS ANDIOR RIGHTS, AND TO COMPLY WITH ALL ORDINANCES AND LAWS PERTAINING TO THIS INSTALLATION.

Installation shall be in accordance with the following drawings, specifications and special requirements. NO CHANGES ARE TO BE MADE IN THE DRAWINGS OR SPECIFICATIONS WITHOUT PRIOR APPROVAL OF THE NRCS TECHNICIAN.

1. Drawings, No.: Sheets $1-15$

2. Practice Specifications: Streambank and Shoreline Protection (580), Control of Water (909), Critical Area Planting (342A) and 342G.

3. Woody Cuttings Min_Dia

Length

4. Planting shall be performed within the period: Post construction, fall 2011

5. Special Requirements:

Woody cuttings shall be harvested from local sources of native trees. No nursery stock will be allowed.

Woody cuttings to be installed as required for erosion control and tree replacement. Sprigs should be at least $1 / 2$-inch in diameter and 18 inches long. Sprigs, 2 to 3 inches in diameter and 3 to 4 feet long work best.

Cuttings should be planted the same day they are cut. If it is not possible, then the entire cutting should be placed in water in a cold area.

Plant the willows with the buds up, after sharpening the basal (bottom) end of the sprig with an axe or pruners right after it is cut from the tree.

Sprigs should be driven into the soil 75 to 80 percent of their total length, at a slight angle downstream.

In hard soils an iron bar or a chain saw powered auger can be used to bore planting holes. This should not be needed at this site.

In soft soils, sprigs can be driven in with a wooden mallet or sledge hammer.

Cut off the tops of the sprigs if they should split while hammering. Leave only one or two buds exposed.

The sprigs should be placed 2 to 3 feet apart.

PRACTICE APPROVAL:

Job Classification:

Show the limiting elements for this job. This job is classified as, Class N/A 


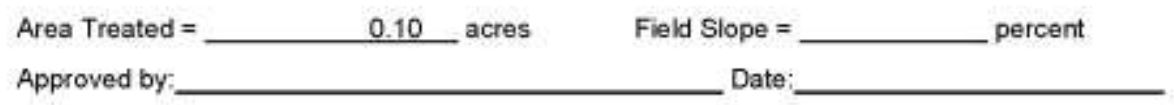

\section{LANDOWNER'S/OPERATOR'S ACKNOWLEDGEMENT:}

The landowner/operator acknowledges that:

A. Heishe has received a copy of the drawings and specifications, and that heishe has an understanding of the contents, and the requirements

B. Helshe has obtained all the necessary permits

C. No changes will be made in the installation of the job without prior concurrence of the NRCS technician.

D. Mairtenance of the installed work is necessary for proper performance duning the project life

Accepted by: Date

\section{PRACTICE COMPLETION:}

I have made an onsite inspection of the site (or I am accepting owner/contractor documentation), and have determined that the job as installed does conform to the dravings and practice specifications.

Completion Certification by:

|s| Date 
PRACTICE STANDARDS 
$342-1$

\section{NATURAL RESOURCES CONSERVATION SERVICE \\ CONSERVATION PRACTICE STANDARD}

342 - CRITICAL AREA PLANTING

(Ac.)

CODE 342

\section{DEFINITION}

Establishing permanent vegetation on stes that have, or are expected to have, high erosion rates, and on sites that have physical, chemical

or biological concitions that prevert the establishment of vegetation with normal practices.

\section{PURPOSE}

$X$ Stabilze stream and channel banks,

And shorelines:

$X$ Stabilize areas with existing or expected high rates of soil erosion by wind of water.

$X$ Rehabilitate and revegetate degraded sites that cannot be stabilized using narmal establishment techniques

X Stabilize coastal areas, such as sand dunes and riparian areas.

\section{CONDITIONS WHERE PRACTICE APPLIES}

This practice applies to highly disturbed areas such as.

$X$ active or abandoned mined lands, $x$ urtan conservation sites; $x$ road construction areas; $x$ conservation practice construction sites, $x$ areas reeding stabilization before or after

Natural disasters such as floods, hurricanes, tornados and wildires;

$X$ eroded barks of natural channels, banks

Of newly constructed channels, and lake shorelines;

$X$ other areas degraded by human activities or natural events.

\section{CRITERIA}

\section{General Criteria Applicable To All Purposes}

Site Preparation. A site investigation shall be concucted to identify any physical, chemical, of biological conditions that could affect the successful establishment of vegatation.

Areas to be planted will be cleared of umwanted materials and smoothed or shaped, if needed, to meet planting and landscaping purposes

A sutable seedbed shall be prepared for all seeded species Compacted layers will be ripped and the soil re-firmed prior to seedbed preparation

Species Selection. Species selected for seeding or plarting shall be suited to current site concitions and intended uses, and be resistant to dseares or insects common to the site of location

Selected species will have the capacity to achieve adequate density and vigor to stablize the site within an appropriate period When soil erosion is a primary concern, select only species that are known to establish relatively quickly

Refer to CA reveg guide for aporoved species for the practice and site

No plants on the Federal of state noxious weeds list shall be planted

Establishment of Vegetation. Seeds will be plarted using the method or methods best suted to site and soll conditions.

Sod placement shall be limited to areas that can naturally supply needed moisture or sites that can be irrigated during the estabishment period

Sod will be placed and anchored using techniques to ensure that it remains in place until estabilished 
Species, rates $\alpha$ seeding or planting, minimum quality of planting stock (e.g pure live seed (PLS) or stem caliper), method of seedbed preparation, and method of estabishment shall be specified before application. Only viable, high quality seed or planting stock will be used

Seeding or planting shall be done at a time and in a manner that best ensures establishment and growth of the selected species. What constitutes successful establishmert (e.g Minimum percent ground/canopy cover, percert survival, stand density) shall be specified before application

Planting shall be done during approved times for the species to be used

Apply soil amendments (e.g. Lime, fertilizer compost) according to the requirements in the local Field Office Techrical Guide.

Plantings shall be muched as necessary to ensure establishment. Other osturbed areas shall be mulched as necessary to prevent erosion.

Additional Criteria to Stabilize Stream and Channel Banks and Shorelines

When slopes are modfied for seeding, topsoil will be stockpiled and spread over areas to be planted as needed to meet planting and landscaping needs

Bank and Channel Slopes. Channel side slopes shall be shaped so that they are stable and allow establistment and maintenance of desired vegetation

Slopes steeper than $2: 1$ shall not be stabilized using vegetation alone. A combination of vegetative and structural measures will be used on these siopes to ensure adequate stability

Species Selection. Plant matenal used for this purpose shall
$X$ acapted to the hydrologic zone (see Fig. 1) into which they will be planted

$X$ be adapted and proven in the regions in which they will be used

$X$ when mature, produce plant communities that are compatible with those in the area

$X$ protect the channel banks but not restrict channel capacity.

Establishment of Vegetation. The species used, plarting rates, spacing and methods and dates of planting shall be based on plant materials program trials or other technica guidance, such as local planting guides or technical notes

identify, mark, and protect desirable existing vegetation during practice installation

A combination of vegetative and structura: measures using living and inert material shall be used when flow velocities, soils, and bank stability preciude stabilization by vegetative establishment alone

If the existing vegetation on a site will compete with species to be established vegetatively (eg. Bare-root, containerized, ball-and-burlap potted), it will be controlled in a manner that ersures the successtul establishment of the planted species

Site Protection and Access Control. Exclude all livestock for one year following establishment Carefully control ivestock access in subsequent years.

All areas to be grazed will have a grazing plan developed in accordance with CPS 528 . Prescribed Grazing

Grazing shall be permanenty excluded on high hazard sites, such as cut barks, areas of seepage or other potentially unstable areas. 


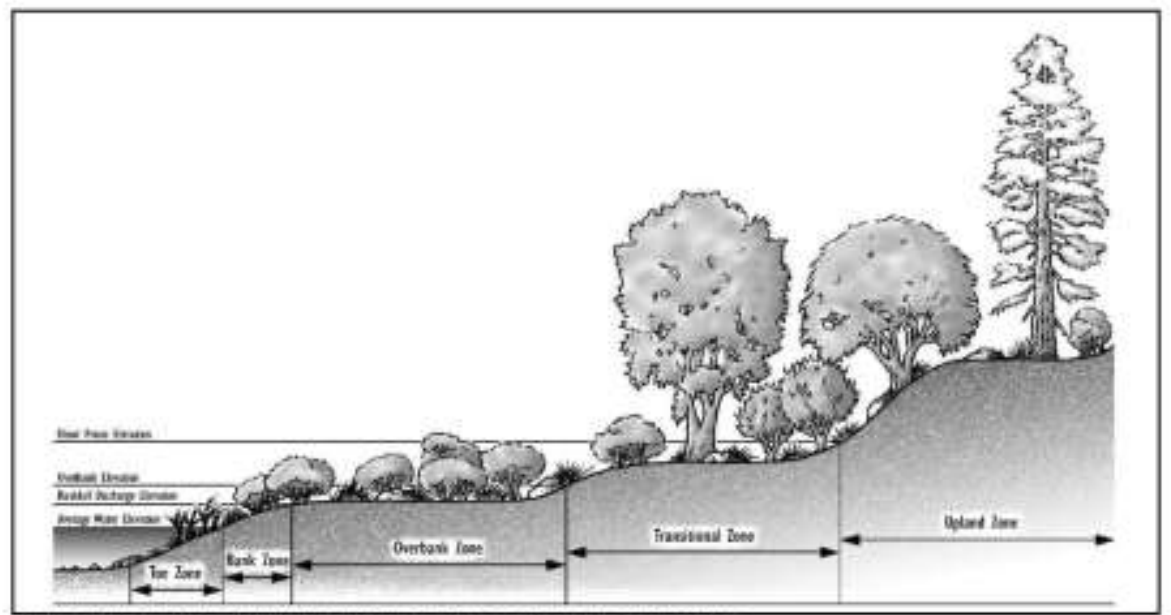

Figuve 1. Location of hydroiogic zones along a channel or shoreline

Definitions and descniptions of hychalogic zones used for channels and shorelines.

Banifuw Discharge Elevation - In natural streams, it is the elevation at which water fills the channed without overllowing crito the lood plain

Bank Zone - The area above the Toe Zone iocated between the average water ievel and the bankfull discharge elevation. Vegetation may be herbaceous $o r$ woody, and is characterized by fiexible stems and hizomatous root systems.

Overbank Zone - The area located above the banicull disctionge eievation continuing upsiope to an elevation equal to two thircls of the flood prone depth Vegetation is generally small to medium shrub species.

Toe Zone. The portion of the bank that is between the average water level and the boltom or the charvel, at the toe of the bank. Vegetation is generally herbaceous emergent aquatic species, tolerant of long periods of inundation

Transitional Zone - The area located between the cverbank zone, and the flood prone width elevation Vegetation is usually larger shrub and tree species

Upland Zone - The area above the Transitional Zone; this area is selbom if ever saturated

Note, some channeis or shorolines have fowor than four hydrologic zones because $o$ differences in sails, topography. entrenchiment andior moisture regime.

\section{Additional Criteria to Rehabilitate and}

Revegetate Degraded Sites that Cannot Be Stabilized through Normal Farming Practices.

If gulles or deep rills are present, they will be filled and leveled as necessary to allow equipment operation and ensure proper site and seecbed preparation.

Based on a soil test and site evaluation, apply soil amendments far enough in advance of establishment for them to ameliorate the adverse conditions.

Additional Criteria to Restore Coastal 
Areas, such as Sand Dunes and Riparian

\section{Areas}

Plants for sand dunes and coastal sites must be able to survive being buried by blowing sand. sand blasting salt spray, salt water flooding. drought, heat, and low nutrient supply.

Local plant lists including appropriate species shall be developed and utilized

Sand trapping devices such as sand fences or brush matting shall be included in the

Revegetation/ stabilization plans where applicable.

\section{CONSIDERATIONS}

Species or mixes that are adapted to the site and have multiple values should be considered Native species may be used when appropriate for the site and purpose.

To benefit pollinators and other wildlife, flowering shrubs and wildflowers with tough root systems and good soil holding capacity also should be considered for incorporation as a small percentage of a larger grass dominated planting. Where appropriate consider a diverse mixture of legumes and forbs to support pollinator habitat

Avoid species that may harbor pests. Species diversity should be considered to avoid loss of function due to species-specific pests

Planning and installation of other conservation practices such as Diversion (code 362) Obstruction Removal (code 500), Subsurface

Drain (code 606), or Underground Outlet (code $620)$ may be necessary to prepare the area or ensure vegetative establishimert.

Areas of vegetation established with this practice can create habitat for various type of wildlife. Maintenance activites, such as mowing or spraying can have detrimental effects on certain species. Perform management activities at the times and in a manner that causes the least disruption to wildiffe.

PLANS AND SPECIFICATIONS
Prepare plans and specifications for each field or management unit according to the criteria and operation and maintenance sections of this standard. Record practice specifications using aporoved specification sheets, job sheets or other acceptable documentation

The following elements shall be addressed in the plan as applicable, to meet the intended purpose

$X$ Site preparation $x$ Topsoil requiremerts

$X$ Fertilizer $\&$ other amendmert rates and application methods

$X$ Seedbedjplanting area preparation $x$ Methods of seeding'planting $x$ Time of seedingiplanting $x$ Species and cultivar $x$ Seed/plant source $x$ Seed analysis $x$ Seeding rate/plart spacing $x$ Mulching

X Supplemertal water needed for establishmert

$x$ Protecton during estabishment $x$ grazing plan (if appropriate)

\section{OPERATION AND MAINTENANCE}

Use of the area shall be managed as long as necessary to ensure the ste remains stable.

Plantings shall be protected from pests (e.g Weeds, insects, diseases, livestock, of wildiffe) as necessary to ensure long-term survival.

Inspections, reseeding or replarting, and fertilzation may be needed to ensure that this practice functions as intended throughout its expected ife Site evaluation shoud be performed at least every three months until the practice has met the criteria for successful establishment and implementation

\section{REFERENCES}

Federal Interagenoy Stream Restoration Working Group. 1998 . Stream corridor restoration: principles, processes, and practices National Engineering Handbook, Part 653

USDA-NRCS 2007. National Engineering Handoook, Part 654 Stream restoration guide

USDA-NRCS. 2010. The PLANTS Database

(http:fiplants. usda gov, checked September 2010). National Plant Data Center. 
$395-1$

\section{NATURAL RESOURCES CONSERVATION SERVICE \\ CONSERVATION PRACTICE STANDARD \\ 395 - STREAM HABITAT IMPROVEMENT AND MANAGEMENT}

\section{(Ac.)}

\section{CODE 395}

\section{DEFINITION}

Mairtain, improve or restore physical, chemica: and biological functions of a stream, and its associated riparian zone, necessary for meeting the life history requirements of desired aquatic species.

PURPOSE

Provide sutable habitat for desired fish and other aquatic species

Provide stream channel and associated riparian conditons that maintain stream corrido ecological processes and hydrological connections of diverse stream habitat types important to aquatic species

\section{CONDITIONS WHERE PRACTICE APPLIES}

All streams and their adjoining backwaters, floodplains, associated wetlands, and riparian areas where geomorphic conditions or habitat deficiencies limit reproduction, growth, survival and diversity of aquatic species.

CRITERIA

Planned stream habitat improvements will; $x$ address the aquatic species and life

History stages for which the stream is being managed.

$\mathrm{X}$ be based on a site-specific assessment of local hydrology, channel morphology. geomorphic setting, fish and other aquatic species present, riparian and flcodplain conditions, and ary habitat limitations including water cuantity and quality, food supply, and restriction of upstream and downstream movement of aquatic species using the NRCS Stream Visual Assessment Protocol, Version 2 or comparable evaluation tool,

When applied, result in a conservation system that meets or exceeds the minimum quality criteria for stream habitat established in Section III of the FOTG

Manage adjoining riparian areas to support a diverse vegetation community suitsble for the site conditions and desired ecological benefits Such benefits include stream temperature moderation, recruitment of instream large wood and fine organic matter, input of nparian nutrients, habitat for terrestrial insects and other riparian dependent species, streambarik integrity, and filtration of contaminants from surface funoff.

Design in-stream structures to be compatible with the dynamic nature of streams and rivers. facilitate natural geomofphic recovery when possible, and minimize disruption of recreationa: and other traditional uses of the stream corridor

Structures installed for the purposes of this standard will not; $x$ impede or prevent passage of fish and other aquatic organisms at any time, unless intended to isolate populations of native species of conservation concern.

$X$ cause excessive bank erosion, $x$ cause unintentional lateral migration, aggradation or degradation of the channel,

$X$ hirder channel-floodplain interactions.

Where practical, restore or maintain stream habitat and channel forming processes such as natural flow regime, meander migration, sediment transpcrt, recruitment and storage of large wood, and floodplain interactions with the stream.

All stream and riparian activities will occur within state and federal guidelines with regard to timing of spawning incubation and rearing

395 - 2

Of aquatic organisms, and breeding and nesting of terrestrial organisms. 
Manage ivestock to sustain a healthy stream corridor and associated habitats.

\section{CONSIDERATIONS}

Any stream habitat maragement project is most effective when applied within the context of overall watershed conditions and with clear objectives for stream management goals. Stream habitat managemert provisions should be planned in relation to other land uses that may affect stream cofricors

Before designing and implemerting stream habitat improvements. consider the known or expected concerns within the watershed, such as: poirt and non-poirt source pollution; water diversions; and land management activities Fikely to infuenoe stream habltat conditions. Additional measures that should be taken singularly or in combination to improve stream nabitat include

Complete a general assessmert of watershed conditions that are likely to affect the functions of the stream and its riparian area.

Incorporate stream habitat improvements into a conservation plan that addresses soil quality. prescribed grazing, nutrient management, pest management, and other management practices for reducing non-point sources of pollution

Provide fish passage upstream and downstream and allow movement of other aquatic species and organio matter to the extent possible and when compatible with state and federal fish management objectives (see Code 396 Aquatic Organism Passage)

Reduce or manage excessive runcff due to watershed development, roach or land-use activities

Restore or protect riparian and floccplain vegetation and associated fiverine wetlands.

Mairtain adequate in-stream flows to susta in diverse habitats for fish and other ackuatic species especially during critical life history stages of spawning, incubation and rearing

\section{NRCS, CA May 2012}

Provide heterogeneous and complex physica: habitat components consistent with the physiographic setting and important to fish and other aquatic species in the watershed. These include suitable spawning substrates, structural elements such as boulders andior large wood whese appropriate, resting pools, overhead cover, and diverse riparian plant communities Provide instream barriers to exclude aquatic nuisance species from upstream habitats where prescribed by state and federal fish management agencies to protect native fish populations

Provide screens on water pumps, diversion ditches, or any area where unintertional entrainment of aquatic species is likely to oocur

Improve flocdplain-to-channel connectivity for development of seasonal or permanent backwater, wetland and off-channel habitats consistent with the local climate and hydrology of the stream.

Maintain naturai surface water, hyporheic, and ground water interactions to the extent possible Control spread of exotic plant and animal species

Manage recreational and other land use activities to minimize impacts on stream banks, riparian vegetation and water quality

Identify and manage potentially adverse impacts of widlife on vegetative establishment and sustainability, such as deer browsing, beaver dams and tree girdling bank burrowing by muskrats and others, and trampling

\section{PLANS AND SPECIFICATIONS}

Plans and specifications shall be developed for each site where stream corridor management and improvement actions are to be implemented.

The plan will include detalled goals and objectives of the planned actions, a site description, the dates and sequence in which improvements or management actions will be completed, a vegetation planking plan, maintenance requirements, and moniloring guidelines for evaluating the effectiveness of the conservation actions. The plan shall specify.

Location and extent of modification of the stream reach to accomplish the planned purpose,

Riparian plant species and stocking rates if needed to accomplish the planned purpose, 
Planting dates, as well as the care and handing of seed or other planted materials to ensure an acceptable rate of survival

Site protection and pregaration requirements for establishment or recruitmert of riparian vegetation if needed,

Drawings to illustrate installation or implemertation requiremerts.

OPERATION AND MAINTENANCE

A detailed operation and maintenance plan shall be developed for all applications. The plan shall provide for periodic inspection and prompt repair or modification of any structures that are found to cause excessive streambank or streambed instability. A.l structural measures shall be evaluated on an amual basis Post-project monitoring and evaluation of stream and riparian habitat conditions shall be conducted to determine if actions implemented are providing for managemert of the stream corridor habitats as planned Any repair actions, if needed, shall comply with state and fecteral guidelines for protecting spawring, incubation and rearing times of aquatic species and breeding and nesting times of terrestrial species

$395-3$

REFERENCES
Bureau of Land Management. 1998. Riparian

Area Management A User Guide to Assessing Proper Functioning Condition and the Supporting Science for Lotic Areas. TR1737-15 Federal Interagency Stream Restoration Working Group (FISRWG), 1998 National Engneering Handbook 653 -Stream Corridor Restoration. Principles, Processes and Practices

NRCS, 1998. The Practical Streambank Bioengineering Guide

NRCS. 2002 Streambank Soil Bioengineering Field Guide for Low Precipitation Areas.

NRCS, 2005. National Biclogy Handbook

Part 620 Aquatic and Terrestrial Habitat Resources.

NRCS 2006. National Engineering Handbook Part 654. Stream Restoration Design Handbook NRCS. 2009. National Elology Handbook Part 614, Subpart B. Stream Visual Assessment Protocol. Version 2

Roni, P 2005. Monitonng stream and watershed restoration. American Fisheries Society.

Bethesda, MD 
$580-1$

\author{
NATURAL RESOURCES CONSERVATION SERVICE \\ CONSERVATION PRACTICE STANDARD \\ 580 - STREAMBANK AND SHORELINE PROTECTION
}

(Ft)

\title{
CODE 580
}

\section{DEFINITION}

Treatment(s) used to stabilize and protect banks of streams or constructed chamels, and shorelines of iakes, reservoirs, or estuaries. PURPOSE

$X$ To prevent the loss of land of clamage to

Land uses, or facilities adjacert to the barks of streams or constructed channels, shoreline of lakes, reservoirs, or estuaries including the protection of known historical, archeological, and traditional cultural properties.

$X$ To maintain the flow capacity of streams of channels.

$X$ Reduce the offsite or downstream effects of sediment resulting from barik erosion

$X$ To improve or enhance the stream corridor for fish and wildife habitat, aesthetics, recreation

\section{CONDITIONS WHERE PRACTICE APPLIES}

This practice apolies to streambanks of natural or constructed channels and shorelines of lakes, reservoirs, or estuaries where they are susceptible to erosion. It does not apply to erosion problems on main ocean frorts. beaches or similar areas of complexity.

CRITERIA

General Criteria Applicable to All Purposes

Treatments shall be in accordance with all applicable local, state and federal lews and regulations

Treatmerts applied shall seek to avoid adverse effects to endangered, threatened, and candidate species and their habitats, whenever possible.
Treatments applied shall seek to avoid acverse effects to archaeological, historic, structural, and tradtional cultural properties, whenever possible

An assessmert of unstable streambarik or shoreline sites shall be conducted in sufficient detali to identify the causes contribusing to the instability (e.g. Livestock access, watershed alterations resulting in significant modifications of discharge or sediment production in channel modifications such as gravel mining; head cutting, water level fuctuations, boat-generated waves, etc.)

Proposed protective treatments to be applied shall be compatible with improvements being planned or installed by others.

Protective treatments shall be compatible with the bank or shoreline materials, water chemistry, channel of lake hydraulics, and slope characteristics above and below the water line

End sections of treatment areas shall be adequately anchored to existing treatrments. terminate in stable areas, or be otherwise stabilized to prevent flanking of the treatment. Protective treatments shail be installed that resut in stable slopes. Design limitations of the bank or shoreline materials and type of measure installed shall determine steepest permissible slopes.

Designs will provide for protection of installed treatmerts from overbank fiows resulting from upslope funolf and flood return flows.

internal drainage for bank seepage shall be provided when needed. Geotextiles or properly designed filter bedding shall be incorporated with structural measures where there is the

Conservation practice standards are reviewed periodcaly, and updated if needed. To obtain NRCS, CA the current version of this stondard, contact the Natural Resources Conservation Service June 2011

State Offine, or wst the Eied Otfcs Tectinical Guide. 
potential for migration of material from behind the measure.

$500-2$

Treatments shall be designed to account for any anticipated ice action, wave action, and fluctuating water levels.

All disturbed areas around protective treatments shall be protected from erosion. Disturbed areas that are not to be cultivated shall be protected as soon as practical after construction.

Vegetation shall be selected that is best suited for the site conditions and achieves the intended purpose(s)

In order to ensure plart community

estabishment and integrity, a vegetative management plan shall be prepared in accordance with NRCS conservation practice standard Critical Area Planting, Code 342

Additional Criteria for Streambarks

Stream segmerts to be protected shall be classified according to a system deemed appropriate by the state. Segments that are incised or that contain the 5-year return period (20 percent probability) or greater flows shall be evaluated for further degradation or aggradation.

A sile assessment shall be performed to determine if the causes of instability are local (e.g Foor soils, high water table in banks. alignment obstructions deflecting flows into bank, etc.) $\mathrm{Cr}$ systemic in nature (e.g. Aggradation due to increased sedimerk from the watershed, increased runoff due to urban development in the watershed, degradation due to channel modifications, etc.) The assessment need only be of the extent and detail necessary to provide a basis for design of the bank treatments and reasornable confidence that the treatments will perform adequately for the design life of the messure.

Changes in channel aligrment shalt not be made without an assessment of both upstream and downstream fluvial geomorphology that evaluates the eflects of the proposed alignmert. The current and future dischange-sediment regime shall be based on an assessment of the watershed above the proposed charnel alignment.

Bank protection treatment shall not be installed in channel systems undergoing rapid and extersive changes in bottom grade andior alignment unless the treatments are designed to control or accommodate the changes. Bank treatmert shall be constructed to a depth at or

Below the anticipated lowest depth of streambed scour

If the failure mechanism is a result of the degradation or removal of niparian vegetation. stream corridor restoration shall be implemented, where feasible, (see Additional Criteria for Stream Corridor Improvemert) as well as treating the banks

Toe erosion shall be stabilized by treatments that redirect the stream flow away from the toe or by structural treatments that armor the toe. Additional design guidance is found in the $\mathrm{EFH}$ Part 650, Chapter 16 , Streambank and Shoreline Protection.

Where toe protection alone is inadequate to stabilize the bank, the upper bank shall be shaped to a stable slope and vegetated, or sha: be stabilized with structural or soil bioengineering treatments.

Charnel clearing to remove stumps, fallen trees, debris; and sedment bars shall orly be performed when they are causing or coud cause unacceptable bank erosian flow restriction, or damage to structures. Habitat forming elements that provide cover, food pools, and water turbulence shall be retained or replaced to the extent possible.

Treatments shall be functional and stable for the design flow and sustainable for higher flow conditions

Treatments shall not induce an increase in natural erosion

Treatments shall not limit stream flow access to the fioodplain.

Where flooding is a concern, the effects of protective treatments shall not increase flow levels above those that existed prior to installation.

Additional Criteria for Sharelines

All revetments, bulkheads or groins are to be no higher than 3 feet ( 1 meter) above mean high tide, or mean high water in non-tidal areas 
Structural shoreine protective treatments shall be keyed to ar depth to prevent scour during low water

For the design of structural treatments, the site characteristics below the waterline shall be evaluated for a minimum of 50 feet ( 15 meters) horizortal distance from the shoreline measured at the design water surface

The height of the protection shall be based on the design water surface plus the computed wave height and freeboard. The design water surface in tidal areas shall be mean high tide

When vegetation is selected as the protective treatment, a temporary breakwater shall be used during establishmemt when wave run up would damage the vegetation.

Additional Criteria for Stream Cocridor Improvement

Stream corricor vegetative components shall be estabished as necessary for ecosystem functioning and stability. The appropriate composition of vegetative components is a key element in preventing excess long-term channel migration in re-established stream corridors. The establishment of vegetation on channel banks and associated areas shall also be in accordance with conservation practice standard Critical Area Planting, Code 342

Treatmerts shall be designed to achieve habitat and population objectives for fish and wildife species or communities of concern as determined by a site-specific assessment or management plan. Objectives shall be basec on the survival and reproductive needs of populations and communities, which include habitat diversity, habitat linkages, daily and seasonal habitat ranges, limiting factors and native plant communities. The type, amount, and distribution of vegetation shall be based on the requirements of the fish and wildife species or communties of concern to the extent possible.

Treatmerts shall be designed to meet aesthetic objectives as determined by a site-specific assessment of management pian. Aesthetic objectives shall be based on human neects, including visual quality, noise control and microclimate control. Construction materials, grading practices, and other site development elements shall be selected and designed to be compatibie with adjacent land uses.

Treatments shall be designed to achieve recreation objectives as determined by a sitespecific assessment or management plan. Safety requirements shall be based on type of human use and recreation cojectives.

\section{CONSIDERATIONS}

When designing protective treatments, consider potential changes that may occur in the watershed hydrology and sedimertation over the cesign life of the treatments

Consider utilizing debris removed from the channel of streambark into the treatment design when it is compatible with the intended purpose to improve benefits for fish, widlife and aquatic systems.

Use construction materials, grading practices vegetation, and other site development elements that mirimize visual impacts and maintain or complement existing landscape uses such as pedestrian paths, climate controls buffers etc. Avoid excessive disturbance and compaction of the site during instailation

Uilize vegetative species that are native andior compatible with local ecosystems. Avoid introduced, invasive, noxious or exotic species that couid become nuisances. Consider species that have multiple values such as those suited for biomass, nuts, fruit, browse, nesting aesthetics and tolerance to locally used herbicides. Avoid species that may be alternate hasts to disease or undesirable pests. Species diversity should be considered to avoid loss of function due to species-specific pests. Species on noxious plant lists shouid not be used.

Select ptant materials that provide habitat requirements for desirable wildife and pollinators. The addition of native forbs and legumes to grass mixes will increase the value of plantings for both wildife and pollinators.

Treatments that promote beneficial sediment deposition and the fitering of sediment, sediment-attached, and dissolved substances should be considered.

Consider maintaining of improving the habtat value for fish and wildife by including treatmerts that provide aquatic habitat in the treatment 
design and that may lower or moderate water temperature and improve water quality.

Consider the need to stabilize side channel inlets and outlets and outlets of tributary streams from erosion

Consider acuatic habitat when selecting the type of toe stabilization

Consider maximizing acjacemt wetland functions and values with the project design and minimize adverse effects to existing wetland functions and values

Livestock exclusion shail be considered during establishment of vegetative treatments and appropriate grazing practices applied after establishment to maintain plant cornmunity integrity. Wildlife may also need to be cortrolled during establishment of vegetative treatments

Temporary and local population control methods should be used with caution and within state and local regulations

When appropriate, establish a buffer strip and/or diversion at the top of the bank or shoreline protection zone to help maintain and protect installed treatments, improve their function, filter out sediments, nutrients, and pollutarts from runotf, and provide additional wildife habitat.

Consider safety hazards to boaters, swimmers or people using the shoreline or streambank when desigring treatrments

Protective treatments should be self-sustaining of require minimum maintenance.

Cultural Resources and Endangered Species
This practice is likely to occur in areas where Cultural Resources or Endangered Species habitat may be found. Follow NRCS Planning Policy to address these concerns

\section{PLANS AND SPECIFICATIONS}

Plans and specifications for streambark anc shoreline protection shall be prepared for specific field sites and based on this standard and shail describe the requirements for applying the practice to achieve its intended purpose. Plans shall include treatments to minimize erosion and sediment production during construction and provisions necessary to comply with conditions of any envircmental agreemerts, boological opinions or other terms of applicable permits.

\section{OPERATION AND MAINTENANCE}

An operation and maintenance plan shall be prepared for use by the owner or others responsible for operating and maintaining the systern. The plan shall provide specific instructions for operating and mairtaining the system to insure that it functions properly. It shall also provide for periodic inspections and prompt repair of replacement of damaged components or erosion.

\section{REFERENCES}

NEH Part 650, Chapter 16, Streambank and Shoreline Protection.

NRCS Technical Note-Engineering-CA-14, September 2003

NEH Part 654, Stream Restoration Design 


\section{NATURAL RESOURCES CONSERVATION SERVICE \\ CONSERVATION PRACTICE STANDARD \\ 734 - FISH AND WILDLIFE STRUCTURE \\ CODE 734 (INTERIM PRACTICE)}

\section{DEFINITION}

A structure designed and installed specifically for fish or wildlife

\section{PURPOSE}

To improve overall habitat conditions for fish or wildife species. This practice may be applied as part of a fish or wildiffe habitat management plan to serve one or more of the following functions:

$X \quad$ Provide structure for loafing, escape, nesting, rearing, roosting perching, or basking

$x \quad$ Provide an escape, avoidance, or exclusionary feature from cherwise lifethreatening conditions.

$x \quad$ Frovide atternative cover when natural oover is not readily available.

$X \quad$ Isolate native species populations from non-natives X Improve or restore habitat connectivity.

\section{CONDITIONS WHERE PRACTICE APPLIES}

This practice applies to all iand uses where the land manager has identified an objective to oonserve fish or wildife

\section{CRITERIA}

Structures shall be designed and installed to meet the targeted species biology and lite history needs

Structures will be designed acoording to the appicable Blology Techrical Notes or other design references approved by the NRCS state office

Plastic and fiberglass structures shall be made of uitraviolet resistant materials and may be coated with non-toxic substances for additional protection from deterioration due to sunlight exposire.
Structures sha be built to withstand expected environmental conditions at the site to maximize structural lifespan stability, and habitat benefits

\section{CONSIDERATIONS}

Give consideration to effects the location of the structure will have on targeted and non-targeted species

Consider the need to prevent increased predation on both targeted and non-targeted fish and wildife species as a result of installation of structures under this practice

Consider combiring this practice with vegetative practices to establish natural habitat features in the long term.

Types of fish and wildlife structures to consider include:

Artificial nest boxes or platforms for species such as cavity-resting birds, bats, pollinators, and waterfow

Artificial cover such as brush piles, rock piles. buried concrete pipe, engineered log jams

Wood structures in or along stream barks for fish cover

Natural cover manipulation, such as giroling trees to encourage snag development

Measures to facilitate passage including elk jumps, escape ramps, road crossings

Measures to inhibit passage including predator guards, non-native fish barriers, beaver dam exclusion features

\section{PLANS AND SPECIFICATIONS}

Plans and specifications for installing fish and wild life structures shall be in keeping with this standard and shall describe the biological and physical requirements for applying the practice 
The plan shall specify the bcation, cuantities. dimensions, materials, and timing of installation for each structure

\section{OPERATION AND MAINTENANCE}

Operation and maintenance provisions shall be provided to and reviewed with the land manager. The provisions shall be site specific and include but not be limited to the following

Structures will be inspected at legst semiannually and after major storms

Necessary maintenance, including temoval of debris, shall be performed

\section{REFERENCES}

May, H. 2001. Artificial Nesting Structures USDA Natural Resources Conservation Service Wildife Habitat Managernent institute and Widife Habitat Council, Fish and Wvidilfe

Habitat Leaflet, No 20

Mueller, J. 1999. American kestrel USDA

Natural Resources Conservation Service

Widife Habitat Management tnstitute and Wildife Habitat Council. Fish and Wild-life Habitat Management Leaflet, No. 3

Mueller, J. 1999. Bats. USDA Natura!

Resources Conservation Service Wiidife

Habitat Management Institute and Wildife Habitat Council, Fish and Wiid-ife Habitat Management Leaflet No. 5

Novinger, D. C And Rahel, F J. 2003, Isolation management with artificial barriers as a

conservation strategy for culthroat trout in headwater streams. Conservation Biology 17

$772-781$.

Oregon NRCS Bology Technical Notes htp: : Werww or nrcs usda qow/technicalecsibiolog yibiology-technotes hitmil

Payne, N. F And F C. Bryant 1994 Techriques for wildife management of uplands MoGraw-Hill, New York, NY.

Payne N F 1992. Technicues for wildlife habitat management of wetlands. MoGraw-Hill New York, NY.

Rewa, C. 1999 Wood duck USDA Natura
Resounces Conservation Service Wildife

Habitat Management Institute and Widife Habitat Council, Fist and Wiid-life Habitat Management Leaflet, $\mathrm{No} 1$

Tuttle, M. D. And D. Hensley, 1993. The bat bulder's hand-book (2000 revision) Bat Conservation International, Austin, Texas,

USA. 30 
PRACTICE SPECIFICATIONS 


\section{NATURAL RESOURCES CONSERVATION SERVICE CONSERVATION PRACTICE SPECIFICATION \\ 342A - CRITICAL AREA PLANTING - STRAW MULCH}

\section{SCOPE}

The work shall consist of furnishing all materials and placing them on all exposed, disturbed, or barren areas within the designated areas to the limits as shown on the drawings, or as staked in the field.

\section{MATERIALS}

\section{Seed}

All seed shall be native grass seed of appropriate species specilied on the attached Native Plant Revegetation Paiette

All seed shall be delivered to the site tagged and labeled in accordance with the Califorria Agricultural Code, and shall be acceptable to the Courty Agricultural Commissioner.

Bag tag figures will be evidence of purity and cermination. Time since date of seed test shall not exceed 9 months.

Seed shall be of a quality that weed seed shall not exceed 0.5 percent of the aggregate of pure live seed (PLS) (percent germination $x$ percent purity) and other material

\section{Fertilizer}

Unless otherwise specified on the Practice

Requirements sheet, all fertilizer shall be Ammonium Phosphate Sultate containing a minimum of 16 percent Nitrogen, 20 percent available phosptioric acid and 0 percent water soluble potash and be uniform in composition ory and free flowing, pelleted or granular.

All fertilizer shall be labeled in accordance with applicable state regulations and bear the warranty of the producer for the grade furnshed

\section{Inoculants}

The inoculant for treating legume seeds shall be a pure culture of Nitrogen fxing bacteria prepared specifically for the plant species and shall not be used later than the date indicated on the container A mixing medium, as recommended by the manufacturer or approved substitute, shat be used to bond the incculant to the seed. For nonpeliet inoculated seed, two times the amount of the inoculant recommended by the manufacturer shall be used and seed shall be sown with 24 hours.

For pellet inoculated seed, at least 30 pounds of incculant shall be used per 1,000 pounds of raw seed and the seed shall be labeled to show the Lo Number, Expiration Date, and Percent Coat of the finished product. Pellet inoculated seed shall be kept cool and sown within 180 days

\section{Straw}

Straw shall be new straw derived from rice wheat, oats, or barley that meets the County Agrocultural Commissioner's standards for weed pests. Clearance shall be obtained from the Courty Agricultural Commissioner, as required by law, before straw obtained outside the courty in which it is to be used is delivered to the site.

\section{Jute Matting}

Jute marting shall be cloth mesh of unform plain weave of undyed and unbleached jute yarn with a minimum weight of one pound per 10 square feet, and a maximum opening size of 1 inch by 1 inch

\section{Plastic Netting}

Plastic nesting shall be a polypropylene extruded plastic netting with square or rectangular openings not greater than $3 / 4$ inches and weight of not less than 26 pounds per 1000 square feet

\section{Excelsior Matting}

Excelsior matting shall consist of a machine. produced mat of wood excelsior fiber with consistert thickness and fiber evenly distributed over the entire area of the blanket. At least 70 percent of the fibers shall be 6 inches or longer in length. The topside of each blanket shall be covered with a biodegradable extruded plastic mesh with a maximum opening sze of 2 -inch by 2-inch.

Staples 
Staples shall be made of 0.09 inch dameter or hesvier wire, "U" shaped. with legs at least 8 inches in length.

Anchor pins may also be used to anchor jute matting Anchor pins shall be made of rigid 0.12 inch diameter or heavier galvanized wire with a mirimum length of 10 inches for hook or " $J$ type pins.

\section{SEEDING MIXTURE AND PLANTING DATE}

The seed(s) and rate(s) specified on the Practice Requirements sheet and Native Plant Revegetation Palette shall be used.

The seeding rate(s) shall be the weight exclusive of any coating material. Any legume seed used shall be inoculated. Based on bag tags, seeding rates shall be acjusted to insure the required amounts of pure live seed.

Planting shall be performed after final grading is completed uniess otherwise speciled on the Practice Requirements sheet

\section{SEEDBED PREPARATION}

The area to be planted shal be weed free and have a firm seedbed which has previously beer roughened by scarifying, disking, harrowing. chiseling, or otherwise worked to a depth of 2 to 4 inches. No implement shall be used that will create an excessive amount of dowrward movement of clods on sloping areas Seedbed may be prepared at time of completion of earth moving work. The horizontal indentations left by tracked equipment is acceptable on steep slopes.

Rocks larger than 6 inches in diameter, trash, weecs, and other debris that will interfere with seeding or maintenance shall be removed

Seedbed preparation shall be suspended when soil moisture conditions are not suitable for obtaining a satisfactory seedbed.

\section{FERTILIZING, SEEDING, MULCHING \\ Fertilizing}

Fertilizer shall be distributed uniformly over the seedbed at the rate of 500 pounds per acre unless a different amount is specified on the Fractice Requirements sheet

Fertilizer shall be appled in any way that will resut in uniform distribution. The fertilizer shall be incorporated into the soil incorporation may be as part of the seedbed preparation, or as part of the seeding operation

\section{Seeding}

Seed shall be drilled or broadcast by hand mechanical hand seeder, of power operated seeder. Seed shall be incorporated into the soil, but not more than 1 inch deep

\section{Mulching}

A straw covering shall be distributed uniformly over the seeded area within 48 hours after seeding. Straw shail be applied at the rate of 2 tons per acre unless a different amount is specified on the Practice Requirements sheet. The straw shall be applied by hand, biower, or other suitable equipment. If straw is applied by blower, it shall not be chopped in lengths less than 6 inches

\section{Anchoring the Mulch}

The mulch shall be anchored in place using one of the following methods as specified on the Practice Requirements sheet.

\section{Method 1}

The straw shall be anchored using hand tools, mulching rollers, straight serrated disks, or similar types of suitable equipmert and shall be performed in a satisfactory marner. The straw shall be tucked in a minimum of 3 inches on a spacing not to exceed one foot in both directions

\section{Method 2}

The straw shall be anchored in place by the placement of fute native brush matting ef exceloior motting. The matting shall be appled up and down the slope and shall continue beyond the edge of the mulched or seeded area at least 1 foot at the sides and at the top and bottom of the mulched area. If existing vegetation or structures mark the boundaries of the area, the matting shall be continued into the stable vegetated area or to the edge of the structure. The matting shall be cut around objects so it will lay flat on the soil surface.

The upper end of the matting at the top of the area shall be buried in a trench at least 6 inches deep. Sides of rolls shall overlap at least 4 inches, and rolls shall overlap at least 3 feet 
where an uphill roll joins a downhill roll. The uphill soll shall overlie the downhill roll

Staples Wooden stakes or native brush cuttings shall be installed perpendicular to the slope and shall be spaced aporoximately 5 feet apart down the sides in the overlap area and center of the roll Staples Wooden stakes $\alpha$ native bursh cuttings spaced not more then 1 foot apart shal be installed across the upoer end of each roll and across the overlap area where an uphill roll joins a downhill roll.

\section{Method 3}

The straw mulch shall be anchored in place by covering the mulch with plastic netting. The netting shall be applied up and down the slope and shall cortinue beyond the edge of the muiched area at least 1 foot at the sides and at the top and bottom of the area

The upper end of the netting at the top of the area shall be buried in a trench at least 6 inches deep. Sides of rolls shall overlap at least 4 inches and rolls shall overlap at least 3 feet where an uohill roll joins a downhill roll. The uphill rall shall overlie the downhill roli

Staples shall be installed perpendicular to the slope and shall be spaced 5 feet apart in both directions. The staples on the exterior edges of the netting shall be spaced 5 feet apart.

\section{Method 4}

No anchoring is requited.

\section{IRRIGATION}

When specified, irrigation water shall be applied duning the establishment period at the times and rates as listed on the Practice Requirements sheet.

\section{OTHER REQUIREMENTS}

Other details for the establishment and maintenance of the plants including but not limited to the need for livestock and traffic control shall be applied when specified on the Practice Requirements sheet.

Measures and methods that enhance fish and wildife values, protect visual resources, and maintain key shade, lood, and den trees shall be performed when specified on the Practice Requirements sheet

Operations shall be done in such a mamer that soil erosion and air and water pollution are minimized and held within legal limits.

The owner, operator, contractor, or other persons shall conduct all work and operations in accordance with proper safety codes for the type of work being performed with due regards to the safety of all persons and property 


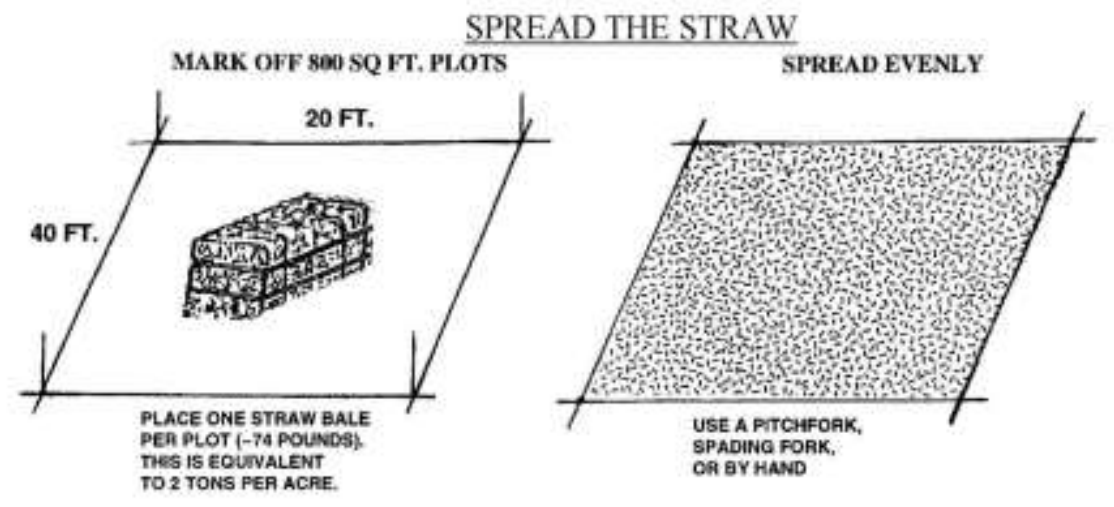

$\triangle$ NCHOR THE STRAW - METHOD 1

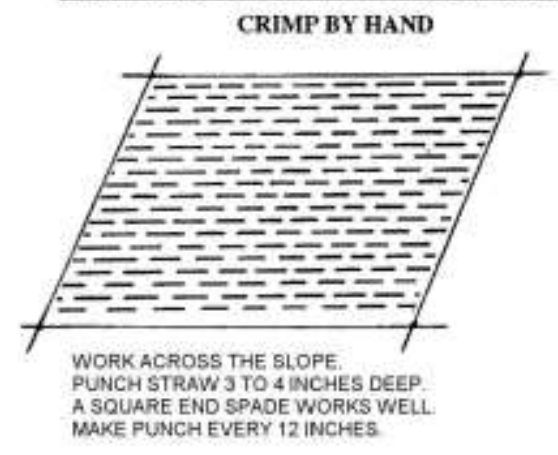




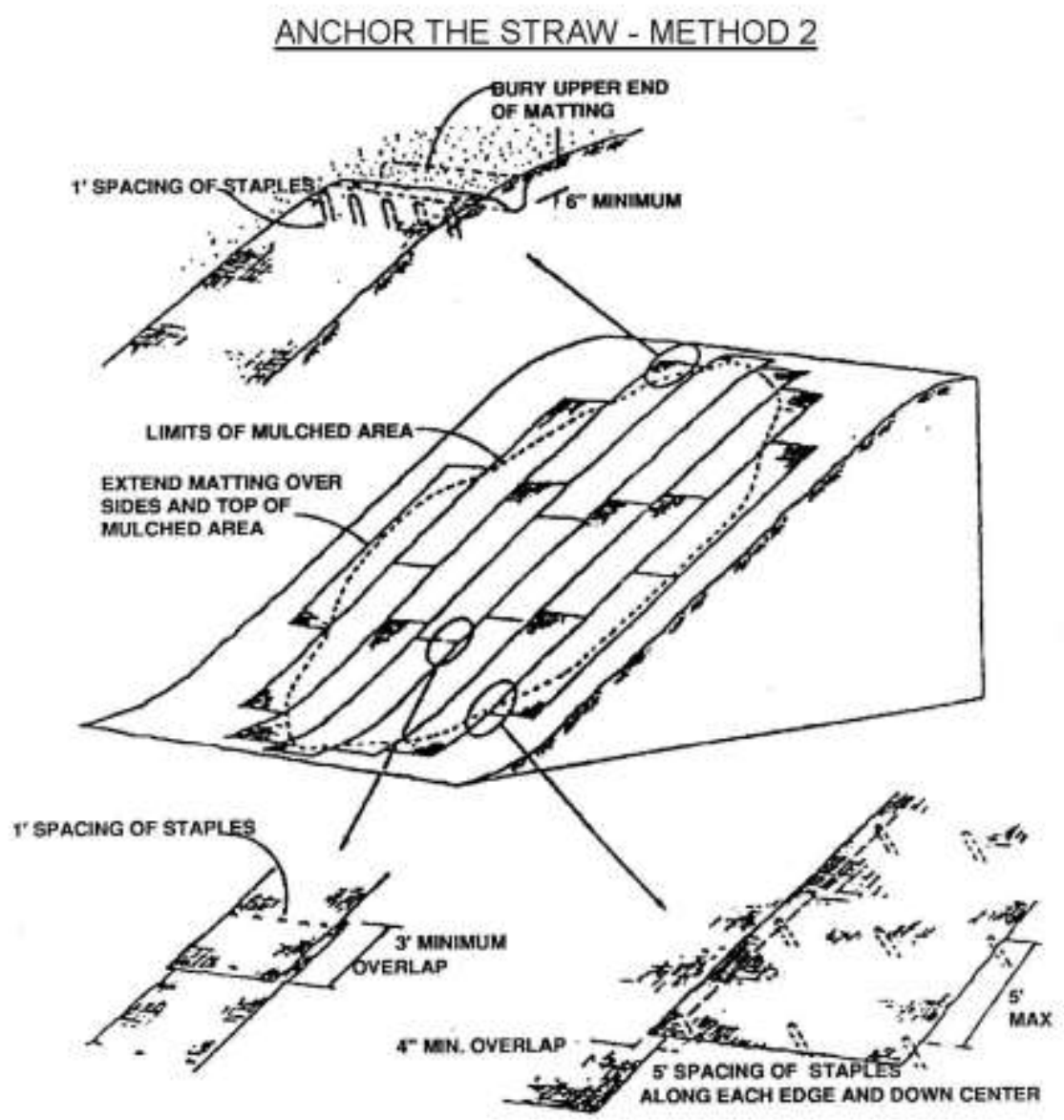




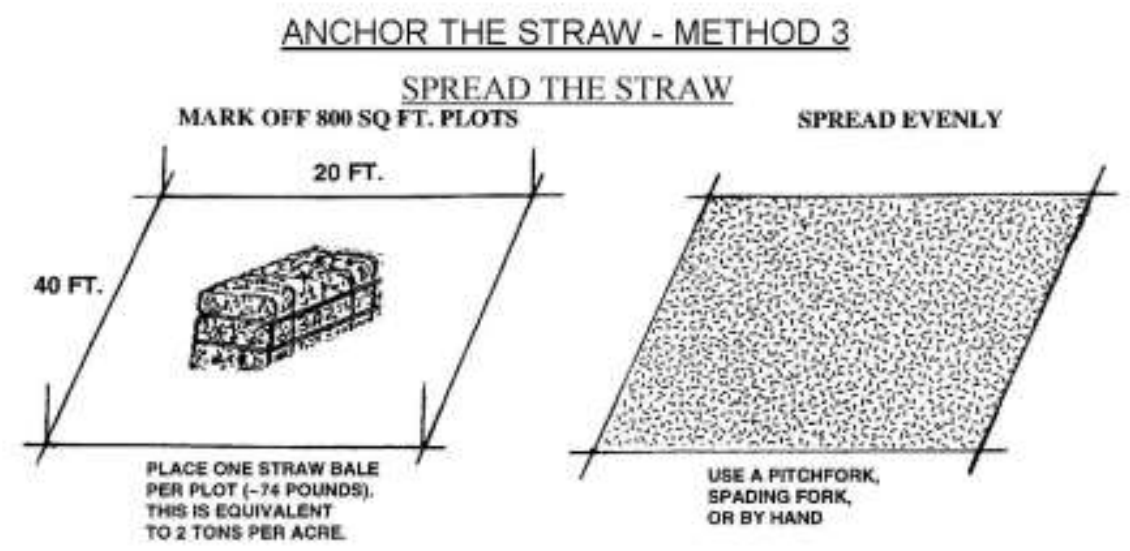

ANCHOR THE STRAW - METHOD 3

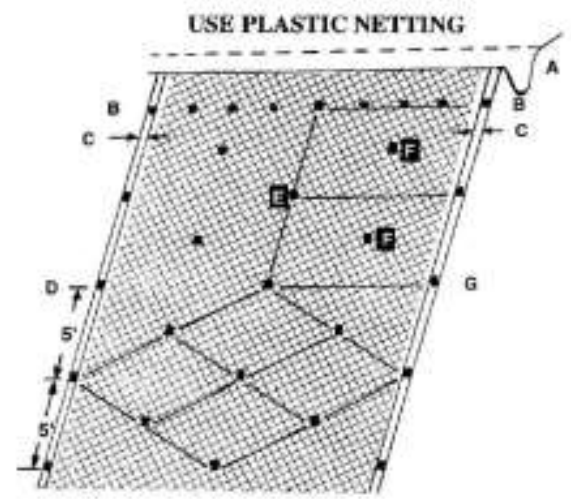

LAY BIRD CONTROL NETTING OR SIMILAR MATTING IN STRIPS DOWN THE SLOPE OVER THE STRAW. BURY UPPER END IN 6-8 INCH DEEP AND WIDE TRENCH. MOST NETTING COMES IN 14 TO 17 FT. WIDE ROLLS.

SECURE THE UPPER END WITH STAKES EVERY 2 FEET.

OVERLAP SEAMS ON EACH SIDE 4-5 INCHES.

SECURE SEAMS WITH STAKES EVERY 5 FEET.

STAKE DOWN THE CENTER EVERY 5 FEET.

STAKE MIDDLES TO CREATE DIAMOND PATTERN THAT PROVIDES STAKES SPACED 45 FEET APART.

USE POINTED $1 \times 2$ INCH STAKES 8 TO 9 INCHES LONG. LEAVE 1 TO 2 INCH TOP ABOVE NETTING, OR USE "U" SHAPED METAL PINS AT LEAST 9 INCHES LONG.

NOTE WHEN JOINING TWO STRIPS, OVERLAP UPPER STRIP 3 FEET OVER LOWER STRIP AND SECURE WITH STAKES EVERY 2 FEET LIKE IN "B* ABOVE. 


\section{NATURAL RESOURCES CONSERVATION SERVICE}

\section{CONSERVATION PRACTICE SPECIFICATION}

\section{G - CRITICAL AREA PLANTING - WOODY CUTTING}

\section{SCOPE}

The work shall corsist of furnishing all materials and placing them within the project area or sile to the limits as shown on the drawings, or as staked in the field.

\section{MATERIALS}

Woody cuttings shall be made from healthy green plarts during the dormant season. No more than 2/3ds of each plant will be removed Select cuttings with leat bucts near the top of each cut

Stem or branch cuttings of soft wood hard wood or firm wood should be taken whenever possible from plants that are native to the locality or grown on similar sites

Cuts shall be made clean with sharp tools. The butt end of the stem shall be a slant cut and the tip end shall be cut square across the stem

Size:

Slips. The diameter of the cutting shall not be more than $11 / 2$ inches at the butt end nor smaller than $1 / 4$ inch at the tip. Cuttings shas have a minimum length of 2 feet and a maximum length of 4 feet unless otherwise specified on the Practice Requirements Sheet.

Poles: The diameter of the cutting shall not be more than 4 inches nor smaler than linch at the butt end and $1 / 2$ inch at the tip. Cuttings shall have a minimum length of the depth to the water table plus 3 feet uniess otherwise specified on the Practice Requirements Sheet

Cuttings shall not be allowed to dry and shall not be more than 7 days old when planted uniess otherwise specified on the Practice

Requirements sheet

\section{PLANT MATERIALS AND PLANTING} DATE

The kinds of cuttings specified on the Practice Requrement sheet shall be used
Planting shall be performed after final crading is completed unless otherwise specified on the Practice Requirements sheet.

\section{SITE PREPARATION}

The area to be planted shall be weed free and have a uniform surface. No implement shall be used that will create an excessive amount of downward movement of clods on sloping areas The site may be prepared at time of completion of earth moving work.

Trash, weeds, and other debris that will interfere with planting or maintenance shall be removed

\section{PLANTING REQUIREMENTS}

Cuttings stall be planted in one or more fows as shown on the drawing(s) as vertical as possible. Cuttings shall be spaced 3 teet apart in the row and in multiple row plantings, specing between rows shall be 3 feet. Cuttings shall be staggered with respect to those in adjacent rows unless otherwise specified on the Practice Requirement sheet

Cuttings shall be planted in prepared holes or "V" furrows to avoid stripping the bark. especially in rocky or hard soils. Cuttings mary be pushed into soil if the soil is saturated wath moisture Cuttings shall be placed in the soil with the butt end in a dowrward position

All cuttings shall have 6 inches to a maximum of 1 foot including at least two nodes above the ground level

Cuttings shall be placed into the soil to a depth specified on the Practice Requirements sheet. If however due to some physical condition in the soil this planting depth cannot be attained, the cuttings shall be set with $3 / 4$ of its length in the soil upon approval of the NRCS technician. At a minimum they must be placed into the sol 18 inches.

Poles: Plant in adequately sized, sod-free holes Auger a hole to the water table. Place materials in the augured hole one-half foot above the growing season water table. 
After planting pack the soil firmly around each pole to eliminate air pockets "Mudding" by

filling the hole with water and then adding more soil to make a slurfy tan remove air pockets.

\section{IRRIGATION}

When specified, irrigation water shall be applied at the times and rates as listed on the Practice Requiremerts sheet to keep the soil in the lower two feet of the planted cutting moist.

\section{SPECIAL MEASURES}

Measures and methocts that enhance fish and wildife values, protect visual resources, and mairtain key shade, focd, and den trees shall be performed when specified on the Practice Requirements sheet

\section{OTHER REQUIREMENTS}

Other details for the establishmert and maintenance of the plants including, but not limited to, the need for Iivestock and traffic control shall be applied when specified on the Practice Requirements sheet.

Operations shall be done in such a manner that erosion and air and water pollution are minimized and held within legal limits.

The owner, operator, contractor, and other persons shall conduct all work and operations in accordance with proper safety codes for the type of equipment and operations being performed with oue regarcts to the safety of all persons and property

Page 63 of 65 


\section{SCOPE}

The work shall consist of furnishing of materials and constructing streambank protection

measures to the lines, grades, elevations and dimensions as shown on the drawings or as staked in the field.

\section{SITE PREPARATION}

Trees and brush on the banks as marked in the fieid or shown on the drawings shall be removed and disposed of in designated areas. Removal of any trees and brush shall be done in such a manner as to avoid damage to other trees and property. Disposal of trees brush, and other materials shail be performed to have the least detrimental effect on the environment

Fallen trees, stumps, debris, minor ledge outcroppings and sand and gravel bars as shown an the drawings shall be removed and disposed of in designated areas

Clearing and disposai methods shail be in accordance with state and county laws with due regard to the safety of persons and property.

\section{BANK PROTECTION MEASURES}

The type and extent of benik protection measures shall conform to the structural requiremerts of the specifications listed on the Practice Requirements sheet

\section{FENCING}

Fencing shall be installed at locations and of the materials shown on the drawings.

\section{VEGETATIVE COVER}

Unless otherwise specified, a protective cover of vegetation shall be established on the disturbed area. The planting of vegetative materials shall conform to the requirements of Practice Specification 342, Critical Area Planting

\section{SPECIAL MEASURES}

Measures and construction methods shall be incorporated as needed and practical that enhance fish and wildife values. Special attention shall be given to protecting visual resources and maintaining key shade, food and den trees

\section{CONSTRUCTION OPERATIONS}

Construction operations shall be done in such a manner that erosion and ait and water pollution are minimized and held within legal limits. The owner, operator, Contractor or other persons wil conduct all work and operations in accordance with proper safety codes for the type of construction being performed with due regards to the safety of all persons and property

The completed job shall be workmanlike and present a good appearance 


\section{NATURAL RESCURCES CONSERVATION SERVICE \\ CONSERVATION CONSTRUCTION SPECIFICATION}

909 - CONTROL OF WATER

\section{SCOPE}

The work shall consist of the removal of surface water and ground water as needed to perform the required construction in accordance with the specifications. It shall include (1) building and maintaining all necessary temporary impounding works, channels, and diversions, (2) furnishing. installing and operating all necessary pumps piping and other facilities and equipment, and (3) removing all such temporary works and equioment after they have served theif purposes. All work shall be done in a manner approved by the engineer.

\section{DIVERT NG SURFACE WATER}

The Contractor shall build, maintain and operate all cofferdarns, channeis, flumes, sumps, and other temporary diversion and protective works needed to divert streamflow and other surface watec through or around the construction site and away from the construotion work while construction is in progress: Urless otherwise specified, a diversion must discharge into the same natural drainage way in which its headworks are located.

\section{iII. DEWATERING THE CONSTRUCTION SITE}

Foundation cutoff trenches and other parts of the construction site shall be dewatered and kept free of standing water or excessively muddy conditions as needed for proper execution of the construction work. The Contractor shall furnish, install, operate and maintain all drains, sumps, pumps, casings, well points, and other equipment needed to pertorm the dewatering as specified

Dewatering methods that cause a loss of fines from the foundation aress will not be permitted

\section{DEWATERING BORROW AREA}

Unless othenwise specified in the 'Practice Requirements" sheet, Contractor shall maintain the borrow areas free of surface water or otherwise provide for timely and effective removal of surface waters that accumulate within the borrow areas from any source.
Borrow material shall be processed as necessary to achieve proper and unform mosture content for placement

If pumping to dewater area is included as an item of work in the bid schedule, each pump used for this purpose shall be equipped with a water meter in the discharge line. Acouracy of the meters shall be such that the measured quartity of water is within 3 percert, plus or minus, of the true quartity

Means shall be provided by the Contractor to check the accuracy of the water meters when requested by the engineer

V. REMOVAL OF TEMPORARY WORKS

After the temporary works have served their purposes, the Contractoc shall remove them or level and grade them to the extent required to present a sightly appearance and to prevent any obstruction of the flow of water or any other interference with the operation of or access to the permanent works

Except as otherwise specfied in the "Practice Requirements' sheet, pipes and casings shail be removed from temporary wells and the wells shall be filled to ground level with gravel or other material approved by the engineer

\section{EROSION AND POLLUTION CONTROL}

Removal of water from the construction site, including the borrow areas, shall be accomplished in a manner that erosion and the transporting of sediment and other pollutants are mirimized. Dewatering activities shall be accomplished in a manner that the water table water quality is not altered.

VII SPECIAL MEASURES

Measures and construction methods shall be incorporated as needed and practical that enhances fish and wildife values Special attertion shall be given to protecting visual resources and maintaining key shade, food, and den trees 
D. PHASE II ENGINEERING DOCKET 


\section{ENGINEERING DOCKET ${ }^{1}$}

\section{LOWER SCOTTS CREEK FLOODPLAIN AND HABITAT ENHANCEMENT PROJECT PHASE ॥}

Project Job Codes: $342 \mathrm{~A}, 342 \mathrm{G}, 395,580$ and 734

Engineering Class: $\mathrm{V}$

Prepared For:

Santa Cruz County Partners in Restoration Permit Coordination Program (PCP)

Santa Cruz County Resource Conservation District (RCDSCC)

In Cooperation with Cal Poly

Brian C. Dietterick, Ph.D.,P.H

Director, Swanton Pacific Ranch

College of Agriculture, Food, and Environmental Sciences

Cal Poly State University, San Luis Obispo

Prepared by:

Ben Cook

Graduate Assistant in Hydrology

Natural Resources Management and Environmental Sciences Departmont

Cal Poly State University, San Luis Obispo, CA 93407

cell: (831) 345-0508

bocook@calpoly.edu

With assistance from:

Mark Barnett, P.E.

Natural Resource Conservation Service

Central Coast Team Engineer

65 South Main Street, Suite 105

Templeton, CA 93465

(805) 434-0396, Ext 117

Mark. Barnett@ca. usda gov

April 2015

1 Please see the LSCFHEP Phase II 100\% Design Submittal Planset for project dimensions and specifications 


\title{
CALIFORNIA NATURAL RESOURCES CONSERVATION SERVICE
}

\author{
Project: \\ Lower Scotts Creek Floodplain and Habitat Enhancement Project Phase II \\ NRCS Practices: $\quad$ Stream Habitat Improvement and Management (395) \\ Streambank and Shoreline Protection (580) \\ Fish and Wildife Structure (734) \\ Critical Area Planting -Straw Mulch (342A) \\ Critical Area Planting -Woody Cuttings (342G) \\ Landowner: Cal Poly Corporation \\ Location: \\ 125 Swanton Road, Davenport, CA \\ County: \\ Santa Cruz \\ $\mathrm{RCD}$ : \\ Santa Cruz County \\ NRCS Office: $\quad$ Templeton Field Office, \\ Contract No: N/A
}




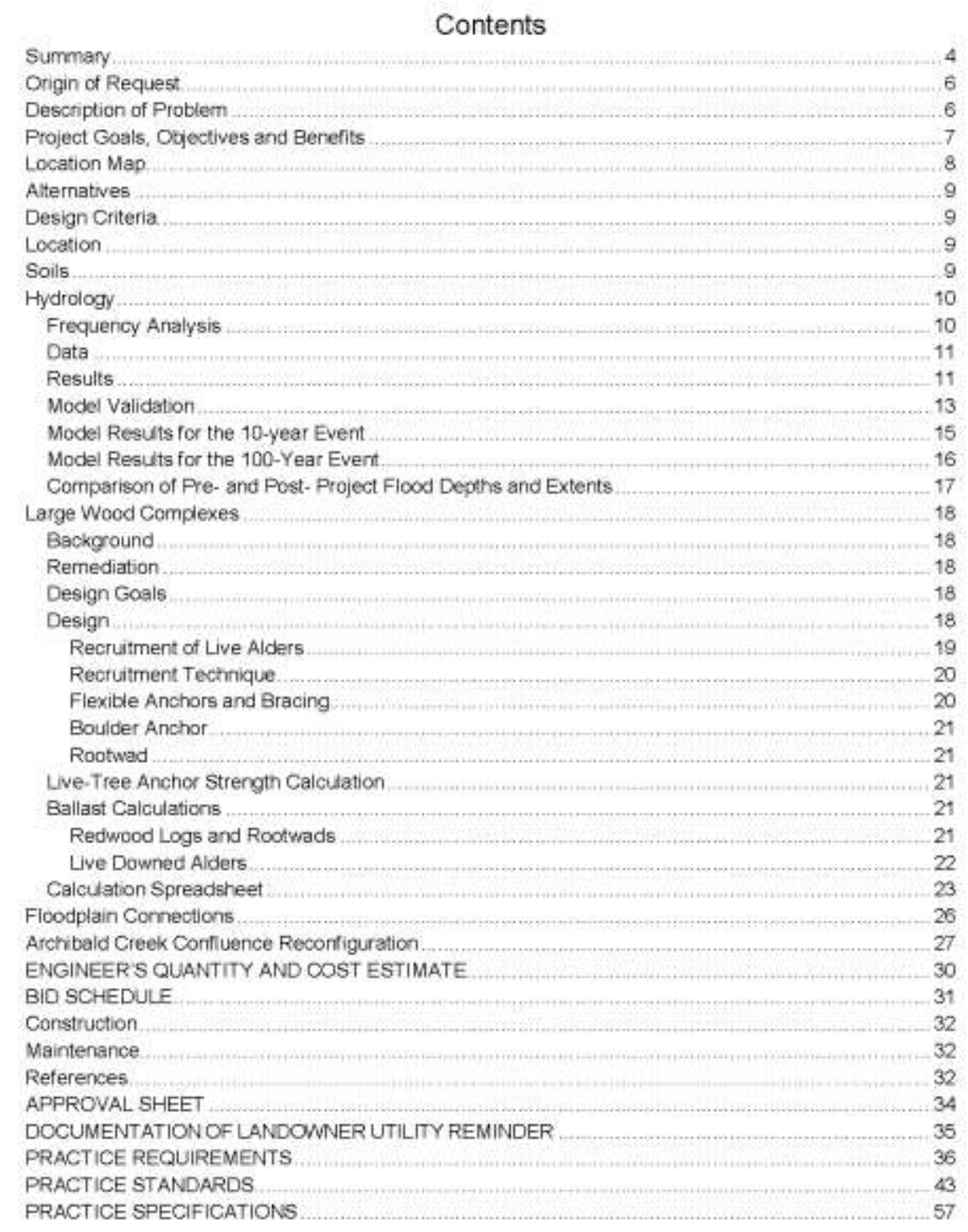




\section{Summary}

The proposed project will construct nine ( 9 ) instream wood complexes, grade two backwater connections with two existing off-channel ponds, grade one backwater connection with an existing floodplain drain, and reconfigure the confluence area of Archibald Creek to form a backwater connection with Scotts Creek. All activities will take place on lower Scotts Creek. located in Santa Cruz county, California, approximately 12 miles north of the city of Santa Cruz. The project reach is between 3100 and 6100 feet upstream from the CA-1 bridge. Below are detailed descriptions of each of the project elements. All features described below are named by river station, and all stationing is in feet upstream from the CA-1 bridge. Please see the attached $100 \%$ design submittal planset for detailed construction drawings, including a table of grading volumes and areas.

\section{0 and 3850}

The proposed project will improve connectivity between Scotts Creek and two existing floodplain ponds by grading connection channels through portions of the left bank and floodplain, and by grading alcove pools where these connection channels meet Scotts Creek. Wood features will be constructed instream to focus flows through or stack water up into the confluence areas of these improved backwater connections. The alcove pools will become functional at baseflow conditions. The connection channels will become functional at or above baseflows and fully connect the ponds and floodplain to Scotts Creek at bankfull. These connections will provide alcove and off-channel refuge and foraging habitat, improve access to floodplain refuge and foraging habitat, and provide a return flow path to the main channel for salmonids on the receding limb of flood flows, thereby reducing the potential for floodplain stranding.

The connection channel bottoms will be graded level at the elevation of the existing pond tail crests. The alcove pool bottoms will be graded level at the elevation of the streambed above the low-flow waterline at the time of construction.

4250

Create one new backwater connection channel connecting the main channel of Scotts Creek to an existing hydrologic feature located on the adjacent floodplain. Where the connection channel meets the main channel of Scotts Creek, one alcove pool will be inset into the left bank of Scotts Creek, and one instream large wood complex will be constructed in Scotts Creek to focus stream flow through or stack water into the alcove pool to maintain connectivity. 
This improved connection is expected to provide alcove and off-channel refuge and foraging habitat for salmonids over a range of flow conditions from winter base to peak flows, improve access to floodplain refuge and foraging habitat for salmonids during peak flows, and provide a return flow path to the main channel for salmonids on the receding limb of flood flows, thereby reducing the potential for floodplain stranding.

The connection channel bottom will be graded level at the elevation of an existing hydrologic feature on the adjacent floodplain. The alcove pool bottom will be graded level at the elevation of the streambed but above the low-flow waterline at the time of construction.

Archibaid Creek Backwater Connection

The following two features will reconfigure the confluence where Archibald Creek meets Scotts Creek to form a backwater connection and alcove pool by utilizing an existing low-gradient secondary channel to Archibald Creek.

$\underline{5850}$

A short connector channel will be excavated to partially divert flow from Archibald Creek into an existing secondary channel to Archibald Creek. This feature will become functional intermittently whenever stormflows are present in Archibald Creek.

$\underline{5650}$

A low-gradient backwater connection channel and alcove pool will be constructed on the left bank and floodplain of Scotts Creek to connect the existing Archibald Creek secondary channel to Scotts Creek. The bottom of the alcove pool will be graded at the elevation of the streambed above the low-flow waterline at the time of construction. The backwater connection channel will be graded at $2-3 \%$, connecting the bottom of the alcove pool to the bottom of the existing secondary channel. One instream large wood complex will be constructed in Scotts Creek to focus stream flow through or stack water into the alcove pool to maintain connectivity.

The new configuration will form a backwater connection with Scotts Creek and a low-gradient side-channel component of Archibald Creek. This feature will become functional as a backwater connection at or above basoflows in Scotts Creek, and as a low-gradient side-channel for Archibald Creek when Archibald Creek flows at or above baseflows.

Instream Wood Complexes

Construct nine instream wood complexes using a combination of materials including in-situ red alders, imported redwood logs and rootwads, and imported boulders, 
Five of these wood complexes will be distributed along two sub-reaches of low complexity: two wood complexes will be constructed between stations 3400 and 3600 , and three wood complexes will be constructed between stations $4600-4900$. These wood complexes will increase channel complexity, provide instream cover, improve sediment sorting, and encourage the formation of instream pool habitat.

Four of these wood complexes will be constructed to focus flows through or stack water up into each of the four proposed backwater connections at stations $3300,3900,4400$, and 5600 (one wood feature at each backwater feature). These four wood complexes will be configured to maintain sediment transport, stack water, provide instream cover, and encourage pool formation at each of these backwater confluence areas.

\section{Project Access}

The project sites are accessible from proposed spur access roads stemming from an existing dirt road which parallels the project reach. Vegetation will be removed to clear the proposed spur access roads. No earthwork is proposed in order to develop access to the project sites.

\section{Origin of Request}

The Resource Conservation District of Santa Cruz County (RCDSCC) requested a design for a restoration project on Lower Scotts Creek, as a component of the Integrated Watershed Restoration Program (WRP), and in fulfiliment of a restoration design funded by the California Coastal Conservancy.

\section{Description of Problem}

Past land practices included straightening and dredging lower Scotts Creek, clearing the riparian corridor for farming, and constructing levees along lower Scotts Creek from the Highway One Bridge to Archibald Creek. Large flood events including the debris torrents of 1940 and 1955 scoured the main channel and riparian corridor of the lower watershed.

These past disturbances are accepted to have impaired critical habitat conditions and hydrologic processes on lower Scotts Creek. Floodplain connectivity is limited by the presence of a deteriorating levee adjacent to lower Scotts Creek. The levee continues to limit the amount of accessible instream, side-channel, and floodplain refuge habitat for ESA listed saimonids. Lower Scotts Creek remains in a channelized state as a result of riparian encroachment and efforts to maximize the area of agricultural land on the adjacent floodplain. Stream complexity remains low compared with upper reaches; limiting the availability of alcove refuge habitat and 
escape cover for salmonids. Channelization has likely increased main channel velocities over pre-agrarian levels, contributing to harsh instream conditions during storm flow events.

Fisheries biologists speculate that harsh instream conditions combined with a lack of refuge habitat limits saimonid production on lower Scotts Creek by increasing overwintering juvenile mortality.

\section{Project Goals, Objectives and Benefits}

The National Marine Fisheries Service Coho Recovery Plan calls for "rehabilitat[ing] and enhanceling] floodplain connectivity" by "encourag[ing] breaching of old levees in the lower riparian reaches of Scott Creek' and 'reclaim[ing] alcove and side channels for winter refugia and summer rearing" (NMFS 2012 [Final Plan], p. 924).

The proposed project is expected to remediate the negative impacts of historic land use practices for the benefit of ESA-listed saimonid species. The proposed backwater connections will increase access to alcove, off-channel, and floodplain refuge habitat for salmonids over a range of flows from base to peak flows.

Secondary benefits to salmonids include reducing the potential for stranding during flood events by providing additional return flow paths between the floodplain and the main channel of Scotts Creek, increasing foraging opportunities for salmonids and increasing nutrient availability in the main channel by improving floodplain exchange, and improving instream habitat conditions by increasing channel complexity.

The construction of instream wood complexes will increase habitat complexity, provide escape cover, and provide instream refuge opportunities by encouraging the formation of scour pools. backwater pools, and by dissipating stream energy. Instream wood complexes are also expected to improve sediment sorting, which may provide additional spawning habitat. Instream wood complexes constructed at the confluence areas of each of the four pond, tributary, and drain connections are expected to provide the additional function of directing flows and maintaining sediment transport through, or stacking water into, the confluence areas of these features. 


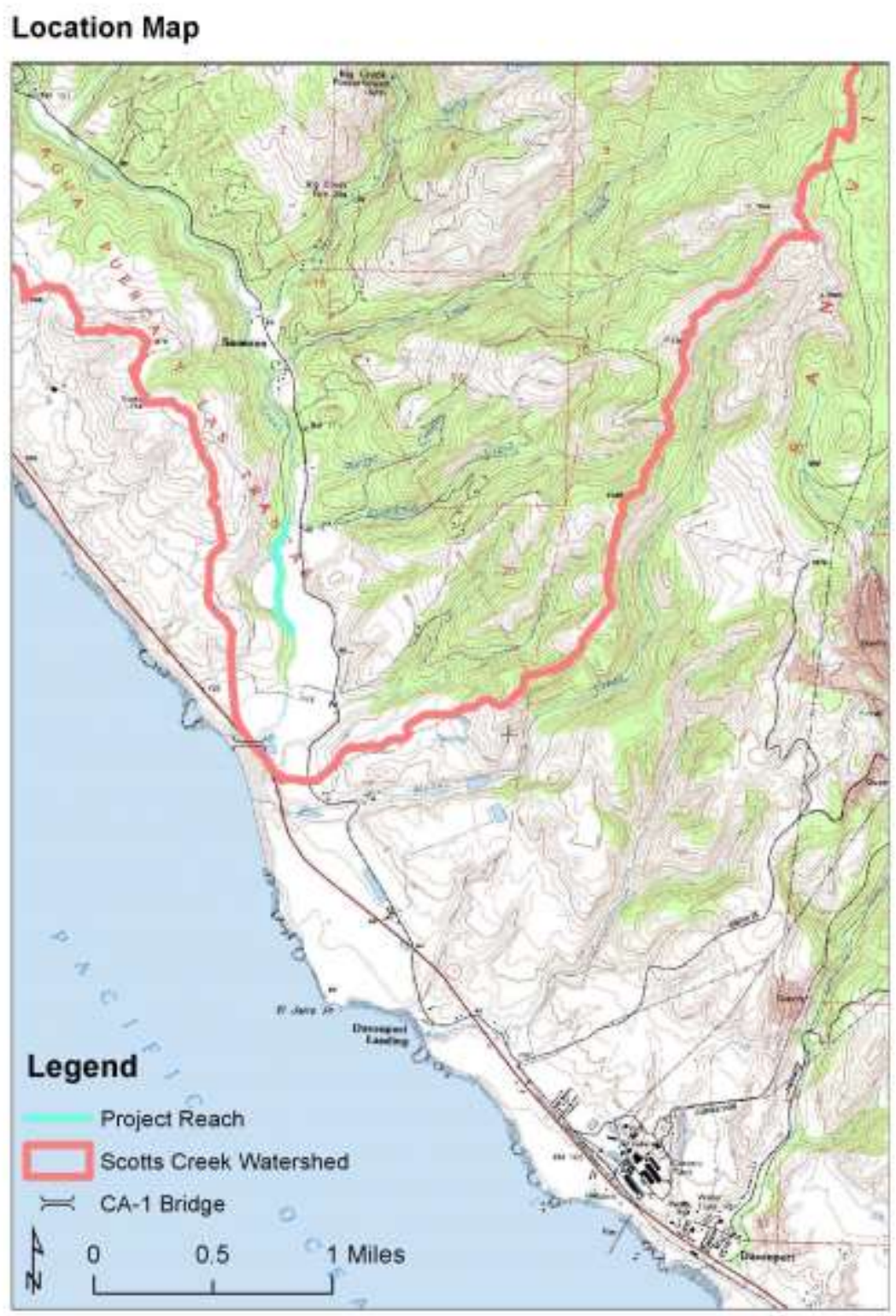

Figure 1. Location of the project reach on the USGS Davenport Topographic Map 


\section{Alternatives}

The two primary alternatives considered were:

1) Do nothing

2) implement the proposed project

Aiternative two was chosen based on the analysis and recommendations provided by the National Marine Fisheries Service Final Coho Recovery Plan, to address the historic loss of critical CCC coho ESU habitat, address the limiting factors in the Scotts Creek watershed, and prevent further decline of the species.

\section{Design Criteria}

The proposed design is in accordance with the following NRCS Design Standards:

Stream Habitat Improvement and Management (395)

Streambank and Shoreline Protection (580)

Fish and Wildlife Structure (734)

\section{Location}

The project is located on lower Scotts Creek, two miles north of Davenport, Calfornia, in Santa Cruz County (see Figure 1). The project reach spans from 3100-5900 feet upstream from the CA-1 Bridge over Scotts Creek. The project site is between 13 and 33 feet in elevation.

\section{Soils}

Soils data for the project area was obtained from the NRCS Web Soil Survey mapping tool and field observations conducted by Cal Poly personnel.

According to NRCS Web Soil Survey data, three types of soils may be present in the project area: Elder sandy loam (0-2\% slopes). Soquel loam ( $0-2 \%$ slopes), and Bonnydoon-Rock outcrop complex (50-85\% slopes). The latter soil type likely applies to the steep cliff formation on the west side of the stream channel.

In general, the project reach flows on the western edge of a low, wide, alluvial floodplain. The present location of the main channel on the western edge of the floodplain is likely a result of historic channel modifications related to agricultural practices dating back 200 years. 
A Cal Poly faculty member and graduate student took soil samples at three locations within the project area on the levee on the east bank of the stream channel in the summer of 2013. The team identified all three samples as sandy loam.

Soils data will inform staging, site access, excavation, backfill and revegetation methods related to the proposed project.

\section{Hydrology}

- Drainage area: 30.0 square miles

- Average annual precipitation: 40 inches

- The Santa Cruz County PCP specifies the 10 year storm event as the required design storm or $2500 \mathrm{cfs}$.

Frequency Analysis

M.C. Scrudato performed an extensive hydrologic analysis of the Scotts Creek vatershed as part of his 2010 Master's thesis. Results from his analysis are summarized below.

Scrudato examined two potential stream gage locations for monitoring peak flow in lower Scotts Creek, near Davenport, CA, to determine the most suitable location for capturing peak flow measurements.

To facilitate this comparison, Scrudato conducted extensive flood frequency analysis of historic flow data using a Log-Pearson III Frequency Analysis, The U.S. Interagency Advisory Committee on Water Data (IACWD) recommends the Log-Pearson Type III analysis. "It is the standard method used by the USGS for flood studies" (Scrudato, 2010). The LACWD describes the procedure in Bulletin 178: Guidelines for Determining Flood Flow Frequency (1982).

Log-Pearson Type III Analysis is a statistical method for estimating the magnitude and recurrence interval for peak discharge events using a Log-Pearson type III frequency distribution. The frequency distribution is estimated from the mean, standard deviation, and skewness of historic data.

Bulletin 17B's procedure for calculating the skew coefficient is:

$$
\left.G S=(N /(N-1)) N-2) S^{3}\right) \sum_{i=1}^{N}\left(X_{i}-\tilde{X}\right)^{3}
$$




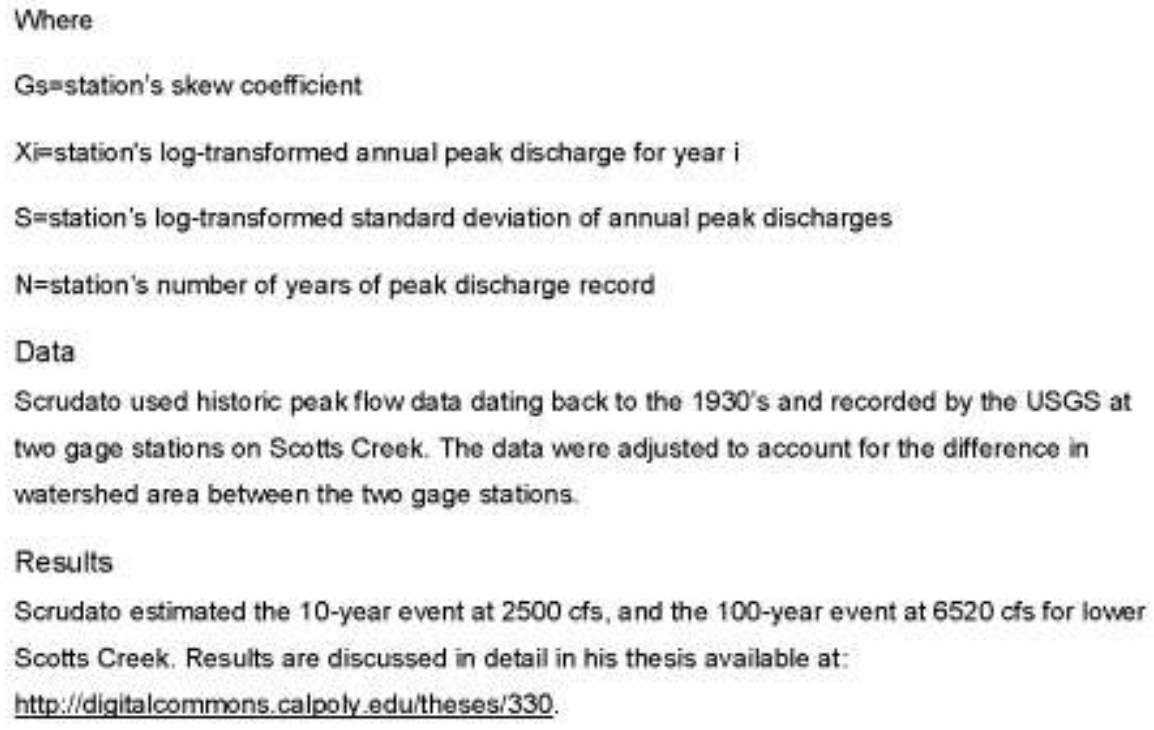




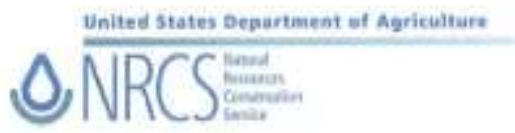

Kelli Camara-Lasher Program Manager

Resource Conservation District of Santa Cruz County

820 Bay Avenue, Suite 128

Capitola, CA 95010

Dear Kelli,

As required by the PCP, a hydraulic evaluation has been developed for the proposed installation of large wood material (LWM) within the main channel of Scotts Creek. The purpose of the LWM is to enhance habitat for Coho and other aquatic wildifife.

Based on hydraulic modeling and field evaluation, installation of the proposed design will not cause a significant increase in the base flood elevation (BFE) or change channel velocity upstream, at or downstream of the project site. Adjacent structures also will not be affected any differently than the current BFE as a result of the project. The fioodplain is large, complex, and has a high roughness which effectively governs water surface elevations for the BFE.

Feel to contact me if you have any questions or comments.

Sincerely,

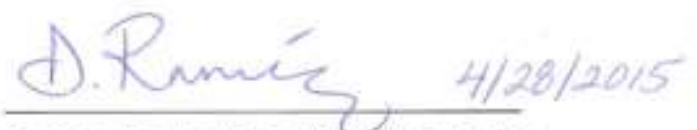

Desideria Ramirez, P.E. NRCS Area Engineer 
Modeling to Determine Hydraulic Design Parameters*

Based on flow parameters found in Scrudato, 2010, a HEC-RAS model of lower Scotts Creek was created to determine flow velocities, shear stresses, and depths in the project reach.

Modeling results and hydraulic calculations for Phase I, implemented in 2014, were utilized and assumed to be representative of the Phase II project reach because the Phase II project reach is immediately upstream from the Phase I reach, and virtually identical in terms of average channel gradient, channel cross-sectional geometry, and flow regime.

Model Validation

Steady flow modeling for lower Scotts Creek was performed for the December 23-24 2012 storm event in the Scotts Creek watershed. The stream gage at Archibald Creek recorded a peak flow depth of 7.02 ; corresponding to an estimated discharge of $1908 \mathrm{cfs}$, derived from a rating curve developed for that gage station. These data, along with roughness estimates were used to parameterize the HEC RAS model. On a technical note, the model geometry was extracted from a digital elevation model (DEM) of the Scotts Creek watershed, using the HEC GeoRAS extension for ESRI ArcMap. The DEM was created from airbome LiDAR data, flown in March of 2010. The LiDAR reflected off of the surface of the water in the main channel, and does not represent the true channel bottom. Cal Poly's stream gage recorded a flow depth of 1.93 ' at a discharge of 88 cfs at the time of the LiDAR flight. Field observations indicate that depth readings at the gage location are representative of the project reach.

This flow event produced significant flooding, and the extents of the flooding were mapped using GPS following the event. The model results were compared to the GPS points and were found to be in close agreement (Figure 2). No adjustments were made to the model parameters to achieve this agreement. All initial estimations of roughness were maintained and default calculation methods were used. The model appears to have slightly overestimated the extent of flooding for most cross sections. 


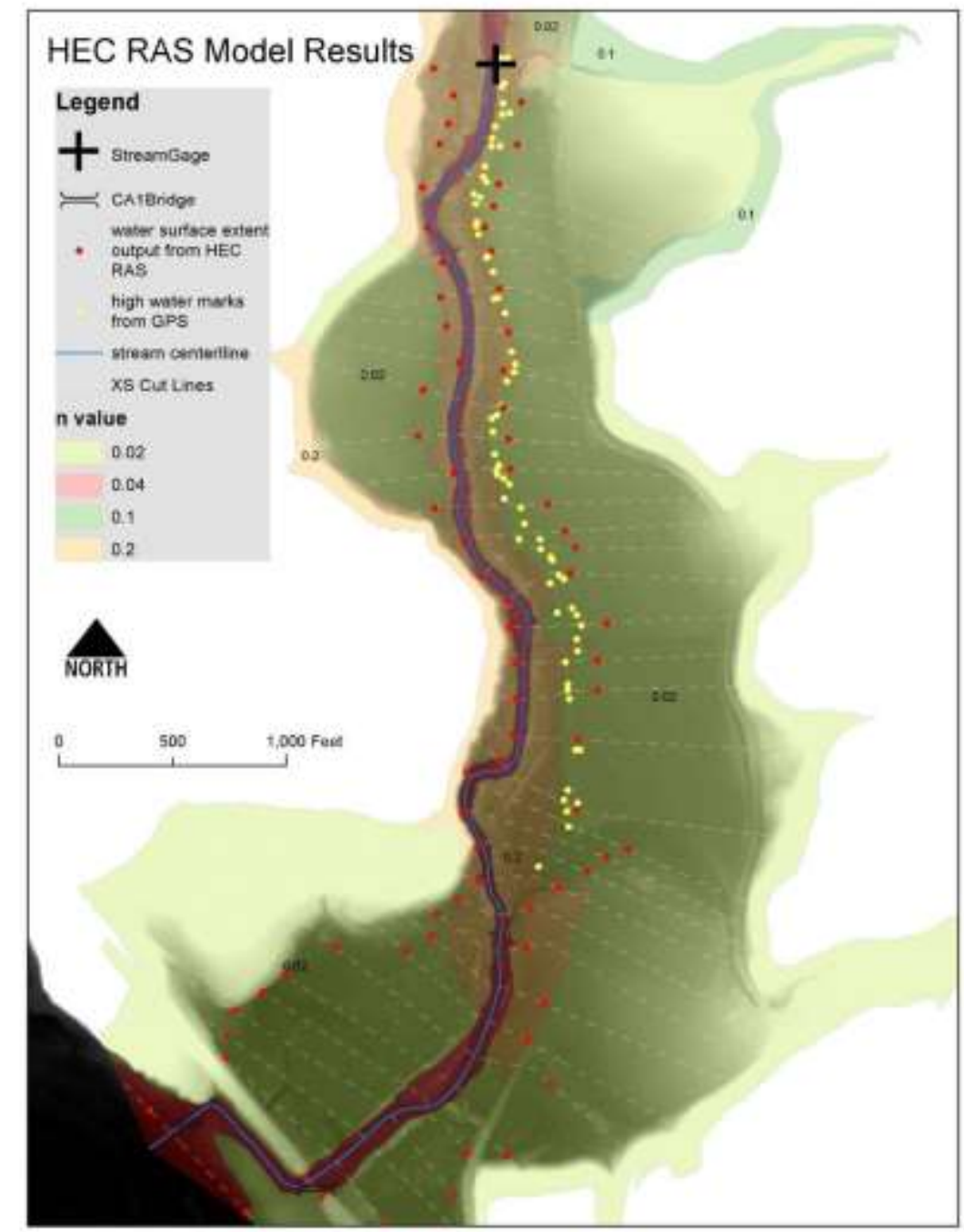

Figure 2. HEC RAS model validation results for lower Scolts Creek comparing actual (yellow) to modeled (red) flood exdents for the December 23-24" 2012 stom event with a discharge of $1908 \mathrm{cts}$. 
Model Results for the 10-year Event

For the 10-year event design storm flow, the average velocity was 5.2 fps with a peak velocity of $7.3 \mathrm{fps}$ in the project reach. The average shear stress was $0.84 \mathrm{lbs}_{\mathrm{ft}} \mathrm{t}^{2}$ and the maximum shear stress was $1.75 \mathrm{lbs} / \mathrm{ft}^{2}$. Hydraulic depth varied from 3.7 to 6.0 feet with an average of 4.9 feet.

These depths exceeded the bankfull depth. Figure 3 shows velocities, shear stresses, and hydraulic depths at each cross section within the project reach for the 10 year event.

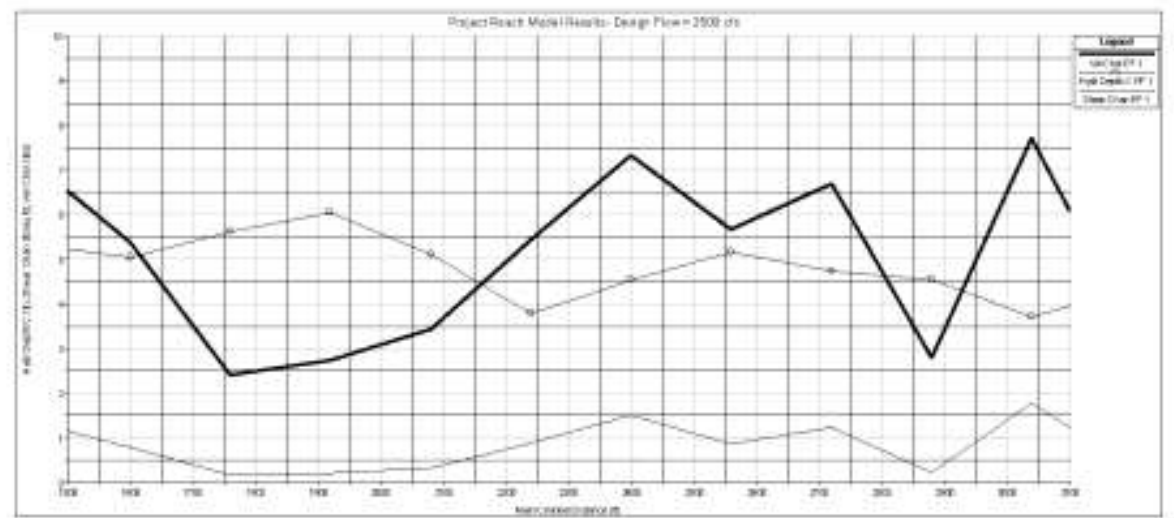

Figure 3. HEC RAS model /esults for velocity, tydraulic depth and shear, in the project reach at the design flow of 2500 cfs.

The model resulted in left and right overbank flow (Figure 4), Most of the flooding occurred on the left bank of the main channel. 


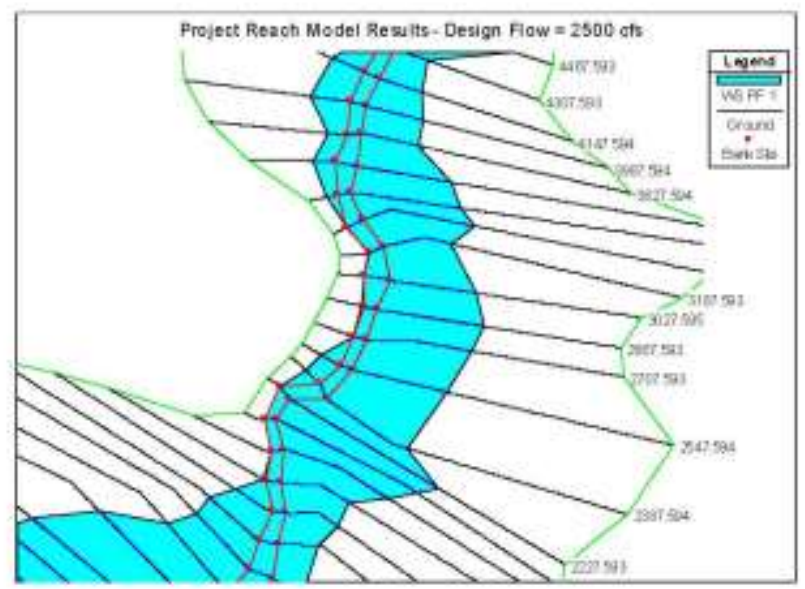

Figure 4. Water surface extents on the lower Scotts Creak fioodplain. The banifull channel is outlined in red. Fiow is from top to bottom. Len overbank ficw is on the night side or the plot.

Model Results for the 100-Year Event

For the 100 -year event storm flow, the average velocity in the project reach was $5.96 \mathrm{fps}$ with a peak velocity of $10.4 \mathrm{fps}$ at station 1588 (not shown below). The average shear stress was 1,06 $\mathrm{lbs} / \mathrm{ft}^{2}$ and the maximum shear stress was $2.69 \mathrm{lbs} / \mathrm{ft}^{2}$. Hydraulic depth varied from 4.9 to 8.4 feet with an average of 6.8 feet. These depths exceeded the bankfull depth. Figure 5 shows velocities, shear stresses, and hydraulic depths at each cross section within the project reach for the 100 year event.

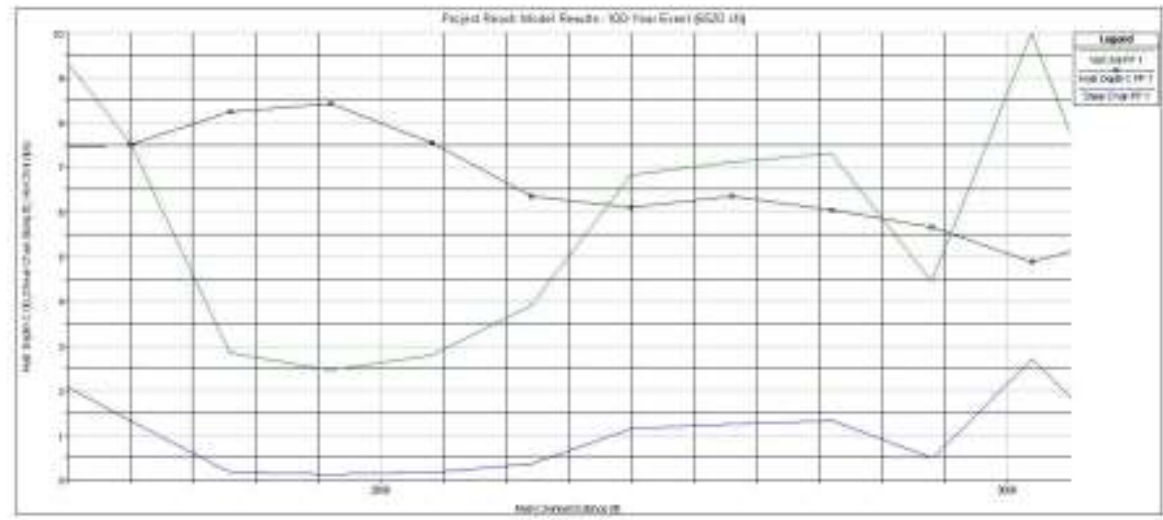


Figure 5. HEC RAS model resuits for velocity, hycraulic depth and shear stress for the 100-year event.

The 100-year event model resulted in substantial overbank flooding, especially on the floodplain on the left bank (Figure 6),

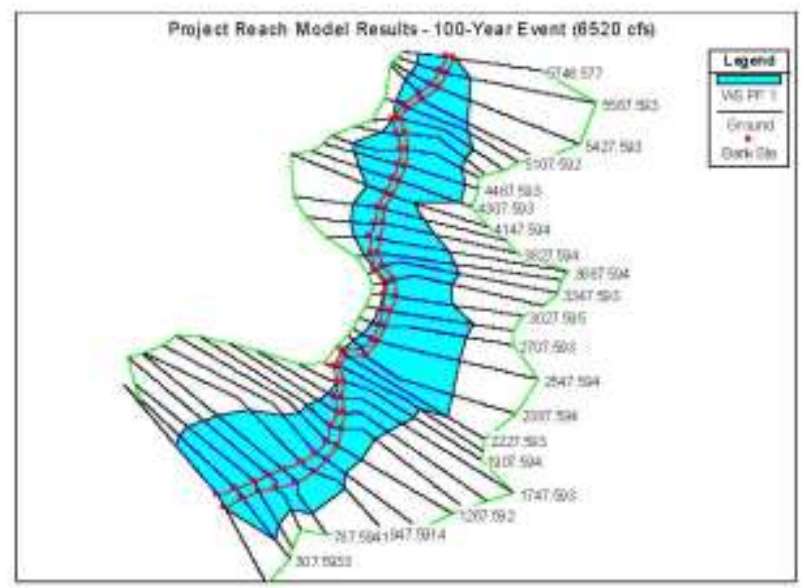

Figure 6. Overhead view plot of HEC RAS model water surface extents (blus) for the 100-year event. Red Whes represent the mann channer of Scatts Creek. Flow is from upper right to lower len. Plot shows lower Scotts Creek from CA-1 Bridge to approximately 6000 feet upstream. Project reach is from station 1500 . 3100

Comparison of Pre- and Post- Project Flood Depths and Extents

Pre- and post-project conditions were modeled. The model results showed slight increases in water surface elevations, and slight decreases in channel velocities, resulting from the proposed project, for the 10-and 100-year events. Overall, the model indicates that the proposed project will not significantly increase flooding in the valley. For a detailed comparison of pre- and postproject flow conditions, see Modeling Results in the Appendix.

The December 2012 event, estimated to have a 5-year recurrence interval, overtopped portions of the deteriorating levee and caused inundation of the lower floodplain, indicating that the levee is no longer effective in protecting the adjacent floodplain in its deteriorated state. The levee is expected to be overwhelmed during the 100 year event regardless of the proposed modifications.

Modeling results show that the majority of the discharge will be routed onto the left overbank flow path on the adjacent floodplain for the 100-year event, with total effective flow areas 
ranging from 1000-3500 square feet. Any instream structures will have a negligible effect on flooding, considering they will have cross-sectional areas on the order of 10 's of square feet.

Each instream wood complex was designed to obstruct no more than $50 \%$ of the low-flow channel. This was done in part to prevent the formation of hazardous debris jams spanning the entire bankfull width.

\section{Large Wood Complexes}

Background

In the summer of 2013, a Cal Poly graduate student conducted a physical habitat survey of 8 miles of the Scotts Creek mainstem (A. Brubaker, 2013, unpublished data). Data on physical habitat conditions including residual pool depth, percent escape cover, and the presence of woody debris were recorded. A sub-reach of low channel complexity, and low quantity and frequency of woody debris within the proposed project reach was identified based on field observations and data from the physical habitat survey.

Remediation

The proposed project will remediate physical habitat conditions within this sub-reach by constructing instream large wood complexes to provide escape cover, pool habitat, and improve sediment sorting. Wood complexes will also function as "seed structures" by trapping entrained debris and forming collections of debris. Wood features will be designed to prevent large and potentially damaging debris jams from forming across the entire width of the channel. First, instream wood features will not span the entire stream channel and second, these features are designed to be flexible, having the ability to give if collected debris begins to exert a large force on the structure.

\section{Design Goals}

Design goals include maximizing habitat benefit for salmonids and structure longevity, and minimizing cost, complexity, and riparian and instream disturbance.

Design

The conceptual design has been through several iterations, based in part on the designs of other local large wood projects that have been implemented in nearby coastal streams in the Santa Cruz Mountains.

Each large wood complex will be constructed from one redviood log, one boulder, one redwood rootwad, one toppled in-situ alder, and two live standing alders located on the left bank. One 
end of the redwood log will be anchored to the streambed by the boulder, and the other end will be braced against the trunk of the upstream live standing alders. The live toppled alder will be pinned beneath the redwood log and braced against the trunk of the downstream live standing alder. The redwood rootwad will be attached to the mid-point of the redwood log.

The redwood log, toppled alder, and redwood rootwad will be located to provide instream cover. trap debris; and facilitate scour within the active channel. The structure will provide cover year round, and facilitate scour and trap debris during winter.

\section{Recruitment of Live Alders}

The project will take advantage of the abundance of large alders growing on the banks of the project reach by incorporating standing and downed live alders in the wood complexes. Livestanding alders will brace the wood complexes against streamflow, and downed live alders will provide cover, facilitate scour, generate instream turbulence, and trap debris.

The technique of using live, standing alders as anchors is outined in ERDC TN-EMRRP-SR-13 (2000). This project is designed to be a category 2 project under ERDC guidelines, with flexible anchors that will allow the structures to move, described in Saldi-Caromile et al., 2004.

The recruitment of live aiders achieves several design goals. Most importantly, these live trees will form large, foliated instream habitat structures that will provide escape cover for saimonids, and facilitate pool formation and sediment sorting. Live alders are expected to cover significantly more stream area than a limbed log of the same length.

Partially unearthing the rootmass of live alders, toppling, and reburying requires only minimal excavation with no net cut/fill, which will minimize disturbance and preclude other anchoring methods such as trenching that are associated with potentially higher levels of disturbance and possibly exporting spoils.

Keeping the alders alive will increase the longevity of the structures by curtailing decay.

Taking advantage of these in-situ alders will also reduce the material costs and time required to construct these structures, Near-stream alders have no material cost, but there will be a labor cost for unearthing and reburying the roots. The estimated volume of excavation needed to unearth the rootmass of a mature alder is 1 cubic yard.

A secondary effect of recruiting live, near-stream alders is to increase sunlight penetration to the riparian zone. Recruitment is not expected to significantly impact sunlight penetration overall within the project reach, however localized increases may occur. 


\section{Recruitment Technique}

Alders will be toppled by excavating portions of the rootmass while leaving large hinge roots intact and anchored to the stream bank. The alder will pivot around the hinge material as it is toppled, similar to the way a tree falls around hinge material created by the face-and back-cuts during felling. The rootmass will be reburied with the excavated material, with zero net cutfill. Downed trees will be pinned under or braced against other structural and habitat elements such as redwood logs, rootwads and boulders.

\section{Elexible Anchors and Bracing}

Flexible anchors have several advantages over fixed anchors. The first is that flexible anchors will allow the structure to move above the bedload, and help prevent the structure from becoming buried by sediment. A second advantage is that under extreme conditions, the structure can move to pass debris jams or debris flows that would othervise cause the structure to fail.

One end of the redwood log will be attached to the boulder while the other end will be braced against a live standing alder tree and free to rise and fall with changes in stage. The rootwad attached near the log's midpoint will also be free to rise and fall relative to the log. The structure will be able to float above the bedload.

The large wood complex will be braced against live standing alders to provide additional resistance against drag forces. Bracing the large wood complex against the trunk of live standing alders rather than creating fixed attachment points will allow the complex to rise and fall above the bedload with changes in stream stage as would occur with naturally recruited large wood pieces.

Flexible joints will be achieved using two eye bolts linked together with a quick link. A hole will be bored through each of the structural elements of the wood complex. The boulder attachment point will consist of one eyebolt epoxied into a slip fit bore hole in the boulder. The log attachment point will consist of one eyebolt fastened through a clearance-fit through hole in the redwood log. secured with a nut and washer. The rootwad attachment point will be identical to the log attachment point, or alternatively, consist of an eyeleted lag screw threaded into a pilot hole bored into the rootwad. Shouldered eyeboits and screws or shoulder washers shall be used to prevent bending at the head of the eyebolt. 


\section{Boulder Anchor}

The weight of the boulder will oppose the buoyant forces of the structure. The boulder will be partially buried in the bed substrate to oppose the drag force on the structure in the direction of flow. The boulder must weigh 3 tons to overcome the buoyant force with a safety factor of 1.5 . The boulder must be embedded 2 feet to oppose the drag force with a safety factor of 2 .

\section{Rootwad}

The redwood rootwad should be attached near the midpoint of the redwood log. If the rootwad is attached to the log nearer to the boulder, the ballast must be increased proportional to the distance the attachment point is moved.

\section{Live-Tree Anchor Strength Calculation}

Two live standing alder trees located on the left bank of lower Scotts Creek will brace each wood complex against drag forces in the direction of streamflow. The large wood complex vill be braced against the trunk as low as possible (at ground level) to minimize torsion on the root ball. The assumed failure mode of a live standing tree will be soil failure in compression and shear as the root ball is pushed laterally in the direction of stream flow by the wood complex. The tractive force of water will act on the submerged large wood complex to produce the lateral force.

The strength of the live standing tree anchor is equal to the effective area of the root ball times the soil strength. The root ball is assumed to be hemispherical with a semicircular effective area equal to one half the square of the root ball's radius times pi. The root ball's radius is assumed to be $40^{\circ}$ which is one half of the standard root ball diameter listed in ANSI Z60.1-2004 for an upright field-grown tree with a caliper of $8^{*}$. The lateral shear strength of a single live standing alder is then estimated to be 52 kips. The tractive force of a typical large wood complex is estimated to be $10 \mathrm{kips}$. The anchoring strength of a single live standing alder is calculated to be sufficient to anchor a typical large wood complex, with a safety factor of 10 , since two trees will be used per wood complex. Please see table 1 below.

Ballast Calculations

\section{Redwood Logs and Rootwads}

Individual logs will be no larger than 30 feet in length with an average diameter of 1.5 feet.

Anchoring requirements were calculated based on the guidelines in NRCS Technical Supplement 14E. A variation from TS $14 \mathrm{E}$ was incorporated into the anchoring calculations, following the example of the NRCS San Vicente LWM Engineering Docket (Ruttenberg. 2011) 
Instead of computing the sum of the buoyant force and the drag force as recommended by TS $14 \mathrm{E}$, the two forces were assumed to be perpendicular to one another, with the total force equal to the square root of the sum of the squares of the individual forces:

$$
F_{\text {totat }}=\sqrt{F_{\text {drag }}^{2}+F_{\text {buoyan }}^{2}}
$$

With a safety factor of 1.5 , each redwood log is required to have an anchoring force of $5950 \mathrm{lbs}$. This variation was maintained for all anchoring calculations below.

Redwood rootwads were modeled as simple spheres, with a diamoter of 5 feet, sharing the same bulk material properties with redwood logs. Each rootwad will require an anchoring force of $4131 \mathrm{lbs}$.

\section{Live Downed Alders}

The buoyant force was calculated by estimating the weight of the entire tree using the Jenkins method described in PNW-RP-584 published by the United States Forest Service Pacific Southwest Research Station. The method estimates aboveground biomass on DBH alone and applies to hardwood and softwood species nationally. The table of parameters given for the Jenkins method did not include alder. For the purpose of this estimate, parameters for aspen/cottonwood/willow vere used. Using a DBH of 1.25 , the Jenkins method gives a total aboveground biomass of $651 \mathrm{~kg}$. This value was used to back-calculate a buoyant force of 1149 lbs for live alder.

Live alders were assumed to have a conical shape for the purpose of calculating drag forces. giving them a triangular drag profile that was calculated by multiplying the radius of the crown by the height. The drag force was calculated to be $5695 \mathrm{lbs}$. The total force required to anchor a live alder was calculated to be $8715 \mathrm{lbs}$. 


\section{Calculation Spreadsheet}

Table 1. Spreactsined of LWC calculations.

NRCS Technical Supplement 14E Warksheet

Structural Element.

Shape

Length (feet)

Averame Ciameter (feet)

Volume $\left(\mathrm{ft}^{2}\right)$

Spec. Grav. Dry

Mbisture Content

Unit WL. H20 (llbs/t?

Unit Weight [itos/fte]

Weighe [lbs)

Wr. Hz20 Displaced (lbs)

Dooyant farce (bs)

Drag Force Calculations

Area $\left(\mathrm{ft}^{2}\right)=\mathrm{DO}$

Angle (Degreas)

Effective Area $\left[\mathrm{ft}^{3}\right)$

Velotity (ft/s)

Debis Fartor D (1<0<1.5)

Permeahility Factor $\mathrm{K}$.

Dreg farce

Pedwood Log
Cylinder
30
1.75
72.2
0.35
0.12
62.4
24
1765
4503
2738

Redwodd Rootwad

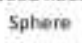

Live Alder (Green) Cylinderitrunk Doty)

Boulder

4

- $\quad 4.5$

33.5
0.35

a.12

fi. 4 .

24

819

2091
$12 n$

4

H14 429

4.7

as

614

3

4088

ax

5 ee Jenkins Methed Below

Drag Forre on to

52.5

Drag Foect on flootwad Drag Furce on Live Aider Draf Force on Boulder

90
52.5

7,3

15

1.

3987

$N / A$
12.6
7.5
1.5
1
954

123

123

7.3

1.5

950 
Table 1 continued.

Jenkins Method Applied to Uive Alder (USDA Forest Service PNW-RP-584)

b0 $\quad-2.2094$ aspen/cottonwood/willow

b1 2.3867 aspen/cottonwood/willow

dbh $(\mathrm{ft}) \quad 1.25$

dbh $(\mathrm{cm})$

mass $(\mathrm{kg}) \quad 651$

equivalent weight (Ibs) $\quad 1432$

volume (cubic feet)

weight of water (lbs) 2581

buoyant force (lbs) 1149

Live Tree Anchor Strength Based on Soil Strength and Standard Root Ball Diameter (rbd)

root ball diameter (inches\})

root ball diameter \{feet

root ball radius (feet)

root ball effective area \{square feet\}

soil strength (psf)

Anchor shear strength (libs)

80 American Standard for Nursery Stock min rad for

8"caliper, shade or upright tree

3.3

17.5 assuming hemispherical shape

3000.0 sand (NRCS Table of Presumptive Allowable

$523599 \quad$ Bearing Stress Values)

Large Wood Complex (LWC) Total Buoyant Force on Boulder

Structural Elemen?

Buoyant Farce

2738

Proportian

Total

Redwood Log

Live Alde

Redwood Rootwad

1149

1271

05

Total Buoyant Force of (WC (lbs)

Safety Factor

" of Boulders Required to Oppose

1389

1149

636

3153

1500

104

Large Wood Complex (LWC) Total Drag Force on Boulder

Structural Element

Drag Farce (lbs)

Redwood Log

Live Alder

Redwood Riootwad

Boulder

\begin{tabular}{lrr} 
Quantity & \multicolumn{1}{c}{ Total Force (lbs) } \\
3987 & 1 & 3987 \\
9720 & 0.5 & 4950 \\
954 & 0.5 & 477 \\
930 & 1 & 930 \\
Total Drog Force of LWC (fbs) & 10254
\end{tabular}


Table 1 continued

Forces on Boulder - Log Joint

Buovant Forte $\quad 3153$

Drag Force 10254

Sum of Component Force: $\quad 10728$

Safety Factor 2

Strength of Boulder - $\log$. 21456

Total Tonnage of Prock Required for Project

\# of Ballasted tWC Featur

\# of Boulders per Feature

Weight of Each Bouldes it

Total Tonnoge

14.45

Thrust Block Calculation for Boulder

Total Drag on LWC in Direx $\quad 10254$

Soil Strength [pst] 3000 sand

Thrust Block Area [st] $\quad 3.42$

Safety Factor 2.0

Depth of Boulder to Oppo. 1.95

Displacement $(d)$

Displacement $(c y) \quad 0.89$

\begin{tabular}{|c|c|c|}
\hline \multicolumn{3}{|c|}{ on rootwad } \\
\hline Rotio of Drag Farce to Buc & 3.25 & 0.75 \\
\hline Angle of Fastener Axis fro & 6 & 53 \\
\hline Log-Boulder & \multicolumn{2}{|c|}{ Log-Rootwad } \\
\hline Tensile Strength of Steel ( & 60000 & 60000 \\
\hline Strength of joint flbs] & 21456 & 3179 \\
\hline Cross-sectional area of $\mathrm{Fa}$ & 0.358 & 0.063 \\
\hline Minimum Diameter of $\mathrm{Fa}$ : & 0. 297 & $\theta . \pm 3 \theta$ \\
\hline
\end{tabular}

RECOMMMEND USE $1^{*}$ DIA FASTENER FOR BOULER-LOG JOINT AND 1/2" DIA FOR LOG.

ROOTWAD, MINIMUM

Epoxy Joint Strength Cale

Strength of Joint

Mnimum Shear Strength $\quad 3000$

Surface Area (sq in) $\quad 7.152$

Diameter of Fastener $\quad 1.000$

Minimum Depth of interft $\quad$ z.2777

RECOMIVEND 12 MANIMUM 


\section{Floodplain Connections}

The project will improve connectivity by grading one connection between the main channel of Scotts Creek and an existing floodplain drain, and one connection with each of two existing floodplain ponds. These three new connections will provide access to additional backwater, offchannel, and floodplain habitat, and provide direct paths of return to the main channel that will reduce the potential for floodplain stranding. These connections will be level trapezoidal channels with side-slopes graded $2 \mathrm{H}: 1 \mathrm{~V}$.

The channels will be revegetated with a palette of locally-sourced native plants including rushes (juncus) to stabilize soils and increase roughness. The connections are expected to improve hydraulic equilibrium between the main channel and floodplain by providing additional connectivity.

Connections will be composed of a channel graded through the existing levee or floodplain on the left bank of Scotts Creek, and a backwater pool at the confluence of the connection channel and the main channel of Scotts Creek. A large wood complex will be constructed near the confluence area, either oriented upstream in a vane configuration, oriented to maintain sediment transport the confluence, or oriented downstream and configured to stack water into the alcove pool and connection channel.

At present, floodwaters inundate the floodplain adjacent to the project area from a variety of sources including through deteriorated sections of the left-bank levee, from overbank flows from Archibald Creek, from subsurface flows, and from direct rainfall. The existing cycle of floodplain inundation is expected to maintain hydraulic equilibrium between the main channel and floodplain, preventing the formation of a hydraulic head required to generate appreciable velocity.

For the pond connections, the channel portion of the connection that perforates the levee will be graded at the elevation of the tail crest of the pond. For the floodplain connection, the channel will be graded level at the elevation of the adjacent floodplain. The channels will be graded level, with no longitudinal gradient.

The bottom width of the connection channel is sized to the minimum size needed to allow debris to pass. Debris that can be expected to pass through the channel are limbs and brush located on the streambanks and floodplain of lower Scotts Creek. The estimated size of the debris that is expected to pass through the channel is $6^{\prime}$ on the intermediate axis. The bottom width was 
sized accordingly, with $2 \mathrm{H}: 1 \mathrm{~V}$ sides, so that any debris would dislodge due to buoyant forces as depth increased above zero in the channel.

The channel may change in cross-sectional area due to scour and deposition or debris racking. but is not expected to initiate mass wasting of the left bank. Velocities are expected to be minimized through the pond connection channels due to the level bottom, the backwater effect from downstream floodplain inundation, and from naturally recruited or replanted vegetation within the connection channel.

The backwater pool portion of the connections will be graded at the elevation of the streambed above the low-flow waterline. No grading will occur in the wetted channel. The backwater pool grading will be circular, with a $12-20$ ' diameter.

Regions of scour and deposition are expected to form around the large wood complexes during stormflows. The region of scour is expected to form where flow velocities are highest (i.e. hydraulic jumps, constrictions, or plunges), typically around or immediately downstream from the portion of the feature that intersects the center of the stream channel.

\section{Archibald Creek Confluence Reconfiguration}

The confluence of Archibald Creek and Scotts Creek will be reconfigured to form a $325^{\prime}$ long low-gradient backwater connection with an alcove pool at the confluence with Scotts Creek. The existing Archibald Creek channel will remain in its current location and configuration, and serve to transport debris and bedload material.

The reconfiguration will grade a backwater alcove pool at the confluence, and construct a large wood complex positioned to facilitate scour through or stack water into the reconfigured confluence area. The constructed wood complex will provide stream cover and instream refuge habitat.

The low-gradient auxillary channel will begin to flow above low-flow conditions in Archibald Creek. The backwater pool will become functional when Scotts Creek rises above low-flow conditions.

Reconfiguration will provide backwater and off-channel refuge habitat during high flows. At baseflow levels, pool habitat will be available as a result of scour around the large wood complex at the bcation of the confluence. Salmonids seeking refuge in pool habitat will be able to quickly escape to the backwater area as flows increase. 
The gradient of the channel will be $2-3 \%$. Channel stability will be maintained by lining the channel with stabilizing vegetation, woody debris, and excavated rock. Overall, velocities will be reduced in Archibaid Creek due to a portion of the flow in Archibald Creek being diverted to the constructed auxiliary channel. 
Lower Scotts Creek Revegetation Plant Palette

\begin{tabular}{|c|c|c|c|}
\hline Corminon Name & Species & Function & Location \\
\hline \multicolumn{4}{|l|}{ Irese } \\
\hline Aex Elder & Aowr negande & $\operatorname{ss} s \mathrm{c}$ & AC \\
\hline Fed Noter & Ahue natre & 58,5 & $\mathrm{RC}$ \\
\hline Red Ederterry & Sambucus nacemoou var. nacemosa & ss, s, d & RC \\
\hline Buse Eldertenry & Sambucua nigra mibsp, comiens & $55,5, \mathrm{C}$ & AC \\
\hline Shiring willow & Safir lasiandha ver haeianitra & ss. $3 . \mathrm{C}$ & FP, RC \\
\hline Anoyo whow & Salk tuoblepen & $35,5, \mathrm{C}$ & FP, RC \\
\hline Creet Dogwood & Comus serices & $55, \mathrm{~s}, \mathrm{C}$ & FP, AC \\
\hline \multicolumn{4}{|l|}{ Onanes } \\
\hline Bearbess wed nee & Blmaus tribcoides & EC & RC \\
\hline \multicolumn{4}{|l|}{ Buahes } \\
\hline Brown nesh & Huncus hespertus & S5, EC & FPA \\
\hline Spreating nush & Aunctis patens & AS. EC & FPA \\
\hline Pacilie nash & Juncest eflusus subep, paofleus & SS, EC & FPA \\
\hline \multicolumn{4}{|l|}{ Sedpen } \\
\hline Bigleat sedpe & Corex ampitolia & $55, \mathrm{EC}$ & FPA \\
\hline Barterpele sedge & Scirpus mierocurpus & SS, EC. & FP, RC: \\
\hline Opensis & Cypenie eragrocts & SS, EC & FP, RC \\
\hline Hough sedoe & Corex obnupts & $25, E C$ & FP, RC \\
\hline \multicolumn{4}{|l|}{ Shnote } \\
\hline Salmorbery & Rubie ipectatilis & EC & RC \\
\hline Blackbeny & Rubua ursinus & EC & $\mathrm{RC}$ \\
\hline Thimbleberny & Pabue parvitonus & EC & RC \\
\hline Woodind strantieny & Fregavia vesced & EC & AC \\
\hline Straggly goosebery & Ribee divericatum var. putilionum & EC & RC \\
\hline Callomia rose & Rosa calitomica & EC & RC \\
\hline Caltbriala hedpe-restle & Stachyen bullati & EC & RC \\
\hline American stinging nettse & Unfica diobica menp. & EC & RC \\
\hline Califomia flowart & Serophutaria califormica & EC & $\mathrm{RC}$ \\
\hline Douplas' nightshade & Solanum douglasil & EC & RC \\
\hline Colten yarrow & Eniophyalam coetersiflonum & EC & คC \\
\hline \multicolumn{4}{|l|}{ Feres } \\
\hline Lady fem & 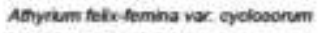 & EC & RC \\
\hline Qimt chain fern & Wootiwartia fimbriata & EC & $R C$ \\
\hline Sward fam & Folyeticham manitum & EC & RC \\
\hline Wood ferm & Dyopheria arguta & EC & $\mathrm{RC}$ \\
\hline \multicolumn{4}{|l|}{ Hentes } \\
\hline Common yarmaw & Achillea milefoliam & EC & RC \\
\hline \multicolumn{4}{|l|}{ Key } \\
\hline $55 \mathrm{n}$.004 mbilizabion & $R C$ - niparian conridor & & \\
\hline$E C$ - erovion contral & FF = flocodplain & & \\
\hline$s=$ made & $F P A=$ mocoparone ares & & \\
\hline choover & & & \\
\hline
\end{tabular}




\section{ENGINEER'S QUANTITY AND COST ESTIMATE}

LSCSHIP Engineer's Cost Estimate 20140307 - B.Cook

\begin{tabular}{|c|c|c|c|c|c|c|}
\hline Item & Units & & nit Price & $\#$ of Units & & Cost \\
\hline Mobilization/Demobilization & Iump sum & $s$ & $3,000.00$ & 1 & $\$$ & $3,000,00$ \\
\hline Clearing/Grubbing & tump sum & $\$$ & $5,000.00$ & 1 & $\$$ & $5,000.00$ \\
\hline Devel op Access & Tump sum & $\$$ & $5,000.00$ & 1 & \$ & $5,000.00$ \\
\hline Stream Diversion & per site & s & 500.00 & 9 & s & $4,500.00$ \\
\hline Excavation and Endhauling: & cubic yards & $\$$ & 80.00 & 647 & 5 & $51,760.00$ \\
\hline \multicolumn{7}{|l|}{ Install LWD } \\
\hline Rock, deli vered & ton & $\$$ & 83.42 & 33 & $\$$ & 2.752 .86 \\
\hline Rootwads & root wad & s & 800.00 & 9 & s & 7.200 .00 \\
\hline Excavate and Deliver Rootwads & root wad & 5 & 200.00 & 9 & $\$$ & $1,800.00$ \\
\hline Local Redwood Logs, desivered & $\log$ & $\$$ & 800.00 & 9 & $\$$ & $7,200.00$ \\
\hline Anchoring Materials & per structure & $\$$ & 500.00 & 9 & $\$$ & $4,500,00$ \\
\hline Installation & perstructure & $\$$ & $2,000.00$ & 9 & \$ & $18,000.00$ \\
\hline \multicolumn{7}{|l|}{ Erosion Control } \\
\hline Eresion Control Instaillation & lump sum & $s$ & $3,000.00$ & 1 & $\$$ & $3,000.00$ \\
\hline Erosion Control Materials & Iump sum & s & $1,000,00$ & 1 & s & $1,000,00$ \\
\hline \multicolumn{7}{|l|}{ Revegetation } \\
\hline Plant installation & Iump sum & 5 & $5,000.00$ & 1 & s & $5,000.00$ \\
\hline Plant Materials & Iump sum & 5 & $5,000.00$ & 1 & s & $5,000.00$ \\
\hline
\end{tabular}




\section{BID SCHEDULE}

Participant: Resource Conservation District of Santa Cruz County

Project: Lower Scotts Creek Floodplain and Habitat Enhancement Project Phase II

\begin{tabular}{|c|c|c|c|c|c|c|}
\hline \multicolumn{7}{|c|}{ LSCSHIP Engineer's Cost Estimate 20140807 -8.Cook } \\
\hline item & Units & \multicolumn{2}{|r|}{ Unit Price } & \multirow{2}{*}{$\begin{array}{c}\text { II of Units } \\
1\end{array}$} & \multicolumn{2}{|r|}{ Bid } \\
\hline Mobilization/Demobilization & lumpsum & 5 & - & & $\$$ & \\
\hline Clesring/Grubbing: & lumpsum & \multicolumn{2}{|r|}{ N/A } & N/A & \multicolumn{2}{|r|}{ N/A } \\
\hline Develop Access & lumpsum & 5 & $\cdot$ & 1 & 5 & \\
\hline Stream Diversion & per site & \multicolumn{2}{|r|}{ N/A } & N/A & \multicolumn{2}{|r|}{ N/A } \\
\hline Excavation and Endhauling & cubic yards & s & 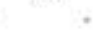 & 647 & $\$$ & \\
\hline \multicolumn{7}{|l|}{ Install LWD } \\
\hline Rock, delivered & ton & s & $\cdot$ & 33 & s & \\
\hline Rootwads & root wad & \multicolumn{2}{|r|}{$N / A$} & $N / A$ & \multicolumn{2}{|r|}{ NA } \\
\hline Excavate and Deliver Rootwads & root wad & 5 & $\therefore$ & 9 & s & \\
\hline Local Redwocd Logs, delivered & N/A & \multicolumn{2}{|r|}{$N / A$} & $N / A$ & \multicolumn{2}{|r|}{$N / A$} \\
\hline Anchoring Materials: & per structure & s & . & 9 & $\$$ & \\
\hline Installation & per structure & 5 & $\cdot$ & 9 & $\$$ & \\
\hline \multicolumn{7}{|l|}{ Erosion Contral } \\
\hline Erosion Control Installation & lumpsum & & N/A & N/A & & N/A \\
\hline Erosion Control Materials: & lump sum & & $N / A$ & N/A & & $N / A$ \\
\hline \multicolumn{7}{|l|}{ Revegetation } \\
\hline Plant Installation & Iump sum & & $N / A$ & $N / A$ & & $N / A$ \\
\hline Plant Materials & Iump sum & & $N / A$ & $N / A$ & & $N / A$ \\
\hline
\end{tabular}




\section{Construction}

All construction shall adhere to the drawings and specifications. All instream wood complexes shall be constructed according to anchoring calculations described in this report.

Staging for construction will occur at the locations specified on the design drawings. The proposed project may be implemented concurrently with a land-levelling project that will utilize the spoils from the proposed gradings. Coordination between potential projects will be outlined prior to construction, and may be a requirement of implementation. No heavy equipment will cross the stream during construction. All construction requiring heavy equipment will occur on the east bank of the stream channel. Workers may be required to cross the stream on foot. If foot traffic is expected to cross the stream, crossing areas will be cleared beforehand by a qualified biologist.

\section{Maintenance}

As part of the PIR program for Santa Cruz County, the RCD SCC vill monitor the project on an annual basis and report on progress and changes for five years after completion of construction. This also includes photo documentation of site progress. The RCD SCC will advise and assist the land owner with project status and any possible maintenance.

\section{References}

Fischenich, J.C., and Morrow, J.V. Jr. 1999. Streambank habitat enhancement with large woody debris. EMRRP Technical Notes Collection (ERDC TN-EMRRP-SR-13), U.S. Army Engineer Research and Development Center, Vicksburg, MS.

Flosi, G., Downie, S., Hopelain, J., Bird, M., Coey, R., Collins, B. 2010. Califomia salmonid stream habitat restoration manual, $4^{\text {th }}$ edition, California Department of Fish and Wildife, Wildlife and Fisheries Division. Sacramento, California.

National Engineering Handbook, Part 654, Stream Restoration Design Handbook, The Use and Design of Soil Anchors (TS 14E). Use of Large Woody material for Habitat and Bank Protection (TS 14J), USDA Natural Resources Conservation Service, August 2007.

Scrudato, M.C. 2010. Comparison of two potential streamgage locations on Scott Creek at Swanton Pacific Ranch, California. Master's thesis. Califomia Polytechnic State University, San Luis Obispo. 
Saldi-Caromile, K., Bates, K., Skidmore, P., Barenti, J., Pineo, D. 2004. Stream habitat restoration guidelines: Final draft. Co-published by the Washington Department of Fish and Wildife and Ecology and the U.S. Fish and Wildlife Service. Olympia, Washington

Zhou, X., and Hemstrom, M.A. 2009. Estimating aboveground tree biomass on forest land in the Pacific Northwest a comparison of approaches. Research Paper PNW-RP-584. Portland,

Oregon: United States Department of Agriculture, Forest Service, Pacific Southwest Research Station. $18 \mathrm{p}$. 


\section{APPROVAL SHEET}

\section{ENGINEERING JOB CLASSIFICATION}

The controlling classification factors for Streambank and Shoreline Prolection (580) are as follows:

1. Design Capacily is $2,500 \mathrm{cts},(2,000 \mathrm{cfs}<2500 \mathrm{cfs}<5,000 \mathrm{cfs}) \rightarrow$ Class 5

2. Drainage area is 30 square miles. ((50 sqmi $<30$ sqmi $<75$ sqmi) $\rightarrow$ Class 3

3. Channel Depth (low bank) is a maximum of 6 foet. $\left(5^{\circ}<6^{\prime}<8^{\prime}\right) \rightarrow$ Class 4

4. Design Volocity is $7.3 \mathrm{fps}$. ( $7.3 \mathrm{fps}<10 \mathrm{fps}) \rightarrow$ Class 5

The controlling classification factor for deslgn and engineering of this project is Streambank and Shoreline Protection (580). Based on the above values of controlling classilication factors, this project falls within an Engineering Class V project. Other NRCS practices for this project are for planning and biological considerations and will be met, but do not fall within engineering delegation of authorily.

DESIGNED 8Y: 2

Ben Cook, Graduate Assistant in Hydrology, California Polytechnic State Universily, San Luis Obispo

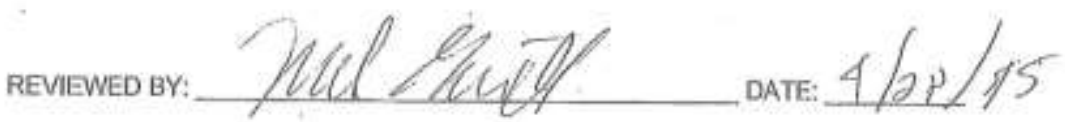

Mark Bamett, Central Coast Team Engineer, Natural Resources Conservation Sorvice

APPROVED BY: $\rightarrow$ DATE: $4 / 29 / 2015$

Desiderla Ramirez, Area Engineer, Natural Resources Conservation Service 


\section{DOCUMENTATION OF LANDOWNER UTILITY REMINDER}

California State Law Says, You Must Call Before You Dig!

If you are caught digging without a Dig Alert ticket you can be fined as much as $\$ 50,000$.

Why risk the possible financial impact?

All you do is dial a toll-free number, give your job site information to the Dig Alert representative, and they will nctify all of its members having underground facilities in the area.

Here are the important highlights of the law.

- Delineation of the proposed excavation site is mandatory. Mark the area to be excavated with water soluble or chalk based white paint on paved surfaces or with other suitable markings such as flags or stakes on unpaved areas.

- Call at least Two (2) full working days prior to digging.

- Permit for digging will not be valid without a Dig Alert ticket number.

- If utility members have facilities within the work area, they will mark them prior to the start of your excavation and if not, they will let you know there is no conflict.

- The Law requires one to hand expose to the point of no conflict $24^{\prime \prime}$ on either side of the underground facility, so one knows the exact location before using power equipment.

Signature:

Landowner/operator

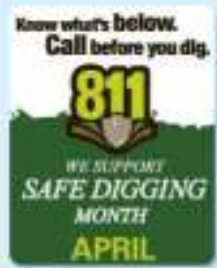

View the Current California Law, Govemment Code 4216 at: hitp///wnww digalert.org/statelew asp 
PRACTICE REQUIREMENTS 
PRACTICE REQUIREMENTS FOR

580 - STREAMBANK AND SHORELINE PROTECTION

For: Resource Conservation District of Santa Cruz County

Job Location:125 Swanton Road, Davenport, CA

County: Santa Cruz: RCD: Santa Cruz

Prepared By: Engineer Date: August 2014

IT SHALL BE THE RESPONSIBILITY OF THE OWNER TO OBTAIN ALL NECESSARY PERMITS ANDIOR RIGHTS, AND TO COMPLY WITH ALL ORDINANCES AND LAWS PERTAINING TO THIS INSTALLATION.

Installation shall be in accordance with the following drawings, specifications and special requirements. NO CHANGES ARE TO BE MADE IN THE DRAWINGS OR SPECIFICATIONS WITHOUT PRIOR APPROVAL OF THE NRCS TECHNICIAN

1. Drawings: Sheets 1-17

2. Practice Specifications: Streambank and Shoreline Protection (580), Control of Water (909), Critical Area Planting (342A) and (342G).

3. Type of bank protection: Large Wood Material and anchor boulders.

4. Special Requirements:

- Grade and excavate project components according to elevation specified on drawing and/or specified cross sections and lengths.

- Separate top soil and duff material from mineral soil for later use as mulch during rehabilitation phase.

- Dewatering required as specified for particular project component. Follow procedures outlined in draving. Dewatering shall comply with NRCS Control of Water (909) Construction Specification, and dewatering plan shown on drawing.

- Apply erosion control according to Erosion Control Plan shown on drawing

- The woody structures must not occupy more than $50 \%$ of active channel

- Site access and staging shall minimize impacts to existing native trees and vegetation. The Contractor shall restore access routes to pre-project grades, install erosion control, and revegetate disturbed areas as shown on the dravings.

- Construction activities must comply with the requirements of all permits.

5. Special Maintenance Requirements:

- The Resource Conservation District of Santa Cruz County (RCD SCC) will monitor the site on an annual basis for 5 years after construction, including photo documentation.

- Progress reports and recommendations from the RCD SCC will be submitted to the Land Owner. 
PRACTICE APPROVAL:

Job Classification: Streambank and Shoreline Protection (580), (Ref: Section 501 NEM)

This job is classified as, Class $\mathrm{V}$

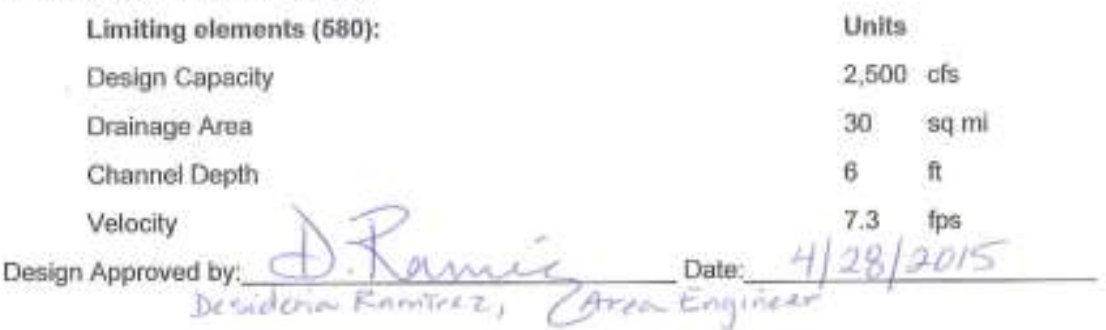

LANDOWWER'SIOPERATOR'S ACKNOWLEDGEMENT:

The landowner/operator acknowledges that:

A. He/she has received a copy of the drawings and specification, and that he/she has an understanding of the contents, and the requirements.

B. Ho/she has obtained all the necessary permits.

C. No changes will be made in the installation of the job without prior concurrence of the NRCS technician.

D. Maintenance of the installed work is necessary fox proper performance during the project life.

Accepted by: Date:

\section{PRACTICE COMPLETION:}

I have made an onsite inspection (or I am accepting owner/contractor documentation), and have. determined that the job as installed does conform to the dravings and practice specifications.

\section{Completion Certification by:}

$|s|$ Date 


\section{PRACTICE REQUIREMENTS FOR \\ 342a - CRITICAL AREA PLANTING - STRAW MULCH}

For: Resource Conservation District of Santa Cruz County

Job Location:125 Swanton Road, Davenport, CA

County: Santa Cruz: RCD: Santa Cruz

Prepared By: Engineer Date: August 2014

IT SHALL BE THE RESPONSIBILITY OF THE OWNER TO OBTAIN ALL NECESSARY PERMITS ANDIOR RIGHTS, AND TO COMPLY WITH ALL ORDINANCES AND LAWS PERTAINING TO THIS INSTALLATION.

Installation shall be in accordance with the following drawings, specifications and special requirements. NO CHANGES ARE TO BE MADE IN THE DRAWINGS OR SPECIFICATIONS WITHOUT PRIOR APPROVAL OF THE NRCS TECHNICIAN.

Drawings: Sheets 1-17

Practice Specifications: Streambank and Shoreline Protection (580), Control of Water (909), Critical Area Planting (342A) and 342G.

Seedbed Preparation: See Practice Specification 342A

Seed: see Native Plant Revegetation Palette

Rate: 200 lbs/ac

Fertilizer: N/A

Mulch: See Practice Specification 342A and drawing general notes. Reuse native duff or a mix of native duff and straw whenever possible.

Rate: 4000 lbs/ac

Mulch anchoring shall be performed using Method: __ Method 1, hand tools,

crimping with shovel.

Planting shall be performed within the period: After completion of construction for erosion control

Special Requirements: Contractor shall minimize disturbance to existing riparian areas for temporary access and staging. Native trees shall be protected in place as much as possible.

Disturbed areas shall be treated with straw mulch and seed as needed for erosion control. 
PRACTICE APPROVAL:

Job Classification:

Show the limiting elements for this job. This job is classified as, Class N/A

Limiting elements:

Units

Area Treated $=$ 0.23

acres

Approved by:

Date

\section{LANDOWNER'SIOPERATOR'S ACKNOWLEDGEMENT:}

The landowner/operator acknowledges that:

A. He/she has received a copy of the drawings and specifications, and that he/she has an understanding of the conterts, and the requirements

B. Helshe has obtained all the necessary permits

C. No changes will be made in the installation of the job without prior concurrence of the NRCS technician

D. Mainterance of the installed work is necessary for proper performance during the project life.

Accepted by:

Date

PRACTICE COMPLETION:

I have made an onsite inspection of the site (or I am accepting ownericontractor documentation), and have determined that the job as installed does conform to the drawings and practice specifications.

Completion Certification by:

$|\mathrm{s}|$ Date 
For: Resource Conservation District of Santa Cruz County

Job Location:125 Swanton Road, Davenport, CA

County: Santa Cruz: RCD: Santa Cruz

Prepared By: Engineer Date: August 2014

IT SHALL BE THE RESPONSIBILITY OF THE OWNER TO OBTAIN ALL NECESSARY PERMITS ANDIOR RIGHTS, AND TO COMPLY WITH ALL ORDINANCES AND LAWS PERTAINING TO THIS INSTALLATION.

Installation shall be in accordance with the following drawings, specifications and special requirements. NO CHANGES ARE TO BE MADE IN THE DRAWINGS OR SPECIFICATIONS WITHOUT PRIOR APPROVAL OF THE NRCS TECHNICIAN.

1. Drawings, No.: Sheets $1-17$

2. Practice Specifications: Streambank and Shoreline Protection (580). Control of Water (909), Critical Area Planting (342A) and 342G.

3. Woody Cuttings Min_Dia

Length

4. Planting shall be performed within the period: Post construction, fall 2011

5. Special Requirements:

Woody cuttings shall be harvested from local sources of native trees. No nursery stock will be allowed.

Woody cuttings to be installed as required for erosion control and tree replacement. Sprigs should be at least $1 / 2$-inch in diameter and 18 inches long. Sprigs, 2 to 3 inches in diameter and 3 to 4 feet long work best.

Cuttings should be planted the same day they are cut. If it is not possible, then the entire cutting should be placed in water in a cold area.

Plant the willows with the buds up, after sharpening the basal (bottom) end of the sprig with an axe or pruners right after it is cut from the tree.

Sprigs should be driven into the soil 75 to 80 percent of their total length, at a slight angle downstream.

In hard soils an iron bar or a chain saw powered auger can be used to bore planting

holes. This should not be needed at this site.

In soft soils, sprigs can be driven in with a wooden mallet or sledge hammer.

Cut off the tops of the sprigs if they should split while hammering. Leave only one or two buds exposed.

The sprigs should be placed 2 to 3 feet apart.

PRACTICE APPROVAL:

Job Classification:

Show the limiting elements for this job. This job is classified as, Class N/A 


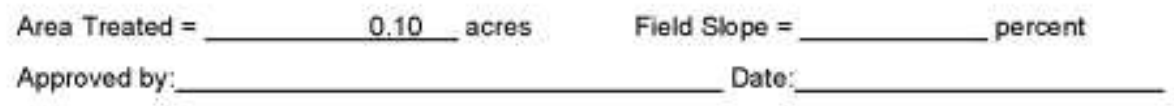

LANDOWNER'S/OPERATOR'S ACKNOWLEDGEMENT:

The landownerioperator acknowledges that:

A. He/she has received a copy of the drawings and specifications, and that he/she has an understanding of the conterts, and the requiremerts

B. He/she has cbtained all the necessary permits.

C. No changes will be made in the installation $\alpha$ the jab without prior concurrence of the NRCS technician

D. Mainterance of the installed work is necessary for proper performance during the project life.

Accepted by:

Date

PRACTICE COMPLETION:

I have made an onsite inspection of the site (or I am accepting owner/contractor documentation), and have determined that the job as installed does conform to the drawings and practice specifications.

Completion Certification by:

$|\mathrm{s}|$ Date 
PRACTICE STANDARDS 
$342-1$

\section{NATURAL RESOURCES CONSERVATION SERVICE \\ CONSERVATION PRACTICE STANDARD}

342 - CRITICAL AREA PLANTING

(Ac.)

CODE 342

\section{DEFINITION}

Establishing permanent vegetation on sites that have, or are expected to have, high erosion rates, and on sites that have physical, chemical

or biological concitions that prevent the establishment of vegetation with normal practices

\section{PURPOSE}

$X$ Stabilize stream and channel banks.

And shorelines.

$X$ Stabilize areas with existing or expected high rates of soil erosion by wind or water.

$X$ Rehabilitate and revegetate degraded sites that cannot be stabilized using normal establishment techniques.

X Stabilize coastal areas, such as sand dunes and niparian areas.

\section{CONDITIONS WHERE PRACTICE APPLIES}

This practice applies to highly disturbed areas such as.

$X$ active of abancioned mined lands; $x$ urban conservation sites, $x$ rasd construction areas; $x$ conservation practice construction sites; $x$ areas reeding stabilization before or after

Naturai dsasters such as floods, hurncanes, tornados and wildires;

$X$ eroded barks of natural channeis, banks

of newly constructed channels, and lake shorelines:

$X$ other areas degraded by human activities or natural events.

CRITERIA

\section{General Criteria Applicable To All Purposes}

Site Preparation. A site investigation shall be conducted to identify any physical, chemical, $\alpha$ biologcal conditions that could affect the successful establishment of vegetation

Areas to be planted will be cleared $\alpha$ unwarted materials and smoothed or shaped, if needed, to meet planting and landscaping purposes

A suitable seecbed shall be prepared for at seeded species. Compacted layers will be ripped and the soil re-firmed prior to seedbed preparation.

Species Selection. Species selected for seeding or planting shall be suited to current site conditions and intended uses, and be resistant to diseases or insects common to the site or Iocation

Selected species will have the capacity to achieve adequate density and vigot to stabilize the site within an appropriate period. When soil ercsion is a primary concern, select only species that are known to establish relatively quickly.

Refer to CA reveg guide for approved species for the practice and site

No plants on the Federal or state noxious weeds list shall be planted

Establishment of Vegetation. Seeds will be planted using the method of methods best suited to site and soil conditions

Sod placement shall be limited to areas that can naturally supply needed moisture or sites that can be irrigated during the establishment period.

Sod will be placed and anchored using techniques to ensure that it remains in place urtil established. 
Species, rates of seeding or planting minimum quality of plarting stock (e.g. pure live seed (PLS) or stem caliper), method of seedbed preparation, and method of establishment shall be specified before application. Orly viable. high quality seed or planting stock will be used.

Seeding or planting stall be done at a time and in a mamer that best ensures establishmen and growth of the selected species What constitutes successful establishment (e.g Minimum percert ground/canopy cover, percent survival, stand density) shall be specified before application.

Planting shall be done during approved times for the species to be used

Apply soll amendments (e g Lime, fertizer compost) according to the requiremerts in the local Field Office Technical Guide.

Plantings shali be mulched as necessary to ensure establishment. Other disturbed areas shall be mulched as necessary to prever erosion.

Additional Criteria to Stabilize Stream and Channel Banks and Shorelines

When slopes are modtied for seeding, topeoil will be stockpiled and spread over areas to be planted as needed to meet planting and landscaping needs

Bank and Channel Slopes. Channel side slopes shall be shaped so that they are stable and alow establishment and mainternance of desired vegetabion

Slopes steeper than $2: 1$ strall not be stabilized using vegetation alone. A combination of vegetative and structural measures will be used on these slopes to ensure adequate stability

Species Selection. Piant matenal used for this purpose shail
$X$ adapted to the hydrologio zone (see Fig 1) irto which they will be planted

$X$ be adapted and proven in the regons in which they will be used

$X$ when mature, produce plant communities that are compatible with those in the area.

$X$ protect the chamel banks but not restnct channel capacity.

Establishment of Vegetation. The spocies used, planting rates, spacing, and methods and dates of planting strall be based on plant materials progyam trials or other technica guidance, such as local planting guides or technical notes

identify, mark, and protect desirable existing vegetation dunng practice installation.

A combination of vegetabve and structural measures using living and inert material shall be used when flow velocities, soils, and bank stability preciude stabulization by vegetative establishmert alone.

If the existing vegetation on a site will compete with species to be established vegetatively (e.g Bare-root, containerized ball-and-burlap potted), it will be controlled in a manner that ensures the successul establishmen of the planted species

Site Protection and Access Control. Exclude all livestock for one year following establishment. Carefuly control livestock acces: in subsequent years.

All areas to be grazed will have a grazing plan developed in accordance with CPS 528 Prescribed Grazing

Grazing shall be permanently excluded on high hazard sites, such as cut banks, areas of seepage or other potentially unstable areas. 


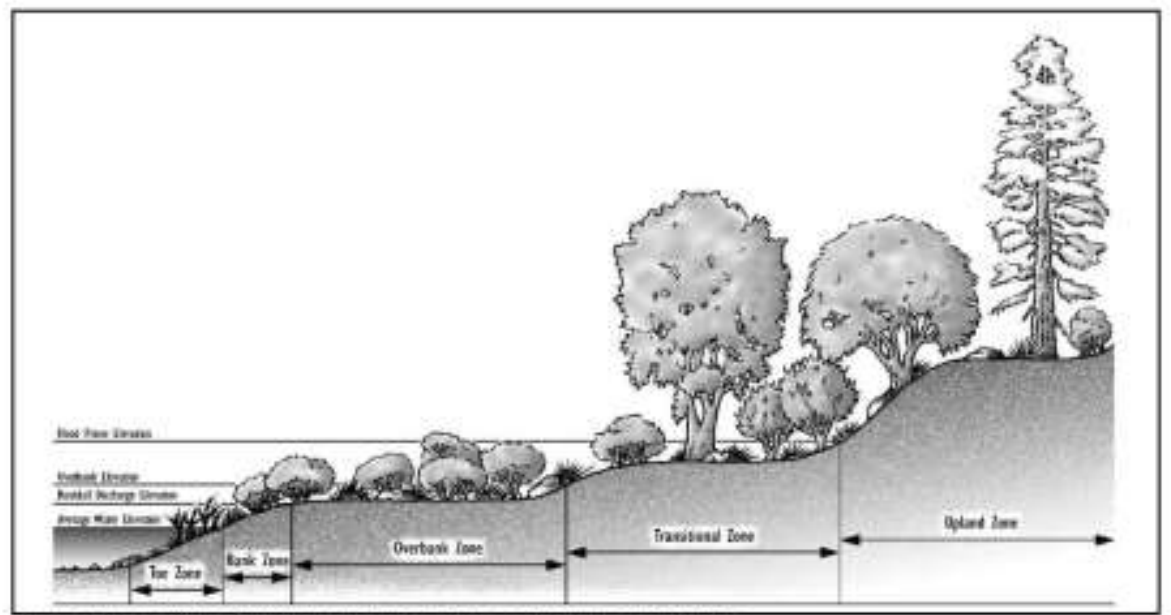

Figure 1. Location of hyorologic zones along a channel or shoreline

Definitions and descniptions of hydrologic zones used for channeis and shorelines:

Baniofuff Discharge Elevation - In natural streams, it is the elevation at which water fills the channel without overflowing onto the flood plain

Bank Zone - The area above the Toe Zone located between the average water lever and the benkful discharge elevation. Vegetation may be herbaceous or woody, and is characterized by flexible stems and thizomatous roof systems.

Overbank Zone. The area located above the bankfull discharge elevation continuing upslope to an elevation equal to two thirds of the flood prone depth. Vegetation is generally small to mectum shrub species.

Tce Zone. The portion of the bank that is between the average water level and the botton of the charvei, at the toe of the bank. Vegetation is generally herbaceous emergent aquatic species, tolerant of long periods of inundation.

Transitional Zone - The area located between the overbank zone, and the flocd prone wicth elevation Vegetation is usually larger shnib and tree species.

Upland Zone - The area above the Transitional Zone: this area is seldom if ever saturated.

Note: some charneis or shorelines have fewer than four hydralogic zones because of aifferences in soils. topography, entrenchment and/or moisture regime.

\section{Additional Criteria to Rehabilitate and}

Revequtate Deqraded Sites that Cannot Be Stabilized through Normal Farming

\section{Practices.}

If gullies or deep rills are present, they will be filled and leveled as necessary to allow equpmem operation and ensure proper site anc seedbed preparation.

Based on a soil test and ste evaluation, apply soil amendments far enough in ackance of establishment for them to ameliorate the acverse condtions.

Additional Criteria to Restore Coastal 


\section{Areas, such as Sand Dunes and Riparian Areas}

Plants for sand dunes and coastal sites must be able to survive being buried by blowing sand, sand blasting salt spray, salt water flooding drought, heat, and low nutrient supply.

Local plant lists including appropriate species shall be developed and utlized

Sand trapping devices such as sand fences or brush matting shall be included in the

Revegetation/ sabilization plans where applicable

\section{CONSIDERATIONS}

Species or mixes that are adapted to the site and have multiple values should be considered. Native species may be used when appropriate for the site and purpose.

To benefit pollinators and other wildife, flowering shrubs and wild lowers with tough root systems and good soil hoding capacity also should be considered for incorporation as a small percentage of a larger grass dominated planting Where appropriate consider a diverse mixture of legumes and forbs to support pollinator habitat

Avoid species that may harbor pests. Species diversity should be considered to avoid loss of function due to species-specific pests

Planning and installation of other conservation practices such as Diversion (code 362), Obstruction Removal (code 500), Subsurface

Drain (code 606 ), or Underground Outlet (code 620) may be necessary to prepare the area or ensure vegetative establishmert.

Areas of vegetation established with this practice can create habitat for various type of wildife Maimtenance activities, such as mowing or spraving can have detrimertal effects on certain species. Perform management activities at the times and in a manner that causes the lesst disruption to wildife

PLANS AND SPECIFICATIONS
Prepare plans and specifications for each field or management unit according to the criteria and operation and mairtenance sections of this standard. Record practice specifications using aporoved spectication sheets, job sheets of other acceptable documentation.

The following elements shall be addressed in the plan, as applicable, to meet the intended puppose.

$X$ Site preparation $x$ Topsoil requirements

$X$ Fertilizer $\&$ other amendment rates and application methods

X Seedbediplanting area preparation $\times$ Methods of seeding'planting $x$ Time of seedingyplanting $\times$ Species and cultivar $x$ Seed/plant source $x$ Seed analysis $\times$ Seeding rate/plant spacing $\times$ Muching

XSupplemental water needed for establishmert

$X$ Protection during estabishment $x$ grazing plan (if appropriate)

\section{OPERATION AND MAINTENANCE}

Use of the area shall be managed as long as necessary to ensure the site remains stable.

Plantings shall be protected from pests (e.g Weeds, insects, diseases, INestock or wildilife) as necessary to ensure long-term survival:

Inspections, reseeding or replanting, and fertilization may be needed to ensure that this practice functions as intended througnout its expected life Site evaluation should be performed at least every three morths until the practice has met the criteria for successful establishment and implementation

\section{REFERENCES}

Federal interagency Stream Restoration Working Group 1998. Stream cornidor restoration; principles, processes, and practices National Engineering Hanobook, Part 653

USDA.NRCS 2007 National Engneering Handoook, Part 654 Stream restoration guide

USDA-NRCS. 2010. The PLANTS Database

(1t:tp.iffplants usda gov, checked September 2010). National Plant Data Center. 
$395-1$

\section{NATURAL RESOURCES CONSERVATION SERVICE \\ CONSERVATION PRACTICE STANDARD \\ 395 - STREAM HABITAT IMPROVEMENT AND MANAGEMENT}

(AC.)

\section{CODE 395}

\section{DEFINITION}

Maintain, improve or restore physical, ohemical and biological functions of a stream, and its associated riparian zone, necessary for meeting the life history requirements of desired aquatic species.

PURPOSE

Provide suitable habatat for desired fish and other aquatic species.

Provide stream charnel and associated nparian conditions that maintain stream corndo ecological processes and hydrological connections of diverse stream habitat types importart to aquatic species

\section{CONDITIONSWHERE PRACTICE APPLIES}

All streams and their adjoining backwaters, floodplains, associated wetlands, and riparian areas where geomorphic conditions or habitat deficiencies limit reproduction, growth, survival and diversity of aquatic species.

CRITERIA

Planned stream habitat improvements will; $x$ address the aquatic species and life

History stages for which the stream is being managed.

$X$ be based on a site-specifio assessment of Iocal hydrology, chennel morphology. geomorphic setting fish and other aquatic species presert, riparian and floocplain conditions, and any habitat limitations including water quantity and cuality, food suppoly, and restriction of upstream and downstream movement of aquatic species using the NRCS Stream Visual Assessment Protocol, Version 2 or comparable evaluation tool,

When applied, result in a conservation system that meets or exceeds the mirimum quality criteria for stream habitat established in Section III of the FOTG

Marage adjoining riparian areas to support a diverse vegetation communily suitable for the site conditions and desired ecological benefits Such benefits include stream temperature moderation, recruitment of instream large wood and fine organic matter, input of riparian nutrients. habitat for terrestrial insects and other riparian dependent species, streambank integrity, and filtration of contaminarts from surface runoff.

Design in-stream structures to be compatible with the dynamic nature of streams and rivers facilitate natural geomorphic recovery when possible, and minimize dsruption of recreational and other traditional uses of the stream corridor.

Structures installed for the purposes of this standard will not; $x$ impede or prevert passage of fish and other aquatic organisms at any time, uniess intended to isolate populations of native species of conservation concern,

$X$ cause excessive bark erosion, $x$ cause unintentional lateral migration aggradation or degradation of the channel;

$X$ hinder channel-floodplain interactions.

Where practical restore or maintain stream habitat and channel forming processes such as natural flow regime, meander migration. sediment transport recruitment and storage of large wood, and floodplain interactions with the stream.

All stream and riparian activities will occur within state and federal guidelines with regard to timing of spawning, incubation, and rearing

$395-2$

Of aquatic organisms, and breeding and nesting of terrestrial organisms. 
Marage Ivestock to sustain a healthy stream corricor and associated habitats.

\section{CONSIDERATIONS}

Any stream habitat maragemert. project is most effective when applied within the context of overall watershed conditions and with clear

objectives for stream management goals.

Stream habitat management provisions should be planned in relation to other land uses that may affect stream corndors

Before designing and implementing stream habitat improvemerts, consider the known or expected concerns within the watershed, such as poirt and non-point source pollution; water diversions; and land management activities likely to influence stream habitat conditions Additional measures that shouid be taken singularly or in cambination to imprave stream nabitat include

Complete a general assessment of watershed conditions that are likely to affect the functions of the stream and its nparian area

Incorporate stream habitat improvements into a conservation plan that addresses soil quality. prescribed grazing, mutrient management, pest. management, and other management practices for reducing non-poirt sources of pollution

Provide fish passage upstream and downstream and allow movement of other acuatic species and orcanic matter to the extent possible and when compatible with state and federal fish management objectives (see Code 396 Aquatic Organism Passage)

Reduce or manage excessive runcff due to watershed development, roads or land-use activities

Restore or protect nparian and tloodplain vegetation and associated riverine wetiands.

Maintain adequate in-stream flows to sustain diverse habitats for fish and other aquatic species, especially during critical Ge history stages of spawning, incubation and rearing

\section{NRCS, CA May 2012}

Provide heterogenecus and complex physical habitat components consistent with the physiographic setting and important to fish and other aquatic species in the watershed. These include suitable spawning subetrates, structural elements such as boulders andior large wood where appropriate, resting pools, overhead cover, and dverse riparian plant communites Provide instream barriers to exciude aquatic nuisance species from upstream habitats where prescribed by state and federal fish management agencies to protect native fish populations

Provide screens on water pumps, diversion ditches, of any area where unirtentional entrairment of aquatic species is likely to occur

Improve floodplain-to-channel connectivity for develcoment of seasonal or permanent backwater, wetland and off-channel habitats consistent with the local climate and hydrology of the stream

Mairtain natural surface water, hyporheic, and ground water interactions to the extent possible Control spread of exotic plant and animal species

Manage recreational and other land use activities to minimize impacts on stream banks fiparian vegetation and water quality

identify and manage potentially adverse impacts of widife on vegetative establishment and sustainability, such as deer browsing, beaver dams and tree girdling bank burrowing by muskrats and others, and trampling

\section{PLANS AND SPECIFICATIONS}

Plans and specifications shall be developed for each site where stream corridor management and improvement actions are to be implemented

The plan will include detaled goals and objectives of the planned actions, a site description, the dates and sequence in which improvements or management actions will be completed, a vegetation planting plan maintenance requirements, and montoting guide lines for evaluating the effectiveness of the conservation actions. The plan shall specify;

Location and extent of modification of the stream reach to accomplish the planned purpose,

Riparian plart species and stocking rates if needed to accomplish the planned purpose, 
Planting dates, as well as the care and handing of seed or other planted matefiais to ensure an acceptable rate of survival,

Ste protection and preparation requirements for establishment or recruitment of niparian vegetation if needed,

Drawings to illustrate irstallation of implemertation requiremerts

OPERATION AND MAINTENANCE

A detailed operation and maintenance plan shall be developed for all applications. The pian shall provide for periodic inspection and prompt repair or modification of any structures that are found to cause excessive streambank or streambed instabelity. All structural measures shall be evaluated on an annual basis. Post-project monitoring and evaluation of stream and riparian habitat conditions shall be conducted to determine if actions implemented are providing for managemert of the stream corridor habitats as planned Any repair actions, if needed, shall comply with state and federal gudelines for protecting spawning, incubation and rearing times of aquatic species and breeding and nesting times of terrestrial species

$395-3$

REFERENCES
Bureau of Land Management. 1998, Riparian

Area Management: A User Guide to Assessing Proper Functioning Condition and the

Supporting Science for Lotic Areas. TR1737-15

Federal interagency Stream Restoration

Working Group (FISRWVG). 1998, National

Engineering Hanctoook 653 -Stream Corridor Restoration. Principles, Processes and

Practices.

NRCS 1998. The Practical Streambank Bioengineering Guide.

NRCS. 2002. Streambank Soil Bioengineering Field Guide for Low Precipitation Areas.

NRCS, 2005. National Bology Handbook

Part 620 . Aquatic and Terrestrial Habitat Resources:

NRCS 2005 National Engineening Handbook Part 654. Stream Restoration Design Handbcok NRCS. 2009, National Biology Hancbook Part 614, Subpart B Stream Visual Assessment Protocol. Version 2

Roni, P. 2005. Montoning stream and watershed restcration. American Fisheries Society,

Bethesda, MD 
$580-1$

\author{
NATURAL RESOURCES CONSERVATION SERVICE \\ CONSERVATION PRACTICE STANDARD \\ 580 - STREAMBANK AND SHORELINE PROTECTION
}

(Ft)

\title{
CODE 580
}

\section{DEFINITION}

Treatment(s) used to stabilize and protect banks of streams or constructed channels, and shorelines of takes, reservcirs, or estuaries. PURPOSE

$X$ To prevern the loss of land or damage to

Land uses, or faclities adjacent to the benks of streams or constructed channels, shoreline of lakes, reservoirs, or estuaries including the protection of known historical, archeological. and traditional cultural properties.

$X$ To maintain the flow capacity $d$ streams or channels.

$X$ Reduce the offste or downstream effects of sediment resulting from bank erosion

$X$ To improve or enhance the stream corridor for fish and wildife habitat, aesthetics, recreation

\section{CONDITIONSWHERE PRACTICE APPLIES}

This practice applies to streambanks of natura or constructed channels and shorelines of lakes, reservairs, or estuaries where they are susceptible to erosion It does not apply to erosion probiems on main ocean fronts beaches or similar areas of complexity.

CRITERIA

General Criteria Applicable to All Purposes

Treatments shall be in accordance with all applicable local, state and federal laws and regulations.

Treatmerts applied shall seek to avoid adverse effects to endangered, threatened, and candidate species and their habitats, whenever possible.
Treatments applied shall seek to avoid adverse effects to archaeological, historic, structural, and traditional cultural properties, whenever possible.

An assessment of unstable streambank or shoreline sites shall be conducted in sufficiert detail to identry the causes contributing to the instability (e g. Livestock access, watershed alterations resulting in significart modifications of discharge or sediment production, in channel modifications such as gravel mining, head cutting. water level fluctuations, boat-generated waves, etc.)

Proposed protective treatments to be applied shall be compatible with improvements being planned or installed by others.

Protective treatments shall be compatible with the bank or shoreline materials, water chemistry. channel or lake hydraulics, and slope characteristics above and below the water line

End sections of treatment areas shall be adequately anchored to existing treatments, terminate in stable areas, or be otherwise stabilized to prevent flankeng of the treatment. Protective treatments shall be installed that resut in stable slopes. Design limitations of the bank or shoreline materials and type of measure installed shall determine steepest permissible siopes

Desigris will provide for protection of installed treatments from overbank flows resulting from upslope funoff and flood retum flows.

Internal drainage for bank seepage shali be provided when needed. Geotextiles or properly designed filter bedding shall be incorporated with structural measures where there is the

Conservation practice standards are reviewed pericditsay, and updated 8 needed. To cotain NRCS, CA ghe current version of this standard, contact the Nahral Rescurces Conservation Serwce June 2011

gige, Office, $\alpha$ vist the Field Otface Tectimicat Guide. 
potential for migration of material from behind the measure

$580-2$

Treatments shall be designed to account for any anticipated ice action wave action and fluctuating water levels.

All disturbed areas around protective treatments shall be protected from ercsion. Disturbed areas that are not to be cultivated shall be protected as soon as practical after construction.

Vegetation shall be selected that is best suited for the site conditions and achieves the intended purpose(s)

In order to ensure plart community

establishment and integnity, a vegetative management plan shal be prepared in accordance with NRCS corservation practice standard Critical Area Planting. Code 342.

Additional Criteria for Streambanks

Stream segments to be protected shall be classified according to a system deemed appropriate by the state. Segments that are incised or that contain the 5-year retum period (20 percent probability) or greater flows shall be evaluated for further degradation or aggradation.

A site assessment shall be perfomed to determine if the causes of instability are loca (e.g Foor soils, high water table in banks. aligment obstructions deflecting flows into bank, etc.) Or aystemic in nature (e.g. Aggradation due to increased sedimert from the watershed, increased runoff due to urban development in the watershed, degradation due to channel mocifications, etc.). The assessmen need only be of the extert and detail necessary to provide a basis for design of the bank treatments and reasonable conficience that the treatments will perform adequately for the design life of the measure.

Changes in channel alignment shall not be made without an assessmert of both upstream and downstream fluvial geomorphology that evaluates the effects of the proposed alignment The current and future dischange-sediment regime shall be based on an assessment of the watershed above the proposed chamel alignment.

Bank protection treatment shall not be installed in channel systems undergoing rapid and extensive changes in bottom grade and/or aligrment uriess the treatments ate designeci to cortrol or accornmodate the changes. Bank treatment shall be constructed to a depth at or

Below the articipated lowest depth of streambed scour

If the failure mechanism is a fesult $\alpha$ the degradation or removal of nparian vegetation, stream corridor restoration shall be implemented, where feasible, (see Additional Criteria for Stream Corridor Improvement) as well as treating the banks

Toe erosion shall be stabilized by treatments that redrect the stream flow away from the toe or by structural treatments that armor the toe. Additional design guidance is found in the EFH Part 650 , Chapter 16, Streambank and Shoreline Protection.

Where toe protection alone is inadequate to stabilize the bank, the upper bank shall be shaped to a stable slope and vegetated, or shall be stabilized with structural or soil bicengineering treatments

Channel clearing to remove stumps, fallen trees debris, and sediment bars shall only be performed when they are causing or could cause unacceptable bank erosian flow restriction, or damage to structures. Habitat forming elements that provide cover, food pools, and water turbuience shatl be retained $\alpha$ replaced to the extent possible.

Treatments shall be functional and stable for the design flow and sustainabie for higher flow conditions

Treatments shall not induce an increase in natural erosion

Treatments shall not limit stream flow aocess to the flocdplain

Where flooding is a concern, the effects of protective treatments shall not increase flow levels above those that existed pricr to installation.

Additional Criteria for Shorelines

All revetmerts, buikheads or groins are to be no higher than 3 feet ( 1 meter) above mean high tide, or mean high water in non-tidal areas 
Structural shoreline protective treatments shall be keyed to a depth to prevent scour during low water

For the design of structural treatments, the ste characteristics below the waterline shall be evaluated for a minimum of 50 feet (15 meters) horizontal distance from the shoreline messured at the design water surface.

The height of the protection shall be based on the design water surface plus the computed wave height and freeboard. The design water surface in tidal areas shall be mean high tide

When vegetation is selected as the protective treatment, a temporary breakwater shall be used during establishment when wove fun up would damage the vegetation

Additonal Criteria for Stream Cocridor Improvement

Stream corndor vegetative components shall be established as necessary for ecosystem functioning and stability. The appropriate compasition of vegetative components is a key element in preventing excess long-term channel migration in re-established stream corridors. The establishment of vegetation on charnel banks and associated areas shall also be in accordance with conservation practice standard Critical Area Planting Code 342

Treatmerts shall be designed to achieve habitat and population objectives for fish and wildife species or communities of concern as determined by a site-specific assessment or management plan. Objectives shall be based on the survival and reproductive needs of populations and communities, which include habitat diversity, habitat linikages, daily and seasonal habitat ranges, limiting factors and native plant communities. The type amount, and distribution of vegetation shal be based on the requirements of the fish and wildife species or communities of concern to the extert possible.

Treatmerts shall be designed to meet aesthetic objectives as determined by a site-specific assessment of management plan. Aesthetic objectives shall be besed on human needs, including visual quality, noise corttrol, and microclimate control. Construction materials. grading practices, and other ste cevelopment elements shall be selected and designed to be compatible with acjacent land uses.

Treatments shall be designed to achieve recreation odjectives as determined by a site. specific assessment or managemert plan Safety requiremerts shall be based on type of human use and fecreation objectives.

\section{CONSIDERATIONS}

When desigring protective treatments, consider potential changes that may oocur in the watershed rydrology and sedimentation cver the design life of the treatmerts

Consider utilizing debris removed from the channel or streambank into the treatment design when it is compatible with the intended purpose to improve benefits for fish, wildlife and aquatic systems.

Use construction materials, grading practices. vegetaton, and other site development elemerts that minimize visual impacts and maintain or complement existing landscape uses such as pedestrian paths, climate controls. buffers etc. Avcid excessive disturbance and compaction of the site during installation

Uilize vegetative species that are natve and/or compatibie with local ecosystems. Avoid introduced invasive, noxious or exobc species thet could become nuisances. Consider species that have multiple values such as those suited for biomass, nuts, fruit, browse, nesting aesthetics and tolerance to locally used herbicides. Avoid species that may be alternate hosts to cisease or underirable pests. Species diversity should be considered to avoid loss of function due to species-specific pests. Species. on noxious plant lists should not be used.

Select plant materials that provide habitat requirements for desirable wildife and pollinators. The addition of native forbs and legurnes to grass mixes will increase the value of plantings for both wildife and pollinators.

Treatments that promote beneficial sediment deposition and the filtering of sediment, sediment-attached, and dissolved substances should be considered.

Consider maintaining or improving the habitst value for fish and wildlife by including treatments that provide aquatic habitat in the treatmert 
design and that may lower or moderate water temperature and improve water quality.

Consider the need to stabilize side channel inlets and outlets and outless of tributary streams from erosion

Consider aquatic habitat when selecting the type of toe stabilization

Consider maximizing adjacent wetland functions and values with the project design and minimize adverse effects to existing wetiand functions and values

Livestock exclusion shail be considered during establishment of vegetative treatmerts and appropriate grazing practices applied atter establishment to maintain plant corrmunity integrity. Wiidlife may also need to be controlled during establishment of vegetative treatments.

Temporary and local population control methods should be used with caution and within state and local regulations

When appropriate, establish a buffer strip andor diversion at the top of the bank or shoreline protection zone to relo maintain and protect installed treatments, improve their function, filter out sediments, nutrients, and poliutants from runoff, and provide acditional wildife habitat

Consicer safety hazards to boaters, swimmers. or people using the shcreline or streambark when designing treatments.

Protective treatments should be self-sustaining or requife minimum mainterance.

Cultural Resources and Endangered Species
This practice is likely to occur in areas where Cutural Resources or Endangered Species habitat may be found. Follow NRCS Planning Policy to address these concerns

\section{PLANS AND SPECIFICATIONS}

Pians and specifications for streambank and shoreline protection shall be prepared for specific field sites and based on this standard and shall describe the requirements for applying the practice to achieve its intended purpose Plans shail include treatments to minimize erosion and sediment production during construction and provisions necessary to comply with conditions of arny ervironmental agreements, biological opinions or other terms of applicable permits.

\section{OPERATION AND MAINTENANCE}

An operation and maintenance plan shall be prepared for use by the owner or others responsible for operating and maintaining the system. The plan shall provide specific instructions for operating and maintaining the system to insure that it functions properly. it shall also provide for periodic inspections and prompc repair or replacement of damaged components or erosion.

\section{REFERENCES}

NEH Part 650, Chapter 16, Streambank and Shoreline Protection

NRCS Techrical Note-Engineening-CA-14, September 2003

NEH Part 654, Stream Restoration Design 


\section{NATURAL RESOURCES CONSERVATION SERVICE}

CONSERVATION PRACTICE STANDARD

\section{4 - FISH AND WLDLIFE STRUCTURE}

\section{CODE 734 (INTERIM PRACTICE)}

\section{DEFINITION}

A structure designed and installed specifically for fish or wildife.

\section{PURPOSE}

To improve overall habitat oonditions for fish of wilcile species. This practice may be applied as part of a fish or wildife habitat management plan to serve one or more of the following functions

X Provide structure for loafing, escape. nesting, rearing, roosting, perching, or basking

X Provide an escape, avoidance, or exclusionary feature fram otherwise lifethreatening condtions

$X \quad$ Provide alternative cover when natural cover is not readily available.

$X \quad$ Isolate native species populations from non-natives $X$ improve or restore habitat connectivity.

\section{CONDITIONS WHERE PRACTICE APPLIES}

This practice applies to all land uses where the land manager has identified an objective to conserve fish or wildife.

\section{CRITERIA}

Structures shall be designed and installed to meet the targeted species biology and life history needs

Structures will be designed according to the applicable Biology Technical Notes or other design references approved by the NRCS state office.

Plastic and fiberglass structures shall be made of uitraviolet resistant materials and may be coated with non-toxic substances for additional protection from deterioration due to sunlight exposure.
Structures shall be built to withstand expected environmental concitions at the site to maximize structural lifespan, stability, and habitat berierits

\section{CONSIDERATIONS}

Give consideration to effects the location of the structure will have on targeted and non-targeted species

Consider the need to prevent increased predation on both targeted and non-targeted fish and wildife species as a result of installation of structures under this practice.

Consider combining this practice with vegetative practices to establigh natural habitat features in the long term

Types of fish and wildifie structures to consider include.

Artificial nest boxes or platforms for species such as cavity-rnesting birds, bats, pollinators, and waterfow

Artificial cover such as brush piles rock piles. buried concrete pipe, engineered log jams

Wood structures in or along stream banks for fish cover

Natural cover manipuation, such as girdling trees to encourage snag development

Measures to facilitate passage including elk jumps, escape rampe, road crossings

Measures to inhibt passage including predato guards, non-native fish barners, beaver dam exclusion features

\section{PLANS AND SPECIFICATIONS}

Plans and specifications for installing fish and wildife structures shall be in keeping with this standard and shall describe the biological and physical requiements for applying the practice. 
The plan shall specify the location, quartities. dimensions, materiais, and timing of installation for each structure

\section{OPERATION AND MAINTENANCE}

Operation and maintenance provisions shall be provided to and reviewed with the land manager. The provisions shall be site specific and include but not be limited to the following

Structures will be inspected at least semiannually and after major storms

Necessary mainterance, including removal of debris, shall be pertomed

\section{REFERENCES}

May, H. 2001. Artificial Nesting Structures. USDA Natural Resources Conservation Service Wildife Habitat Managernent institute and Wildife Habitat Council, Fish and Wildlife

Habitat Leaflet, No 20

Mueller, J. 1999. Amenican kestrel USDA

Natural Resources Conservation Service

Widife Habitat Management Institute and Wildife Habitat Council, Fish and Wild-life Habitat Management Leafiet, No 3

Muetler, J 1999 Bats. USOA Natura:

Resources Conservation Service Wildife

Habitat Management Institute and Wilclife Habtat Council, Fish and Wid- Life Habitat Maragement Leaflet, No. 5.

Novinger, D. C. And Rahel, F.J. 2003 . Isolation management with artificial barriers as a

conservation strategy for cutthroat trout in headwater streams. Conservation Biology 17

772.781 .

Oregon NRCS Biology Technical Notes

thtp ilowm or nrcs usda govitechnicaliecs/biolog yfbiology-technotes himi

Payne, N.F And F. C. Bryant 1994

Techriques for wildife management of uplands McGraw-Hill, New York, NY

Payne, N. F, 1992. Techniques for wildife habitat managemert of wetlands. MoGraw-Hill, New York, NY

Rewa, C 1999 Wood duck. USDA Natural
Resources Conservation Service Wildife

Habitat Manscement Institute and Wildife Habitat Council, Fish and Wild -life Habitat Management Leaflet, No 1

Tuttle, M. D And D. Hensley. 1993. The bat bulder's hand-book (2000 revision). Bat Conservation International; Austin, Texas,

USA. 30 
PRACTICE SPECIFICATIONS 


\section{NATURAL RESOURCES CONSERVATION SERVICE CONSERVATION PRACTICE SPECIFICATION \\ 342A - CRITICAL AREA PLANTING - STRAW MULCH}

\section{SCOPE}

The work shall consist of furnishing all materials and placing them on all exposed, asturbed, or barren areas within the designated areas to the limits as shown on the drawings, or as staked in the field

\section{MATERIALS}

\section{Seed}

All seed shall be native grass seed of appropriate species specified on the attached Native Plant Revegetation Palette.

All seed shall be delivered to the site tagged and labeled in accordance with the California Agricultural Code, and shall be acceptable to the County Agricultural Cormmissioner.

Bag tag figures will be evidence of purity and germination. Time since date of seed test shall not exceed 9 months

Seed shall be of a quality that weed seed shall not exceed 0.5 percent of the aggregate $\alpha$ pure Iwe seed (PLS) (percent germination $x$ percent purity and other material

\section{Fertilizer}

Unless cthermise specified on the Practice

Requrements sheet, sil fertilizer shall be Ammonium Phosphate Sulfate containing a minimum of 16 percent Nitrogen, 20 percent available phosptoric acid and 0 percent water soluble potash and be uniform in composition, dry and free flowing, pelleted or gramulat:

All fertilizer shall be iabeled in accordance with applicable state regulations and beat the warranty of the producer for the grade furnistied.

\section{Inoculants}

The inoculant for treating legume seeds shall be a pure culture of Nitrogen fixing bacteria prepared specifically for the plant species and shall not be used later than the clate indicated on the container A mixing medium, as recommended by the manufacturer or approved substitute, shall be used to bond the inoculant to the seed. For nonpellet inoculated seed, two times the amount of the inoculant recommended by the manufacturer shall be used and seed shall be sown with 24 hours

For pellet incculated seed, at least 30 pounds of inoculant shall be used per 1,000 pounds of raw seed and the seed shall be labeled to show the Lo Number, Expiration Date, and Fercent Coat of the finished product. Pellet inoculated seed shall be kep cool and sown within 180 days

\section{Straw}

Straw shall be new straw derived from rice. wheat, oats, or barley that meets the County Acricultural Commssioner's standards for weed pests. Clearance shall be obtained from the County Agricultural Commissioner, as required by law, before straw obtained outside the county in which it is to be used is delivered to the site

\section{Jute Matting}

Jute matting shail be cloth mesh of uniform plain weave of undyed and unbleached jute yarn with a minimum weight of one pound per 10 square feet, and a maximum opening size of 1 inch by 1 inch.

\section{Plastic Netting}

Plastic netting shall be a polypropylene extruded plastic netting with square or rectangular openings not greater than $3 / 4$ inches and weight of not less than 2.6 pounds per 1000 square feet.

\section{Excelsior Matting}

Excelsior matting shall consist of a machine. produced mat of mood excelsior fiber with consistert thickness and fiber everly distributed over the entire area of the blanket. At least 70 percert of the fibers shall be 6 inches or longer in length. The topside of each blarket shall be covered with a biociegradable extruded plastic mesh with a maximum opening size of 2 -inch by 2 -inch

Staples 
Staples shall be made of 009 inch diameter or heavier wire, "U" shaped with legs at least 8 inches in length.

Anchor pins may also be used to anchor jute matting. Anchor pins shall be made of rigid0.12 inch diameter or heavier galvanized wire with a mirimum length of 10 inches for hook or " $J$ " type pins.

\section{SEEDING MIXTURE AND PLANTING DATE}

The seed(s) and rate(s) specified on the Practice Requirements sheet and Native Plant Revegetation Palette shall be used.

The seeding rate(s) shall be the weight exclusive of any coabing material. Any legume seed used shall be inoculated. Based on bag tags, seeding rates shall be adjusted to insure the required amoums of pure ive seed

Planting shall be performed after final grading is completed unless otherwise spectied on the Practice Requirements sheet

\section{SEEDBED PREPARATION}

The area to be planted shall be weed free and have a firm seedbed which has previously been roughened by scarifyng, dsking, harrowing chiseling, or otherwise worked to a depth of 2 to 4 inches. No implement shall be used that will create an excessive amount of dowrward movemert of clods on sloping areas Seedbed may be prepared at time of completion of earth moving work. The horizortal indentations left by tracked equipment is acceptable on steep siopes.

Rocks larger than 6 inches in dameter, trash, weeck, and other debris that will interfere with seeding or maintenance shall be removed

Seedbed preparation shall be suspended when soil moisture conditions are not suitable for obtaining a satisfactory seedbed

\section{FERTILIZING, SEEDING, MULCHING \\ Fertilizing}

Fertilizer shall be distributed uniformly over the seedbed at the rate of 500 pounds per acre unless a different amount is specified on the Practice Requirements sheet

Fertilizer shall be applied in any way that will result in uniform distribution. The fertilizer shall be incorporated irto the soil Incorporation may be as part of the seedbed preparation, or as part of the seeding operation

\section{Seeding}

Seed shall be drilled or broadcast by hand mechanical hand seeder, or power operated seeder. Seed shall be incorporated irto the soil but not more than 1 inch deep

\section{Mulching}

A straw covering shall be distributed uniformly over the seeded area within 48 hours after seeding. Straw shall be applied at the rate $\alpha 2$ tons per acre unless a different amount is specified on the Practice Requirements sheet. The straw shall be applied by hand, blower, or other suitable equipmert. If straw is applied by blower, it shall not be chopped in lengths less than 6 inches

\section{Anchoring the Mulch}

The mulch shall be anchored in place using one of the fallowing methods as specified on the Practice Requirements sheet.

\section{Method 1}

The straw shall be anchored using hand toois, mulching rollers, straight serrated disks, or similar types of suitable equipment and shall be performed in a satisfactory manner. The straw shall be tucked in a mirimum of 3 inches on a spacing not to exceed one foct in both directions

\section{Method 2}

The straw shall be anchored in place by the placement of fute native brish matting of exeeteief matting The matting shall be applied up and down the slope and shall continue beyond the edge of the mulched or seeded area at least 1 foot at the sides and at the top and bottom of the mulched area. If existing vegetation or structures mark the boundaries of the area, the matting shall be continued irto the stable vegetated area $c r$ to the edge of the structure. The matting shall be cut around objects so it will lay flat on the soil surface.

The upper end of the matting at the top of the area shall be buried in a trench at least 6 inches deep. Sides of rolls shall overlap at least 4 inches, and rolls shall overlap at least 3 feet 
where an uphill roll joins a downhill roll. The uphill roll shall overlie the downhill foll

Staples Wooden stakes or native brush cuttings shall be installed perpendicular to the slope and shall be spaced approximately 5 feet apart dow the sides in the overtap area and certer of the roll Staples Wooden stakes or native brush cuttings spaced not more than 1 foot apart shal be installed across the Lpper end of each roll and across the overlap area where an uphill roll joins a downhill roll.

\section{Method 3}

The straw mulch shall be anchored in place by covering the mulch with plastic netting. The netting shall be applied up and down the slope. and shall continue beyond the edine of the muiched area at least 1 foot at the sides and at the top and bottom of the area.

The upper end of the netting at the top of the area shall be buried in a trench at least 6 inches deep Sides of rolls shall overlap at least 4 inches and rolls shall overlap at least 3 fee where an ughill roll joins a downhill roll. The uphill roll shall overlie the oownhill roll

Staples shall be installed perpendioular to the slope and shal be spaced 5 feet apart in both directions The staples on the exterior edges of the netting shall be spaced 5 feet apart

\section{Method 4}

No anchoring is required

\section{IRRIGATION}

When specified, irrigation water shall be applied during the establishment period at the times and rates as listed on the Practice Requirements sheet.

\section{VII, OTHER REQUIREMENTS}

Other detaits for the establishment and maintenance of the plants including but not limited to the need for ivestock and traffic control shail be applied when specified on the Practice Requirements sheet

Measures and methods that enhance fish and wildife values, protect visual resources, and maintain key shade, focd, and den trees shall be performed when specified on the Practioe

Requitemerts sheet

Operations shall be done in such a marner that soil erosion and air and water pollution are minimized and held within legal limits.

The owner, operator, contractor, or other persons shall oonduct all work and operations in accordance with proper safety codes for the type of work being performed with due regards to the safety of ali persons and property. 


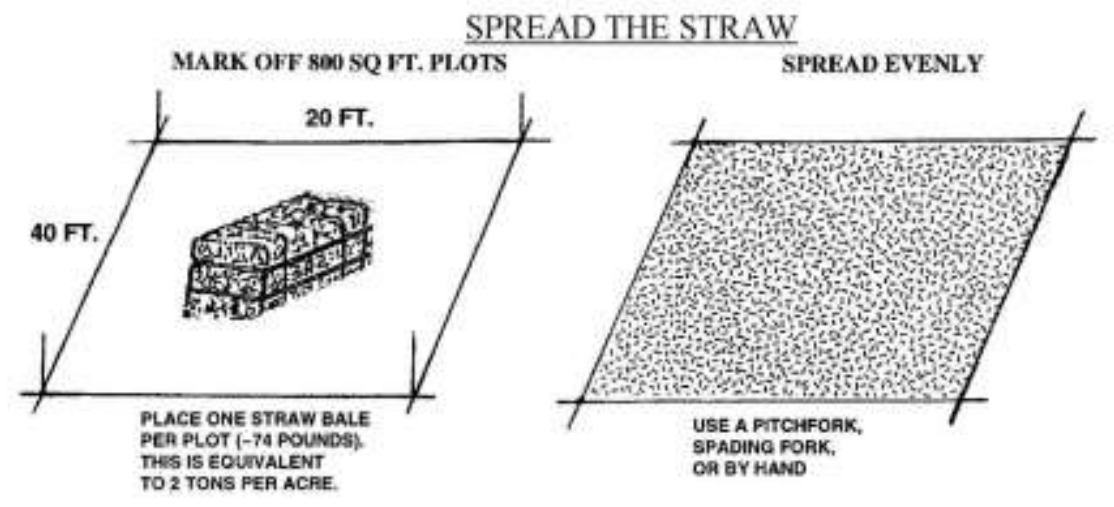

$\triangle$ NCHOR THE STRAW - METHOD 1

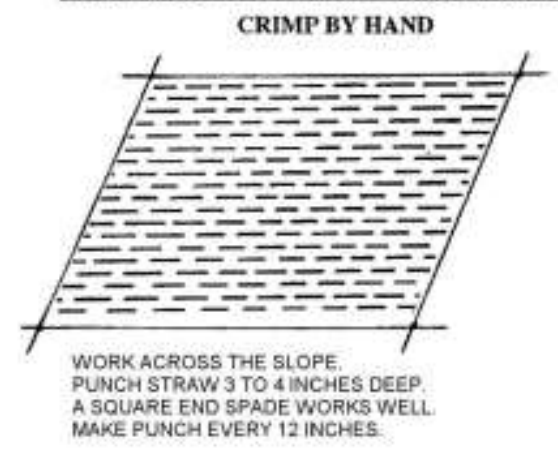




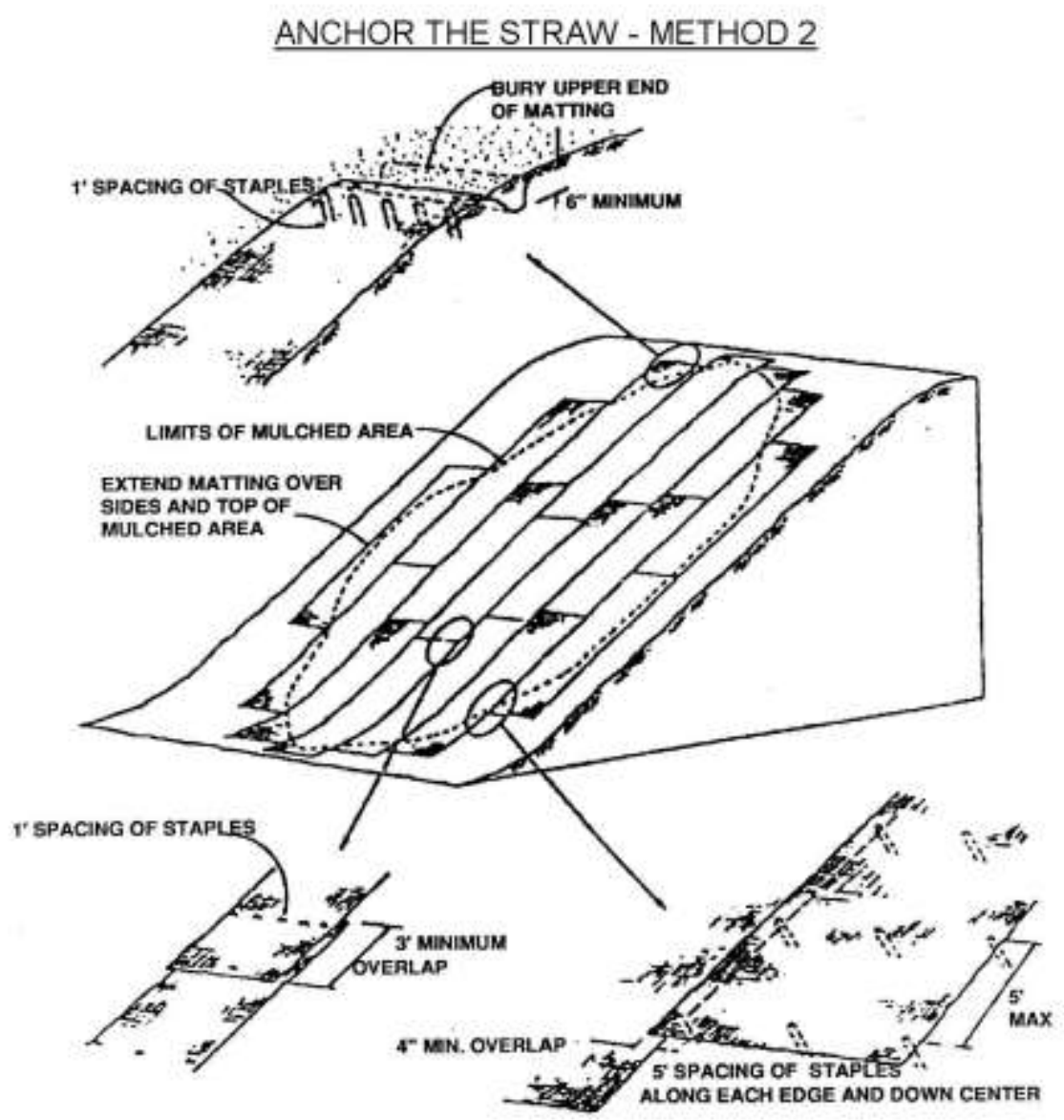




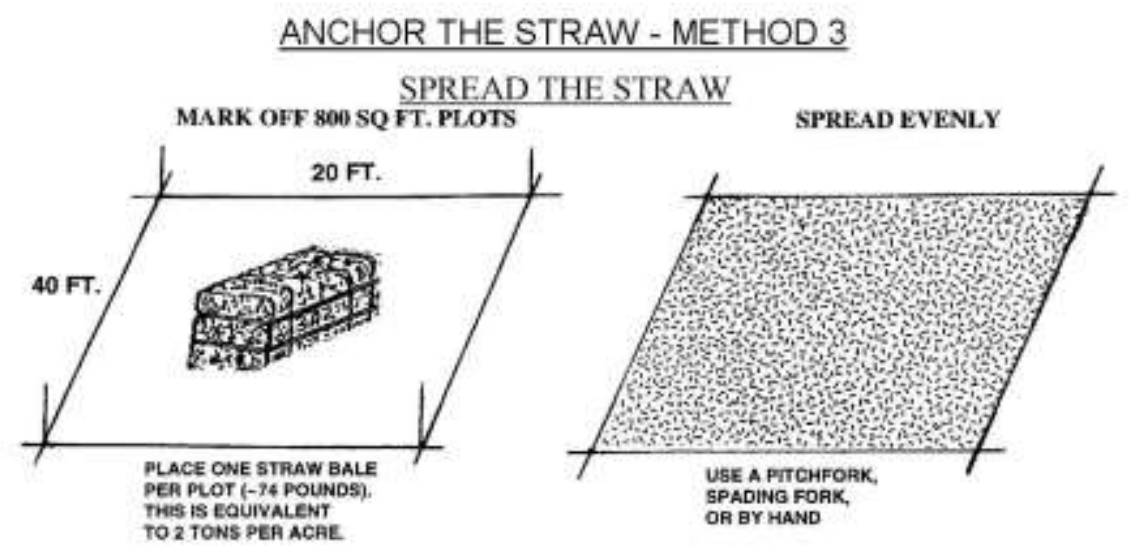

ANCHOR THE STRAW - METHOD 3

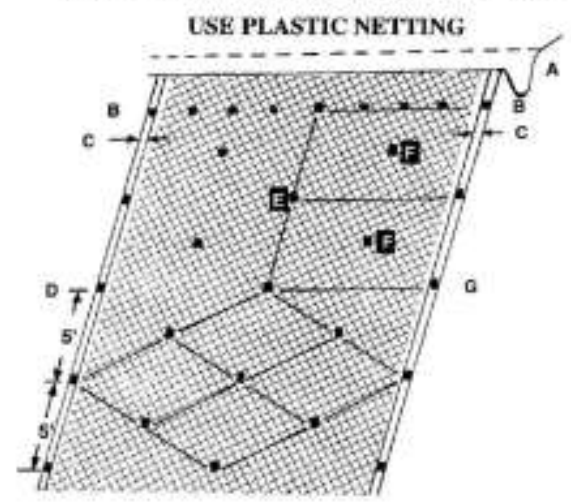

LAY BIRD CONTROL NETTING OR SIMILAR MATTING IN STRIPS DOWN THE SLOPE OVER THE STRAW. BURY UPPER END IN 6-8 INCH DEEP ANDWIDE TRENCH. MOST NETTING COMES IN 14 TO 17 FT. WIDE ROLLS.

SECURE THE UPPER END WITH STAKES EVERY 2 FEET

OVERLAP SEAMS ON EACH SIDE $4-5$ INCHES.

SECURE SEAMS WITH STAKES EVERY 5 FEET.

STAKE DOWN THE CENTER EVERY 5 FEET.

STAKE MIDDLES TO CREATE DIAMOND PATTERN THAT PROVIDES STAKES SPACED 45 FEET APART.

USE POINTED $1 \times 2$ INCH STAKES \& TO 9 INCHES LONG. LEAVE 1 TO 2 INCH TOP ABOVE NETTING, OR USE "U" SHAPED METAL PINS AT LEAST 9 INCHES LONG.

NOTE WHEN JOINING TWO STRIPS, OVERLAP UPPER STRIP 3 FEET OVER LOWER STRIP AND SECURE WITH STAKES EVERY 2 FEET LIKE IN "B" ABOVE. 


\section{NATURAL RESOURCES CONSERVATION SERVICE}

\section{CONSERVATION PRACTICE SPECIFICATION}

\section{$342 \mathrm{G}$ - CRITICAL AREA PLANTING - WOODY CUTTING}

\section{SCOPE}

The work shiall consist of furnishing all materials and placing them within the project area or ste to the limits as shown on the drawings or as staked in the field.

\section{MATERIALS}

Woody cuttings shall be made from healthy green plants during the dormant season. No more than $2 / 3$ ds of each plant will be removed Select cuttings with leaf buds near the top of each cut

Stem or branch cuttings of soft wood, hard wood or firm wood should be taken whenever possible from plarts that are native to the locality or grown on similar sites.

Cuts shall be made clean with sharp tools The butt end of the stem shall be a slant cut and the tip end shall be cut square across the stem

Size:

Slips. The diameter of the cutting shall not be more than $11 / 2$ inches at the but end nor smaller than $1 / 4$ inch at the tip. Cuttings shat have a minimum length of 2 feet and a maximum length of 4 feet unless otherwise specified on the Practice Requirements Sheet.

Poles: The diameter of the culting shall not be more than 4 inches nor smaller than. 1inch at the butt end and $1 / 2$ inch $3 t$ the tip. Cuttings shall have a minimum length of the depth to the water table plus 3 feet uniess otherwise spectied on the Practice Requirements Sheet.

Cuttings shall not be allowed to dry and shall not be more than 7 days old when planted uniess otherwise specified on the Practice

Requirements sheet

\section{PLANT MATERIALS AND PLANTING}

DATE

The fonds $\alpha$ cuttings specilied on the Practice Requirement sheet shall be used
Planting shall be peiformed after final grading is completed unless otherwise specified on the Practice Requirements sheet

\section{SITE PREPARATION}

The area to be planted shall be weed free and have a uriform surface No implement shall be used that will create an excessive amount of downward movement of clods on sloping areas The site may be prepared at time of completion of earth moving work.

Trash, weeds, and other debris that will irterfere with planting or maintenance shall be removed

\section{PLANTING REQUIREMENTS}

Cuttings shall be planted in one or more tows as shown on the drawing(s) as vertical as possible. Cuttings shall be spaced 3 feet apart in the row and in multiple row plantings, spacing between fows shail be 3 feet. Cuttings shail be staggered with respect to those in adacent rows uniess otherwise specitied on the Practice Requirement sheet.

Cuttings shall be planted in prepared holes or $\checkmark$ " furrows to avoid stripong the bark. especially in rocky or hard soils. Cuttings may be pushed into soil if the soil is saturated with moisture. Cuttings shall be placed in the soil with the butt end in a downward position

All cuttings shall have 6 inches to a maximum of 1 foot including at least two nodes above the ground level

Cuttings shall be placed into the soil to a depth specified on the Practice Requirements sheet. If however, due to some prysical condition in the soil this planting depth cannot be attained, the cuttings shall be set with $3 / 4 \mathrm{of}$ its length in the soil upon approval of the NRCS techrician At a minimum they must be placed into the soil 18 inches

Poles: Plant in acequately sized, sod-free holes Auger $a$ hole to the water table. Place materials in the augured hole one-half foot above the growing season water table 
After plarting. pack the soil firmly around each pole to eliminate air pockets. "Mudding" by

filling the hole with water and then adding more soil to make a slurry can remove air pockets.

\section{IRRIGATION}

When specified irrigation water shall be appled at the times and rates as listed on the Practice Requirements sheet to keep the soil in the lower two feet of the planted cutting mast.

\section{SPECIAL MEASURES}

Measures and methods that enthance fish and widite values, protect visual resources, and maintain key shade, food, and den trees shall be performed when specitied on the Practice Requirements sheet

\section{VIIL. OTHER REQUIREMENTS}

Other details for the establishment and maintenance of the plarts including but not limited to, the need for livestock and traffic controt shall be applied when specified on the Practice Requirements sheet.

Operations shall be done in such a manner that erosion and air and water pollution are minimized and held within legal limits.

The awner, operator, contractor, and other persons shall conduct all work and operations in accordance with proper safety codes for the type of equipment and operations being performed with due regards to the safety of all persons and property 


\section{SCOPE}

The work shall consist of furnishing of materials and constructing streambank protection

measures to the lines, grades, elevations and dimensions as shown on the drawings or as staked in the field.

\section{SITE PREPARATION}

Trees and brush on the banks as marked in the field or shown on the dramings shall be removed and disposed of in designated areas. Removal of any trees and brush shall be done in such a manner as to avoid damage to other trees and property. Disposal of trees brush, and other materials shall be performed to have the least detrimentai effect on the envirorment

Fallen trees, stumps, debris, minor ledge outcroppings and sand and gravel bars as shown on the drawings shall be removed and disposed of in designated areas

Clearing and disposal methods shall be in accordance with state and county laws with due regard to the safety of persons and property.

\section{BANK PROTECTION MEASURES}

The type and extent of bank protection measures shall corform to the structural requirements of the specifications listed on the Practice Requirements sheet

\section{FENCING}

Fencing shall be installed at locations and of the materials shown on the drawings.

\section{VEGETATIVE COVER}

Unless otherwise specified, a protective cover of vegetation shall be established on the disturbed area. The planting of vegetative materials shall conform to the requirements of Practice Specification 342, Critical Area Planting

\section{SPECIAL MEASURES}

Measures and construction methods shall be incorporated as needed and practical that erhance fish and wildife values. Speoial attention shall be given to protecting visual resources and mairtaining key shade, food and dentrees

\section{CONSTRUCTION OPERATIONS}

Construction operations shall be done in such a manner that erosicn and air and water pollution are mirimized and held within legal limits. The owner, operator, Contractor or other persons wil conouct all work and operations in accordance with proper safety codes for the type $\alpha$ construction being performed with oue regards to the safety of all persons and property

The completed job shall be workmanlike and present a good appearance. 


\section{NATURAL RESOURCES CONSERVATION SERVICE \\ CONSERVATION CONSTRUCTION SPECIFICATION \\ 909 - CONTROL OF WATER}

\section{SCOPE}

The work shall consist of the femoval of surtace water and ground water as needed to perform the required construction in accordance with the specifications. It shall incluce (1) buiking and maintaining all necessary temporary impounding works, channeis, and diversions, (2) furrishing. installing and operating all necessary pumps piping and other facilities and equipment, and (3) removing all such temporary works and equioment after they have served their purposes. All work shall be done in a marner approved by the engineer.

\section{DIVERTING SURFACE WATER}

The Contractor shall build, maintain and operate all cofferdams, charnels, flumes, sumps, and other temporary diversion and protective works needed to divert streamflow and other surface water through or around the construction site and away from the construction work while construction is in progress. Uniess otherwise specified, a diversion must discharge into the same natural drainage way in which its headworks are located

\section{DEWATERING THE CONSTRUCTION SITE}

Foundation cutoff trenches and other parts of the construction site shall be dewatered and kept free of stancing water or excessively muddy conditions as needed for proper execution of the construction work. The Contractor shall furrish, install, operate and maintain all drains, sumps, pumps, casings, well poirts, and other equipment needed to perform the dewatering as specified

Dewatering methods that cause a loss of fines from the foundation areas will not be permitted.

\section{DEWATERING BORROW AREA}

Uniess othermise specified in the "Practioe Requirements' sheet, Cortractor shall maintain the borrow areas free of surface water or otherwise provide for timely and effective removal of surface waters that accumulate within the borrow areas from any source.
Borrow material shall be processed as necessary to achieve proper and uniform mossture cortent for placement.

If pumping to dewater area is included as an tem of work in the bid schedule, esch pump used for this purpose shall be equipped with a water meter in the discharge line. Accuracy of the meters shall be such that the measured quartity of water is within 3 percent, plus or minus, of the true quantity

Means shall be provided by the Contractor to check the accuracy of the water meters when requested by the engineet

V. REMOVAL OF TEMPORARY WORKS

After the temporary works have served their purposes, the Contractor shall remove thern or level and grade them to the extent required to present a sightly appearance and to prevent ary obstruction of the flow of water or any other interference with the operation of or access to the permanert works.

Except as otherwise specified in the "Practice Requirements' sheet, pipes and casings shall be removed from temporary wells and the wells shall be filled to gound level with gravel $\alpha$ other material approved by the engineer

\section{EROSION AND POULUTION CONTROL}

Removal of water from the construction site including the botrow ateas, shall be accomplished in a manner that erosion and the transporting of sediment and other pollutants are minimized. Dewatering activities shall be sccomplished in a manner that the water table water quality is not altered.

VII. SPECIAL MEASURES

Measures and construction methods shall be incorporated as needed and practical that enhances fish and wildife values Special attention shall be given to protecting visua resources and maintairing key shade, food, and den trees 
E. PHASE I PHOTO MONITORING PACKET 


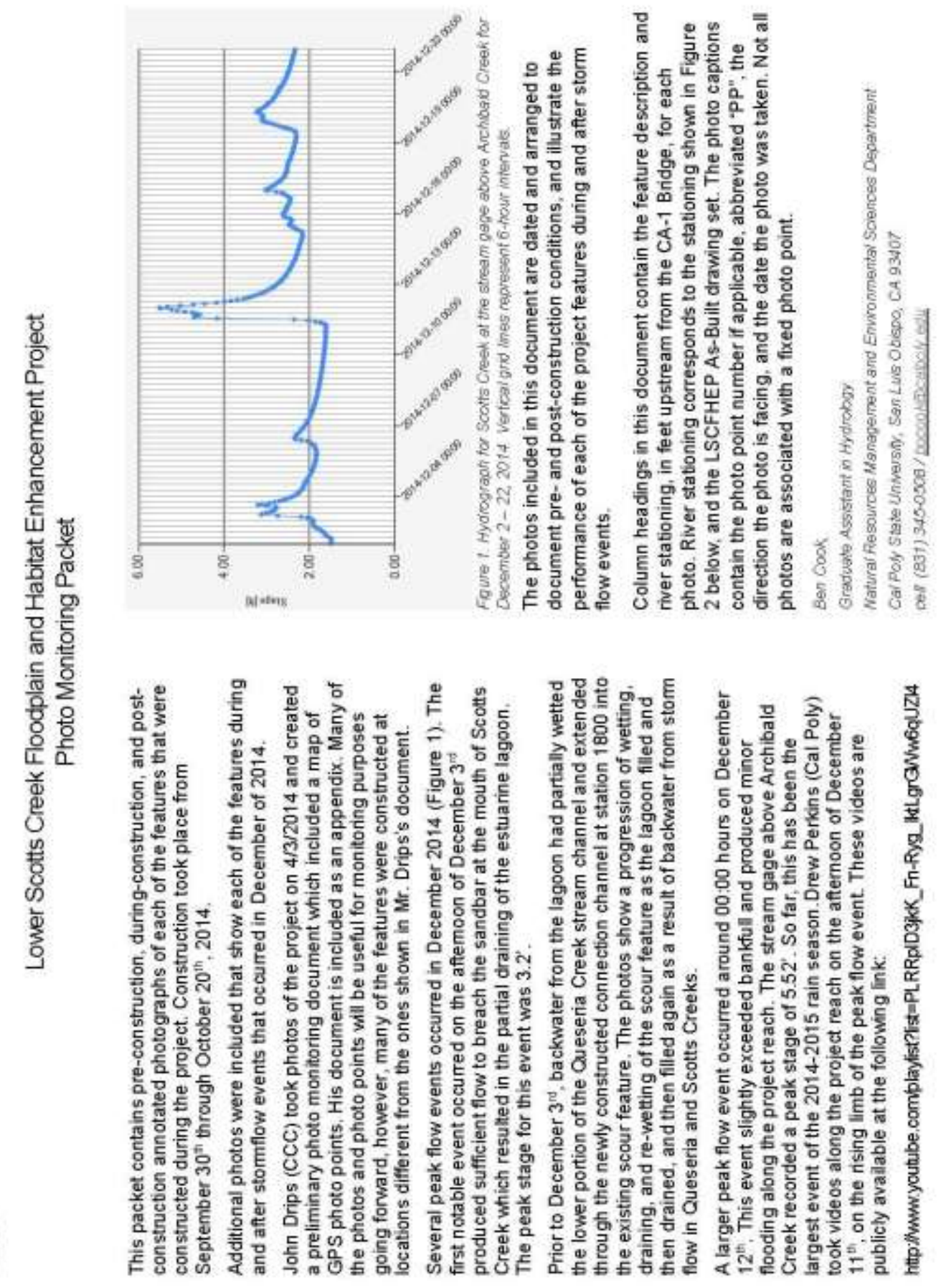




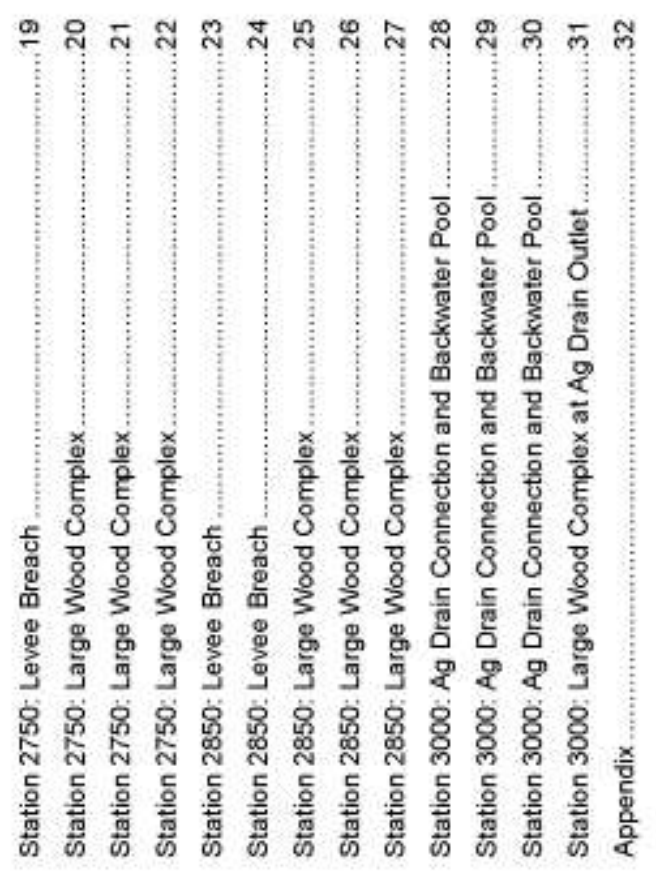

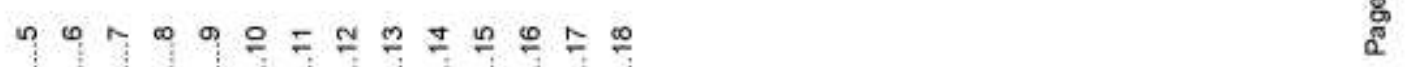



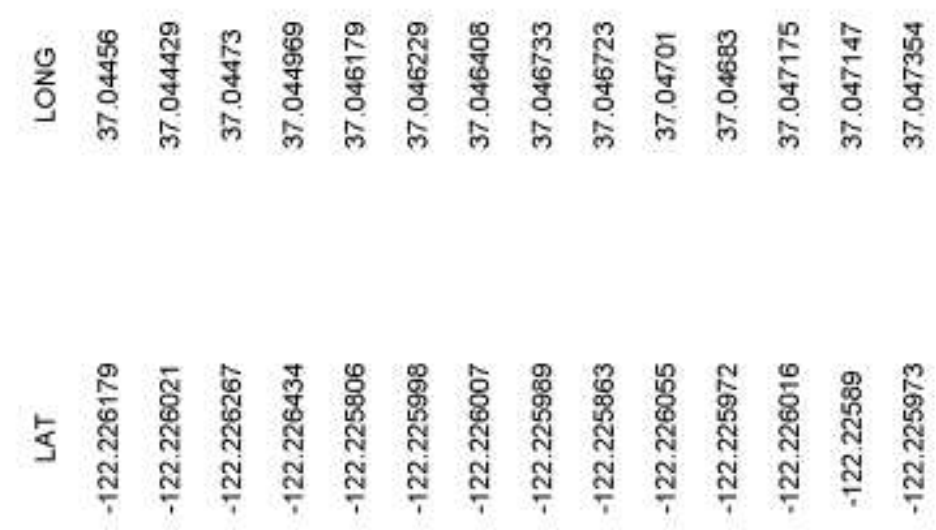

0
0
0
0
8
8
8

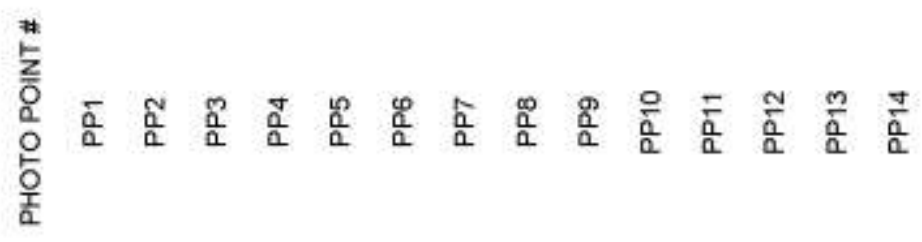




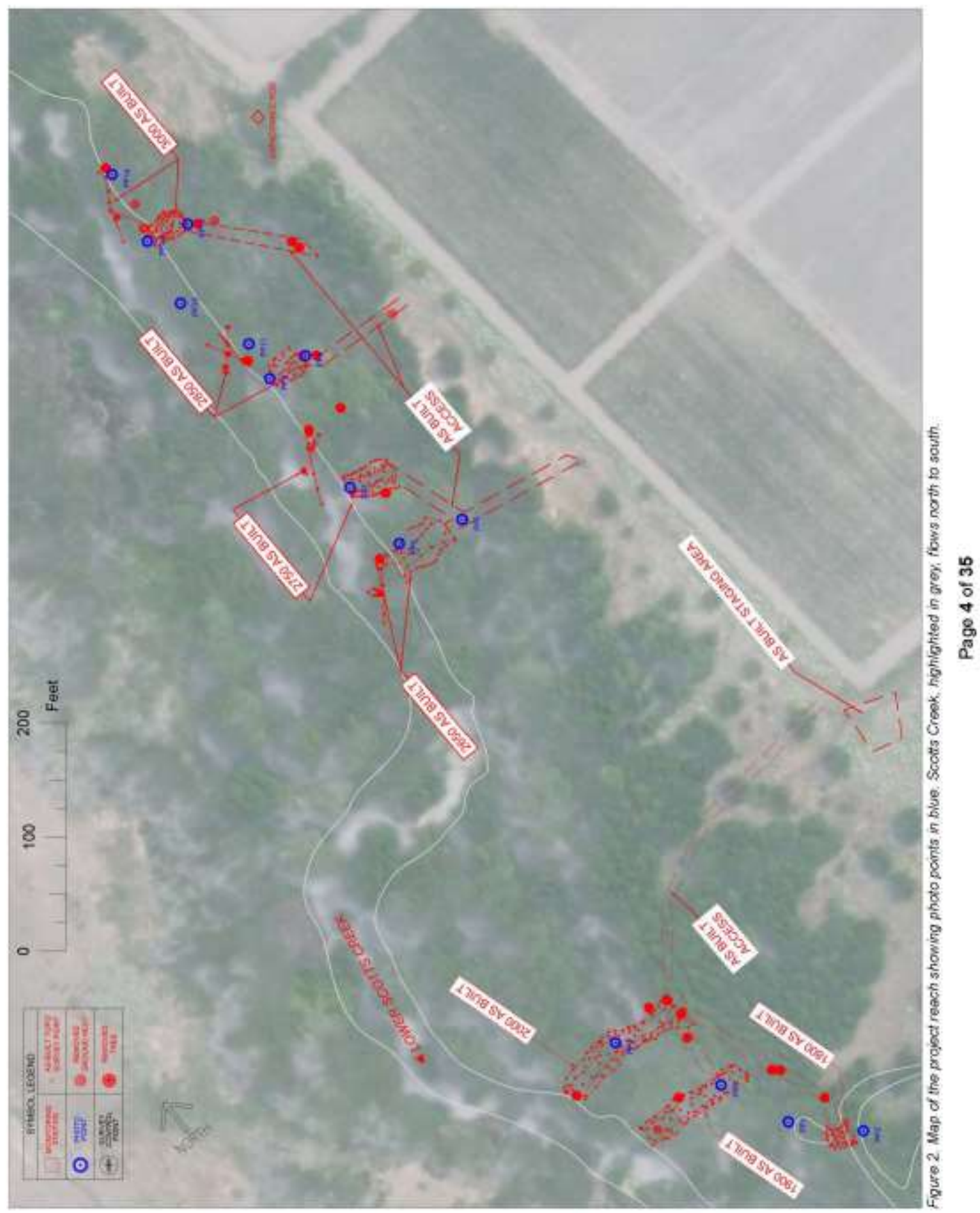



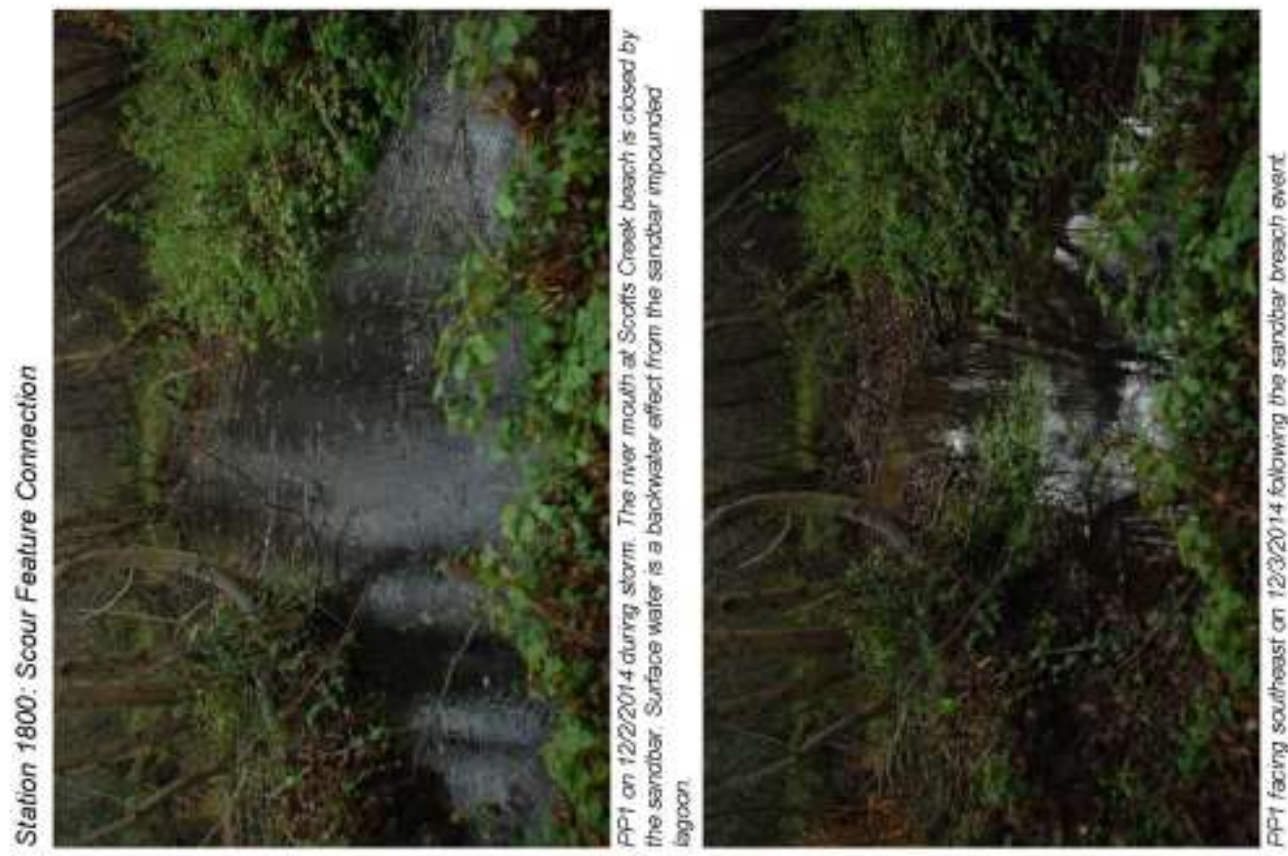

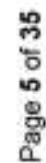
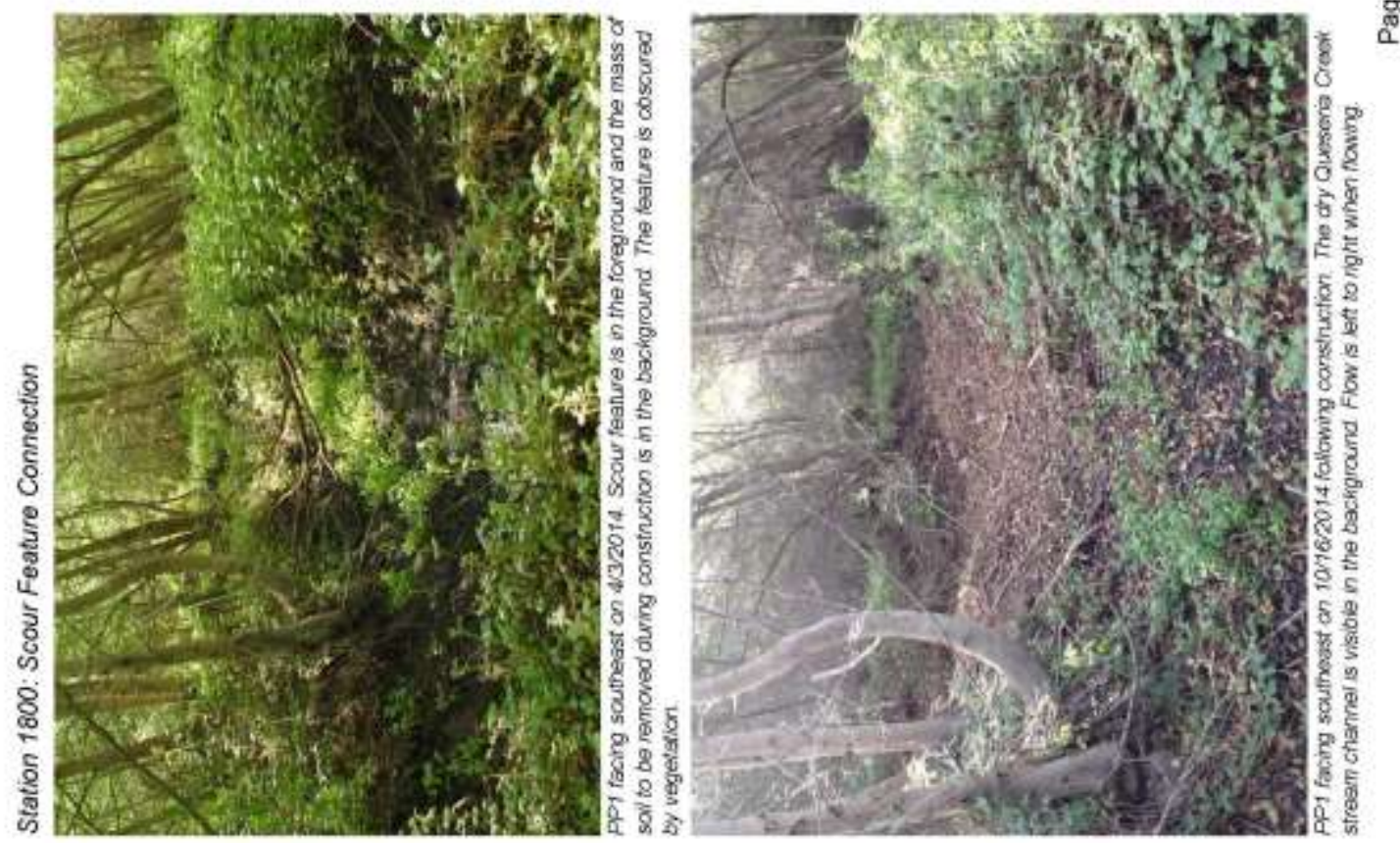

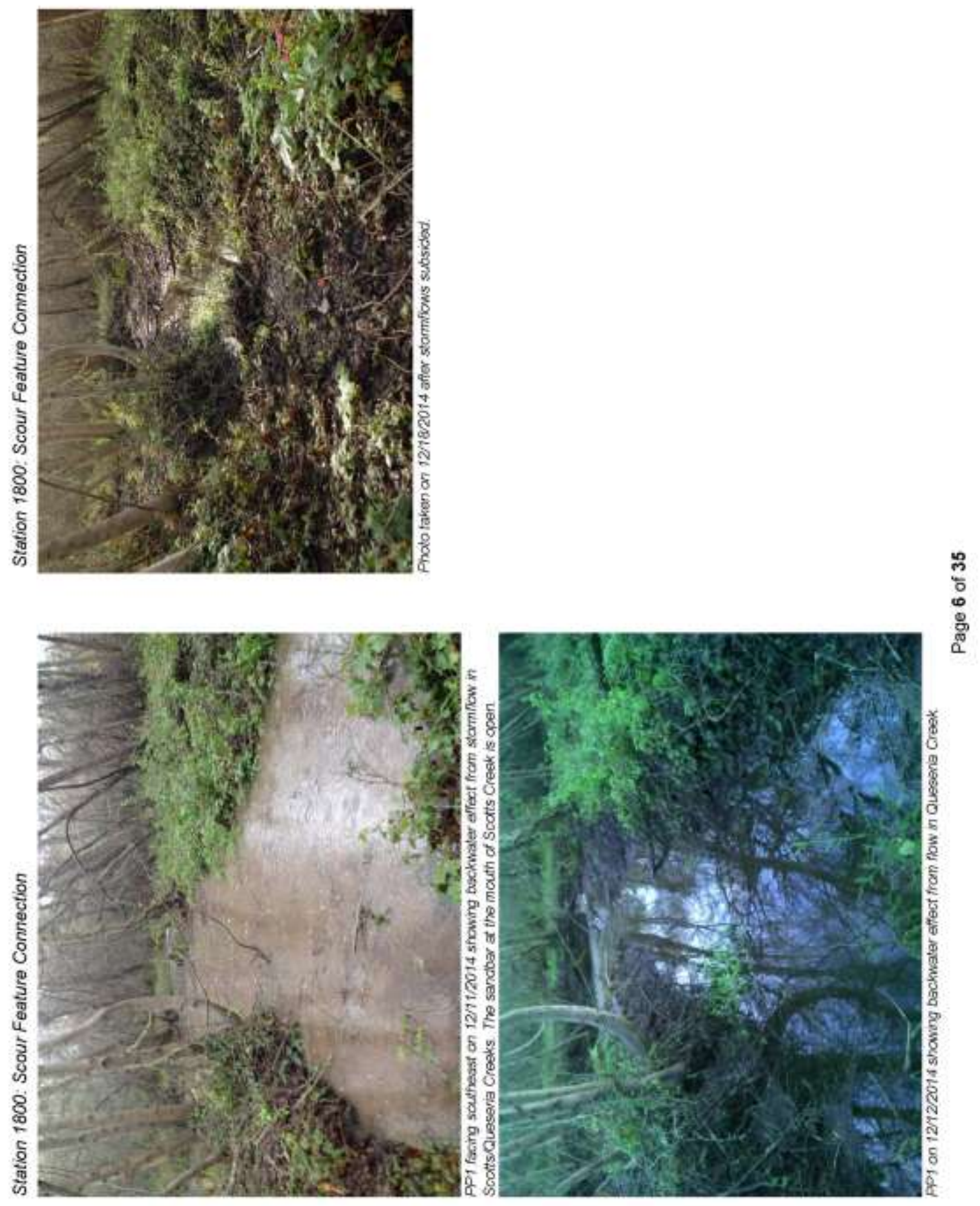

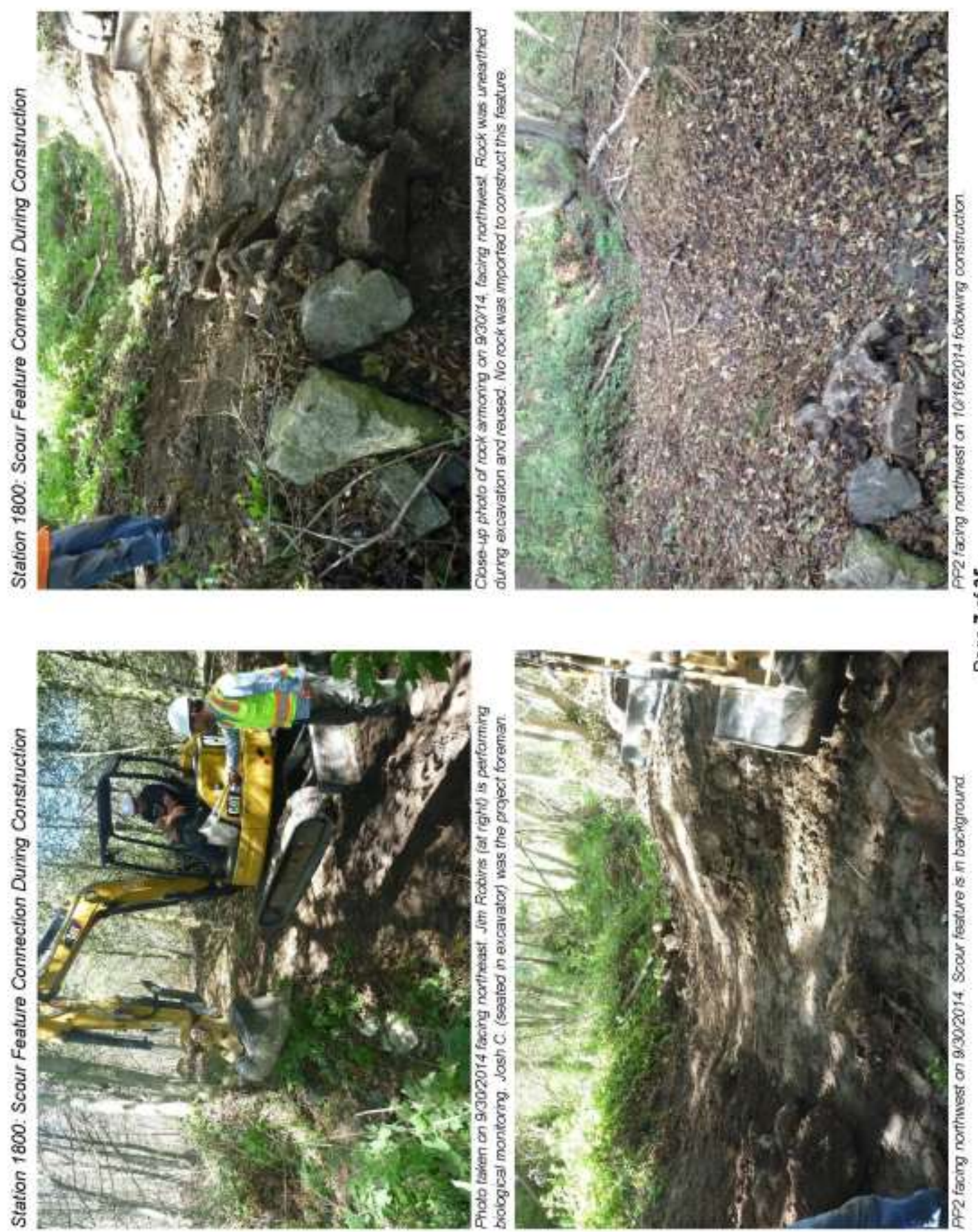

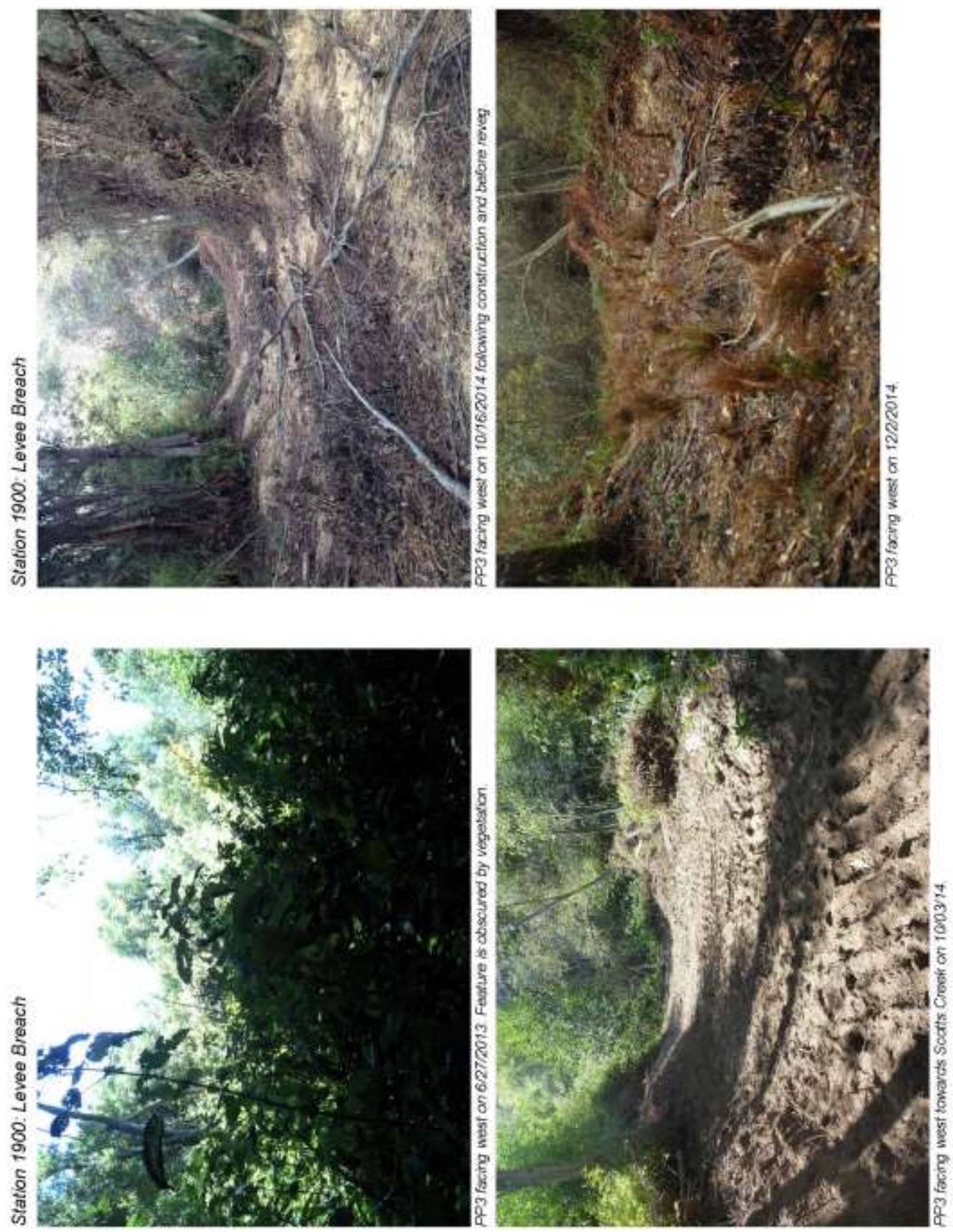

m
"ర
$\infty$
8
8
0 


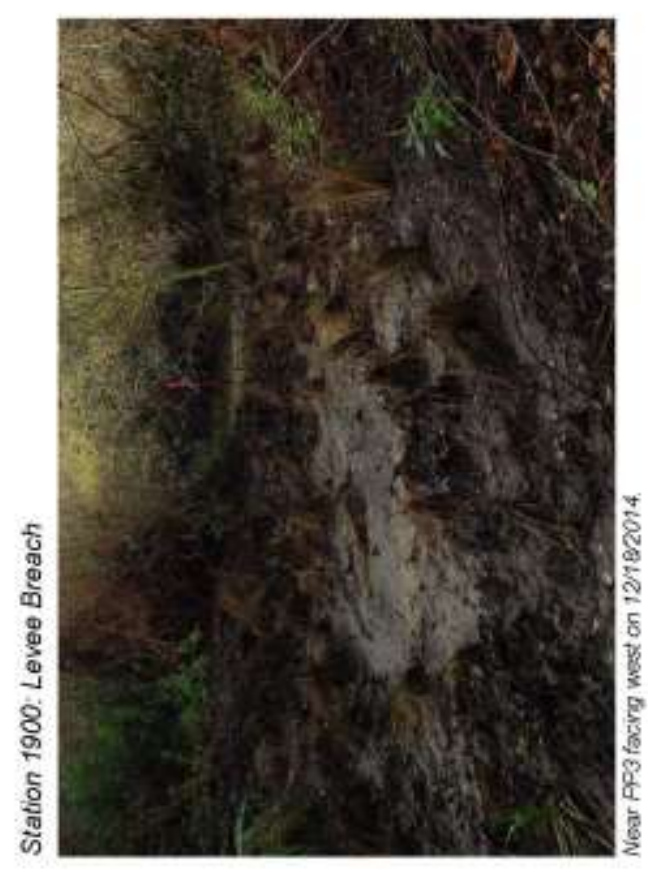

5
$\%$
5
0
8
8
0
0
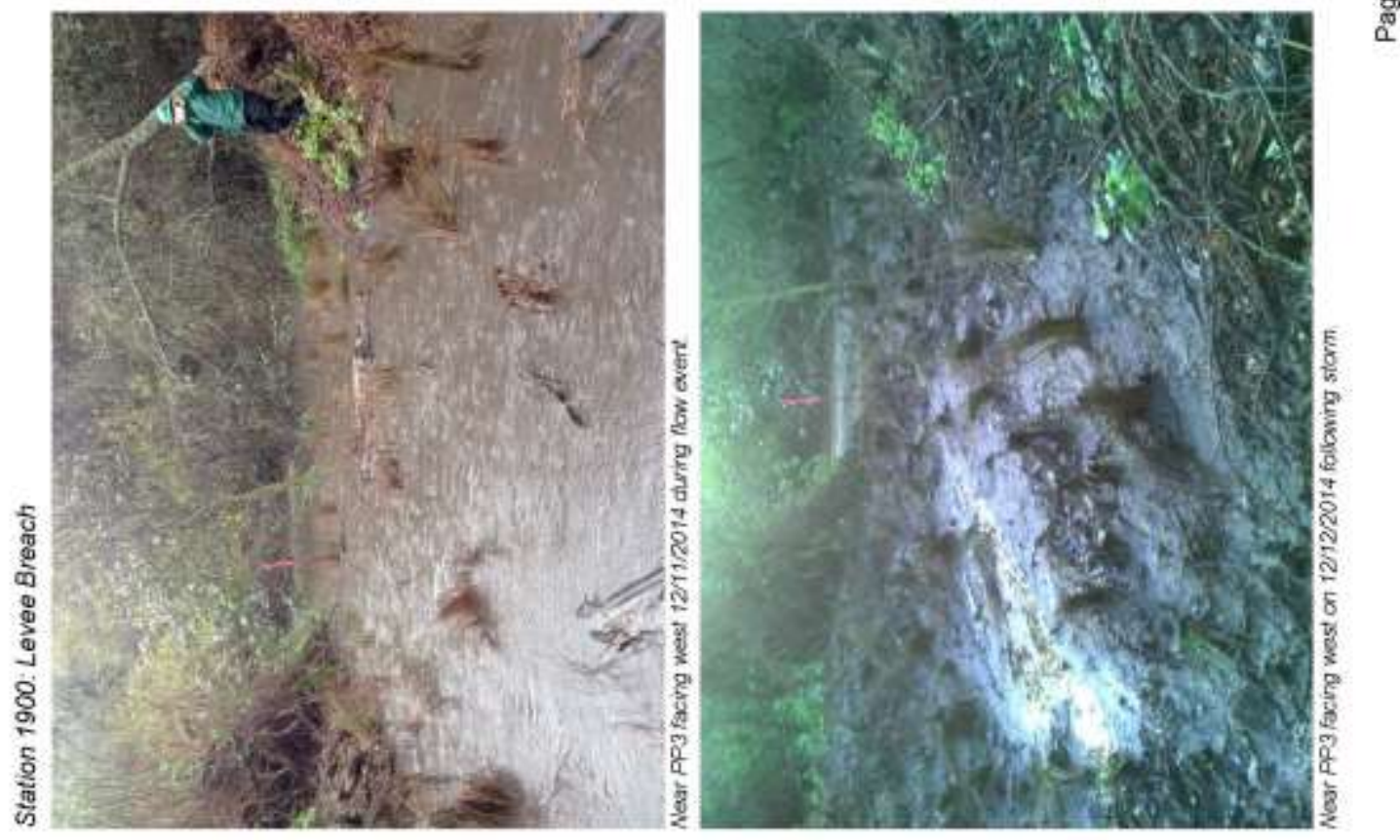

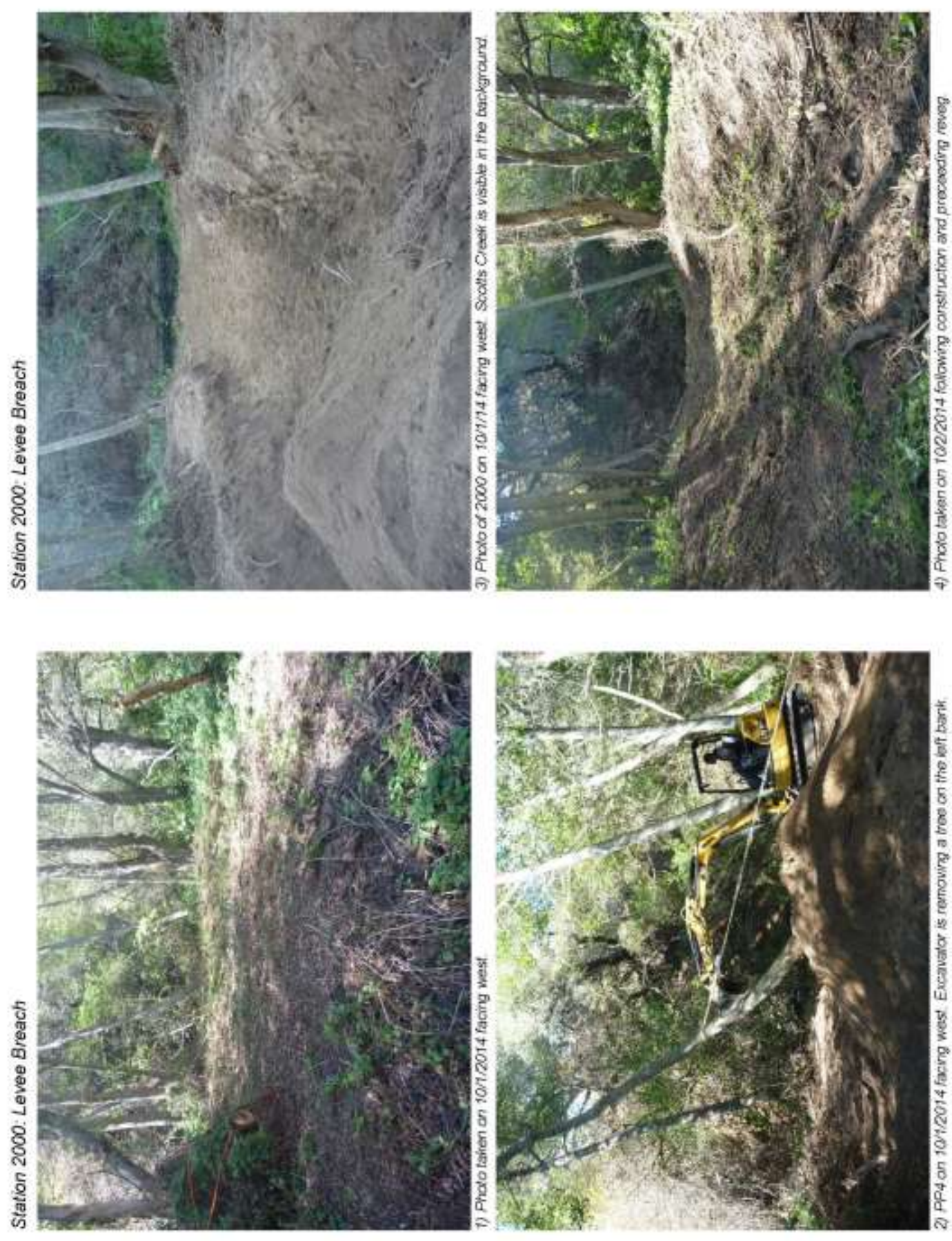

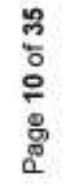

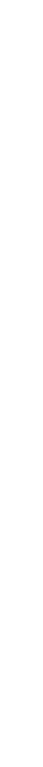



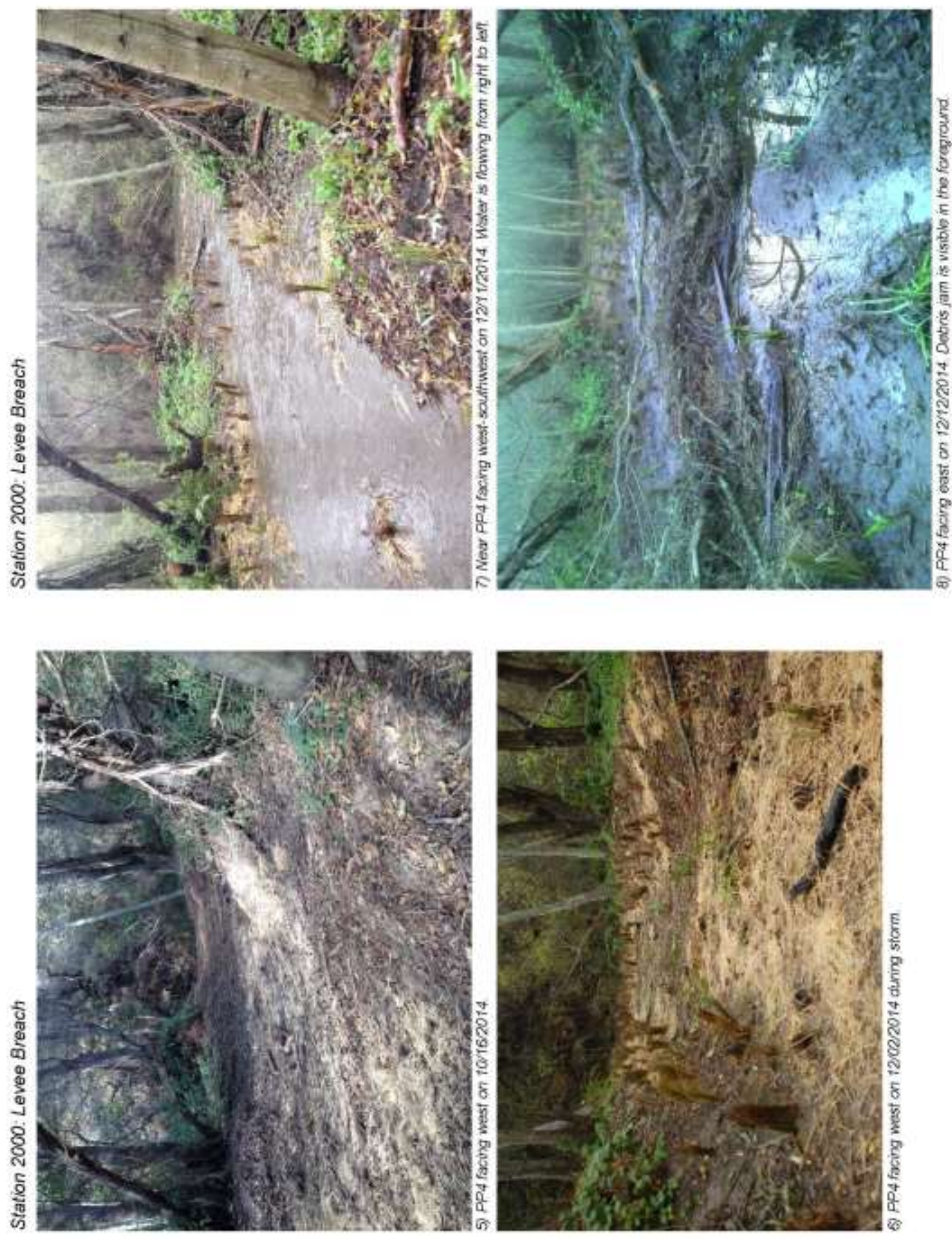

$\frac{2}{5}$
$\frac{5}{5}$
8
8
0 

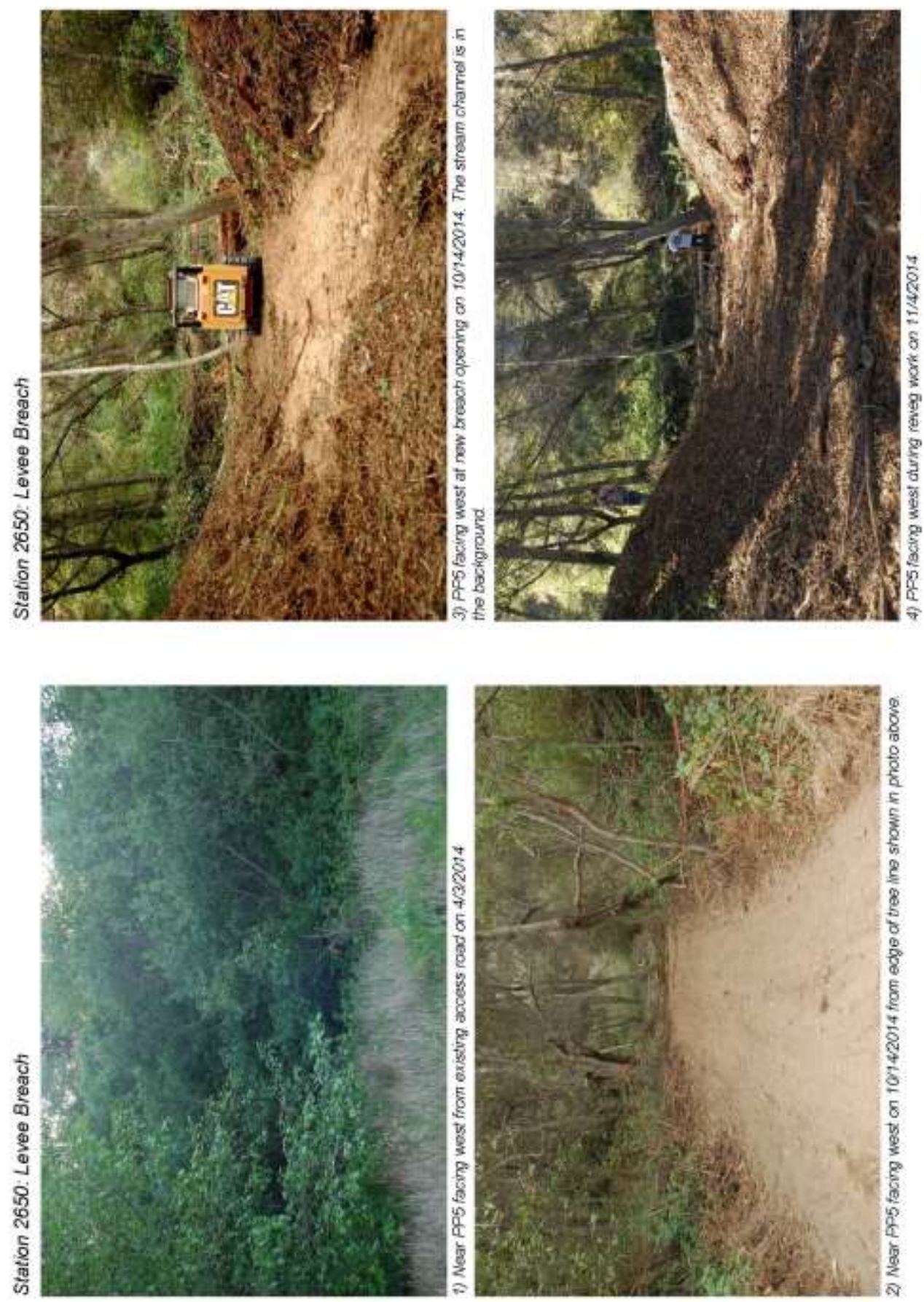

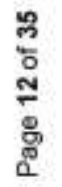




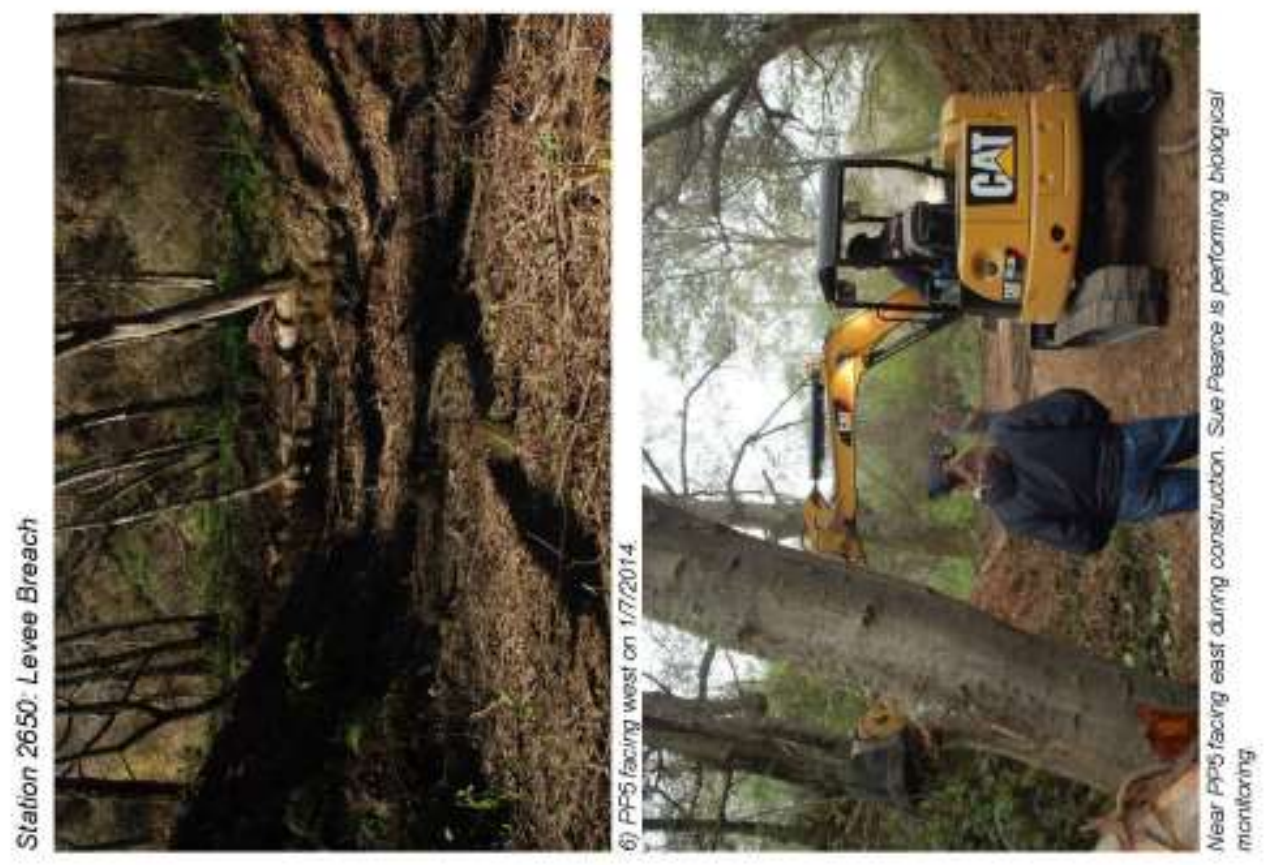

2
$\frac{2}{0}$
$\frac{2}{8}$
8
0
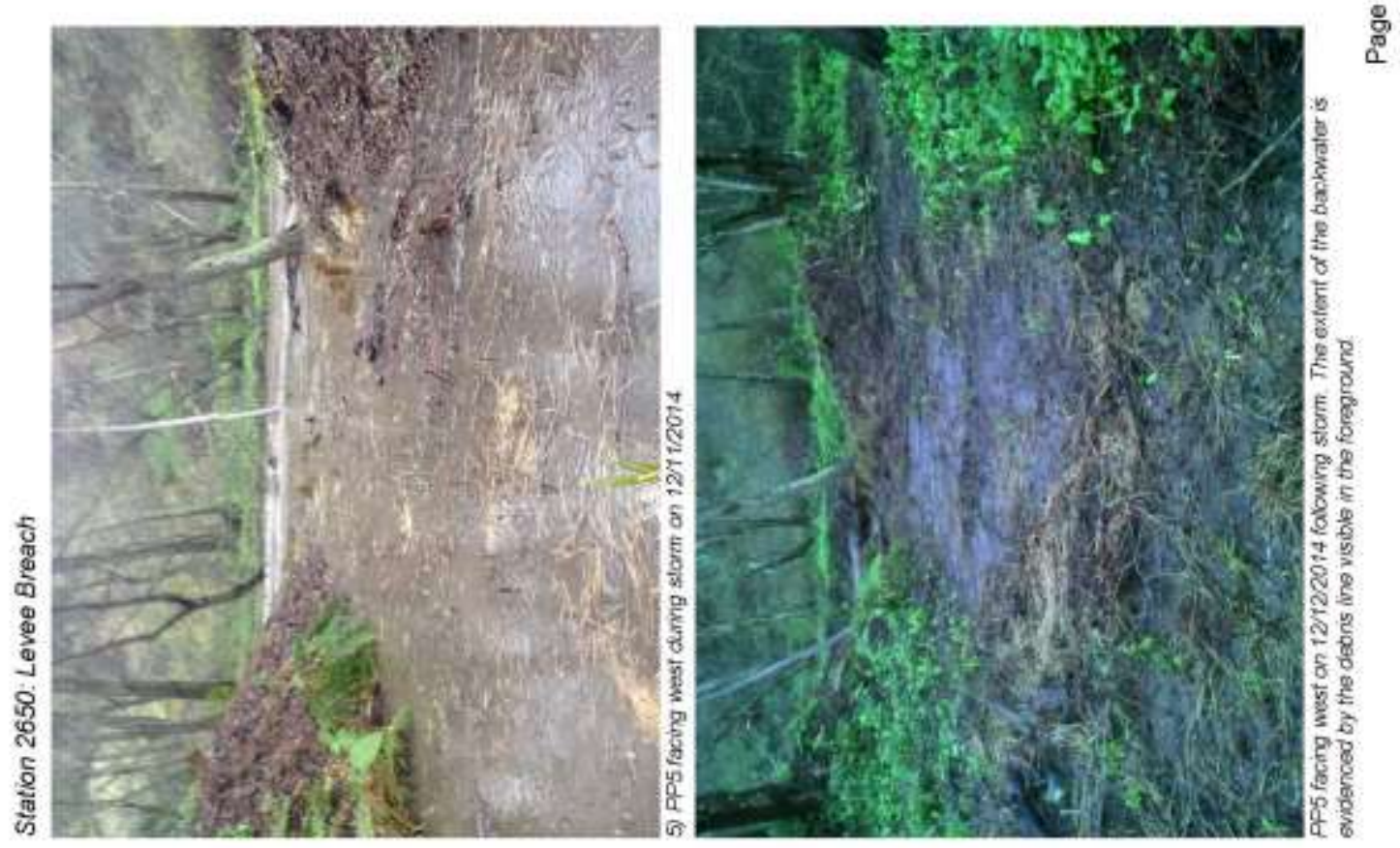

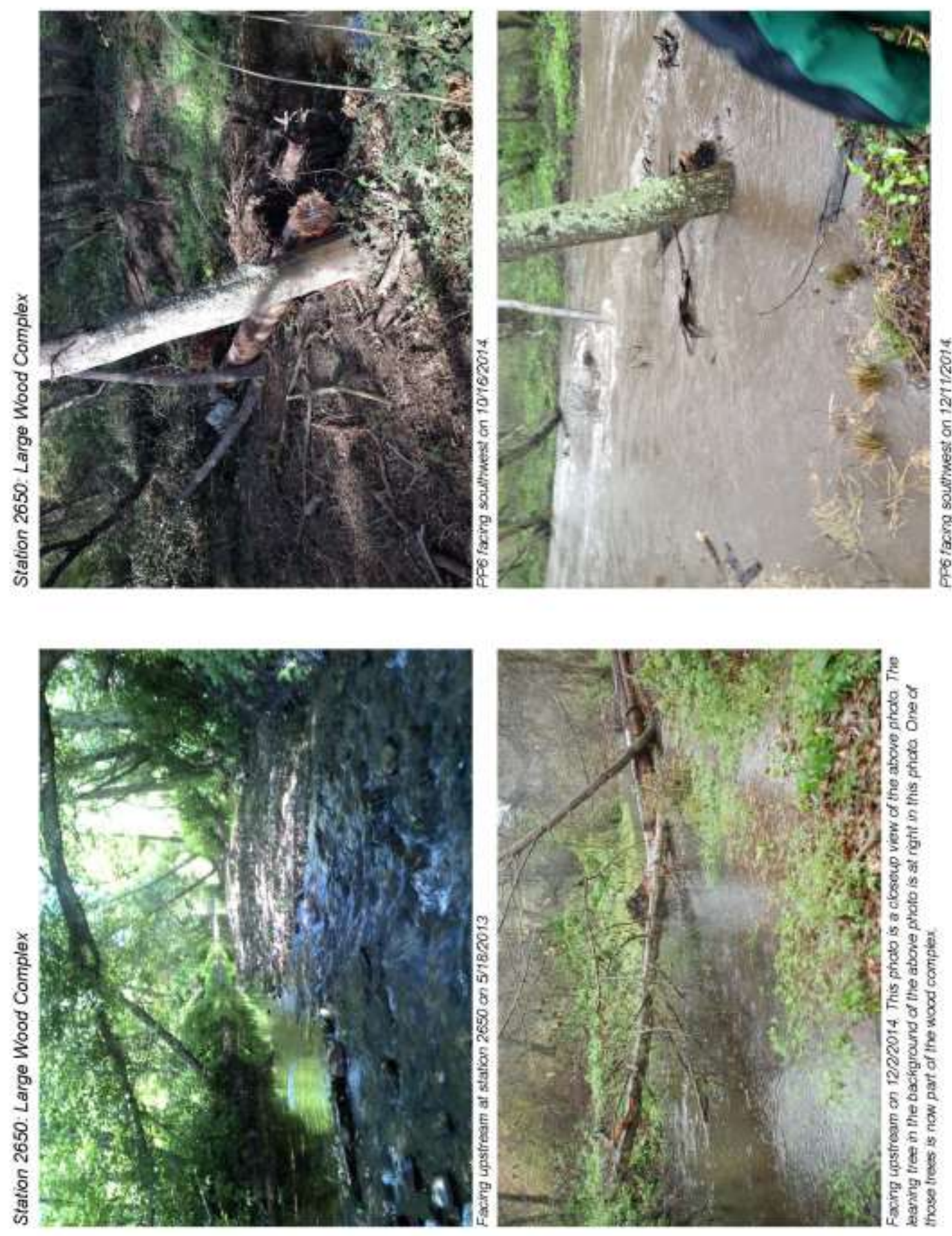

2
$\frac{2}{0}$
$\frac{5}{2}$
8
8
8 

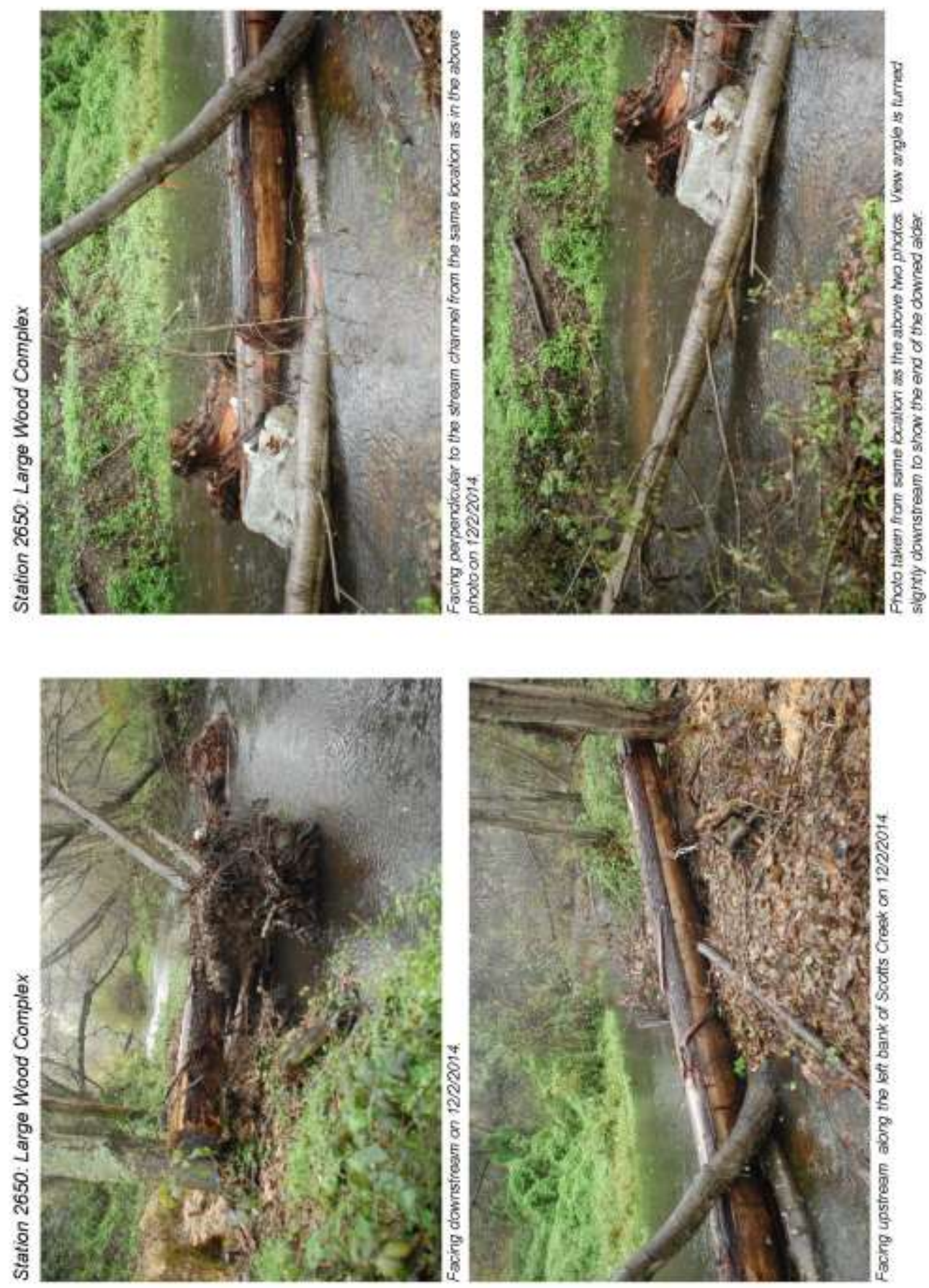

$\frac{2}{5}$
$\frac{0}{8}$
$\frac{0}{8}$ 

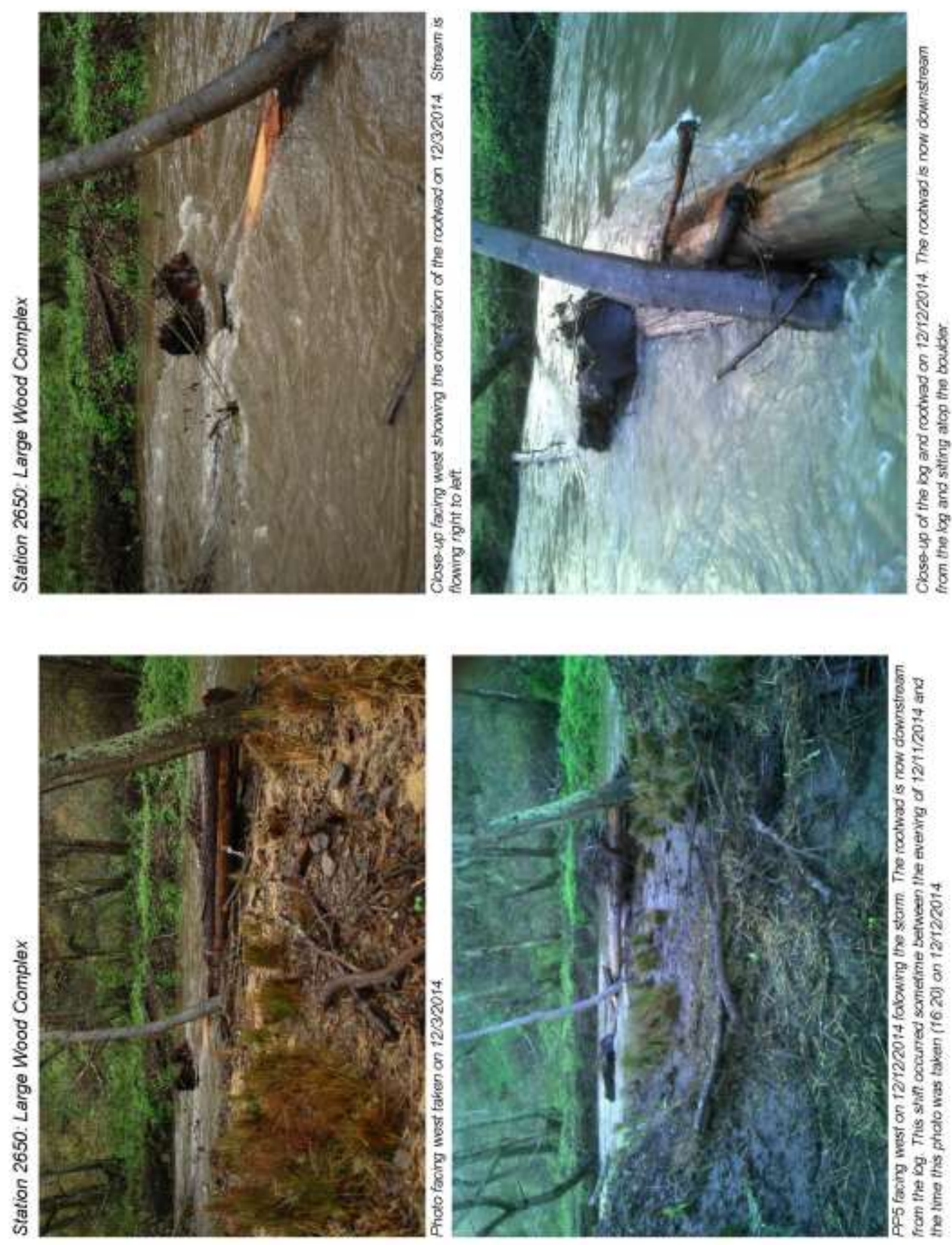

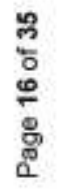




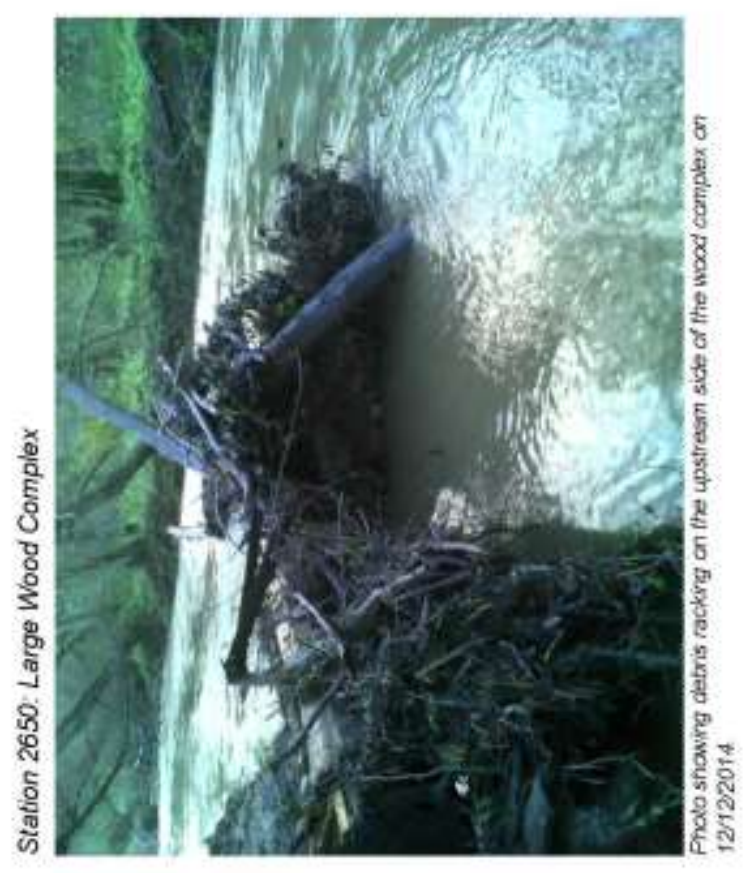

2
5
5
0
8
8
8

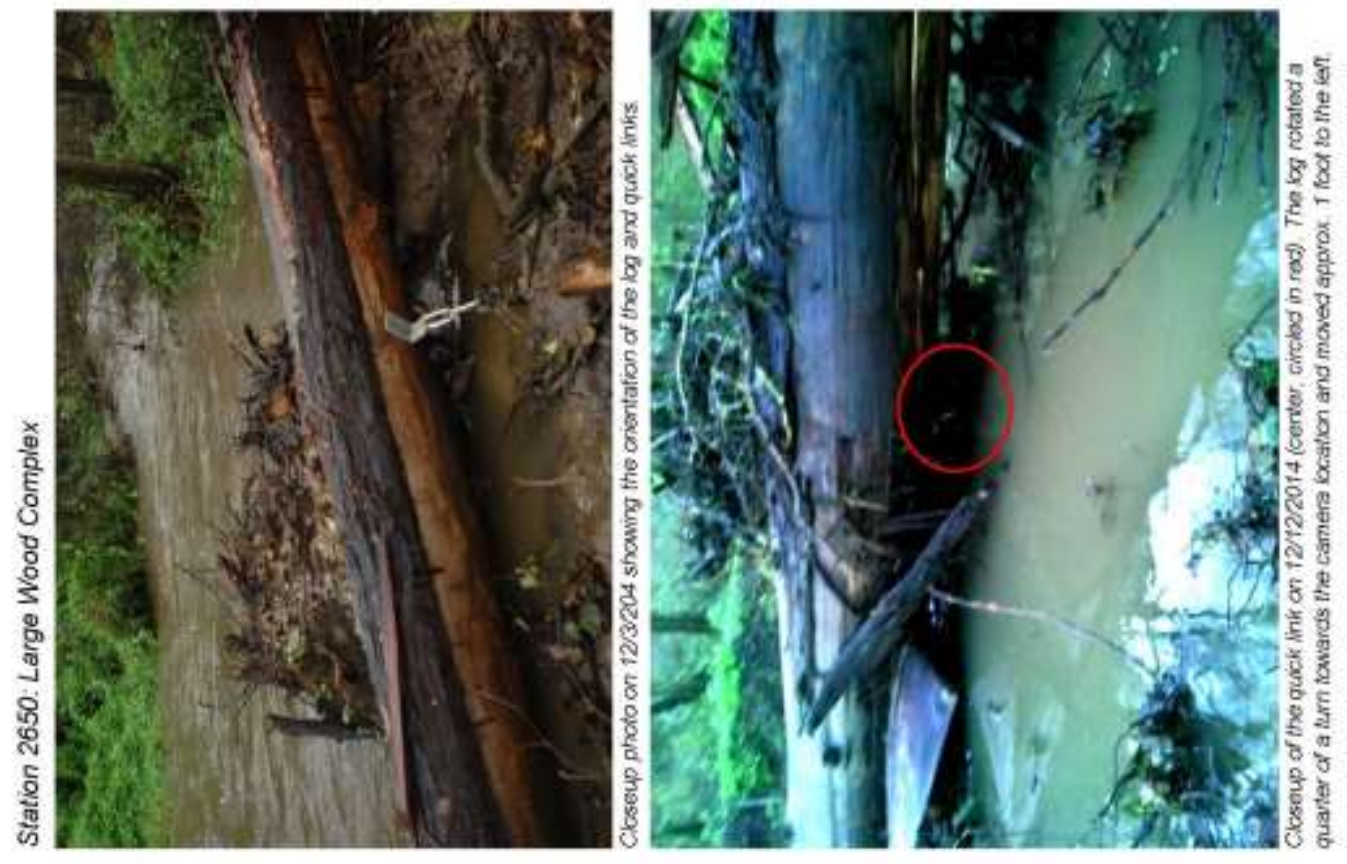




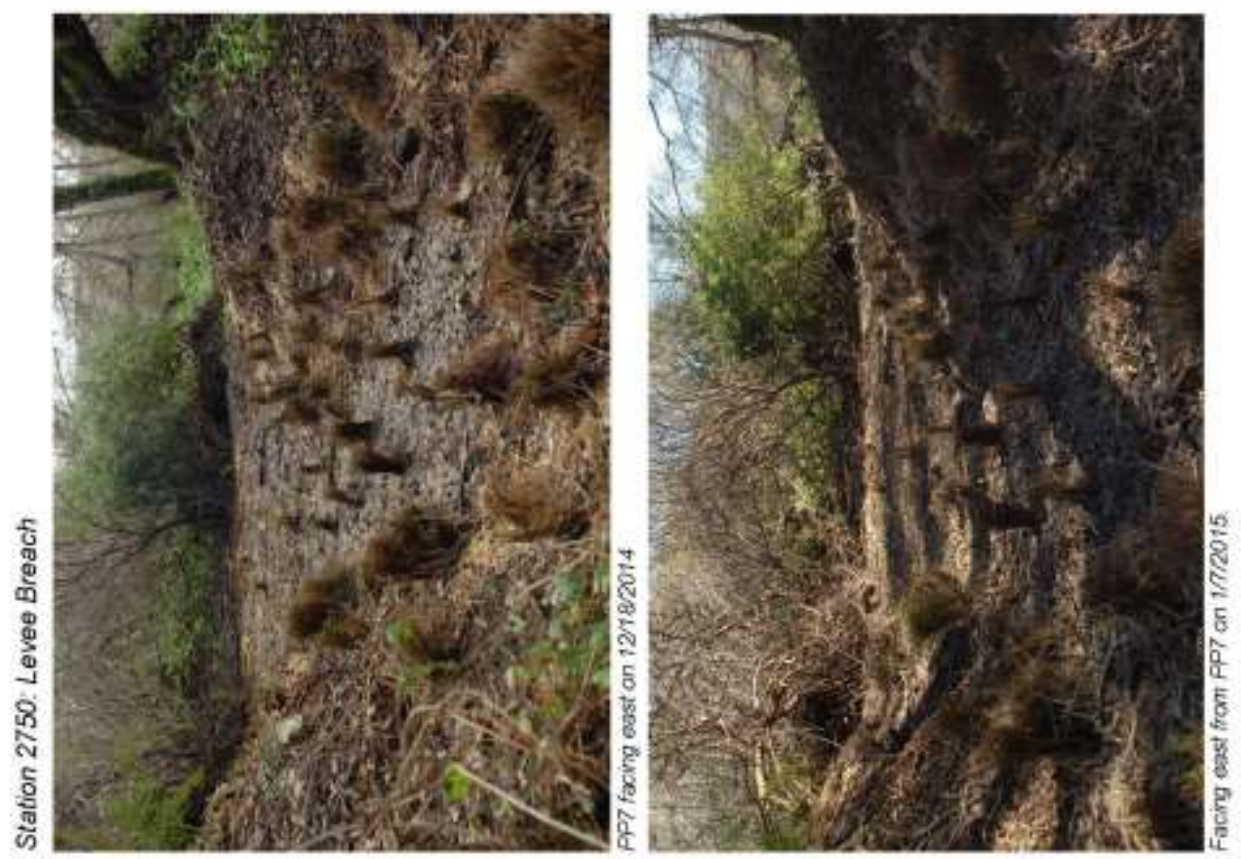

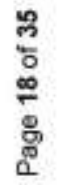
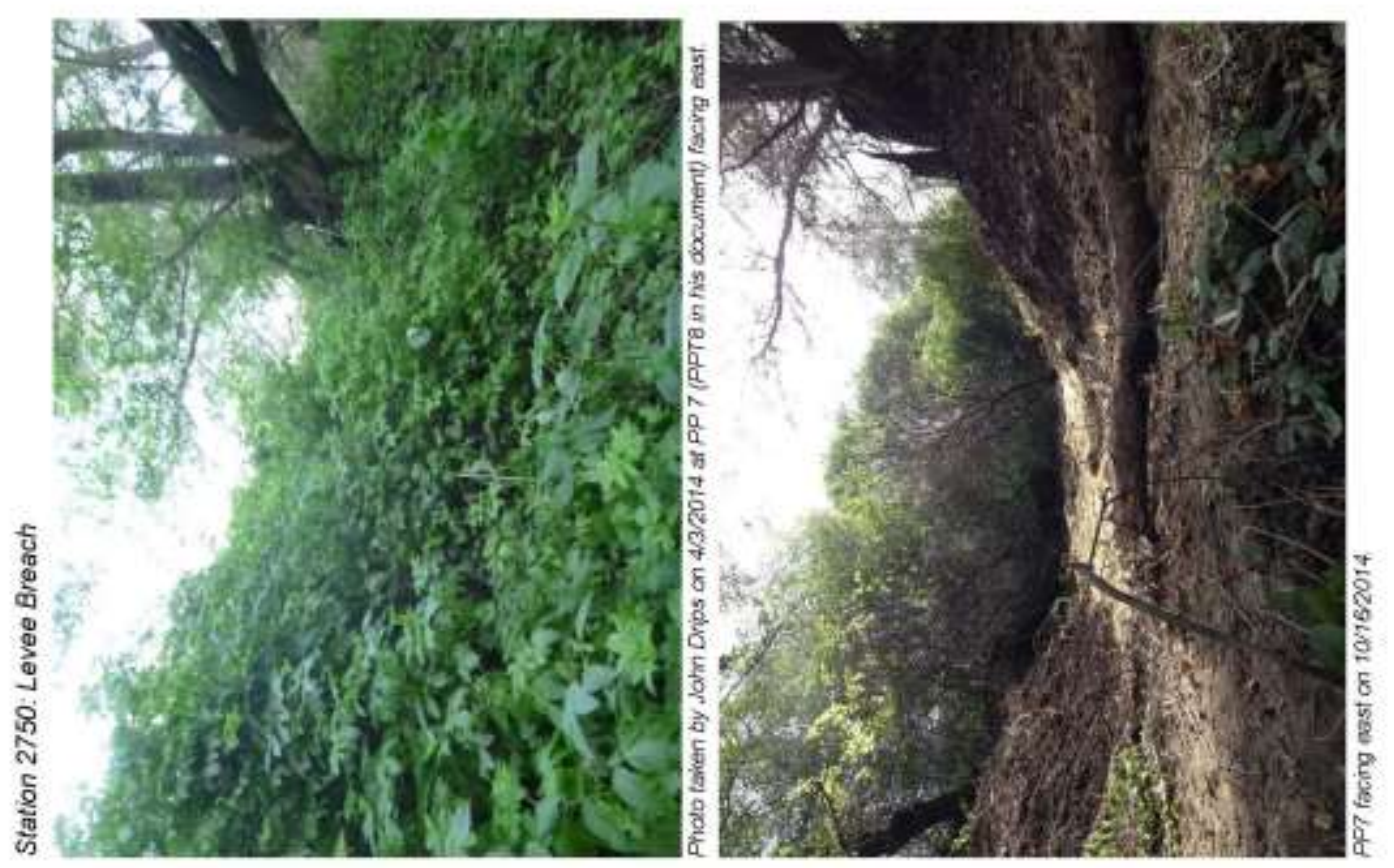

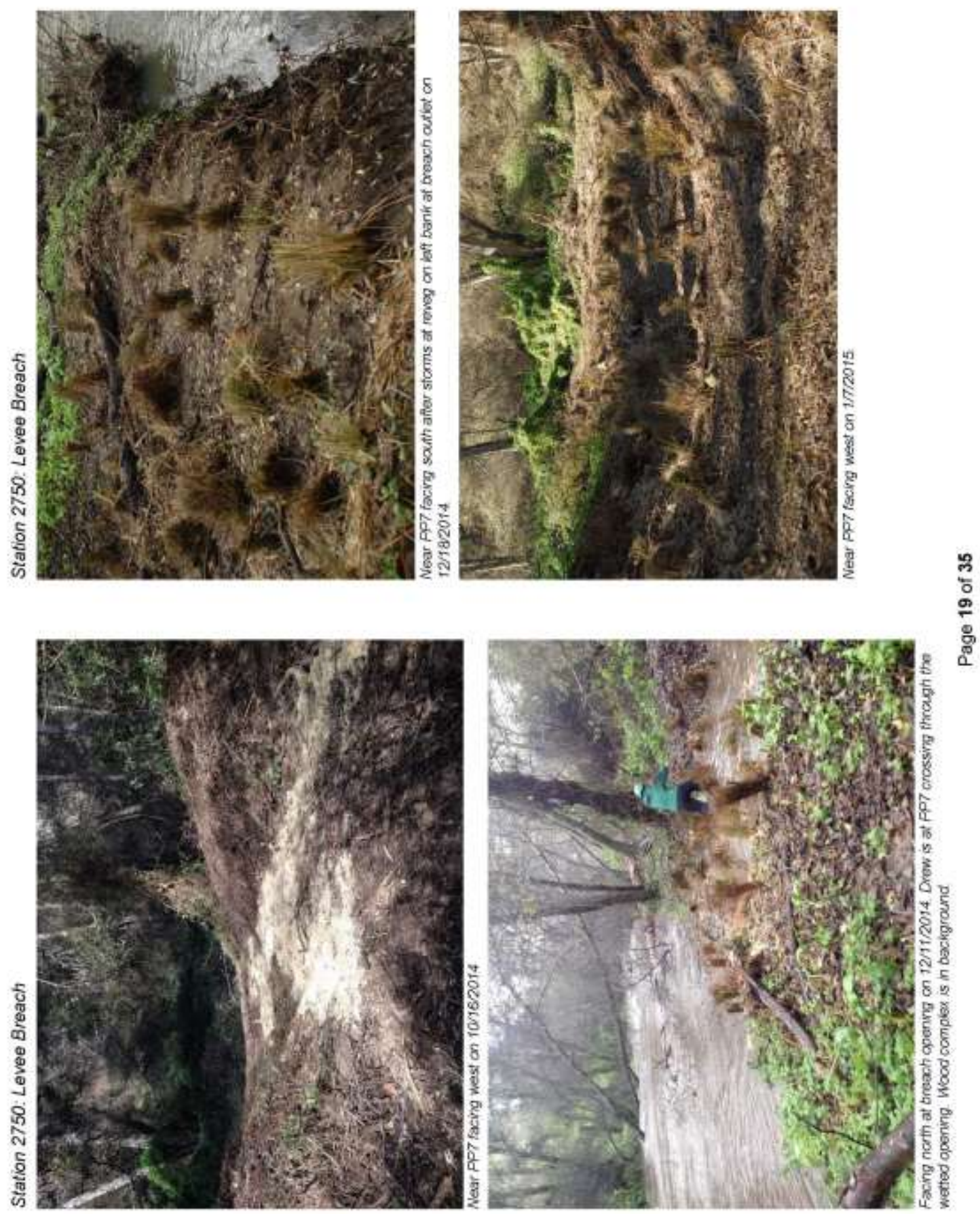

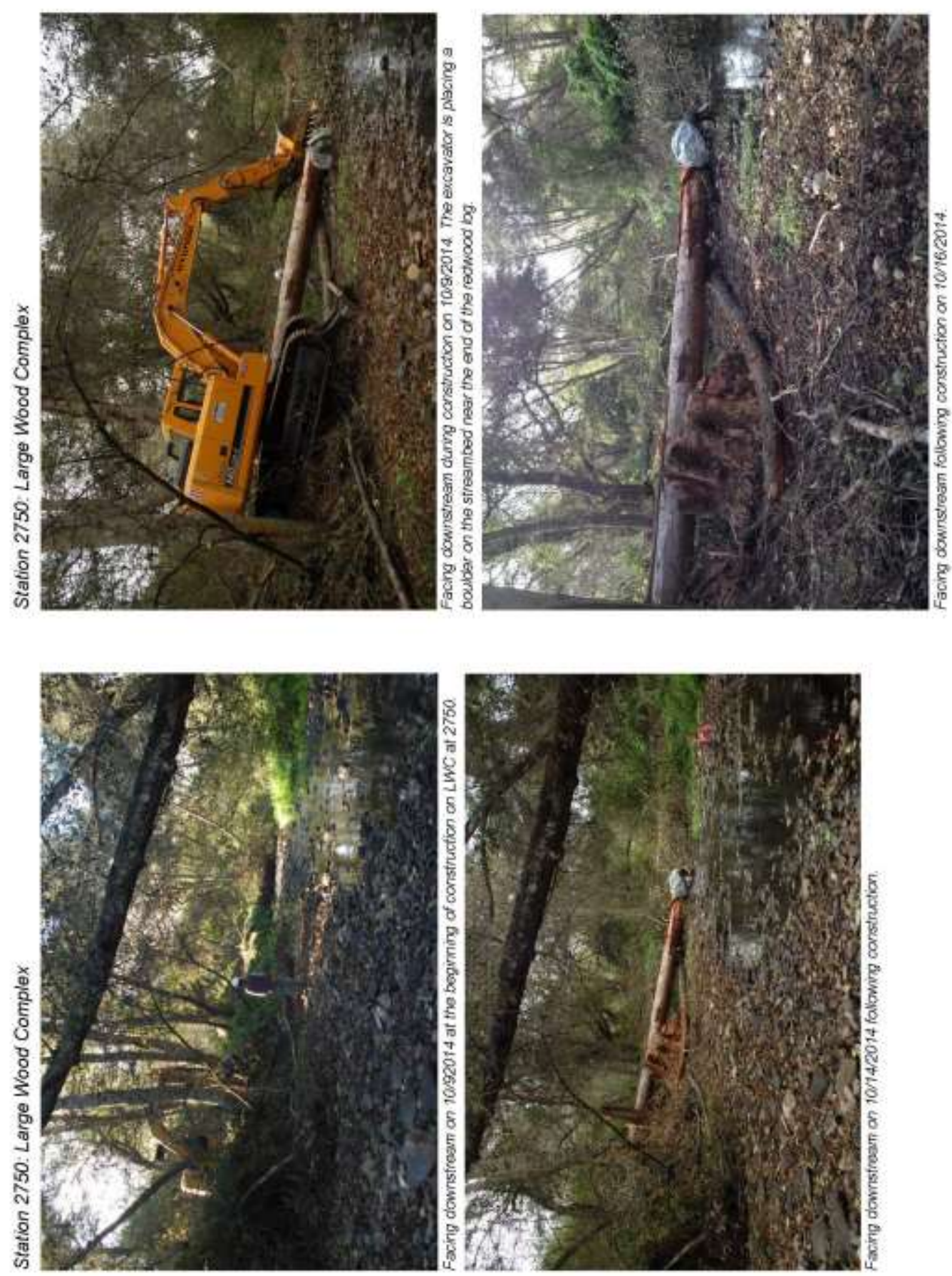

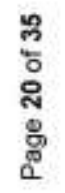



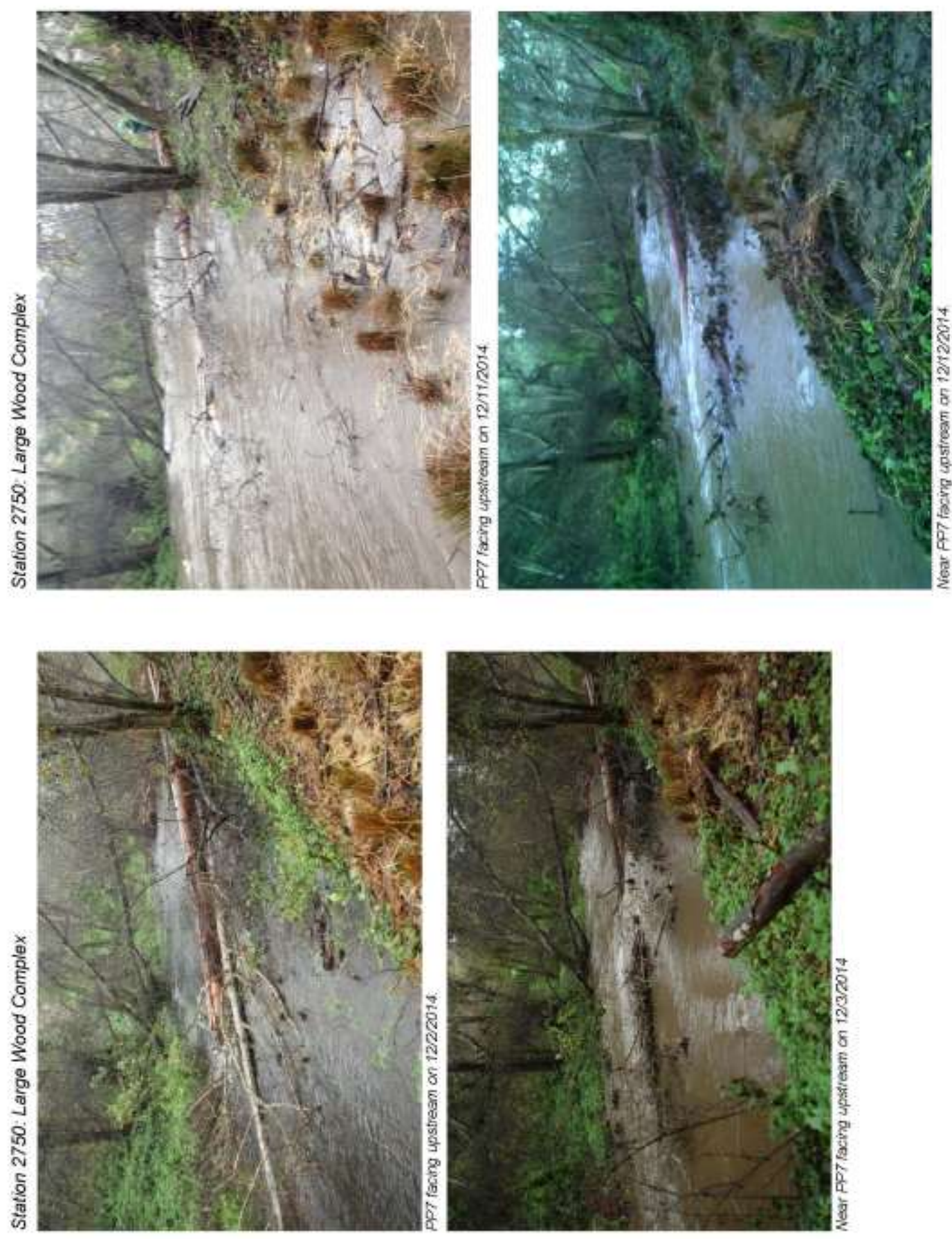

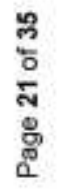



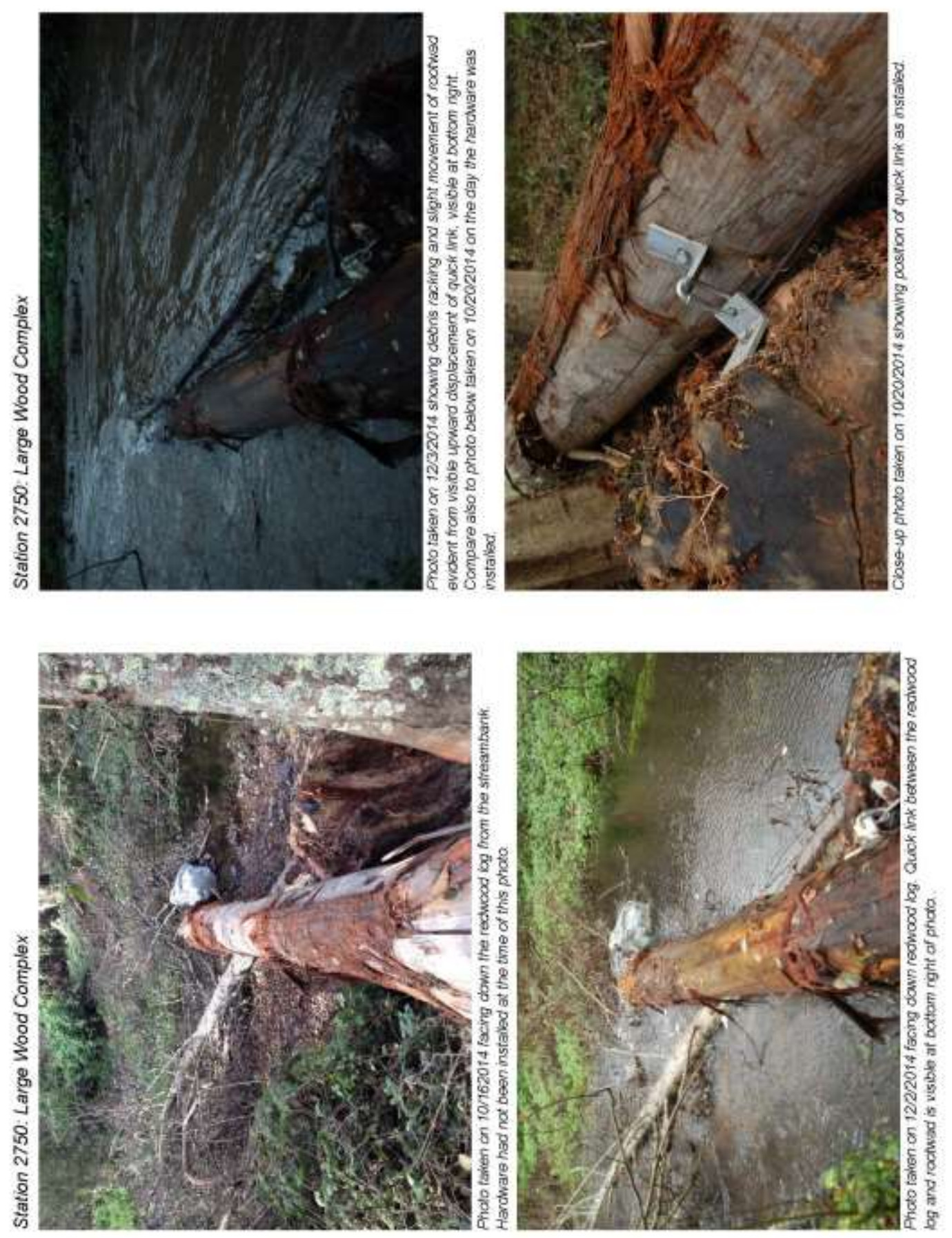

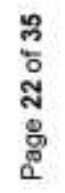



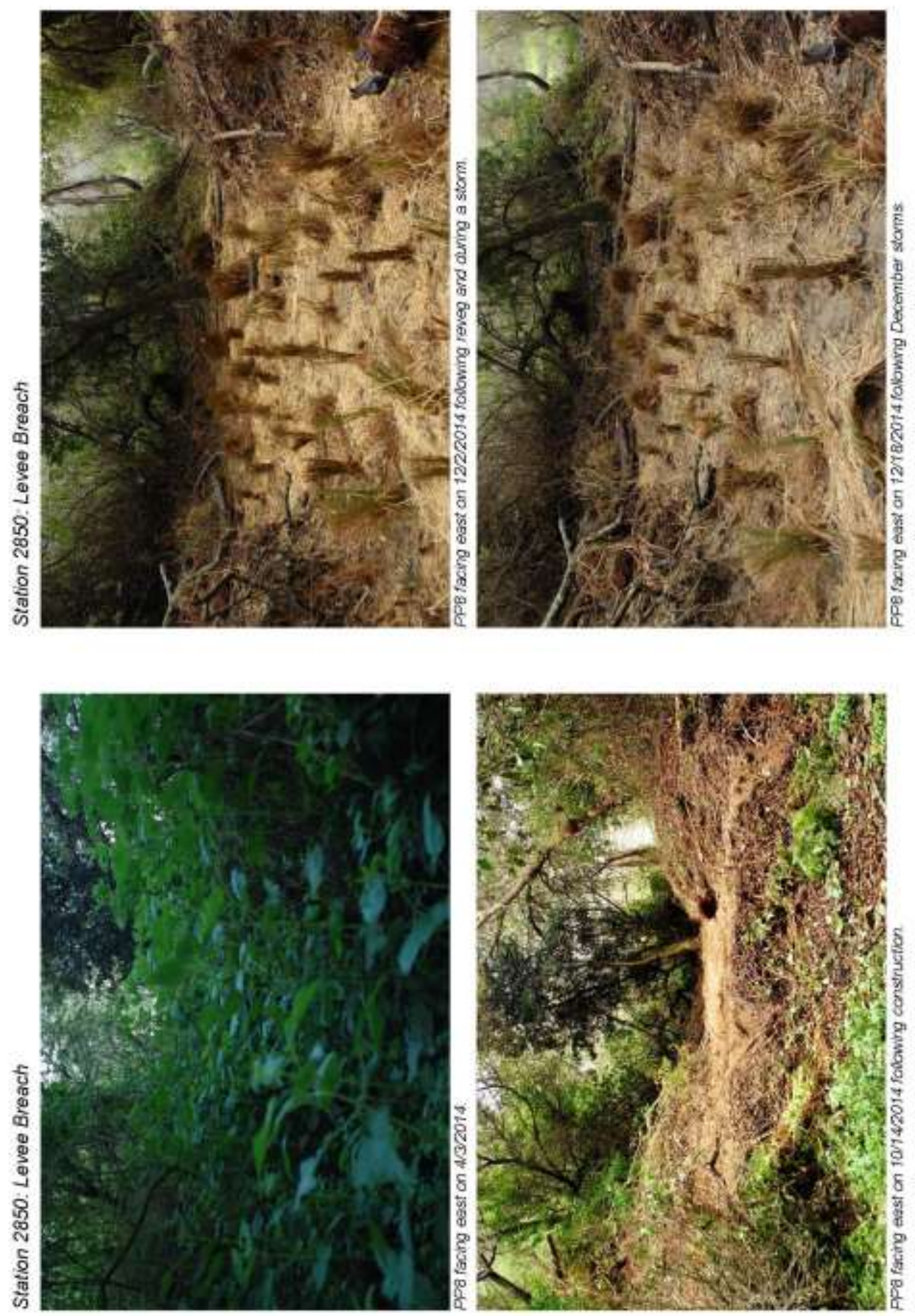

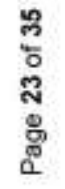



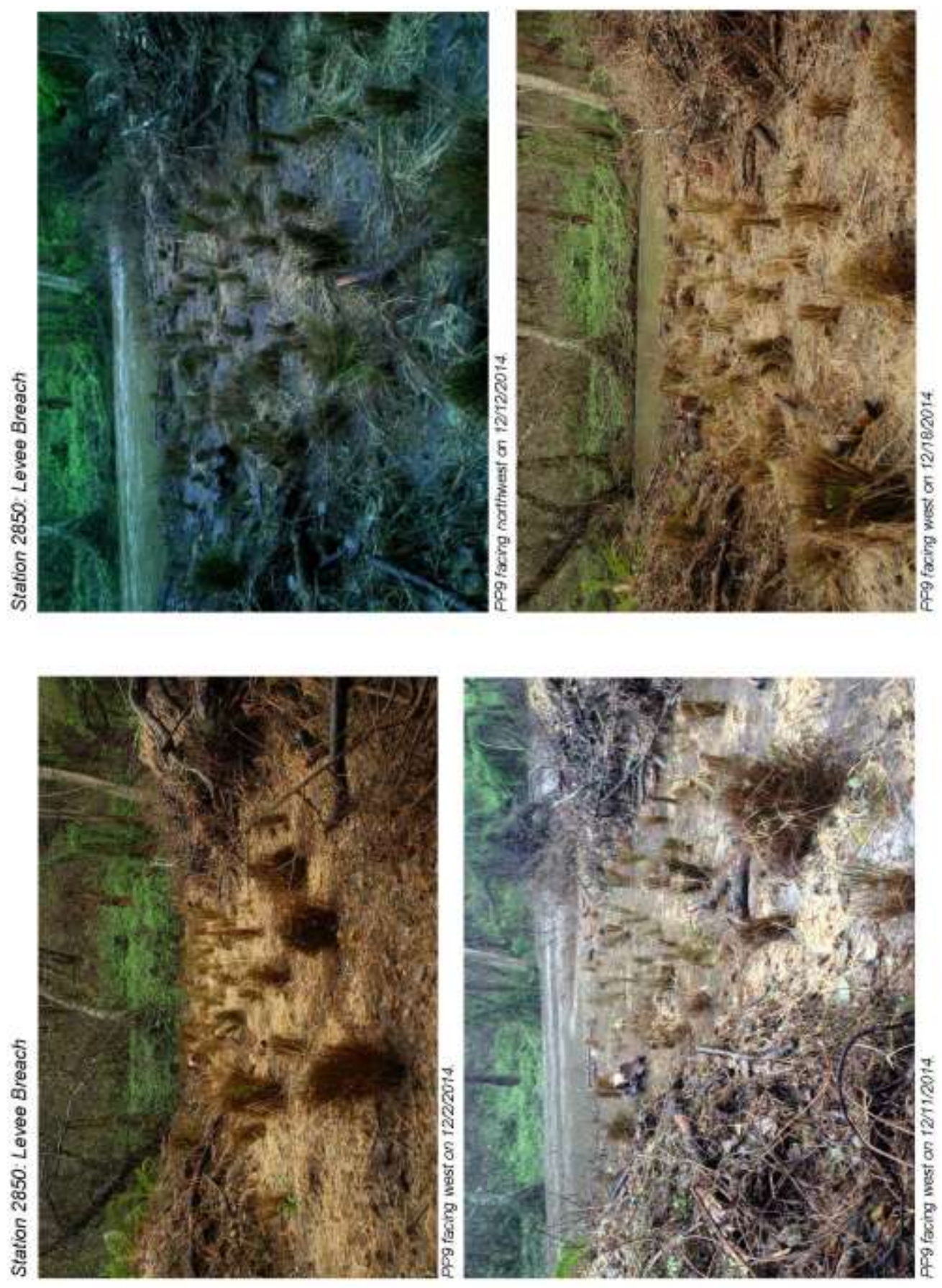

2
5
ล
8
8
8 

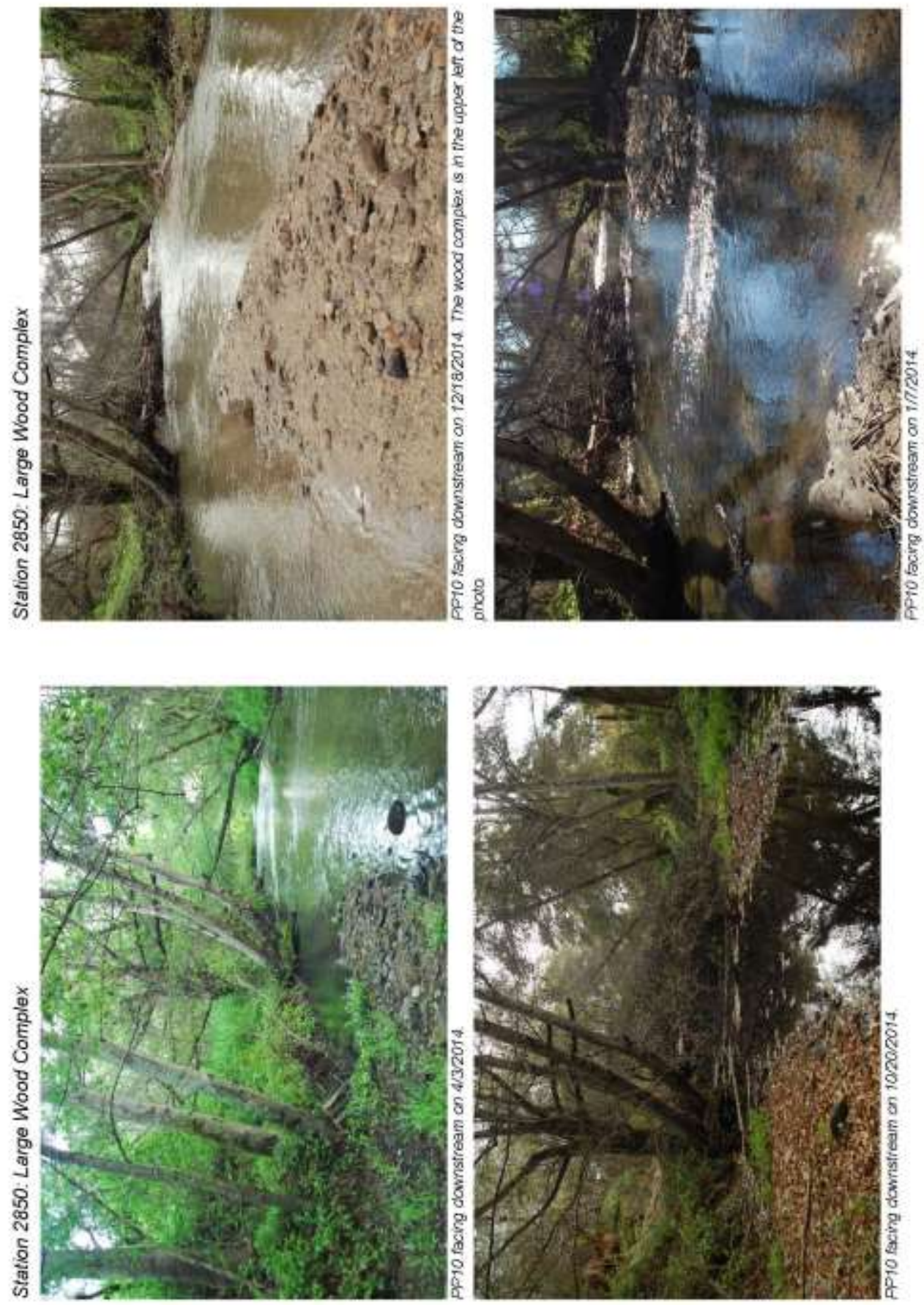

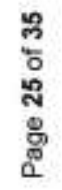



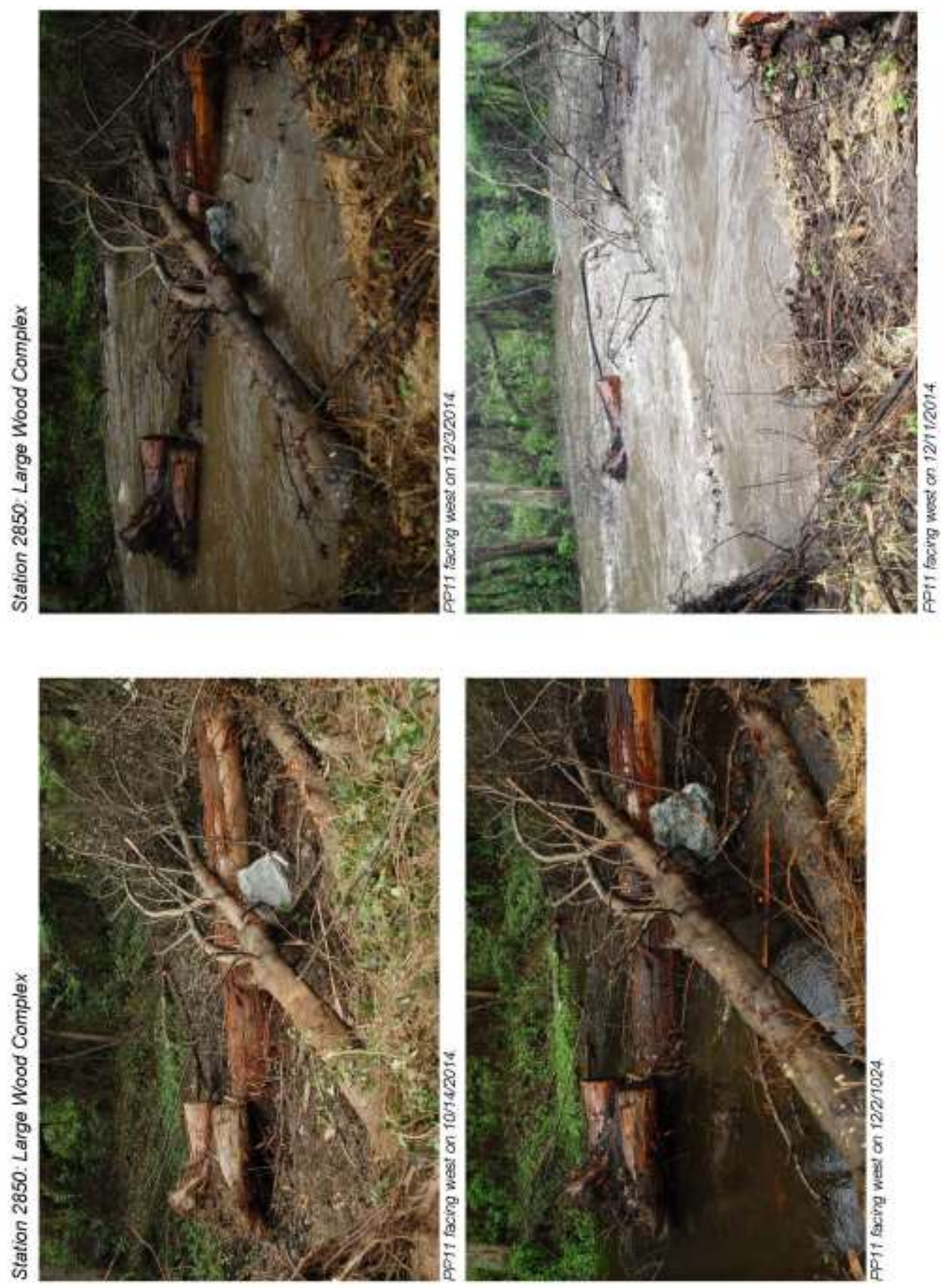

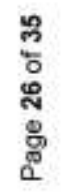




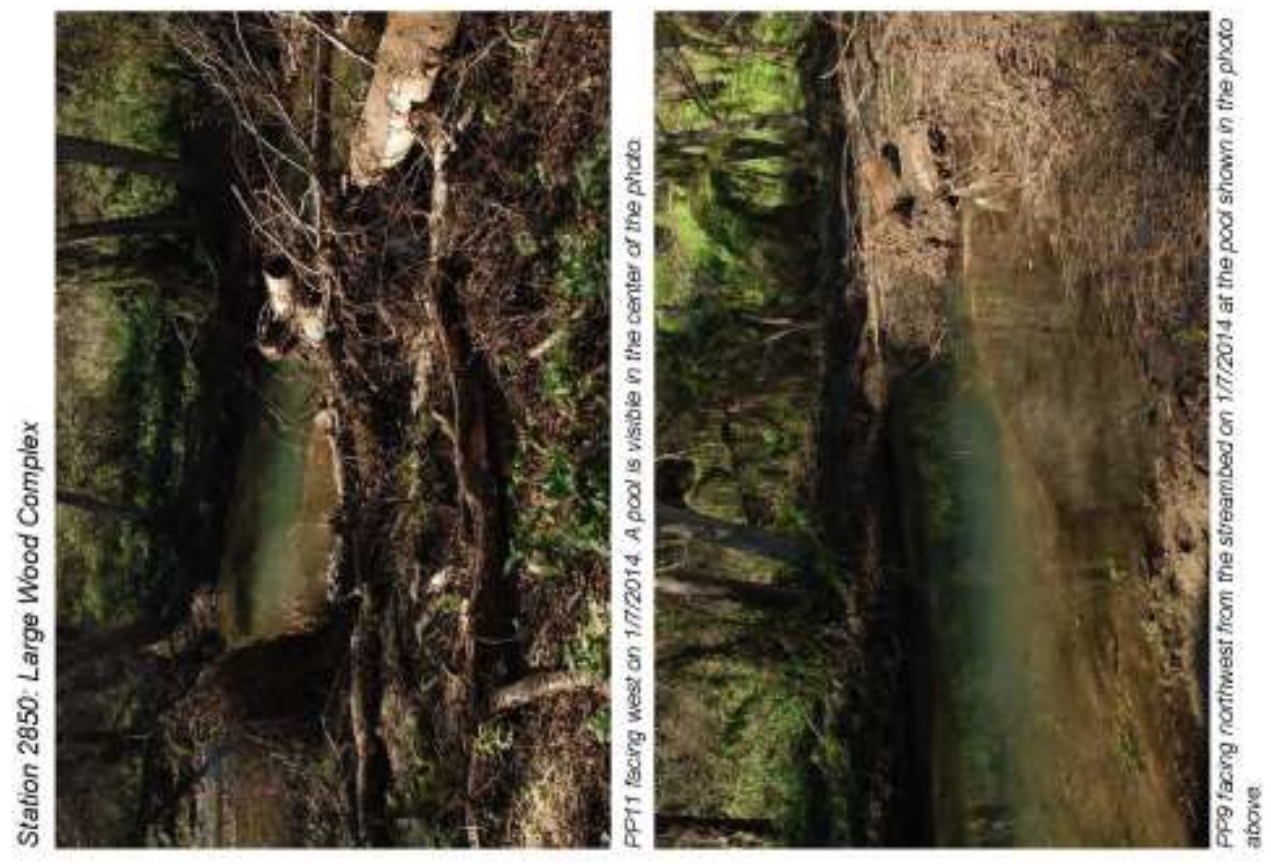

2.
ลे
ล
8
0

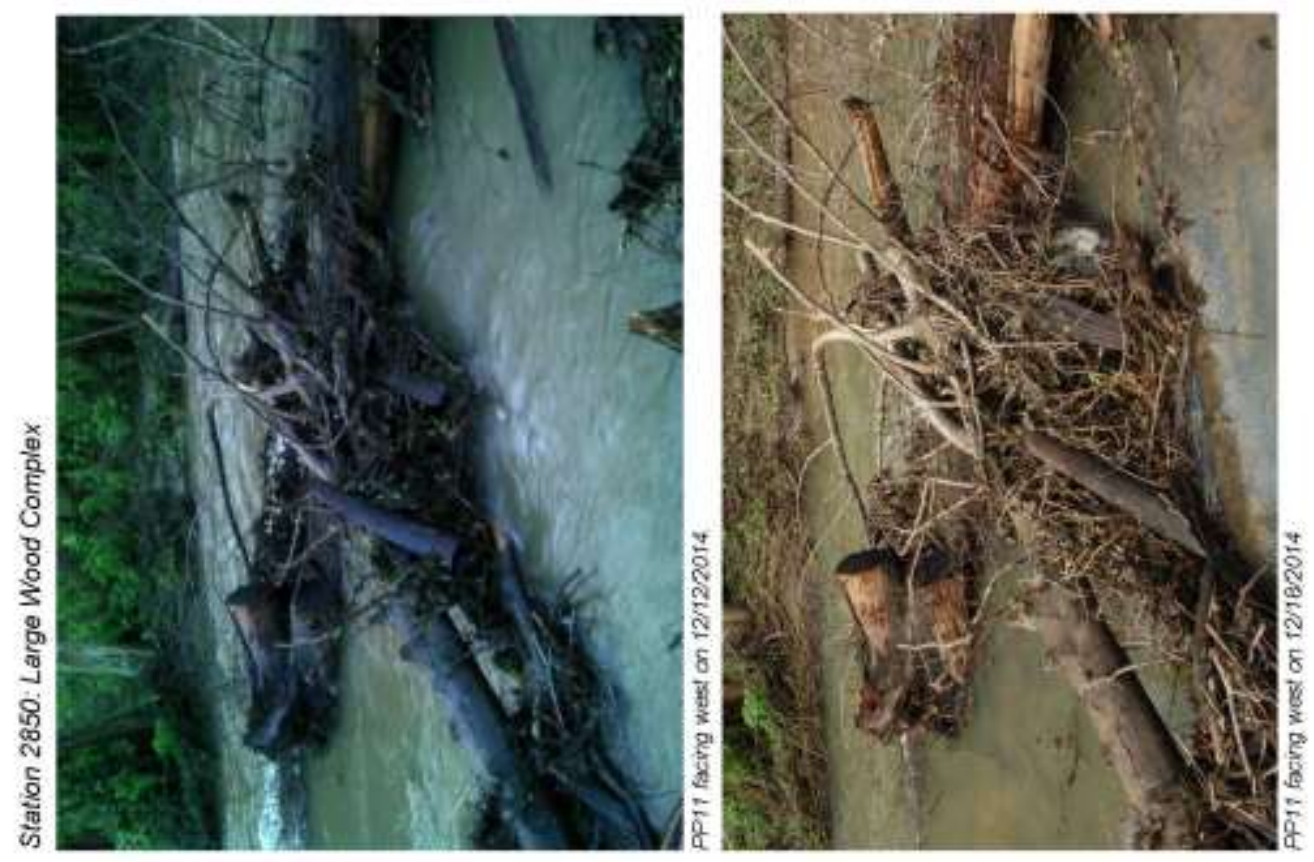



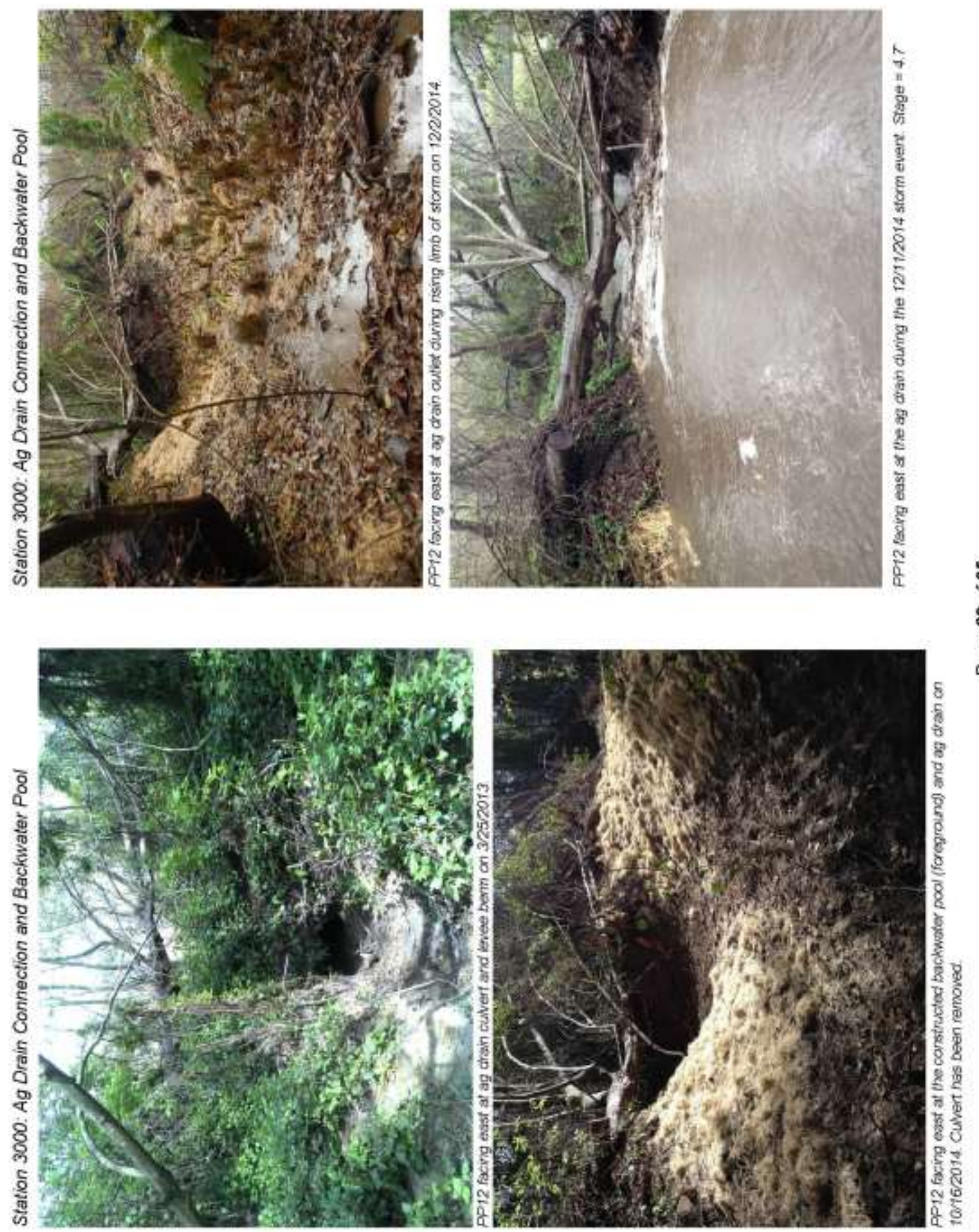


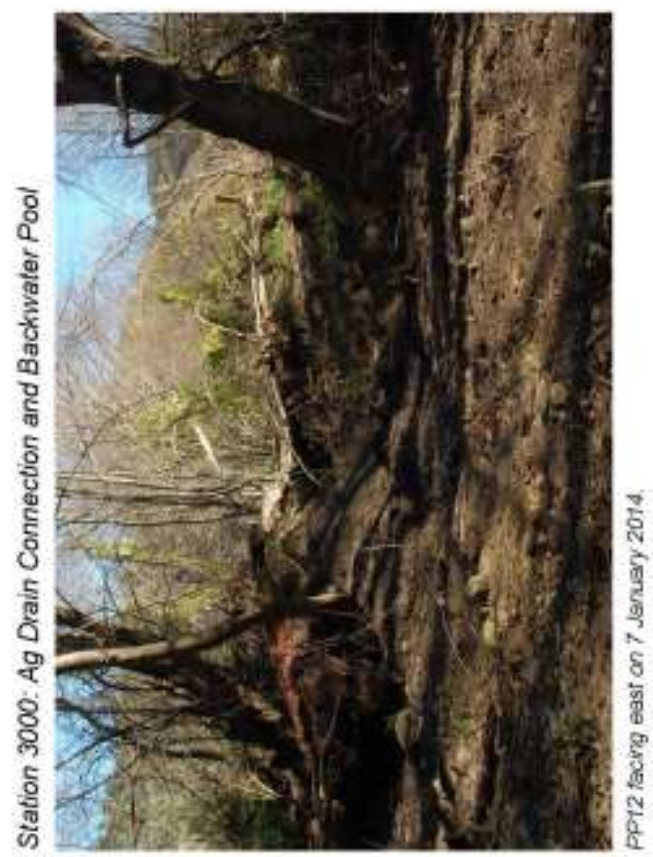

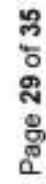
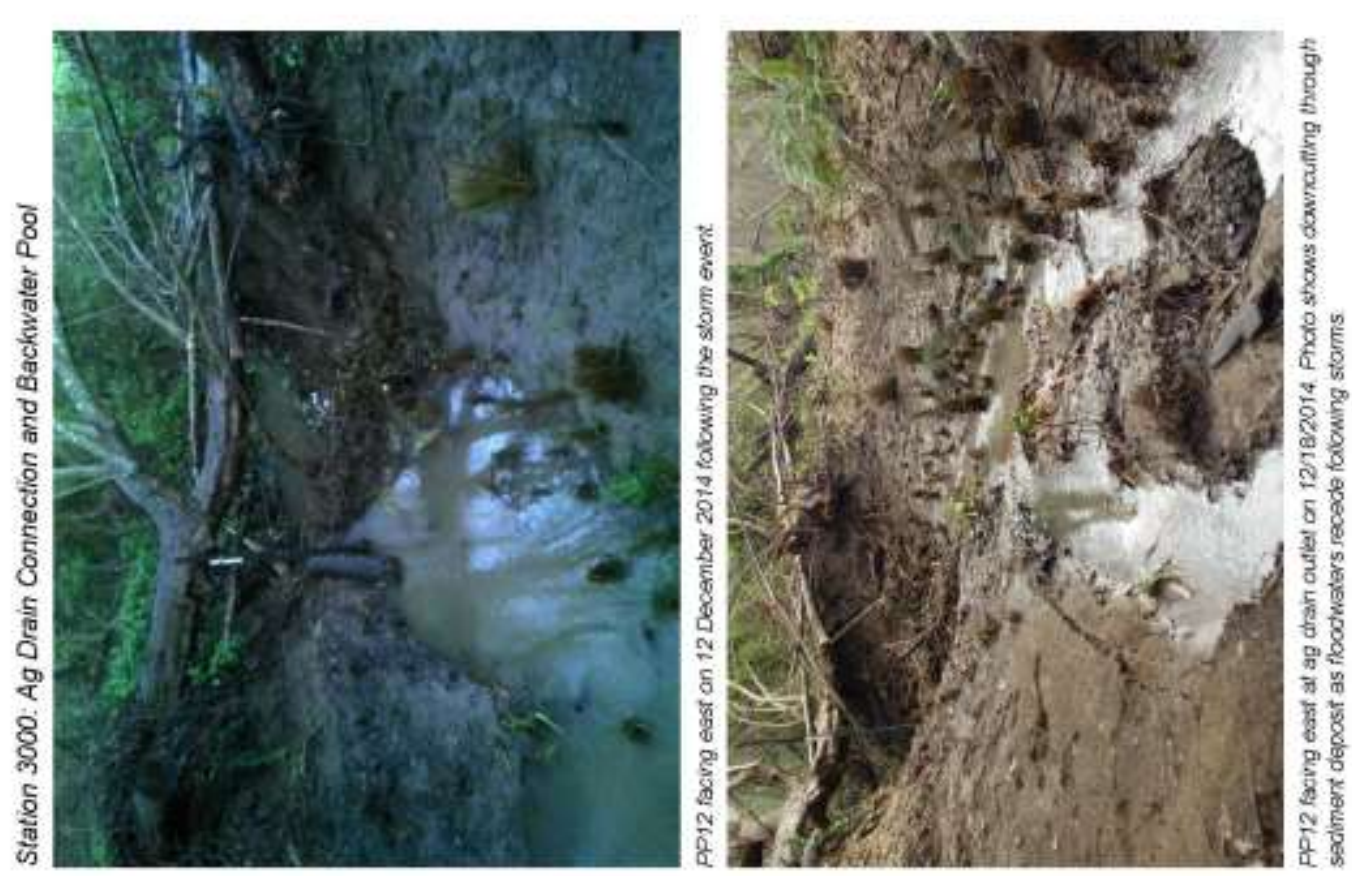

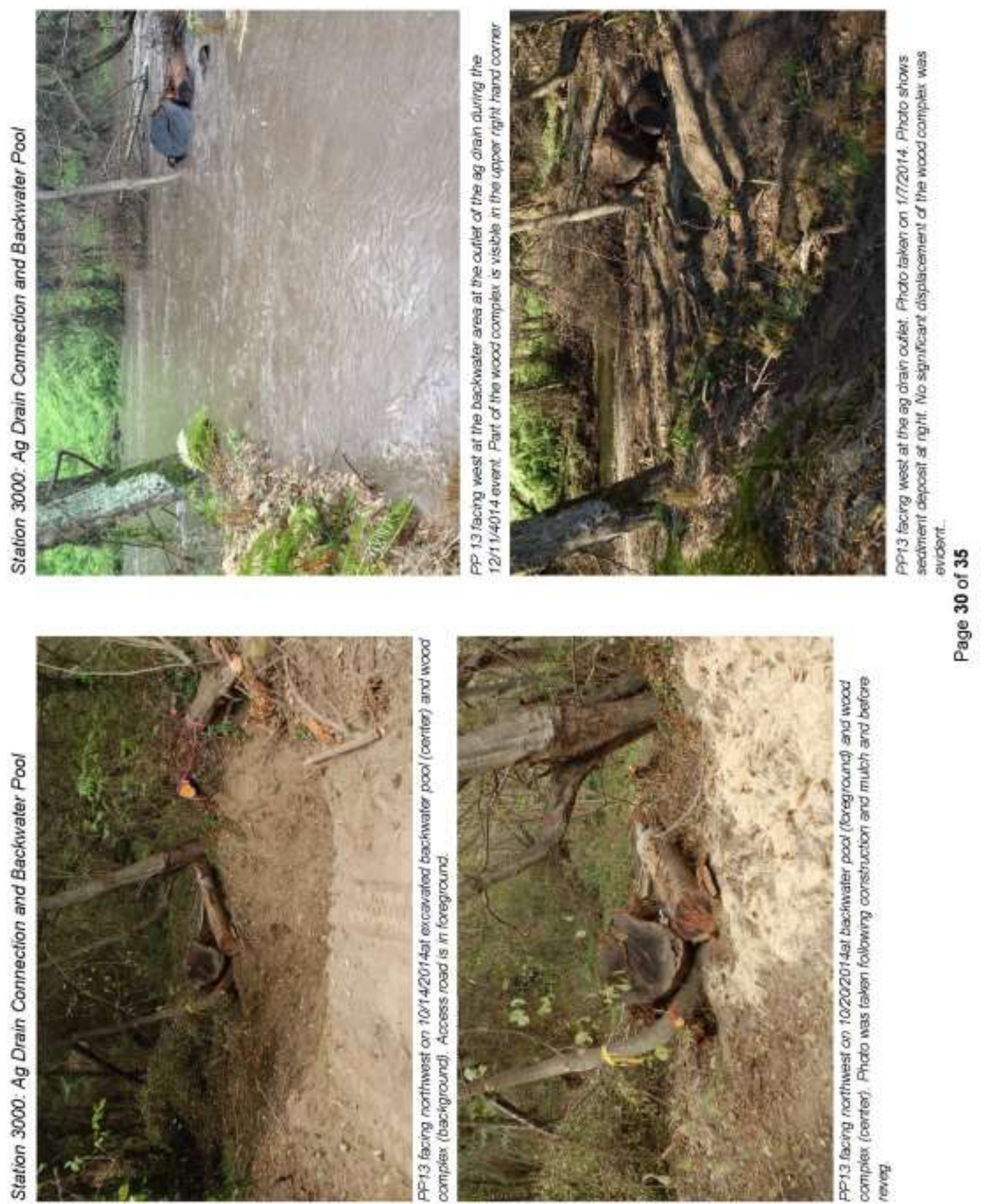

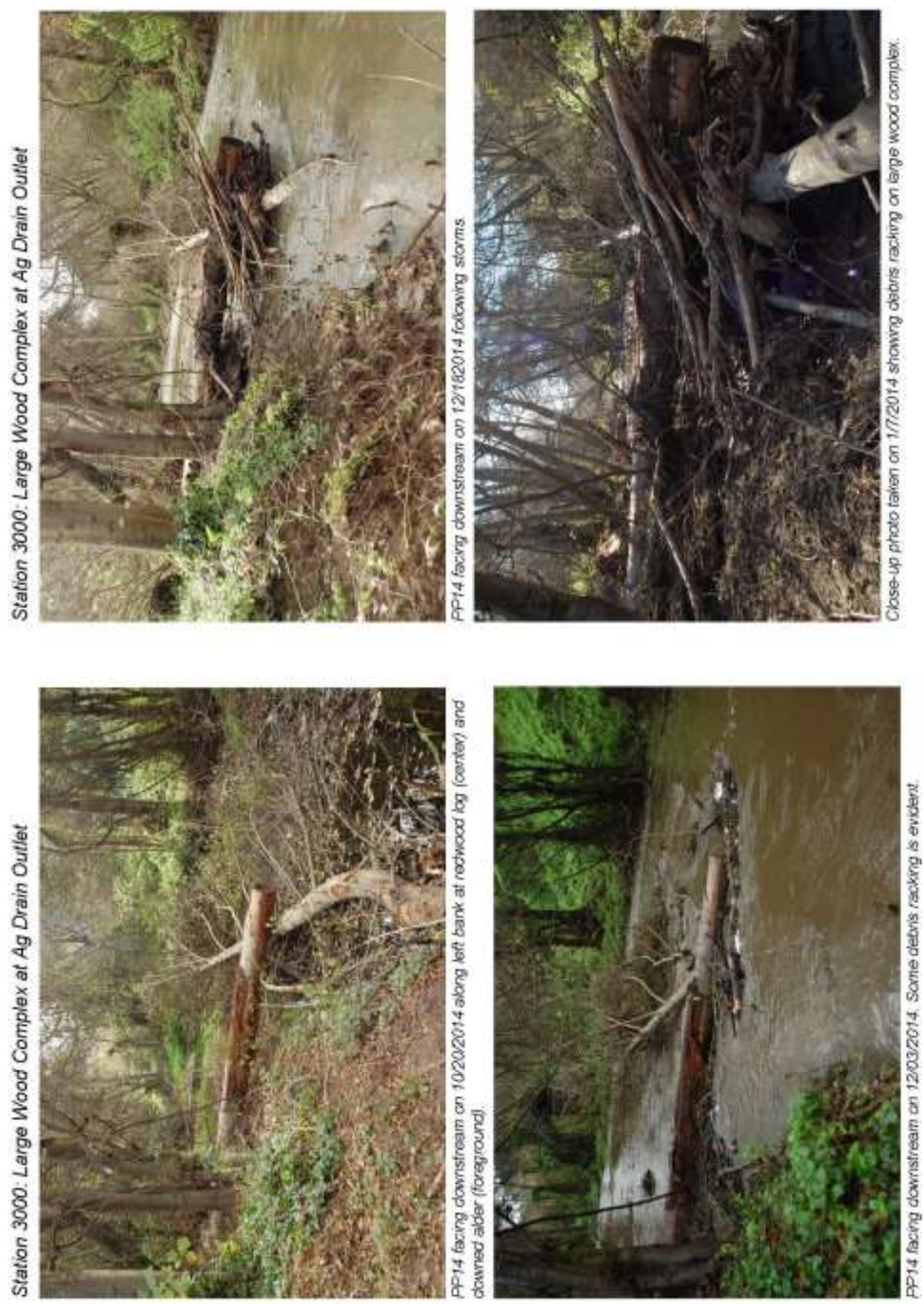

2
$\frac{2}{0}$
$\frac{0}{2}$
8
8
0 


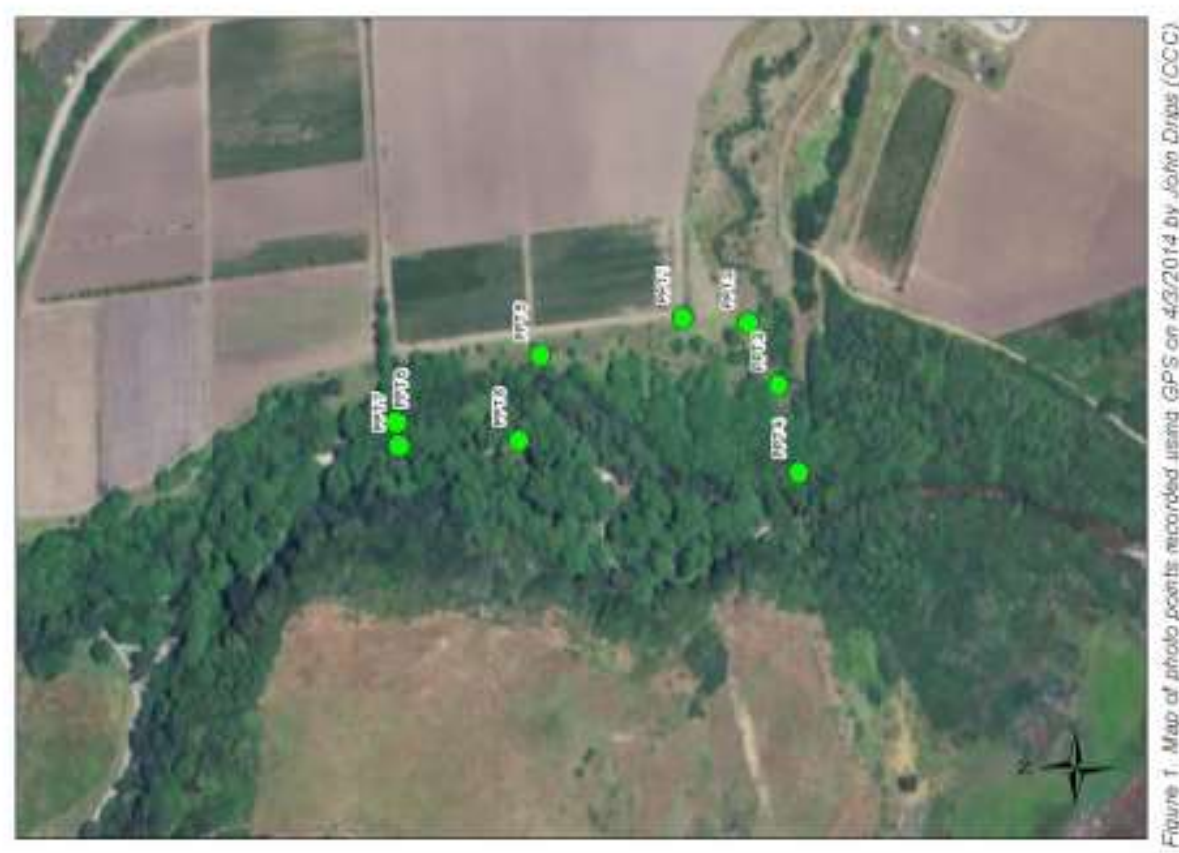

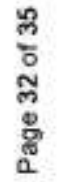

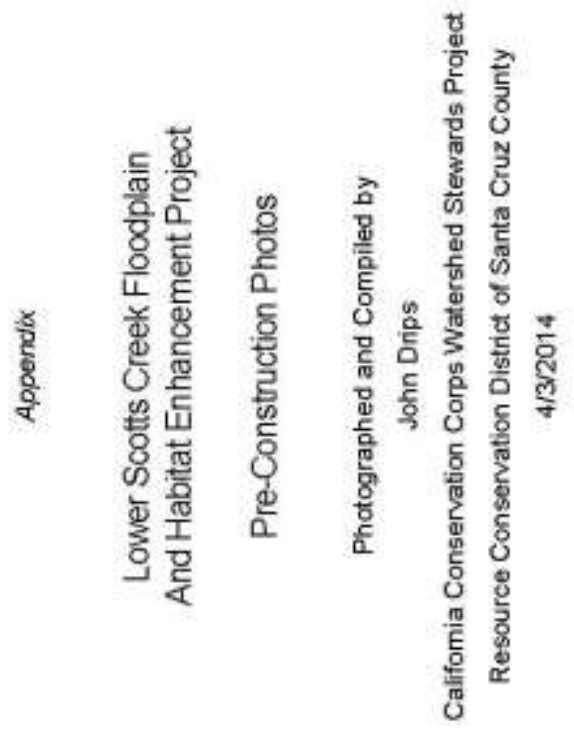



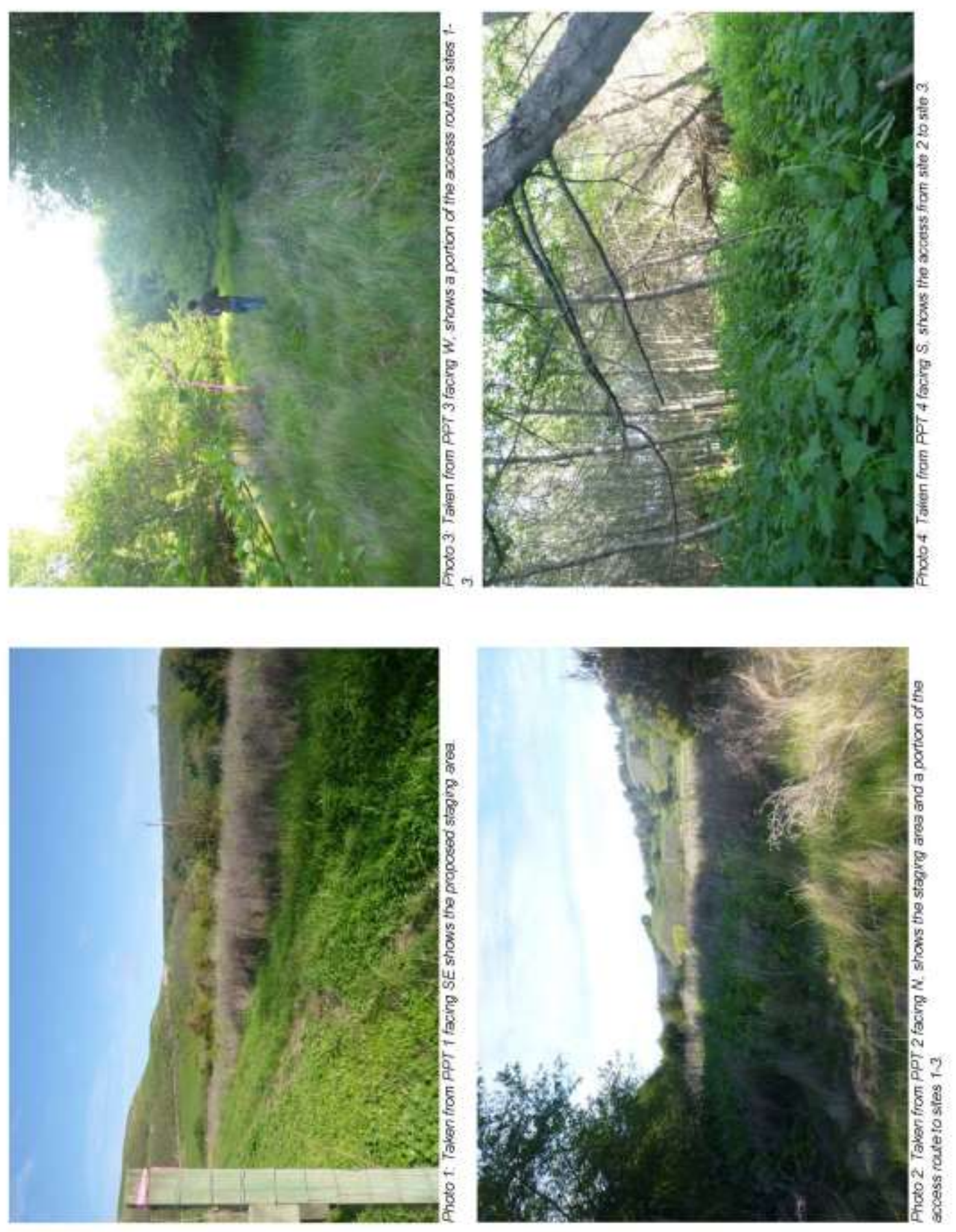

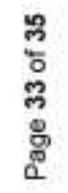



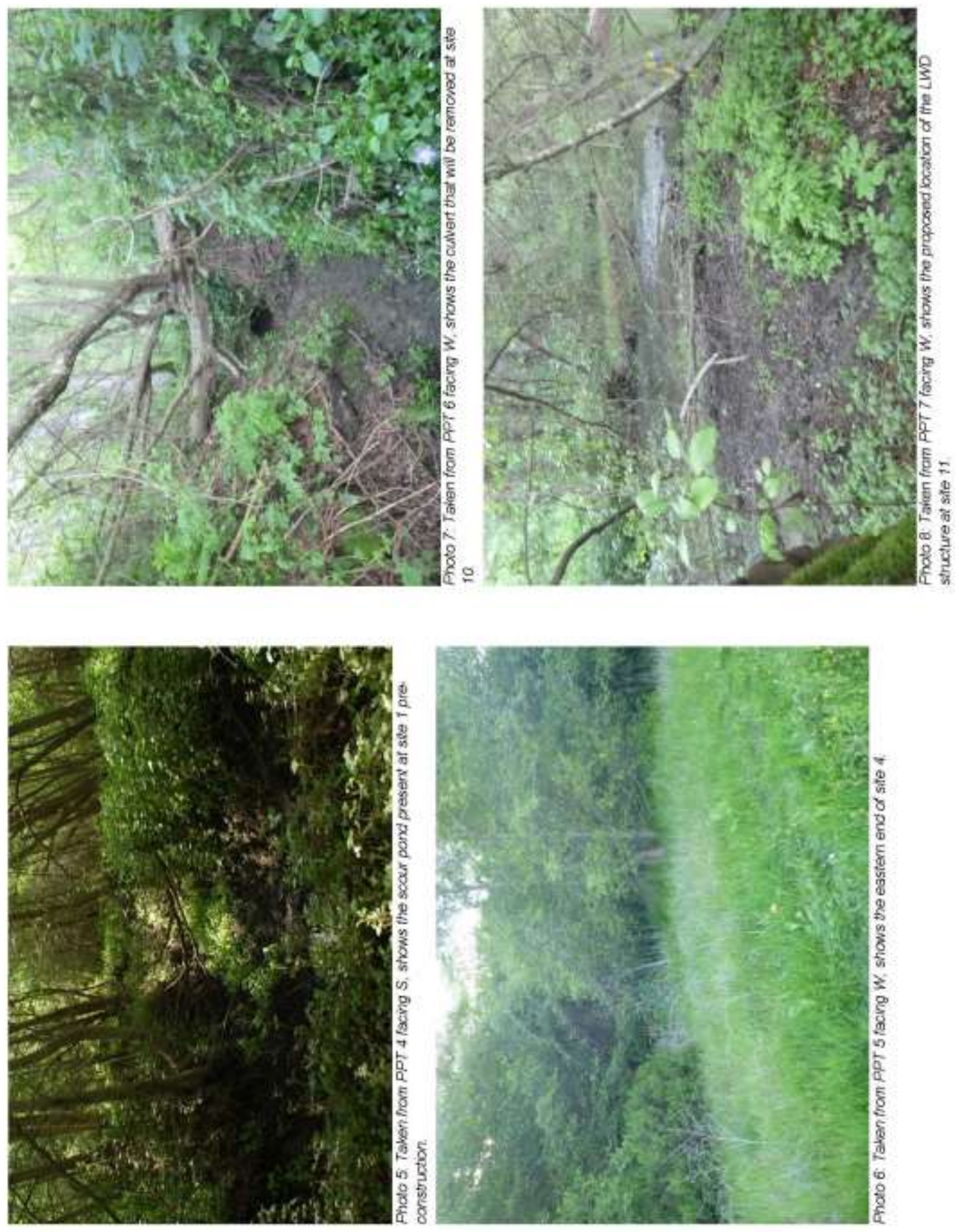

$\%$
"ू
ले
8
8 
5
है
8
8
8
8
4

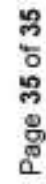
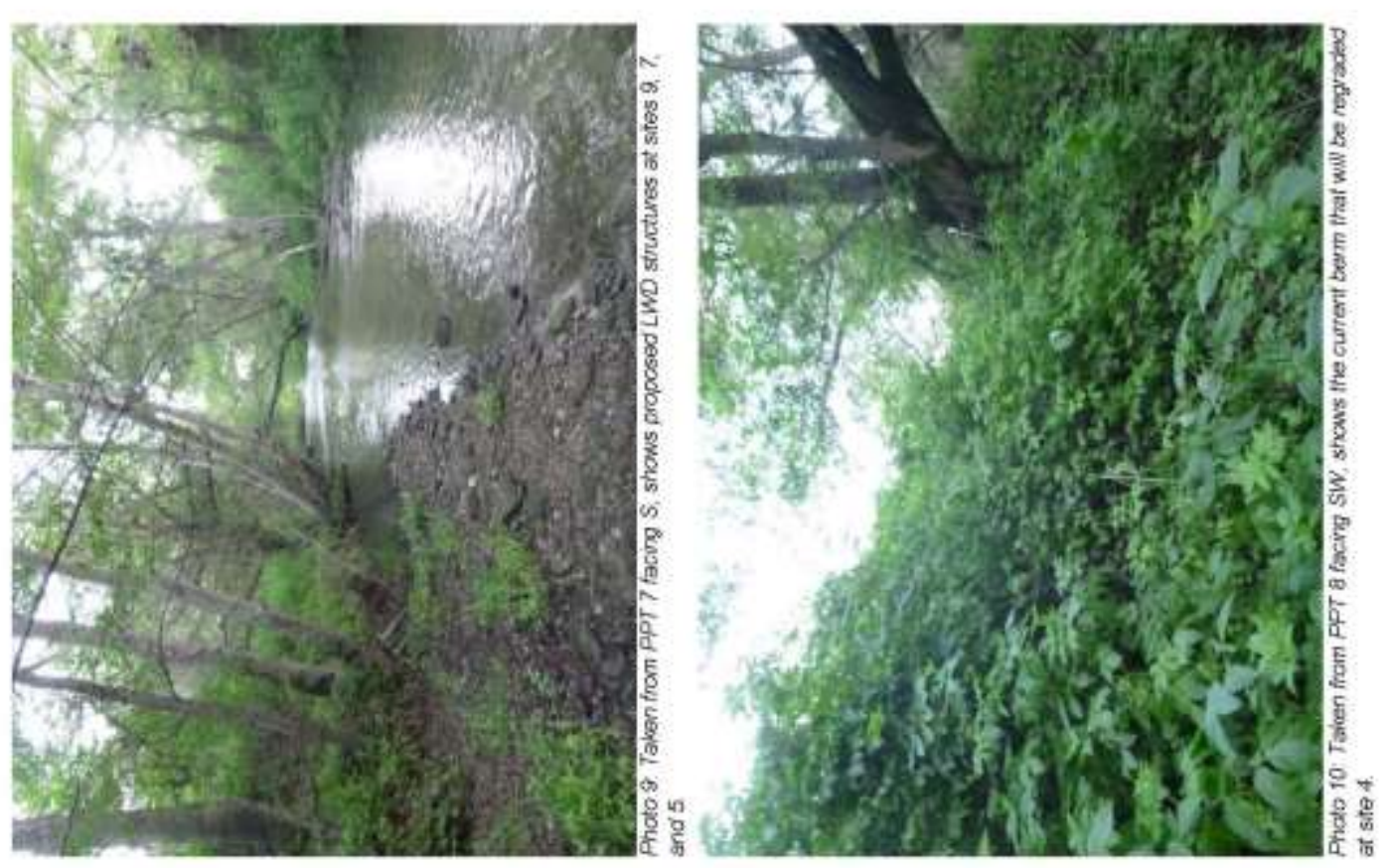
F. PHASE II PHOTO MONITORING PACKET 


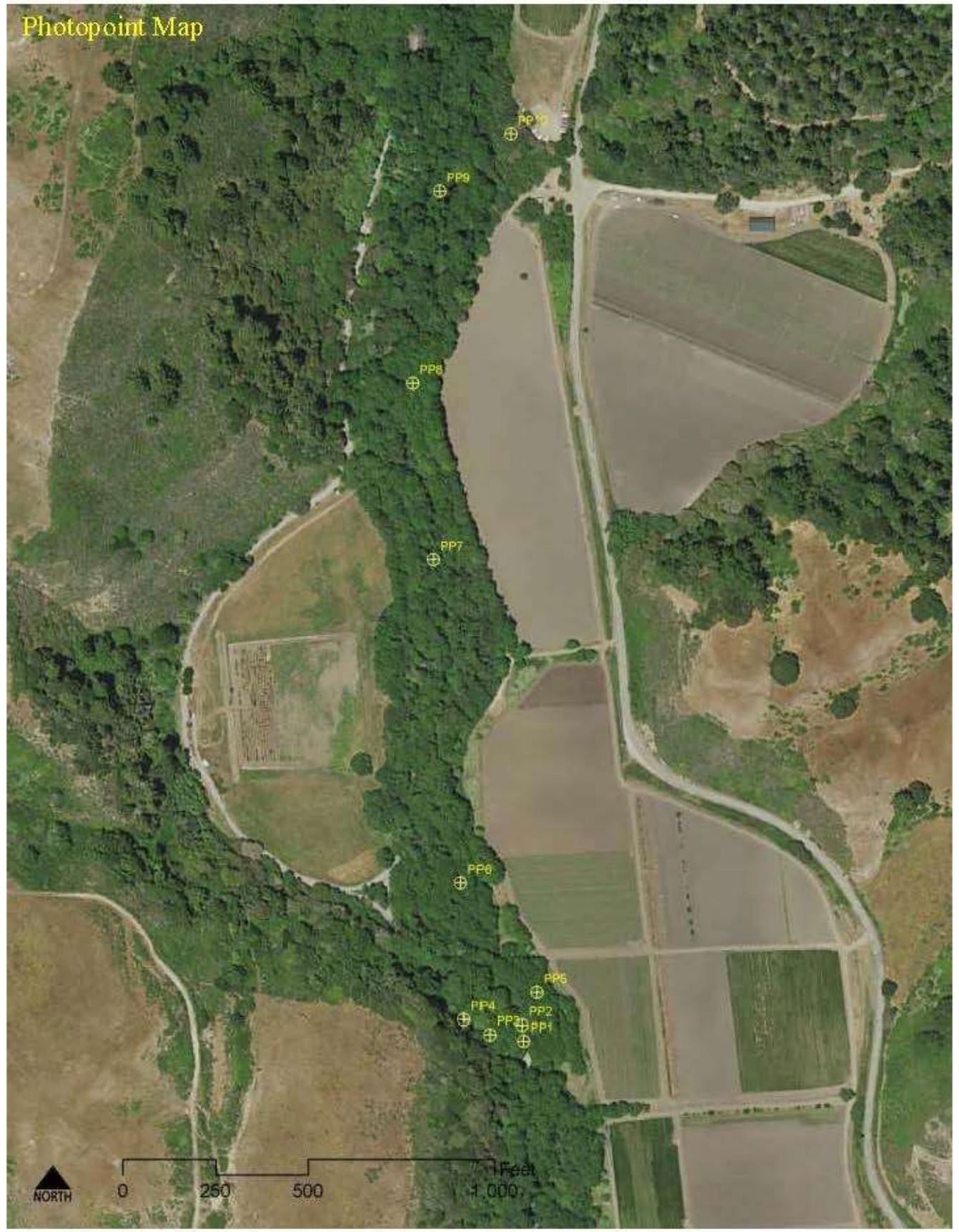


Pre-Project Photos (8/4/2015)

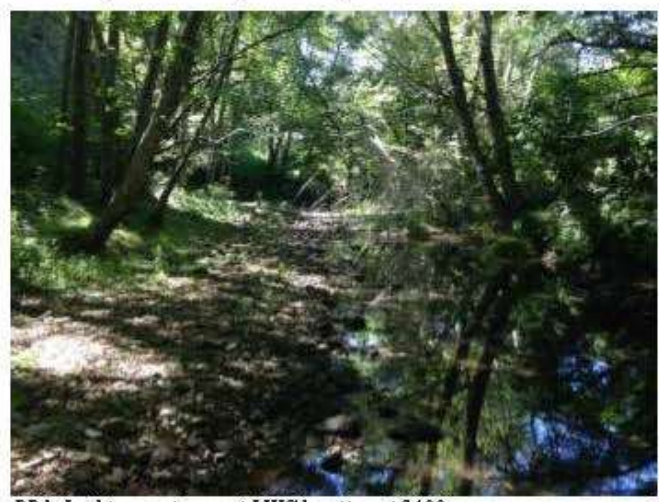

PP1. Looking upstream at LWClocation at 3400
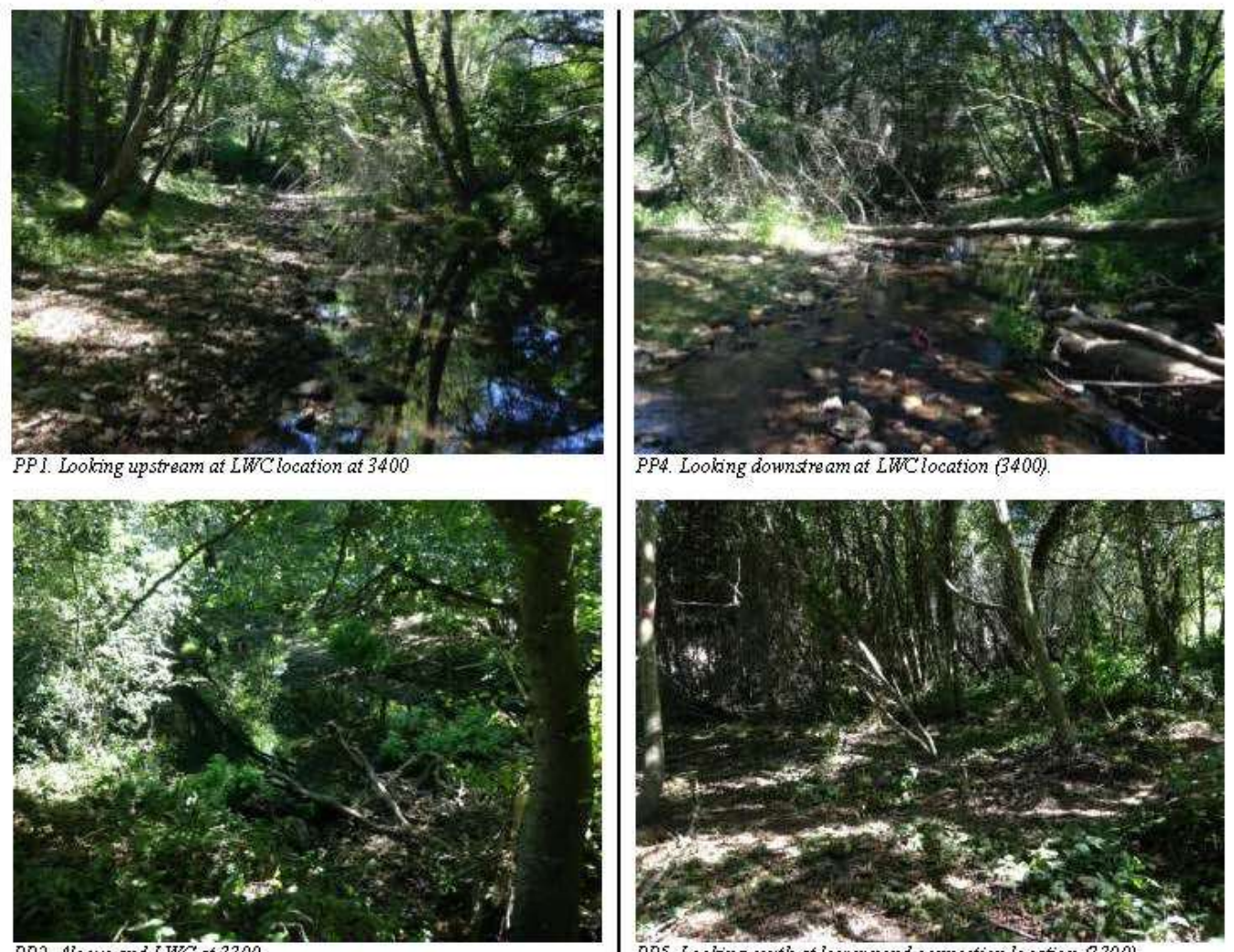

PP4. Looking downstream at LWC location (3400).
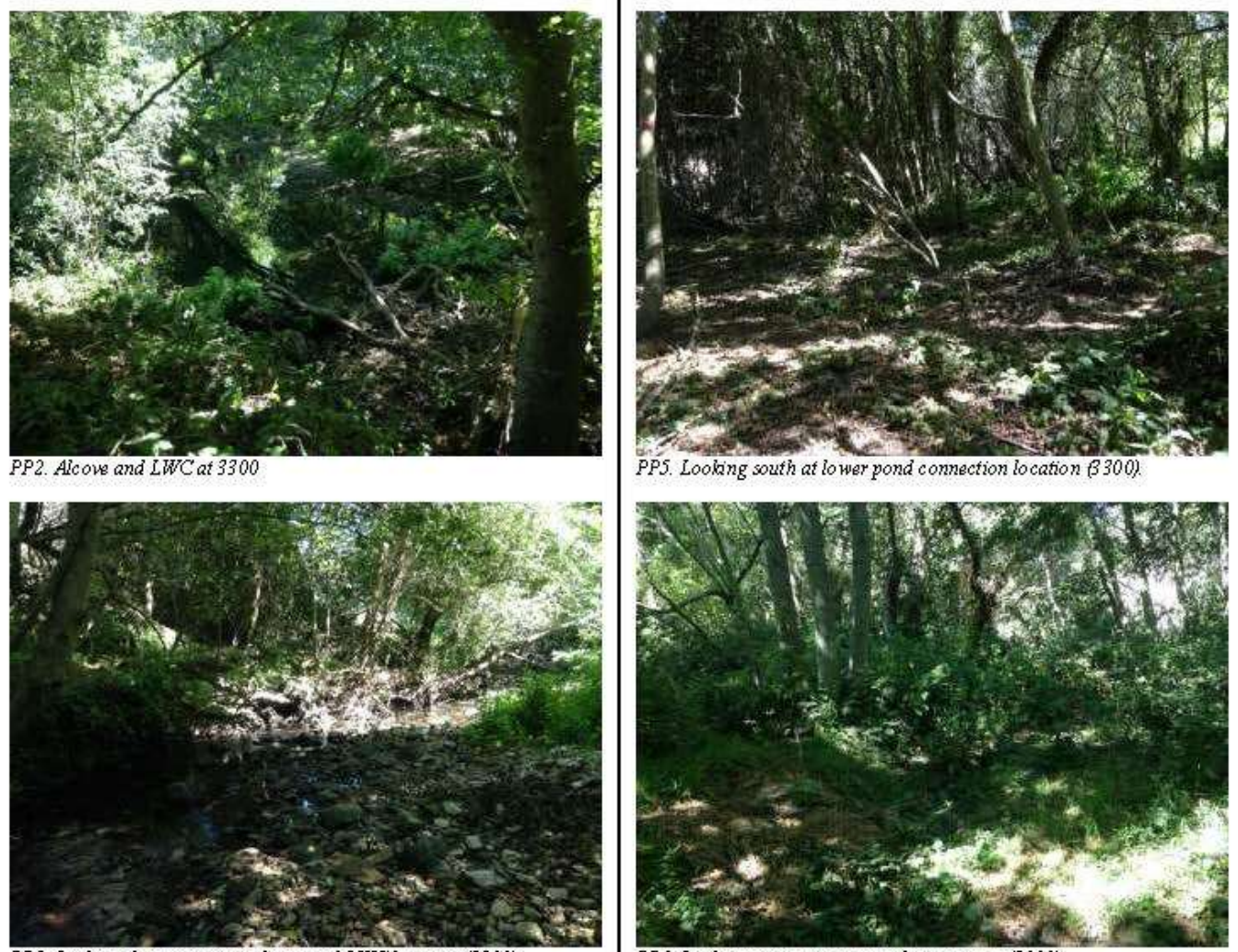

PPS. Looking south at lower pond connection location $(3300)$

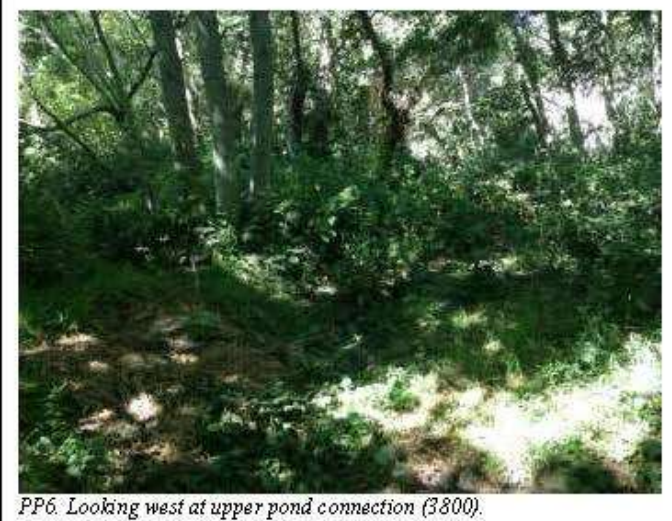

PP3. Looking downstream at alcove and LWC location (3300).

PP6. Looking west at upper pond connection (3800) 
Pre-Project Photos (8/4/2015)

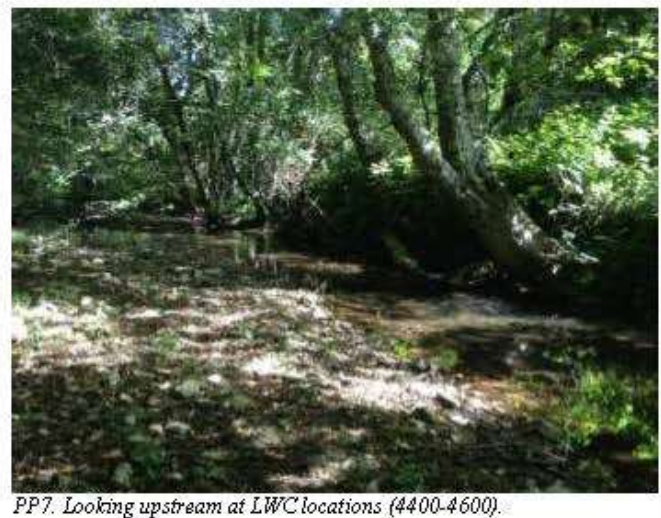

PP7. Looking upstream at LWC locations (4400-4600).
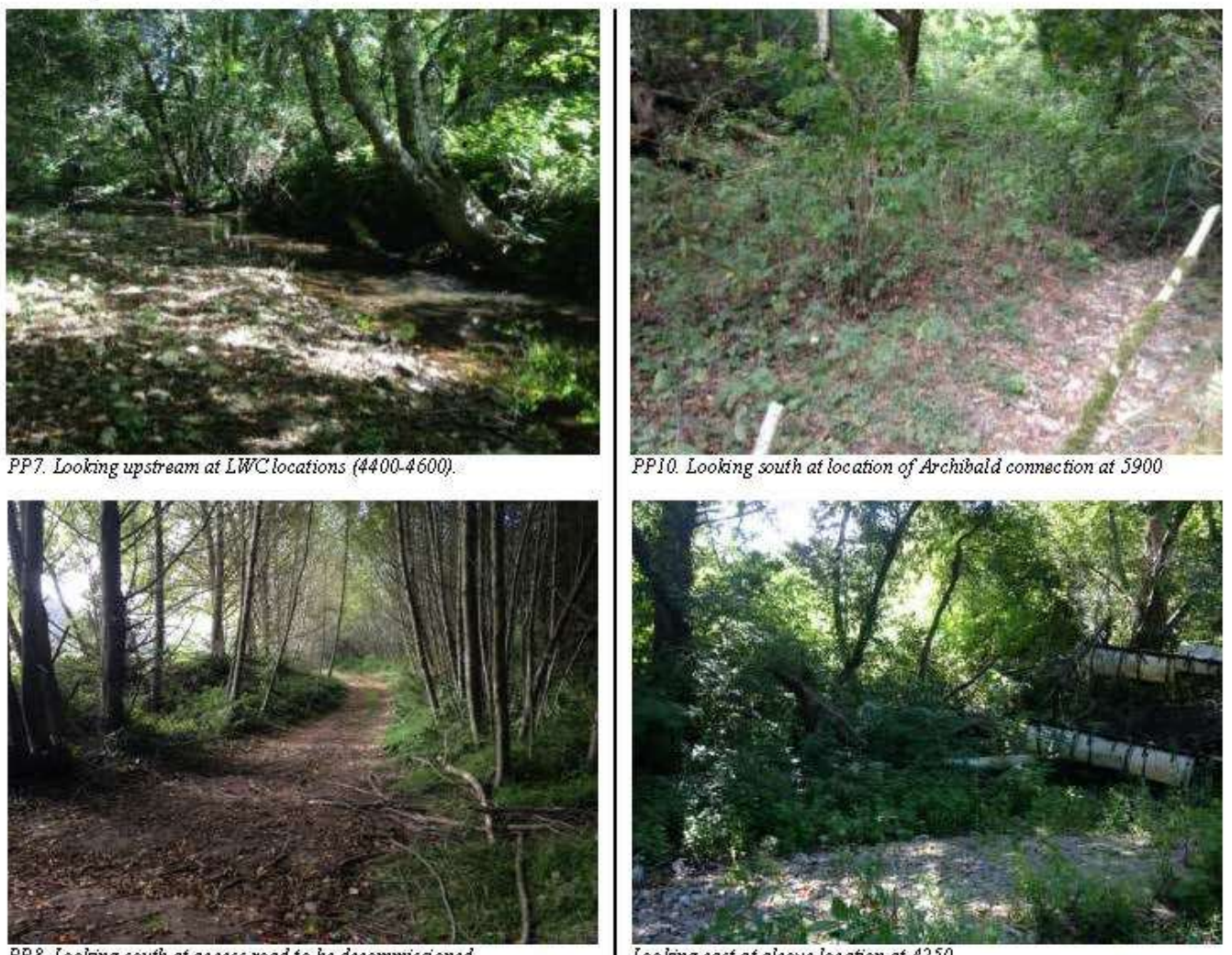

PPIO. Looking south at location of Archibald connection at 5900

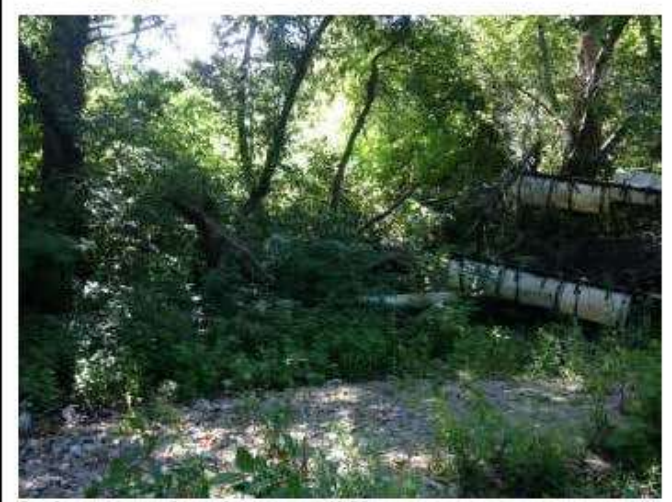

PP8. Looking south at access road to be decommissioned.

Looking east at alcove location at 4250

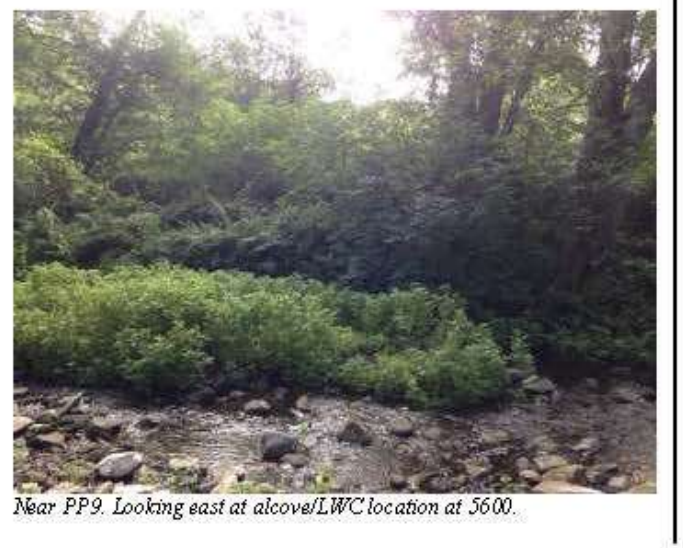


During Construction Photos (September 2015)

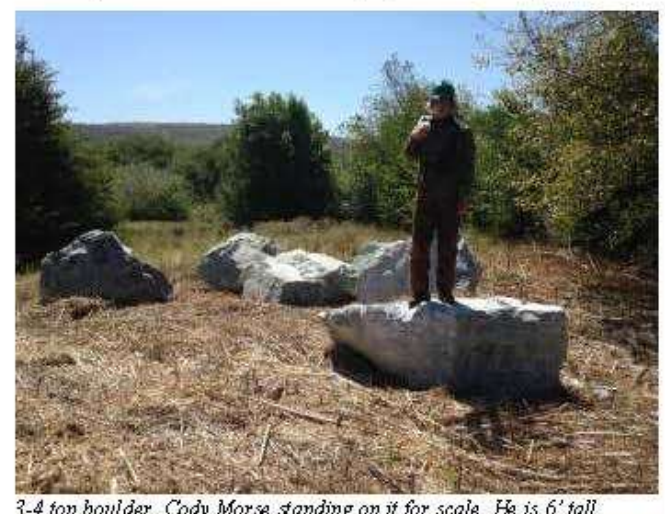

3-4 ton boulder. Cody Morse tanding on it for scale. He is 6 'tall.
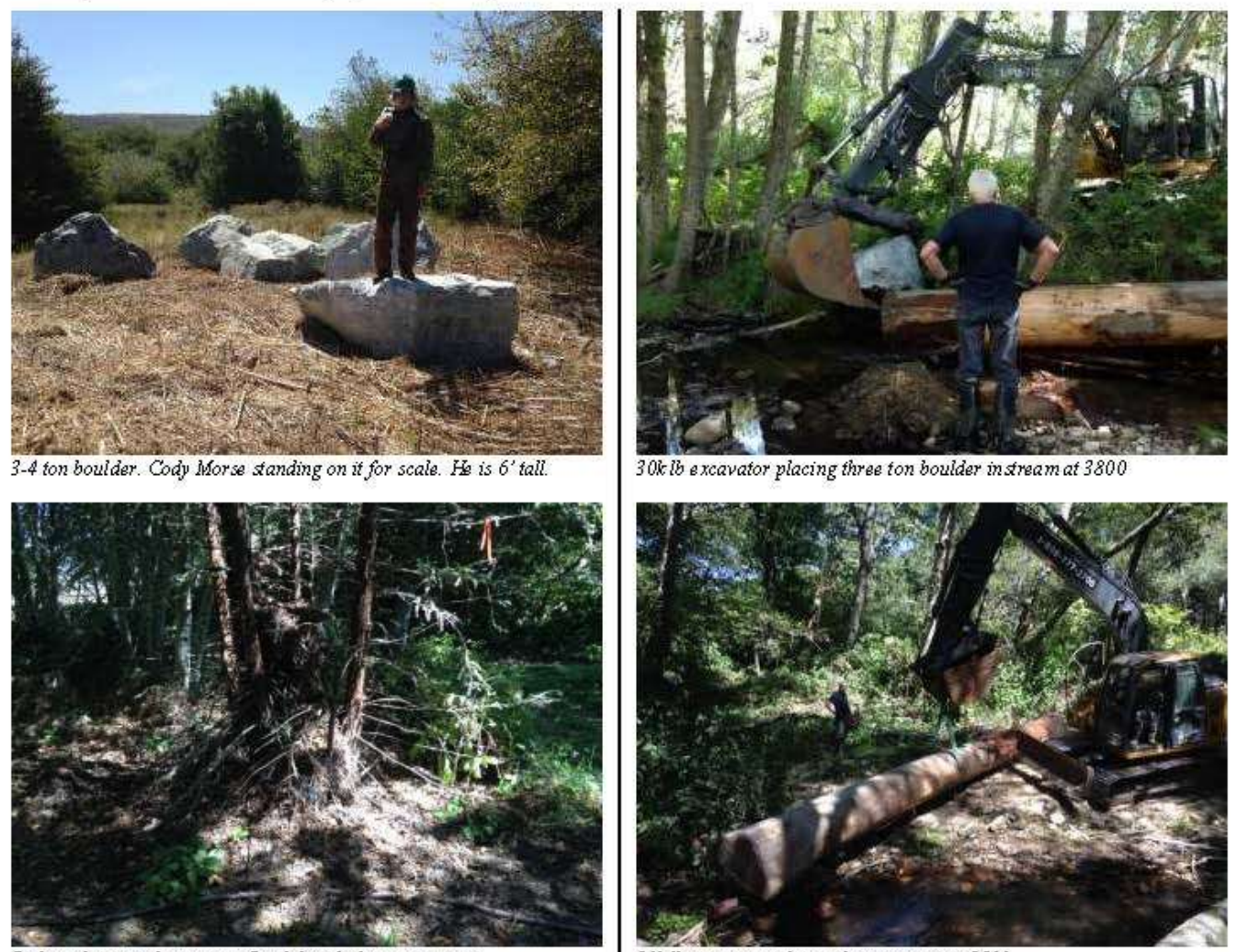

$30 \mathrm{k} l \mathrm{~b}$ excavator placing three ton boulder in stream at 3800

Redwood rootwad in-situ on floodplain before excavation
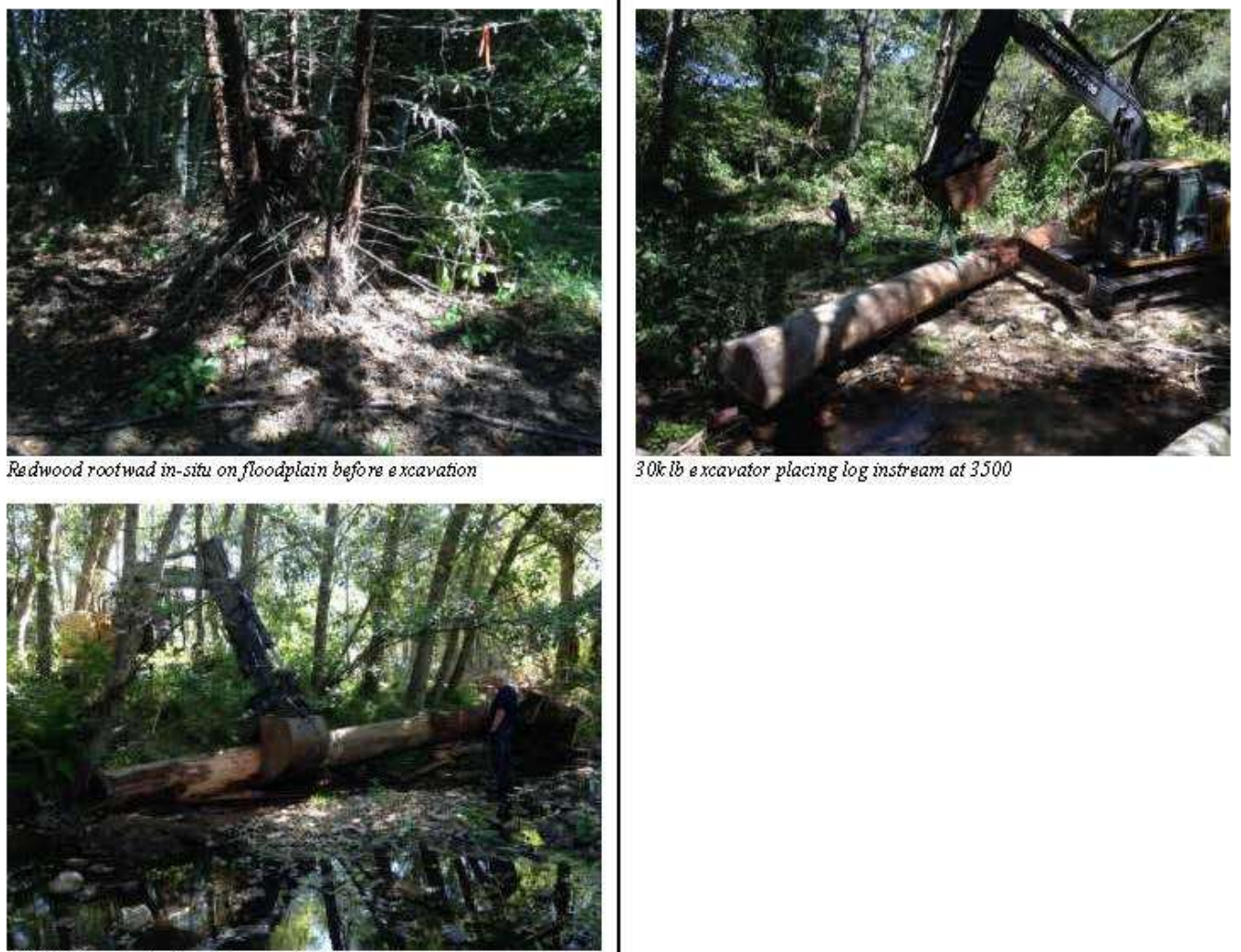

$30 \mathrm{k}$ lb excavator placing log instream at 3500

30,000 ib ex placing log instream at 380 
Post-Project Photos (January 2016)
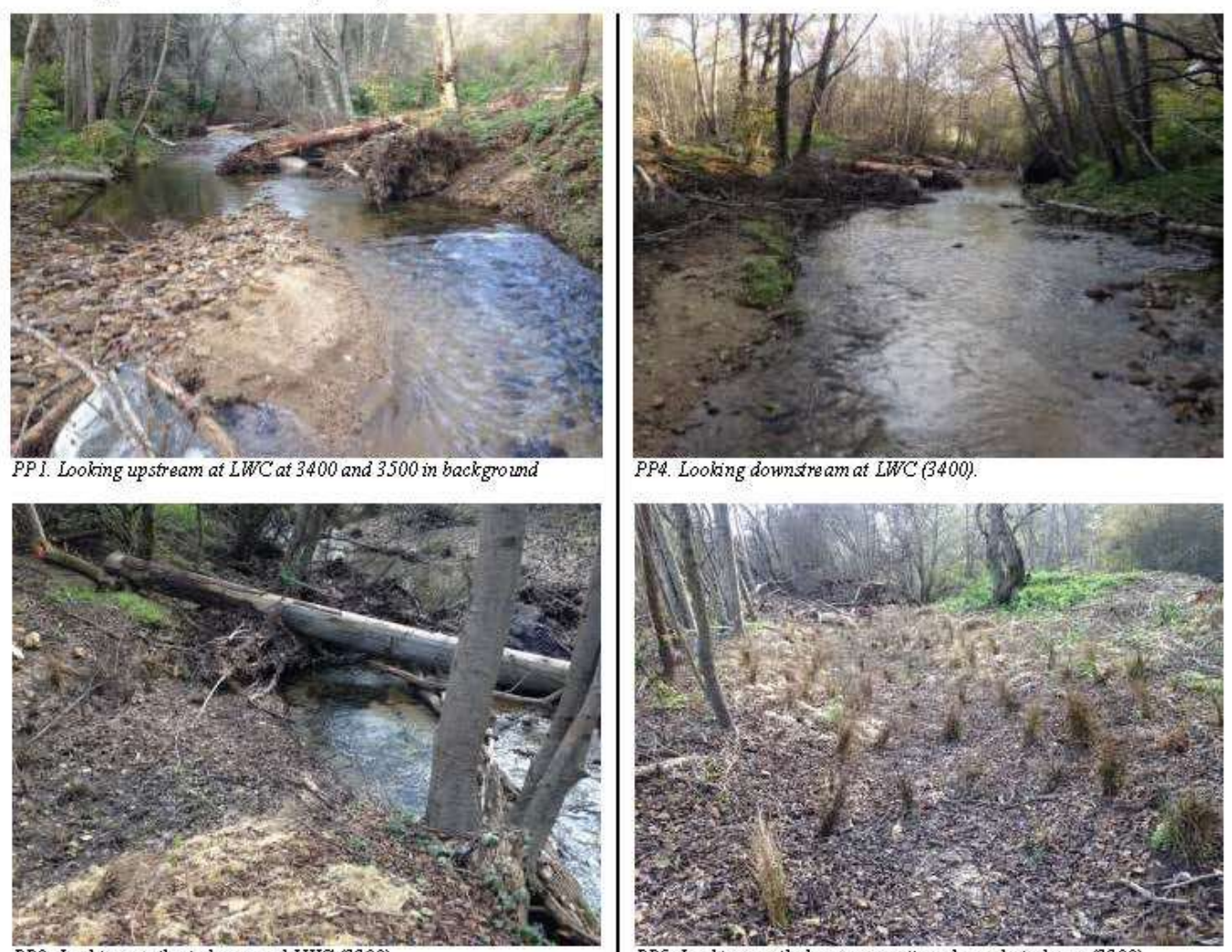

PP2. Looking south at alcove and $L W C(3300)$
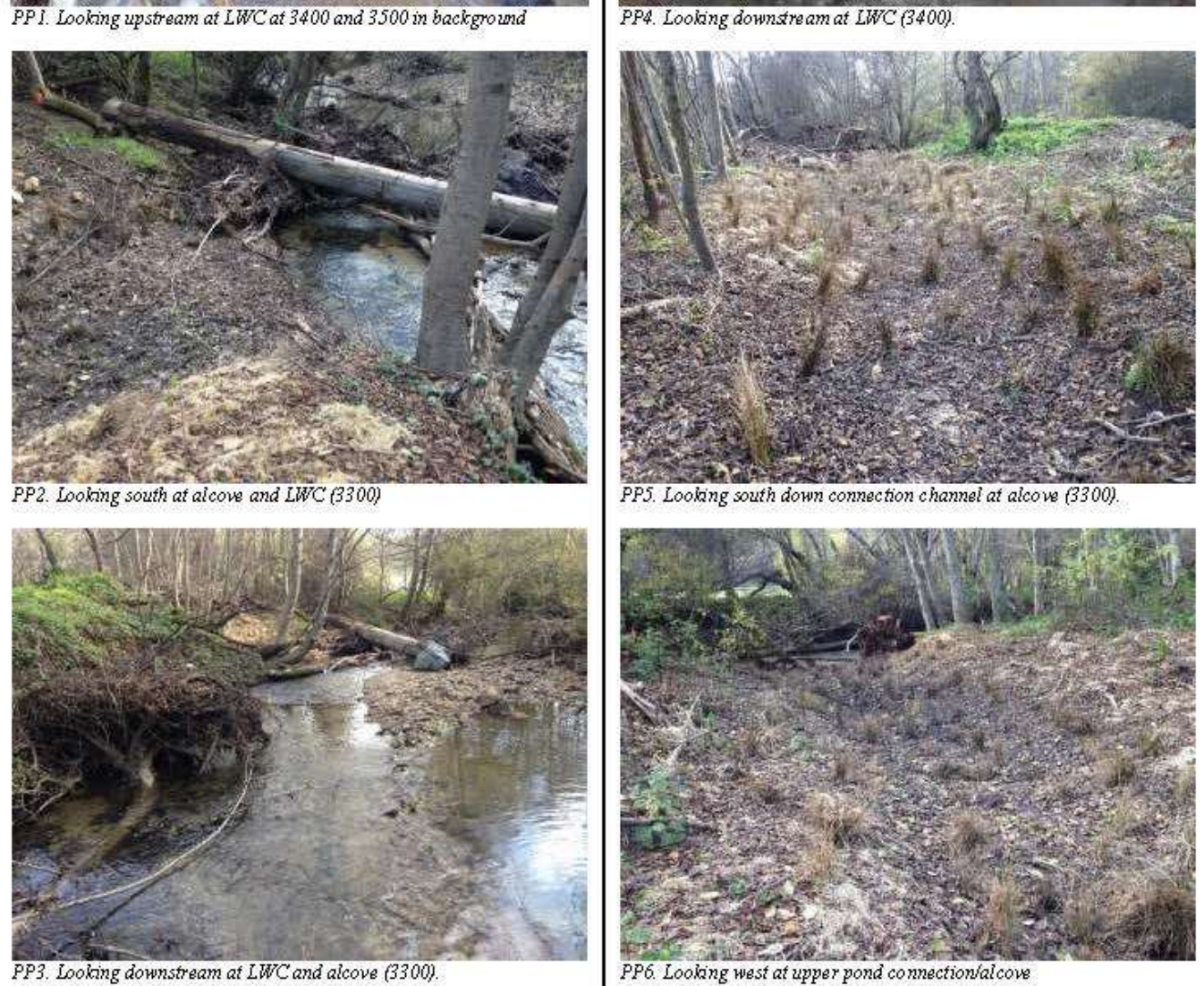

PPS. Looking south down connection channel at alcove (3300).

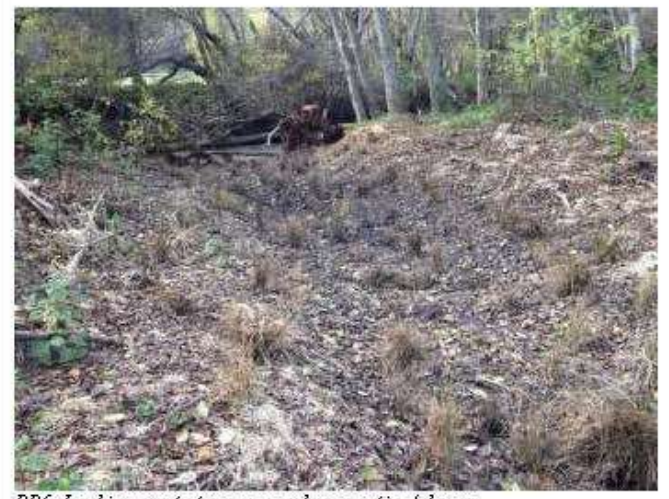

PP6. Looking west at upper pond connectionfalcove 
Post-Project Photos (January 2016)

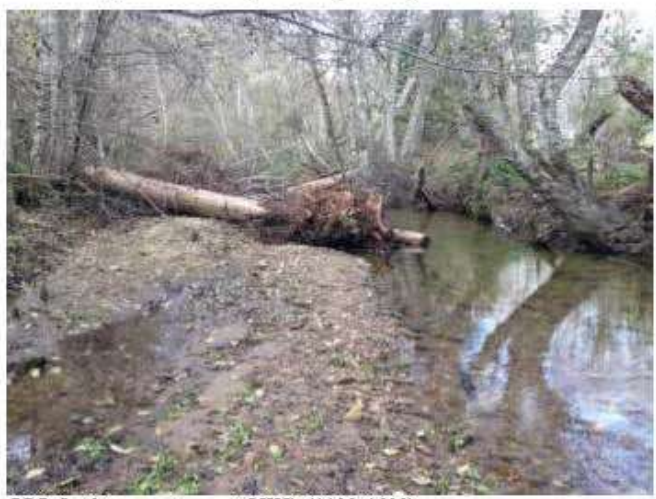

PP7. Looking upstream at LWCS (4400-4600)
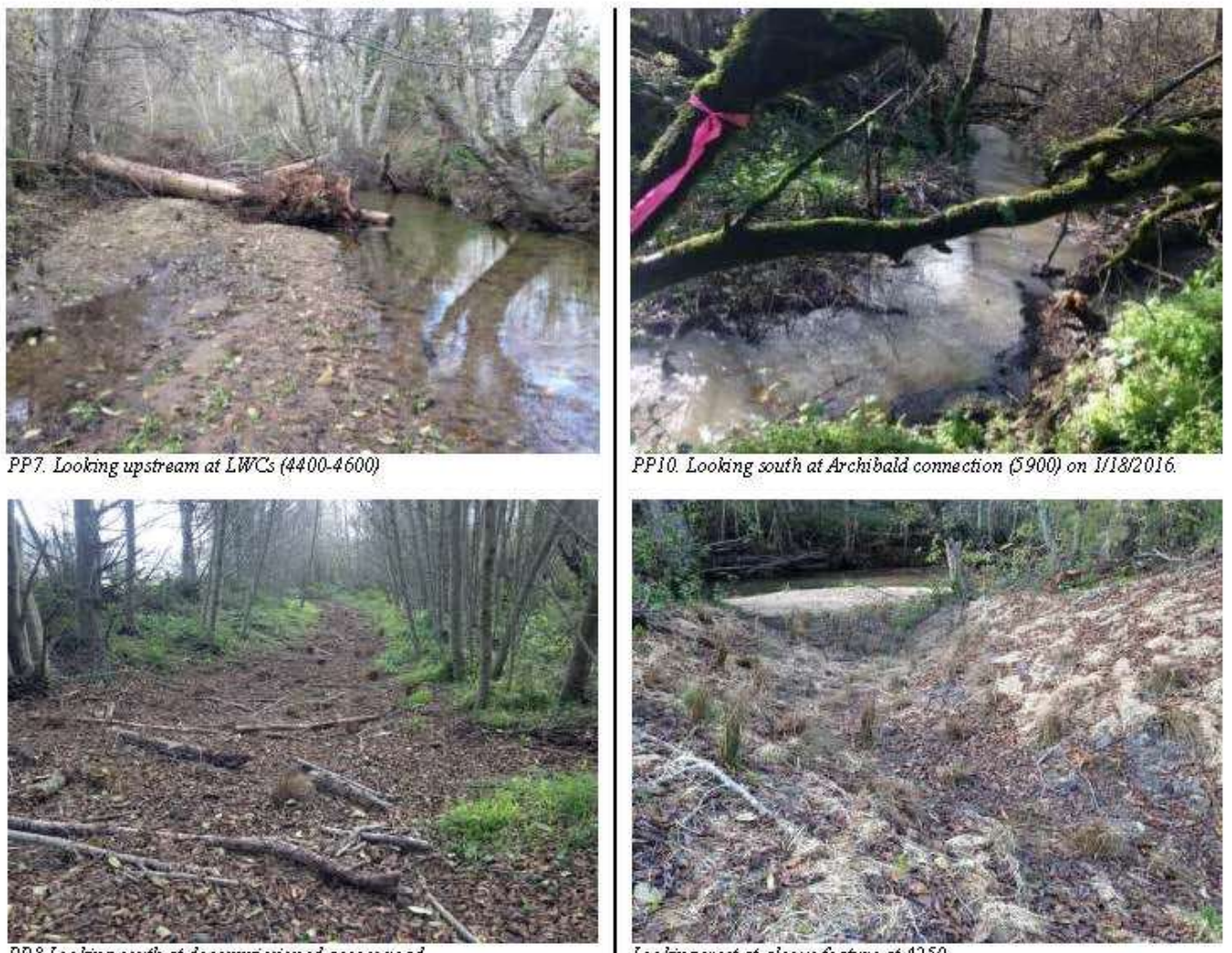

PP10. Looking south at Archibald connection (5900) on 1/18/2016

PP8 Looking south at decommissioned access road.
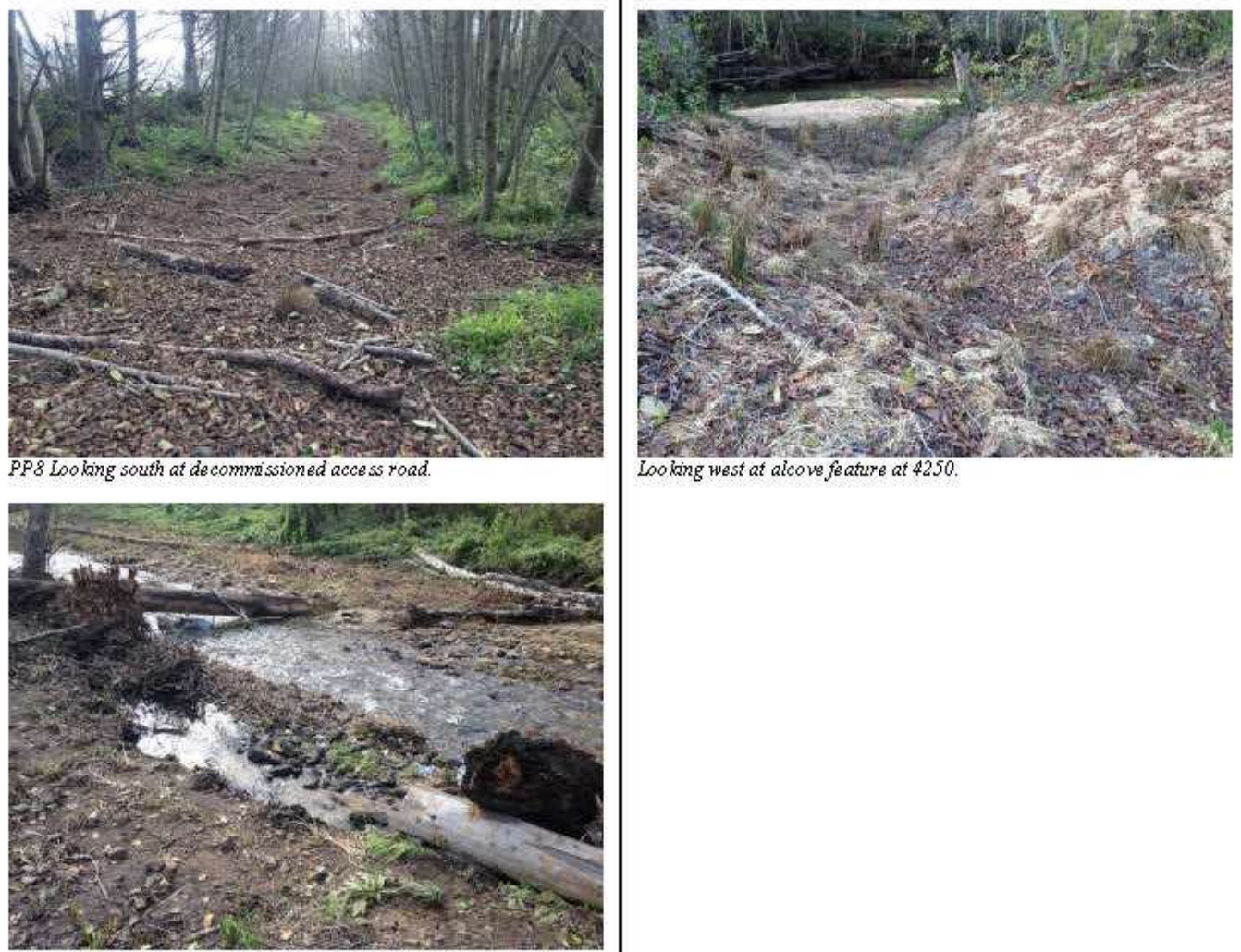

Looking west at alco ve feature at 4250 .

PP9. Looking southwest from left bank at alcove and LWCs (5600) 
G. PHASE I 100\% DESIGN SUBMITTAL 


\section{LOWER SCOTTS CREEK FLOODPLAIN AND HABITAT ENHANCEMENT PROJECT $100 \%$ DESIGN SUBMITTAL}

\section{DESGONTEMA}

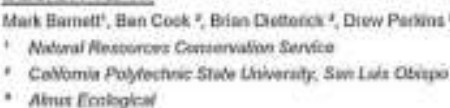

DRAMNG INDEX

1600-3100 PROJECTLAYOU

1650-2100 PLAN

1000.3100 PROJECT REACH PROFILE

1900 PROFILE AND SECTION

2000 PROFLE AND SECTON

2650 PROFLE ANO SECTION

2850 PROFLE AND SECTION

3000 PROFLLE AND SECCION
LARGE WOOD COMPLEX TYPIC

STREAM DIVERSION PLAN

16. STAGING ANO SURVEY CONTROL MAP

ENGINEFRING CRTTERA

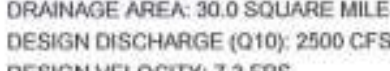

DESIGN VELOCITY: 73 F
DESIGN DEPTH 8 FEET

PROJECT DESCRPPTION

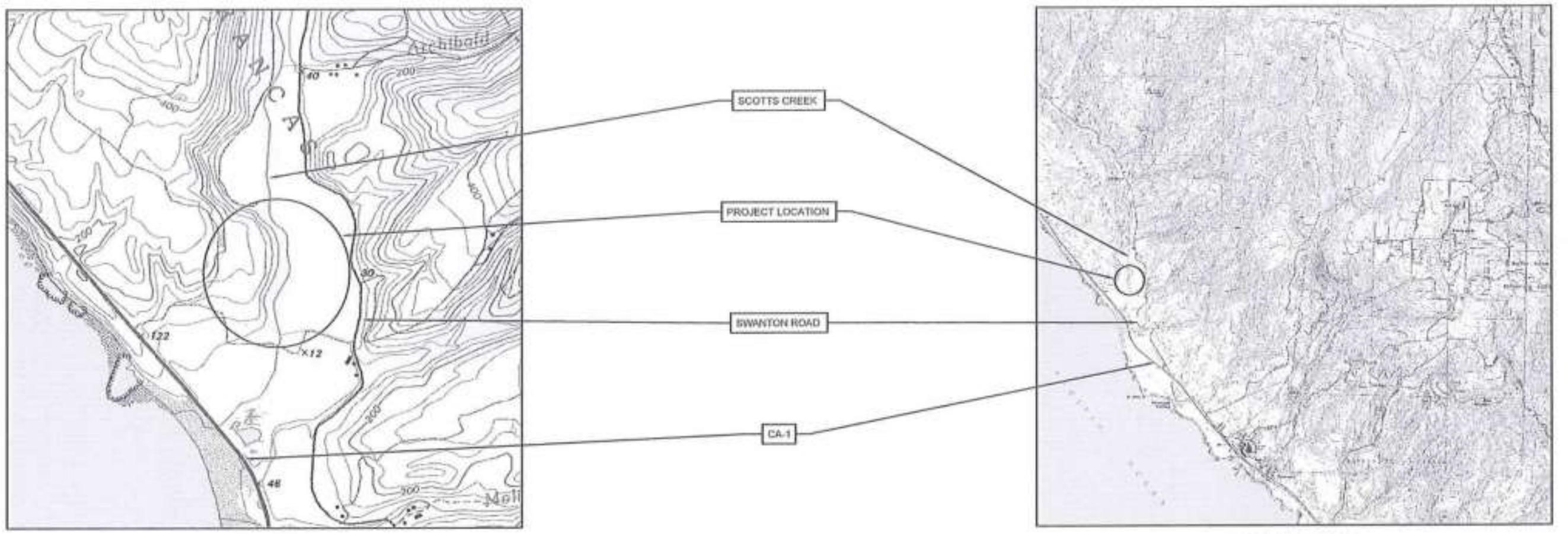

VICINITY MAP

CONTOUR INTERVAL: 4

FLOODPLAN, BETWEEN 1600 AND 3100 FEET UPSTREAM FROM THE CA GRDOE SCOTTS CREEK IS LOCATED IN SANTA CRUZ COUNTY, CALIFORNAA, APPROXIMATEIY 12 MLES NORTH OF THE CITY OF SANTA

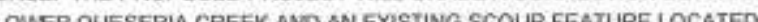
ON THE ADNACENT FLOODPLAN, CONSTRUCT FOUR INSTREAM WOOOCOAFLEXES IN SCOTIS CREEK GRADE FIVE FLOOPPLAIN CONNECTIONS MPROVED CONNECTION GETWEEN AN EXISTING FLOOLPPLAIN ORAIN AND GENERAL NOTES

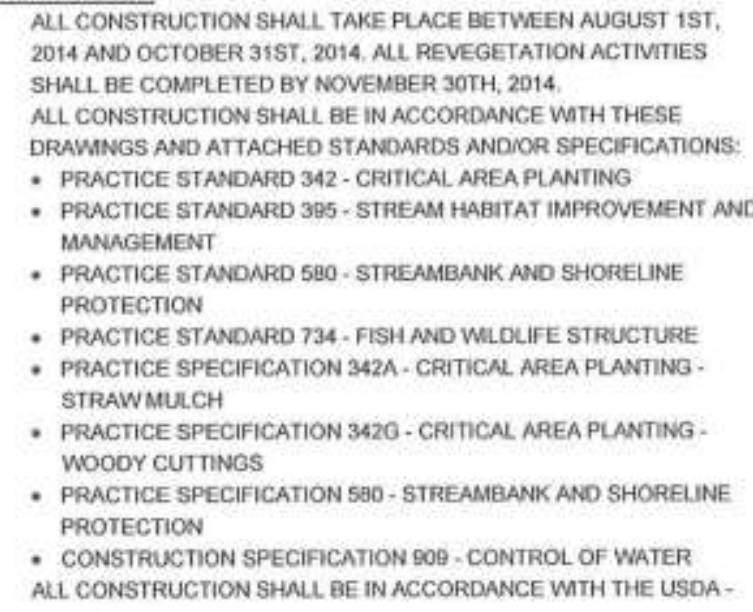
(a)

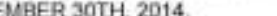

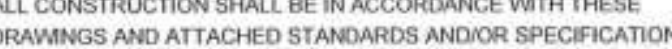
PRCITE STANDARD 342 - CRTIICAL AREA P PANTING

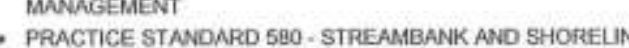
2. ALL CONSTRUCTION SHALL BEIN ACCORDANCE WTH THE USDA

REGIONAL MAP ONTOUR INTERVAL: 40

SOURCE: USGS
NRCS NATIONAL ENGINEERING HANDBOOK PART O54: STREAM A WLLUIFE CALLFFRNIA SALMONIO STREAM HABITAT RESTORATIO

ENGINEER

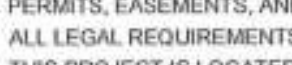
AVOIDANCE OF SENSTIVE HABIAT AREAS, AND COORDINAT PROTECTING ALL UTLLTIES. SPECIAL. SAFETY PRECAUTIONS TO BE

(USA) AT 1-0002227-2000 PPIOR TO ANY CONSTS

CAL-OSHA SAEETY REOUIREMENTS SHALL BE IN EFFECT DUPBN

ALI CONSTRUCTION.

APPROXIMATE THE PRSO HOUN ON THESE DRAMNGS ARE MARKED GY THE NRCS ENOENESR STRCTURE LOCATIONS WULL BE ANDLOG ORIENTATION TO BE

NRCS ENGINEER
CONTAGT THE NATURAL RESOURCES CONSERVATION SERVICEAT

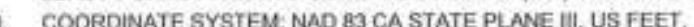

1. SITE TOPOGRAPHY GENERATED FROM AIRBORNE LIDAR FLOUN ON
SPECIFICATIONS WTHHOUT THE PRIOR APPROVAL OF THE NRCS

CONTRACTOR SHALL EE RESPONSIILL FOR OBTANNG ANY NEEDED

CONTRACTOR MUL RE PESPONSIEE FOR LCATHG AND A
MARCH $210,2010$. NOR INTERVAL IS FNE FEET ANO MINOR IS ONE FOO

ABBREVIATONS

cFs

CY
DTL

FEET

INEERT

LARGE WOOO COMPL NOT TO SCAL 10.YEAR, 10.Y YEAR DISCHARG SOUARE FEET
RNER STATION

ROEREDETERMINE

TYPICAL

WATER SURFACE ELEVATION 


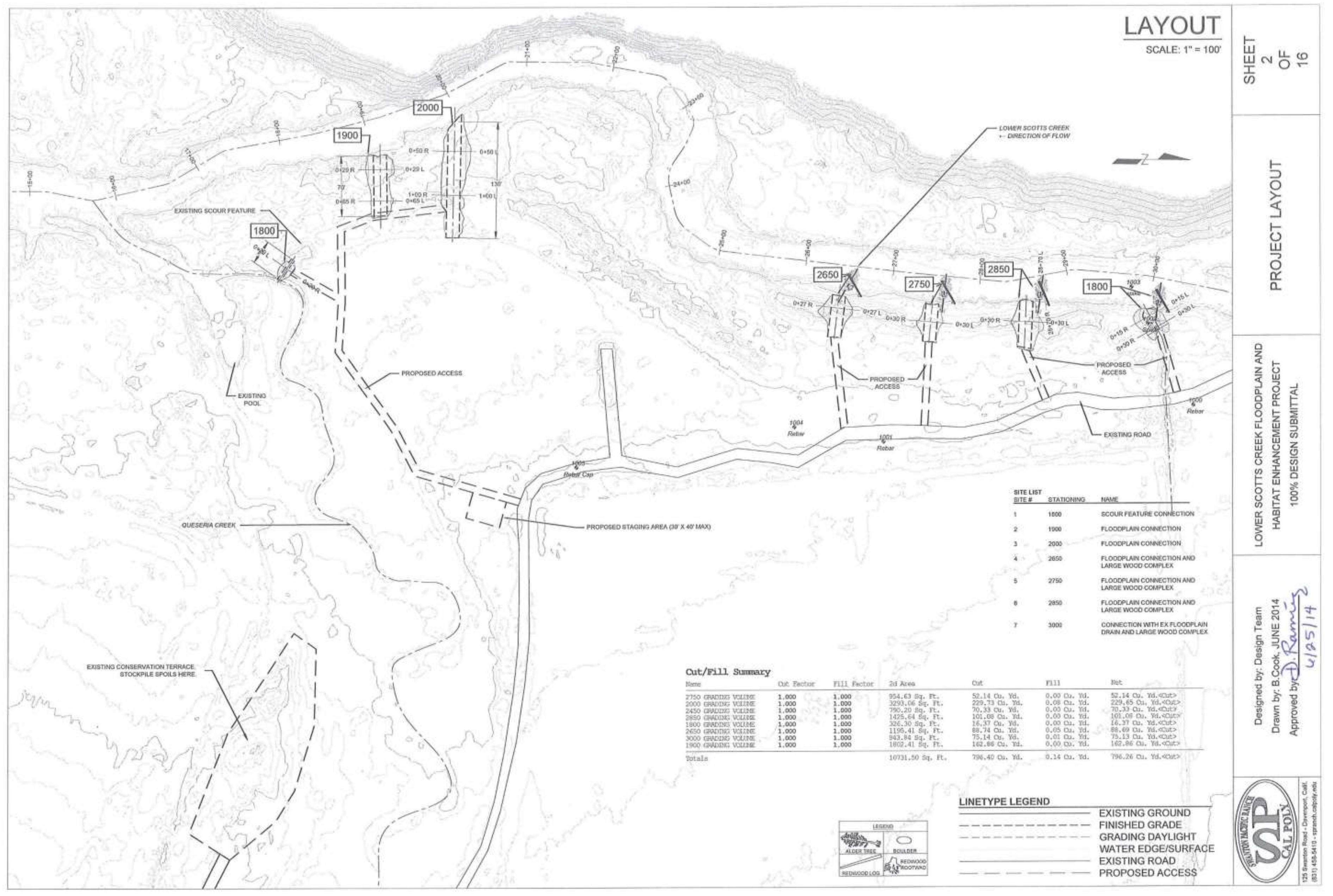




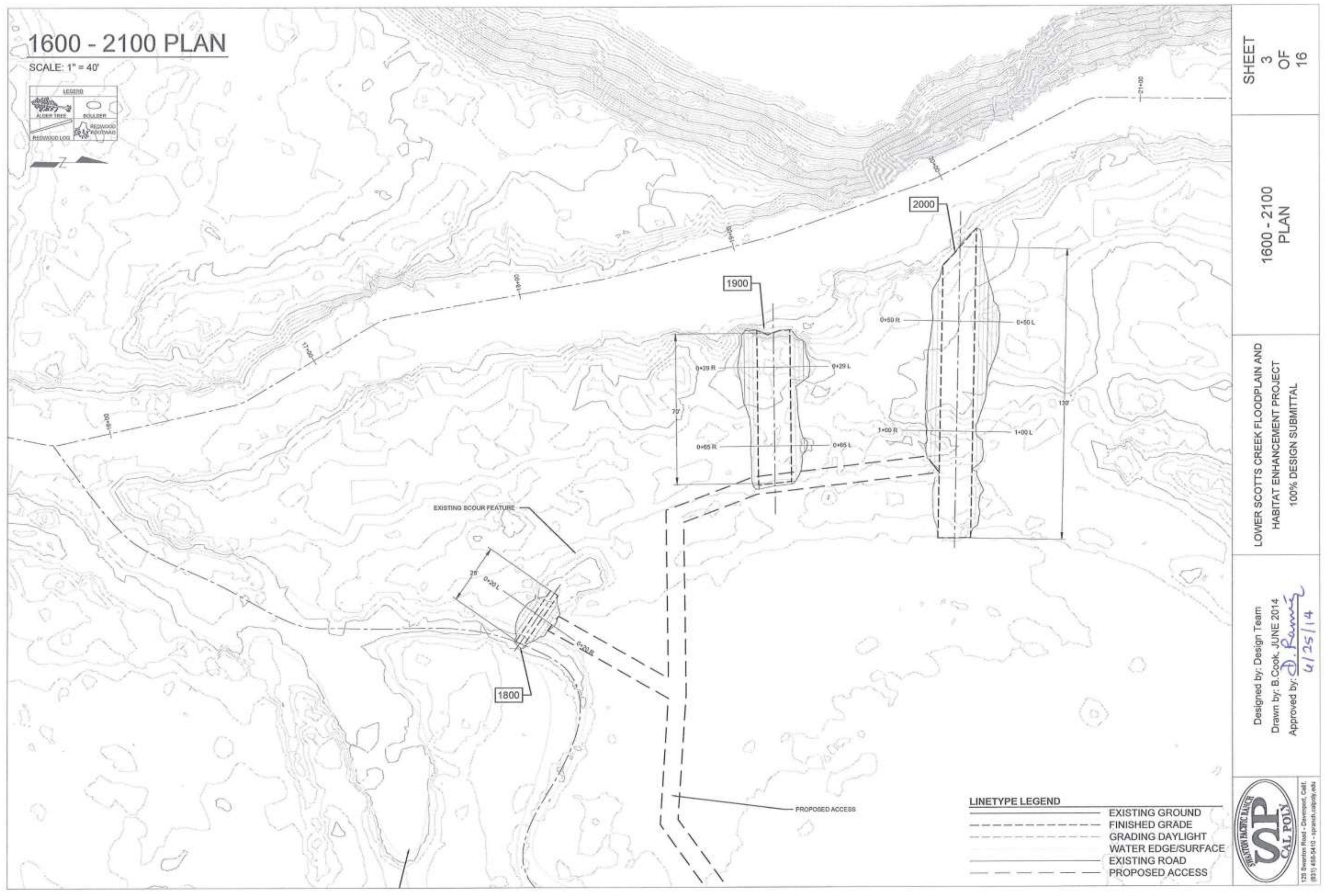




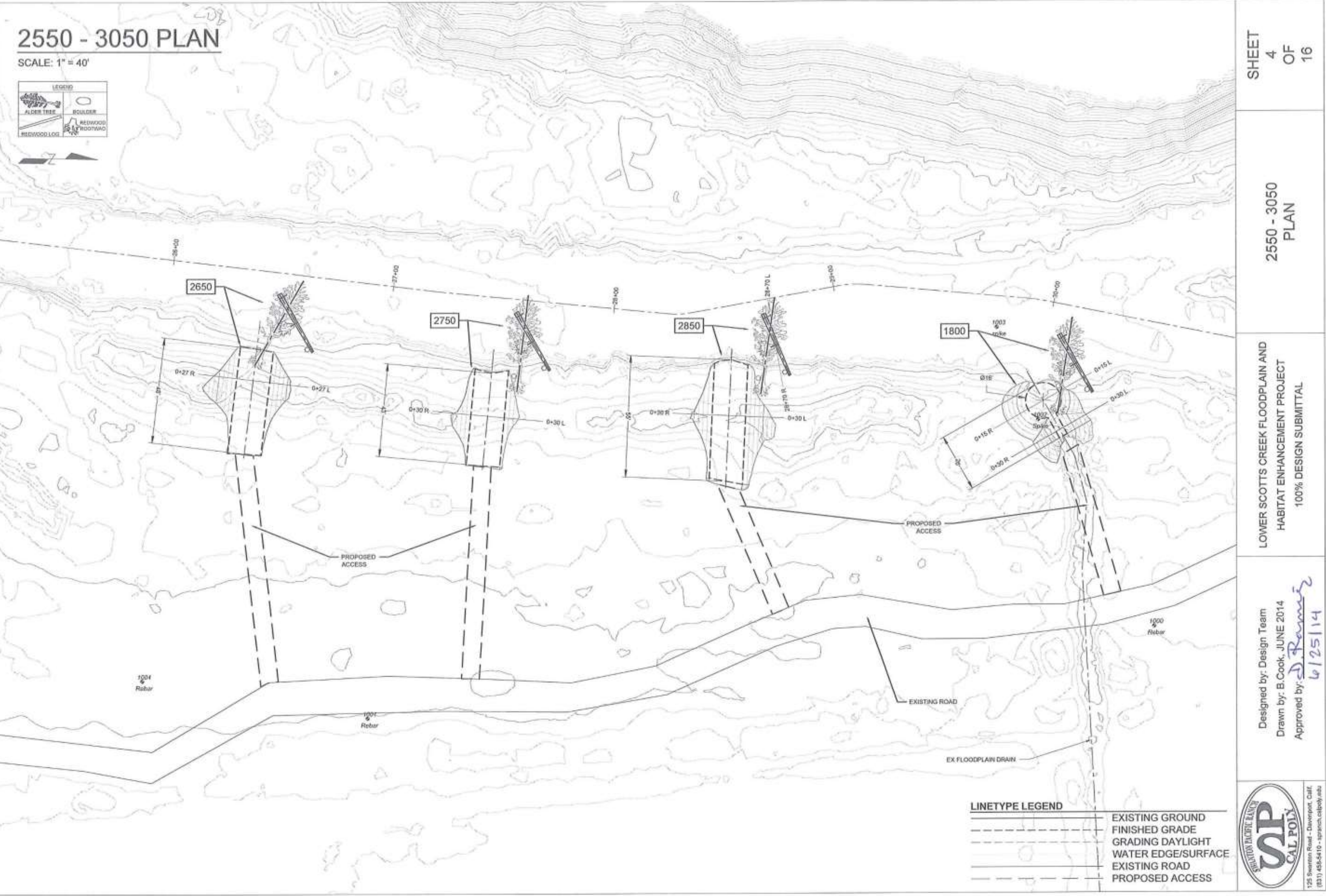




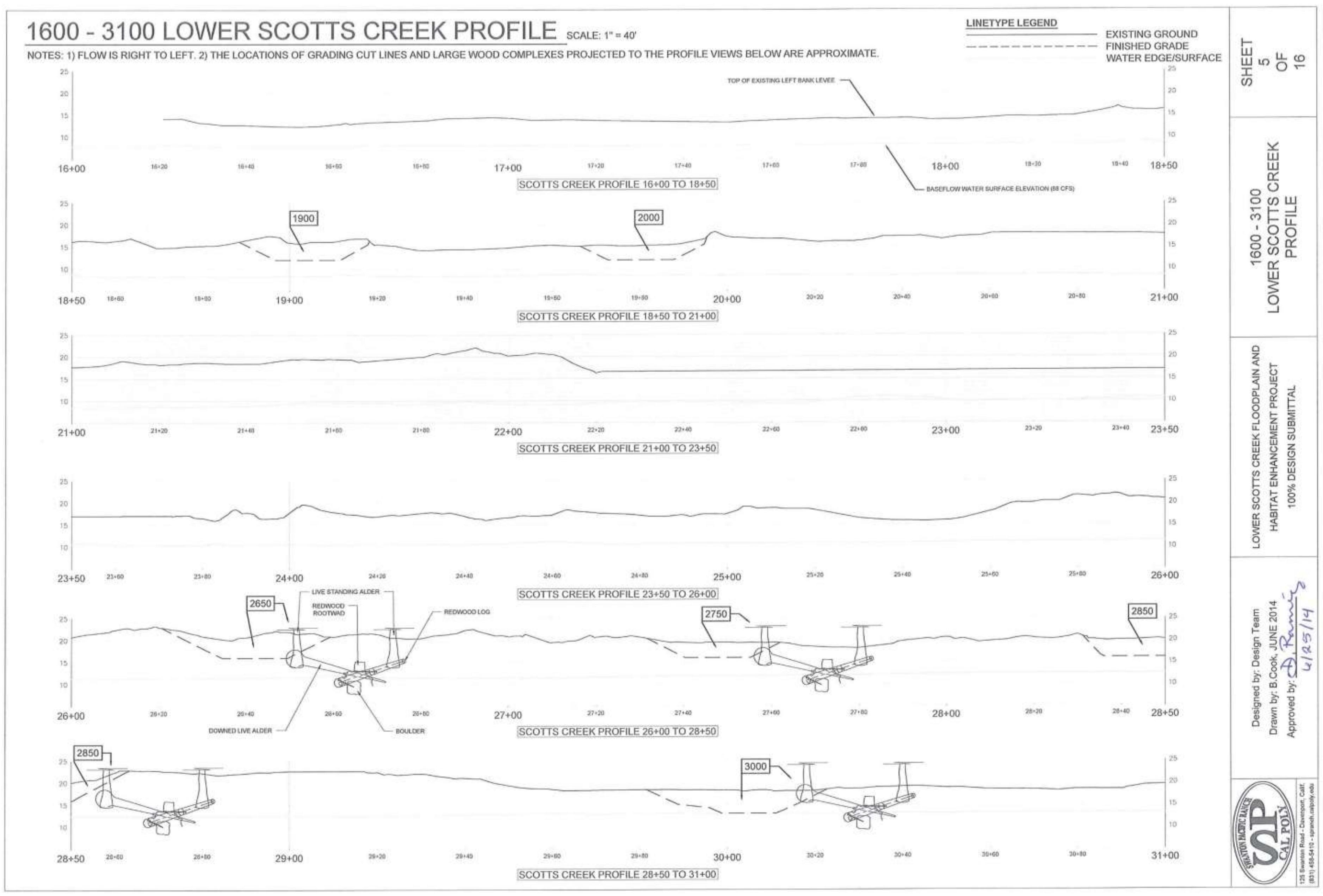



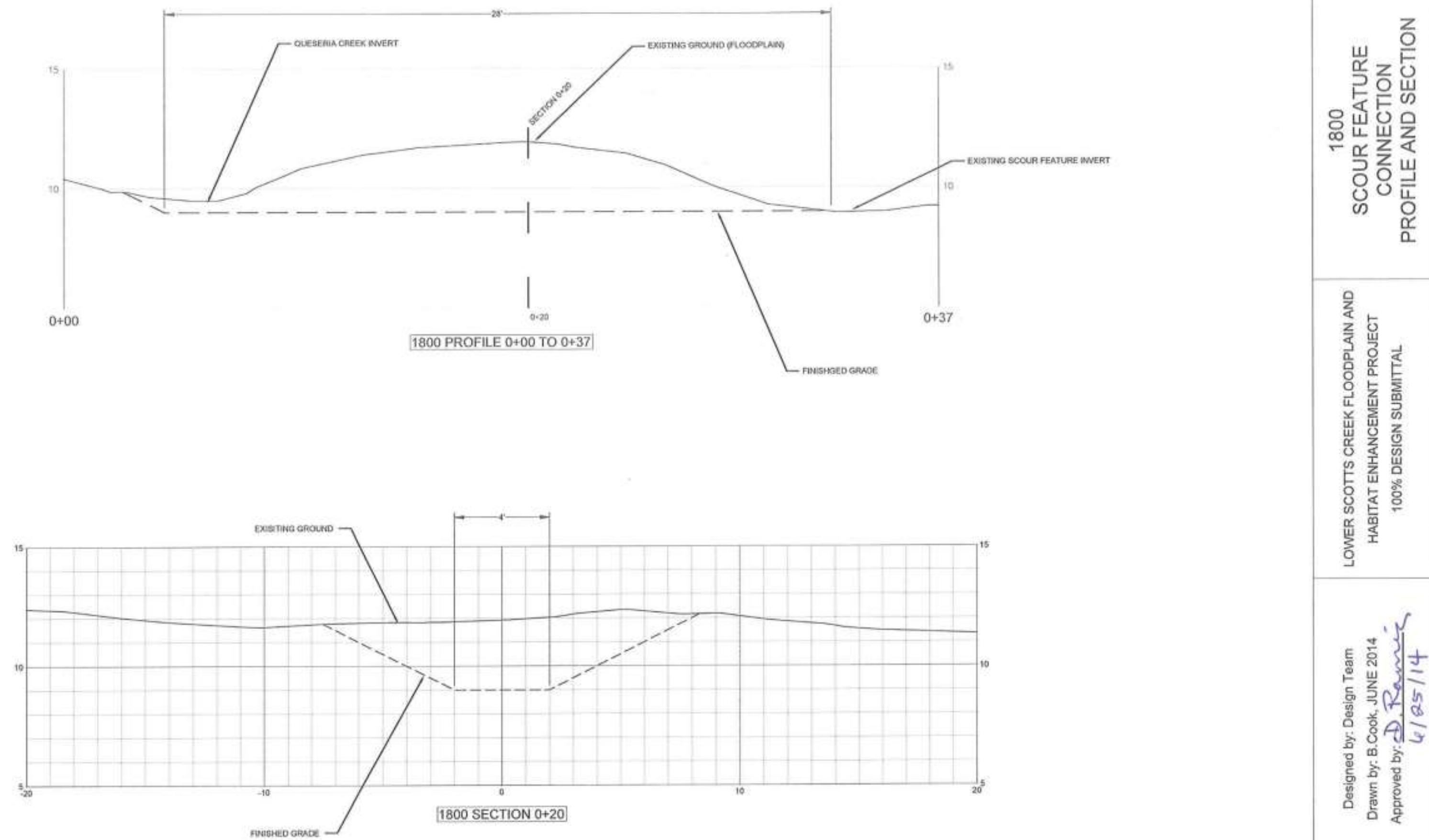

1. LWC NOT SHOWN ON THIS SHEET. SEE LWC TYPICAL (SHEET 13) AND LOWER SCOTTS CREEK PROFILE (SHEET 5) FOR LWC PLAN, PROFILE AND SECTION VIEWS 2. EG SURFACE MAY NOT REPRESENT ACTUAL CONDITIONS. ALL CONSTRUCTED FEATURES WILL BE FIELD FIT AT TIME OF CONSTRUCTION

SEE SOIL VOLUME TABLE ON COVER SHEET (SHEET 1) FOR GRADING VOLUME AND AREA

LINETYPELEGEND

5. BOTTOM WIDTH OF CONSTRUCTED CHANNEL IS $15^{\prime}$ UNLESS OTHERWISE SPECIFIED.

. TREAT GRADING ACCORDING TO EROSION CONTROL AND REVEGETATION TYPICAL (SHEET 16).

DEWATER ACCORDING TO DIVER 


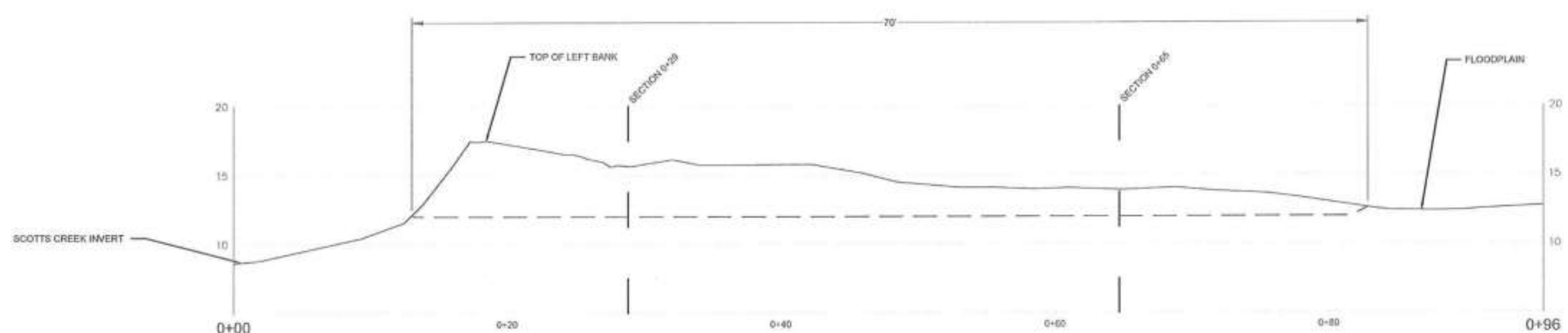

1900 PROFILE $0+00$ TO $0+96$
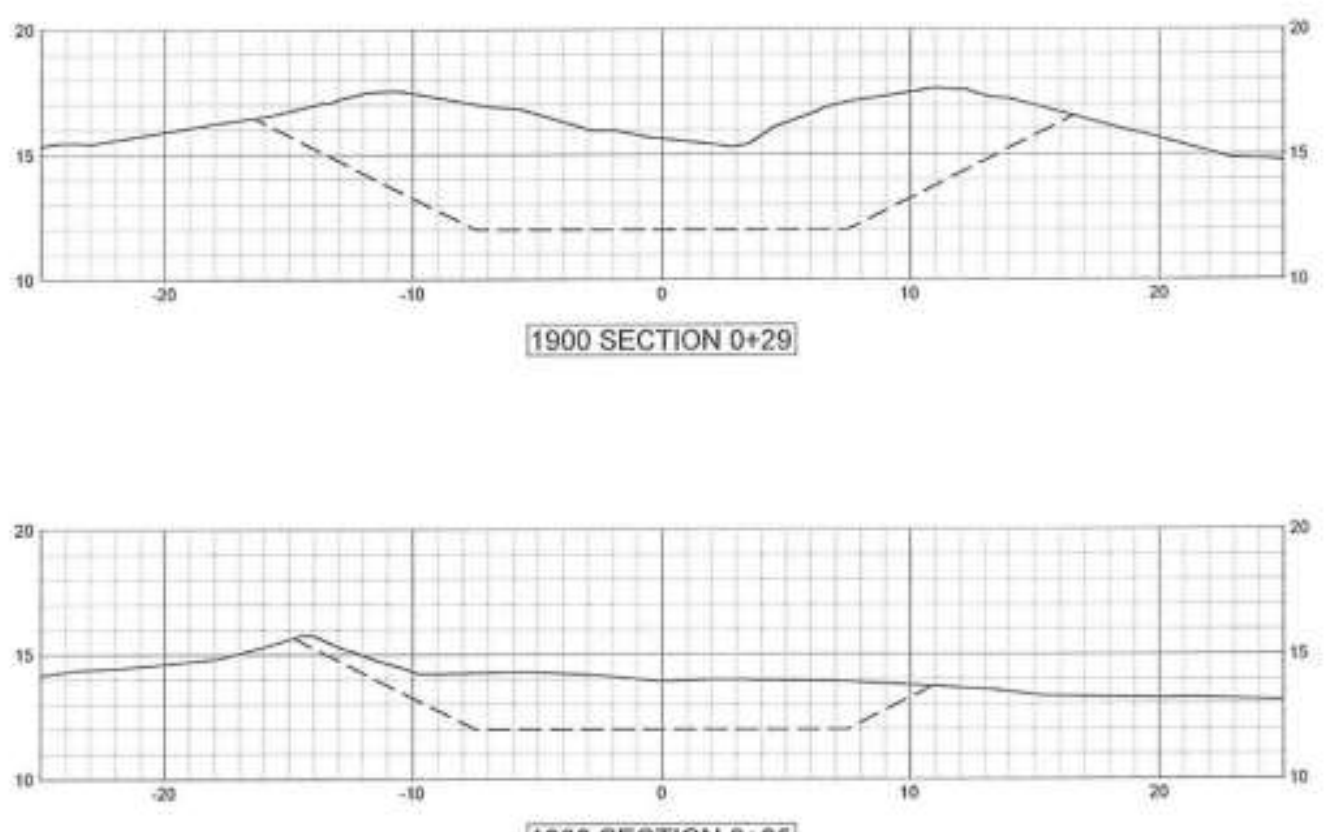

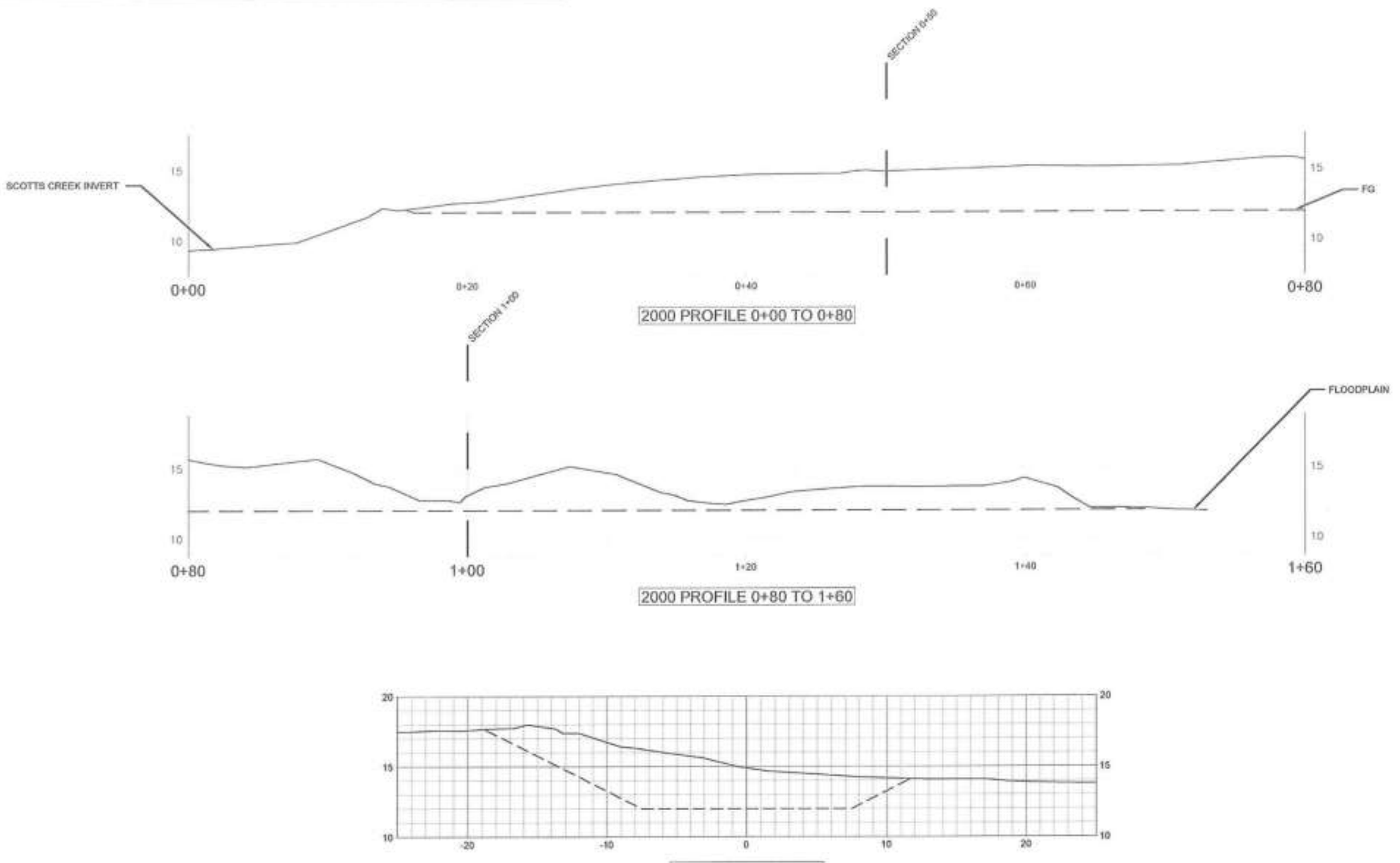

2000 SECTION $0+50$

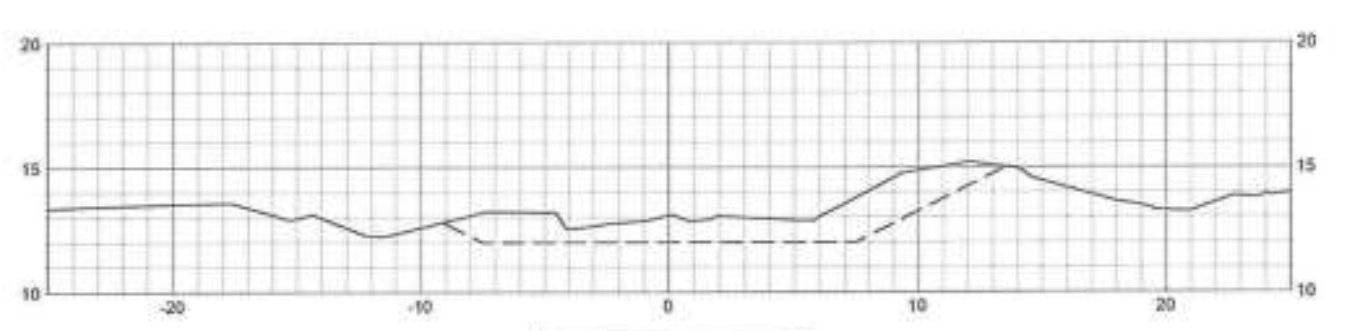

2000 SECTION $1+00$

NOTES 1 . LWC NOT SHOWN ON THIS SHEET. SEE LWC TYPICAL (SHEET 13) AND LOWER SCOTTS CREEK PROFILE (SHEET 5) FOR LWC PLAN. PROFILE AND SECTION VIEWS

2. EG SURFACE MAY NOT REPRESENT ACTUAL CONDITIONS. ALL CONSTRUCTED FEATURES WILL BE FIELD FIT AT TIME OF CONSTRUCTION

3. SEE SOIL VOLUME TABLE ON COVER SHEET (SHEET 1) FOR GRADING VOLUME AND AREA

5. BOTTOM WIDTH OF CONSTRUCTED CHANNEL IS 15 ' UNLESS OTHERWISE SPECIFIED.

TREAT GRADING ACCORDNG TOEROSION CONTROL AND REVEGETATION TYPICAL (SHEET 16).

O SHALL OCCUR. CONSTRUCT SILT FENCE AS NEEDED BETWEEN CONSTRUCTION 


\section{GRADING PROFILE AND SECTIONS}

\section{SCALE: $1 "=5$}
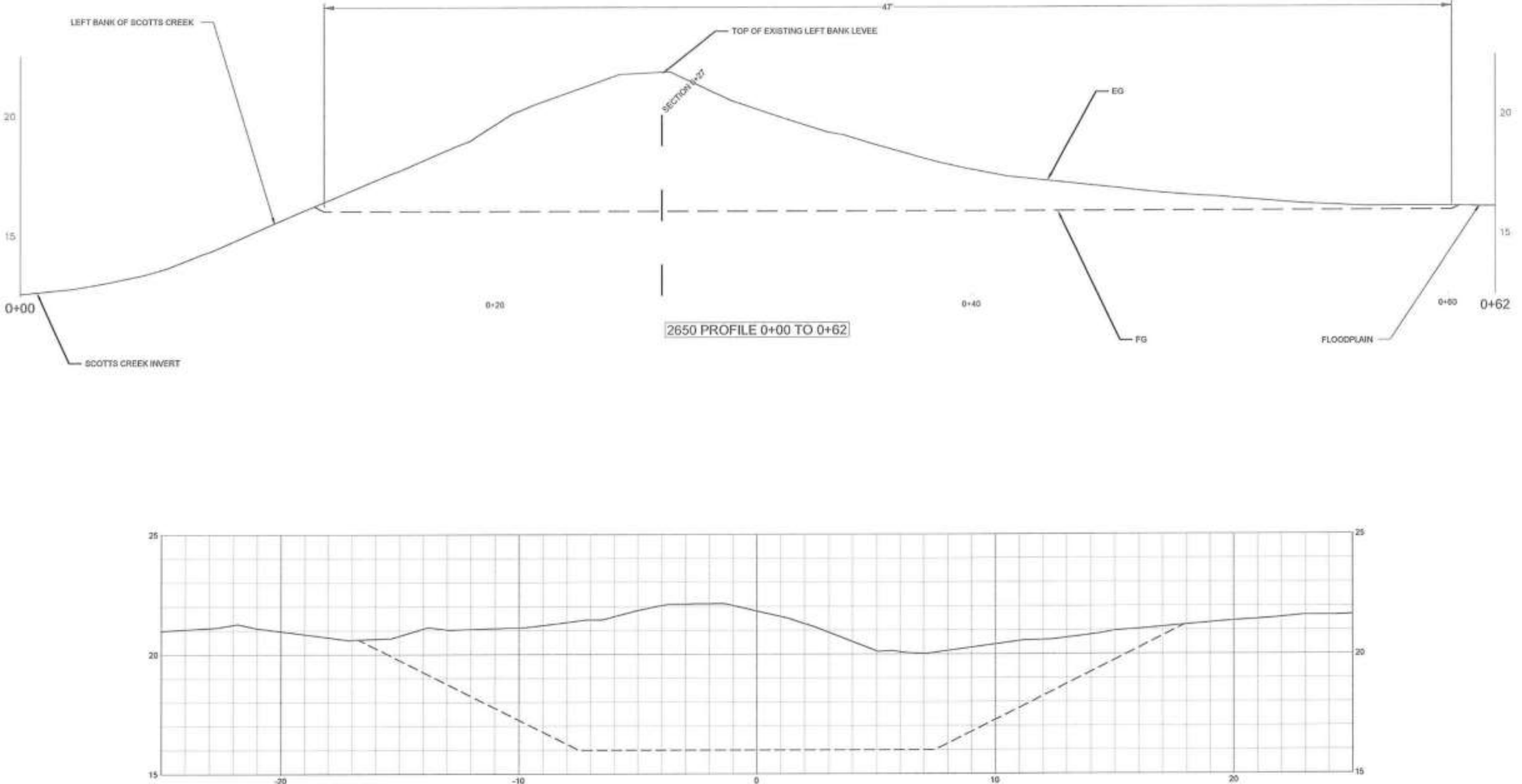

2650 SECTION $0+27$

LWC NOT SHOWN ON THIS SHEET. SEE LWC TYPICAL (SHEET 13) AND LOWER SCOTTS CREEK PROFILE (SHEET 5) FOR LWC PLAN, PROFILE AND SECTION VIEWS. 2. EG SURFACE MAY NOT REPRESENT ACTUAL CONDITIONS. ALL CONSTRUCTED FEATURES WILL BE FIELD FIT AT TIME OF CONSTRUCTION. 3. SEE SOIL VOLUME TABLE ON COVER SHEET (SHEET 1) FOR GRADING VOLUME AND AREA

5. BOTTOM WIDTH OF CONSTRUCTED CHANNEL IS $15^{\circ}$ UNLESS OTHERWISE SPECIFIED. 

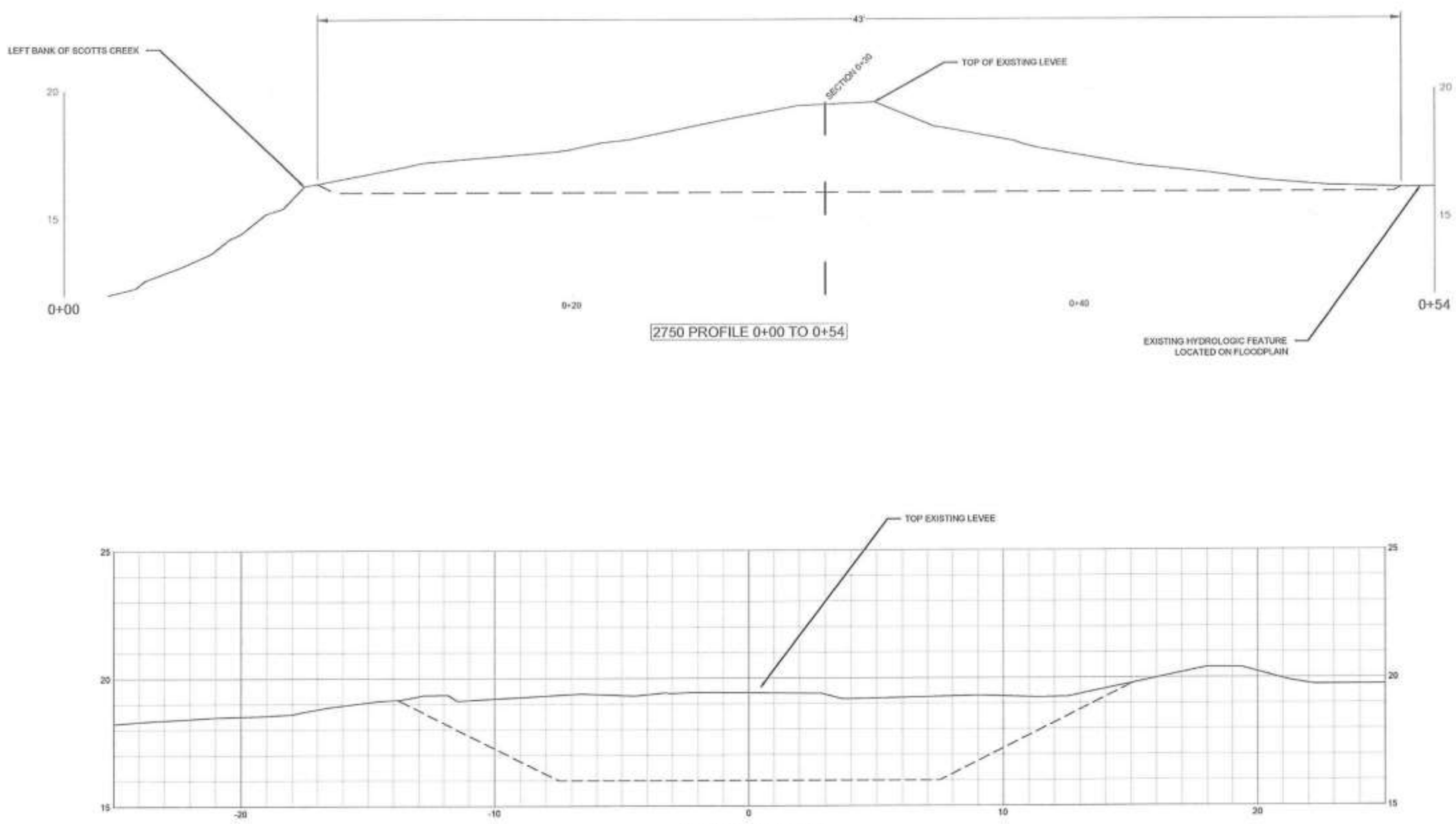

2750 SECTION $0+30$ 

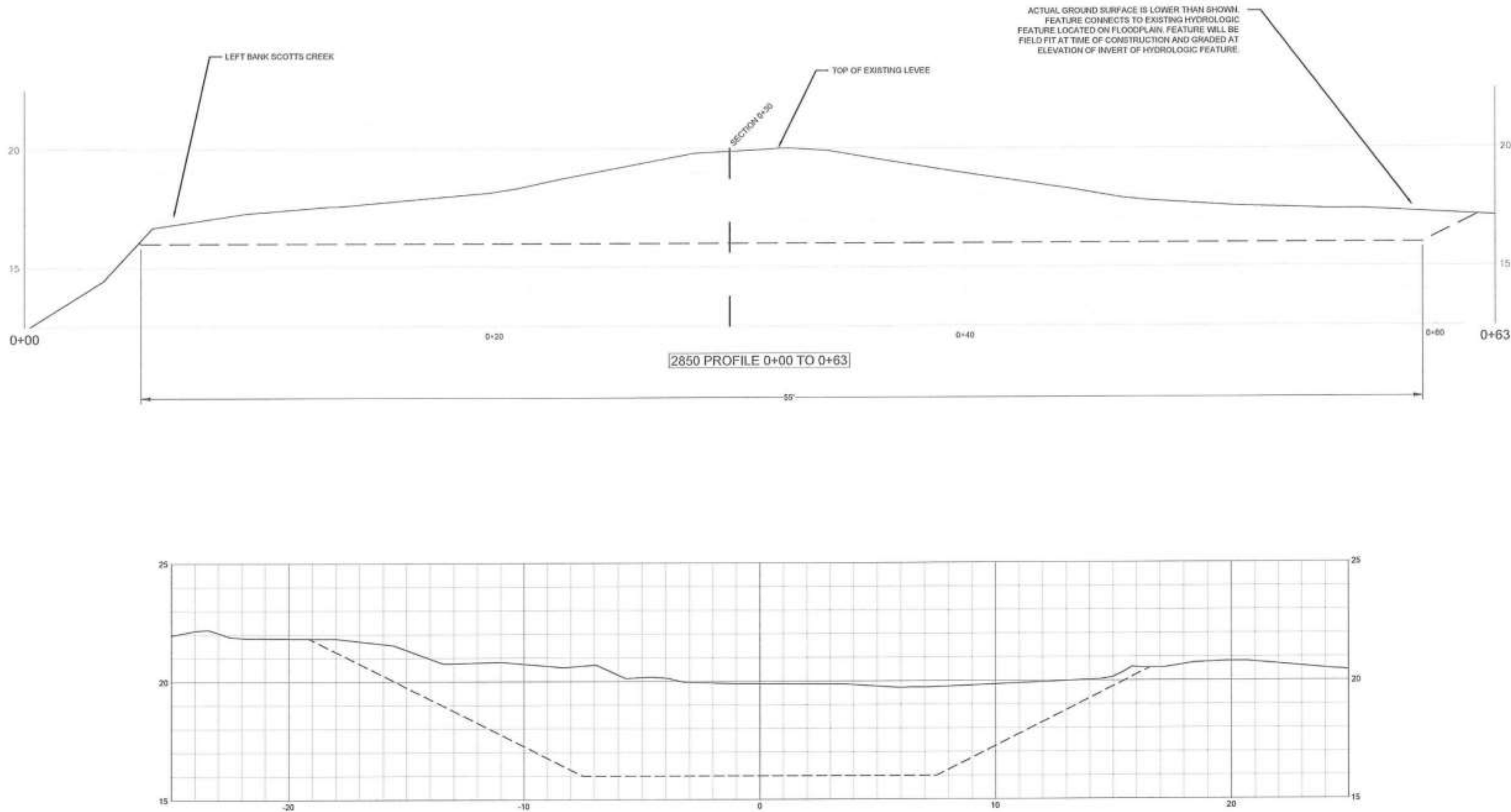

2850 SECTION $0+30$

1. LWC NOT SHOWN ON THIS SHEET. SEE LWC TYPICAL (SHEET 13) AND LOWER SCOTTS CREEK PROFILE (SHEET 5) FOR LWC PLAN, PROFILE AND SECTION VIEWS.

2. EG SURFACE MAY NOT REPRESENT ACTUAL CONDITIONS. ALL CONSTRUCTED FEATURES WILL BE FIELD FIT AT TIME OF CONSTRUCTION

3. SEE SOIL VOLUME TABLE ON COVER SHEET (SHEET 1) FOR GRADING VOLUME AND AREA

5. BOTTOM WIDTH OF CONSTRUCTED CHANNEL IS $15^{\prime}$ UNLESS OTHERWISE SPECIFIED. 


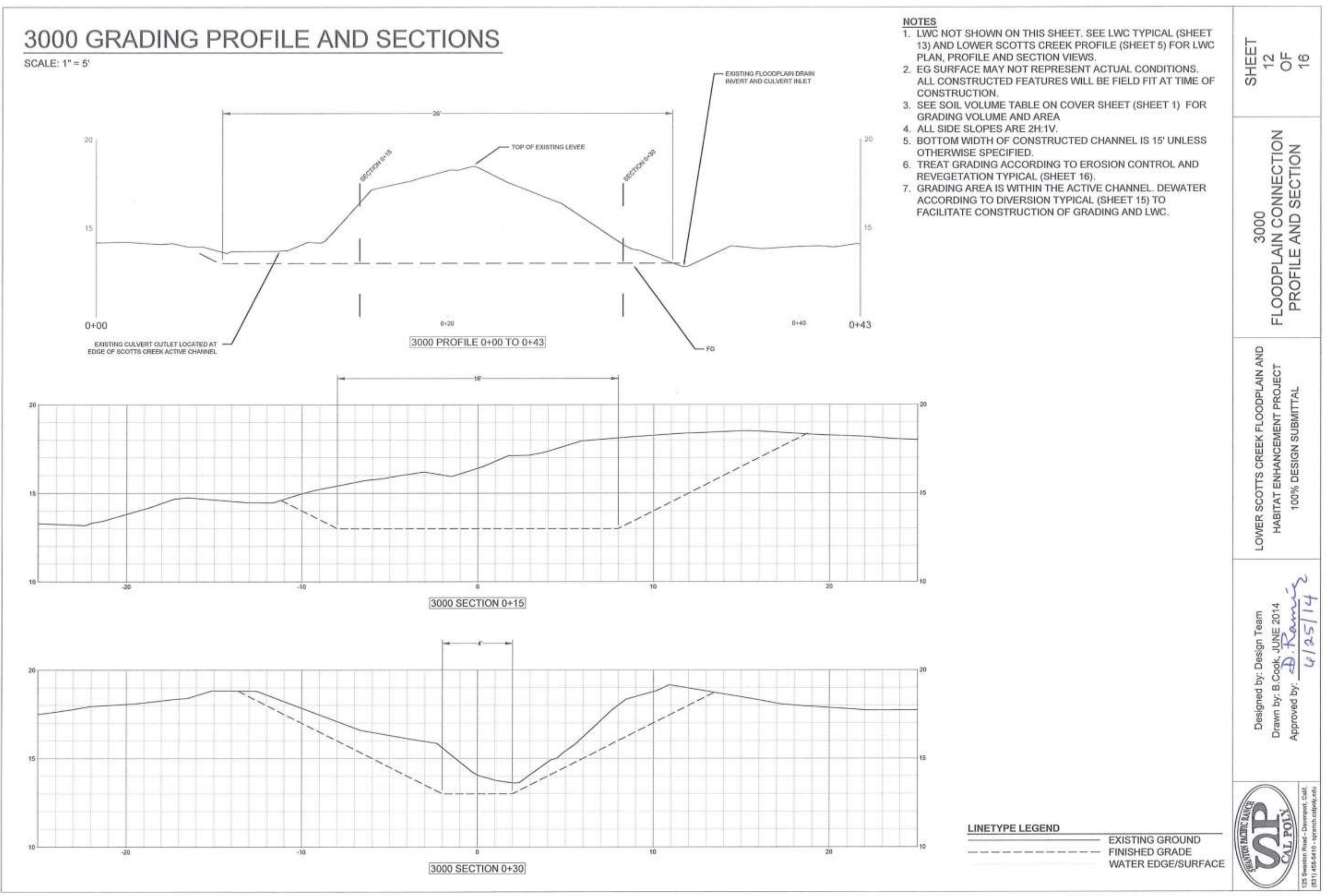




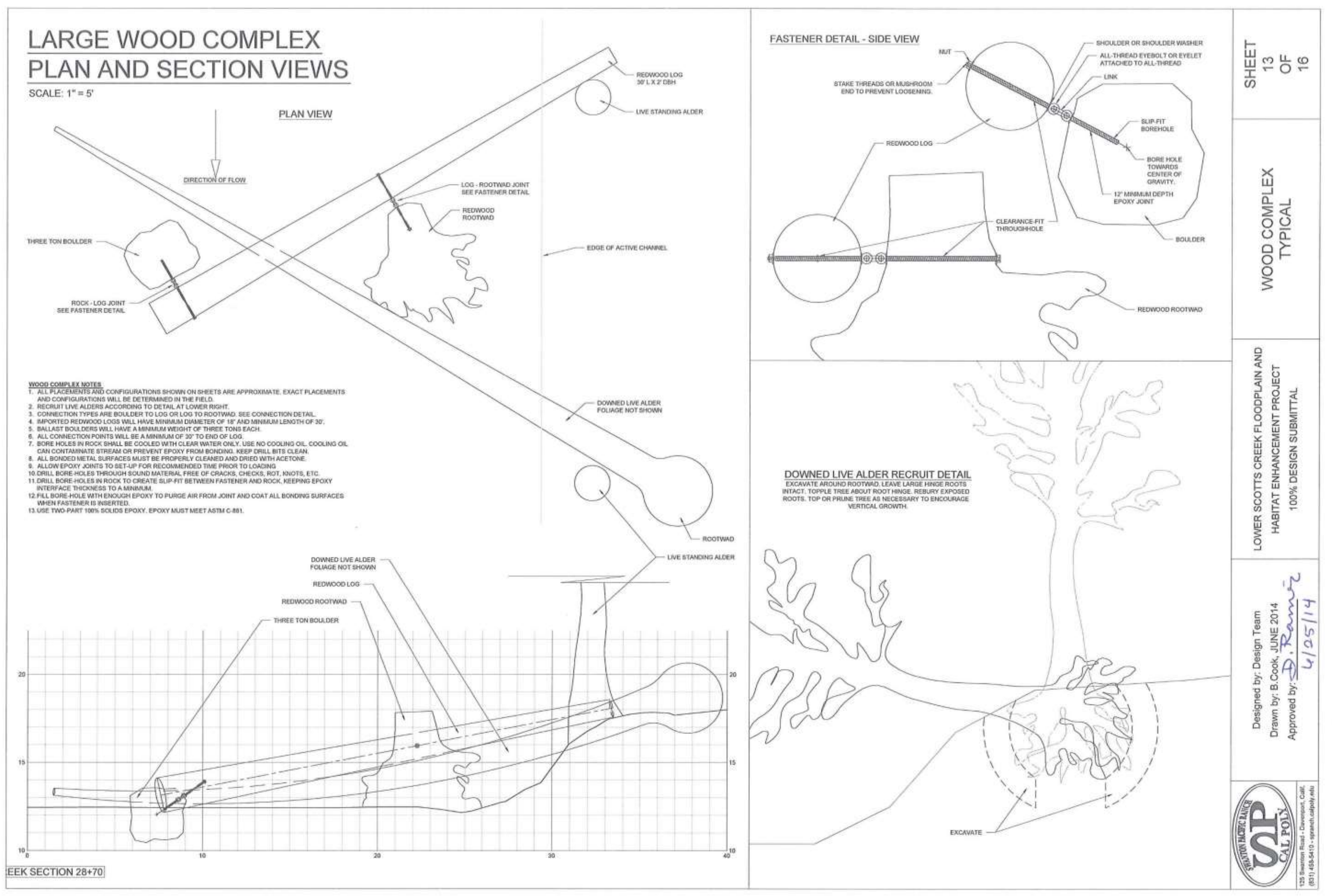




\section{Lower Scotts Creek Revegetation Plant Palette}

\begin{tabular}{|c|c|c|c|}
\hline Common Name & Species & Function & Location \\
\hline \multicolumn{4}{|l|}{ Trees } \\
\hline Box Elder & Acer negundo & ss, S, C & RC \\
\hline Red Alder & Alnus rubra & ss, s & $\mathrm{RC}$ \\
\hline Red Elderberry & Sambucus racemosa var. racemosa & ss, s, C & $\mathrm{RC}$ \\
\hline Blue Elderberry & Sambucus nigra subsp. caerulea & Ss, S, C & $\mathrm{RC}$ \\
\hline Shining willow & Salix lasiandra var. lasiandra & SS, S, C & $\mathrm{FP}, \mathrm{RC}$ \\
\hline Arroyo willow & Salix lasiolepis & ss, S, C & FP, RC \\
\hline Creek Dogwood & Cornus sericea & Ss, S, C & FP, RC \\
\hline \multicolumn{4}{|l|}{ Grasses } \\
\hline Beardless wild rye & Elymus triticoides & EC & $\mathrm{RC}$ \\
\hline \multicolumn{4}{|l|}{ Rushes } \\
\hline Brown rush & Juncus hesperius & SS, EC & FPA \\
\hline Spreading rush & Juncus patens & SS, EC & FPA \\
\hline Pacific rush & Juncus effusus subsp. pacificus & SS, EC & FPA \\
\hline \multicolumn{4}{|l|}{ Sedges } \\
\hline Bigleaf sedge & Carex amplifolia & SS, EC & FPA \\
\hline Barberpole sedge & Scirpus microcarpus & SS, EC & FP, RC \\
\hline Cyperus & Cyperus eragrostis & SS, EC & FP, RC \\
\hline Slough sedge & Carex obnupta & SS, EC & FP, RC \\
\hline \multicolumn{4}{|l|}{ Shrubs } \\
\hline Salmonberry & Rubus spectabilis & $\mathrm{EC}$ & $\mathrm{RC}$ \\
\hline Blackberry & Rubus ursinus & EC & RC \\
\hline Thimbleberry & Rubus parviflorus & EC & $\mathrm{RC}$ \\
\hline Woodland strawberry & Fragaria vesca & EC & $\mathrm{RC}$ \\
\hline Straggly gooseberry & Ribes divaricatum var, pubiflorum & EC & $\mathrm{RC}$ \\
\hline California rose & Rosa californica & EC & $\mathrm{RC}$ \\
\hline California hedge-nettle & Stachys bullata & EC & RC \\
\hline American stinging netlle & Urtica dioica subsp. & $\mathrm{EC}$ & RC \\
\hline California figwart & Scrophularia californica & $\mathrm{EC}$ & RC \\
\hline Douglas' nightshade & Solanum douglasii & EC & RC \\
\hline Golden yarrow & Eriophyllum confertiflorum & EC & $\mathrm{RC}$ \\
\hline \multicolumn{4}{|l|}{ Ferns } \\
\hline Lady fern & Athyrium felix-femina var. cyclosorum & EC & $\mathrm{RC}$ \\
\hline Giant chain fern & Woodwardia fimbriata & EC & $\mathrm{RC}$ \\
\hline Sword fern & Polystichum munitum & $\mathrm{EC}$ & RC \\
\hline Wood fern & Dryopteris arguta & EC & RC \\
\hline \multicolumn{4}{|l|}{ Herbs } \\
\hline Common yarrow & Achillea millefolium & EC & $\mathrm{RC}$ \\
\hline \multicolumn{4}{|l|}{ Key: } \\
\hline SS $=$ soil stabilization & $R C=$ riparian corridor & & \\
\hline$E C=$ erosion control & $F P=$ floodplain & & \\
\hline$S=$ shade & $F P A=$ floodprone area & & \\
\hline
\end{tabular}

REVEGETATION AND EROSION CONTROL DETAIL - PLAN VIEW

DDGE OF ACTWE OUWHEL 㟧ே㟔ำ

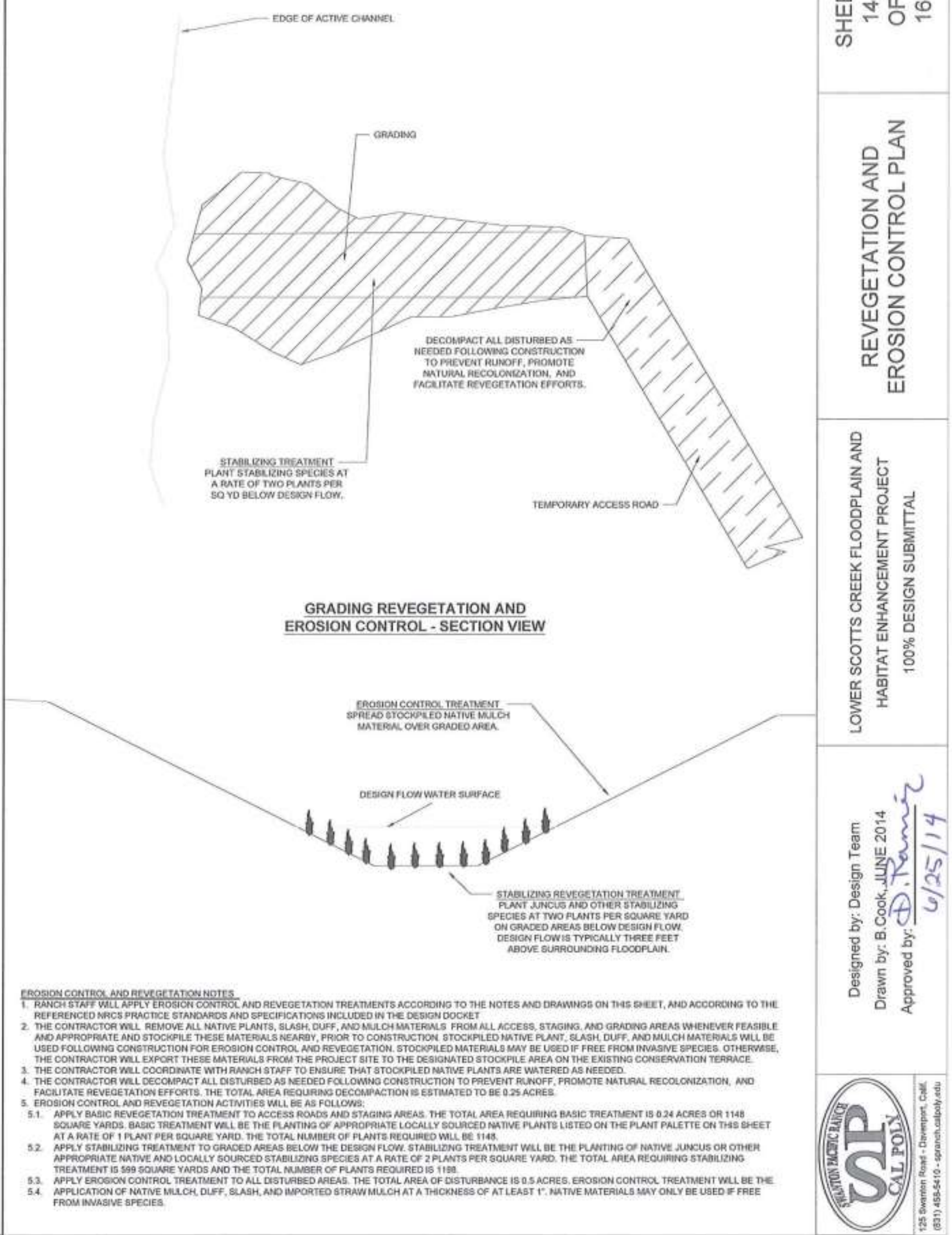




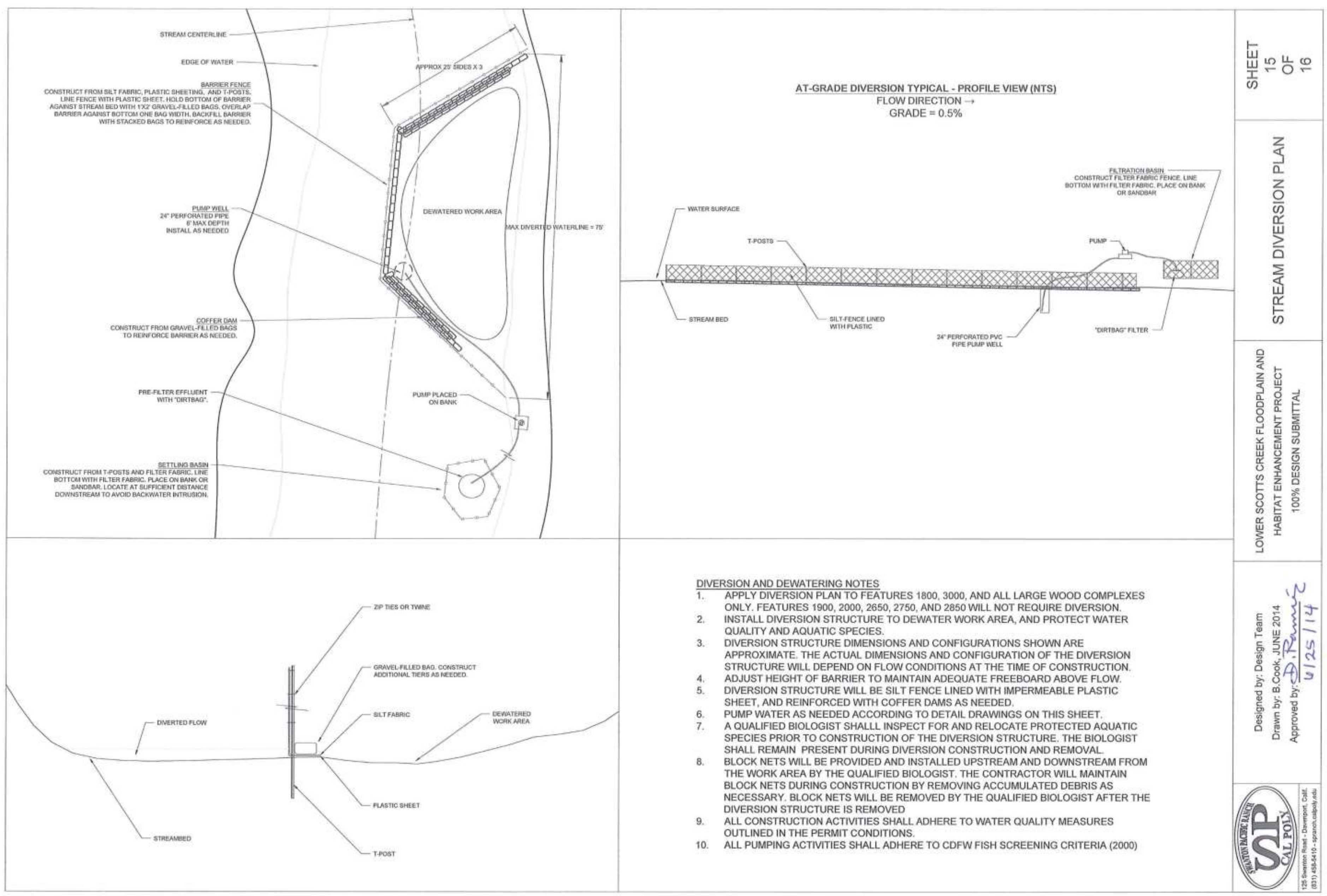




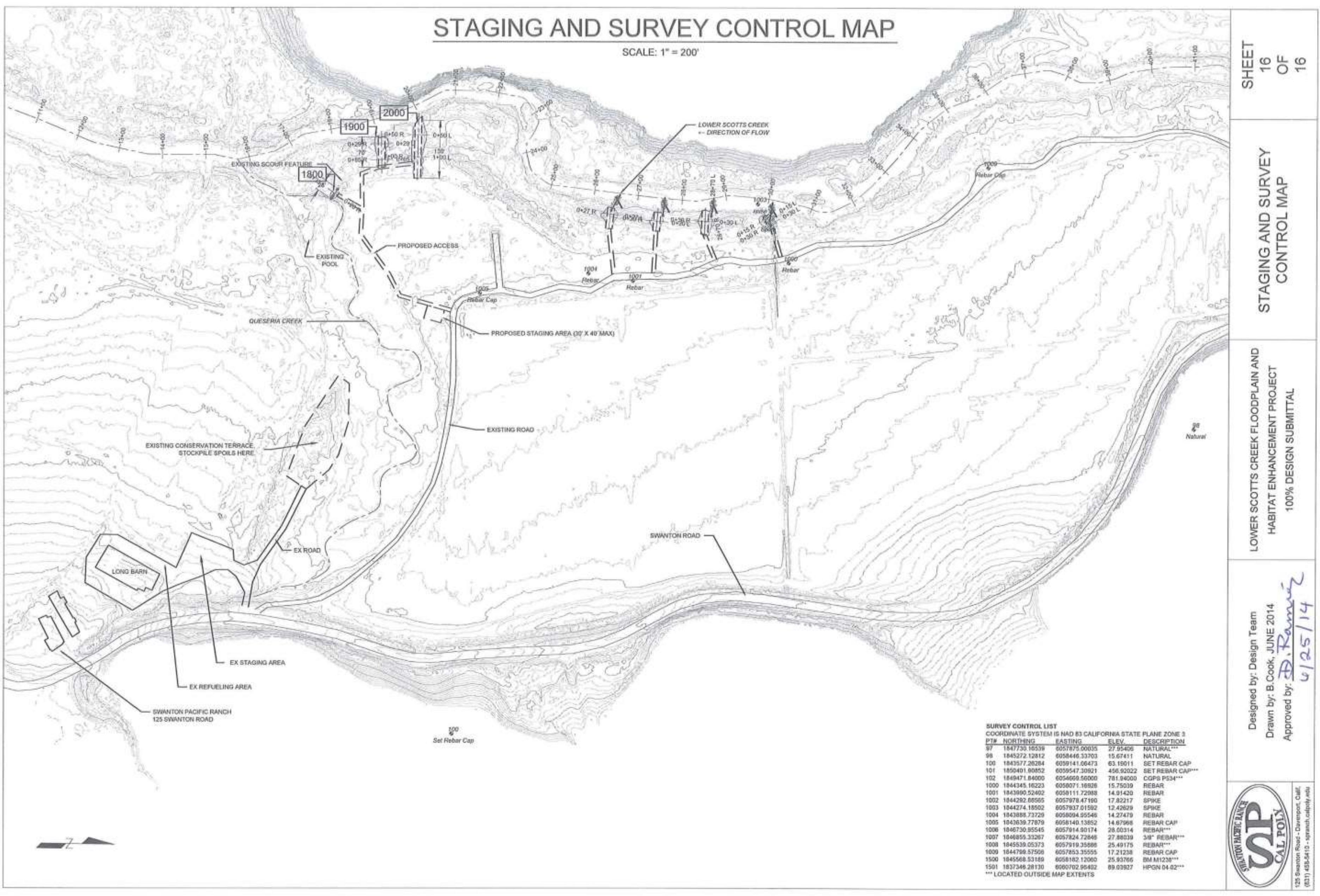


H. PHASE II 100\% DESIGN SUBMITTAL 


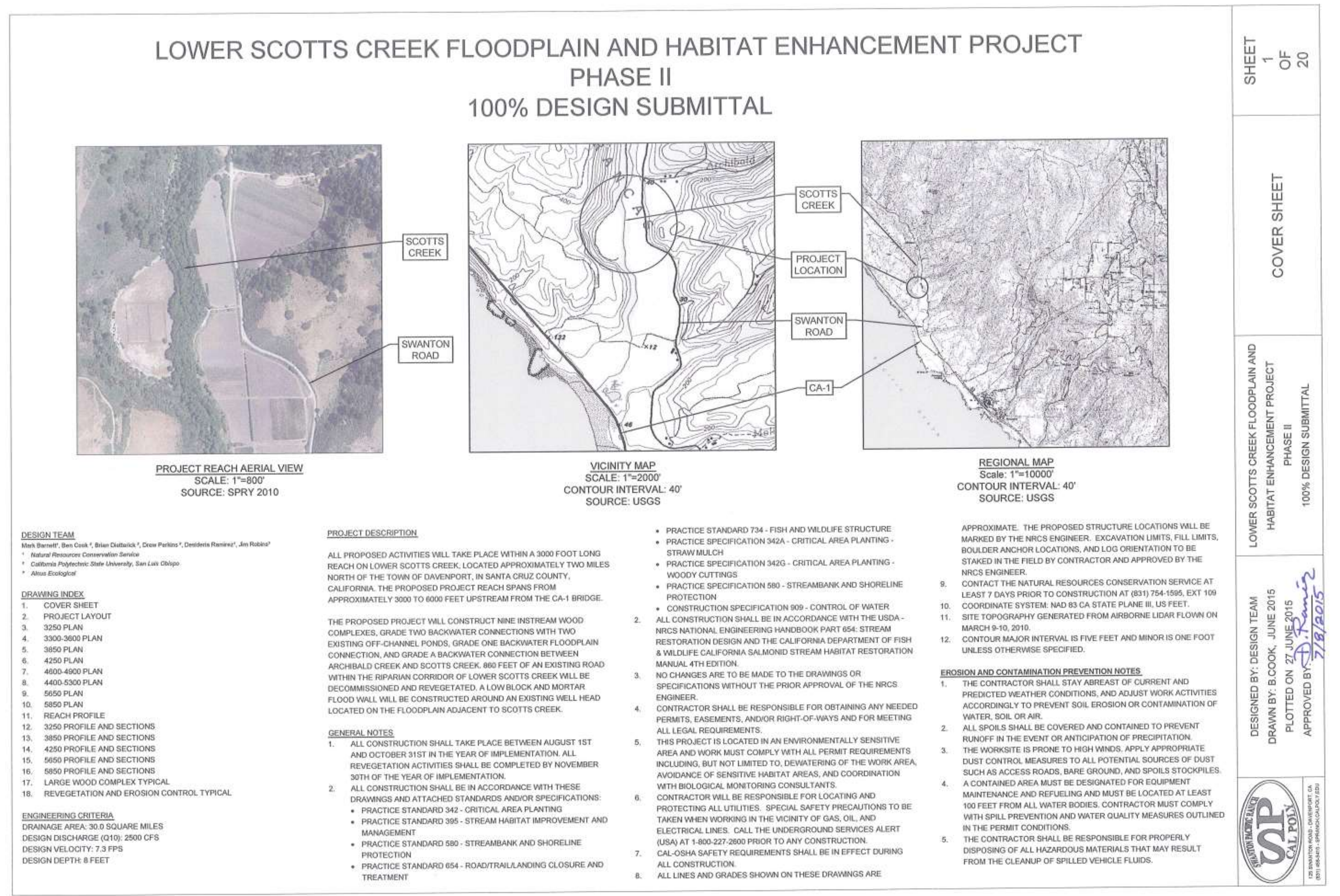




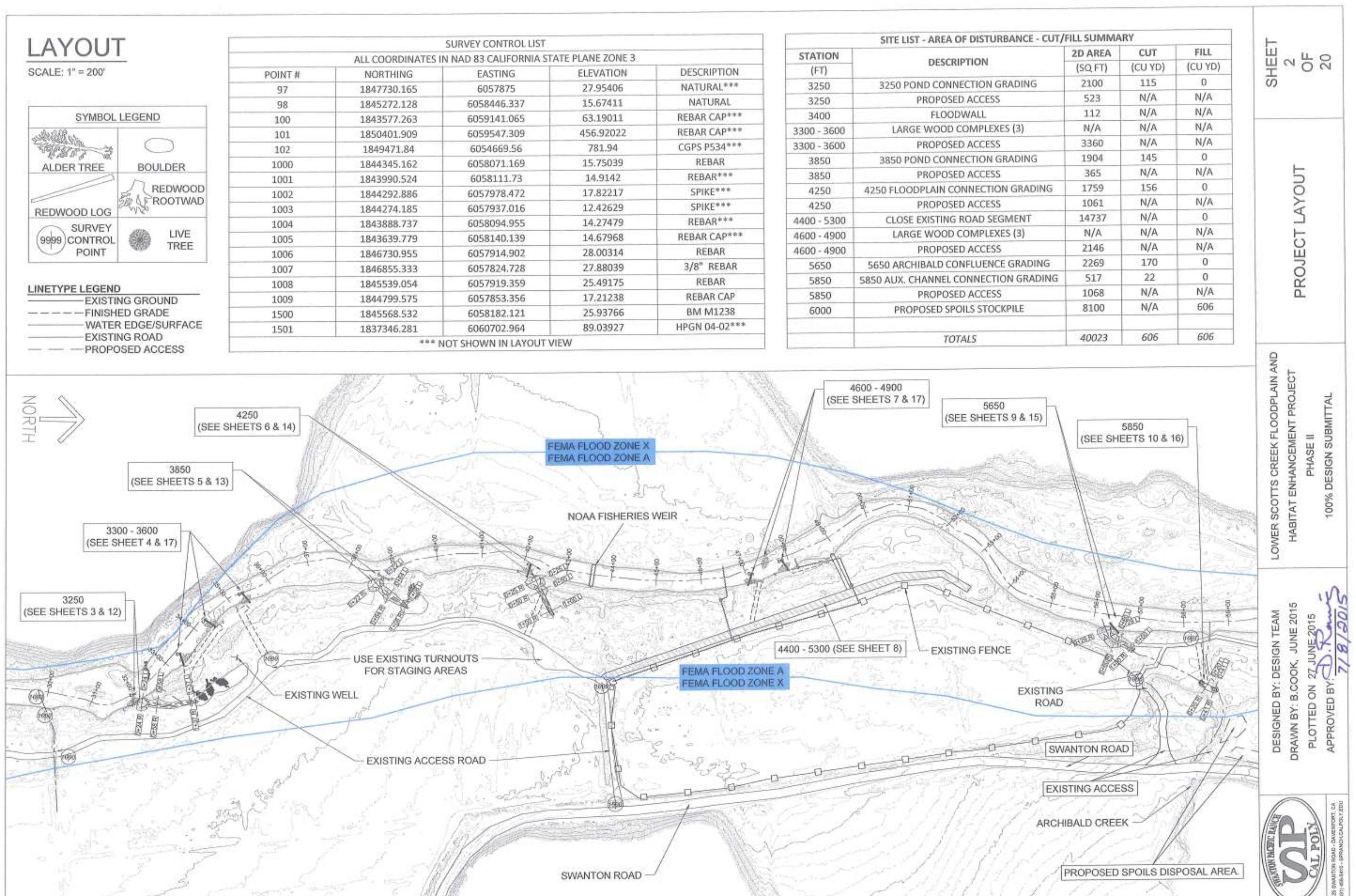




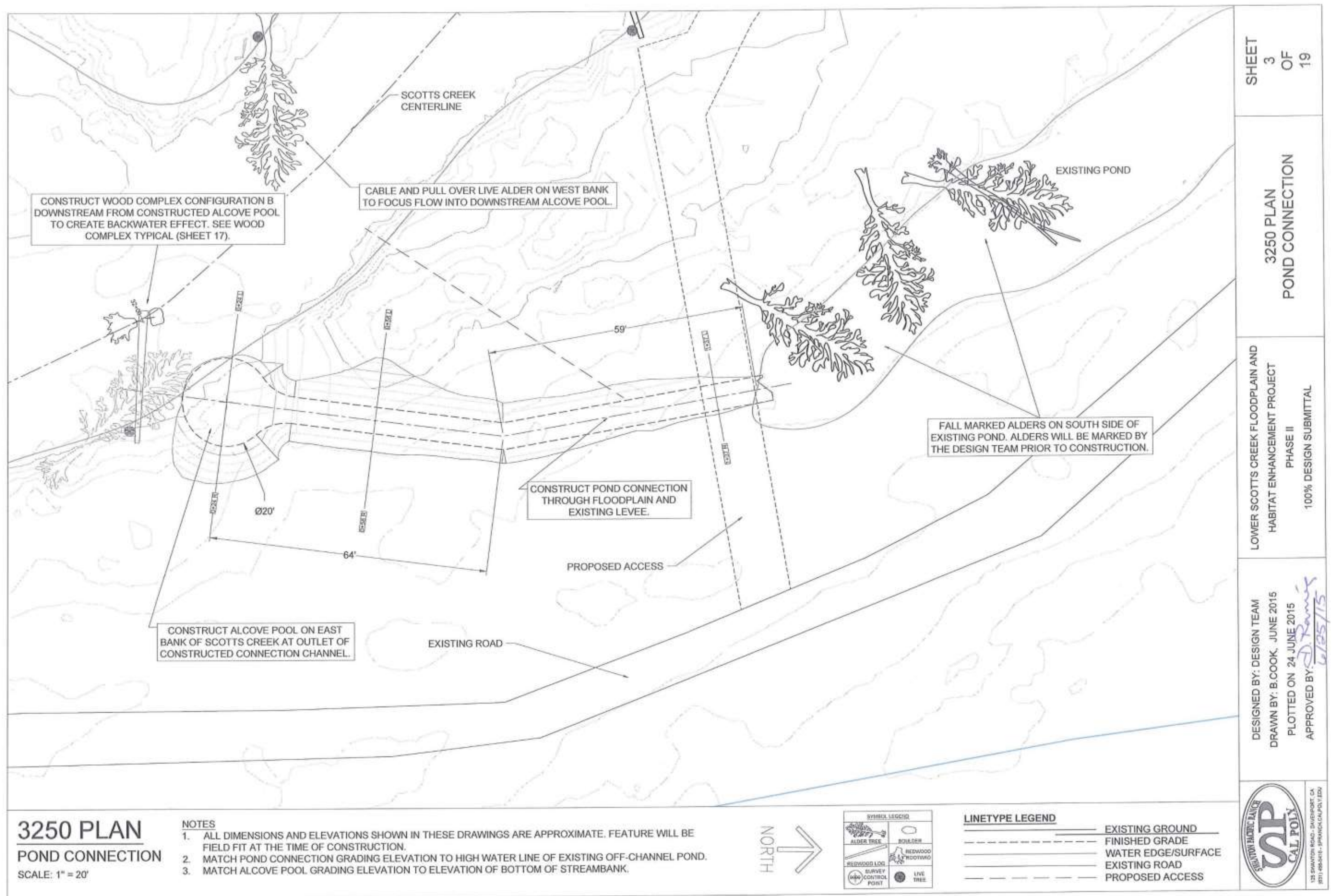




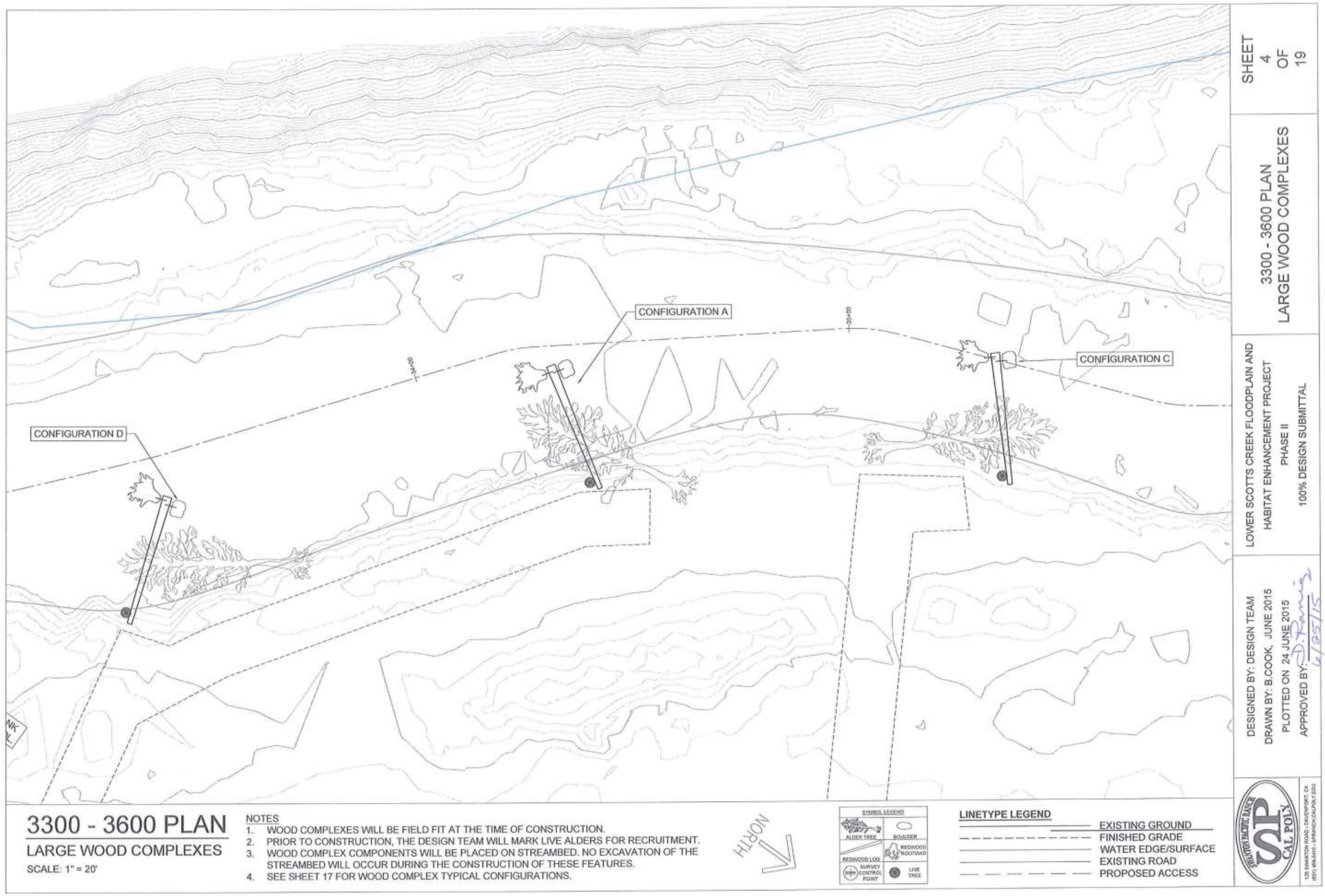




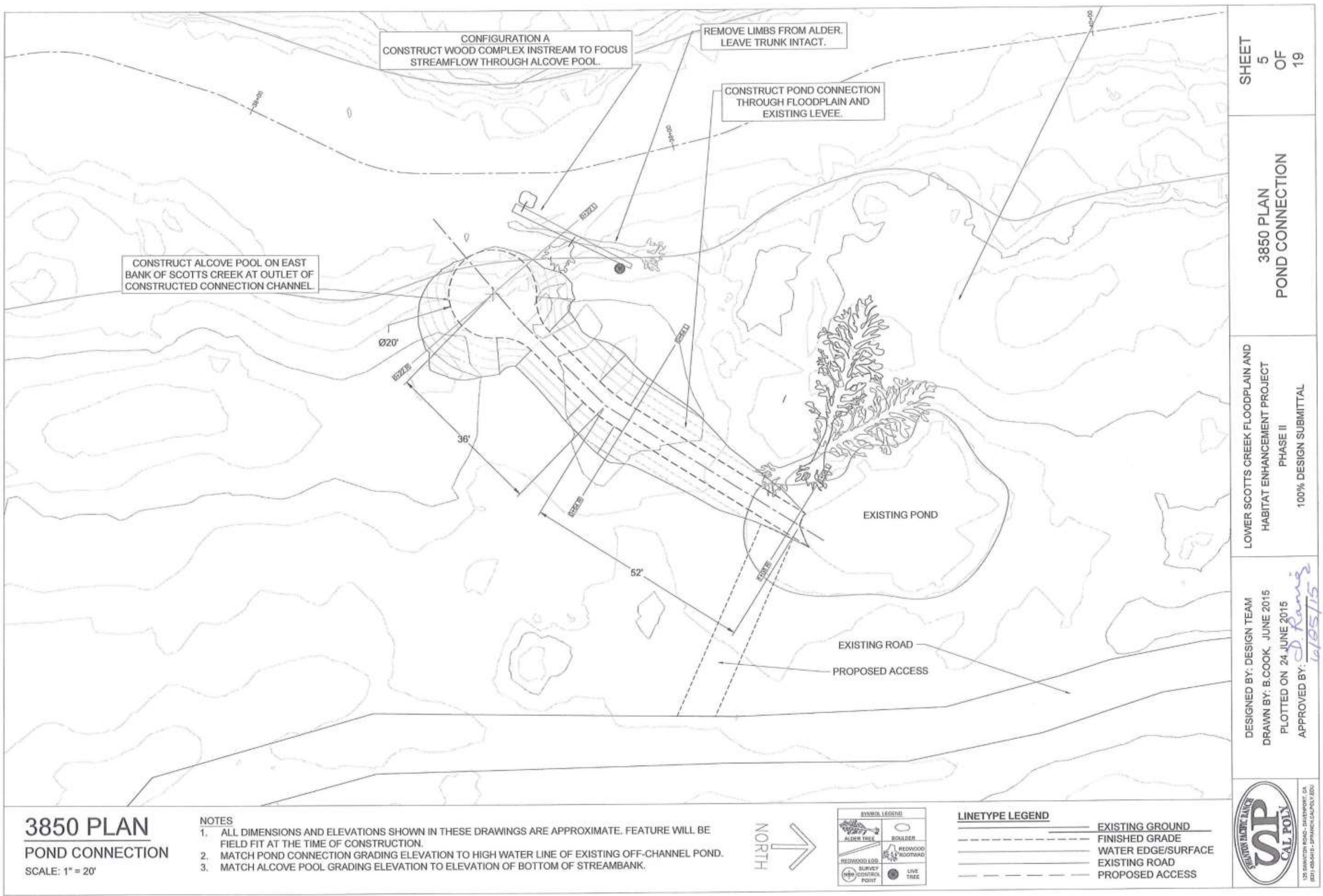




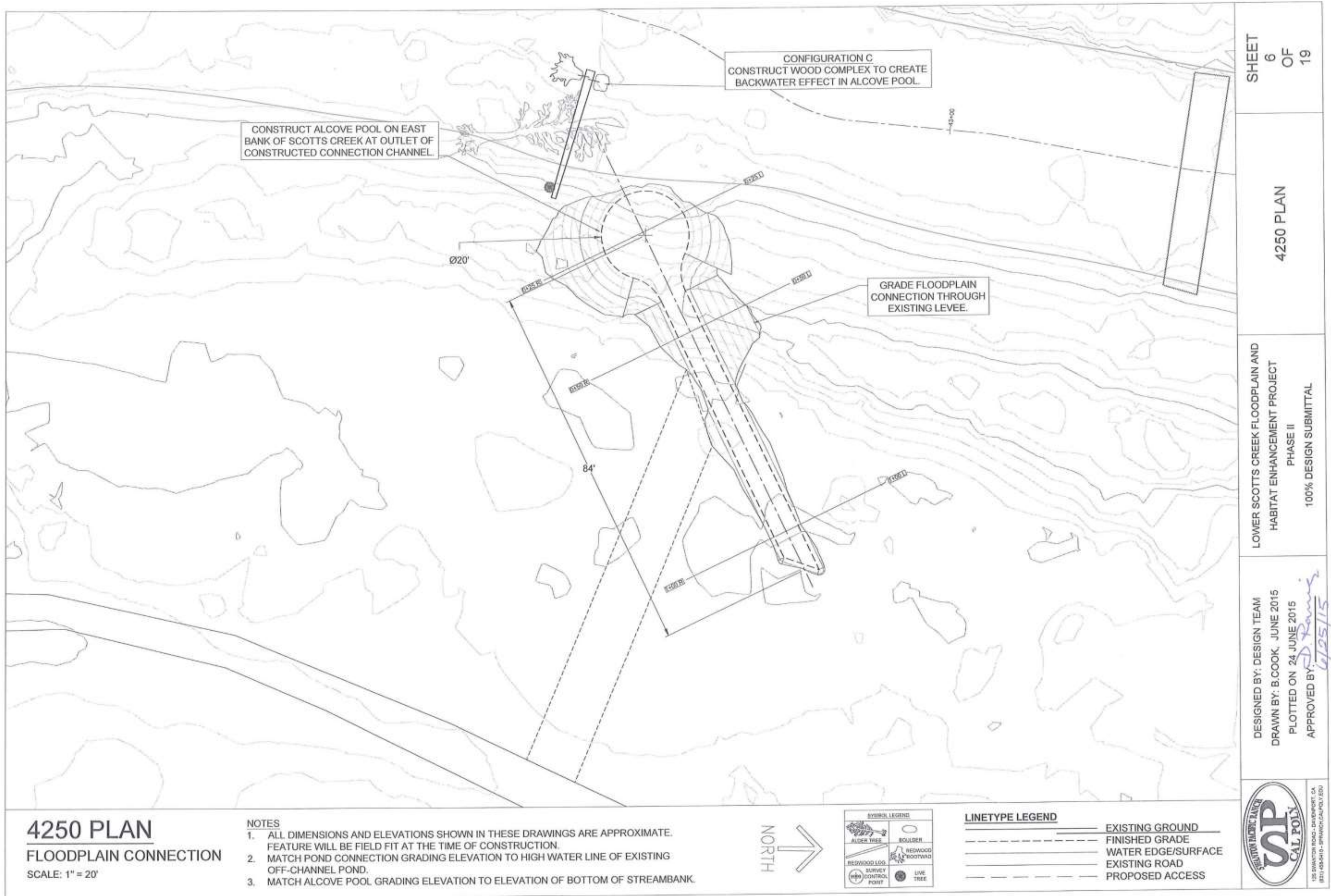




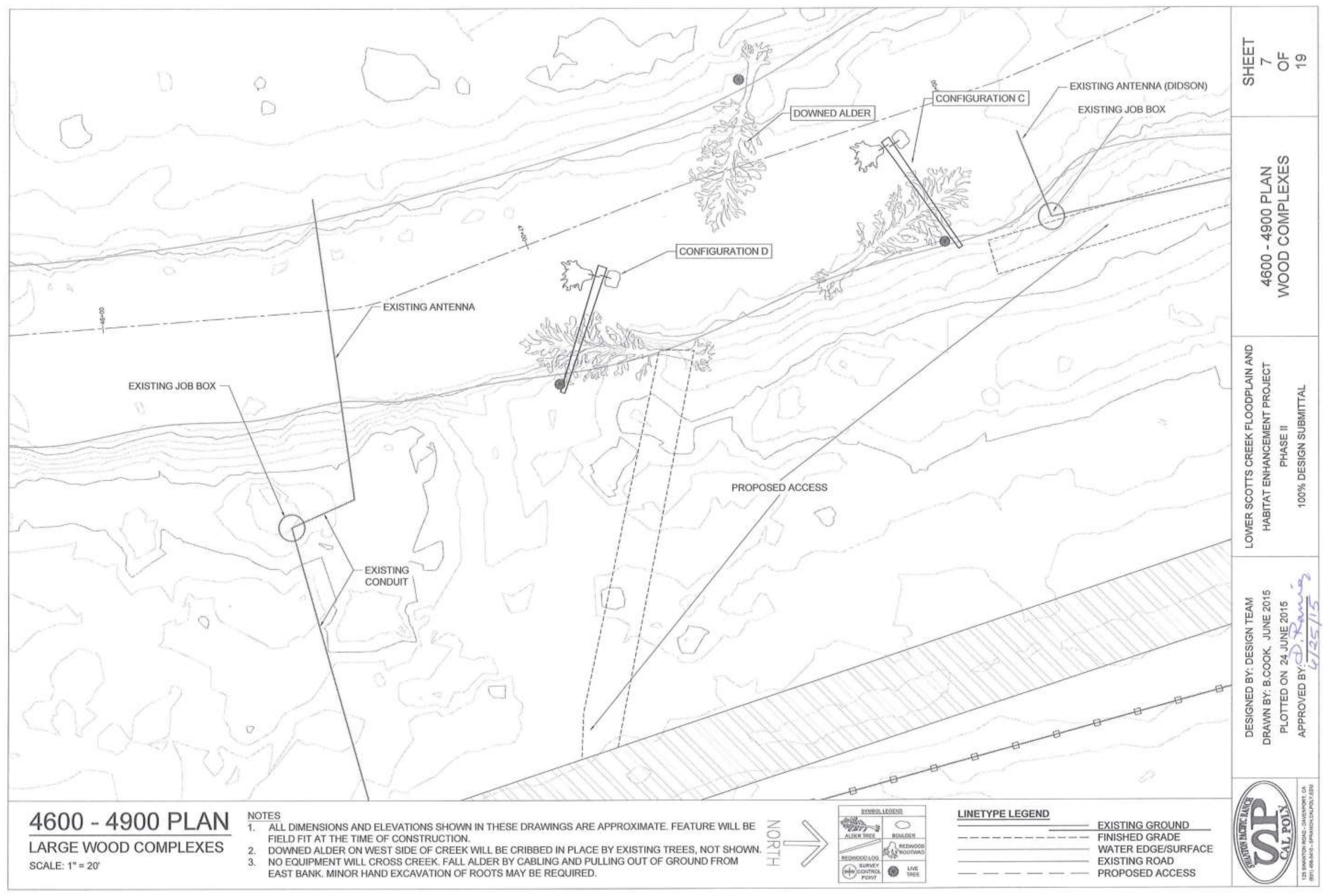




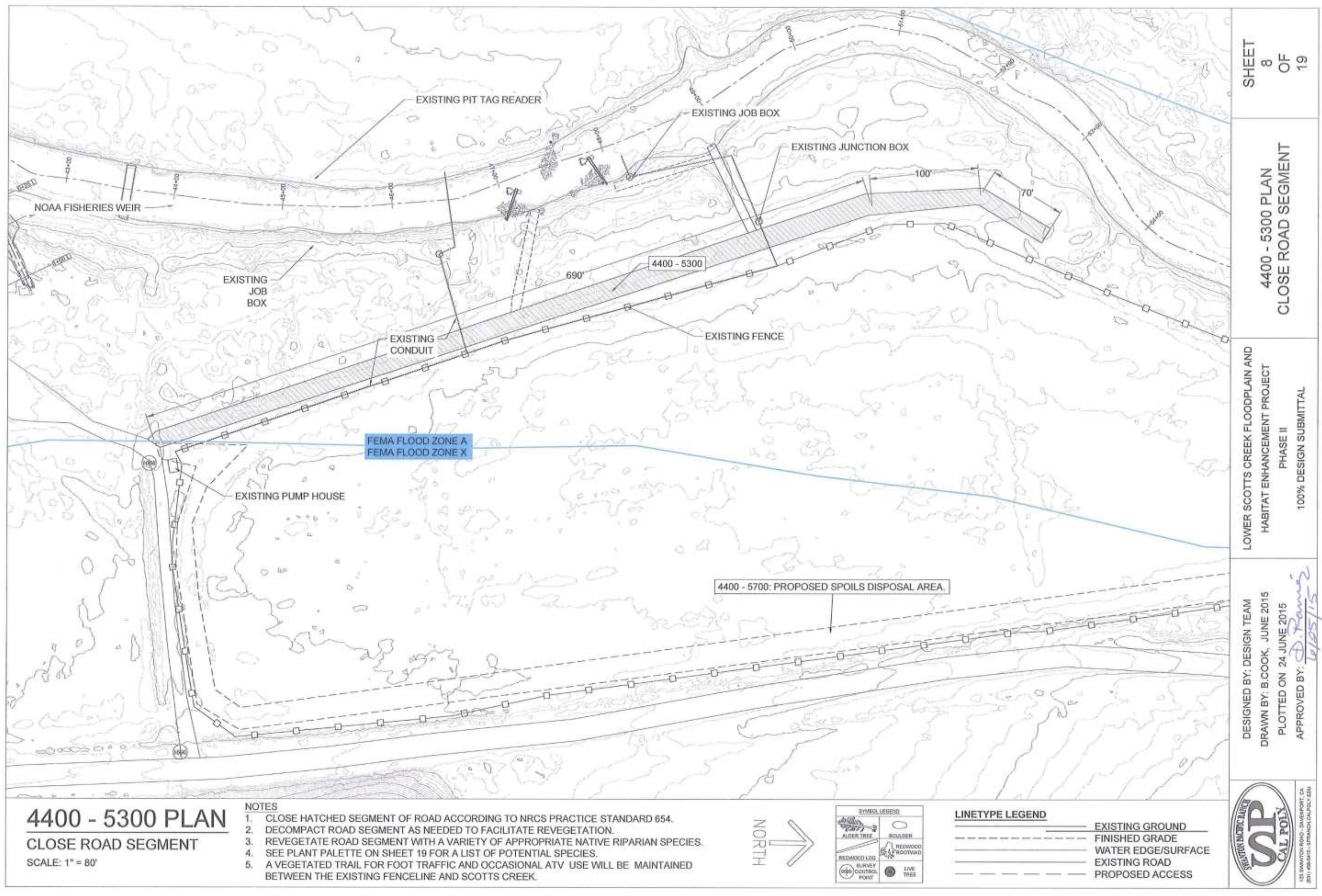




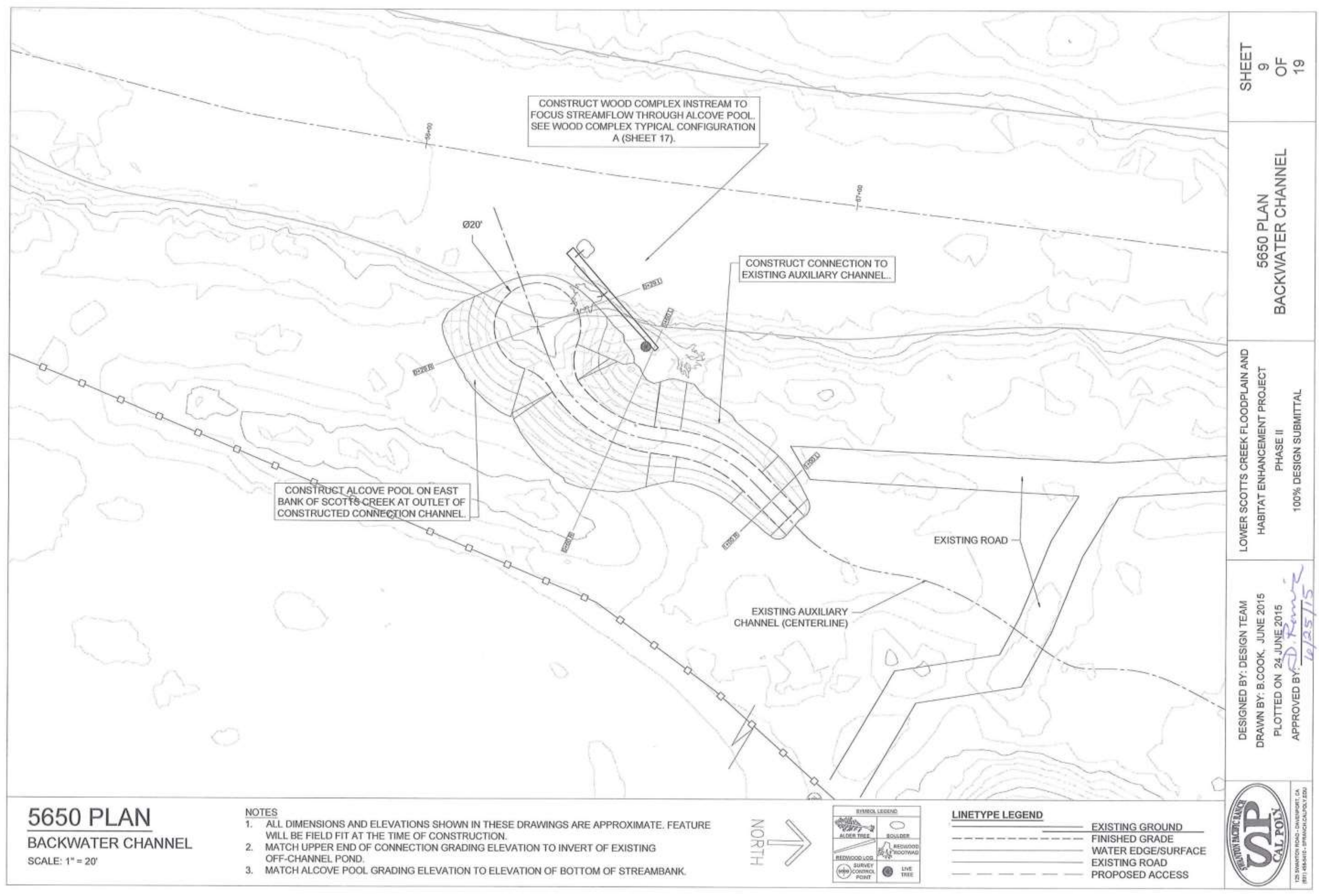




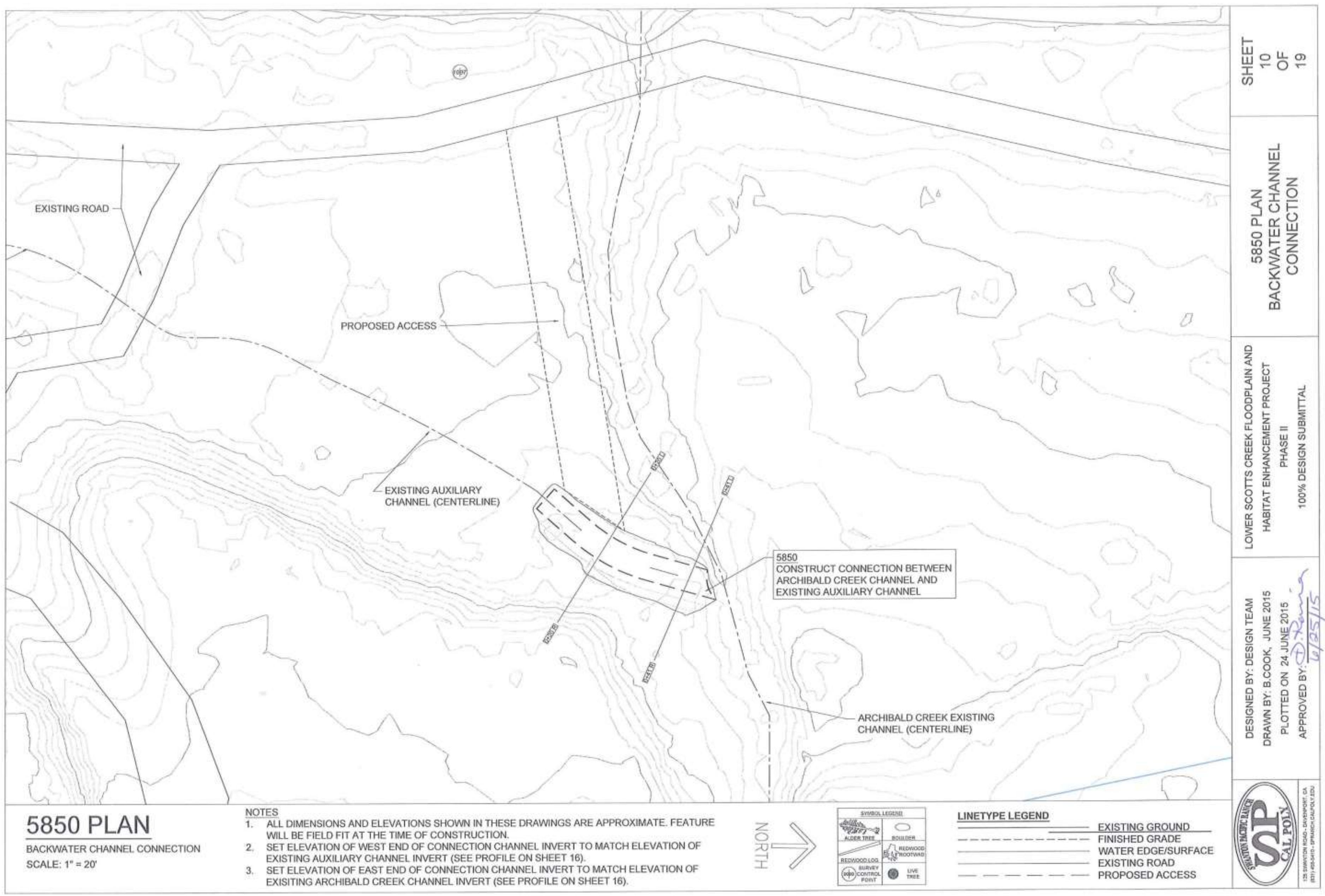




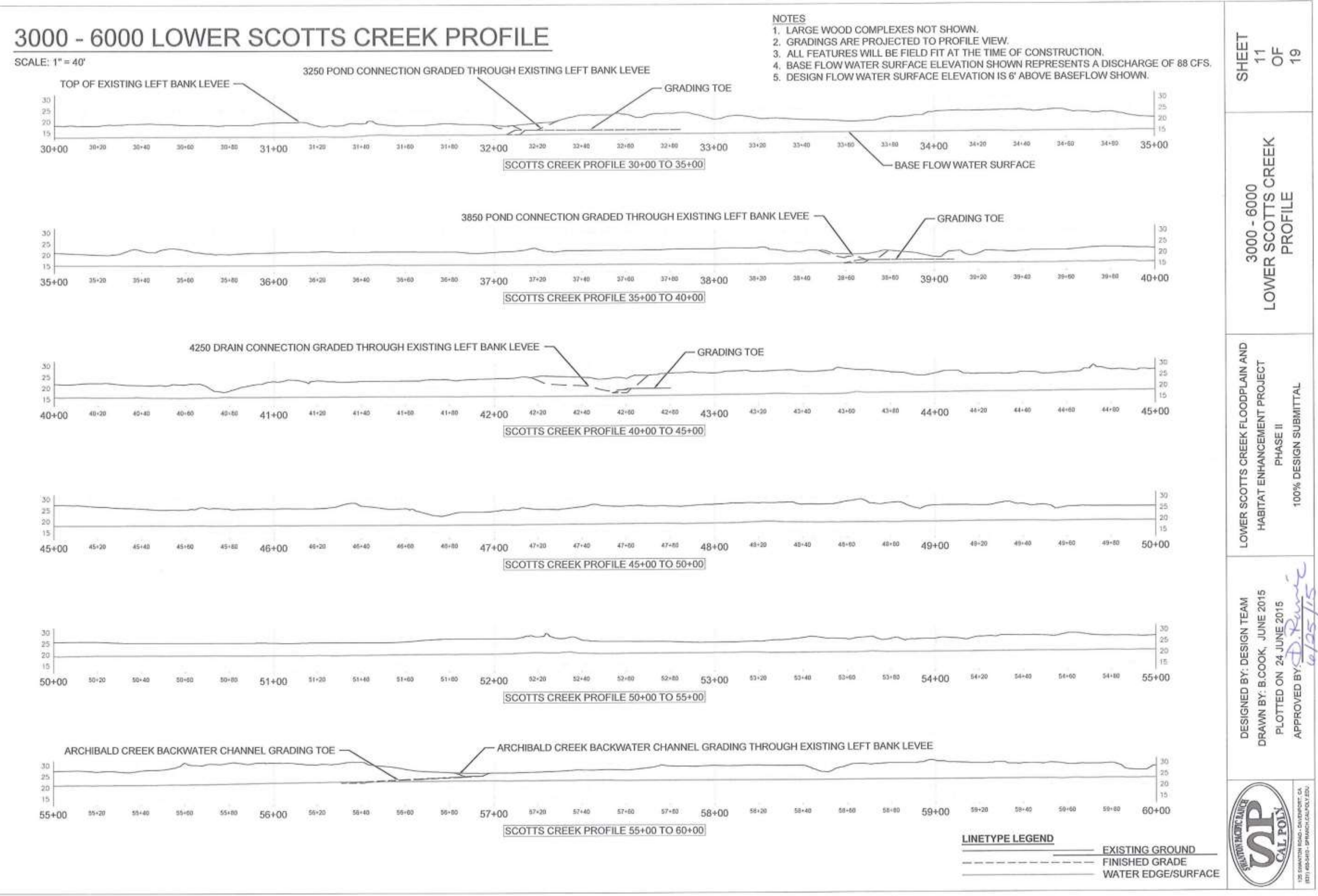




\section{POND CONNECTION PROFILE AND SECTIONS}

SCALE: $1 "=10^{\circ}$
NOTES

TOR GRADING VOLUME AND AREA

. AL SIDE SLOPES ARE 2H:IV.

4. TREAT GRADING ACCORDING TO EROSION CONTROL AND REVEGETATION TYPICAL (SHEET 19)

5. DEWATER AS NEEDED ACCORDING TO DIVERSION TYPICAL (SHEET 18).

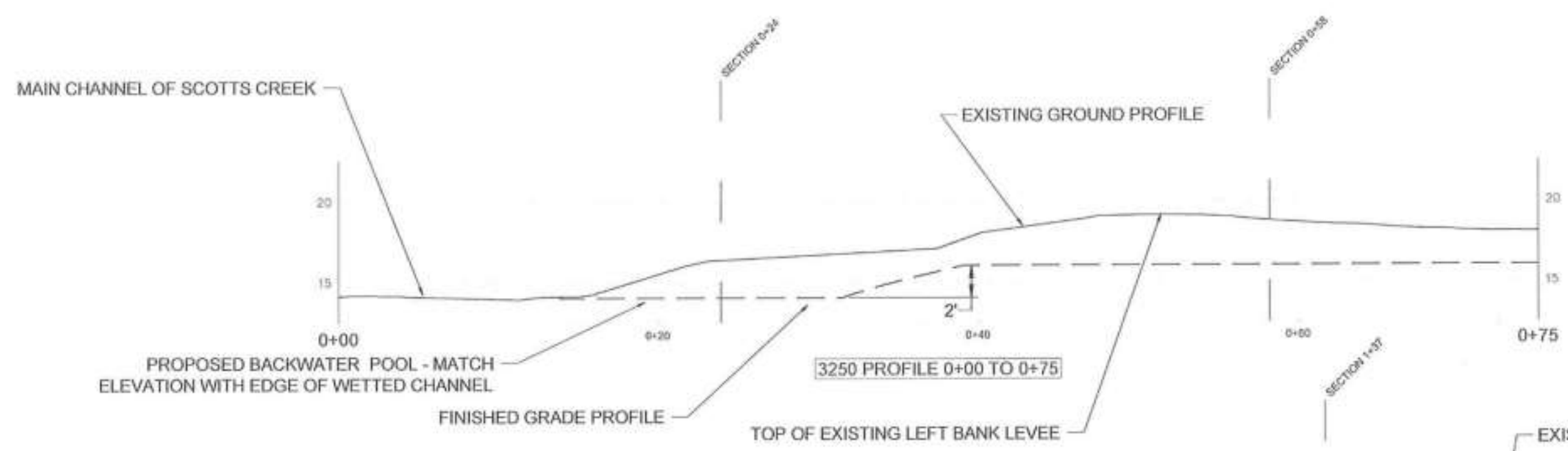

TOP OF EXISTING LEFT BANK LEVEE -

PROPOSED BACKWATER POOL -MATCH
EVATION WTH EDGE OF WETTED CHANNE

FINISHED GRADE PROFILE

FING FLOODPLAIN POND TALL. CREST

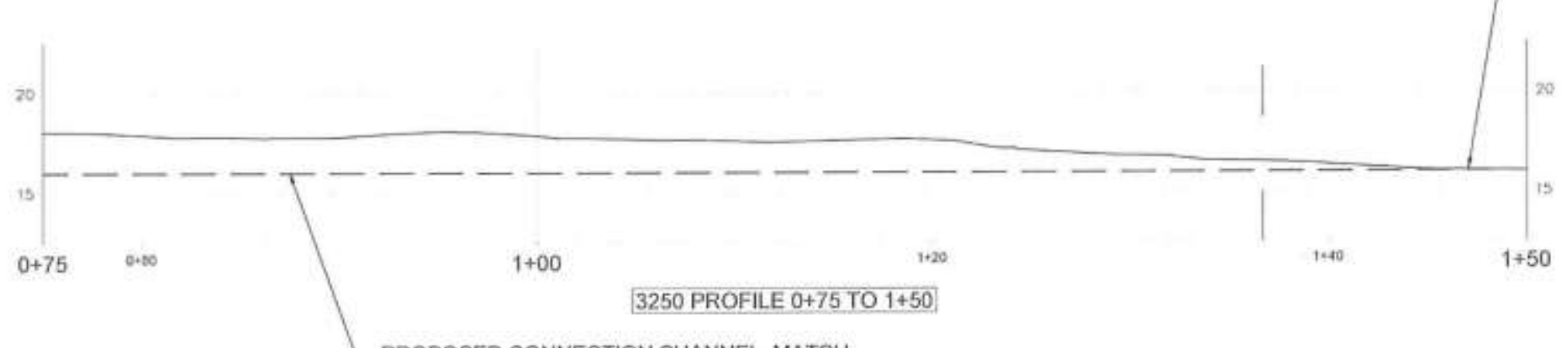

PROPOSED CONNECTION CHANNEL. MATCH EIEVATION TO POND HIGH WATER MARK.

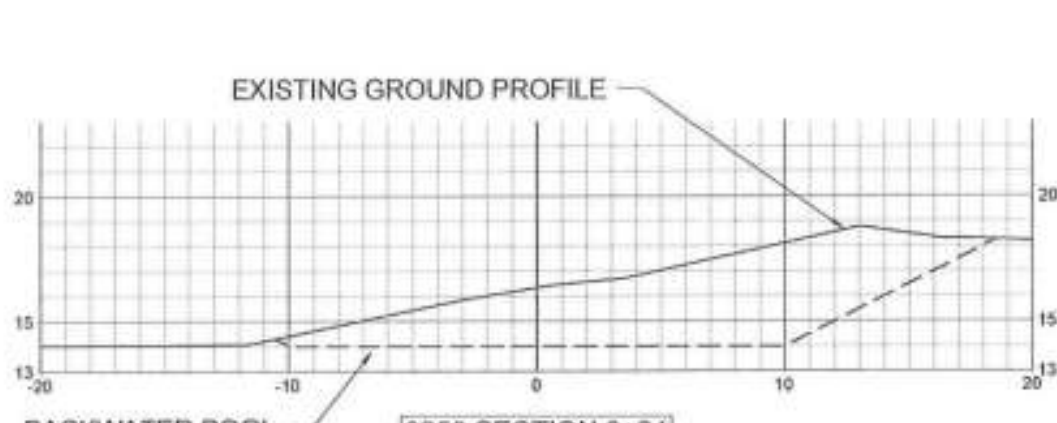

3250 SECTION 0+24]

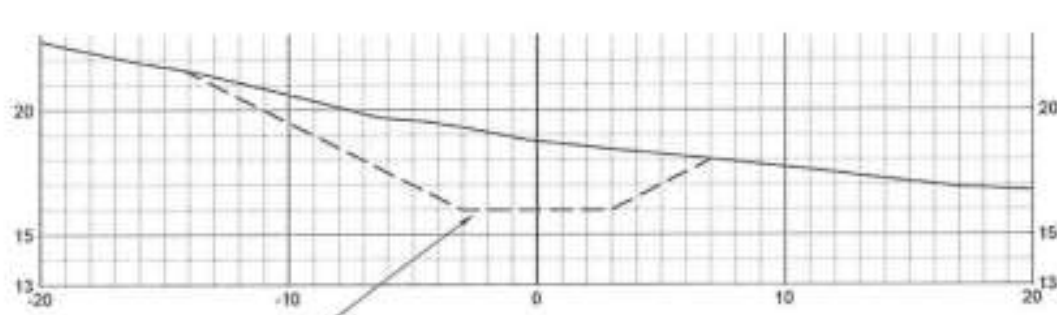

3250 SECTION 0+58

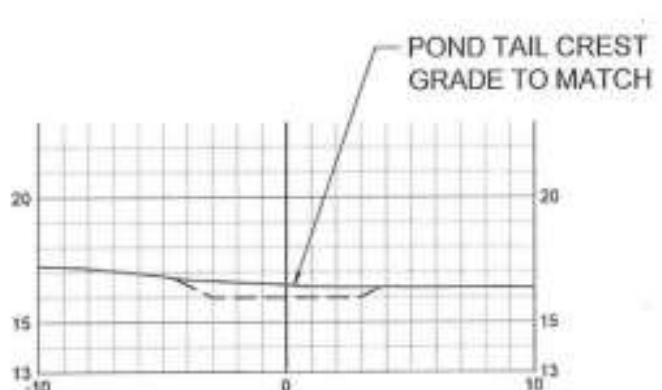

3250 SECTION 1+37, 


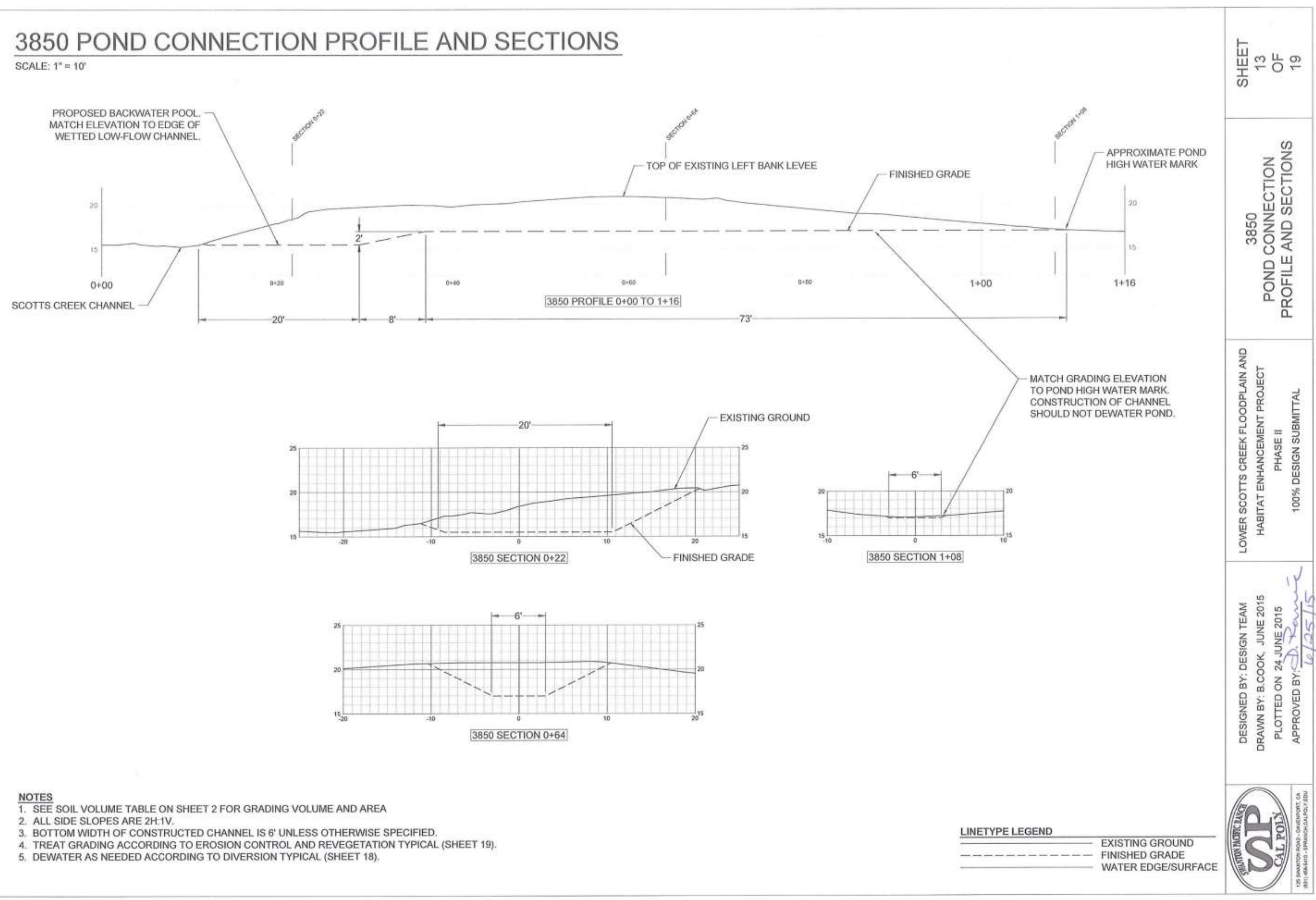



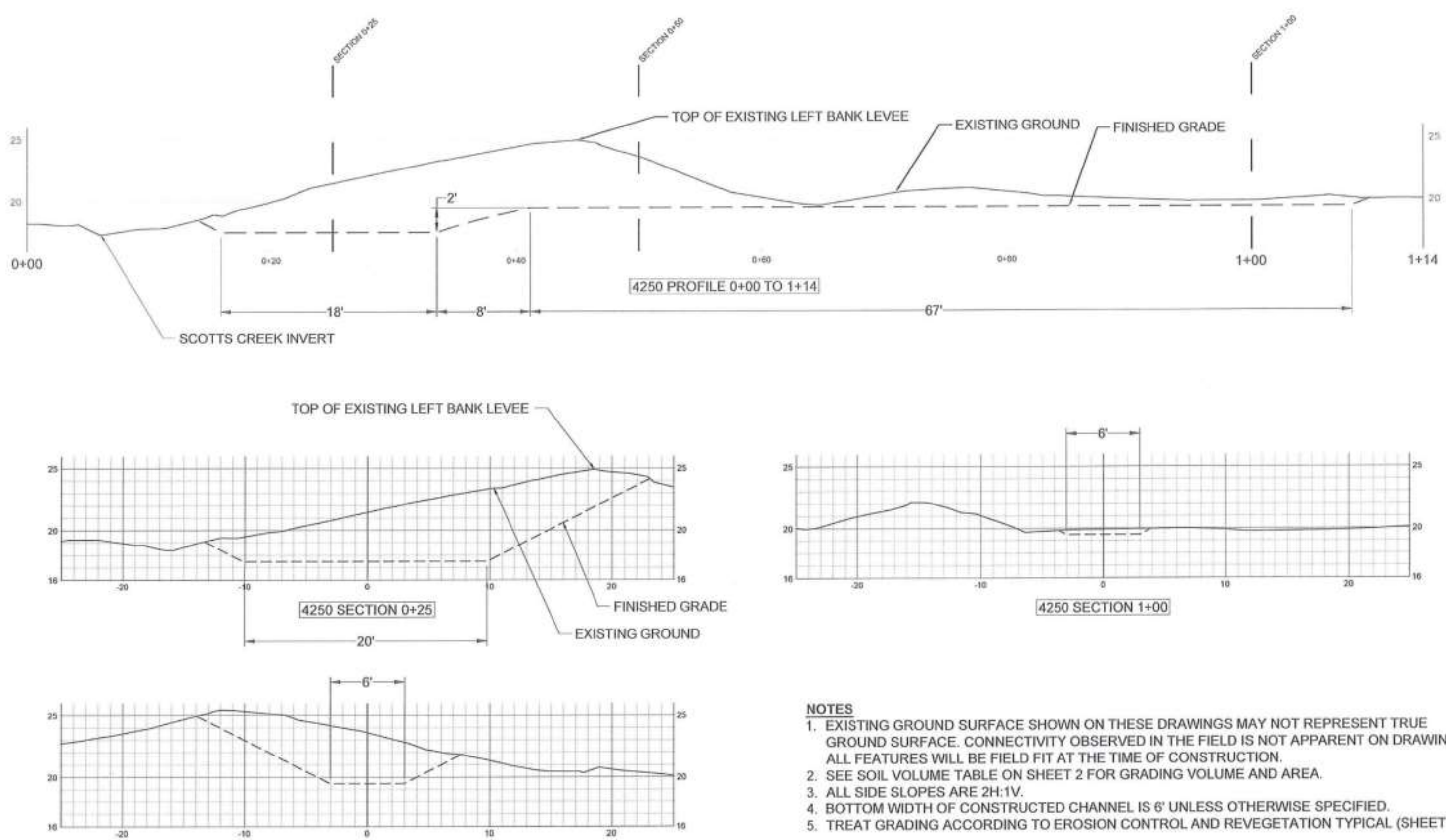

NOTES 1 EXISTING GROUND SURFACE SHOWN ON THESE DRAWINGS MAY NOT REPRESENT TRUE GROUND SURFACE. CONNECTIVITY OBSERVED IN THE FIELLD IS NOT APPARENT ON DRAWING ALL FEATURES WILL BE FELD FIT AT THE TMEE OF CONSTRUCHON.

2. SEE SOIL VOLUME TABLE ON

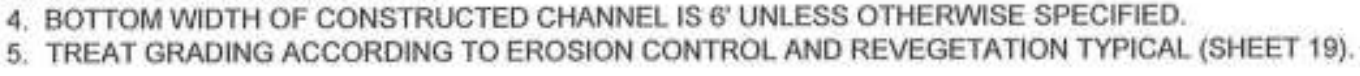

4250 SECTION $0+50$ - 


\section{ARCHIBALD CREEK BACKWATER CHANNEL}

SCALE: $1 "=10$
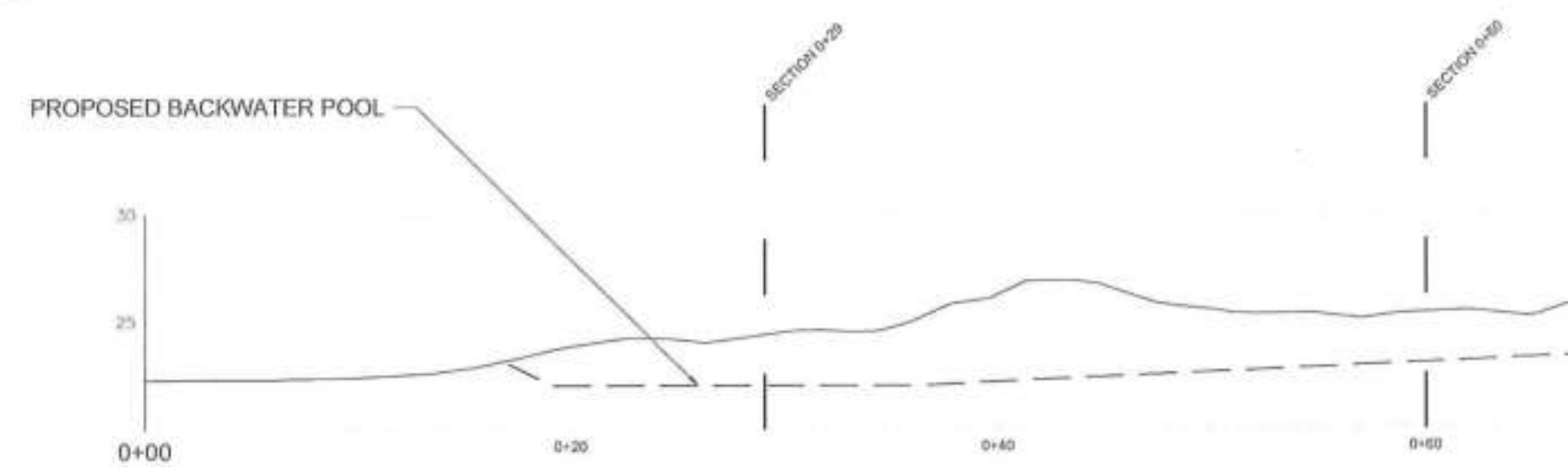

5650 PROFILE 0+00 TO 1+12]

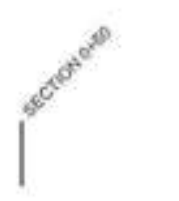

PROPOSED BACKWATER POOL AT CONFLUENCE

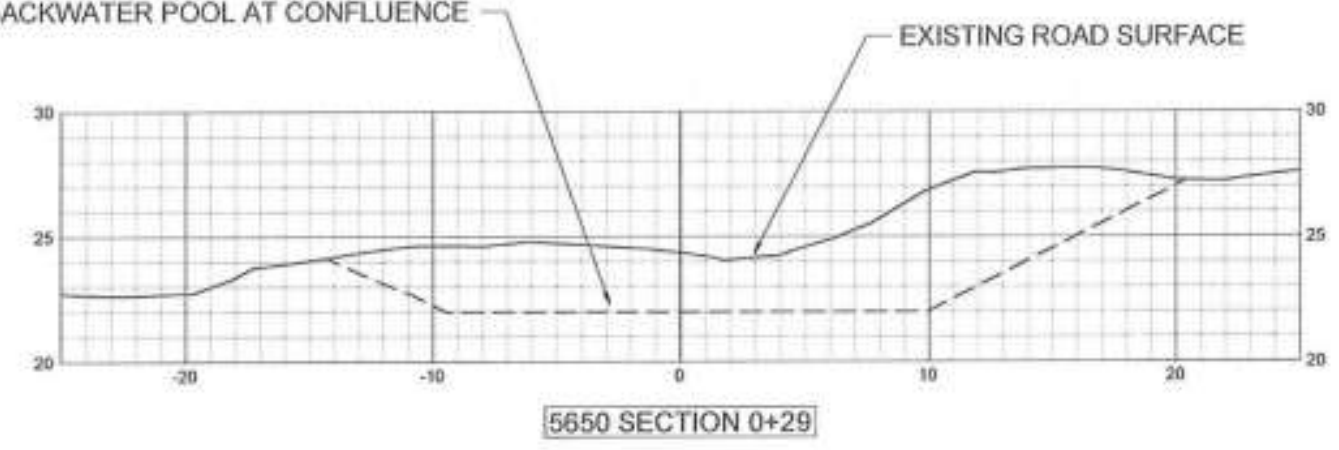

5650 SECTION $0+29$

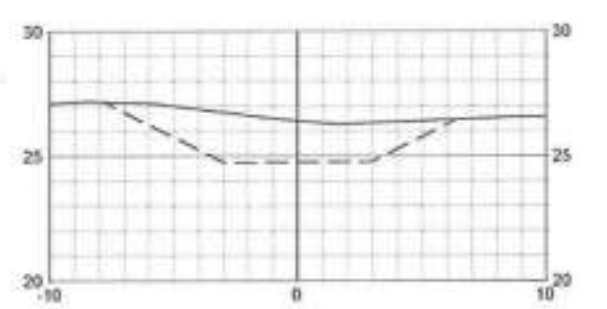

5650 SECTION $1+00$

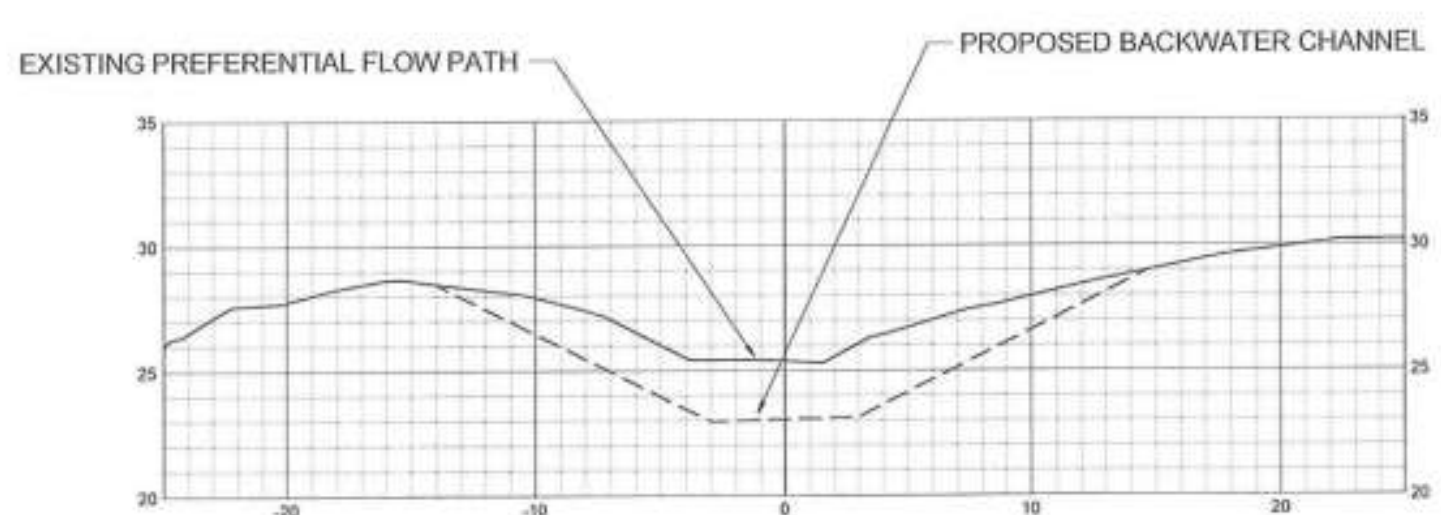

5650 SECTION $0+60$

NOTES

VOLUME TABLE ON SHEET 2 FOR GRADING VOLUME AND AREA

2. ALL SIDE SLOPES ARE 2H:1V.

4. TREAT GRADING ACCORDING TO EROSION CONTROL AND REVEGETATION TYPICAL (SHEET 19)

5. DEWATER AS NEEDED ACCORDING TO DIVERSION PLAN (SHEET 18). 


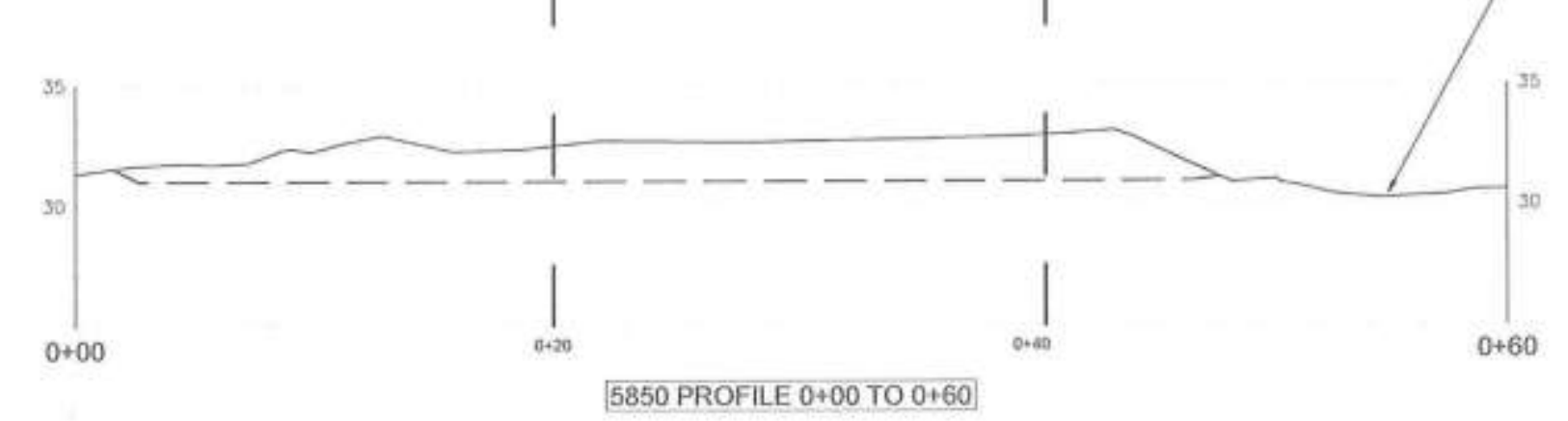

[5850 PROFILE $0+00$ TO $0+60$ ]

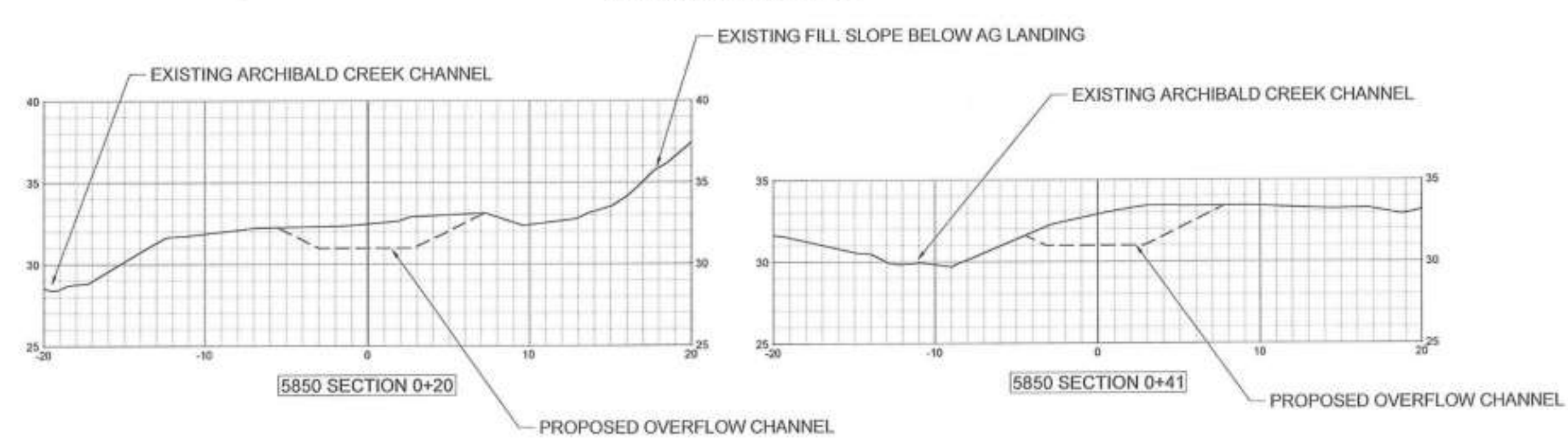




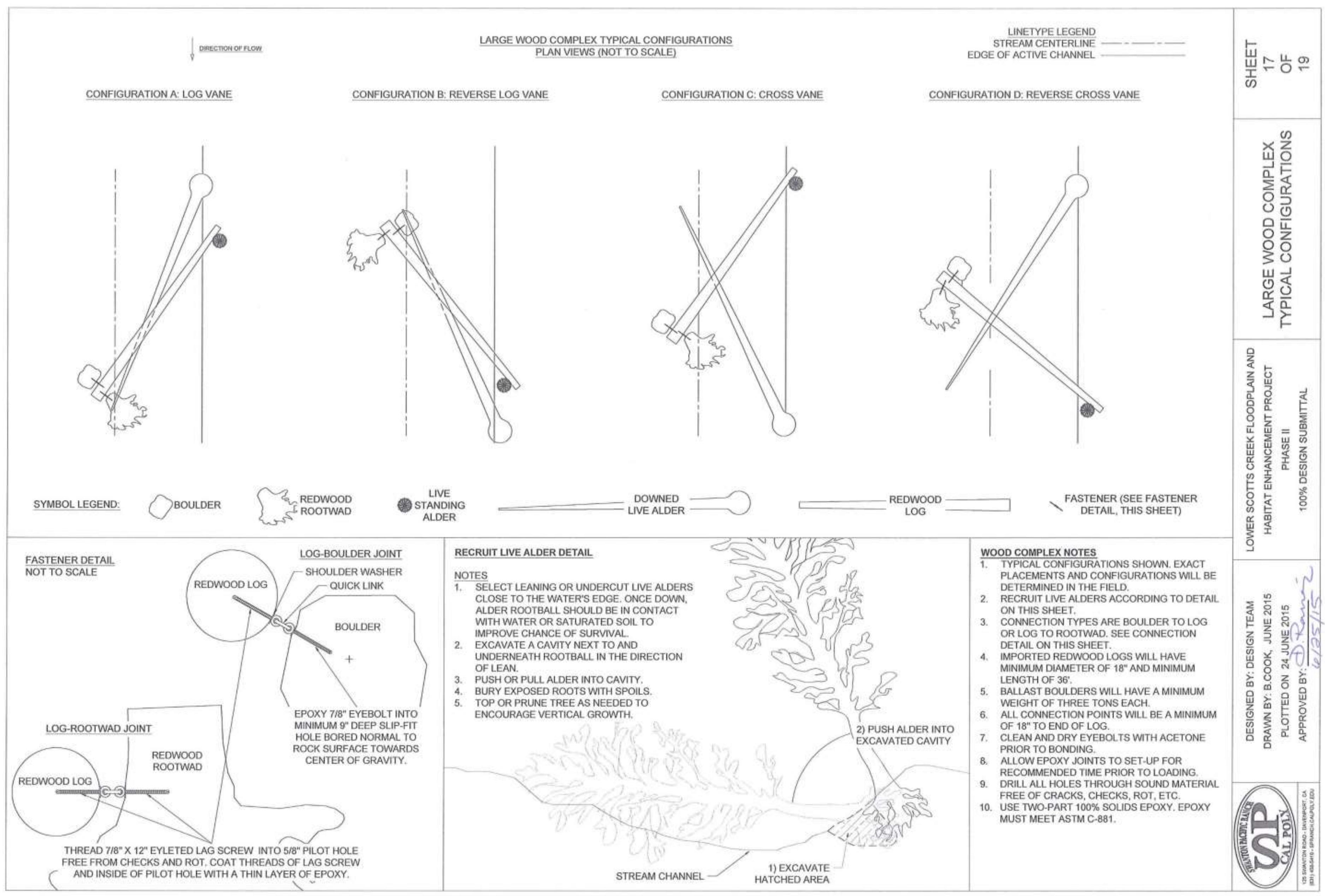




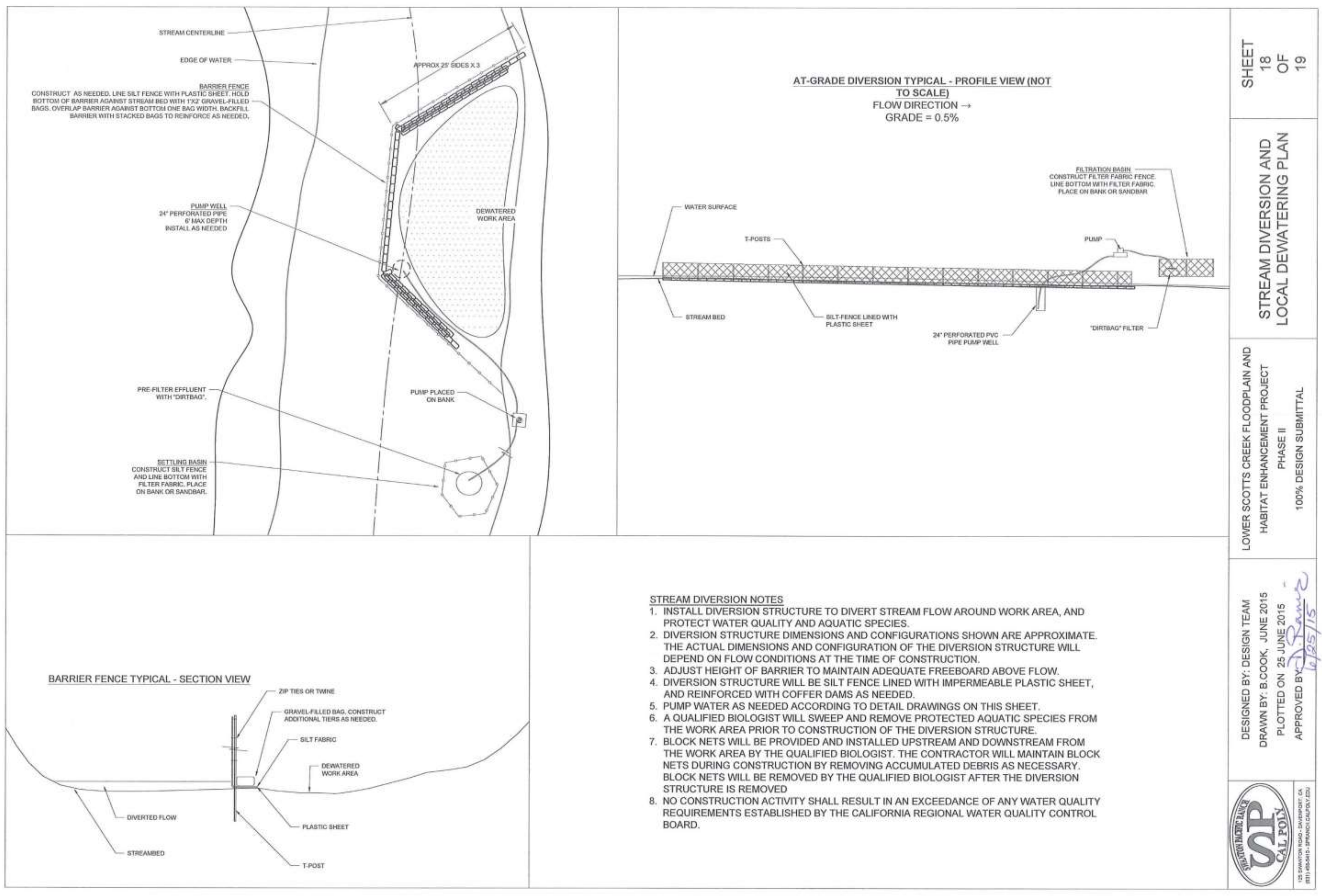




\section{Lower Scotts Creek Revegetation Plant Palette}

\begin{tabular}{|c|c|c|c|}
\hline Common Name & Species & Function & Location \\
\hline \multicolumn{4}{|l|}{ Trees } \\
\hline Box Elder & Acer negundo & ss, s, C & $\mathrm{RC}$ \\
\hline Red Alder & Alnus rubra & ss, s & $\mathrm{RC}$ \\
\hline Red Elderberry & Sambucus racemosa var. racemosa & ss, s, C & $\mathrm{RC}$ \\
\hline Blue Elderberry & Sambucus nigra subsp. caerulea & ss, S, C & $\mathrm{RC}$ \\
\hline Shining willow & Salix lasiandra var, lasiandra & Ss, S, C & FP, RC \\
\hline Arroyo willow & Salix lasiolepis & ss, s, C & FP, RC \\
\hline Creek Dogwood & Cornus sericea & ss, S, C & FP, RC \\
\hline \multicolumn{4}{|l|}{ Grasses } \\
\hline Beardless wild rye & Elymus triticoides & EC & RC \\
\hline \multicolumn{4}{|l|}{ Rushes } \\
\hline Brown rush & Juncus hesperius & SS, EC & FPA \\
\hline Spreading rush & Juncus patens & SS, EC & FPA \\
\hline Pacific rush & Juncus effusus subsp. pacificus & SS, EC & FPA \\
\hline \multicolumn{4}{|l|}{ Sedges } \\
\hline Bigleaf sedge & Carex amplifolia & SS, EC & FPA \\
\hline Barberpole sedge & Scirpus microcarpus & SS, EC & FP, RC \\
\hline Cyperus & Cyperus eragrostis & SS, EC & $\mathrm{FP}, \mathrm{RC}$ \\
\hline Slough sedge & Carex obnupta & SS, EC & FP, RC \\
\hline \multicolumn{4}{|l|}{ Shrubs } \\
\hline Salmonberry & Rubus spectabilis & EC & $\mathrm{RC}$ \\
\hline Blackberry & Rubus ursinus & EC & $\mathrm{RC}$ \\
\hline Thimbleberry & Rubus parvillorus & EC & $\mathrm{RC}$ \\
\hline Woodland strawberry & Fragaria vesca & EC & $\mathrm{RC}$ \\
\hline Straggly gooseberry & Ribes divaricatum var, pubifforum & EC & $\mathrm{RC}$ \\
\hline California rose & Rosa californica & EC & $\mathrm{RC}$ \\
\hline California hedge-nettle & Stachys bullata & EC & $\mathrm{RC}$ \\
\hline American stinging nettle & Urtica dioica subsp. & $\mathrm{EC}$ & $\mathrm{RC}$ \\
\hline California figwart & Scrophularia califomica & EC & $\mathrm{RC}$ \\
\hline Douglas' nightshade & Solanum douglasii & $\mathrm{EC}$ & $\mathrm{RC}$ \\
\hline Golden yarrow & Eriophyllum confertiflorum & EC & RC \\
\hline \multicolumn{4}{|l|}{ Ferns } \\
\hline Lady fern & Athyrium felix-femina var. cyclosorum & EC & $\mathrm{RC}$ \\
\hline Giant chain fern & Woodwardia fimbriata & EC & RC \\
\hline Sword fern & Polystichum munitum & EC & $\mathrm{RC}$ \\
\hline Wood fern & Dryopteris arguta & EC & $\mathrm{RC}$ \\
\hline \multicolumn{4}{|l|}{ Herbs } \\
\hline Common yarrow & Achillea millefolium & EC & $\mathrm{RC}$ \\
\hline \multicolumn{4}{|l|}{ Key: } \\
\hline SS $=$ soil stabilization & $R C=$ riparian corridor & & \\
\hline$E C=$ erosion control & $F P=$ floodplain & & \\
\hline$S=$ shade & $F P A=$ floodprone area & & \\
\hline
\end{tabular}

FeVegetation Diagram - Plan VIEW

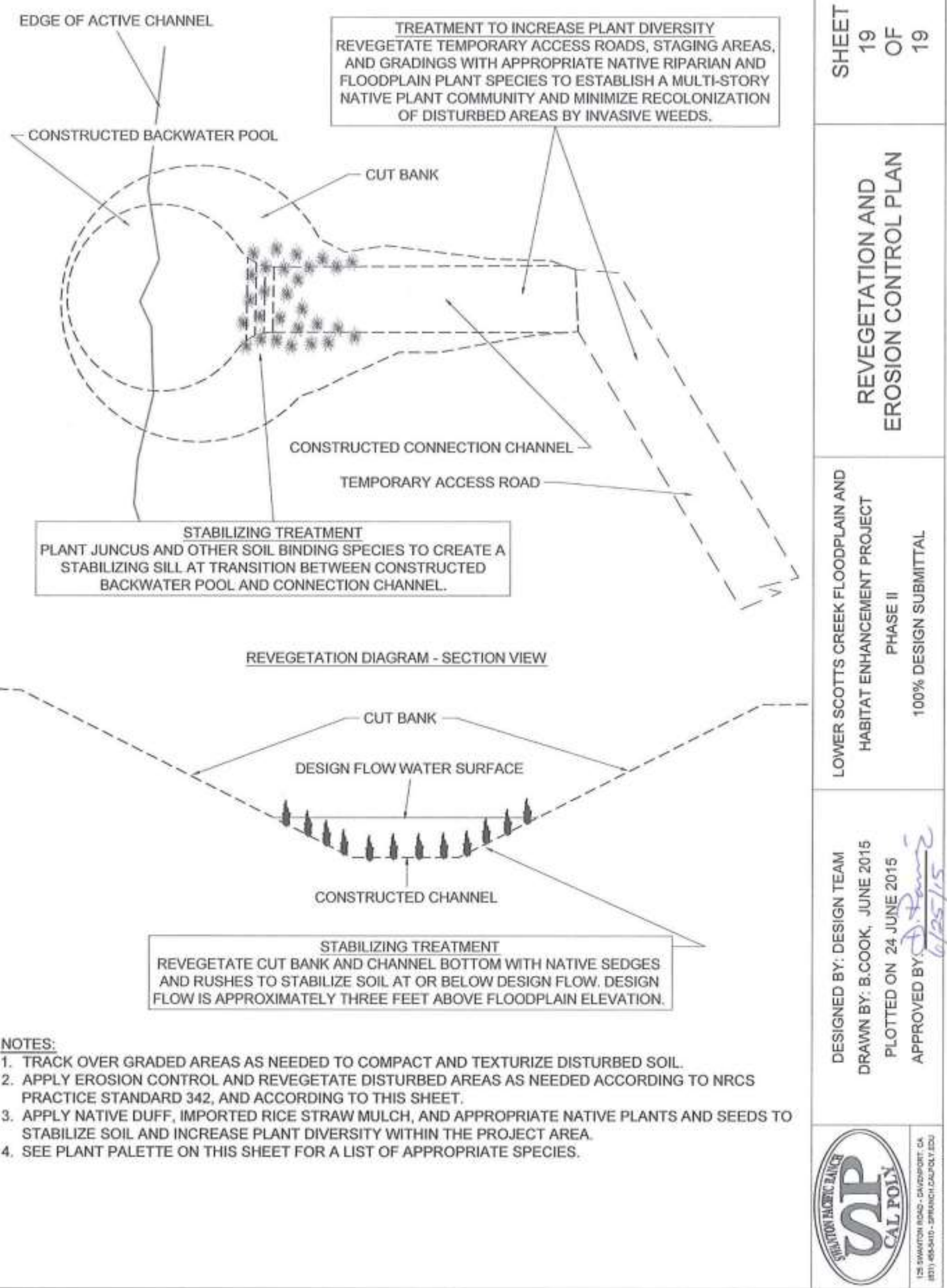




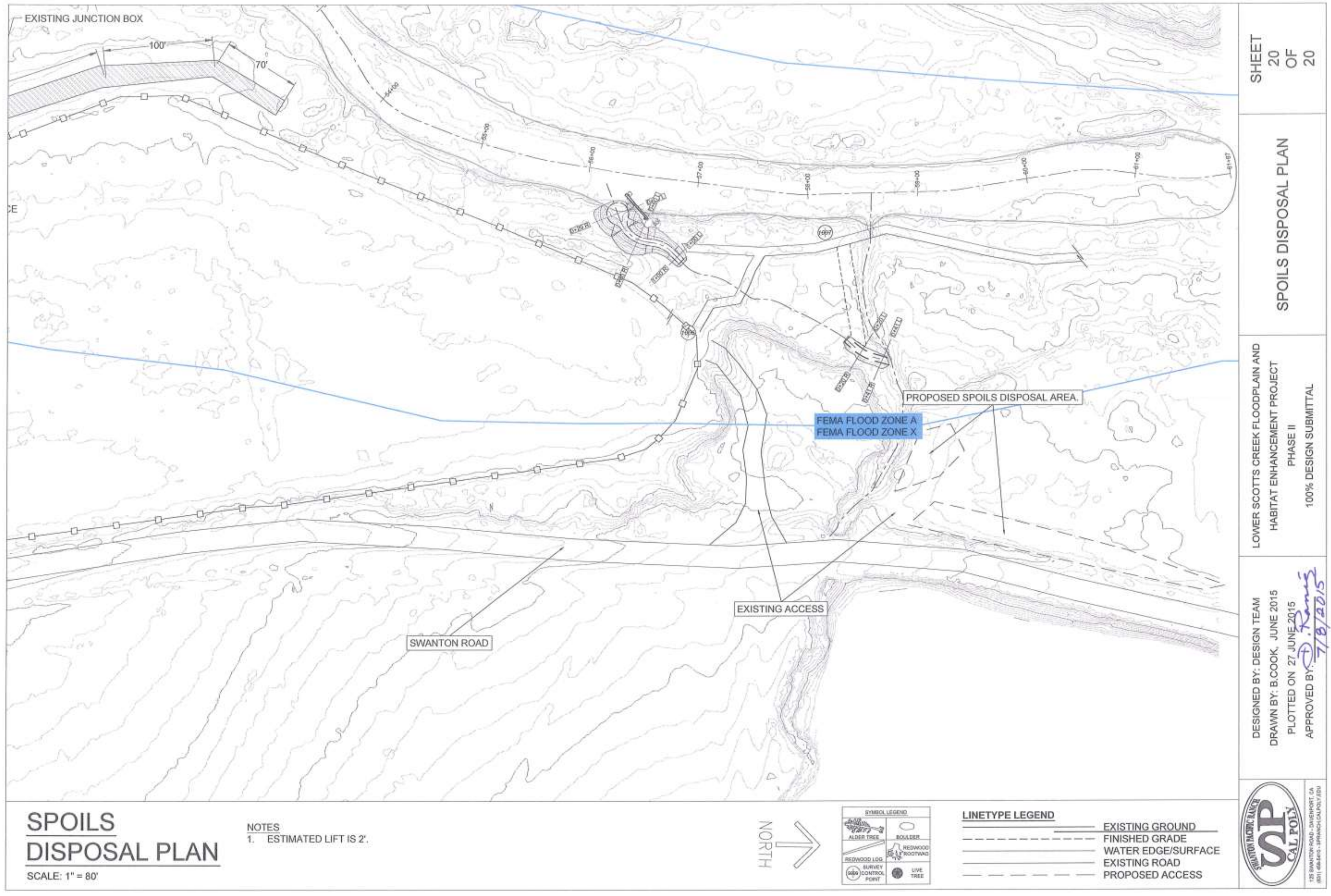




\section{SURVEY CONTROL DATA}

All coordinates are in NAD 83 State Plane III (ft).

\begin{tabular}{|c|c|c|c|c|}
\hline Point & Northing & Easting & $\underline{\text { Elevation }}$ & $\underline{\text { Description }}$ \\
\hline 97 & 1847730.165 & 6057875 & 27.95 & Natural \\
\hline 98 & 1845272.128 & 6058446.337 & 15.67 & Natural \\
\hline 100 & 1843577.263 & 6059141.065 & 63.19 & Set Rebar Cap \\
\hline 101 & 1850401.909 & 6059547.309 & 456.92 & Set Rebar Cap \\
\hline 102 & 1849471.84 & 6054669.56 & 781.94 & CGPS P534 \\
\hline 1000 & 1844345.162 & 6058071.169 & 15.75 & Rebar \\
\hline 1001 & 1843990.524 & 6058111.73 & 14.91 & Rebar \\
\hline 1002 & 1844292.886 & 6057978.472 & 17.82 & Spike \\
\hline 1003 & 1844274.185 & 6057937.016 & 12.43 & Spike \\
\hline 1004 & 1843880.441 & 6058092.712 & 14.23 & $\mathrm{CP}$ \\
\hline 1005 & 1843639.779 & 6058140.139 & 14.68 & Rebar Cap \\
\hline 1006 & 1846730.955 & 6057914.902 & 28 & Rebar \\
\hline 1007 & 1846855.333 & 6057824.728 & 27.88 & 38 rebar \\
\hline 1008 & 1845539.054 & 6057919.359 & 25.49 & Rebar \\
\hline 1009 & 1844799.575 & 6057853.356 & 17.21 & Rebar Cap \\
\hline 1050 & 1843578.134 & 6058026.543 & 12.87 & Rebar \\
\hline 1051 & 1843458.088 & 6057867.525 & 13.06 & Rebar \\
\hline 1052 & 1843461.342 & 6057769.406 & 11.87 & rebar 1052 \\
\hline 1053 & 1843406.774 & 6057785.112 & 11.3 & Rebar \\
\hline 1054 & 1843346.123 & 6057890.644 & 12.34 & Rebar \\
\hline 1055 & 1844455.778 & 6058075.962 & 16.39 & Rebar \\
\hline 1056 & 1844546.923 & 6058056.857 & 16.86 & Rebar \\
\hline 1057 & 1844564.002 & 6057924.92 & 23 & Rebar \\
\hline 1058 & 1844566.977 & 6057823.637 & 14.94 & Rebar \\
\hline 1059 & 1844464.657 & 6057973.285 & 18.86 & Rebar \\
\hline 1085 & 1844643.129 & 6057941.727 & 15.51 & Rebar \\
\hline 1086 & 1844464.755 & 6057973.446 & 18.77 & Rebar \\
\hline 1087 & 1844794.962 & 6057685.405 & 14.53 & Rebar \\
\hline 1088 & 1846687.552 & 6057763.804 & 22.33 & Rebar \\
\hline 1089 & 1845016.089 & 6058221.519 & 23.02 & Rebar \\
\hline 1090 & 1845218.07 & 6058198.952 & 24.03 & Rebar \\
\hline 1091 & 1845362.071 & 6057685.953 & 24.09 & Rebar \\
\hline 1092 & 1845080.656 & 6057687.835 & 19.42 & Rebar \\
\hline 1093 & 1844747.808 & 6057751.533 & 19.09 & Rebar \\
\hline
\end{tabular}




$\begin{array}{rrrrr}1094 & 1844785.805 & 6057899.555 & 17.74 & \text { Rebar } \\ 1095 & 1845985.992 & 6057738.964 & 22.61 & \text { Rebar } \\ 1096 & 1845889.937 & 6057798.843 & 24.06 & \text { Rebar } \\ 1097 & 1845931.418 & 6057690.7 & 25.93 & \text { Rebar } \\ 1098 & 1845104.822 & 6057678.522 & 19.582 & \text { Rebar } \\ 1099 & 1844688.526 & 6057768.964 & 18.691 & \text { Rebar } \\ 1500 & 1845568.532 & 6058182.121 & 25.94 & \text { BM M1238 } \\ 1501 & 1837346.281 & 6060702.964 & 89.04 & \text { HPGN 04-02 } \\ 2066 & 1843954.087 & 6057960.51 & 20.14 & \mathrm{CP} \\ 2067 & 1844022.054 & 6057975.298 & 20.22 & \mathrm{CP} \\ 2068 & 1844146.073 & 6057976.495 & 20.67 & \mathrm{CP} \\ 2069 & 1844278.351 & 6057971.921 & 18.34 & \mathrm{CP} \\ 3000 & 1843791.134 & 6058110.428 & 14.15 & \mathrm{CP} \\ 4000 & 1844217.803 & 6057919.494 & 12.11 & \mathrm{CP} \\ 5000 & 1844010.397 & 6057955.278 & 16.6 & \mathrm{CP} \\ 5100 & 1843943.159 & 6057879.855 & 17.39 & \mathrm{CP} \\ 5999 & 1843931.924 & 6057961.222 & 19.89 & \mathrm{CP} \\ 7001 & 1844277.448 & 6057937.032 & 12.52 & \mathrm{BM} \\ 8185 & 1843880.604 & 6058092.56 & 14.24 & \mathrm{CP} \\ 8785 & 1844276.114 & 6057934.999 & 14.18 & \mathrm{CP} \\ 9132 & 1844311.081 & 6058010.97 & 14.79 & \mathrm{CP}\end{array}$


J. SURVEY CONTROL MAP

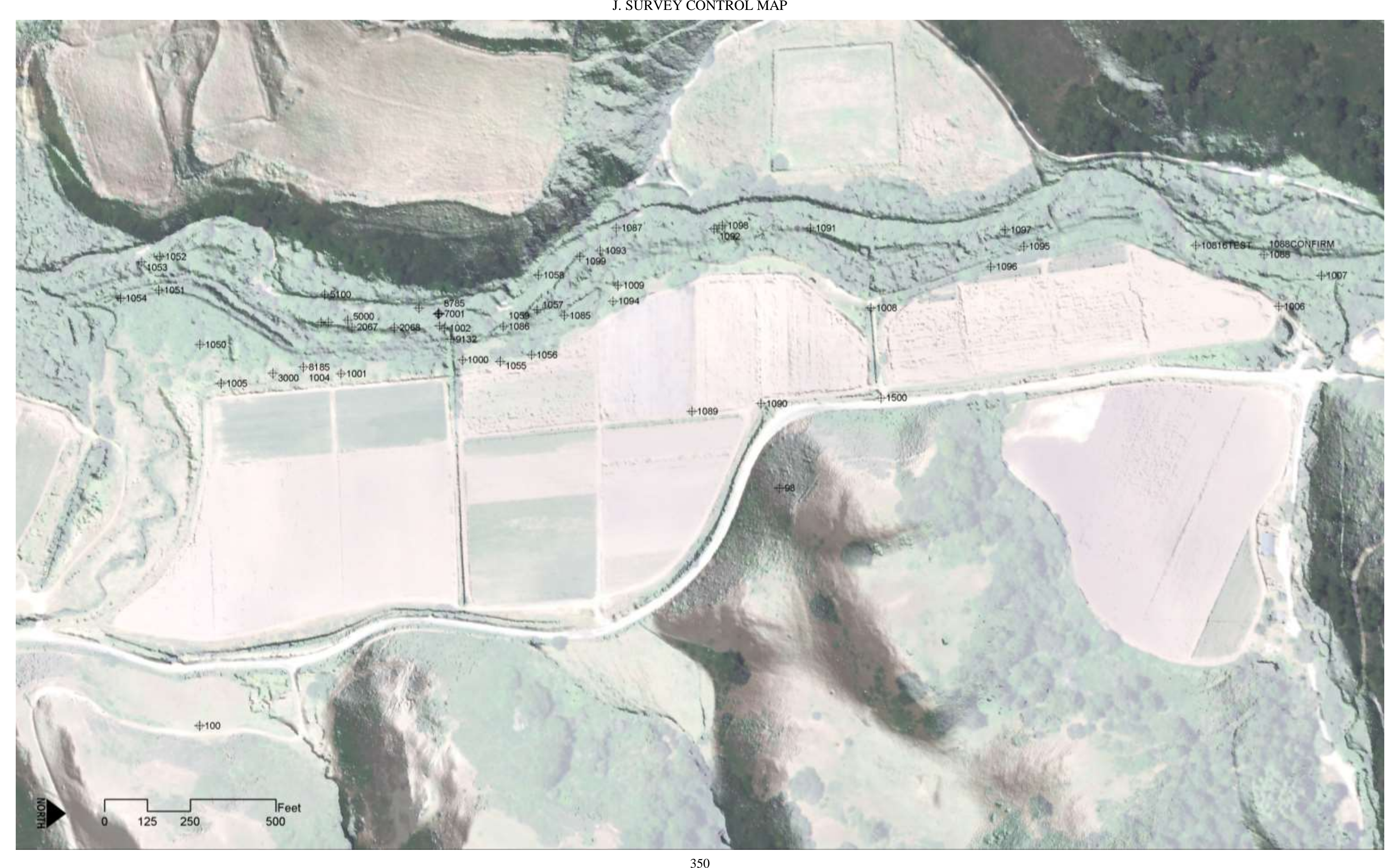

